\title{
Sprache und Kommunikation im Alter
}

\author{
Reinhard Fiehler • Caja Thimm (Hrsg.)
}

Die PDF-Dateien bewahren die ursprünglichen Seitenumbrüche und Positionen der Fußnoten in der ersten Auflage des Buches. Alle Zitationen bleiben also gültig. Bei Zeilenumbrüchen und Layout mussten jedoch Veränderungen vorgenommen werden.

Radolfzell: Verlag für Gesprächsforschung 2003

ISBN 3 - 936656 - 08 - 8 (früher: 3 - 531 - 13036 - 6)

http://www.verlag-gespraechsforschung.de

\section{Alle Rechte vorbehalten. \\ ๑ Verlag für Gesprächsforschung, Dr. Martin Hartung, Radolfzell 2003}

Das Werk einschließlich aller seiner Teile ist urheberrechtlich geschützt. Jede Verwertung außerhalb der engen Grenzen des Urheberrechtgesetzes ist ohne Zustimmung des Verlages unzulässig und strafbar. Das gilt insbesondere für Vervielfältigung, Übersetzungen, Mikroverfilmungen und die Einspeicherung und Verarbeitung in elektronischen Systemen. 





\section{Inhalt}

Reinhard Fiehler / Caja Thimm

Das Alter als Gegenstand linguistischer Forschung eine Einführung in die Thematik

\section{Theoretisch-methodologische Aspekte}

Manfred Kohrt / Kerstin Kucharczik

'Sprache' - unter besonderer Berücksichtigung von 'Jugend' und 'Alter'

Reinhard Fiehler

Modelle zur Beschreibung und Erklärung altersspezifischer

Sprache und Kommunikation

\section{Manifestationen von Alter in mündlicher Kommunikation}

Ellen B. Ryan / Sheree T. Kwong See

Sprache, Kommunikation und Altern

Caja Thimm

Kommunikative Konstruktion der sozialen Kategorie 'Alter' im Gespräch.

Achim Pothmann

Altersspezifisches Kommunikationsverhalten in Verkaufsgesprächen

Guido Schnieders

„Weil alte Leute übert Ohr hauen find ich wirklich nicht gut“"

Zur Funktion von altersthematisierenden Äußerungen im Diskurs

\section{Anne Betten}

Ist 'Altersstil' in der Sprechsprache wissenschaftlich nachweisbar?

Überlegungen zu Interviews mit 70- bis 100-jährigen Emigranten

Svenja Sachweh

„so frau adams $\downarrow$ guck mal $\downarrow$ ein feines bac-spray $\downarrow$ gut $\uparrow$ “

Charakteristische Merkmale der Kommunikation zwischen

Pflegepersonal und BewohnerInnen in der Altenpflege.

Margitta Lambert

$\mathrm{Zu}$ unterschiedlichen Realisierungen des Komplimentmusters

in Altentagesstätten- bzw. Altenheimkommunikation 
Daniela Heidtmann

Alter, Familienhierarchie und Kommunikationsstatus

Stefanie Maier

Der Einfluß von Altersstereotypen auf sprachliche Instruktionen 195

Roselore Brose

Lebenssituation und Sprache 214

\section{Schriftsprachliche Manifestationen von Alter}

Dieter Cherubim / Suzanne Hilgendorf

Sprachverhalten im Alter.

Beobachtungen und Diskussionen zum Begriff des Alters

Undine Kramer

AGEISMUS - Zur sprachlichen Diskriminierung des Alters

\section{Klinisch-pathologische Manifestationen}

Michael Schecker

Sprache und Demenz

Markus Gress-Heister

Abbau sprachverarbeitender Prozesse bei dementiellen

Syndromen am Beispiel pronominaler Formen

Die Autorinnen und Autoren 


\title{
Das Alter als Gegenstand linguistischer Forschung - eine Einführung in die Thematik
}

\author{
Reinhard Fiehler / Caja Thimm
}

\begin{abstract}
"Altern hat Konjunktur und ist für viele Vertreter und Vertreterinnen in Politik, Publizistik und Wissenschaft das 'Zukunftsthema' schlechthin", so beginnen Prahl \& Schroeter (1996) ihre Einführung in die Soziologie des Alterns. Zumindest für die deutsche Sprachwissenschaft trifft dies jedoch (bisher) nicht zu. Im Gegenteil: Die Kommunikation älterer Menschen, sowohl untereinander wie mit jüngeren, darf als "sträflich vernachlässigtes Feld in der sprachwissenschaftlichen Forschung der Bundesrepublik" (Fiehler 1997, 345) bezeichnet werden. Obwohl es Teil unseres Altagswissens ist und unsere alltäglichen Kommmunikationserfahrungen immer wieder zu bestätigen scheinen, daß die Sprache und das Kommunikationsverhalten älterer Menschen Besonderheiten aufweisen, stehen sprachwissenschaftliche Untersuchungen und gesicherte Belege für solche Eindrücke und Annahmen noch ganz am Anfang. Dies gilt für die gesprochene Sprache älterer Menschen ebenso wie für ihre schriftsprachliche Kommunikation. Geht man davon aus, daß Kommunikation für das Wohlbefinden älterer Menschen eine große Bedeutung hat, eine Auffassung, die allen Beiträgen dieses Bandes zugrunde liegt, so überrascht die geringe Beachtung, die die Sprachwissenschaft diesem Thema bisher geschenkt hat, um so mehr. Gründe für dieses Forschungsdefizit lassen sich in der negativen gesellschaftlichen Bewertung von Alter finden, darüber hinaus sicherlich aber auch in der vielfach anzutreffenden persönlichen Unlust, sich mit einen solchermaßen negativ besetzten Thema zu befassen. Auf diesem Hintergrund wird z.T. auch das Ungleichgewicht verständlicher, das zwischen der Vielzahl der Arbeiten zur sprachlichen und kommunikativen Entwicklung in Kindheit und Jugend auf der einen Seite und dem Mangel an Arbeiten zum höheren Alter auf der anderen Seite besteht.

Die Arbeitsgruppe "Sprache und Kommunikation im Alter", die im Rahmen der 18. Jahrestagung der Deutschen Gesellschaft für Sprachwissenschaft (DGfS) vom 28.2.-1.3.1996 in Freiburg zusammentraf und dieser Sammelband, der die dort gehaltenen Vorträge - ergänzt durch einige weitere Beiträge - dokumentiert, stellen so für die Bundesrepublik den ersten größeren Versuch dar, den Gegenstandsbereich, der durch die Begriffe 'Alter', 'Sprache' und 'Kommunikation' aufgespannt wird, systematisch in Angriff zu nehmen.
\end{abstract}

\section{Alltagsweltliche Konzepte von Alter}

Es gibt nur wenige Aspekte des Lebens, die sich als eine Universalie menschlicher Entwicklung ansehen lassen. Der Prozeß des Alterns ist jedoch eine solche: Wir waren alle einmal jung, wir werden kontinuierlich älter und, zumindest die meisten von uns, werden auch alt oder sogar hochaltrig.

So sicher dies ist, so wenig eindeutig ist jedoch das, was unter 'Alter' verstanden wird. Alter ist in dieser Sichtweise des Alltags keine einheitliche bzw. konsistente Kategorie. Das Phänomen Alter wird in verschiedenen Bezugsrahmen verortet. All- 
tagsweltlich existieren mindestens vier Konzepte, die aufeinander bezogen sind und die häufig miteinander vermischt werden:

\section{Alter als zeitlich-numerische Größe}

Das geläufigste Konzept ist eine zeitlich-lineare und chronologisch-numerische Vorstellung von Alter. Sie findet Ausdruck in der Kategorie des Lebensalters. Alter wird hier mit der Anzahl der Lebensjahre assoziiert. Die Anwendung dieser Kategorie ist dabei nicht auf hohes Lebensalter beschränkt: 'Schon im Alter von drei Jahren begann er mit dem Klavierspiel.' Hohes Alter beginnt bei einer bestimmten Quantität von Jahren, wobei diese Quantität je nach Kontext sehr unterschiedlich bestimmt werden kann. So wird z.B. der Bereich der Erwerbstätigkeit mit den bekannten 'Altersgrenzen' zunehmend mehr numerisch strukturiert, während in Bereichen wie Politik oder Kunst andere Konzepte von Alter gelten: 'Als Politiker ist man mit 70 doch noch nicht alt.'.

\section{Alter als biologisches Phänomen}

Alter ist hier verbunden mit Vorstellungen von biologischer Entwicklung, z.B. Reifung und Abbau. Alterungsprozesse werden in diesem Zusammenhang als Naturphänomen verstanden. Dieses Konzept kommt z.B. in einer Äußerung zum Tragen wie: 'Für dein Alter hast du dich gut gehalten.'. Hier wird eine positive Diskrepanz zwischen numerischem und biologischem Alter konstatiert.

\section{Alter als soziales Phänomen}

Alter wird in diesem Konzept in Beziehung gesetzt zur Integration in den sozialen Prozeß. In dem Maße wie Zuwendung und Teilnahme am sozialen Leben bestehen, ist man nicht alt. Erst wenn soziale Isolierung stattfindet und andere Einstellungen und Werte ausgebildet werden, setzt Alter ein. Diese Altersvorstellung findet z.B. Ausdruck in Äußerungen wie: 'Für dein Alter bist du aber ganz schön aufgeschlossen und rege.' und 'Deine Ansichten sind ja richtig modern.' Mit ihnen wird eine positive Diskrepanz zwischen numerischem und sozialem Alter ('alterstypischen' Verhaltensweisen, Einstellungen und Werten) thematisiert.

\section{Alter als interaktiv-kommunikatives Phänomen}

Dieses Konzept betont, daß Alter keine feststehende objektive Größe ist, sondern daß Interaktionsbeteiligte mittels verschiedener Verfahren die Möglichkeit haben, die Kategorie 'Alter' in der Interaktion relevant zu machen und sich als alt oder jung zu präsentieren. Eine Äußerung, die auf dieses Konzept Bezug nimmt, ist z.B.: 'Du machst dich älter als du bist.'

Diese vier Konzepte - teils einzeln, teils miteinander interferierend - bilden den mentalen Hintergrund für die Erfahrung von Alter und das explizite oder implizite Relevantwerden von Alter in der Interaktion und Kommunikation. 


\section{Kommunikationssituationen im Alter}

Das Kommunikationsaufkommen - als Gesamtheit der individuellen kommunikativen Aktivitäten - verändert sich über die Lebensspanne. Dies gilt in quantitativer Hinsicht, aber auch bezüglich der Verteilung von mündlicher und schriftlicher Kommunikation, der Benutzung von Kommunikationsmedien und der Verwendung von spezifischen Textsorten und Gesprächsformen.

Die Beschreibung der Veränderungen, die hier mit dem Alter eintreten, ist weitgehend noch zu leisten. Es ist aber zu vermuten, daß sowohl im Bereich schriftlicher wie auch im Bereich mündlicher Kommunikation deutliche Umstrukturierungen erfolgen.

Betrachtet man die mündliche Kommunikation, so lassen sich die kommunikativen Kontakte älterer Menschen vier deutlich unterschiedlichen Konstellationen zuordnen. Diese vier Konstellationen ergeben sich aus der Kreuzklassifikation der Merkmale 'innergenerationell vs. intergenerationell' und 'innerfamiliär vs. außerfamiliär'. Den Begriff 'familiär' möchten wir dabei in seiner lateinischen Bedeutung verstanden wissen, also nicht im Sinne formaler Familienbeziehungen, sondern im Sinne einer langen wechselseitigen Vertrautheit.

\section{Gespräche mit anderen alten Menschen - innerhalb der Familie}

Die erste Konstellation ist die Kommunikation zwischen alten Menschen, die durch familiäre Beziehungen miteinander verbunden sind, seien es Ehepartner, Geschwister oder sehr gute Bekannte, die über eine weite Strecke gemeinsam alt geworden und die auf dem Hintergrund ihrer langen Interaktionsgeschichte miteinander kommunizieren.

\section{Gespräche mit anderen alten Menschen - außerhalb der Familie}

Die zweite Konstellation ist die Kommunikation zwischen alten Menschen, die sich zufällig oder nur sporadisch (als Bekannte) begegnen, sei es im Park, in Altentreffs, im Altersheim oder sonstwo.

\section{Gespräche mit den anderen Generationen - innerhalb der Familie}

Die dritte Konstellation ist das innerfamiliäre Gespräch zwischen den Generationen bzw. entlang der Generationslinien, also etwa im Rahmen der Eltern-Kind-Beziehung (sofern die Eltern nur hinreichend 'alt' sind) oder in der Großeltern-EnkelBeziehung.

\section{Gespräche mit den anderen Generationen - außerhalb der Familie}

Die vierte Konstellation ist die Kommunikation zwischen alten Menschen und innen fremden jüngeren (Gespräche mit dem Arzt, auf Ämtern, im Zug etc.). (Für jüngere Menschen mag es instruktiv sein, sich zu vergegenwärtigen, wann sie zuletzt mit älteren Menschen außerhalb der eigenen Familie gesprochen haben).

Es steht zu vermuten, daß das Kommunikationsverhalten in diesen vier Konstellationen deutlich differiert und daß sie deshalb gesondert untersucht und beschrieben werden müssen. 
Elementare Voraussetzung hierfür wäre aber zunächst einmal, daß in einem ausreichenden Umfang in diesen Konstellationen Gespräche aufgezeichnet werden und so eine reichhaltige empirische Grundlage für entsprechende Untersuchungen geschaffen wird. Ein Zugang zur Realität der Kommunikation im Alter und ihren vielfältigen Erscheinungen ist nur hierüber zu gewährleisten. Systematisch erhobene Korpora sind aber im Moment noch weitgehend ein Desiderat. Ähnliches gilt für Korpora schriftlicher Texte von älteren Menschen.

\section{Forschungssituation}

Während alte Menschen in der deutschsprachigen Linguistik nicht vorkommen, zeigt sich in anderen geisteswissenschaftlichen Disziplinen ein anderes Bild. Sowohl Psychologie, Sozialpsychologie und Soziologie haben wohletablierte Bereiche, in denen die Altersthematik bearbeitet wird. Daneben hat sich die Gerontologie als eigenständige Disziplin etabliert. Beiträge zur Altersforschung leisten darüber hinaus z.B. die Pädagogik (Kade 1994a,b), die Pflegewissenschaft oder die Sprecherziehung (Geißner 1995). Ausdruck dieses multi- und interdisziplinären Interesses an der Altersproblematik ist auch das Funkkolleg "Altern" (1996), das Alter und Altern aus einer Vielzahl von Perspektiven behandelt, das aber bezeichnenderweise keine gesonderte Einheit zu Sprache und Kommunikation im Alter enthält.

Auch im internationalen Forschungskontext stellt sich die Forschungssituation weitaus positiver dar. Hier zeigt sich auch ein ganz anderes Bild, was Untersuchungen zu den Zusammenhängen zwischen Alter und sprachlich-kommunikativen Phänomenen angeht. Vor allem in den Vereinigten Staaten, in Kanada und in Großbritannien hat sich 'Communication und Aging' seit Ende der 80er Jahre als eigenständiges Forschungsgebiet in Soziologie, Sozialpsychologie und Sprachwissenschaft, hier speziell in den Bereichen Soziolinguistik und Diskursanalyse, etabliert (vgl. z.B. das Handbuch von Nussbaum \& Coupland 1995, oder die Sammelbände von Coupland \& Nussbaum 1993 und Hummert, Wieman \& Nussbaum 1994). Dabei bildeten sich verschiedene Untersuchungsschwerpunkte heraus. So wurde z.B. die Frage nach den Zusammenhängen zwischen Sprache und Gesundheit thematisiert und zum Gegenstand der Konferenzserie 'Language, Aging and Health' (vgl. Giles, Coupland \& Wieman 1990), und auf der anderen Seite sind es anwendungsorientierte Perspektiven, die im Mittelpunkt des Interesses stehen (vgl. das Sonderheft von Applied Communication Research (1) 1998).

So liegt inzwischen im englischsprachigen Raum zum Thema Alter, Sprache und Kommunikation eine erhebliche Anzahl von Arbeiten vor: Allein das Literaturverzeichnis in Coupland, Coupland \& Giles (1991) enthält bereits annährend 400 Titel (vgl. auch den Forschungsüberblick in Thimm i.V.).

Betrachtet man die Entwicklung des Forschungsgebietes 'Sprache und Kommmunikation im Alter', so läßt sich feststellen, daß die bis in die 70er Jahre vorherrschende Forschungsstrategie zu den interaktiven und kommunikativen Beziehungen im Alter durch quantitative Aspekte, durch Fragen nach dem 'wieviel' und 'wie oft' bestimmt war. Seit Ende der 70er Jahre wurde jedoch in soziologischen (Connors, Powers \& Bultena 1979), in sprachpsychologischen (Ryan, Giles, Bartolucci \& Henwood 1986, vgl. Ryan \& Kwong See i.d.Bd.) und kommunikationswissenschaftlichen Arbeiten (Nussbaum 1983) demgegenüber die Notwendigkeit einer Hinwendung zu qualitati- 
ven Problemstellungen, zur Erforschung der Funktion und Bedeutung von Sozialkontakten im Alter gefordert. Nussbaum $(1983,262)$ formuliert: "Though much is known concerning communication patterns and perceptions of children and college-aged adults, very little is known concerning communicative patterns or the functions of communication for individuals entering their sixth decade of life."

Den meisten Untersuchungen lag bis dahin implizit die Annahme des 'Geselligkeitsfundus' zugrunde (Connors et al. 1979). Dabei wird davon ausgegangen, daß jedes Individuum ein bestimmtes Maß an Interaktionen notwendig braucht und darunter leidet, wenn die Summe der Beziehungen zu anderen dieses Maß unter- oder überschreitet. Der Qualität der Sozialkontakte und ihrer Kommunikationsform wurde dabei zunächst keine große Bedeutung beigemessen.

Kritik an diesem betont quantitativen Ansatz galt vor allem der mangelnden Berücksichtigung der Verschiedenheit sozialer Beziehungen und deren jeweils spezifischer Funktionalität. So läßt sich gerade im Alter der Verlust einer Bezugsperson nicht ohne weiteres durch Quantität (vermehrte Kontakte) oder Qualität (Intensivierung weniger Kontakte) ersetzen. Connors et al. $(1979,119)$ stellen fest, daß das Wohlbefinden älterer Menschen maßgeblich nicht bestimmt wird "[...] by 'how often' or 'with how many' one interacts, but rather under what circumstances, for what purposes, with what degree of intimacy and caring the interaction takes place." Auf diesem Hintergrund kann die Qualität der sprachlichen Interaktion als eine der Grundlagen für erfolgreiches Altern angesehen werden.

Betrachtet man die Forschungslage unter dem Aspekt theoretischer Grundpositionen, denen dann je spezifische Forschungsperspektiven und Fragestellungen für empirische Untersuchungen entsprechen, so lassen sich vor allem drei Ansätze unterscheiden:

- Alterskommunikation als eine durch spezifische sprachlich-kommunikative Merkmale ('age markers') bestimmte Form von Sprache und Sprechen, wobei sich 'Altersmerkmale' als Abweichung von einer als 'Normalform' angenommenen basalen Konstruktion definieren.

- Alter als Auslöser von stereotypen Einstellungen und einer daraus resultierenden sprachlichen Anpassung (kommunikative Akkommodation), die in Form von Sprechstilen linguistisch manifest wird.

- Alter als interaktiv konstituierte soziale Kategorie, die in jeder Interaktion von den Interagierenden kontextspezifisch hervorgebracht und durch bestimmte kommunikative Verfahren und Mittel relevant gesetzt wird.

Der Ansatz, Altersspezifik als Menge abweichender Merkmale zu konzeptualisieren, darf als der früheste und verbreitetste Zugang zur Alterskommunikation angesehen werden. Betrachtet man die methodische Herangehensweise bei der Identifizierung von sprachlich-kommunikativen Altersspezifika, so werden sie in vielen Untersuchungen an dem Komplex der 'Sprachfähigkeit' im Alter festgemacht und mithilfe des Maßstabs der Veränderungen bzw. Abweichungen von einer als 'normal' gesetzten Sprachfähigkeit beschrieben (Helfrich 1979). In solchen defizitorientierten Modellen wird davon ausgegangen, daß der Spracherwerb in einem spiegelbildlichen Verhältnis zu Erscheinungsformen des Sprachverlusts steht. Im überwiegenden Teil der Forschung wurde versucht, dieses Modell des Sprach- und Kommunikationsverlusts 
über die Herausarbeitung spezifischer Merkmale von Sprache und Kommunikation im Alter zu belegen. Gegenstand dieser Forschungsrichtung waren isolierte Merkmale der Sprache und des Sprechens, die in Vergleichsstudien zwischen älteren und jüngeren Sprecherinnen und Sprechern herausgearbeitet wurden. Dabei wurden vor allem quantitative Unterschiede konstatiert (z.B. weniger komplexe Syntax, Gebrauch veralteter Lexeme und Idiome, häufigeres Vorkommen einer Vergangenheitsperspektive, geringere Sprechrate). Auf diese Weise wird ein 'typisches' Bild von Sprache und Kommunikationsverhalten im Alter entworfen. Problematisch an Untersuchungen im Rahmen dieses Ansatzes ist das zumeist experimentelle Design und die fehlende Berücksichtigung der Interaktionskonstellation und natürlicher $\mathrm{Ge}-$ sprächsbedingungen (vgl. Fiehler i.d.Bd.).

Ebenso gravierend wie die methodischen Probleme dieses Ansatzes ist das in diesem Rahmen vertretene Modell der sprachlichen Entwicklung im Alter. Ein Großteil der Forschungsarbeiten geht von einer defizitären Entwicklung aus und steht damit in der Tradition der Defizit- bzw. Regressionshypothese, die jedoch in der Gerontologie seit langem stark kritisiert wird. Die zugrunde gelegte Modellvorstellung ist die des 'inversen U' (Coupland \& Coupland 1990): Die Sprachkompetenz beginnt auf niedrigem Niveau im Kindesalter, steigt auf ihren höchsten Wert im mittleren Erwachsenenalter und fällt dann mit zunehmendem Alter steil ab, um letztlich wieder auf kindlichem Niveau zu enden. Das Modell geht davon aus, daß das mittlere Erwachsenenalter durch hohe Variabilität ausgezeichnet ist, während sich die stilistische Variationsbreite im Alter deutlich verringert. Damit entsteht ein Konzept von Sprache im Alter, das die Sprachentwicklung nicht nur als Verringerung von Kompetenz, sondern als einen regressiven Prozeß ansieht, der zu einer Rückkehr zu den Verhaltensweisen der frühen Lebensjahre führt (vgl. auch Mattheier 1987).

Wie gegenwärtig dieses Modell auch in Alltagsvorstellungen vom Alter ist, zeigt nicht zuletzt die Redeweise vom Alter als 'zweiter Kindheit'. Daß jedoch die Vorstellung über einen Abbau im sprachlichen Bereich nur selten den Tatsachen entspricht, betonen Ryan \& Cole (1990):

"Among the great majority of elders, communication skills for everyday interactions are altered only mildly in aging, if at all. - The most important generalisation about speech and language in late life is that chronological age indicates very little about the level of skill of an individual." (Ryan \& Cole 1990, 179)

Nicht nur, daß ein solches Defizitmodell die vielen Facetten sprachlicher Realität nicht adäquat beschreiben kann, es verstellt auch andere, möglicherweise komplexere Sichtweisen auf linguistische Spezifika der Sprache im Alter. So z.B. gibt es erste Hinweise auf eine höhere Variabilität semantischer Kompetenzen, die möglicherweise durch die längere Lebensdauer und einen entsprechend größeren Fundus an Erfahrungen bedingt ist (Light 1993).

Auch andere Autoren warnen aufgrund von experimentellen Untersuchungen vor einer voreiligen Annahme von kommunikativen Defiziten bei älteren Menschen:

\footnotetext{
"In the current literature, communication is often treated as a 'problem' for the elderly. It may be that this orientation with its emphasis on clinical and experimental studies of both healthy and impaired persons, has missed an important point. 'Communication' is not merely episodic exchange between patient and health care provider, not between general service providers and the senior community, but rather an ongoing daily activity which needs to be studied as such." (Boden \& Bielby 1986, 85)
} 
Genau dieser Blickwinkel auf das 'normale' Alter in alltäglichen Situationen und die spezifischen Leistungen in variierenden Gesprächstypen bildet den Hintergrund vieler Beiträge in diesem Band, die sich damit deutlich vom Defizitmodell absetzen.

Der zweite Ansatz - das Stereotypenmodell der Alterskommunikation - entwickelte sich Ende der 80er Jahre aus der 'language attitude'-Forschung. Die Diskrepanz zwischen dem Eindruck, sprachlich und kommunikativ uneingeschränkt kompetent zu sein, dennoch aber mit negativen Erwartungen hinsichtlich ihres kommunikativen Verhaltens konfrontiert zu werden, ist für viele ältere Sprecher und Sprecherinnen eine alltägliche und z.T. frustrierende Erfahrung. Die Beobachtung von Divergenzen zwischen der Selbsteinschätzung älterer als kompetente Sprecher und Sprecherinnen und dem Verhalten der anderen ihnen gegenüber führte zu der Vorstellung, daß das Kommunikationsverhalten älteren Menschen gegenüber als präformiert anzusehen ist, eine Beobachtung, die Palmore schon $(1982,333)$ zu der Feststellung führte, daß "many if not most of the 'problems of aging' stem from or are exacerbated by prejudice and discrimination against the aged." Grund für diese Verhaltensweisen sind - so das Stereotypenmodell - Erwartungen und Stereotype, die jüngere Personen hinsichtlich des Alters haben und die bei ihnen zu bestimmten sprachlichen (Über-)Anpassungen führen. Im Gegensatz zum age-marker-Ansatz werden also vermehrt interaktive Perspektiven erfaßt.

Theoretisch fußt diese Herangehensweise auf der sozialpsychologischen Stereotypenforschung und auf der Sprachakkommodationstheorie. Im Zentrum stehen vor allem die negativen Stereotype über das Altern und alte Personen, die sich in Form 'patronisierender Kommunikation' niederschlagen. Betont wird entsprechend die Interdependenz zwischen den Problemen des Alter(n)s, den auf das Alter bezogenen stereotypen Erwartungen und der sprachlichen Kommunikation. Dieser Ansatz wird vor allem von Ellen Ryan und ihrer Forschergruppe vertreten. Ausgangspunkt ist die Arbeit von Ryan et al. (1986), in der mit dem 'Communication Predicament of Aging' ein Beschreibungsmodell für stereotypgeleitete intergenerationelle Diskurse vorgelegt wurde (vgl. dazu Ryan \& Kwong See i.d.Bd.).

Erst in den letzten Jahren hat sich - als dritte Perspektive - ein interaktionistischer Ansatz herausgebildet, der Prozesse der interaktiven Aushandlung eines variabel definierbaren sozialen Alters in das theoretische Zentrum stellt. Untersucht wurden vor allem von der Forschergruppe um $\mathrm{H}$. Giles und J. und N. Coupland - dialogische Interaktionen zwischen Personen der gleichen oder unterschiedlicher Altersgruppen und deren gemeinsame Konstituierung der sozialen Kategorie 'Alter'. Die ersten Arbeiten, die auf dem Hintergrund einer interaktionistisch-konstruktivistischen Theorie entstanden, sind die von Coupland, Coupland \& Giles (1991) in Form einer Monographie zusammengefaßten Aufsätze über Gespräche zwischen älteren und jüngeren Frauen. Alter wird von den Autorlnnen primär nicht als natürliche bzw. biologische Gegebenheit, sondern als Konstrukt verstanden, dessen Erscheinungsweisen interaktional hervorgebracht werden. Es liegt - zumindest ein Stück weit - in der Hand der Sprecher und Sprecherinnen, ob sie die Kategorie 'Alter' in der Interaktion relevant setzen und ob und wie sie sich als 'alt' oder als 'jung' darstellen. Dieser Ansatz geht davon aus, daß soziale Kategorien in Interaktionen keine festen Größen sind, sondern interaktiven Konstruktionsprozessen unterliegen. So wird auch Altsein bzw. Jungsein in seiner spezifischen Ausprägung und Funktion in jeder Interaktion wechselseitig zwischen den Sprechenden mithilfe bestimmter Verfahren konstituiert. 
Alter ist also nicht nur als 'contextual age' (Rubin \& Brown 1975), sondern als interaktiv konstituiertes Phänomen anzusehen. Dabei steht nicht mehr der/die einzelne Sprecher/in im Zentrum, sondern der Austausch. Das linguistische Analyseinteresse richtet sich in diesem Rahmen auf die Frage, mit welchen Verfahren und sprachlichen Mitteln Alter im Gespräch relevant gesetzt wird.

\section{Das Spektrum des Bandes}

Obwohl die Beiträge dieses Bandes eine breite Spanne erfassen, können sie das Gebiet, das mit den Begriffen 'Alter', 'Sprache' und 'Kommunikation' abgesteckt wird, in keiner Weise vollständig bearbeiten. Zu groß ist das Untersuchungsfeld, zu gering die existierende empirische Datenbasis, auf die man sich stützen könnte, und zu vielschichtig die zu berücksichtigenden Forschungsergebnisse aus anderen Disziplinen. So ist es die Hauptaufgabe des Bandes, die Breite dieses Feldes zu explorieren und exemplarisch zu verdeutlichen, welche empirischen Phänomene zur Untersuchung anstehen, welche Methodiken dabei verwendet werden und auf welchen theoretischen Hintergründen solche Untersuchungen erfolgen können.

Die Beiträge des Bandes reichen ihrem Charakter nach vom Überblicksartikel (Ryan \& Kwong See, Schecker) bis zur Detailuntersuchung. Neben den vielfältigen empirischen Analysen ist es vor allem gerade die theoretisch-methodologische Fundierung dieses neuen Forschungsgebietes, die in mehreren Beiträgen behandelt und aus unterschiedlichen Perspektiven diskutiert wird (Brose, Fiehler, Kohrt \& Kucharczik, Ryan \& Kwong See).

Gegenstand der Beiträge ist das normale Alter(n) ebenso wie Auswirkungen pathologischer Prozesse auf das Sprachverhalten im Alter (Gress-Heister, Schecker).

Ein Untersuchungsschwerpunkt ist die Frage, wie Stereotype und Erwartungen über ältere Menschen sich im sprachlichen Handeln jüngerer Personen (Maier, Sachweh, Schnieders), aber auch z.B. in Wörterbucheinträgen niederschlagen (Kramer). Einen weiteren Schwerpunkt bilden die Verfahren und sprachlichen Mittel, mit denen die Kategorie 'Alter' interaktiv relevant gesetzt werden kann (Fiehler, Schnieders, Thimm).

Die Beiträge des Bandes verwenden verschiedene Typen empirischer Daten. Im Bereich der mündlichen Kommunikation sind dies authentische Gespräche (Heidtmann, Pothmann, Lambert, Sachweh, Schnieders), Interviews (Betten, Brose, Heidtmann), experimentell gewonnene Gesprächsdaten (Thimm) und experimentell gewonnene monologische Daten (Gress-Heister, Maier). Im Bereich der schriftlichen Daten werden Briefe (Cherubim \& Hilgendorf) und Wörterbücher (Kramer) untersucht. Sie verteilen sich wie folgt über die o.g. Konstellationen: Innergenerationelle Kommunikation außerhalb der Familie (Cherubim \& Hilgendorf, Lambert), intergenerationelle Gespräche innerhalb der Familie (Heidtmann) und intergenerationelle Gespräche außerhalb der Familie (Pothmann, Sachweh, Schnieders, Thimm). Es kommen also nicht alle wesentlichen Konstellationen vor, und sie sind auch nicht gleich stark vertreten.

Anhand der Daten wird das Gesprächsverhalten im Rahmen verschiedener Institutionen untersucht: in Wirtschaftsunternehmen (Pothmann, Schnieders), Altentagesstätten (Lambert), Altenheimen (Lambert, Sachweh) und in der Mehrgenerationenfamilie (Heidtmann). 
Die Methodik variiert von der qualitativen gesprächsanalytischen Untersuchung (Brose, Heidtmann, Lambert, Pothmann, Sachweh, Schnieders, Thimm) über die ethnographische Beschreibung (Heidtmann) und die Interviewauswertung (Betten) bis zum sprachpsychologischen Experiment (Gress-Heister, Maier). Die schriftsprachlichen Daten werden textanalytisch ausgewertet (Cherubim \& Hilgendorf, Kramer).

Die Beiträge des Bandes zeigen u.E. gerade durch ihre Vielfältigkeit auf, wie interessant und vielversprechend dieses Forschungsgebiet ist. Der Sammelband erfüllt seinen Zweck, wenn er dies vermitteln kann und zu weiteren Arbeiten in diesem Bereich anregt.

Abschließend möchten wir Daniela Heidtmann sehr herzlich danken, die nicht nur inhaltlich zu diesem Band beigetragen, sondern auch in mühevoller Arbeit die Druckvorlage erstellt hat.

\section{Literatur}

Applied Communication Research (1998). Special issue: Ageing and communication. Applied perspectives (ed. by H. Giles), 1.

Boden, Deirdre \& Bielby, Denise (1986). The way it was: Topical organization in elderly conversation. In: Language and Communication 6(1/2), 73-89.

Connors, K., Powers, E. \& Bultena, G. (1979). Social interaction and life satisfaction: An empirical assessment of late-life patterns. In: Journal of Gerontology 34, 116-121.

Coupland, Nikolas \& Coupland, Justine (1990). Language and later life: The diachrony and decreement predicament. In: H. Giles \& P. Robinson (eds.), Handbook of language and social psychology. Chichester: Wiley, 451-468.

Coupland, Nikolas, Coupland, Justine \& Giles, Howard (1991). Language, society and the elderly: Discourse, identity and ageing. Oxford/Cambridge, Mass.: Blackwell.

Coupland, Nikolas \& Nussbaum, John (eds.) (1993). Discourse and lifespan identity. Newbury Park: Sage.

Deutsches Institut für Fernstudienforschung (Hrsg.) (1996). Funkkolleg Altern. Studienbriefe 1-7. Tübingen.

Fiehler, Reinhard (1997). Kommunikation im Alter und ihre sprachwissenschaftliche Analyse. Gibt es einen Kommunikationsstil des Alters? In: B. Sandig \& M. Selting (Hrsg.), Sprech- und Gesprächsstile. Berlin/New York: de Gruyter, 345-370.

Geißner, Hellmut (1995). Sprecherziehung für Ältere. In: Metelerkamp, Jürgen (Hrsg.): Lernziel: Gesprächsfähigkeit. Frankfurt a.M.: DIE, 113-126.

Giles, Howard, Coupland, Nikolas \& Wiemann, John (eds.) (1990). Communication, health and the elderly. London: Manchester University Press.

Helfrich, Hede (1979). Age markers in speech. In: K. Scherer \& H. Giles (eds.), Social markers in speech. Cambridge: University Press, 63-107.

Hummert, Mary Lee, Wiemann, John \& Nussbaum, John (eds.) (1994). Interpersonal interaction in older adulthood. Thousand Oaks: Sage.

Kade, Sylvia (1994a). Altersbildung: Ziele und Konzepte. Frankfurt a.M.: DIE.

Kade, Sylvia (1994b). Altersbildung: Lebenssituation und Lernbedarf. Frankfurt a.M.: DIE.

Light, Leah (1993). Language changes in old age. In: G. Blanken, J. Dittmann, H. Grimm, J.C. Marshall \& C.-W. Wallesch (eds.), Linguistic disorders and pathologies. An international handbook. Berlin/New York: de Gruyter, 900-918. 
Mattheier, Klaus (1987). Alter, Generation. In: U. Ammon, N.Dittmar \& K. Mattheier (Hrsg.),. Sociolinguistics/Soziolinguistik. An international handbook of the science of language and society/Ein internationales Handbuch zur Wissenschaft von Sprache und Gesellschaft, Bd.1. Berlin/New York: de Gruyter, 78-82.

Nussbaum, John (1983). Successful aging: a communication model. In: Communication Quarterly 33(4), 262-269.

Nussbaum, John \& Coupland, Justine (eds.) (1995). Handbook of communication and aging research. Mahwah, New Jersey: Erlbaum.

Palmore, E. B. (1982). Attitudes toward the aged: What we know and need to know. In: Research on Aging 4(3), 333-348.

Prahl, Hans-Werner \& Schroeter, Klaus (1996). Die Soziologie des Alterns. Frankfurt: UTB.

Rubin, Kenneth \& Brown, lan (1975). A life-span look at person perception and its relationship to communicative interaction. In: Journal of Gerontology 30(4), 461-468.

Ryan, Ellen, Giles, Howard, Bartolucci, Giampiero \& Henwood, Karen (1986). Psycholinguistic and social psychological components of communication by and with the elderly. In: Language and Communication 6(1/2), 1-24.

Ryan, Ellen \& Cole, Richard (1990). Evaluative perceptions of interpersonal communication with elders. In: H. Giles, N. Coupland \& J.M. Wiemann (eds.), Communication, health and the elderly. London: Manchester University Press, 172-191.

Thimm, C. (i.V.). Alter - Sprache - Interaktion. Theoretische, methodische und empirische Ansätze zur einer Linguistik des höheren Erwachsenenalters. Habilitationsschrift: Universität Heidelberg. 


\title{
'Sprache' - unter besonderer Berücksichtigung von 'Jugend' und 'Alter'
}

\author{
Manfred Kohrt / Kerstin Kucharczik
}

\section{Vorbemerkungen}

Deutschsprachigen Sprechern und Sprecherinnen dient der Ausdruck Sprache als bequemes Vehikel dafür, über 'Sprachliches' (im weitesten Sinne des Wortes) zu sprechen, in ähnlicher Weise, wie man den Ausdruck Schrift benutzt, wenn es - in welcher Hinsicht auch immer - um Geschriebenes zu tun ist (das dann seinerseits auch wieder in den Bereich der 'Sprache' gehört). Dieser Ausdruck Sprache ist Teil einer lingua franca zwischen ganz unterschiedlichen Gruppen von Sprecher/inne/n des Deutschen: Er ist überaus nützlich, z.B. Laien in Sachen Linguistik alltagssprachlich zu erklären, was man selbst beruflich tut ("Ich beschäftige mich mit deutscher Sprache"), und er dient im wissenschaftlichen Rahmen dazu, Kommunikation über die Grenzen der Einzeldisziplinen hinweg möglich zu machen (so daß man dann, wenn man z.B. etwas über die 'Sprache der Bienen' oder die 'Formensprache des Kubismus' zu hören bekommt, sich wenigstens einigermaßen darauf einzustellen vermag, was denn damit gemeint ist resp. gemeint sein könnte). Dieses gemeinsame Band verlängert sich zugleich in die Linguistik selbst hinein, wo der vielfache Gebrauch des Ausdrucks Sprache das beruhigende Gefühl schafft, daß man sich gemeinsam um denselben wissenschaftlichen Gegenstand bemüht (die 'Sprache' im allgemeinen und die 'deutsche Sprache' bei germanistischen Linguist/inn/en im besonderen). Kurzum: Die gemeinsame Verwendung des Wortes Sprache genügt, um grundsätzliche Vertrautheit zu suggerieren, trotz aller sonstigen unterschiedlichen Annahmen und Sichtweisen im einzelnen.

Was aber macht nun diejenige 'Sprache' aus, die man - in einem verengenden Gebrauch des Wortes Sprache - als Linguist/in jeweils als Forschungsgegenstand konzipiert, und dies jenseits aller anderen möglichen und/oder gebräuchlichen Verstehensweisen für diesen Ausdruck? In diesem Punkt orientieren wir uns zunächst an dem von de Saussure $(1916,23)$ geprägten Diktum: "Bien loin que l'objet précède le point de vue, on dirait que c'est le point de vue qui crée l'objet" (wobei man die vorsichtigen drei Wörter on dirait que u.E. besser streichen sollte). Es geht also um die vorherige Konstitution desjenigen wissenschaftlichen 'Gegenstands', den man untersuchen will, und es ist u.E. ebenso sinnvoll wie notwendig, sich gerade dann über eine solche Objektkonzipierung genauere Gedanken zu machen, wenn man es mit einem neuen, bislang noch wenig beackerten Forschungsfeld zu tun hat, hier mit dem der Kommunikation älterer resp. alter Sprachteilhaber/innen des Deutschen untereinander und im Gespräch mit Personen anderer Altersstufen.

Sofern man sich bislang mit altersspezifischen Besonderheiten gewisser Sprechergruppen beschäftigt hat, ist zur Kennzeichnung des Untersuchungsfelds normalerweise auf den Ausdruck Sprache zurückgegriffen worden, und dies in einem recht diffusen Sinne dieses Wortes: So war zunächst von einer 'Kindersprache' die Rede, deren Analyse genauere Aufschlüsse über Prozesse des Spracherwerbs liefern sollte, und in den letzten Jahrzehnten von einer 'Jugendsprache' im Altersbereich 
von Pubertät und Adoleszenz. Von einer 'Erwachsenensprache' ist hingegen eher selten gesprochen worden, sondern es wurde einfach davon ausgegangen, daß eben diese Erwachsenensprache letztlich mit der 'Standardsprache' zu identifizieren sei und daß die letztere den wesentlichen Bezugspunkt für einen kontrastiven Vergleich mit der 'Sprache' von Sprecher/inne/n unterschiedlicher Altersgruppen abgebe. In einer schlichten Verlängerung der bisherigen Linie ist (leider) zu erwarten, daß man demnächst wohl auch noch von einer 'Altensprache' sprechen wird oder um sich in dieser Hinsicht möglichst 'politisch korrekt' auszudrücken - von einer 'Senior/inn/ensprache'. Eine solche Redeweise würde unserer Meinung nach allerdings falschen Hypostasierungen geradezu Vorschub leisten, und sie sollte deshalb von Beginn an besser vermieden werden.

$\mathrm{Ob}$ und, wenn ja, inwieweit man aus Erfahrungen und Fehlern der Vergangenheit lernen kann, ist notorisch strittig; völlig unstrittig scheint uns hingegen, daß man es zumindest versuchen sollte. Und im gegenwärtigen Kontext bietet sich da direkt ein historisches Lehrstück an, das zudem den Vorteil hat, erst kurz zurückzuliegen und immer noch aktuell zu sein - nämlich die Erforschung der sog. 'Jugendsprache'. Eine genauere Betrachtung der betreffenden linguistischen Bemühungen kann oder könnte zumindest dazu dienen, bei der Untersuchung des Sprechens und der Kommunikation älterer und alter Menschen gewisse frühere 'pitfalls' bei der Untersuchung altersspezifischer sprachlicher Besonderheiten zu vermeiden und den o.g. 'point de vue' bei der Konstitution des wissenschaftlichen Objekts klarer herauszuarbeiten, als es ohne diese vorgängigen Erfahrungen möglich wäre. Während sonst bevorzugt gilt, daß Jüngere von Älteren lernen, können wir hier auf der Metaebene den Spieß vielleicht einmal umdrehen, indem die künftige Erforschung des Sprachverhaltens älterer Sprecher/innen etwas aus der vorherigen Analyse der Kommunikation jugendlicher Sprachteilhaber lernt.

In diesem Zusammenhang ist kurz darauf einzugehen, warum die Untersuchung von Besonderheiten jugendlicher Kommunikation der Analyse des Sprechens älterer und alter Sprachteilhaber/innen forschungshistorisch vorangegangen ist. In Überblicksartikeln über altersspezifische Besonderheiten des Sprachgebrauchs stößt man notorisch auf kaum verhüllte Offenbarungseide bezüglich des letzteren Bereichs wie z.B. "little information is available concerning the development in older people" (Helfrich 1979, 92) oder "little is known about the language of the elderly, despite its importance for language pathology" (Cheshire 1987, 766); hinsichtlich des erstgenannten Bereichs wird hingegen inzwischen befriedigt die "bemerkenswerte Anzahl von Veröffentlichungen zu diesem Thema" registriert (so Heinemann 1993, 84).

Man mag dieser bisherigen Vernachlässigung der einen und der Präferenz für die andere Seite eventuell auch einen positiven Aspekt abgewinnen - daß nämlich ältere und alte Sprachteilhaber einfach zur Kategorie der 'Erwachsenen' gezählt wurden und deshalb vermeintlich keinerlei eigener Aufmerksamkeit bedurften, sofern nicht sprachpathologische Erscheinungen zu beobachten waren. Ungleich gewichtiger scheinen jedoch grundsätzliche negative Einstellungen hinsichtlich des höheren Alters und - konterkarierend - positive Attitüden hinsichtlich des jugendlichen Alters zu sein (wobei die letzteren durch neuere gesellschaftliche Entwicklungen noch verstärkt sein mögen, vgl. Januschek 1989, 140f.). Um es vereinfacht und pointiert auszudrücken: Man kennt die Liedzeile "Man müßte noch mal zwanzig sein ...", aber von einem Analogon wie "Man müßte endlich achtzig sein ..." hat man noch nie et- 
was gehört - da fällt einem nur "Will you still need me, will you still feed me, when I'm sixtyfour" von den Beatles ein.

All das läßt sich jedoch linguistisch-germanistisch auch sehr viel seriöser ausdrücken, nämlich mit Jacob Grimm und seiner "Rede über das Alter", die er am 26. Januar 1860, also gut drei Jahre vor seinem Tode, in Berlin gehalten hat. Grimm (1864, 194) wies dabei auf einen eigentümlichen "widerspruch" hin, nämlich: "dasz während alle menschen alt zu werden wünschen, sie doch nicht alt sein wollen", und er machte weiter darauf aufmerksam, daß sich bei der Charakterisierung betagter Menschen "alle sprachen in ausdrücken [erschöpfen], die ungünstig lauten" (Grimm 1864, 201). Es gab und gibt also (durchaus verständliche) Hemmnisse für Sprachwissenschaftler/innen, sich mit dem sprachlichen Verhalten einer Altersgruppe zu beschäftigen, deren gesellschaftliche Wertschätzung eher gering (gewesen?) ist, und es bedarf offenkundig besonderer historischer Umstände, gegenwärtig grob charakterisiert durch das Wort von der 'Umkehrung der Alterspyramide', damit auch das linguistisch bislang kaum Behandelte einer wissenschaftlichen Behandlung für wert befunden wird (vgl. Abschnitt 3).

Als Resümee seines Vortrags und gleichzeitig als positive Utopie für eine zukünftige linguistische Forschung hat Jacob Grimm $(1864,207 f$.$) damals ausgeführt:$

"Ich glaube [...] manches zur stütze der ansicht vorgebracht zu haben, dasz das alter nicht einen bloszen niederfall der virilität, vielmehr eine eigene macht darstelle, die sich nach ihren besonderen gesetzen und bedingungen entfalte [...]."

Nun gut: Wir wissen, daß Jacob Grimm diesen Satz im Alter von 75 Jahren gesagt/geschrieben hat und daß die Motivation für Erklärungen dieser Art auch eine gewisse Selbstrechtfertigung gewesen sein mag. Dies kann und darf uns jedoch nicht daran hindern, solche Aussagen möglichst ernstzunehmen und dem genauer nachzugehen, was Jacob Grimm damals - eher andeutend und wenig präzise - in diesem Zusammenhang als "eigene macht" resp. als "besondere gesetze und bedingungen" bezeichnet hat.

Zu Beginn der 80er Jahre mochte die "These", "daß die germanistische Linguistik [...] sich zu lange und zu ausschließlich von Fragen der Theorie- und Methodenkonstitution hat leiten lassen" (Henne 1981, 371), forschungsstrategisch ihre Berechtigung gehabt haben, um neue Themen wie das der 'Jugendsprache' als linguistisch akzeptabel zu präsentieren. Empirie und Theorie sind aber, einem bekannten Diktum zufolge, jeweils blind, wenn sie sich nicht produktiv miteinander verbinden, und theoretische Überlegungen im Vorfeld einer empirischen Analyse der Kommunikation älterer und alter Menschen sind in unseren Augen nicht nur legitim, sondern unerläßlich, wenn man zu einer realistischen Einschätzung des zu Untersuchenden gelangen will.

\section{2. 'Sprache' und 'Jugend'}

Was den Gebrauch des Ausdrucks Jugendsprache in der neueren Forschung anlangt, so gibt es einen eigentümlichen Widerspruch in den wissenschaftlichen Arbeiten zu diesem Thema: Wieder und wieder wird erklärt, daß dieser Ausdruck doch falsch oder zumindest mißverständlich sei - und dennoch greift man plakativ immer wieder auf ihn zurück. Da lautet der Titel einer Monographie z.B. "Jugend und ihre Sprache" (Henne 1986); im Text hingegen erfährt man dann, daß diese besagte 'Ju- 
gendsprache' letztlich "nichts weniger als systematisch" sei und daß dieser Ausdruck eigentlich nur "in Anführungsstrichen" verwendet werden sollte - aber dennoch wird er, "der Erleichterung wegen", trotz solcher grundsätzlichen Bedenken weitestgehend ohne Anführungszeichen gebraucht (ebd. 208). In einem Buch über "Jugendsprache und Dialekt" (Ehmann 1992a) wird ausdrücklich darauf hingewiesen, daß es "überaus problematisch [sei], unreflektiert von einer jugendspezifischen Sonderlexik oder gar von der Jugendsprache zu sprechen" (ebd. 15) - aber ungeachtet dessen ist im weiteren z.B. die Rede davon, "daß Jugendsprache in erster Linie gesprochene Sprache ist" (ebd. 52). Und in einer Gemeinschaftsarbeit, die mit der Überschrift "Jugendsprache - Fiktion und Wirklichkeit" (Schlobinski et al. 1993) versehen ist, wird zwar schon im Vorwort von einem bloßen "Mythos von der Jugendsprache" gesprochen (ebd. 7) - schon der Titel des betr. Buches zeigt jedoch, daß der besagten 'Jugendsprache' doch in irgendeiner Hinsicht jenseits des bloß Fiktionalen auch eine gewisse 'Wirklichkeit' zugeschrieben wird, und im "Fazit" heißt es verdinglichend dann z.B.: "Jugendsprache manifestiert sich in bestimmten Ausdrücken und Redeweisen, die überwiegend in der Gleichaltrigengruppe Anwendung finden" (ebd. 204). Kurzum: 'Jugendsprache' gibt es, gibt es aber eigentlich nicht, aber irgendwie doch, und der Ausdruck Jugendsprache wird weiterhin gebraucht, auch wenn man der Meinung ist, daß er im Grunde genommen unpassend ist, weil es sich dabei um keine eigenständige 'Sprache' handele. Die 'Jugendsprache' ist überall gegenwärtig, aber als 'Sprache' nirgendwo recht faßbar.

Wie begründet man überhaupt die 'Eigenständigkeit' einer bestimmten Sprache? Überlieferte Rechtfertigungsstrategien haben insbes. auf den lexikalischen Bereich abgehoben: Eine eigene 'Sprache' könne im wesentlichen dann postuliert werden, wenn sie (möglichst viele) eigene Lexeme aufweise, die in anderen Sprachen (resp. Teilsprachen einer Gesamtsprache) nicht enthalten seien. Diese Sichtweise bestimmt nicht nur die frühe Konzeption sog. "Sondersprachen" bei Hirt (1909, 238ff.), bei der mit einem jeweils "eigentümlichen Wortschatz" (ebd. 3) eben solcher Sprachen gerechnet wird, sondern sie wird auch noch in verschiedenen Formulierungen greifbar, mit denen de Saussure (1916) sein homogenisierendes Konzept der einzelsprachlichen 'langue' erläutert: Diese gilt im wesentlichen als "somme des images verbales" (ebd. 30) bzw. als "somme d'empreintes déposées dans chaque cerveau, à peu près comme un dictionnaire dont tous les exemplaires, identiques, seraient répartis entre les individus" (ebd. 39). Einer derart verkürzenden und vereinfachenden Sicht der 'Sprache' als 'Wörterbuch', nunmehr im Rahmen einer solchen einzelsprachlichen 'langue' selbst, leisten natürlich alle sog. 'Wörterbücher der Jugendsprache' Vorschub, die nach irgendwelchen Ordnungsaspekten Lexeme und Phraseologismen aneinanderreihen (vgl. z.B. Welter 1960; Müller-Thurau 1985; Heinemann 1989; Ehmann 1992b u.a.m.). Es sollte jedoch eigentlich von vornherein klar sein, daß eine begrenzte Anzahl lexikalischer Einheiten selbst dann, wenn deren Gebrauch auf eine gewisse altersspezifische Gruppe beschränkt sein sollte, noch lange keine gültige Rechtfertigung dafür abgeben kann, von einer eigenen 'Sprache' zu sprechen, angesichts der Vielzahl von Übereinstimmungen, die schon im lexikalischen Bereich und auch sonst den Sprachgebrauch jugendlicher Sprecher mit dem anderer Sprachteilhaber des Deutschen eint.

Natürlich ist dies keine neue Einsicht: Die Kritiken an einem rein lexikalischen Zugriff bei der Etablierung irgendwelcher besonderer 'Sprachen' sind mittlerweile Legion, und es wäre müßig, sie hier im einzelnen noch einmal an- und aufzuführen. Dennoch und zugleich aber wird nicht selten die Vorstellung weiter genährt, daß es 
sich bei der sog. 'Jugendsprache' um eine eigenständige 'Sprache' handelt. Wir nehmen der Einfachheit halber nur ein einziges Beispiel heraus, nämlich das bekannte und oben bereits erwähnte Buch von Henne (1986) über "Jugend und ihre Sprache". Die Verwendung des Ausdrucks Sprache in Begriffen wie 'Jugendsprache' und z.B. 'Standardsprache' "suggeriert" nach Meinung des Autors lediglich, daß hier überhaupt eine Vergleichbarkeit bestehe (Henne 1986, 208), und letztlich "verwirr[e] [...] der parallele Gebrauch des Determinandums -sprache in Standardsprache und Fach- und Gruppensprache" (ebd. 5). Dies ist allerdings nur die eine Seite. Auf der anderen Seite wird nämlich zugleich versucht, die 'Jugendsprache' gemäß dem Titel des Buches "Jugend und ihre Sprache" als eigenständiges Objekt wissenschaftlichen Bemühens um Erkenntnis wieder zu retten. Das wesentliche Vehikel ist dabei der Gedanke einer 'Unvollkommenheit' von 'Fach- und Gruppensprachen': Es handle sich nämlich jeweils um "defizitäre Sprachsysteme, die oft [!] nur in der gleichzeitigen Übernahme standardsprachlicher Grammatik und Lexik eine 'Lebenschance' haben" (ebd. 5). Kurzum: Die besagten Sondersprachen sind eigentlich autark; sie passen sich aber (gemäß der alten Organismusmetapher) um des lieben Überleben-Wollens der Standardsprache an. Und dementsprechend werden die besagten 'Gruppensprachen' in diesem Buch dann, durch graphische Linien fein säuberlich von allen anderen 'Sprachen' separiert und somit als eigenständig ausgewiesen, an der Peripherie eines konzentrisch organisierten Schemas angesiedelt, in dessen Mitte die 'Standardsprache' steht (ebd. 220). Das Faktum, daß sich die besagten 'Gruppensprachen', wenn man sie denn überhaupt annehmen will, weitestgehend mit der 'Standardsprache' überschneiden, findet bei einer derartigen Darstellung bezeichnenderweise keinerlei Ausdruck.

Die Annahme, daß die 'Jugendsprache' ein eigenes sprachliches System besitze, wird in der linguistischen Fachliteratur zwar gern als bloße "Fiktion" bezeichnet (so z.B. Heinemann 1991, 6) - aber durch Bezeichnungen wie "altersspezifische Gruppensprache" (ebd. 6) oder "sozial geprägte Gruppensprache", die "nur im Umgang mit anderen Jugendlichen gebraucht" werde (ebd. 7), wird zugleich der Eindruck erweckt, als stünde den Jugendlichen eine eigenständige Sprache zur Verfügung. Das Ausmaß der faktischen Irritationen möge der folgende kuriose Satz belegen: "Jugendsprache entwickelt kein eigenes System und ist damit keine eigene Sprache" (Heinemann 1991, 9). Eine 'Sprache' ist also letztlich keine 'Sprache', weil sie es versäumt hat, das ihr gemäße eigene System auszubilden! Es ist kaum ein besseres Beispiel denkbar, um zu illustrieren, wie gründlich man sich im Netz des Gebrauchs des Wortes Sprache angesichts der sog. 'Jugendsprache' verheddern kann.

Wo eine besondere 'Sprache' als Zentrum des linguistischen Interesses nicht mehr klar identifizierbar und kaum noch erkennbar ist, gibt es offenbar im wesentlichen zwei Strategien, das reichlich Diffuse dennoch bearbeitbar zu machen. Die eine dieser Optionen ist, daß man sich metasprachlich in den Bereich eines metaphorischen Sprechens flüchtet; die andere ist die, daß man sich für die Analyse auf das Glatteis all jener vielfältigen Ausdrücke und Begriffe begibt, die irgendwo und irgendwie etwas zwischen der Einzelsprache selbst und ihrer faktischen Anwendung generalisierend kenntlich zu machen suchen (wie 'Stil', 'Sprechweise', 'Soziolekt', 'Register' usw.). Belegt sei zunächst das Erstgenannte, bevor wir uns dem zweiten und unserer Meinung nach sehr viel mehr Versprechenden zuwenden.

Metaphorisches Sprechen in der Wissenschaft ist sicherlich nicht grundsätzlich abzulehnen, und es mag - sofern die dabei verwandte Metaphorik in sich einigermaßen konsistent ist - bisweilen auch durchaus erhellend und weiterführend sein. 
Oft genug aber werden dabei klare, verständliche Aussagen nur durch etwas ersetzt, was in diffuser Weise 'Geahntes' irgendwie umsetzt, und dies in der stillen Hoffnung, daß der wissenschaftliche Leser es in ähnlicher Art und Weise empfinden möge. Als Beispiel sei wiederum das oben schon mehrfach genannte Buch von Henne (1986) genommen, aus dem im folgenden eine kleine Blütenlese metaphorischer Formulierungen angeführt sei.

In der sog. 'Jugendsprache' sollen Henne $(1986,209)$ zufolge z.B. "griffige Namen- und Sprachwelten" zu finden sein, und (die Verwendungen von) sog. 'Dehnungszeichen' wie und so gäben "jugendlichen Gesprächstexten einen 'schlingernden' Charakter" (ebd. 148). Insgesamt gesehen sei bei der Betrachtung solcher 'Texte' ein gewisser "Jugendton" festzustellen, "verstärkt durch einen eminent sprechsprachlichen Duktus" und "gepaart mit Partikelsucht" (ebd. 209ff.). 'Jugendsprache' sei im Grunde genommen nicht nur ein "spielerisches Sekundärgefüge, das [bestimmte] Sprachformen favorisiert", sondern vielmehr sei "Jugendsprache ein fortwährendes Ausweich- und Überholmanöver": "Zwar wandelt sie systematisch ab, aber sie ist nichts weniger als systematisch" (ebd. 208), denn "Jugendsprache in der Gruppe ist experimentell" (ebd. 210). "Das Sekundärgefüge 'Jugendsprache' erweitert das Sprachvermögen Jugendlicher und bedeutet zugleich Irritation ihrer Sprecher" (ebd. 211f.) - aber sicherlich nicht weniger irritiert ist man als Linguist/in, wenn man all dies und solche Formulierungen liest, die letztlich zu einer Partition der sog. 'Jugendsprache' in mehrere 'Dimensionen' führt: "Jugendsprache hat eine funktionelle, strukturelle und pragmatische Dimension. Hinzu kommt die Dimension der inneren Mehrsprachigkeit." (ebd. 214).

An all dem hier Wiedergegebenen mag in irgendeiner Art und Weise jeweils etwas richtig Gesehenes, Gefühltes oder Geahntes sein (wenn man die Formulierungen entsprechend interpretiert), aber es bleibt weitestgehend diffus und ohne klaren Bezug. An der Stelle eines bestimmenden "point de vue" bei der Konstruktion des Untersuchungsgegenstands erscheinen unversehens ein, zwei, drei, vier, viele Aspekte mit ganz unterschiedlichen Bezügen, und es ist letztlich völlig unklar, was denn die besagte 'Jugendsprache' als wissenschaftliches Objekt überhaupt ausmacht. Von einer 'Sprache', die 'systematisch abwandelt', ohne daß ihr selbst ein System zugrundeläge, haben wir noch nie etwas vernommen, ebensowenig von einer 'Sprache', die ein "Ausweich- und Überholmanöver" darstellt (mag letzteres auch von anderen gar als "treffend" bezeichnet werden, vgl. z.B. Oksaar 1996, 7). Wo der Bezugs- und Forschungsgegenstand diffus bleibt, feiert die Augenblicksmetaphorik fröhliche Urständ, und die besagte 'Jugendsprache' gilt dann letztlich als alles mögliche: als "eine Antwort auf die Arsenik-Wörter des öffentlichen Deutsch" (MüllerThurau 1985, 18), ein "Sprachgebaren" (Bausinger 1987, 172), ein "Signal, das Abgrenzung und Ausgrenzung bewirkt" (ebd. 173), "häufig verbaler Terror" (ebd.), als ein "Vehikel von Reifung und Ablösung" (ebd. 175) usw.usf.

Spätestens hier wissen wir nun, wie der Ausdruck Sprache in der Zusammensetzung Jugendsprache in sehr vielen Fällen zu verstehen ist, nämlich im überaus globalen Sinne des Begriffs 'langage', und eben dieser 'langage' hatte de Saussure $(1916,25)$ bereits Anfang unseres Jahrhunderts attestiert, daß sie auf Grund der Vielfältigkeit unterschiedlichster Aspekte letztlich überhaupt nicht sinnvoll untersucht werden könne:

"Pris dans son tout, le langage est multiforme et hétéroclite; à cheval sur plusieurs domaines, à la fois physique, physiologique et psychique, il appartient encore au domaine individuel et au domai- 
ne social; il ne se laisse classer dans aucune catégorie des faits humains, parce qu'on ne sait comment dégager son unité."

In diesem allgemeinen Sinne von 'langage' umfaßt die sog. 'Jugendsprache' in empirischer Hinsicht alles, was irgendwie mit der Kommunikation jugendlicher Sprachteilhaber zusammenhängt; in theoretischer Hinsicht entspricht dieser Vielfältigkeit dann aber schlichtweg nichts, was sich auf eine einheitliche, methodisch klare und konsistente Art und Weise untersuchen ließe.

Es wäre allerdings falsch und ungerecht, wenn man der gesamten Forschung zur sog. 'Jugendsprache' einfach unterstellen würde, daß sie den zweiten Bestandteil des Wortes Jugendsprache immer und überall nur als langage verstanden hätte, denn gerade in jüngster Zeit hat es mancherlei Versuche gegeben, den eigentlichen Forschungsgegenstand durch die Verwendung zusätzlicher linguistischer Termini aus dem diffusen Gesamtfeld herauszulösen. Die Vorschläge waren (und sind) dabei sehr heterogen, und sie offenbar(t)en vielfach wesentliche konzeptionelle Unterschiede. Verwandt wurden vor allem die Ausdrücke Subsprache, Sondersprache, Gruppensprache, Suppletivsprache, Varietät, (Sprech-)Stil, Register, Sprechweise, Spielart des Sprechens u.a.m. Nicht unbedingt ist dabei in jedem Fall wirklich klar, was mit der Verwendung der betreffenden Ausdrücke faktisch gemeint ist (vgl. z.B. Suppletivsprache bei Cherubim 1986, 88), und wo das jeweils deutlicher wird, muß die Verwendung ein und desselben Ausdrucks noch lange nicht heißen, daß diejenigen, die inn gleichermaßen verwenden, auch konzeptionell dasselbe darunter verstehen würden. Immerhin sind solche Formulierungsversuche aber hilfreich, wenn es darum geht, den Untersuchungsgegenstand zu präzisieren, und deshalb wollen wir sie und die dahinterstehenden Konzepte im folgenden kurz (kritisch) diskutieren.

Gehen wir zunächst auf die Ebene des Idiolekts herab, und interpretieren wir den Satz "Jeder Jugendliche hat seine, jede Jugendliche ihre Sprache" (Bausinger 1987, 175) in der Art und Weise, daß es dabei um den jeweiligen Sprachbesitz einzelner Individuen geht. Jeder Idiolekt hat notwendigerweise ein eigenes sprachliches System, da sich Idiolekte schon per definitionem niemals völlig decken können. Die Frage ist nun, ob sich aus den verschiedenen Idiolekten von Sprechern einer bestimmten Altersklasse so etwas wie ein übergreifendes System konstruieren läßt, das ihnen und nur ihnen unverwechselbar eigen ist. Eben dies läßt sich im vorliegenden Fall offenbar nicht behaupten: Daß gewisse sprachliche Erscheinungen bevorzugt in Äußerungen jugendlicher Sprecher auftauchen, rechtfertigt noch lange "nicht den Status einer selbständigen Subsprache des Deutschen" (Cherubim 1986, 88), und es verbietet sich demzufolge gleichermaßen, von einer jugendlichen 'Sondersprache' im Rahmen des Deutschen zu reden.

Statt von 'Sondersprache' wird in der neueren Forschung vielfach von der sog. 'Jugendsprache' als einer 'Gruppensprache' gesprochen: "Zur Gruppensprache der Jugend" überschreibt Henne $(1986,207)$ einen Abschnitt seines Buches, "Jugendsprache ist selbstverständlich auch eine Gruppensprache", heißt es apodiktisch bei Cherubim $(1986,88)$, und für Heinemann $(1991,6)$ handelt es sich um eine "altersspezifische Gruppensprache". Nun ist 'Gruppe', wie Bausinger $(1984,118)$ mit Fug und Recht festgestellt hat, allerdings ein "sehr relativer Begriff", was seine Extension anlangt - und tatsächlich oszilliert denn auch die Verwendung des Ausdrucks Gruppensprache gerade in der wissenschaftlichen Literatur zur sog. Jugendsprache außerordentlich stark. Wenn etwa bei Henne (1986, 204f.) von 'Gruppensprache' die Rede ist, dann geht es um einzelne 'Gruppen von Jugendlichen'; 
wenn im weiteren hingegen wiederum von 'Gruppensprache' gesprochen wird (Henne 1986, 207ff.), dann ist es um die gesamte 'Gruppe der Jugendlichen' zu tun. In diesem fraglosen Übergang ganz unterschiedlicher Deutungen des Ausdrucks Gruppe und, damit direkt verbunden, des Ausdrucks Sprache liegt u.E. die Crux eines großen Teils der bisherigen Forschung zur sog. 'Jugendsprache'.

Die Konstruktion einer vermeintlichen 'Jugendsprache' verdankt sich im wesentlichen fragwürdigen Verallgemeinerungen von bloßen Ausschnitten der Gesamtempirie - zum einen in lexikalisch-phraseologischer Hinsicht, indem auffällige Ausdrucksweisen, die Jugendliche quasi als Streugut auch in der Kommunikation mit Erwachsenen benutzen, zu einer vermeintlich eigenständigen 'Sprache' gebündelt wurden, zum anderen in konversationsanalytischer Hinsicht, bei der allein die Kommunikation innerhalb jugendlicher peer-groups in den Blick genommen wurde und die besagte 'Jugendsprache' als etwas erschien, was "nur im Umgang mit anderen Jugendlichen gebraucht" werde (Heinemann 1991, 6). All das läßt sich nirgendwo auch nur einigermaßen zur Deckung bringen. Was den Erwachsenen als besondere Indikatoren jugendlicher Sprachverwendung im lexikalisch-phraseologischen Bereich erscheint, spielt in der faktischen Kommunikation unter den Jugendlichen selbst offenbar keinerlei wesentliche Rolle (vgl. Schlobinski et al. 1993), und angesichts des 'experimentellen' Charakters der Kommunikation innerhalb solcher peer-groups läßt sich gar behaupten, daß es "so viele Jugendsprachen wie Jugendgruppen gibt" (ebd. 40). Angesichts der Vielfältigkeit des empirisch Beobachtbaren löst sich somit der Untersuchungsgegenstand letztlich auf, und an die Stelle von Generalisierungen tritt tendenziell eine Krimskramskrämerei der peniblen Analyse von Einzelbelegen mit zweifelhafter Aussagekraft.

Notwendig sind also Konzepte, die weder auf singuläre Besonderheiten des Sprechens noch auf eine generelle eigenständige 'Sprache' bezogen sind. Entsprechende Ausdrücke und Begriffe gibt es in der neueren Linguistik zuhauf, und sie tauchen allesamt auch in den verschiedenen wissenschaftlichen Arbeiten zur sog. 'Jugendsprache' auf, zumeist im Wechsel miteinander und normalerweise ohne besondere theoretische Explikation. Zunächst ist es dabei um eine bestimmte 'Art und Weise des Sprechens' zu tun, greifbar in Formulierungen wie "Sprechweise der Jugendlichen" (Heinemann 1989, 7) oder "eine die jugendlichen Gruppenstile übergreifende Spielart des Sprechens" (Henne 1986, 211). Die besagte 'Art und Weise des Sprechens' wird dann vielfach auch mit dem Begriff 'Stil' belegt; es gehe im wesentlichen um eine "Sprechstilanalyse" (Schlobinski et al. 1993, 40ff.), und letztlich sei bei der Kommunikation unter Jugendlichen "Alles [...] eine Frage des Stils" (so jüngst Schlobinski \& Schmid 1996). Nicht selten ist auch die Rede davon, daß sich die Jugendlichen bei der Kommunikation gewisser 'Register' bedienen (s. etwa Cheshire 1987, 761; Schlobinski et al. 1993, 12), und schließlich wird gesagt und geschrieben, daß es sich bei der sog. 'Jugendsprache' um eine 'Varietät' des Deutschen handle (vgl. Beneke 1986; Ehmann 1992a, 16). All diese Termini und Begriffe erscheinen in der Literatur in vielfacher Vermischung, mit unterschiedlichen Bezügen, Konkretisierungen und Abgrenzungen voneinander und in oftmals unklarem Rekurs darauf, ob nun (eher) Faktoren des Sprachgebrauchs oder des Sprachsystems gemeint sind.

Über all die damit zusammenhängenden Probleme ließen sich, über die bereits vorhandenen hinaus, mühelos viele umfangreiche Monographien schreiben. Da für detaillierte Erörterungen hier kein Platz ist, sei an dieser Stelle nur angedeutet, warum wir im folgenden Ausdrücke wie Art und Weise des Sprechens, Stil und Varietät 
zu meiden suchen und sie zumindest nicht in den Vordergrund stellen. Begriffe wie 'Sprechart' oder 'Sprechweise' (vgl. z.B. Lapp 1989) gelten uns als zu parolebezogen und in der Extension als allzu weitreichend und diffus zugleich, als daß ihre Verwendung im fachsprachlichen Rahmen der Linguistik klärend wirken könnte. Eben diese Bedenken bestehen auch hinsichtlich des Begriffs des 'Stils', der in Arbeiten zur sog. 'Jugendsprache' in vielfältigen Verbindungen auftaucht. Bekanntlich existiert (nicht nur) in der Linguistik eine übergroße Fülle von divergierenden Stilkonzeptionen und Auffassungen bezüglich der Natur 'stilistischer' Erscheinungen, so daß der Ausdruck Stil ganz unterschiedliche Deutungen erhalten kann. Der Terminus 'Varietät' hingegen ist ebenso sachlich wie allgemein gehalten; seine durchgängige Verwendung im gegenwärtigen Zusammenhang würde u.E. jedoch fälschlich suggerieren, daß wir im Bereich einer langue als übergreifend gültigen Gemeinsprache weitestgehend kohärente und homogene Subsysteme ausmachen könnten, die von den Sprachteilhaber/innen einer bestimmten Altersstufe gebraucht würden. Eben dies aber ist, wie die bisherige Forschung gezeigt hat, offenkundig nicht der Fall.

Angesichts dieser Sachlage scheint es uns sinnvoll zu sein, auf den in der britischen Linguistik entwickelten Begriff des 'Registers' zurückzugreifen, der in der germanistischen Linguistik bislang eher selten und zögernd verwandt worden ist. Nun ist es keinesfalls so, daß dieser Terminus in linguistischen Arbeiten überall auf die gleiche Art und Weise verwendet würde, sondern es gibt eine ganze Vielzahl von unterschiedlichen Auffassungen hinsichtlich seiner inhaltlichen Füllung (vgl. etwa Hess-Lüttich 1974; Biber 1995, 7ff.). Auf diese Unterschiede und Verästelungen im einzelnen kommt es im gegenwärtigen Zusammenhang zunächst nicht weiter an, sondern es geht allein um Grundsätzliches.

Die Verwendung des Registerbegriffs in der Sprachwissenschaft steht offensichtlich mit früheren nicht-linguistischen Verwendungsweisen des Ausdrucks Register in Beziehung. Zwei Traditionslinien kommen dabei in Betracht. Zum einen ist es um das 'Register' im Sinne eines (normalerweise alphabetisch) geordneten 'Index' zu tun, das gleichsam einen 'Querzugriff' auf im Text zuvor bereits gelieferte, dort aber im thematischen Fortgang anders geordnete Informationen ermöglicht; zum anderen geht es um das 'Register' im musikalischen Bereich, wo durch das Ziehen eines solchen Registers bei Orgel, Harmonium oder Cembalo ein Ensemble von Tönen gleicher Klangfarbe erzeugt wird (und linguistische Redeweisen wie die von einem speziellen "Jugendton" bei Henne (1986) fügen sich zwanglos zu einem solchen Hintergrund). Verbunden sind die beiden genannten nicht-sprachwissenschaftlichen Gebrauchsweisen durch den Aspekt der Selegierung: Das 'Register' im ersteren Sinne ermöglicht partielle, aber zugleich freie Zugriffe auf zuvor Existentes, das 'Register' im zweiten Sinne bedingt eine Beschränkung der Auswahl bei der musikalischen Gestaltung. Der Registerbegriff läßt sich von daher ohne weiteres mit jener Interpretation des Ausdrucks Stil verbinden, der als "selektive[r] Stilbegriff“ (Sanders 1973, 18) bezeichnet bzw. unter dem groben Schlagwort vom 'Stil als Auswahl' geführt wird. Selbst wenn der Registerbegriff nicht weiter präzisiert würde, so hätten wir doch schon den Vorteil, daß er nicht in gleicher Weise vielfältigen Mißverständnissen ausgesetzt ist, wie wir sie bei der Verwendung des überaus diffusen Ausdrucks Stil zur Genüge kennen.

Von Halliday et al. (1964, 87) wird das 'Register' bestimmt als „a variety of language according to use“, und zwar strikt geschieden von „varieties according to users (that is, varieties in the sense that each speaker uses one variety and uses it all 
the time)“, die als 'Dialekte' bezeichnet werden (ebd. 77). Entscheidend für die Etablierung von Registern ist die jeweilige Situation(sklasse), in der die Sprachteilhaber agieren und der entsprechend sie ihre Äußerungen gestalten; es existieren also "differences in the type of language selected as appropriate to different types of situation" (ebd. 87). Von diesen Vorgaben her gilt es bei der Untersuchung von Registern zunächst die relevanten Klassen von Situationen genauer zu bestimmen, die gewisse Besonderheiten des Sprachgebrauchs bedingen, und solche Charakterisierungen haben ohne primären Rekurs auf rein sprachliche Faktoren zu geschehen: „Register distinctions are defined in non-linguistic terms, by differences in purpose, interactiveness, production circumstances, relation among participants, etc." (Biber 1995, 7). Bei der Bestimmung von 'Situationen' resp. von 'Situationsklassen' ist offenkundig eine ganze Fülle von Variablen zu berücksichtigen, und das Alter der Gesprächsteilnehmer ist dabei nur eine einzige unter vielen, vielen anderen (wie $\mathrm{Ge}-$ schlechtszugehörigkeit, Bekanntheitsgrad der Gesprächsteilnehmer, privater oder institutioneller Zusammenhang, Gesprächsanlaß usw.usf.).

Allerdings läßt sich auf diese Art und Weise eine letztlich unüberschaubare Menge von ganz unterschiedlichen Situationsklassen (auf verschiedenen Generalisierungsebenen) konstruieren, die sich z.T. nur geringfügig voneinander unterscheiden und deren Besonderheiten womöglich gar keine Auswirkungen mehr auf die Gestaltung der sprachlichen Produkte haben. Sekundär sind deshalb auch sprachliche Faktoren für die Etablierung von Situationen herangezogen worden, gemäß der terminologisch eigentlich inkonsistenten - Festlegung von Firth $(1957,7)$,[that] the text $(\ldots)$ is regarded as an integral part of the context, and (...) as relevant in the statement of the context“. Dieses Verfahren führt dann tendenziell dazu, daß es sprachliche Faktoren sind, die letztlich über die Existenz von 'Situationen' entscheiden (Halliday et al. 1964, 89):

"If two samples of language activity from what, on non-linguistic grounds, could be considered different situation-types show no differences in grammar or lexis, they are assigned to one and the same register: for the purposes of description of the language there is only one situation-type here, not two."

Wie die jeweils relevanten Situationsklassen genau zu bestimmen sind, ist weiterhin eine offene und vieldiskutierte Frage, die hier nicht detailliert erörtert werden kann. Im gegenwärtigen Zusammenhang genügt die einfache Feststellung, daß die besagten 'Register' eindeutig situationsspezifisch sind und nicht sprecher/innenspezifisch; vielmehr zeigen die Sprecher/innen durch die Benutzung unterschiedlicher Register, daß sie ihren momentanen Sprachgebrauch auf situationelle Besonderheiten des kommunikativen Austauschs einstellen.

Wenn wir all dies auf die sog. 'Jugendsprache' (und deren bisherige Erforschung) zurückbeziehen, dann ist festzustellen, daß vielfach bloß situationell gebundene Formen des Sprachgebrauchs von Jugendlichen verdinglicht und zu eigenständigen Sprachausprägungen ernannt wurden (als 'Subsprache', 'Soziolekt' usw.). Faktisch aber war es im wesentlichen um ein besonderes situationsabhängiges Register (mit verschiedenen Ausprägungen) zu tun, dessen sich die Jugendlichen bedienen, und die dabei relevante Situation läßt sich grob folgendermaßen umreißen: mündlicher Austausch, Kommunikationspartner einer Altersstufe (die Kinderrolle nicht mehr akzeptierend, sich gleichzeitig aber nicht als erwachsen fühlend), längere Vertrautheit miteinander, freies Gespräch ohne von außen vorgegebene Ziele usw. Daß die betreffenden Kommunikationsformen rein situationsspezifisch sind, zeigt sich schon 
darin, daß die bloße Anwesenheit von Erwachsenen in einer peer-group von Jugendlichen und erst recht deren Einbeziehung in den kommunikativen Austausch zu Veränderungen des Sprachverhaltens führen (vgl. etwa Ehmann 1992a, 51f.; Schlobinski et al. 1993, 45). Unzweifelhaft verfügen die Jugendlichen über eine ganze Reihe von unterschiedlichen Registern, zwischen denen sie ohne weiteres wechseln können; das Problem ist nur, daß solch ein „unterschiedliche[s] Reden [von Jugendlichen] mit verschiedenen Partnern in verschiedenen Situationen“ für gewöhnlich nur als „denk- und vorstellbar" angesehen wird (vgl. Heinemann 1989, 10), ohne daß es selbst zum wissenschaftlichen Thema gemacht und eigens kontrastiv untersucht würde.

Die bisherige Forschung zur sog. 'Jugendsprache' hat es, wie wir meinen, noch relativ einfach gehabt, wenn man sie mit einer genaueren Erhellung des Sprachgebrauchs von Älteren und Alten vergleicht. Ausgehend von lexikalischen Auffälligkeiten im Sprachgebrauch von Jugendlichen hat man sich sehr schnell auf besondere Kommunikationsformen innerhalb jugendlicher 'peer-groups' eingelassen und dabei festgestellt, daß sie in anderer Form anders gestaltet sind als die von Erwachsenen. Daß sich dann bei genauerem Hinsehen so manches, was Erwachsene als 'typisch jugendsprachlich' empfinden, nur bedingt fand und daß anderes, was Erwachsene über das rein Lexikalische hinaus kaum bemerkt hatten, sich letztlich als wichtiger erwies, sei hier dahingestellt. Registerunterschiede können sich in vielfältiger Art und Weise zeigen, nicht nur lexikalisch-phraseologisch, syntaktisch usw., sondern auch rein pragmatisch. Was die bisherige 'Jugendsprachforschung' jedenfalls - und z.T. unbewußt und quasi 'in ihrem Rücken' - bewiesen hat, ist die Nützlichkeit der Untersuchung von bestimmten 'Stituationsklassen' - hier in begrenzten Rahmen, bestimmt durch die Zusammengehörigkeit und die mehr oder minder eingespielten sprachlichen Kommunikationsverfahren in Kleingruppen.

\section{3. 'Sprache' und 'Alter'}

Etwa seit dem Beginn der 80er Jahre gibt es - allerdings kaum aus dem deutschsprachigen Raum, sondern wesentlich aus den Vereinigten Staaten - eine wahre Publikationsflut zu dem neuen Trendthema 'Kommunikationsverhalten älterer und alter Menschen'. Auch wenn dieser neue Forschungsgegenstand in Europa noch in den allerersten Kinderschuhen steckt, ist es an der Zeit, die früher geltende Formel 'Jugend ist in, Alter ist out' - zumindest in bezug auf das Forschungsinteresse - zu relativieren. Allerdings präsentiert sich die bisherige Forschung zu diesem Thema u.E. noch diffuser und unklarer als im Bereich der sog. 'Jugendsprachforschung'. Um diese Heterogenität zu demonstrieren, werfen wir zunächst einen Blick auf die Forschungsergebnisse der letzten Jahre im Bereich der 'Altenkommunikation', und dies sowohl unter soziologischen als auch unter linguistischen Aspekten.

Im Gegensatz zu linguistischen Arbeiten wurde die soziologische Auseinandersetzung mit dem Thema 'Alter' bereits sehr viel früher gesucht. So wies Thomas (1972) schon zu Beginn der 70er Jahre im Rahmen einer medizinischen Arbeit zum Thema 'Altersstereotypien' nach, wie negativ alte Menschen von jüngeren dargestellt werden. Dabei erläutert Thomas (1972, 37ff.), der sich mit seiner Arbeit wiederum auf eine Skala von Tuckman \& Lorge (1953) berief, die von inm befragten jüngeren Probanden seien der Ansicht gewesen, „daß die körperliche Verfassung mit zunehmendem Alter nachläßt“, daß „fast alle alten Menschen Lesebrille (...) und 
Zahnersatz [...] benötigen, empfindlicher auf Lärm reagieren“, daß sie „Zwar noch geistig rege [...], jedoch schon sehr vergeßlich“ seien, daß der alte Mensch „vergangenen Zeiten nach[trauere]“, „stark an Traditionen fest[halte]“ sowie „Respekt von seiner Umgebung" erwarte (vgl. jüngst auch Thimm 1995). All diese - auch heute aktuellen - Vorurteile verhindern jedoch nicht die wissenschaftliche Auseinandersetzung mit dem Thema 'Alter', im Gegenteil: Die demographischen Daten der letzten zehn Jahre (s. exemplarisch Dieck 1987, 192; Bottke, bearb. 1989; Tews 1991, 2 sowie jüngst Lehr 1997, 64) zeigen eindeutig ein starkes Anwachsen der Alterspopulation im Verhältnis zur Gesamtbevölkerung sowie eine immer größer werdende Gruppe der sog. 'Hochaltrigen' (s. Tews 1991, 23), und dieses Phänomen der "Umkehrung der Alterspyramide“ (so etwa Dieck 1987, 195), in der Bevölkerung charakteristisch mit dem 'Unwort des Jahres 1996', nämlich Rentnerschwemme, bezeichnet, wird sich zudem nach der bevorstehenden Jahrtausendwende noch stärker konsolidieren, so daß unsere Gesellschaft sich einfach aus unterschiedlichen Perspektiven mit dem Thema 'Alter' auseinandersetzen muß.

Es handelt sich bei diesem neuen - auch vermehrt linguistischen - Forschungsbereich also weniger um ein Trendthema als um eine gesellschaftliche Notwendigkeit, wobei sich allerdings bereits der Versuch eines ersten Zugangs zu dem Thema 'Alter' als diffizil erweist, denn die Frage, wie die Variable 'Alter' eigentlich exakt zu definieren sei, wird ähnlich heterogen beantwortet wie die Frage nach der Bedeutung der Variable 'Jugend'. So legt etwa Henne $(1981,373)$ zur Definition von 'Jugend' den Parameter 'Lebensalter' zugrunde, wenn er schreibt, das Stadium der Jugend sei „von 13 ab zu rechnen" und habe „ein variables Ende“, während Heinemann $(1991,6)$ sich zwar ebenfalls am Lebensalter orientiert, jedoch zu der Einschätzung kommt, daß das "Sprachverhalten von Jugendlichen im Alter von etwa zwölf bis achtzehn Jahren" untersucht werden sollte. Kurios und reichlich diffus erscheinen Definitionsversuche von 'Jugend', wenn die Parameter 'biologische Geschlechtsreife' und 'soziale Reife' in Kombination zugrundegelegt werden, wie etwa Henne $(1986,202)$ es versucht hat:

„Die Phase der Jugend liegt für den einzelnen zwischen biologischer Geschlechtsreife, also 12 bis 13 Jahren, und sozialer Reife, die vielfach mit 25 Jahren noch nicht erreicht ist. [...] Jugendlicher ist also, wer die biologische Reife erlangt hat, aber noch nicht die soziale Reife."

Bedenkt man zudem, daß die zahlreichen soziologischen Definitionen von 'Jugend' häufig gerade nicht mit den skizzierten biologischen und lebensalterorientierten Definitionen kompatibel sind, dann ist es nicht weiter erstaunlich, daß diese Diffusion sich ebenfalls dort vorfinden läßt, wo es um die Präzisierung des Begriffs 'Alter' geht. Rosenfeld $(1993,354)$ fragt zu Recht: „What is old age? Is it a biological characteristic based merely on chronology, or is it a social characteristic based on a person's role in society?"

Soziologische Definitionen von 'Alter' etwa sind dann nicht allein zureichend, wenn der Beginn des Alters ausschließlich mit dem Ende der Berufstätigkeit resp. dem Rentenzugangsalter ineins gesetzt wird; insbesondere älteren Frauen, die in ihrem Leben kaum die Gelegenheit hatten, eine konsistente Berufstätigkeit auszuleben, wird diese Definition nicht gerecht (s. schon Palmore 1968, 320ff. sowie zum immer früheren Renteneintrittsalter Tews 1987, 871), und diejenige biologische Definition, die 'Alter' als Rückgang der Fortpflanzungsfähigkeit auffaßt, hätte im Extremfall zur Folge, daß Frauen mit 45 Jahren, Männer aber noch nicht mit 90 Jahren als 
'alt' zu bezeichnen wären. Olbrich $(1976,16)$ bewertet insofern auch rein biologisch orientierte 'Abnutzungstheorien' zu Recht kritisch:

„Wenn von Veränderung als Funktion biologischer Prozesse in der Zeit gesprochen wird, so scheint diese am ehesten auf einen Vorgang oder besser ein ganzes System miteinander verknüpfter Vorgänge zurückzuführen sein, die in der Person ablaufen und deren Relationen zueinander bzw. zu Außenbedingungen schwerlich eindeutig funktional oder gar kausal zu erklären sind."

„Vielmehr“, so Olbrich weiter, „finden sich einige Wahrscheinlichkeitsrelationen zwischen Dimensionen biologischen Geschehens und solchen des Verhaltens und Erlebens" (ebd.). Wenn die „Variabilität der biologischen Auswirkungen [tatsächlich] groß" ist, wie Olbrich (1976, 13f.) im Rahmen einer umfassenden Untersuchung des älteren Menschen und seiner Interaktion mit seiner sozialen Umwelt feststellen konnte, dann sind auch biologische Modelle nicht zureichend in der Lage, den Faktor 'Alter' genauer zu definieren.

Vor diesem Hintergrund einer völlig heterogen aufzufassenden Variable 'Alter' (und im übrigen auch der Variable 'Generation', s. Cheshire 1987) ist es erforderlich, sich die Frage zu stellen, inwiefern das sprachliche Verhalten alter Menschen überhaupt mit Ausdrücken wie Altensprache, Altersstil (so Betten i.d.Bd. und Cherubim i.d.Bd.), altersspezifischer Kommunikation, Altersstereotypen, Altersdialekten (so Hörmann et al. 1976), oder - in der amerikanischen Tradition - Kennzeichnungen wie elderly adults' speech (Kemper 1987) umschrieben werden kann.

Sieht man sich dazu einmal genauer an, aufgrund welcher Forschungsergebnisse überhaupt von einer 'Altensprache' gesprochen werden kann, dann sind es zu allererst die Stimmveränderungen, die als sog. primäre „age markers“ (s. Helfrich 1979) angeführt werden. Stimmveränderungen bei steigendem Lebensalter sowie die Gründe für diese Stimmveränderungen sind von Phonetikern oder aber geriatrisch orientierten Medizinern und Psychologen umfassend erforscht worden. Da wird bekanntlich, um nur die zentralen Bereiche anzuführen, eine allgemeine Abnahme des Stimmumfanges verzeichnet sowie - dadurch vermittelt - ein relatives Ansteigen der Sprechstimme; häufig wird bei steigendem Alter der Verlust der Bruststimme festgestellt sowie eine generelle Veränderung der Frequenz, der Stimmqualität und des Timbres; es werden Beobachtungen gemacht, daß das Sprechtempo älterer Menschen geringer wird, daß größere Sprechpausen auftreten und daß eine höhere Anzahl von Versprechern und eine geringere Lautstärke zu verzeichnen sind (s. etwa Gerritsen 1985, 80ff.; Heinl-Hutchinson 1975, 23ff. und Helfrich 1979, 79ff.). Die Gründe dafür sind zum einen biologischer Natur: so werden etwa Verknöcherungen des Kehlkopfes, atrophische Veränderungen der Muskeln und Bindegewebe, Veränderungen in den Resonanzhöhlen (Lunge, Brustkorb) sowie der Spannungsverlust der Stimmlippen für eine veränderte Stimme verantwortlich gemacht; und wesentlich für das Besondere der Kommunikation alter Menschen sind ebenso die mögliche Abnahme des Hörvermögens sowie ein eventueller Zahnersatz. Insgesamt ist für den biologischen Organismus bekanntlich (nicht nur von Vertretern der Defizittheorie) eine objektive Abnahme der Vitalkapazität festzustellen, ein Nachlassen des Kurzzeitgedächtnisses und der Konzentrationsfähigkeit sowie die Zunahme von Kreislaufschwächen, einer Verengung der Blutbahnen und eine Verminderung der Blutzufuhr an das Gehirn.

Die angeführten anatomischen Veränderungen, die allerdings in dieser gedrängten Form faktisch nur einige wenige Individuen betreffen, haben - auch in ihrem 
vereinzelten Auftreten - sicherlich einen mehr oder minder großen Einfluß auf Stimme und Kommunikation von älteren Menschen. Jedoch konnten Ursache-WirkungsVerhältnisse bislang leider nur sehr begrenzt nachgewiesen werden. So wäre es hilfreich, wenn tatsächlich belegt werden könnte, inwiefern durch die Abnahme des Hörvermögens im Alter bei einigen alten Menschen eine Isolation im Gespräch entsteht oder daß notwendiger Zahnersatz zu Ausspracheschwierigkeiten führen und daß es dementsprechend zu Verständnisschwierigkeiten und gar zu Mißverständnissen kommen kann. Durchaus plausibel erscheinen auch Überlegungen, denen zufolge etwa - nachgewiesene - Stimmhöhenveränderungen, insbes. die bei alten Männern, nicht allein auf biologische, sondern auch auf soziale Veränderungen zurückzuführen sind (etwa als unbewußte Anpassungsstrategie an die Stimmhöhe der Partnerin). Derartigen Fragestellungen, die biologische Erscheinungen im Zusammenhang mit linguistisch relevanten und/oder sozialen Faktoren behandeln, ist bisher leider selten nachgegangen worden; das Aufzählen geriatrisch nachzuweisender stimmlicher Fehlleistungen mit wachsendem Alter allein ist linguistisch allenfalls peripher relevant.

Betrachtet man diejenigen Untersuchungsergebnisse der amerikanischen Forschung, die auf morphologische und syntaktische Sprachveränderungen aufgrund des steigenden Lebensalters eingehen, so ist schnell festzustellen, daß in diesen Bereichen nur wenig verläßliche Daten vorliegen. Da wird etwa beobachtet, daß ältere Probanden insgesamt weniger Morpheme pro Äußerung sowie weniger Äußerungen pro Minute vorbringen, und es wird weiterhin davon ausgegangen, daß die Probanden mit wachsendem Alter häufiger obligatorische grammatische Morpheme sowie auch Artikel und Possessivpronomina auslassen, daß die Äußerungen insgesamt mit steigendem Alter kürzer werden, daß Alte seltener als junge Probanden korrekte Verbtempora sowie andere korrekte morphologische Formen verwenden und daß sie einen Hang zu monotonen grammatischen Konstruktionen (etwa durch das Vermeiden des Gebrauchs unterschiedlicher grammatischer Formen) zeigen (s. Stover \& Haynes 1989 sowie Kemper \& Kynette 1986). Weiterhin beobachtet Kemper $(1987,325)$ eine altersabhängige Reduktion komplexer syntaktischer Strukturen im Bereich der geschriebenen Sprache, wobei auch für die gesprochene Sprache gilt: komplexe syntaktische Konstruktionen werden von älteren Probanden seltener (und auch weniger korrekt) verwendet als von jüngeren (vgl. Kemper \& Kynette 1986 sowie zusammenfassend Light 1993, 905f.).

Für diese grammatischen Ebenen im engeren Sinne ist die Datenlage ausgesprochen spärlich; anders - zumindest quantitativ - sieht es in den Bereichen Semantik und Pragmatik aus. So untersuchte etwa schon Riegel (1968) anhand zahlreicher Arbeiten mit Hilfe von fünf zugrundeliegenden Leistungstests die Fähigkeit von Jugendlichen und älteren Menschen, semantische Relationen zu erkennen, und kam zu dem Ergebnis, daß das Identifizieren von Synonymien und Antonymien ausgesprochen altersstabil ist, während etwa bei den Selektions- und Klassifizierungstests schon nach Vollendung des 16. Lebensjahrs stark abfallende Leistungen zu beobachten sind. Ebenso wie für die sog. Jugendsprachforschung liegen auch hier Arbeiten zum Wortschatz alter Menschen vor sowie eine deutsche Studie von Hörmann et al. (1976) zu unterschiedlichen lexematischen Konnotationen bei jungen und alten Menschen (leider mißverständlich 'Altersdialekte' genannt); ärgerlicherweise ist das angewendete Meßverfahren wiederum selbst 'altersdialektabhängig' (wie die Autoren auch erkennen) und deshalb leider nur in geringem Maße aussagekräftig. Abgesehen von steigenden "word finding difficulties“ älterer Menschen ist die Organisati- 
on semantischer Information insgesamt offenkundig wesentlich altersstabil (vgl. Light 1993, 900).

Im Bereich der Pragmatik (im weitesten Sinne) liegen mittlerweile derartig viele wesentlich amerikanische - Publikationen vor, daß hier nur ein kurzer Überblick über die verschiedenen Themenschwerpunkte gegeben werden soll. Neben zahlreichen Arbeiten zum Gesprächsthema alter Menschen, die sich im wesentlichen auf den Vergangenheitsbezug kaprizieren, existieren Arbeiten zur Gesprächsorganisation, zur Tendenz des Monologisierens, zur verminderten Bereitschaft zur turnAbgabe, zum biographischen Erzählen, zu Altersstereotypen, Diskursstrategien im Alter (vgl. etwa die sog. 'off-target-verbosity'), Struktur und Dramaturgie von Gesprächsbeiträgen sowie zur kommunikativen Interaktion zwischen Alten und Jungen (etwa aufgrund von 'elderspeak', einem simplifizierten Register) etc.pp.

Schon diese grobe Skizze der bisherigen Forschungsbemühungen zeigt, daß die in diesem Bereich vorliegenden Untersuchungen überaus heterogen und nachgerade disparat sind. Zusammengehalten werden sie letztlich nur dadurch, daß sie sich allesamt auf einem thematisch sehr allgemein zu umreißenden Untersuchungsfeld bewegen, das man durch 'Sprache im (höheren und hohen) Alter' umschreiben kann. Der Sprachbegriff ist dabei für gewöhnlich ebenso diffus, wie es in Abschnitt 2 für die Forschung zur sog. 'Jugendsprache' festgestellt wurde: 'Sprache' wird im wesentlichen als bloße 'langage' verstanden, also als 'Sprachliches überhaupt', und aus diesem Gesamtbereich werden dann jeweils einzelne Aspekte isoliert und einzeln analysiert. Die theoretischen Grundlagen und methodischen Zugriffe sind dabei ebenso unterschiedlich wie die jeweiligen empirischen Basen der betreffenden Untersuchungen: mal geht es um Gesprochenes, mal um Geschriebenes, mal um Experimente, mal um (teilnehmende) Beobachtung, mal bildet das sog. 'Defizitmodell', mal die 'Aktivitätstheorie', mal die 'Disengagement-Theorie' usw. den generellen Hintergrund, und mal ist die Analyse im Rahmen der Psychologie, mal in dem der Soziologie, mal in dem der Medizin und bisweilen, allerdings eher selten, auch im Rahmen der Linguistik angesiedelt. Zu konstatieren ist gegenwärtig eine große Bandbreite von Forschungsperspektiven, -modellen und -methoden sowie eine Fülle von sehr unterschiedlichen Einzelanalysen in verschiedenen Wissenschaftsdisziplinen.

Die Vielfalt der Zugangsmöglichkeiten, die Disparatheit und oftmals Unvergleichbarkeit der Untersuchungen und ihrer Ergebnisse ist natürlich im wesentlichen der Tatsache geschuldet, daß es sich hier um ein neues 'interdisziplinäres' Untersuchungsfeld handelt, auf dem sich Wissenschaftler/innen ganz unterschiedlicher Provenienz tummeln. Was 'zwischen den wissenschaftlichen Disziplinen' liegt und allen zugänglich ist, das wird die Linguistik nicht zu okkupieren und ihrerseits einfach zu disziplinieren versuchen, weil sie die 'Sprache' (in welchem Sinne auch immer) zu ihrem ureigenen Gegenstand erkoren hat. Zu verlangen ist jedoch, daß sich die Linguist/inn/en genauere Gedanken darüber machen, was an Sprachlichem in diesem Zusammenhang unter einer generellen Perspektive, die zugleich viele Differenzierungen ermöglicht, linguistisch sinnvoll zu untersuchen ist, jenseits bloßer Oberflächlichkeit und falscher Hypostasierungen. Im Jahre 1982 hat die Deutsche Akademie für Sprache und Dichtung die folgende Preisfrage gestellt: „Spricht die Jugend eine andere Sprache?“. Lassen wir die (veröffentlichten) Antworten (vgl. Pörksen \& Weber 1984) beiseite - wahren wir uns besser vor der Befürchtung, daß es demnächst eine weitere Frage dieser Art geben könnte, nämlich: „Sprechen die Senior/inn/en eine andere Sprache?". Sicherlich würde es auch darauf so manch es- 
sayistische Antwort geben, je nachdem, was dabei jeweils unter „Senior/inn/en“ und "Sprache" verstanden wird, und vermutlich würden wir dann, wie schon in der Vorgängerpublikation, so manch klugen Gedanken finden, ohne daß damit eine klare Untersuchungsperspektive verbunden wäre.

Nehmen wir das oben Gesagte einfach ernst: Kann man vernünftigerweise fragen, ob die Zugehörigkeit zu einer bestimmten, rein zahlenmäßig festgelegten Altersklasse für die sprachliche Kompetenz und/oder Performanz der betreffenden Sprachteilhaber/innen entscheidend ist? Eben solches wird augenscheinlich nur allzu oft unterstellt. Faktisch aber gibt es in dem zu analysierenden empirischen Datenmaterial jeweils allzu viel, was sich überhaupt nicht auf irgendein numerisches Alter einzelner Beteiligter zurückführen läßt, und dementsprechend schwach begründet sind Untersuchungen dieser Art. Experimente, bei denen Angehörige verschiedener rein numerisch bestimmter Altersklassen in ihrem Sprachverhalten miteinander verglichen werden, sind u.E. wenig bis gar nicht aussagekräftig, und es scheint uns sinnvoller, sich auf eine sehr nüchterne und klare Position zurückzuziehen, bei der nicht vorgängig die Existenz einer bestimmten 'Jugendsprache', 'Altensprache', 'Senior/inn/ensprache' unterstellt wird. Dies heißt keinesfalls, daß man all dasjenige, was in anderen Wissenschaftsbereichen unter anderen Vorzeichen bislang erarbeitet worden ist, nicht zur Kenntnis nehmen sollte - es gilt vielmehr, all dies möglichst nutzbar zu machen und es in einen sprachwissenschaftlichen Zusammenhang zu integrieren.

\section{4. 'Sprache', 'Altersspezifik' und Sprecher/innen}

Wer gegenwärtig in alltäglichem Zusammenhang von 'Alter' spricht, tut dies, wenn er sich der deutschen Gegenwartssprache bedient, gleich in zweierlei Art und Weise. Die erste Verwendungsweise des Ausdrucks Alter ist eher unspezifisch und unmarkiert, denn alle Sprachteilhaber des Deutschen haben notgedrungen ein gewisses Alter, und in unserem Gesellschaftssystem läßt sich eben dieses Alter auch sehr genau spezifizieren (qua Konsultation von Geburtsurkunden, Auszügen aus Geburtsregistern usw.). Dieser allgemeine und unmarkierte Altersbegriff steht jedoch in Kontrast zu einem anderen Begriff des 'Alters', demzufolge derjenige oder diejenige 'alt' ist, der oder die (wesentlich) mehr an Jahren zählt als der Durchschnitt der erwachsenen, noch im Arbeitsprozeß stehenden Bevölkerung. Und genau auf diesem - markierten - Altersbegriff basieren die aktuellen linguistischen Untersuchungen, die Sprechweisen älterer und alter Menschen als markiert auffassen und diese Markiertheiten wiederum an das numerische Alter der Sprechenden binden. Die Schlußfolgerungen bestehen dann per se in dem Konstatieren von auffälligem Sprachverhalten, das wiederum als Besonderheit einer vermeintlichen 'Alten-' bzw. 'Senior/inn/ensprache' aufgefaßt wird.

Bereits durch die Gegenüberstellung der beiden Aussagesätze Das Alter der Jugendlichen betrug durchschnittlich 15 Jahre und Meine Großmutter lebt auch im Alter noch allein wird deutlich, daß der Ausdruck Alter in keiner Weise generell auf eine reale und damit absolute (Zeit-)Größe Bezug nimmt, sondern daß der Altersbegriff grundsätzlich als eine relative Größe aufzufassen ist. Wir haben oben im dritten Abschnitt ausführlicher auf die Schwierigkeit einer rein soziologisch resp. rein biologisch ausgerichteten Definition von 'Alter' hingewiesen und den Begriff 'Alter' als ausgesprochen heterogen bezeichnet. Bezieht man diesen Begriff wiederum auf linguistische Untersuchungen und zieht zudem in Betracht, daß vermeintliche 'age 
markers' übergreifend sowohl beim Sprechen von Kindern als auch dem von Jugendlichen, der Elterngeneration sowie bei alten Menschen zu finden sind (s. auch Cheshire 1987, 761), dann wird deutlich, daß das numerische Alter nicht für eine Differenzierung unterschiedlicher 'Sprachstile', 'Sprachvarietäten' etc.pp. verantwortlich gemacht werden kann, zumal nicht in einer Zeit, in der in zunehmendem Maße von 'Jungen Alten', 'Aktiven Alten' und 'Neuen Alten' (s. etwa Bottke, bearb. 1989) gesprochen wird. So schreibt Lehr $(1997,64)$ zu Recht:

„Es kommt [...] nicht auf die Anzahl der Jahre an, sondern auf Fähigkeiten, Fertigkeiten, auf das Erleben und Verhalten, auf die physische und psychische Funktionsfähigkeit, auf das sogenannte 'functional age'.[...] Mit zunehmendem Lebensalter wird [...] das chronologische Alter [...] ein immer fragwürdigeres Kriterium zur Beurteilung von körperlichen und geistigen Fähigkeiten."

Der Versuch also, sprachliche Charakteristika eindeutig an das jeweilige numerische Alter der Kommunikationsteilnehmer/innen anzubinden, ist aufgrund der großen Varianzbreite der Variable 'Alter' zum Scheitern verurteilt. So zeigen sich auch in Tismers $(1971,17)$ Analyse des Vergangenheitsbezugs im höheren Alter zwischen den 60- und 70jährigen „keine alters-, hingegen verschiedene geschlechtsspezifische Differenzen zwischen der Gesamtgruppe der Männer und Frauen“, und das, obwohl gerade zwischen 60- und 70-jährigen Sprachteilhaber/inne/n Unterschiede zu erwarten wären.

Wie verhält es sich dann jedoch mit der Existenz von den allüberall angenommenen 'salient features' resp. 'age markers', die Helfrich $(1979,63)$ sorgsam in „sender age markers" und "receiver age markers" unterteilt hat? Daß einige Merkmale sprachlichen Verhaltens junger und alter Menschen, die in gewisser Weise als 'markiert' und damit als marker angesehen werden können, existieren, soll hier nicht in Frage gestellt werden. Sieht man sich jedoch einmal an, wie schon Helfrich diese 'age markers' beschreibt, nämlich als „speech cues which potentially differentiate between members of different age groups" (ebd.), dann wird durch die Wahl des Ausdrucks potentially eine gewisse Vorsicht und auch Skepsis gegenüber einem allzu engem Bezug zwischen sprachlicher Markierung und numerischem Alter deutlich. Und Helfrich $(1979,65)$ weist wenige Seiten später auch ganz ausdrücklich darauf hin, ,[that] the occurrence of a particular feature in speech is not directly governed by chronological age, but rather by certain related factors, such as linguistic, cognitive or social competence."

Bei dem Versuch einer Beantwortung der Frage, ob überhaupt sinnvollerweise von 'age markers' gesprochen werden könne, hat Cheshire $(1987,761)$ immerhin zwischen sog. „age-exclusive features“ und "age-preferential features“ unterschieden, die sie folgendermaßen kennzeichnet:

„The characteristic forms may be age-exclusive, in that they are used only during a certain stage of life, or they may be age-preferential, in that they occur more frequently in some stages of life than in others."

Zudem betont Cheshire (ebd.) zu Recht, daß beide Formen sowohl kulturspezifisch auftreten können als auch kulturübergreifend (wie etwa die sog. „trembling voice“). Dennoch ist auch mit dieser Unterscheidung noch nicht viel gewonnen. Sieht man sich einmal genauer an, welche sprachlichen Merkmale als 'age-exclusive features' aufgefaßt werden könnten, dann wären das nur diejenigen sprachlichen Besonderheiten, die wesentlich aufgrund von körperlichen Veränderungen einer bestimmten Altersstufe auftreten, so etwa der Stimmbruch bei männlichen Jugendlichen, die 
Stimmveränderungen alter Menschen aufgrund von sinkender Muskelelastizität etc.pp. (vgl. genauer Abschnitt 3). Diese Merkmale sind jedoch biologisch bedingt und damit parasprachlicher Art, d.h. linguistisch nur eingeschränkt relevant. Von tatsächlichem linguistischen Interesse ist nur die zweite Gruppe der Merkmale, die Cheshire als 'age preferential features' bezeichnet. Das Auftreten solcher sprachlichen Merkmale ist jedoch, wie bereits dargelegt, nicht strikt an das jeweilige numerische Alter gebunden, sondern hängt von speziellen situativen Umständen ab, die den Gebrauch dieser Art von Ausdrücken nahelegen. Ebenso, wie wir es im Hinblick auf die Kommunikation junger Menschen angenommen haben (vgl. Abschnitt 2), gehen wir auch bei älteren und alten Menschen davon aus, daß das meiste, was vorschnell als 'typisch für die Sprache alter Menschen' bezeichnet wird, letztlich dadurch zu erklären ist, daß aufgrund unterschiedlicher situativer Umstände unterschiedliche Register gezogen werden, und dies sowohl in lexikalischer wie auch in grammatischer und/oder pragmatischer Hinsicht (vgl. dazu jüngst auch Fiehler 1997, 353f.).

Ohne Zweifel gibt es auch in der Altersgruppe der über 60-jährigen Menschen peer-groups mit eingespielten Kommunikationsusancen, aber dennoch ist gegenüber der Untersuchung des Sprachverhaltens jugendlicher Sprecher/innen ein wesentlicher Unterschied zu konstatieren. Die Linguist/inn/en müssen gewärtig sein, daß sie bei zukünftigen Untersuchungen des Sprachverhaltens älterer und alter Menschen nicht auf ähnlich günstige Bedingungen werden treffen können, wie das bei den jugendlichen Sprecher/inne/n der Fall war. Jugendliche Sprachteilhaber/innen ziehen spezielle 'Jugendregister' offenkundig, um qua Sprachverhalten als Mitglieder einer peer-group anerkannt zu werden. Ältere und alte Menschen sind aufgrund ihrer Lebenserfahrung, ihres (erworbenen) sozialen Status etc. - nicht mehr dergestalt auf Gruppenanerkennung aus, wie es die Jugendlichen noch sind, und deshalb auch nicht unbedingt auf eine sprachliche Profilierung über eine peergroup angewiesen (vgl. die Annahmen von Cheshire $(1987,762)$ und Hörmann et al. $(1976,92)$, die von einem gesunkenen Normdruck bei älteren Menschen ausgehen, der eventuell mit einem geringeren Anpassungsdruck einhergehen könnte). Zudem befinden alte Menschen sich - im Vergleich zu jüngeren - häufig in einer gänzlich anderen sozialen Situation. So stellt Olbrich $(1976,138 f$.) im Rahmen einer gerontologischen Längsschnittstudie eine „Tendenz zu einem Rückgang sozialbezogener Aktivitäten in den Rollen als Nachbar, Freund, Vereinsmitglied und Staatsbürger" fest. Eine Aktivitätsveränderung, die in den meisten Fällen in eine Aktivitätsminderung führt, kann für viele alte Menschen bedeuten, daß sich ihr alltägliches Leben dahingehend verändert hat, daß sie stärker (als vorher) sozial isoliert sind und sich dadurch (auch) ihr Kommunikationsverhalten zuungunsten von face-to-face-Kommunikation und zugunsten steigender Telephonkommunikation verändert. Zudem bedingt der gesellschaftliche Zerfall bürgerlicher Familienstrukturen, daß den alten Menschen im letzten Drittel ihres Lebens häufig nur noch altershomogene Kleingruppen bleiben, in denen sie kommunizieren können. Will man diese Art von altershomogenen Kleingruppen ebenfalls als peer-groups auffassen, dann gibt es natürlich auch für diese Gruppen eine Art von 'Gruppensprache', die jedoch nicht wesentlich lexikalisch geprägt ist, sondern sich eher in der Wahl der Gesprächsthemen präsentiert (so zeigen einige Untersuchungen, daß sich alte Menschen in ihren Gesprächen untereinander (und auch im Gespräch mit Jüngeren) sehr viel stärker an der Vergangenheit orientieren als junge Menschen (s. Boden \& Bielby 1983 und Tismer 1971) und daß ihre Gesprächsthemen sich eher auf bisher Erlebtes (etwa 
Krieg, Eheschließung, Krankheit, Tod von Freunden und Verwandten) konzentrieren. Aus diesen - wesentlich soziologischen - Günden erscheint uns die Untersuchung sprachlicher Besonderheiten älterer und alter Menschen auf der Basis unterschiedlicher situativer Umstände und unterschiedlicher Registerunterschiede zwar erschwert zu sein; wir halten ein solches Vorgehen jedoch für unumgänglich, da das numerische Alter von Sprachteilhaber/innen u.E. als Folie zur Untersuchung sprachlicher Auffälligkeiten nicht zureichend ist. Es gibt gute Gründe für die Annahme, "[that] style-shifting is sharper for younger speakers and less sharp for older speakers“ (Cheshire 1987, 762), und wenn sich diese Hypothese bestätigen sollte, dann würden alterspezifische Unterschiede zwischen jungen und alten Sprachteilhabern vor allem in der Variabilität resp. Verfestigung der Benutzung sprachlicher Register bestehen.

Hypothesen haben allerdings, wenn wir den frühen Überlegungen von Popper (1934) folgen, keinerlei Wahrheit a priori, sondern müssen sich prüfen lassen, und eben diese Prüfung mag dazu führen, daß qua positiver Evidenz die betreffende $\mathrm{Hy}-$ pothese als 'bestätigt' (nicht und niemals: verifiziert) gelten kann oder daß sie qua widerstreitender Evidenz als falsifiziert und demnach als zu verwerfen angesehen werden muß. Wie dem im gegenwärtigen Falle auch sei: Sicherzustellen ist zunächst, daß Hypothesen dieser Art auch wirklich überprüfbar werden. Eine solche (Über-)Prüfbarkeit hängt im wesentlichen davon ab, ob es in Zukunft gelingen wird, den Begriff des 'Registers', von dem wir hier ausgegangen sind, mit einem präzis(er)en Inhalt zu versehen. Jenseits eines bloß intuitiven Verständnisses dessen, was im linguistischen Rahmen mit dem Gebrauch des Wortes Register gemeint ist (oder zumindest gemeint sein könnte), benötigen wir eine klare Vorstellung davon, was solche Register faktisch konstituiert. "In most of this work the practical has run well ahead of the theoretical, and a decisive case here is precisely the concept of 'register'" (de Beaugrande 1993, 14). Die wissenschaftliche Berufung auf das Register-Konzept verdankt sich vielfach einem eher intuitven Verständnis des betreffenden Ausdrucks, und wenn es sich tatsächlich um "a concept in search of a theory" handeln sollte (s. de Beaugrande 1993), dann wäre es mittlerweile allerhöchste Zeit, eben eine solche Theorie und ein genaueres Verständnis des Begriffs 'Register' zu entwickeln, gerade im Hinblick auf besondere Ausprägungen des Sprachgebrauchs jugendlicher und/oder älterer sowie alter Sprachteilhaber/innen.

\section{Literatur}

Bausinger, Hermann (1984). Deutsch für Deutsche. Dialekte - Sprachbarrieren - Sondersprachen. 2. Auflage. Frankfurt a.M.: Fischer.

Bausinger, Hermann (1987). Jugendsprache. In: Neue Praxis 17, 170-176.

de Beaugrande, Robert (1993). 'Register' in discourse studies: A concept in search of a theory. In: Ghadessy, Mohsen (ed.), Register analysis. Theory and practice. London/New York: Pinter, 725.

Beneke, Jürgen (1986). Die jugendspezifische Sprachvarietät - ein Phänomen unserer Gegenwartssprache. In: Linguistische Studien, Reihe A, Arbeitsberichte 140, 1-83.

Biber, Douglas (1995). Dimensions of register variation. A cross-linguistic comparison. Cambridge/New York/Melbourne: Cambridge University Press.

Boden, Deirdre \& Bielby, Denise Del Vento (1983). The past as resource. A conversational analysis of elderly talk. In: Human Development 26, 308-319. 
Bottke, Brigitte, bearb. (1989). 'Aktive Alte - 'Junge Alte' - 'Neue Alte'. Projektbeschreibungen, Diskussionsbeiträge, Literaturhinweise. Köln: Kuratorium Deutsche Altershilfe.

Cherubim, Dieter (1986). Jugendsprache und Soziolinguistik. In: Kühlwein, Wolfgang (Hrsg.), Neue Entwicklungen der Angewandten Linguistik. Tübingen: Narr (= Forum Angewandte Linguistik, 9), 87-89.

Cheshire, Jenny (1987). Age and generation-specific use of language. In: Ammon, Ulrich, Dittmar, Norbert \& Mattheier, Klaus J. (eds.), Sociolinguistics. An international handbook of the science of language and society. First volume. Berlin/New York: de Gruyter (= Handbücher zur Sprachund Kommunikationswissenschaft, 3.1), 760-767.

Dieck, Margret (1987). Die ältere Generation im Spiegelbild der großen Regierungserklärungen von 1949 bis 1987. In: Deutsches Zentrum für Altersfragen (Hrsg.), Die ergraute Gesellschaft. Berlin: Deutsches Zentrum für Altersfragen e.V., 189-218.

Ehmann, Hermann (1992a). Jugendsprache und Dialekt. Opladen: Westdeutscher Verlag.

Ehmann, Hermann (1992b). Affengeil. Ein Lexikon der Jugendsprache. München: Beck (Beck'sche Reihe, 478).

Fiehler, Reinhard (1997). Kommunikation im Alter und ihre sprachwissenschaftliche Analyse. Gibt es einen Kommunikationsstil des Alters? In: Selting, Margret \& Sandig, Barbara (Hrsg.), Sprechund Gesprächsstile. Berlin/New York: de Gruyter, 345-370.

Firth, John Rupert (1957). A synopsis of linguistic theory, 1930-1955. In: Studies in linguistic analysis. Oxford: Blackwell, 1-32.

Gerritsen, Marinel (1985). Alters- und geschlechtsspezifische Sprachverwendung. In: Besch, Werner \& Mattheier, Klaus J. (eds.), Ortssprachenforschung. Beiträge zu einem Bonner Kolloquium. Berlin: Schmidt, 79-108.

Grimm, Jacob (1864). Rede über das Alter. In: Grimm, Jacob, Kleinere Schriften. Bd. 1. Berlin: Dümmler, 188-210.

Halliday, M. A. K., McIntosh, Angus \& Strevens, Peter (1964). The linguistic sciences and language teaching. London: Longman.

Heinemann, Margot (1989). Kleines Wörterbuch der Jugendsprache. Leipzig: Bibliographisches Institut.

Heinemann, Margot (1991). Zur Varietät „Jugendsprache“. In: Praxis Deutsch 110, 6-9.

Heinemann, Margot (1993). Jugendsprache. Theoretische Standpunkte und methodische Zugriffe. In: Der Deutschunterricht 45, H. 3, 84-86.

Heinl-Hutchinson, Melinda (1975). Untersuchung zur Sprechweise und deren Beziehung zur Lebenszufriedenheit bei älteren Menschen. Diplomarbeit, Universität Gießen.

Helfrich, Hede (1979). Age markers in speech. In: Scherer, Klaus R. (ed.), Social markers in speech. Cambridge etc.: Cambridge University Press, 63-107.

Henne, Helmut (1981). Jugendsprache und Jugendgespräche. In: Schröder, Peter \& Steger, Hugo (Hrsg.), Dialogforschung. Jahrbuch 1980 des Instituts für deutsche Sprache. Düsseldorf: Schwann (Sprache der Gegenwart, 54), 370-384.

Henne, Helmut (1986). Jugend und ihre Sprache: Darstellung, Materialien, Kritik. Berlin/New York: de Gruyter.

Hess-Lüttich, Ernest W. B. (1974). Das sprachliche Register. Der Register-Begriff in der britischen Linguistik und seine Relevanz für die Angewandte Sprachwissenschaft. In: Deutsche Sprache 2, 269-286.

Hirt, Hermann (1909). Etymologie der neuhochdeutschen Sprache. Darstellung des deutschen Wortschatzes in seiner geschichtlichen Entwicklung. München: Beck.

Hörmann, Hans, Pieper, Ulrike \& Engelkamp, Johannes (1976). Zur psychologischen Problematik sogenannter Altersdialekte. In: Psychologische Rundschau 27, 12-27.

Januschek, Franz (1989). Die Erfindung der Jugendsprache. In: Osnabrücker Beiträge zur Sprachtheorie 41, 125-146.

Kemper, Susan (1987). Life-span changes in syntactic complexity. In: Journal of Gerontology 42, 323328.

Kemper, Susan \& Kynette, Donna (1986). Aging and the loss of grammatical forms: A cross-sectional study of language performance. In: Language \& Communication 6, 65-71.

Lapp, Edgar (1989). „Jugendsprache“: Sprechart und Sprachgeschichte seit 1945. Ein Literaturbericht. In: Sprache und Literatur in Wissenschaft und Unterricht 63, 53-75. 
Lehr, Ursula (1997). Demographischer Wandel. Herausforderungen einer alternden Gesellschaft. In: Forschung \& Lehre 2, 63-67.

Light, Leah L. (1993). Language changes in old age. In: Blanken, Gerhard et al. (eds.), Linguistic disorders and pathologies. An international handbook. Berlin/New York: de Gruyter (= Handbücher zur Sprach- und Kommunikationswissenschaft, 8), 900-918.

Müller-Thurau, Claus Peter (1985). Lexikon der Jugendsprache. Düsseldorf/Wien: Econ.

Oksaar, Els (1996). Laudatio auf Helmut Henne. In: Henne, Helmut, Sprachliche Erkundung der Moderne. Mannheim/Leipzig/Wien/Zürich: Dudenverlag (= Duden-Beiträge zu Fragen der Rechtschreibung, der Grammatik und des Stils, 53), 5-9.

Olbrich, Erhard (1976). Der ältere Mensch in der Interaktion mit seiner sozialen Umwelt: Inter- und intraindividuelle Unterschiede. Diss. phil., Universität Bonn.

Palmore, Erdmann B. (1968). Unterschiede hinsichtlich der Pensionierung bei Männern und Frauen. In: Thomae, Hans \& Lehr, Ursula (Hrsg.), Altern. Probleme und Tatsachen. Frankfurt a.M.: Akademische Verlagsgesellschaft, 320-331.

Pörksen, Uwe \& Weber, Heinz (1984). Spricht die Jugend eine andere Sprache? Antworten auf die Preisfrage der Deutschen Akademie für Sprache und Dichtung vom Jahr 1982. Heidelberg: Schneider.

Popper, Karl (1934). Logik der Forschung. Zur Erkenntnistheorie der modernen Naturwissenschaft. Wien: Springer.

Riegel, Klaus F. (1968). Untersuchungen sprachlicher Leistungen und ihrer Veränderungen. In: Zeitschrift für experimentelle und angewandte Psychologie 15, 649-692.

Rosenfeld, Elif Tolga (1993). When and how old age is relevant in discourse of the elderly: A case study of Georgia O'Keeffe. In: Alatis, James E. (ed.), Language, communication, and social meaning. Washington, D.C.: Georgetown University Press, 353-377.

Sanders, Willy (1973). Linguistische Stiltheorie. Probleme, Prinzipien und moderne Perspektiven des Sprachstils. Göttingen: Vandenhoek \& Ruprecht.

de Saussure, Ferdinand (1916). Cours de linguistique générale. Paris/Lausanne: Payot.

Schlobinski, Peter, Kohl, Gaby \& Ludewigt, Irmgart (1993). Jugendsprache - Fiktion und Wirklichkeit. Opladen: Westdeutscher Verlag.

Schlobinski, Peter \& Schmid, Katja Alexandra (1996). Alles ist eine Frage des Stils. Zur sprachlichen Kommunikation in Jugendcliquen und -szenen. In: Muttersprache 106, 211-225.

Stover, Susan E. \& Haynes, William O. (1989). Topic manipulation and cohesive adequacy in conversations of normal adults between the ages of 30 and 90. In: Clinical Linguistics \& Phonetics 3, 137-149.

Tews, Hans Peter (1987). 'Neue Alte'? Veränderungen des Altersbildes und des Altersverhaltens. In: Universitas 9, 868-879.

Tews, Hans Peter (1991). Altersbilder. Über Wandel und Beeinflussung von Vorstellungen vom und Einstellungen zum Alter. Köln: Kuratorium Deutsche Altershilfe (= Forum, 16).

Thimm, Caja (1995). Intergruppenkommunikation, soziales Vorurteil und konversationale Implikaturen: Alt und Jung im Dialog. In: Liedtke, Frank (Hrsg.), Implikaturen. Grammatische und pragmatische Analysen. Tübingen: Niemeyer (= Linguistische Arbeiten, 343), 187-208.

Thomas, Wolfgang (1972). Untersuchungen über Altersstereotypien anhand der modifizierten Skala „Attitudes toward old people“ von Tuckman und Lorge. Diss. med., Universität Düsseldorf.

Tismer, Karl-Georg (1971). Vergangenheitsbezug im höheren Alter. In: Zeitschrift für Entwicklungspsychologie und Pädagogische Psychologie 3, 14-24.

Tuckman, Jacob \& Lorge, Irving (1953). Attitudes toward old people. In: The Journal of Social Psychology 37, 249-260.

Welter, Ernst Günther (1960). Die Sprache der Teenager und Twens. Frankfurt a.M.: dipa. 


\title{
Modelle zur Beschreibung und Erklärung altersspezifischer Sprache und Kommunikation
}

\author{
Reinhard Fiehler
}

\section{Einleitung}

Im Laufe der letzten Jahrzehnte hat die (soziolinguistische) Sprachwissenschaft den verschiedensten sozialen Gruppen spezifische Varietäten, Soziolekte oder Teilsprachen zugeschrieben und eine nicht unerhebliche Mühe darauf verwendet, sie in ihrer Spezifik zu beschreiben. Die Debatte, die z.B. die 70er Jahre geprägt hat, war die um den restringierten und den elaborierten Code, wobei diese Codes mit Unterschicht bzw. Mittelschicht in Zusammenhang gebracht wurden. Parallel dazu verlief der Versuch, eine Arbeitersprache zu charakterisieren (z.B. Bielefeld \& Lundt 1977). Die nächste wesentliche Etappe war die Diskussion um geschlechtsspezifische Unterschiede in Sprache und Kommunikationsverhalten. Ein weiterer Strang ist die Erforschung der Jugendsprache (kritisch hierzu Kohrt \& Kucharczik (i.d.Bd.)). Bis auf das Alter hat die Soziolinguistik fast alle relevanten sozialen Parameter für die Konstitution von Varietäten durchgespielt.

Alle diese Versuche sind aus meiner Sicht relativ unbefriedigend geblieben, und sie sind schließlich mit abnehmendem Interesse an der betreffenden Fragestellung mehr oder weniger versandet. Hierfür gibt es m.E. zwei Hauptgründe: Zum einen ist der Status dieser Varietäten, Soziolekte, Teilsprachen oder wie auch immer man diese Gebilde bezeichnen mag, unklar geblieben: Handelt es sich um eine heterogene Menge punktueller Besonderheiten oder wird ein eigenständiges System vermutet. ${ }^{1}$ Zum anderen ist es nicht gelungen, diese Varietäten in ihrer Extension empirisch klar zu konturieren, also eine halbwegs umfassende Beschreibung der jeweiligen Besonderheiten zu geben.

Dieser Sammelband und die Arbeitsgruppe, aus der er hervorgeht, sind ein Versuch, die bisher nur am Rande bearbeitete Kategorie 'Alter' in den Blick zu nehmen und die Besonderheiten von Sprache und Kommunikation im Alter der Linguistik als Forschungsgegenstand nahezubringen. Dabei erscheint es mir notwendig und vielleicht auch möglich, einige methodologische Probleme der vorangegangenen Untersuchungen zu vermeiden, indem drei zentrale soziolinguistische Konzepte zur Erfassung und Beschreibung von Varianz reflektiert werden (Abschnitt 2). Hieraus sind Konsequenzen für die Beschreibung altersbedingter Varianz zu ziehen (Abschnitt 3). Anschließend werden verschiedene Ansätze behandelt, die zur Erklärung von altersbedingter Varianz benutzt werden (Abschnitt 4). Der Beitrag behandelt also ausschließlich methodologische Probleme. Es geht nicht um substantielle Analysen altersspezifischer sprachlicher Phänomene.

\footnotetext{
Dieses Manko formuliert - bezogen auf Soziolekte - auch Kubczak: "Wenn sich in diesem Zusammenhang die Formulierung "Gruppensprache" findet, wird üblicherweise leider nicht dazugesagt, ob damit vollständige Sprachsysteme mit genügender Kapazität zur Bezeichnung sämtlicher Sachverhalte oder nur größere bzw. kleinere Listen von sprachlichen Spezifika einer Sprechergruppe (z.B. die "Reitersprache") gemeint sind." (Kubczak 1987, 268)
} 


\section{Modelle zur Erfassung und Beschreibung altersbedingter Varianz}

Daß die Sprache und das Kommunikationsverhalten vieler älterer Menschen - mal mehr, mal weniger auffällig - aus der Sicht jüngerer irgendwie anders ist, stellt sich dem alltagsweltlichen Verständnis als eine unproblematische Gewißheit dar. Jede und jeder könnte aus der Erfahrung mühelos Beispiele dafür anführen, daß Sprache und Kommunikationsverhalten alter Menschen sich von dem jüngerer Menschen unterscheiden, wobei jede und jeder wohl auch sofort hinzufügen würde, daß dies nicht immer und für alle älteren Menschen gelte, sondern daß es natürlich große Unterschiede gäbe.

Dieser alltagsweltliche Umgang mit sprachlich-kommunikativer Varianz unterscheidet sich jedoch deutlich von dem wissenschaftlichen. Die Sprachwissenschaft hat verschiedene allgemeine Modelle entwickelt, um sprachlich-kommunikative Varianz - sowohl zwischen Personengruppen als auch sprachlich-kommunikative Unterschiede im Verhalten in verschiedenen Situationen - zu beschreiben. Diese Modelle beziehen sich generell auf Varianz, sie sind nicht speziell für die Erfassung altersbedingter Varianz konzipiert. Zu fragen ist also zum einen, welche Modelle faktisch verwendet werden, um die Andersartigkeit altersbedingter Sprache und Kommunikation wissenschaftlich zu erfassen und zu beschreiben, und zum anderen ist zu untersuchen, wie gut sie geeignet sind, um die spezifischen empirischen Verhältnisse im Bereich altersbedingter Varianz abzubilden.

Zur ersten Frage: Soweit ich sehe, kommen hauptsächlich drei Modelle zum Tragen: die Auflistung differierender Merkmale, das Varietätenmodell und das Stilkonzept.

\subsection{Die Liste differierender Merkmale}

Der überwiegende Teil der bisherigen Forschung hat versucht, die Altersspezifik zu charakterisieren, indem spezifische Merkmale der Sprache und Kommunikation im Alter angegeben werden. Einzeluntersuchungen sind dabei zwar in der Regel auf spezielle Merkmale beschränkt, aber in ihrer Gesamtheit explizieren diese Arbeiten Altersspezifik als eine Liste spezifischer Merkmale. Diese Auflistung ist gleichsam ein Ausbuchstabieren der Spezifik von Sprache und Kommunikation älterer Menschen. Beispiele für solche Merkmale wären: 'höhere Rate an Wortfindungsproblemen', 'Gebrauch veralteter Lexik', 'häufigere Etablierung einer Vergangenheitsperspektive', 'höhere Zahl von Themensprüngen' etc. Diese Merkmale beziehen sich auf sprachlich-kommunikative Verhaltensweisen, die beobachtet werden können.

Betrachtet werden bei diesen Untersuchungen Personen, die im Sinne des numerischen Alters $^{2}$ eine angebbare, in verschiedenen Kontexten jedoch unterschiedlich bestimmte Grenze überschritten haben. Ihre Sprache und ihr Kommunikationsverhalten werden implizit oder explizit verglichen mit dem jüngerer Personen, und es werden in verschiedenen Bereichen des Sprach- und Kommunikationsverhaltens Unterschiede konstatiert, die listenmäßig zusammengestellt werden. Diese Unterschiede

2 'Alter' ist im Verständnis des Alltags keine einheitliche bzw. konsistente Kategorie. Alltagsweltlich existieren mindestens vier Konzepte, die aufeinander bezogen sind und die häufig miteinander vermischt werden: Alter als zeitlich-numerische Größe, Alter als biologisches Phänomen, Alter als soziales Phänomen und Alter als interaktiv-kommunikatives Phänomen. Vgl. Fiehler (1997). 
beziehen sich - wie gesagt - auf beobachtbare Verhaltensweisen. Im Fokus sind hier also nicht Unterschiede auf der Ebene von Regeln oder Konventionen.

Die so gewonnenen Merkmale bestimmen die Spezifik in der Regel als einen quantitativen, nicht als einen absoluten Unterschied. D.h. es gibt kaum Merkmale, die exklusiv nur in der einen, nicht aber in der anderen Gruppe auftreten. Der Nachweis solcher quantitativen Unterschiede ist jedoch - methodisch sauber - schwer zu führen: Das Erkaufen von Vergleichbarkeit und Quantifizierbarkeit durch experimentelle Settings einerseits und die Schwierigkeiten mit der Vergleichbarkeit bei der Verwendung authentischer Materialien andererseits sind hier die bekannten Pole, zwischen denen es anscheinend kaum einen Mittelweg gibt.

Daher geht es - zumindest bei Untersuchungen, die sich auf authentisches Gesprächsmaterial stützen - im Regelfall wohl weniger um einen Nachweis von quantitativen Unterschieden als vielmehr um die materialgestützte Explikation und das punktuelle Belegen eines Vorverständnisses, das auf Erfahrungen, aber auch auf Stereotypen beruht. Eine Gefahr dieses Vorgehens liegt darin, daß eine Verhaltensweise, die man im Material bei einer alten Person feststellt und die dem eigenen Vorverständnis nach altersspezifisch ist, vorschnell generalisierend der gesamten Gruppe alter Menschen zugeschrieben wird. D.h. es wird nicht mehr geprüft, ob diese Verhaltensweise nur einer spezifischen Teilgruppe der alten Menschen zukommt.

Die im Anhang wiedergegebene Liste ist ein Beispiel für diese additive Vorgehensweise. Sie erfaßt Spezifika des Kommunikationsverhaltens. Diese Liste ist Ergebnis einer zweisemestrigen Lehrveranstaltung 'Kommunikation im Alter' (WS 1993/94 und SS 1994), in der u.a. sechs längere Gesprächsaufzeichnungen extensiv gemeinsam analysiert wurden. Die Analysen dienten der Explikation dessen, was die Teilnehmerlnnen als altersspezifische Phänomene betrachteten. Im Durchgang durch die Aufnahmen und Transkripte wurden jeweils Phänomene identifiziert, die bei einzelnen oder mehreren TeilnehmerInnen den Eindruck erweckten, altersspezifisch zu sein. Vergleichsmaßstab war dabei in der Regel das eigene sprachlichkommuni-kative Verhalten. In die Identifikation entsprechender Phänomene ging neben dem Vorverständnis natürlich auch zunehmend die Kenntnis der in der Literatur behandelten alterstypischen Merkmale ein.

Das Material wurde also nicht zu quantitativen Analysen benutzt, sondern es war Mittel zur Explikation des Vorverständnisses - mit der Einschränkung, daß das Vorverständnis natürlich nur so weit expliziert werden konnte, wie sich auch wirklich Belege im Material finden ließen. Die entsprechenden Phänomene wurden unter dem Gesichtspunkt ihrer Altersspezifik diskutiert, wobei durchaus nicht alle ins Auge gefaßten Merkmale in der Seminargruppe Bestand hatten. Das empirische Material half so beim Aussprechen bzw. Formulieren von Wissensbeständen, die (wie deutlich auch immer) vorhanden waren. Es stellte zugleich auch ein Anregungspotential dar, das zur Präzisierung und Erweiterung, aber auch zur Korrektur vorverständlicher Annahmen diente.

Die in der Liste enthaltenen gegenteiligen Aussagen machen das Problem deutlich, daß altersspezifische Sprache und Kommunikation nicht homogen sind, sondern daß Teilgruppen unterschieden werden können, die sich in ihrem sprachlichkommunikativen Verhalten - bis hin zur Gegensätzlichkeit - unterscheiden. Vom Ausgangspunkt des 'durchschnittlichen' Kommunikationsverhaltens eines nicht-alten Erwachsenen sind also je nach Persönlichkeitsstruktur und Kontextbedingungen Abweichungen in unterschiedliche Richtungen möglich. Wie auch immer dieses durchschnittliche Kommunikationsverhalten zu operationalisieren ist, bildet es doch 
eine unverzichtbare Basis des Vergleichs. Meistens wird hierfür wohl die Wahrnehmung des eigenen Kommunikationsverhaltens eingesetzt.

\subsection{Das Varietätenmodell}

Die zweite Möglichkeit, altersbedingte Varianz zu beschreiben, ist, sie als eigene Varietät zu verstehen. Man geht dann davon aus, daß die Alten eine für sie charakteristische und spezifische Teilsprache im Rahmen einer Sprachgemeinschaft sprechen.

Die eben beschriebene Suche nach einzelnen spezifischen Merkmalen auf der Verhaltensebene und ihre listenmäßige Zusammenstellung charakterisiert m.E. recht gut das forschungspraktische Vorgehen in der gegenwärtigen Situation. Es wird aber überlagert von theoretischen Konzepten, die solche Differenzen bzw. Gemeinsamkeiten primär nicht empirisch herauszuarbeiten und nachzuweisen versuchen, sondern sie voraussetzen. Dies geschieht insbesondere im Rahmen des Varietätenkonzepts. Seine Grundannahme ist, daß sich in einer Sprache (was auch immer 'eine Sprache' sei) verschiedene Teilsprachen oder Varietäten ${ }^{3}$ unterscheiden lassen bzw. daß sich eine Sprache aus verschiedenen Teilsprachen bzw. Varietäten zusammensetzt. Paradigmatische Definitionen finden sich z.B. bei Kanngießer (1980) und Ammon (1987):

\footnotetext{
"Eine synchron beschränkte natürliche Sprache - eine Zustandssprache S, die in einer Sprachgemeinschaft $C$ gesprochen wird - besteht aber aus einer endlichen Menge von Teilsprachen $T_{1}, \ldots$, $T_{r}$, und diese Sprachen $T_{m}$ sind es, die von den Mitgliedern von $C$ gesprochen werden. Im Rahmen der Theorie der Sprachkompetenz wird nun spezifiziert, welche C-Mitglieder für welche dieser Teilsprachen kompetent sind, über welche der Teilsprachen $T_{r}$ sie verfügen - und mit der Spezifizierung dieser Verfügungsrelationen wird offenbar ein partielles Modell der Infrastruktur der Sprachgemeinschaft C geliefert." (Kanngießer 1980, 1)
}

"Languages are sets of varieties and thus varieties are elements of languages; standard varieties and dialects (= dialectal varieties) on the other hand are various types of such elements (varieties). So a language can contain dialects and one or more standard varieties [...] as well as other types of varieties." (Ammon 1987, 317)

"The question now is according to which criteria varieties are grouped together to form such sets that we call languages [...] A particularly important, if not the most important group-forming relation between varieties or between their speakers is mutual intelligibility." (Ammon 1987, 319)

Diese Vorstellung von Teilsprachen im Rahmen einer Sprache ist der Kern von Konzepten wie Varietät, Soziolekt und Ideolekt. Das Teilsprachenmodell aber hat nun eine Reihe von Implikationen und wirft Fragen auf, die nachfolgend kritisch behandelt werden müssen.

(a) Das Teilsprachenmodell reproduziert ersichtlich das Konzept verschiedener distinkter natürlicher Sprachen auf einer tieferen - jetzt sprachinternen - Ebene. Eine Konsequenz dieser Übertragung ist, daß die Unterschiede zwischen den Teilsprachen relativ groß erscheinen (entsprechend der fehlenden Verständigungsmöglichkeit zwischen verschiedenen Sprachen), während die varietäteninterne Varianz nicht im Fokus steht. Die Teilsprachen werden so als intern relativ homogen ver-

3 Ich verwende in diesem Beitrag die Begriffe 'Teilsprache' und 'Varietät' synonym. 
standen, während sie untereinander als deutlich unterschiedlich gesehen werden. ${ }^{4}$ Soweit das Teilsprachenmodell die Transposition des Sprachenkonzepts auf einzelsprachinterne Verhältnisse ist, ist es eher ein theoretisches Konstrukt oder ein Postulat. Es ist nicht aus empirischer Arbeit heraus entwickelt worden und stützt sich nicht auf eine empirische Fundierung.

(b) Die genannten Definitionen klären zwar das Verhältnis zwischen Sprache und Teilsprachen/Varietäten. Aber in welchem Verhältnis stehen die verschiedenen Varietäten zueinander? Entspricht jeder Varietät ein eigenes, von den anderen Varietäten verschiedenes System (das wird man vielleicht auf der Ebene von Einzelsprachen, schwerlich aber auf der Ebene von Varietäten im Rahmen einer Sprache behaupten wollen), oder gibt es Überschneidungen zwischen den Systemen? Wenn es Überschneidungen gibt - und es muß sie wohl geben -, wie groß sind sie und welche Bereiche betreffen sie? Oder anders herum gefragt: Welches sind die - beim Vergleich zweier Varietäten - unterschiedlichen und damit varietätskonstitutiven Bereiche?

Dieses Problem wird noch dadurch verschärft, daß die einzelnen Varietäten nicht homogen sind. Es gilt also das Abgrenzende gegenüber anderen Varietäten herauszuarbeiten bei gleichzeitiger interner Varianz der einzelnen Varietäten:

\begin{abstract}
"Wo mit Rücksicht auf Soziolekte von Systemen oder Subsystemen einer Sprache die Rede ist, geht man nicht selten davon aus, daß solche Systeme oder Subsysteme als Diasysteme begriffen werden müssen, d.h. als aus verschiedenen ähnlichen Ideolekten gebildete Sprachsysteme, die sich einerseits durch konstitutive Züge unterscheiden (sonst könnte man nicht von verschiedenen Soziolekten einer Sprache reden) und die andererseits nicht homogen sind, sondern selbst wieder sprecher- und sprechergruppenrelevante Gliederungen aufweisen." (Kubczak 1987, 268)
\end{abstract}

(c) Eine weitere Frage ist die nach dem Substrat der Varianz: Für was wird im Teilsprachen- bzw. Varietätenkonzept Varianz behauptet? Anders als beim Listenmodell geht es hier nicht um eine Varianz von Merkmalen, die sich auf Verhaltensweisen beziehen, sondern um eine Varianz im Sprachsystem, und das heißt, daß es um unterschiedliche Regeln bzw. Konventionen geht. Dies ist allerdings insofern uneindeutig, als sich - unter der Voraussetzung der Unterscheidung von Kompetenz und Performanz - zwei verschiedene Positionen ausmachen lassen, die einerseits Varianz als ein Performanzphänomen und andererseits als ein Kompetenzphänomen beschreiben: Ist Varianz das Result der Tatsache, daß die Beteiligten über unterschiedliche Regeln verfügen, oder machen sie nur unterschiedlichen Gebrauch von Regeln, über die sie gleichermaßen verfügen? Oder - dritte Möglichkeit - ist die Varianz Resultat einer Mischung von beiden?

(d) Alle drei Möglichkeiten setzen voraus, daß man weiß, welche Regeln zur Kompetenz der SprecherInnen der verschiedenen Varietäten gehören. Regeln bzw. Konventionen sind nun nicht in irgendeiner Weise gegeben oder beobachtbar, sondern sie sind allenfalls auf der Grundlage von beobachteten Verhaltensweisen rekonstruierbar. Hier liegt die Schnittstelle des Varietätenkonzepts zur Empirie - ein Weg, der allerdings kaum beschritten wird. Dies hat zur Konsequenz, daß weder die Frage der Lokalisierung der Varianz (Performanz- oder Kompetenzphänomen?) ver-

4 Es entfällt auf dieser sprachinternen Ebene allerdings der Gesichtspunkt, daß eine Verständigung zwischen den verschiedenen Teilsprachen nicht möglich ist und damit das zentrale Kriterium für die Unterscheidung verschiedener Sprachen. Der Kern des Sprachenkonzepts besteht in der Annahme einer endlichen Menge verschiedener, disjunkter Sprachen, die jeweils intern, aber nicht untereinander Verständigung ermöglichen. 
nünftig entschieden werden kann, noch daß die Unterschiede zwischen den verschiedenen Varietäten zugrundeliegenden Kompetenzen genau beschrieben und charakterisiert werden können.

(e) Das Varietätenkonzept steht ferner, da die Teilsprachen nie völlig homogen sind, vor dem Problem, wie es mit varietäteninterner Varianz umgehen soll. Je näher Untersuchungen an der Empirie sind, desto weniger läßt sich die Tatsache teilspracheninterner Varianz übersehen und aus der Welt schaffen. Es lassen sich im wesentlichen zwei Lösungen des Problems beobachten:

- Ignorierung/Vernachlässigung/ldealisierung

Das Problem wird entweder nicht gesehen oder nicht thematisiert, es wird (für die Zwecke der jeweiligen Untersuchung) für irrelevant oder vernachlässigbar erklärt oder es wird im Zuge einer konstruktiven Idealisierung aus der Welt geschafft.

\section{- Feinere Differenzierung in Subvarietäten}

Bei dieser Lösung werden im Rahmen einer Teilsprache weitere Differenzierungen vorgenommen, indem Subvarietäten unterschieden werden. Dies ist z.B. der Fall, wenn im Rahmen eines Dialekts Ortssprachen unterschieden werden. Eine solche Differenzierung kann vorangetrieben werden, bis man bei Ideolekten landet, wo man dann feststellt, daß auch das Individuum sich sprachlich nicht immer gleich verhält, sondern z.B. je nach Situationstyp variiert.

Ersichtlich wird hier das gleiche Modell auf unterschiedlichen Ebenen immer wieder angewendet. Diese Iteration löst aber nicht das Dilemma von (postulierter) Einheitlichkeit und (faktischer) Varianz, sondern reproduziert es lediglich auf immer feineren Ebenen.

(f) Stellt sich abschließend die Frage nach der empirischen Adäquatheit dieses Modells, also die Frage, ob es die innerhalb einer Sprache vorfindliche Varianz zumindest in ihrer Grundstruktur zufriedenstellend beschreiben kann. Dieses Problem der strukturellen empirischen Adäquatheit wird in der Literatur durchaus gesehen:

\footnotetext{
"Innerhalb einer Varietät muß eine gewisse Homogenität und Stabilität gefordert werden (auch wenn viele Soziolinguisten für jede Varietät eine innere Variabilität annehmen) [...] Kontroverser ist die Frage der Diskretheit der Varietäten. Während man sicher behaupten kann, daß 'Varietät' 'Diskretheit' implizieren müßte, [...] so scheint es den Tatsachen doch oft angemessener zu sein, die Varietäten als (konventionell bestimmte, nicht gut abgegrenzte) Verdichtungspunkte in einem Kontinuum zu verstehen." (Berruto 1987, 265)
}

So unscharf letztlich diese Ausführungen sind, sind sie doch als Ausdruck der Suche nach alternativen theoretischen Modellen verstehbar, die die faktischen Verhältnisse besser abbilden. ${ }^{5}$

Im folgenden sollen die Zusammenhänge zwischen der Erfahrung von Varianz und dem Varietätenkonzept thematisiert werden. Der Ausgangspunkt für die Konstatierung von Varianz ist ein doppelter: zum einen Varianzerfahrungen in der konkreten Interaktion, zum anderen die Sozialisierung in entwickelte Varianzraster, die (homogene) Varietäten als gegeben voraussetzen.

Zunächst zum Ausgangspunkt Interaktion: Wir bemerken in konkreten Interaktionen immer wieder, daß jemand an einer bestimmten Stelle des sprachlich-kommu-

5 Hierzu einige Andeutungen weiter unten in Abschnitt 3. 
nikativen Handelns etwas anderes tut, als wir erwarten oder als wir an seiner Stelle tun würden. Dies ist die punktuelle, individuelle Erfahrung von Abweichung bzw. Varianz. Aus dieser Varianz erwachsen für die Verständigung in unterschiedlichen Dimensionen und mit unterschiedlicher Gewichtigkeit Verständigungspro-bleme, die bis zum Nichtverstehen reichen können. Aus solchen Varianzerfahrungen erwachsen aber auch für zukünftige Interaktionen stabile Erwartungen ${ }^{6}$ hinsichtlich des Wiederauftretens der Varianz.

Die konkreten Varianzerfahrungen werden dann üblicherweise erklärt, indem sie mit bestimmten sozialen Kategorien in Zusammenhang gebracht werden: $X$ spricht anders, weil $X$ ein unverwechselbares Individuum ist, weil er/sie aus $Y$ ist, alt ist, ein Arbeiter/Intellektueller, ein Mann ist etc. Und sie können auch kategoriengebunden generalisiert werden: Alle aus (der Straße/demOrt/der Region/dem Staat) Y, alle jungen/alten Menschen, alle aus der sozialen Gruppe Z, alle Frauen/Männer etc. handeln sprachlich-kommunikativ in Hinblick auf das Phänomen A (und u.U. auch hinsichtlich weiterer 'verwandter' Phänomene) einheitlich anders als ich bzw. als meine Gruppe. Varietäten sind in dieser Sichtweise keine objektiven Gegebenheiten, sondern menschliche Konstrukte, die sich aus der Verallgemeinerung von Erfahrungen punktueller Varianz ergeben.

Diesen Generalisierungen ist also eine Tendenz zur Verdinglichung inhärent, nämlich die Tendenz, diese Verallgemeinerungen nicht mehr als heuristische Hilfe bei der Handlungsorientierung zu verstehen, sondern als objektive Gegebenheiten. Dieser Prozeß der Verdinglichung (von hypothetischen Verallgemeinerungen zu faktischen Gegebenheiten) wirkt dann seinerseits organisierend auf die Wahrnehmung der Erscheinungen zurück. 'Nach innen' wird homogenisiert, die Grenzen bzw. Unterschiede 'nach außen' hingegen werden überakzentuiert. So kommt es zur Sichtweise von (vermeintlich) homogenen und deutlich abgegrenzten Varietäten. Bezeichnungen z.B. wie Dialekt, Frauensprache oder Altersvarietät/-sprache sind in dieser Hinsicht nicht Bezeichnungen für vorab gegebene Entitäten, sondern es sind Bezeichnungen für Konstrukte, und die Verwendung der Bezeichnungen trägt dazu bei, diese Konstrukte zu stabilisieren und zu verdinglichen.

Die in beschriebener Weise konstituierten Varietäten stellen dann das Forschungsprogramm dar, das durch Untersuchungen weiter ausgearbeitet und aufgefüllt werden soll.

Varianzerfahrung in der Interaktion ist aber nicht der einzige Ausgangspunkt für die Konstatierung von Varianz. Daneben stehen - Ausgangspunkt Sozialisation tradierte alltagsweltliche wie wissenschaftliche Varietätenraster, in die hinein wir sozialisiert werden und die die Wahrnehmung vorstrukturieren. Die aktuellen Prozesse der Konstitution von Varietäten erfolgen in einer Umwelt, in der immer schon ausgebildete Varietätenraster existieren und tradiert werden, so daß die aktuellen Prozesse häufig auf diese Raster zulaufen, sie übernehmen und sie so verstärken.

\subsection{Das Stilkonzept}

Häufig wird der Stilbegriff verwendet, um die Besonderheiten von alterstypischer Sprache und Kommunikation zu charakterisieren. Es wird von einem besonderen

6 Die Dialektologie z.B. operationalisiert und beschreibt diese Erwartungen u.a. mit dem Konzept der Isolinien (Isophone und Isoglossen). 
Sprach- und Kommunikationsstil des Alters gesprochen (so auch Betten und Cherubim i.d.Bd.). Gelegentlich werden auch verschiedene Altersstile unterschieden. ${ }^{7}$ Beim Sprach- und Kommunikationsstil des Alters handelt es sich um einen Gruppenstil (im Gegensatz zum Individualstil), der sich auf Art und Weise des Kommunizierens und/oder der Verwendung sprachlicher Mittel bezieht (im Gegensatz z.B. zum Schreibstil, Malstil, Lebensstil etc., die andere Domänen haben). Um zu überprüfen, ob 'Stil' ein geeignetes Konzept zur Erfassung alterstypischer Varianz ist, muß zunächst der Stilbegriff genauer expliziert werden.

Stil ist m.E. keine inhärente Eigenschaft von Äußerungen, Texten oder Kommunikationsweisen. Stil ist zwar eine Kategorie, die sich immer auf menschliche Handlungen bzw. deren Resultate bezieht, Stil ist aber nicht in einem materiellen Sinn in diesen Handlungen bzw. Handlungsresultaten enthalten. Stil ist ein relationales Phänomen (vgl. Sandig 1995, 33). Stil als Kategorie emergiert immer dann, wenn eine vergleichende Betrachtungsweise eingenommen wird, wenn etwas auf der Folie oder vor dem Hintergrund alternativer Realisierungsmöglichkeiten wahrgenommen wird. Diese Sichtweise muß nicht notwendig immer eingenommen werden. Man kann etwas für sich betrachten, Handlungen oder Handlungsresultate als solche wahrnehmen. Dann ist Stil keine relevante Kategorie. In diesem Sinne folge ich Sandig $(1995,28)$, wenn sie feststellt: "es kann jede Sprachverwendung zum Gegenstand stilistischer Untersuchung gemacht werden". Ich folge aber nicht ihrer Aussage: "Jede Äußerung und jeder Text hat Stil" (ebd.), weil sie zumindest die Gefahr einer verdinglichenden Sichtweise auf den Stilbegriff beinhaltet.

Stil wird erst dann relevant und thematisch, wenn etwas in seinem So-Sein nicht einfach hingenommen wird, sondern - aus welchen Gründen auch immer - sich die Frage nach einem möglichen Anders-Sein, nach Alternativen, stellt. Der Vergleichshintergrund, die möglichen Alternativen, können dabei unterschiedlich deutlich ins Bewußtsein treten. So zentral der Vergleich als Methode für die Identifizierung und Beschreibung von Stil ist (vgl. Fix 1991, 300), so wenig deutlich ist häufig, was (welches Phänomen, welche Entität genau) dabei womit (mit welchen Alternativen) hinsichtlich welcher Merkmale nach welchen Kriterien auf welcher Ebene verglichen wird. Ja, sogar die Tatsache, daß etwas verglichen wird, muß nicht besonders deutlich ins Bewußtsein treten.

Es bestehen dabei sehr verschiedene Möglichkeiten des Vergleichs: So kann z.B. synchron-interpersonal oder personal-diachron verglichen werden. Im ersten Fall werden Handlungen miteinander verglichen, die von verschiedenen Personen im gleichen Zeitintervall getätigt werden, im zweiten die Handlungen einer Person zu verschiedenen Zeitpunkten. Der personal-diachrone Vergleich ist z.B. relevant, wenn etwa bei einem Schriftsteller Jugend- und Altersstil unterschieden werden. Bei der Untersuchung des Kommunikationsstils des Alters hingegen dominiert der synchron-interpersonale Vergleich: Zum Untersuchungszeitpunkt wird das Kommunikationsverhalten alter Menschen mit dem anderer, nicht-alter Personen in Beziehung gesetzt.

Auf dem Hintergrund des dargestellten Verständnisses von Stil ist die Frage nach der Existenz eines Sprach- und Kommunikationsstils des Alters nur eine andere Formulierung der Frage nach der Spezifik bzw. den Spezifika der Sprache und der

Dies ist abhängig von der Ebene der Abstraktion, die im jeweiligen Kontext relevant ist. Es ist ebenso möglich, Besonderheiten eines allgemeinen Kommunikationsstils des Alters (z.B. im Vergleich mit dem Stil von nicht-alten Erwachsenen) ins Auge zu fassen wie auf einer weniger allgemeinen Ebene interne Differenzierungen des Altersstils zu betrachten. 
Kommunikation im Alter. In beiden Fällen geht es um den Vergleich des Sprach- und Kommunikationsverhaltens alter Menschen mit dem von jüngeren erwachsenen Menschen und die Bestimmung der Differenzdimensionen und -qualität. Es gibt einen Sprach- und Kommunikationsstil des Alters genau in dem Maße, wie es gelingt, die Spezifik von Sprache und Kommunikation im Alter herauszuarbeiten und zu beschreiben. Damit besteht theoretisch kein wesentlicher Unterschied zu dem in 2.1 diskutierten Listenmodell, das ja ebenfalls auf die Explikation einer Spezifik hinausläuft. Das Stilkonzept, sofern es in der hier skizzierten Weise verstanden wird, ist lediglich die Verdoppelung der Frage nach der Spezifik in einer anderen Terminologie und Traditionslinie. Und es ist eine Frage des Stils, welcher Terminologie und Traditionslinie man folgen möchte.

\section{Konsequenzen für die Beschreibung altersbedingter Varianz}

Aus den vorgetragenen Überlegungen ergeben sich m.E. zwei Konsequenzen: eine eher forschungsstrategische und eine theoretische.

Forschungsstrategisch scheint es mir geboten, nicht von der Existenz einer Alterssprache oder Altersvarietät auszugehen. Dies ist eine ebenso unnötige wie unzutreffende Pauschalisierung. Sinnvoll scheint es beim gegenwärtigen Stand der Forschung zu sein, die empirische Arbeit im Rahmen des Listenmodells fortzuführen, d.h. sukzessive den Versuch zu machen, einzelne Kandidaten für Verhaltensweisen zu identifizieren, die möglicherweise altersspezifisch sind. Dabei sollte dreierlei im Bewußtsein bleiben: Zum einen, daß diese Verhaltensweisen nicht notwendig bei allen alten Menschen zu finden sind; daß also die Spezifik in einem quantitativen Aspekt besteht. Daraus folgt zweitens die Notwendigkeit einer maximalen Differenzierung und Explizitheit: Für welche Verhaltensweise nimmt man auf welcher Datengrundlage für welche spezifische Personengruppe unter den Alten (Kriterien der Konstitution dieser Gruppe) an, daß sie in welchem Grade bzw. Ausmaß häufiger (und damit in diesem Sinne spezifisch) ist als bei welcher anderen nicht-alten Gruppe (Kriterien der Konstitution dieser Gruppe). Diese Binnendifferenzierung sowohl der Gruppe der Alten als der Vergleichsgruppe scheint mir der beste Schutz vor Pauschalierung zu sein. Zum dritten sollte deutlich gemacht werden, daß die Liste der spezifischen Merkmale bzw. Verhaltensweisen lediglich einen aktuellen Forschungsstand wiederspiegelt, also einen heuristischen Stellenwert hat, aber nicht die Explikation einer in irgendeiner Hinsicht präexistenten Alterssprache bzw. Altersvarietät darstellt. Damit sollte eine Verdinglichung der Untersuchungsergebnisse vermieden werden.

Theoretisch scheint es mir geboten, Modelle, die Homogenitätsannahmen implizieren oder nahelegen (wie das Sprachen- und Varietätenkonzept es tun), durch ein anderes theoretisches Grundmodell zu ersetzen, das ein Kontinuum von Varianz erfassen kann. Ein Vorschlag von Kummer (1975), der wenig Beachtung gefunden hat und der noch keineswegs hinreichend ausgearbeitet ist, weist genau in diese Richtung:

"Die Beherrschung der Konventionstypen und Einzelkonventionen, die eine Sprache konstituieren, könnte als Explikat für den Begriff 'Sprachbeherrschung' gelten, wobei allerdings zu berücksichtigen ist, daß 'Sprachbeherrschung' ein irreführender Terminus ist. Es gibt nach der hier vertretenen Auffassung keine einzelne Sprache, die durch ein festliegendes System von Regeln definiert ist, 
sondern nur untereinander ähnliche offene Systeme von Konventionen, die in Grenzen von Individuum zu Individuum variieren und niemals vollständige Verständigung erlauben." (Kummer 1975, 163)

Relativiert wird hier die Vorstellung der Existenz von einheitlichen und homogenen Sprachen:

"In diesem Sinn hebt die Auffassung von dem Aufbau einer Sprache aus Konventionen verschiedenen Typs teilweise das Konzept eines idealisierten 'Sprachsystems' auf, das für alle Mitglieder einer 'Sprachgemeinschaft' Gültigkeit hätte und dessen Grenzen die Grenzen dieser Gemeinschaft markieren. Einzelne Konventionen, etwa Verkettungskonventionen, können in ihrem Geltungsbereich weit über eine 'Sprachgemeinschaft' hinausreichen und im Extremfall sprachuniversal sein, andere Konventionen gelten nur in Subgruppen innerhalb einer angenommenen 'Sprachgemeinschaft'." (Kummer 1975, 161)

Diese beiden Modellvorstellungen zusammen, nämlich daß Individuen über untereinander ähnliche - aber eben nicht identische - offene Systeme von Konventionen verfügen und daß sich Konventionen in der Reichweite ihrer Verbreitung unterscheiden, ermöglichen die Modellierung kontinuierlicher Übergänge. Der Preis ist klar: Es gibt keine klar abgrenzbaren Gruppensprachen, Varietäten, Soziolekte, Register etc. mehr.

Verwiesen wird man mit diesem Programm auf die Notwendigkeit, die individuellen Konventionssysteme und das, worin sie sich genau unterscheiden, zu rekonstruieren und zu beschreiben sowie empirisch fundiert die Reichweite bzw. Verbreitung einzelner Konventionen anzugeben. M.E. ist dies ein heilsames Korrektiv gegen vorschnelle Verallgemeinerungen und gegen eine Zuschreibung von Konventionen oder entsprechenden Verhaltensweisen allein aufgrund der Zugehörigkeit zu einer bestimmten sozialen Gruppe.

\section{Erklärungsmodelle für altersbedingte Varianz}

Fragt man nach Zusammenhängen zwischen dem (numerischen) Alter auf der einen Seite und sprachlich-kommunikativen Phänomenen auf der anderen Seite, so lassen sich zwei grundlegend unterschiedliche Sichtweisen unterscheiden. Die eine versteht Alter als etwas Naturhaftes und für jeden Menschen objektiv Gegebenes, wobei zwischen diesem Alter und sprachlich-kommunikativen Phänomenen Zusammenhänge systematischer Wechselbeziehung und Kovarianz bestehen (Korrelationsansatz).

Die andere Sichtweise versteht Alter als etwas, was in Prozessen gemeinsamer Interaktion von den Beteiligten mit Hilfe von sprachlich-kommunikativen Mitteln als ein interaktionsrelevantes Phänomen erst hergestellt werden muß (Konstitutionsansatz). Das objektive Alter ist dabei solange irrelvant, wie es nicht von den Beteiligten mental fokussiert und in der Interaktion relevantgesetzt und thematisch wird.

Beide Ansätze betrachten also das Konzept 'Alter' aus unterschiedlichen Perspektiven, und sie unterscheiden sich auch in Hinblick auf die Art der Beziehungen, die sie zwischen Alter und sprachlich-kommunikativen Phänomen konstatieren: Im ersten Fall 'produziert' das Alter bestimmte sprachlich-kommunikative Phänomene und kommt in innen zum Ausdruck, im zweiten Fall 'produzieren' sprachlich-kommunikative Mittel Alter als interaktionsrelevantes Phänomen. 


\subsection{Der Korrelationsansatz}

'Sprache und Kommunikationsverhalten verändern sich mit dem Alter.', 'Sprache und Kommunikationsverhalten sind bei alten Menschen anders als bei jüngeren.' etc.: Aussagen dieser Art basieren auf einer grundlegenden Voraussetzung, nämlich der, daß zwischen dem Alter auf der einen Seite und sprachlich-kommunikativen Phänomenen auf der anderen Seite eine Korrelation, eine systematische Wechselbeziehung besteht: Sprachlich-kommunikative Phänomene werden als Funktion des (numerischen) Alters gesehen. Das Alter ist dabei die unabhängige, die sprachlichkommunikativen Phänomene die abhängige Variable. Die Beziehung zwischen den Variablen wird dabei so verstanden, daß Ausprägungen der einen Variable - von 'überzufällig' bis 'immer' - mit bestimmten Ausprägungen der anderen Variablen korrelieren. ${ }^{8}$ Bezogen auf die Beteiligten heißt dies, daß sich mit der Veränderung des Alters bei innen bestimmte Veränderungen auf der sprachlich-kommunikativen Seite mit einer gewissen inhärenten Automatik ergeben. Die Veränderungen 'geschehen', 'ereignen sich' - als Folge des Alters - bei den Betroffenen: sie sind daran nicht (aktiv) beteiligt.

Zwischen solchen Variablen kann nun bekanntermaßen ein kausales Verhältnis (die Ausprägung der einen Variablen verursacht, bzw. ist der Grund für die Ausprägung der anderen) oder ein Verhältnis der (nichtkausalen) systematischen Kovariation bestehen (zwei Variablen kovariieren, zwischen ihnen besteht aber kein direkt kausales Verhältnis).

Es ist unmittelbar ersichtlich, daß zwischen dem numerischen Alter und sprachlich-kommunikativen Phänomenen kein kausales Verhältnis besteht, sondern daß es sich nur um systematische Kovariation handeln kann. Kausal verantwortlich für die beobachteten Veränderungen müssen also andere Faktoren sein, deren zeitliche Varianz die Veränderungen auf der sprachlich-kommunikativen Seite direkt bewirkt. Diese anderen Faktoren korrelieren dann ihrerseits mit dem numerischen Alter. Diese Explikation macht deutlich, daß Alter nur eine sekundäre Variable ist, mit der der Einfluß anderer (möglicherweise kausaler) Faktoren zusammengefaßt wird. ${ }^{9}$ Sie ist damit ausgesprochen 'grob' und ihr Erklärungswert sehr beschränkt.

Die Frage nach der Erklärung altersbedingter Varianz muß also eher die nach den mit dem numerischen Alter korrelierenden kausalen Faktoren sein. Ganz überwiegend werden dabei Faktoren aus zwei Bereichen angeführt: zum einen Faktoren, die mit der Biologie der Personen zu tun haben, zum anderen Faktoren, die die soziale Situation (einschließlich ihrer psychischen Repräsentation und Verarbeitung) betreffen. Es koexistieren und konkurrieren also vor allem biologische und soziologische Modelle zur Erklärung altersbedingter Varianz. Um es noch einmal zu betonen: Beiden gemeinsam ist (im Gegensatz zum Konstitutionsansatz), daß sie den Zusammenhang zwischen biologischen bzw. soziologischen Phänomenen auf der einen Seite und sprachlich-kommunikativen Veränderungen auf der anderen Seite als Korrelation, als Beziehung zwischen unabhängigen und abhängigen Variablen konzeptualisieren.

Diese Ausführungen machen m.E. deutlich, daß das Ziel einer altersbezogenen Forschung nicht sein kann, sprachlich-kommunikative Phänomene lediglich mit nu-

8 Es ist deutlich, daß diese Auffassung zugrundeliegt, wenn Merkmale altersspezifischer Sprache und Kommunikation ermittelt und listenmäßig zusammengestellt werden bzw. wenn von 'age markers' (Helfrich 1979) gesprochen wird.

9

Der Beitrag von Brose (i.d.Bd.) demonstriert dies in aller Deutlichkeit. 
merischem Alter in Beziehung zu bringen. Will man über die Phase der Beobachtung und Beschreibung systematischer Kovariation hinausgelangen, so muß es vielmehr darum gehen, möglichst viele der oben angesprochenen kausalen biotischen und sozialen Faktoren zu isolieren, sie zu explizieren und ihren Einfluß auf sprachlich-kommunikative Aspekte möglichst detailliert aufzudecken. Und ferner ist auch das Zusammenspiel dieser verschiedenen Faktoren im Allgemeinen wie im individuellen Einzelfall aufzuklären.

\subsubsection{Das biologische Erklärungsmodell}

Biologische Erklärungsmodelle korrelieren Veränderungen im sprachlich-kommunikativen Bereich mit physischen Veränderungen. Für sie ist konstitutiv, daß die Einzelperson im Zentrum steht. Die physischen Veränderungen werden dabei in normale und außergewöhnliche differenziert. Die normalen Veränderungen werden häufig in einem stadienbezogenen Entwicklungsmodell (Entfaltung, Reife, Abbau) interpretiert, die außergewöhnlichen können durch Krankheit, krankhaft beschleunigte Abbauprozesse (z.B. Alzheimer-Demenz), Verletzungen etc. verursacht sein (vgl. Schecker und Gress-Heister i.d.Bd.).

Die wesentlichen physischen Bereiche, die zur Erklärung sprachlich-kommunikativer Veränderungen herangezogen werden, sind die Organe der Stimmerzeugung und das Gehör sowie das Gehirn mit seinen kognitiven und affektiven Funktionen, wobei insbesondere Veränderungen der Gedächtnisleistungen eine wichtige Rolle spielen.

\subsubsection{Das soziologische Erklärungsmodell}

Soziologischen Erklärungsmodellen geht es darum, bestimmte sprachlich-kommunikative Phänomene mit den strukturellen Veränderungen der sozialen Lebenssituation im Alter, mit den Veränderungen der sozialen Beziehungen und alterstypischen Erfahrungen zusammenzubringen und sie aus innen herzuleiten. Einige solcher typischen Veränderungen und Erfahrungen, die im Alter häufig eintreten und gemacht werden, sind im Anhang in einer kusorischen Auswahl zusammengestellt. Auch hier ist wieder zu beachten, daß diese Veränderungen und Erfahrungen nicht alle alten Personen gleichermaßen betreffen, sondern daß dies individuell - sowohl in Hinblick auf die Auswahl, den Zeitpunkt und die persönliche Bedeutsamkeit - sehr variabel sein kann.

In dieser Perspektive kann man dann z.B. versuchen, die kommunikativen Folgen des mit der Generationsablösung verbundenen Dominanzverlusts (Fiehler 1997) oder die kommunikativen Auswirkungen des Endes der Berufstätigkeit im Detail zu bestimmen. Diese Auswirkungen sind zum einen thematischer Art in dem Sinn, daß diese Veränderungen und Erfahrungen häufig Gegenstand von Gesprächen sind. Darüber hinaus geht es aber gerade auch darum, ihre kommunikationsstrukturellen und sprachlichen Folgen herauszuarbeiten. Auf diese Weise abgeleitete sprachlichkommunikative Phänomene sind nicht nur beschrieben, sondern auch in ihrer Genese erklärt.

Dabei ist klar, daß man alterstypische Sprache und Kommunikation nicht nur als Folge der Veränderung eines Faktors verstehen kann. Die aufgelisteten Verände- 
rungen und Erfahrungen wirken, wenn sie eintreten, zusammen, und ihre jeweiligen kommunikativen Folgen interferieren. Auf der Ursachenseite sind also Bündel von Faktoren anzusetzen, wobei diese Faktoren bei der einzelnen Person bzw. bei Personengruppen in je individuellen Konstellationen zusammenwirken und unterschiedlich gewichtet sind. Unter dieser Annahme wird dann die Rekonstruktion von unterschiedlichen Gruppen bzw. individuellen Differenzen in der Alterskommunikation also eine interne Differenzierung - möglich. Dieser Erklärungsansatz erlaubt es also, die beobachtbare breite Varianz innerhalb der Gruppe der älteren Menschen abzubilden.

\subsection{Der Konstitutionsansatz}

Der Kern des Konstitutionsansatzes besteht darin, Alter nicht primär als etwas Naturhaftes, allen Personen auf ähnliche Weise Widerfahrendes zu verstehen, das ihnen jederzeit und konstant anhaftet, sondern als etwas, was im Gestaltungsbereich der Personen liegt, als etwas, was sie in der Interaktion mit sprachlich-kommunikativen Mitteln hervorheben oder im Hintergrund halten können.

Es ist das große Verdienst von Coupland, Coupland \& Giles (1991), daß sie dem dominierenden naturalistischen Verständnis der Kategorie 'Alter' diese interaktionelle Sichtweise an die Seite gestellt haben, die den Herstellungsaspekt von Alter in der Kommunikation betont. Für diese Sichtweise sind Konzepte wie Definition, Aushandlung und interaktive Hervorbringung zentral.

"We argue that 'elderliness' is in significant ways manufactured and modified in sequences of talk in which older speakers are involved, through the agency of elderly and younger speakers." (Coupland, Coupland \& Giles 1991, 55)

"Membership of the category 'old' is therefore at one level a token to be manipulated for immediate purposes in the discourse. A speaker is not uniformly 'old' or 'not old'; rather, she self-selects and self-projects in and out of the category, [...]." (Coupland, Coupland \& Giles 1991, 68)

Alter bzw. die mit inm korrelierenden biotischen und sozialen Faktoren werden hier nicht als Ressource für Erklärungen benutzt, sondern primär wird beschrieben, wie und warum Alter 'gemacht' wird. Herausgearbeitet werden die Verfahren, mit denen Interaktionsbeteiligte sich selbst oder den anderen als 'alt' oder 'jung' typisieren bzw. mit denen sie eine solche Altersdifferenz interaktiv markieren und signalisieren. Durch die Anwendung dieser Verfahren wird die Identifikation mit bzw. die Distanzierung von Alter oder Jugend sprachlich-kommunikativ geleistet.

Coupland, Coupland \& Giles holen mit dieser Veränderung der Blickrichtung für die Kategorie 'Alter' einen Prozeß nach, der für Kategorien wie 'Geschlecht', 'Ethnizität' etc. schon weiter fortgeschritten ist und gesellschaftlich zu einem veränderten Verständnis solcher Kategorien geführt hat.

Die Erfassung und Systematisierung der Verfahren und Mittel zur interaktiven Relevantsetzung von Alter steht erst am Anfang. Coupland, Coupland \& Giles (1991, 5865) unterscheiden in einem ersten Versuch sechs Verfahren, mit denen Alter in der Interaktion thematisiert bzw. relevant gesetzt werden kann und mit denen sich Interaktionsbeteiligte als 'alt' oder 'nicht alt' darstellen können: ${ }^{10}$

10 Für empirische Beispiele und eine Ergänzung dieser Verfahren vgl. Fiehler (1997). 
(1) Nennung des numerischen Alters ('disclosure of chronological age')

Das erste Verfahren besteht in der zahlenmäßigen Nennung des Alters. Entweder die Person selbst oder andere können durch eine solche Zahlenangabe Alter thematisch machen.

(2) Nennung altersgebundener Kategorien und Rollen

Alter kann ferner relevant gesetzt und akzentuiert werden durch qualitative Altersbestimmungen oder durch die Nennung von Kategorien oder Rollen, die in der Regel mit einem bestimmten Alter verbunden sind. In diesem letzten Fall ist das Relevantwerden von Alter an Schlußprozesse gebunden: Wenn jemand von sich als 'Pensionär' spricht, kann daraus auf ein bestimmtes Alter geschlossen werden.

(3) Thematisierung von mit Alter assoziierten Phänomenen wie Abbau, Krankheit, Tod etc.

Auch die Thematisierung der genannten Phänomene führt dazu, daß die Kategorie 'Alter' interaktiv relevant wird.

Die folgenden drei Verfahren fassen Coupland, Coupland \& Giles als 'temporal framing processes' zusammen, wobei sie betonen, daß die Unterscheidung zwischen innen nicht besonders trennscharf ist. Gemeinsam ist innen aber, daß sie die Kategorie 'Alter' interaktiv relevant machen.

(4) Hinzufügen bzw. Etablieren einer Vergangenheitsperspektive

Bei diesem Verfahren wird die Behandlung eines Themas in die Vergangenheit perspektiviert. Dem Thema wird so eine Vergangenheitsperspektive hinzugefügt, bzw. es wird eine solche generell etabliert.

(5) Thematisierung von kulturellem und gesellschaftlichem Wandel

Ein weiteres Verfahren, die Kategorie 'Alter' interaktiv relevant zu setzen, ist die Konstatierung von Wandel im Vergleich mit einer früheren Zeit. Ein Topos dabei ist, daß die früheren Zeiten besser waren. Auch hier wird eine Vergangenheitsperspektive etabliert. Es handelt sich also um einen Spezialfall von (4).

(6) Identifikation mit der Vergangenheit

Bei diesem Verfahren identifiziert sich der Sprecher weitgehend mit der Vergangenheit. Z.T. hat dies die Form eines gedanklichen Lebens in der Vergangenheit, in Erinnerungen, die mit der Gegenwart nicht mehr vermittelt sind.

Die Verfahren (4) bis (6) stellen ein Kontinuum dar, bei dem sich der Schwerpunkt immer mehr aus der Aktualität in die Vergangenheit verlagert (vgl. auch Boden \& Bielby 1983). 
Eine weitere Möglichkeit, Alter nicht als Fixum zu verstehen, sondern interaktiv zu definieren, beschreibt Thimm (i.d.Bd.), indem sie zeigt, wie die Zuschreibung von altersbezogenen Kategorien und die Identifizierung mit bzw. Distanzierung von ihnen für diese Zwecke genutzt werden kann.

\section{Abschließende Bemerkungen}

Die hier vorgetragenen methodologischen Überlegungen kommen zu dem gleichen Schluß, den auch Kohrt \& Kucharczik (i.d.Bd., 32) ziehen:

"[...] es scheint uns sinnvoller, sich auf eine sehr nüchterne und klare Position zurückzuziehen, bei der nicht vorgängig die Existenz einer bestimmten [...] 'Altensprache', 'Senior/inn/ensprache' unterstellt wird."

Es handelt sich bei der Vorstellung einer Alterssprache um ein Konstrukt, das viel zu generell und verallgemeinernd ist, als daß es der Vielfältigkeit der empirischen Verhältnisse entsprechen und ihr gerecht werden könnte.

Gleichwohl scheint es mir Sinn zu machen, sprachlich-kommunikative Besonderheiten bestimmter Gruppen älterer Menschen zu untersuchen. Alter ist für die Konstitution dieser Gruppen aber nur ein Kriterium; viel wichtiger für die Gruppenbildung ist die Berücksichtigung der Faktoren, die sprachlich-kommunikative Veränderungen kausal induzieren. ${ }^{11}$ Ziel dieser Untersuchungen sollte einerseits sein, diejenigen sprachlich-kommunikativen Phänomene zu explizieren, die zu dem alltagsweltlichen Eindruck führen, daß es so etwas gibt wie alterstypische Sprache und Kommunikation. Auf der anderen Seite besteht die Aufgabe darin, diejenigen biologischen, psychologischen und sozialen Faktoren herauszuarbeiten, die wesentlich dazu beitragen, daß diese Phänomene im Alter verstärkt auftreten.

Besonderes Interesse verdienen darüber hinaus m.E. die interaktiven Verfahren, mit denen die Beteiligten sich selbst als 'alt' präsentieren bzw. mit denen sie von ihrer Umgebung als 'alt' dargestellt werden.

11 Um ein Beispiel zu nennen: Es scheint mir nicht sinnvoll, erwachsene Berufstätige mit nichtberufstätigen Alten hinsichtlich ihres kommunikativen Verhaltens miteinander zu vergleichen, weil nicht entscheidbar ist, welcher Variablen ggf. beobachtete Unterschiede zugeschrieben werden sollen. Idealtypisch gesprochen wären erwachsene Berufstätige, erwachsene Nichtberufstätige, berufstätige Alte und nichtberufstätige Alte miteinander zu vergleichen. 


\section{Literatur}

Ammon, Ulrich (1987). Language - Variety/Standard Variety - Dialect. In: Ammon, U., Dittmar, N. \& Mattheier, K. J. (Hrsg.), Soziolinguistik. Ein internationales Handbuch zur Wissenschaft von Sprache und Gesellschaft. 1. Halbband. Berlin/New York: de Gruyter, 316-335.

Boden, D. \& Bielby, D. D. (1983). The Past as Resource: A Conversational Analysis of Elderly Talk. In: Human Development 26, 308-319.

Berruto, Gaetano (1987). Varietät. In: Ammon, U., Dittmar, N. \& Mattheier, K. J. (Hrsg.), Soziolinguistik. Ein internationales Handbuch zur Wissenschaft von Sprache und Gesellschaft. 1. Halbband. Berlin/New York: de Gruyter, 263-267.

Bielefeld, Hans-Ulrich \& Lundt, André (1977). Zur Untersuchung von 'Arbeitersprache'. In: Bielefeld, Hans-Ulrich et al. (Hrsg.), Soziolinguistik und Empirie. Wiesbaden: Athenaion, 97-140.

Coupland, N., Coupland, J. \& Giles, H. (1991). Language, Society and the Elderly. Discourse, Identity and Ageing. Oxford/Cambridge: Blackwell.

Fiehler, R. (1997). Kommunikation im Alter und ihre sprachwissenschaftliche Analyse. Gibt es einen Kommunikationsstil des Alters? In: Selting, Margret \& Sandig, Barbara (Hrsg.), Sprech- und Gesprächsstile. Berlin/New York: de Gruyter, 345-370.

Fix, U. (1991). Vorbemerkungen zu Theorie und Methodologie einer historischen Stilistik. In: Zeitschrift für Germanistik. Neue Folge I. 2/1991, 299-310.

Helfrich, Hede (1979). Age markers in speech. In: Scherer, Klaus R. (ed.), Social markers in speech. Cambridge: Cambridge University Press, 63-107.

Kanngießer, Siegfried (1980). Stichworte zur Sprachvariabilität. Manuskript.

Kubczak, Hartmut (1987). Soziolekt. In: Ammon, U., Dittmar, N. \& Mattheier, K. J. (Hrsg.), Soziolinguistik. Ein internationales Handbuch zur Wissenschaft von Sprache und Gesellschaft. 1. Halbband. Berlin/New York: de Gruyter, 268-273.

Kummer, Werner (1975). Grundlagen der Texttheorie. Reinbek: Rowohlt.

Sandig, Barbara (1995). Tendenzen der linguistischen Stilforschung. In: Stickel, G. (Hrsg.), Stilfragen. Berlin/New York: de Gruyter, 27-61. (Jahrbuch 1994 des Instituts für deutsche Sprache). 


\section{Anhang}

\section{Eine offene Liste von Merkmalen}

\section{Kommunikative Haltung / Stil}

- Hinzufügen einer Vergangenheitsperspektive

- Vergleiche Gegenwart - Vergangenheit

- Thematisierung von kulturellem und sozialem Wandel

- Erzählen/Berichten von Vergangenem

- Selbstassoziation/-identifikation mit Vergangenheit

- größere kommunikative Kontaktfreudigkeit (weniger Hemmungen)

- Vergrößerung des Kommunikationsaufkommens

- Verringerung des Kommunikationsaufkommens

- größerer Selbstbezug in der Kommunikation

\section{Interaktionstypen}

- Erzählungen

- größere Anteile biographischen Erzählens

- Klatsch

\section{Kommunikative Muster}

- Painful Selfdisclosure / Anteilnahmemuster

- Muster der Bewertungsteilung

- Beziehungskommunikation (phatische Kommunikation)

Quantitatives Verhältnis zwischen sachbezogener und phatischer Kommunikation

\section{Themenbehandlung}

- altersspezifische Themen

- Vergangenheit

- Lebenssituation/Abbau/Krankheit/Tod etc.

- Familie

- Klatschen über Familie/Bekannte/Nachbarn

- Ausführlichkeit/Umständlichkeit der Themenbehandlung

- Wiederaufnahmen/Wiederholungen von Themen

- ausführliche Planungskommunikation 
- Sprünge / Assoziative Verknüpfung zwischen Themen (Kohärenz)

- Kohärenz von Äußerungen (thematische Kohärenz eigener Äußerungen, Themensprünge, wechselseitiges Aufeinandereingehen)

\section{Strategien}

- Stilisierung/Typisierung als 'alt'

- Benennung/Betonung von Altersrollen (Großvater/-mutter, Rentner/in, Pensionär/in)

- Benennung/Betonung des numerischen Alters (Disclosure of chronological age)

\section{Sprachlich-stimmliche Merkmale}

- Stimmliche Charakteristika

- 'alte' Stimme

- übergroße Emphase

- Dialektgebrauch

- Lexikon

\section{Merkmale der Produktion/Rezeption}

- Formulierungs-/Wortfindungsstörungen

- Monologisieren/Nichtaufeinandereingehen

- mangelnder Partnerbezug/Adressatenzuschnitt ('recipient design')

- mangelnde Adressierung (Sprechen für sich)

- Sprechen mit sich selbst/Selbstgespräche

- nicht zuhören/jeder verfolgt seine Themenlinie

- Verständigungsprobleme aufgrund körperlicher Gebrechen/Einschränkungen (Schwerhörigkeit etc.) 


\section{Typische soziale Veränderungen und Erfahrungen im Alter}

\section{Typische Veränderungen der sozialen Situation}

- Ende der Berufstätigkeit - Erschließung alternativer Tätigkeitsfelder

- Rollenwandel: Ende der Elternrolle, Großelternrolle Generationsablösung / Dominanzwechsel Aus der Gestalterrolle in die Unterstützungsrolle

- Sozialer Abstieg, Armut / Alter im Wohlstand

- Verringerung sozialer Kontakte / der Kontaktfähigkeit

- Zunahme an Freiheit

\section{Typische Veränderungen der sozialen Beziehungen}

- Tod von Ehegatten, Verwandten, Bekannten

- Veränderungen / Abbau der Sexualität

\section{Typische Erfahrungen in der Interaktion}

- Notwendigkeit des Umgangs mit der Zuschreibung von Alter / mit herangetragenen Altersstereotypen

- Erfahrung, nicht mehr für voll genommen zu werden

\section{Typische Erfahrungen mit sich selbst}

- Zunahme an physischen, mentalen und psychischen Beeinträchtigungen/ Krankheiten

- Nachlassende Fähigkeiten (Abnahme von Lernfähigkeit / Lernbereitschaft; Abnahme der Beherrschung von Kulturtechniken; Erfahrung, daß Entwicklungen über einen hinweggehen)

- Zunehmende Routinen, weniger Spontaneität/Flexibilität

- Zunahme von Toleranz / Intoleranz

- Akkumulation von (sozialer) Erfahrung

- Beschäftigung mit / Vorbereitung auf den eigenen Tod 


\title{
Sprache, Kommunikation und Altern ${ }^{1}$
}

\author{
Ellen B. Ryan / Sheree T. Kwong See
}

\section{1. Überblick}

Erfolgreiches Altern ist ein kontinuierlicher Prozeß des Ausbalancierens von Gewinnen und Verlusten, des Formulierens von Zielen, der Entwicklung von Strategien, um diese Ziele zu erreichen und der Fortentwicklung der eigenen Identität (Baltes 1993).

Geht man davon aus, daß Sprach- und Kommunikationsfähigkeit das ganze Leben hindurch eine zentrale Rolle sowohl im intellektuellen wie im sozialen Bereich spielt, so heißt dies, daß die sprachliche und kommunikative Kompetenz älterer Menschen ihr Erleben des höheren Lebensalters nachhaltig bestimmt. Darüber hinaus sagt die Art und Weise, mit der diese Fähigkeiten aufrechterhalten werden oder sich im Alter wandeln, viel über die Mechanismen erfolgreichen bzw. weniger befriedigenden Alterns aus. Daher ist es wichtig, Auswirkungen des Alterns auf die Fähigkeiten zur Sprachproduktion und -rezeption zu erforschen und die Besonderheiten und Probleme intergenerationeller Kommunikation zu untersuchen.

Untersuchungen zur Sprache und Kommunikation von gesunden älteren Menschen, die selbständig leben und in eine Gemeinschaft integriert sind, wurden bisher hauptsächlich aus kognitiver, psycholinguistischer und klinischer Perspektive durchgeführt (Bayles \& Kaszniak 1987; Brownell \& Joanette 1993; Light \& Burke 1988). Die Untersuchungen zeigten eine große Bandbreite von altersbedingten Veränderungen (vgl. Kemper 1992; Überblick bei Stine, Soederberg \& Morrow 1996). Um altersbedingte sprachlich-kommunikative Unterschiede verstehen zu können, ist es notwendig, eine Anzahl von Einflußfaktoren zu berücksichtigen.

Erstens erscheint es nützlich, zwischen Sprachkompetenz und dem konkreten sprachlichen Handeln zu unterscheiden. Bei pathologischem Altern, wie zum Beispiel im Fall der Alzheimer-Demenz, ist ein deutlicher Verlust erworbener linguistischer Kompetenzen zu verzeichnen (Bayles \& Kaszniak 1987; Brownell \& Joanette 1993). Im allgemeinen kann man aber feststellen, daß die sprachliche Kompetenz bei gesunden älteren Personen stabil bleibt (Light 1988). Altersbedingte sensorische und kognitive Faktoren können jedoch das konkrete sprachliche Handeln beeinträchtigen. Altersbezogene Unterschiede in der Sprache spiegeln deshalb den Einfluß von solchen performanzbeeinträchtigenden Faktoren wider. Dazu gehören beispielsweise die Seh- und Hörfähigkeit, die Geschwindigkeit der Informationsverarbeitung, das Gedächtnis und die selektive Aufmerksamkeit, dabei insbesondere das Ausblenden irrelevanter Informationen (Kwong See \& Ryan 1996).

Zweitens bedingen eine Reihe von methodologischen Beschränkungen, daß Generalisierungen von Untersuchungsergebnissen nur unter Vorbehalt erfolgen kön-

1 Die Fertigstellung dieses Aufsatzes wurde unterstützt durch eine Förderung des „Social Sciences and Humanities Research Council of Canada“. Wir danken Ann Anas für ihre Mithilfe.

Übersetzt wurde dieser Beitrag von H. Ehmer, R. Fiehler und C. Thimm. 
nen. Außer denjenigen Untersuchungen, in denen Wortschatz und andere sprachliche Maße im Rahmen von Langzeitstudien zur Intelligenzentwicklung erhoben wurden, sind die meisten Untersuchungen über Alter und Sprache als Gruppenvergleiche konzipiert. Darüber hinaus beziehen sich diese Untersuchungen zumeist auf kleine Gruppen, differieren in der Berücksichtigung von männlichen und weiblichen Teilnehmern und verwenden uneinheitliche Definitionen der Kategorie 'alt'. Nicht zuletzt gibt es trotz der großen Anzahl von Einzelstudien kaum ForscherInnen, die mit einer Folge aufeinander aufbauender Untersuchungen systematisch an die Frage des Alterns herangehen oder die in Längsschnittstudien wiederholt sprachlichkommunikative Leistungen älterer Menschen erheben. Auch werden Faktoren wie Bildungsstand, sozioökonomischer Status, Englisch als Mutter- oder Zweitsprache, Aktivitätsgrad und Gesundheit nicht systematisch kontrolliert.

Als dritter Punkt ist zu erwähnen, daß viele ältere Erwachsene, trotz bestehender Performanzunterschiede im Vergleich mit jüngeren Altersgruppen, durchaus in der Lage sind, Einschränkungen in der Sprachverarbeitung aufgrund nachlassender sensorischer und kognitiver Fähigkeiten zu kompensieren (Stine et al. 1996). Der lebenslange Umgang mit Sprache führt dazu, daß Sprache und Sprechen hoch trainierte Fähigkeiten darstellen. Aufgrund dieser durch Lebenserfahrung gewonnenen Stärken kann davon ausgegangen werden, daß ein normal alternder Erwachsener im Alltagsleben eine gute sprachliche Performanz beibehalten wird. Zu den erworbenen Stärken gehören beispielsweise ein erweitertes Vokabular und Weltwissen (Bayles \& Kaszniak 1987), aber auch die Fähigkeit, sich auf veränderte Kompetenzen und wandelnde Aufgaben und Anforderungen einzustellen (Bäckman \& Dixon 1992). Diese kompensatorischen Strategien sind jedoch in solchen Situationen weniger leicht aufrechtzuerhalten, die ungewohnt oder angsteinflößend sind, Schnelligkeit erfordern oder eine Unterstützung durch die Umgebung vermissen lassen. Andererseits kann sprachliche Performanz auch dann als eingeschränkt erscheinen, wenn ältere Erwachsene andere Absichten, Strategien und Motivationen haben, als dies von den Gesprächspartnern antizipiert wurde (Ryan, Kwong See, Meneer \& Trovato 1992).

Viertens gibt es eine Vielzahl von Einflüssen auf das sprachliche Handeln im höheren Lebensalter (Ryan et al. 1992). Wie schon gesagt, wird das sprachliche Handeln in starkem Maße durch altersbedingte Unterschiede in der Verarbeitung von Informationen beeinflußt (Kwong See \& Ryan 1996). Sprachliches Handeln wird außerdem von dem sozialen Kontext geprägt, in dem das Sprechen erfolgt (Ryan, Giles, Bartolucci \& Henwood 1986). Ein wichtiger Aspekt des sozialen Kontextes sind die Stereotype, die Kommunizierende in die sprachliche Interaktion einbringen. In diesem Beitrag werden wir uns vor allem mit der Kommunikation zwischen jüngeren und älteren Menschen beschäftigen und den Einfluß negativer altersbezogener Einstellungen jüngerer Erwachsener auf die Effektivität des intergenerationellen Austauschs behandeln. Letztlich illustrieren wir ein offensichtliches Paradox. Obwohl es ein wichtiges Ziel der Alterssprachforschung ist, die bestmögliche Form von kommunikativen Beziehungen zu erreichen, sind Wissenschaftler, genau wie Ärzte und Familienangehörige, jedoch zu schnell bereit, Veränderungen im Sprachgebrauch und Sprachverstehen als einen Beweis für abnehmende Kompetenz im Alter zu interpretieren. Dies wiederum sorgt für ein soziales Umfeld, in dem es Schranken gibt, die ein effektives Kommunizieren behindern.

Unser Beitrag ist wie folgt gegliedert: In Abschnitt 2 stellen wir - am Beispiel neuerer Untersuchungen zum Thema 'Verbosität' (Gold, Arbuckle \& Andres 1994) - 
die vielfältigen Faktoren vor, die sprachliches Handeln im höheren Lebensalter beeinflussen. In Abschnitt 3 untersuchen wir den Einfluß, den negative, mit Alter verbundene Erwartungen bei den Gesprächspartnern auf das sprachliche Handeln älterer Menschen haben. Wir stellen die These auf, daß ältere Menschen hierbei oft die Erfahrung einer kommunikativen Präjudizierung („Communication Predicament“) machen, wodurch ihre Möglichkeiten, erfolgreich zu kommunizieren, von ihrer jeweiligen Umgebung eingeschränkt werden (Ryan et al. 1986; Ryan, Hummert \& Boich 1995). Abschließend erörtern wir in Abschnitt 4 Möglichkeiten zur Verbesserung der intergenerationellen Kommunikation und skizzieren in Abschnitt 5 Entwicklungsmöglichkeiten der Forschung in diesem Bereich.

\section{Vielfältige Einflüsse auf die Sprachproduktion: Verbosität im höheren Alter}

Es wird weithin angenommen, daß das Altern mit einem gesteigerten Redebedürfnis einhergeht. Entgegen dieser gängigen Meinung kommt ein extremes Redebedürfnis aber nur bei einer kleinen Gruppe der älteren Menschen vor, Schätzungen liegen bei $17-21 \%$ (Gold et al. 1994). Ein kanadisches Forschungsteam hat den Ausdruck „off-topic-verbosity“ [im folgenden übersetzt als „Verbosität"] geprägt, um das gewundene und ziellos erscheinende Erzählen dieser älteren Menschen zu charakterisieren (Gold et al. 1994). Zentrale Merkmale der Verbosität sind ein ungebremster Redefluß und der Mangel von Fokussierung und Kohärenz. Diese Charakteristika werden in dem folgenden Textausschnitt deutlich. Wiedergegeben wird die Antwort einer 74jährigen Versuchsperson in einem strukturierten Interview auf die Frage: „Wie oft sehen Sie ihre Tochter?"

\footnotetext{
„Ich war nur zweimal dort unten, sie ist erst seit drei Jahren dort. Mit dem Flugzeug dauert es nur eine Stunde und 23 Minuten, aber sie hat gesagt: 'Warum zum Teufel kommst Du?' Weil, da war die Royal Commonwealth Konferenz, und da sie sich ja auf Prinz Edward vorbereiteten, und deswegen hat sie gesagt: 'Kommst Du?' Also hab ich Air Canada angerufen und gesagt, daß ich ein Ticket möchte. So bin ich am nächsten Tag da hin, und ich hatte Geburtstag und weil ich Geburtstag hatte, hatte ich 12 kleine Rosen aus meinem Garten in einer Blumenvase. Und ich bin nochmal zurück und ich hab gesagt: 'Kriegen wir armen Rentner keine Verbilligung?' und sie hat gesagt: 'Natürlich, meine Liebe' und hat 90 Dollar von meiner Rechnung abgezogen. Aber ich war keine Delegierte der Konferenz, also konnte ich da nicht hingehen, also hat meine Tochter Richter $X$ angerufen und der Richter hat gesagt: 'Nein, es ist nur für Delegierte'. Und ich habe gesagt: 'Heißt das, ich bin den ganzen Weg umsonst gekommen?' Na ja, wir sind dann zu einem Tanz gegangen und meine Tochter hat mit all diesen Leuten aus Neufundland rumgeschäkert. Du lieber Himmel, und sie hat all diesen Leuten erzählt, daß ihre Mutter Geburtstag hat und dann haben alle Happy Birthday gesungen und sie hat mir eine Langspielplatte geschenkt." (Antwort einer 74jährigen Frau im Rahmen eines strukturierten Interviews; aus: Gold et al. 1994, 108)
}

Es wird deutlich, daß Verbosität sich durch exzessives Sprechen auszeichnet, das schnell vom eigentlichen Thema abweicht. Wichtig ist hierbei, daß diese Art des Sprechens nicht interaktiv ist, wie üblicherweise bei Gesprächen, sondern eher einem Monolog gleicht.

Wir erörtern Verbosität in diesem Abschnitt aus mehreren Gründen. So gibt diese Art des Sprechens Hinweise auf soziale und kognitive Mechanismen bei älteren Menschen, die einen solchen Sprechstil zeigen. Angesichts der egozentrischen Natur dieses Stils, könnte man danach fragen, wie Menschen, die mit dieser älteren verbosen Person zu tun haben, darauf reagieren. Gleichermaßen von Interesse sind die zugrundeliegenden kognitiven und sozialen Faktoren, die eine solche Sprech- 
weise auslösen. Einen Ansatz, der solch umfassende Fragestellungen einbezieht, verfolgten Gold, Arbuckle und deren Mitarbeiter (Gold et al. 1994) bei der Untersuchung dieses Phänomens. Ihre Forschungsergebnisse unterstützen unsere Behauptung, daß sprachliches Handeln - hier Verbosität als Beispiel - durch vielfältige Faktoren bestimmt wird.

Bei der Erforschung der psychologischen Prozesse, die der Verbosität zugrunde liegen, untersuchten Gold und Arbuckle den Einfluß verschiedener demographischer und psychosozialer Faktoren. Besondere Aufmerksamkeit wurde der Behauptung geschenkt, Verbosität würde durch psychosoziale Faktoren verursacht wie Einsamkeit, altersbedingten Streß und ein Bedürfnis nach Selbstbestätigung zu einer Zeit, in der die Personen mit bedeutsamen und sich wiederholenden Verlusten konfrontiert werden. Über eine Reihe von Untersuchungen hinweg wurden Belege dafür gefunden, daß Verbosität mit höherem Alter zunimmt. Darüber hinaus steht Verbosität mit einer Reihe von psychosozialen, kognitiven und Persönlichkeitsvariablen in Zusammenhang.

\section{Persönlichkeitseigenschaften}

Verbosität korreliert vor allem mit einem hohen Maß an Extrovertiertheit und Gesprächigkeit. Hinzu kommt, daß verbose Personen weniger um soziale Erwünschtheit bemüht sind (wie sie von anderen wahrgenommen werden) und sich weniger bewußt sind, daß sie dazu tendieren, übermäßig viel zu sprechen.

\section{Aktuelle psychosoziale Bedingungen}

Die Studien zeigten, daß ein größeres Ausmaß an Streß, geringere soziale Unterstützung und ein weniger ausgeprägtes Bewußtsein für Verbosität mit einem höheren Grad an Verbosität in Zusammenhang stehen. Besonders erwähnenswert erscheint die negative Beziehung zwischen sozialer Unterstützung und dem Bewußtsein über sozial erwünschtes Verhalten. Obwohl die verbosen Älteren sich ihrer Redseligkeit kaum bewußt waren, wurden sie von Personen, die sie kennen, mit Attributen versehen, die positiv mit Verbosität korrelierten. Im Zusammenhang mit den von uns angeführten vielschichtigen Einflüssen auf das sprachliche Handeln gibt letzteres einen Hinweis auf ein möglicherweise negatives Feedback oder auf problematische Konsequenzen, wenn dieser verbose Sprechstil angenommen wird. Dies betrifft nicht nur das unmittelbare Kommunikationsumfeld, sondern möglicherweise auch die gesamte gegenwärtige Lebenssituation und das soziale Umfeld der älteren Person.

\section{Aktuelle kognitive Bedingungen}

Wie schon gesagt ist ein zentrales Merkmal bei der Definition von Verbosität die mangelnde Fokussierung des Sprechens. In einer Studie, die mit über 200 Senioren durchgeführt wurde, fanden Arbuckle und Gold (1993) heraus, daß die Fähigkeit, irrelevante Informationen auszublenden, in engem Zusammenhang mit dem jeweiligen Grad an Verbosität steht. Die altersbedingte Abnahme der Fähigkeit zur Ausblendung irrelevanter Informationen könnte ein wichtiges Bindeglied zwischen Alter und Verbosität bilden.

Vielfältige Determinanten der Verbosität: Offene Fragen

Sowohl psychosoziale als auch kognitive Faktoren tragen zu Verbosität bei. In einem Überblick über Verbositätsstudien weisen Gold et al. (1994) jedoch darauf hin, 
daß diese Faktoren nur $20-25 \%$ der Varianz hinsichtlich Häufigkeit und Ausmaß von Verbosität erklären. Es gibt also noch viele andere Faktoren, die als Ursachen von Verbosität erforscht werden müssen. Unser Ansatz, von vielfältigen Faktoren auszugehen, die das sprachliche Handeln im Alter beeinflussen, wirft eine Reihe von Fragen für weitere Untersuchungen zur Verbosität auf. (1) Verwenden ältere Menschen, die altersbedingt schlechter hören, eine verbose Sprechweise, um so Gesprächen nicht folgen zu müssen? (2) Geben jüngere Zuhörer, die von dem älteren Gegenüber erwarten, daß er verbos ist und sich nur auf die Vergangenheit konzentriert, nicht hinreichend korrigierendes Feedback und zeigen mehr Ungeduld? (3) Werden manche ältere Erwachsene verbos, weil sie keinen befriedigenden wechselseitigen Austausch mit jüngeren Leuten mehr erwarten?

Diese offenen Fragen führen uns in eine Diskussion über das Kommunikationspräjudiz („Communication Predicament“) gegenüber älteren Erwachsenen, dessen Wirkung ganz wesentlich auf negativen Erwartungen beruht.

\section{Das Kommunikationspräjudiz des Alters}

„Früher oder später merken die Schlauen, daß du nicht blind, taub und verblödet bist. Du bist nur eine alte Frau in einem Rollstuhl." (Informantin in Hamilton, Ontario, Kanada)

Das Zitat illustriert auf treffende Weise das Kommunikationspräjudiz des Alters, durch das die Möglichkeiten einer älteren Person, effektiv zu kommunizieren, eingeschränkt werden (Ryan et al. 1986). Das Kommunikationspräjudiz des Alters ist modellhaft in Abbildung 1 dargestellt.

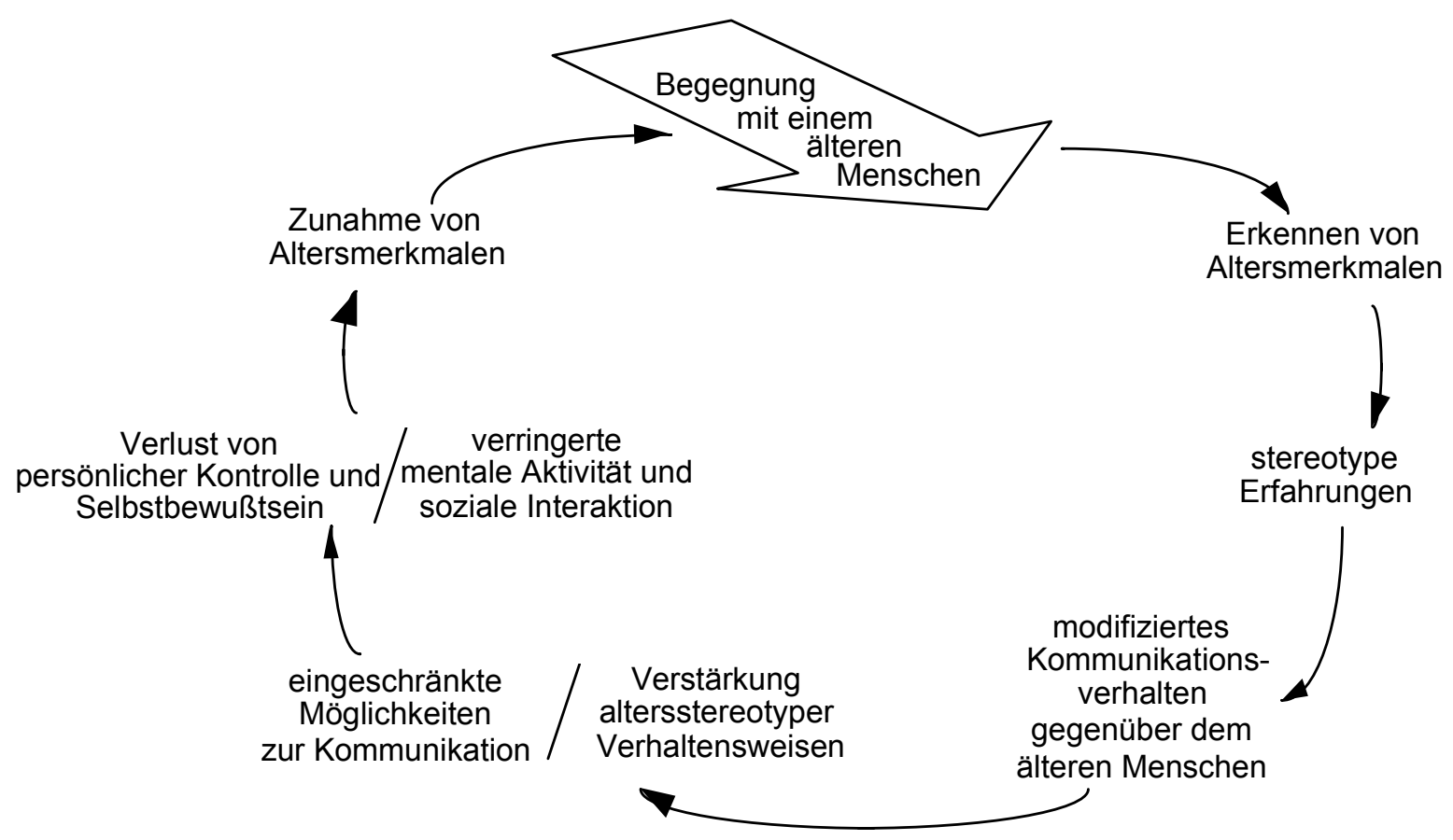

Abb. 1: Kommunikationspräjudiz des Alters 
Das Modell ist aus der Theorie der kommunikativen Anpassung („communication accommodation theory“) (vgl. Coupland, Coupland \& Giles 1991) und früheren Modellen negativen Feedbacks abgeleitet (z.B. Rodin \& Langer 1980). Die Theorie der kommunikativen Anpassung besagt, daß die Gesprächspartner ihr verbales und nonverbales Verhalten an unterschiedliche Partner angleichen und partnerorientiert modifizieren, um eine größtmögliche Effektivität des verbalen Austauschs zu erreichen. Angewendet auf intergenerationelle Kommunikation geht das Modell der kommunikativen Präjudizierung des Alters davon aus, daß jüngere Sprecherinnen und Sprecher die Anpassung ihres Kommunikationsverhaltens häufig auf der Basis falscher Annahmen und stereotyper Erwartungen hinsichtlich altersbezogener Abbauprozesse und Inkompetenzen bei ihren GesprächspartnerInnen vornehmen. Solche auf Altersvorurteilen beruhenden Anpassungen unterstützen stereotypes Verhalten und können so effektives Kommunizieren behindern. Für den älteren Menschen kann das sowohl ein verringertes Selbstwertgefühl als auch Einschränkungen des psychischen Wohlbefindens zur Folge haben. Im Extremfall kann die Wirkung der kommunikativen Präjudizierung u.U. darin bestehen, daß junge und alte Menschen von intergenerationellen Kontakten Abstand nehmen. Im folgenden erläutern wir einige Komponenten des Modells ausführlicher.

\section{Der Erstkontakt in intergenerationeller Kommunikation}

Ausgangspunkt des Modells ist das Zusammentreffen mit einer älteren Person und die Wahrnehmung von äußeren Merkmalen des Alters (old age cues) durch die jüngere Person. Man kann den Kreislauf der negativen Verstärkung gut am Beispiel des Erstkontakts einer Pflegeperson mit einer älteren Person darstellen (obwohl viele ältere Leute auch von Personen, mit denen sie regelmäßig zusammentreffen, die sie aber noch nicht näher kennengelernt haben, so behandelt werden, als ob es das erste Mal wäre). Das Pflegepersonal kann auf vielfältige Weise das Alter der Klienten erkennen: aus Listen, die Namen und Geburtstage enthalten; anhand der äußeren Erscheinung (der Klient/die Klientin hat graues Haar, Falten, eine langsame Gangart, eine gebückte Haltung, klingt alt); an Hilfsmitteln für die Beweglichkeit und das Hören (Rollstuhl, Gehstock, Hörgerät); an einer Art, sich zu verhalten, die man normalerweise mit Alter assoziiert (z.B. die Bitte um die Wiederholung des eben Gesagten oder die Feststellung, daß man etwas vergessen hat); anhand sozialer Rollen (z.B. Eltern eines erwachsenen Kindes, Großeltern, Rentner); oder an der Umgebung (z.B. eine städtische Einrichtung für ältere Menschen, Alten- und Pflegeheim, Seniorenclub).

\section{Auslösung stereotyper Erwartungen}

Die Wahrnehmung von Altersmerkmalen kann stereotype Erwartungen auslösen (Hummert 1994). Studien haben gezeigt, daß es vielfältige Stereotype über ältere Menschen gibt - die einen positiv, die anderen negativ (Hummert 1990). In dem Modell sind es die negativen Stereotype, die die kommunikative Präjudizierung bewirken. Einige der negativen Altersstereotype besagen, daß ältere Erwachsene weniger kompetent und weniger produktiv sind, ein schlechtes Gedächtnis haben, sich keiner guten Gesundheit erfreuen, schlecht hören und mehr Hilfe benötigen (vgl. Hummert 1990; Kite \& Johnson 1988; Ryan \& Kwong See 1993; Ryan et al. 1992). Da in allen Stereotypen ein Körnchen Wahrheit steckt, finden sich diese Eigenschaften in der Tat bei einigen älteren Menschen. Wie jedoch schon zuvor erwähnt, ist die Gruppe der Älteren sehr heterogen, was ihre Fähigkeiten zur Kompensation von altersbe- 
dingten Abbauprozessen betrifft. Daher müssen Altersmerkmale (z.B. graues Haar, 85 Jahre) nicht zwangsläufig bedeuten, daß diese Person weniger kompetent ist, ein schlechteres Gedächtnis hat oder andere negative, mit Alter in Verbindung zu bringende Eigenschaften besitzt. Sowohl die kommunikative Überanpassung als Reaktion auf ausgelöste negative Stereotype (z.B. das Erheben der Stimme, weil man denkt, daß alle älteren Menschen schlecht hören) als auch die Unteranpassung an die Bedürfnisse der anderen Person (z.B. die Unterstellung, daß diese Person kein Hörproblem hat), sind Scylla und Charybdis der kommunikativen Präjudizierung des Alters (Ryan, Hummert \& Boich 1995).

Patronisierende Kommunikation

Eine negative Erwartungshaltung hinsichtlich der Fähigkeiten älterer Menschen kann bei Gesprächspartnern dazu führen, daß sie sich kommunikativ in besonderer Weise verhalten, z.B. indem sie stark vereinfachend sprechen, „baby talk“ gebrauchen oder den Gesprächspartner ignorieren. Ryan, Hummert \& Boich (1995) verwenden den Begriff 'patronisierende Kommunikation' für eine solche Überanpassung in der Kommunikation, die auf stereotypen Erwartungen über Inkompetenz und $\mathrm{Ab}$ hängigkeit der Älteren beruht. Die folgenden Listen 1 und 2 stellen die verbalen und nonverbalen Aspekte von patronisierender Kommunikation zusammen (vgl. Ryan, Hummert \& Boich 1995).

\section{Liste 1: Sprachliche Merkmale patronisierender Kommunikation²}

Vokabular

- Einfach

- Wenig mehrsilbige Wörter

- Kindliche Begriffe

- Verkleinerungen (z.B. bißchen, wenig, halt nur)

- Modifikationen von Pronomen

\section{Grammatik}

- Einfache Konstruktionen und Sätze

- Wiederholungen

- Angehängte Fragen (tag questions)

- Imperative

- Fragmente

\section{Themensteuerung}

- Eingeschränkte Themenwahl, z.B. Schwerpunkt auf der Vergangenheit

- Oberflächliche Inhalte

- Unterbrechungen

- Nichtbeachtung der Themen anderer

2 Aus: Ryan, Hummert \& Boich (1995). 
- Übertriebenes Loben

Anredeformen

- Übertrieben familiär

- Vornamen und Spitznamen

- Kosenformen (z.B. meine Süße)

- Kinderbezeichnungen (z.B. gutes Mädchen, böses Mädchen, süßer Junge)

- Referenz in der dritten Person

- über jemanden sprechen statt mit

\section{Liste 2: Vokale und nonverbale Merkmale patronisierender Kommunikation ${ }^{3}$}

Vokale Merkmale

- Hohe Stimmlage

- Übertriebene Intonation

- Laut

- Übertriebene Betonung

- Mehrdeutig: langsam

Nonverbale Merkmale

- Negative Merkmale (eher häufig):

- Sich wegdrehen

- Augenrollen

- Grinsen

- Hände in die Hüfte stemmen

- Arme verschränken

- Abrupte Bewegungen

- Positive Merkmale (weniger wahrscheinlich):

- Augenkontakt

- Lächeln

- Nicken

- Sich herunterbücken (z.B. zum Rollstuhl der Älteren)

- Sanfte Bewegungen

- Mehrdeutig: Arm/Schulter klopfen

Eine Aussage wird u.a. durch Diskrepanzen zwischen verbalen und nonverbalen Merkmalen als patronisierend empfunden. So beinhaltet beispielsweise die Frage "Möchten Sie im Speisezimmer essen?" auf semantischer Ebene eine Wahlmöglichkeit. Wird diese Frage jedoch mit einer lauten Stimme und einer ungeduldigen Geste gestellt, so wird sie zu einer Feststellung oder einem Befehl. Das bedeutet, die Person hat im Speisezimmer zu essen, egal ob sie sich dafür entscheidet oder nicht. In beiden Auflistungen findet sich eine Vielzahl von Merkmalen. Eine Botschaft, die als

3 Aus: Ryan, Hummert \& Boich (1995). 
patronisierend wahrgenommen wird, kann ein oder mehrere dieser Merkmale ausweisen, muß sie aber nicht alle enthalten.

Die Funktionen dieses Kommunikationsstils können entlang zweier Dimensionen beschrieben werden: Respekt (Kontrolle) und Fürsorge (Hummert \& Ryan 1996; Ryan, Hamilton \& Kwong See 1994). Patronisierendes Handeln zeichnet sich durch fehlenden Respekt aus. Das Motiv für die Verwendung dieses Kommunikationsstils mag in der Alltagsroutine liegen, zum Beispiel in dem Problem, alle Bewohner eines Altenheims dazu bewegen zu wollen, im Speisezimmer zu essen. Solche unpersönlichen, nicht auf den Partner zugeschnittenen Aussagen zeigen fehlenden Respekt. Ein weniger offensichtliches Motiv für patronisierendes Sprechen kann darin bestehen, dem anderen Fürsorge und Unterstützung entgegenbringen zu wollen. So z.B. wenn man sicherstellen will, daß der ältere Bewohner im Speisezimmer eine warme Mahlzeit zu sich nimmt. Auch wenn es die Absicht ist, fürsorglich zu sein, kann die verbale Botschaft dennoch als respektlos empfunden werden.

\section{Altersvoreingenommene Wahrnehmung und Interpretation von Verhalten}

Sind negative Stereotype wachgerufen, so kann dies zu einer vorurteilsgeleiteten Interpretation von Verhaltensweisen führen. Das bedeutet, daß jüngere Menschen die Verhaltensweisen älterer möglicherweise selektiv wahrnehmen: sie reagieren auf solche, die mit ihren Erwartungen übereinstimmen, und ignorieren die, die nicht zu ihren Erwartungen passen. Zum Beispiel kann die Erwartung, daß ältere Menschen weniger kompetent sind, dazu führen, daß jüngere ein erfolgreiches Handeln von älteren Erwachsenen nicht bemerken, innen aber auf der anderen Seite ein Mißlingen von Handlungen vorhalten. Beispiele für Mißerfolge oder fehlerhaftes Verhalten im täglichen Leben sind z.B.: sich Verirren, einen Verkehrsunfall haben oder einen Termin vergessen. Eine altersvoreingenommene Interpretation liegt dann vor, wenn man bei einer jungen Person die Gründe für ein solches Versagen nicht in ihrem Alter, sondern in externen Umständen sucht (eine schlechte Karte, falsche Richtungsangabe, die Person ist im Moment außergewöhnlich belastet und wird wahrscheinlich nicht noch einmal einen Termin vergessen), während man das Versagen in einer der genannten Situationen bei älteren Erwachsenen als einen Beweis für altersbedingte Defizite interpretiert. Erber und seine Mitarbeiter haben altersvoreingenommene Verhaltensinterpretationen in Bezug auf das Erinnerungsvermögen nachgewiesen. Wenn jüngere und ältere Erwachsene gleiche Erinnerungsprobleme zeigen, werden sie bei den älteren als schwerwiegender angesehen und eher auf interne Faktoren zurückgeführt (z.B. Erber, Szuchman \& Rothberg 1990).

Wir haben eine ähnliche Altersvoreingenommenheit im Kommunikationskontext aufgezeigt: In einer Untersuchung erhoben Ryan und Laurie (1990) die Reaktionen junger Erwachsener auf männliche Sprecher, die entweder jung (zwischen 20 und 30) oder alt (zwischen 70 und 80) waren. Die Teilnehmenden sollten auf drei Aussagen von unterschiedlichen Sprechern der gleichen Altersgruppe reagieren. In wechselnder Folge hörte man junge und alte Sprecher, die entweder präzise Aussagen machten, die es dem Hörer ermöglichten, die Anweisungen problemlos zu befolgen, oder sie hörten unpräzise und mehrdeutige Aussagen. Als dritte Variante wurden ihnen Aufnahmen von schlechter Qualität vorgespielt, die bedingt durch Störgeräusche im Hintergrund verzerrt klangen. Die Ergebnisse dieser Untersuchung sind in Abbildung 2 zu sehen. 


\section{Kompetenzeinschätzungen von jüngeren und älteren Sprechern in drei Bedingungen}

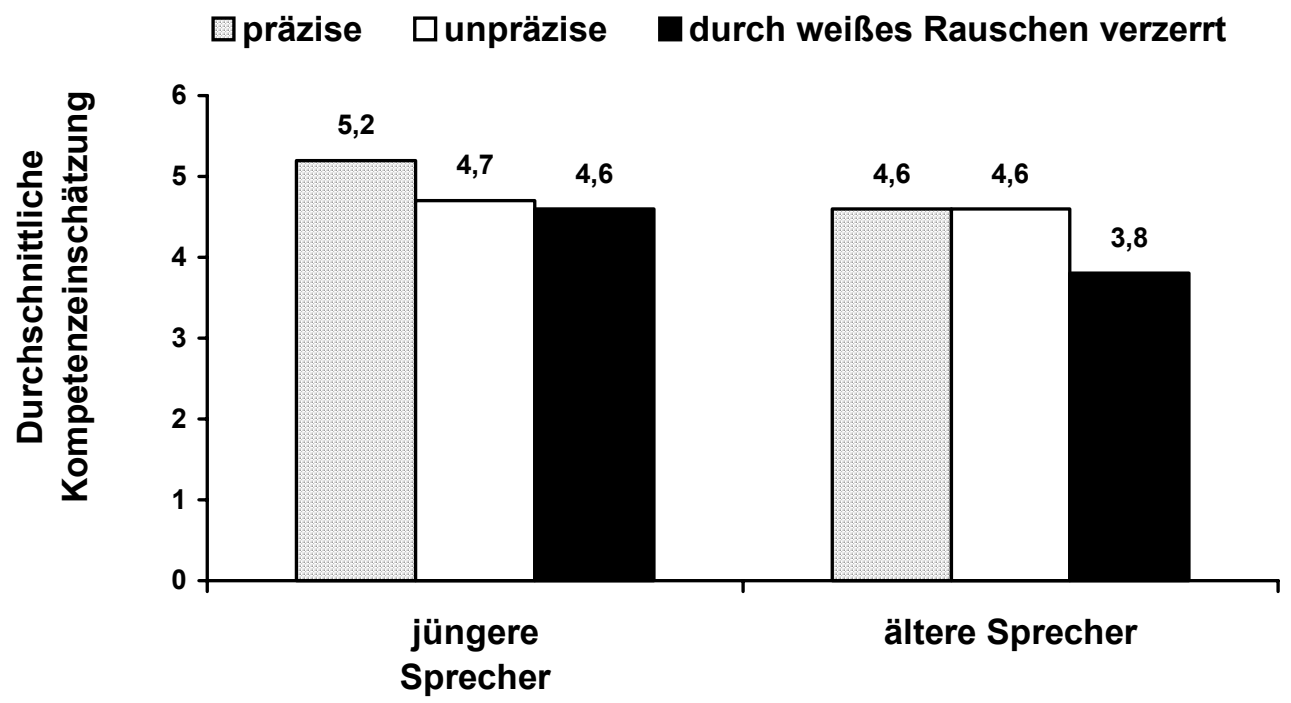

Verwendet wurde eine 7-Punkte Skala

Abb. 2: Kompetenzeinschätzungen von jüngeren und älteren Sprechern in drei Bedingungen

Wie Abbildung 2 zeigt, wurden die älteren Sprecher generell als weniger kompetent bewertet als die jüngeren. Zwei andere Ergebnisse sind jedoch noch wichtiger. Erstens bewerteten junge Hörer einen alten präzisen Sprecher nicht höher als seinen weniger präzisen Altersgenossen, obwohl sie diese Differenzierung bei jungen Sprechern durchaus vornahmen. Zweitens wurde der alte Sprecher, dessen Äußerungen auf dem Band durch Hintergrundgeräusche verzerrt war (ein Umstand, für den sich der Untersuchungsleiter explizit entschuldigte), am schlechtesten bewertet. Das zeigt, daß das Kommunikationsverhalten für ältere und jüngere Sprecher unterschiedlich interpretiert wurde, und zwar zum offensichtlichen Nachteil der älteren Sprecher: Älteren Sprechern wurde eine erfolgreiche (präzise) Ausführung nicht positiv angerechnet, und zugleich wurde innen häufiger eine negative Situation angelastet, auch wenn sie für diese nicht verantwortlich waren.

\section{Verstärkung altersstereotyper Verhaltensweisen}

Eine Folge patronisierender Kommunikation und altersvoreingenommener Verhaltensinterpretation ist eine Verstärkung von Verhaltensweisen, die den Altersstereotypen entsprechen. So haben Baltes und seine Mitarbeiter (siehe z.B. Baltes, Wahl \& Reichert 1991) in einer institutionellen Umgebung zeigen können, daß Pflegepersonal oft die Selbständigkeit von Bewohnern ignoriert, unselbständige Verhaltensweisen jedoch bestärkt. So haben beispielsweise Bewohner, die sich selbst ankleiden oder selbständig essen, weniger soziale Kontakte mit dem Personal. Im Gegensatz dazu werden Bewohner, die Hilfe bei der persönlichen Pflege benötigen und akzeptieren, durch soziale Interaktion positiv bestärkt. Mit der Zeit versetzt diese positive soziale Unterstützung die Bewohner in eine faktische Abhängigkeit und verstärkt die Einstellung des Personals, alte Menschen seien generell unselbständig. 
Für dieses Phänomen gibt es zahlreiche weitere Beispiele. Oft beharren junge Leute darauf, daß eine ältere Person zu alt ist, um noch zu arbeiten oder Auto zu fahren, oder daß die Person zu alt ist, um etwas Neues zu lernen (z.B. den Führerschein zu machen). Das schränkt nicht nur die Möglichkeiten älterer Erwachsener ein, sondern kann sie darüber hinaus auch veranlassen, das Fahren von sich aus aufzugeben oder generell nichts neues mehr zu lernen.

Letztlich ist es auch nicht ungewöhnlich, zu hören, daß ältere Erwachsene ihr Alter als eine Entschuldigung für das Vergessen eines Termins oder eines Namens benutzen. Das Alter als Entschuldigung zu gebrauchen mag dabei durchaus positiven Zwecken dienen. Ein älterer Untersuchungsteilnehmer nannte zum Beispiel als Grund, warum er sein Alter als Entschuldigung gebraucht: „Wenn ich mir in einer sozialen Situation dumm vorkomme, dann hilft das meinem Selbstwertgefühl." Ein anderer erklärte: „Ich tue dies ab und zu auf der Bank. Die Angestellten haben dann mehr Verständnis und sind hilfsbereiter." (Bieman-Copland, Ryan, Ellis \& Anas i.V.). Ein anderer Teilnehmer verwies jedoch auch auf negative Folgen: „Ich habe mein Alter als Entschuldigung gebraucht, weil es so glaubwürdig klingt. Ich tue dies nicht mehr, weil ich anfing, es selbst zu glauben." Obwohl Menschen jeden Alters Dinge vergessen, verstärkt die Verwendung von Alter als Rechtfertigung sowohl bei bei alten als auch bei jungen Menschen das Stereotyp, alle älteren Leute seien vergeßlich.

Das Kommunikationspräjudiz des Alters und seine Konsequenzen

Wir haben bereits einige der negativen Folgen beschrieben, die die kommunikative Präjudizierung des Alters mit sich bringt, so beispielsweise eine erhöhte Abhängigkeit und der Verlust der persönlichen Kontrolle auf seiten der Älteren (Baltes et al. 1991) oder die Verstärkung einer negativen Auffassung vom Altern bei älteren und jüngeren Menschen. Eine andere beklagenswerte Konsequenz ist die Tatsache, daß junge und alte Sprecher - gefangen im Teufelskreis der kommunikativen Präjudizierung des Alters - mit intergenerationellen Kontakten tendenziell eher unzufrieden sind (vgl. z.B. Ryan, Bourhis \& Knops 1991; Ryan et al. 1994). Dies kann zur Folge haben, daß sich Junge und Alte frühzeitig aus einer intergenerationellen Interaktion zurückziehen oder sie sogar völlig vermeiden. Es wäre eine interessante Aufgabe für weitere Untersuchungen, die Auswirkungen unbefriedigender intergenerationeller Kommunikation in solchen Situationen zu erforschen, in denen ein Ausweichen oder ein Abbruch nicht möglich ist. Ein Beispiel wäre der Fall junger Leute, die ältere Erwachsene im Rahmen einer Umfrage interviewen sollen. Führt es zur Verzerrung der Ergebnisse, wenn bei einer Umfrage über ältere Erwachsene und deren Bedürfnisse versucht wird, das Interview schnell zu Ende zu bringen oder wenn die Antworten der älteren Menschen auf eine altersvoreingenommene Weise interpretiert werden? Verweigern auf der anderen Seite ältere Erwachsene manchmal eine Teilnahme an einer Umfrage, weil sie nicht mit einem jungen Interviewer sprechen wollen?

Eine letzte zu erwähnende Folge ist, daß die kommunikative Präjudizierung nicht nur die Beteiligten, sondern auch die Beobachter einer Interaktion beeinflußt. Ryan, Boich und Klemenchuck-Politeski (1994) beispielsweise ließen Außenstehende eine ältere Person beurteilen, die in einem Dreiergespräch entweder ignoriert oder aber direkt angesprochen wurde. Die Beobachter beurteilten die ältere Person als weniger kompetent, wenn sie ignoriert wurde, und als kompetenter, wenn sie direkt angesprochen wurde. 
Kontextabhängigkeit des Alterns

Um es zusammenzufassen: Das Wissen darüber, daß eine Person alt ist, kann stereotype Erwartungen auslösen. Als Folge dieser Erwartungen kann der Gesprächspartner sein verbales wie auch sein nonverbales Kommunikationsverhalten ändern. Dies führt zu einer negativen Verstärkung, indem altersstereotype Verhaltensweisen (z.B. Abhängigkeit) befördert werden. Hierdurch wird die Möglichkeit für einen befriedigenden Austausch eingeschränkt und kann bei der älteren Person zu einer Schwächung des Selbstbewußtseins oder zu einem Rückzug aus den sozialen Aktivitäten führen. Dies trifft besonders dann zu, wenn die ältere Person selbst an ihren Fähigkeiten und an ihrem Kommunikationsvermögen zu zweifeln beginnt. Ist eine Person wiederholt solchen kommunikativen Präjudizierungen ausgesetzt, kann dies letztlich dazu führen, daß ihre Gesundheit geschwächt wird und - als letzte Konsequenz - daß sie älter wirkt und sich „älter“ verhält.

\section{Möglichkeiten zur Verbesserung der Kommunikation mit älteren Menschen}

In unserem Beitrag haben wir dargestellt, wie stereotype Erwartungen und Veränderungen im Kommunikationsverhalten die intergenerationelle Kommunikation belasten können. Liste 3 zeigt Strategien auf, mit deren Hilfe der Teufelskreis der kommunikativen Präjudizierung des Alters durchbrochen werden kann.

\section{Liste 3: Verbesserung der Kommunikation mit älteren Menschen ${ }^{4}$}

\section{Grundprinzipien:}

- Zeige Respekt für die Person und

- ermögliche ihr die bestmögliche Kommunikation.

\section{Strategien:}

- Höre zu

- um Respekt und Bemühen zu zeigen, um zu erfahren, wie dein Sprachverhalten so verändert werden kann, daß es für diese Person angemessen ist, um zu lernen, wie gut oder schlecht deine Bemühungen um Kommunikation aufgenommen werden.

- Achte auf deine automatischen Überreaktionen (auf Merkmale des Alters oder auf Beeinträchtigungen beim anderen)

- z.B. die ältere Person zu laut anzusprechen,

- das Vokabular zu stark zu vereinfachen,

- eine Telegrammstil-Grammatik zu gebrauchen,

- überzogen familiär zu sprechen (z.B. Namen, Spitznamen),

- für die andere Person etwas zu erledigen, anstatt sie selbst zu befähigen, es zu tun,

- das Treffen von Entscheidungen zu übernehmen,

- Gesprächsthemen einzuschränken.

4 Aus; Ryan, Meredith, MacLean \& Orange (1995). 
Die Grundprinzipien der Verbesserung intergenerationeller Kommunikation sind, (1) der einzelnen Person Respekt zu zollen und (2) es ihr zu ermöglichen, auf die bestmögliche Weise zu kommunizieren (Ryan, Meredith, MacLean \& Orange 1995). Dies zu tun erfordert, auf die jeweilige Person und ihre Bedürfnisse individuell einzugehen, anstatt die Interaktion durch stereotype Erwartungen über Fähigkeiten und Möglichkeiten alter Personen steuern zu lassen. Darüber hinaus ist es wichtig, die eigenen nonverbalen Verhaltensweisen genau zu beachten und $z u$ kontrollieren, sowohl solche, die Aufmerksamkeit, Trost und Verständnis ausdrücken, als auch solche, die Verärgerung, Frustration und Unverständnis zum Ausdruck bringen.

Als Beispiel und um an unsere Erörterung der Verbosität anzuknüpfen: Wenn man jede Woche mit einer äußerst verbosen Person Kontakt hätte, wie könnte man diese Prinzipien anwenden, um kommunikativen Erfolg zu vergrößern? Wenn man sich die vielfältigen Bedingungsfaktoren des sprachlichen Handelns in Erinnerung ruft, ist es ratsam, sich auf solche zu konzentrieren, die beeinflußbar sind. Die eigenen stereotypgeleiteten Erwartungen über den älteren verbosen Gesprächspartner sind ein wichtiger Faktor, der modifiziert werden kann. Eine genaue Beobachtung des eigenen Verhaltens wird erweisen, ob man, wenn man verboses Verhalten erwartet, ein wichtiges Gespräch zu schnell beendet oder ob man es nicht geschafft hat, das Gespräch zum passenden Zeitpunkt wieder in andere Bahnen zu lenken. Ebenso sollte man sich die Frage stellen, ob man Anzeichen für Langeweile oder Ungeduld nonverbal übermittelt hat.

Auch das physische Umfeld ist veränderbar. Hat man negative Einflüsse aus der Umwelt bedacht, die möglicherweise die Fähigkeit einer Person, einer Unterhaltung oder ihren eigenen Gedanken zu folgen, herabsetzen können? Eine Strategie, die helfen könnte, einige der automatischen Verhaltensweisen der verbosen älteren Person wie auch die eigenen zu überwinden, wäre, vorab einen Zeitrahmen zu bestimmen (und dem Partner zu verdeutlichen), in dem man seinen Ausführungen mit Interesse und Aufmerksamkeit folgen will. Darüber hinaus sollte man verschiedene Möglichkeiten ausprobieren, um Ablenkungen zu reduzieren (z.B. eine Unterhaltung im Flur zu führen statt in der Küche). Schließlich könnte man versuchen, die Aufmerksamkeit des Sprechers immer wieder auf das Thema des Gesprächs hinzulenken.

\section{Zusammenfassung und zukünftige Perspektiven}

Der wichtigste Punkt unseres Beitrags ist die Aussage, daß das sprachliche Handeln im höheren Lebensalter von vielfältigen Faktoren beeinflußt wird (Ryan et al. 1992). Auch bei intakter sprach-kommunikativer Kompetenz kann ein altersbedingtes Nachlassen der kognitiven Informationsverarbeitung oder der soziale Kontext der Kommunikation zu einem unbefriedigenden kommunikativen Verhalten führen. Vorgestellt wurde ein Modell der kommunikativen Präjudizierung des Alters, das den Einfluß von Rollen und Erwartungen auf das Gesprächsverhalten beschreibt. In der Darstellung dieses Modells haben wir mehrfach aufgezeigt, wie traditionelle Arbeitsgebiete und Methoden der Linguistik auf den Gegenstandsbereich „Sprache und Kommunikation im Alter" angewendet wurden. Das Modell der kommunikativen Präjudizierung des Alters betont die pragmatische Kompetenz Älterer und ihrer Gesprächspartner, die Rolle kommunikativer Anpassung an unterschiedliche Sprecher, 
durch negative Stereotype verursachte Beschränkungen der Kommunikation und die wichtige Wechselwirkung zwischen verbalen und nonverbalen Botschaften.

Es bedarf weiterer Forschung seitens der Psycholinguistik, der Psychologie und der Soziolinguistik im Bereich von Mehrsprachigkeit, Geschlechterforschung sowie sozioökonomisch bedingter Varianz. Patronisierende Kommunikation wurde bisher in Nordamerika (Ryan, Hummert et al. 1995), in Großbritannien (Ryan et al. 1986), in Deutschland (Ryan, Wood, Sachweh \& Kroger 1995) und in Holland (de Wilde \& de Bot 1989) dokumentiert. Weitere Untersuchungen sind nötig, um festzustellen, ob diese Form der Kommunikation in Kulturen, die eine unterschiedliche Auffassung vom Altern haben, variiert. Kulturvergleichende Forschung muß der erste Schritt dazu sein, die einzigartige Streßsituation zu verstehen, in der sich ältere Immigranten befinden, die zwischen zwei Kulturen mit unterschiedlichen Auffassungen vom Altern stehen.

Gelingende Kommunikation im höheren Alter ist der Schlüssel zur Bewahrung von Unabhängigkeit. Durch die stetig wachsende Anzahl von älteren Menschen ist die Aufgabe, effektive Kommunikation zu fördern, unabweisbar. Als Folge davon ist auch der Bedarf nach multidisziplinärem Wissensaustausch größer denn je. Beispielsweise lag der Schwerpunkt der klinischen Forschung bislang auf Problemen der Sprachproduktion und -rezeption von älteren Erwachsenen mit Kommunikationsstörungen (Brownell \& Joanette 1993). Managementstrategien in Institutionen würden davon profitieren, einen größeren sozialen Kontext in Betracht zu ziehen, wie es z.B. das Modell der kommunikativen Präjudizierung des Alters anregt. Gleichzeitig ist die kommunikative Präjudizierung von älteren Patienten, die eine Kommunikationsstörung haben (z.B. eine Aphasie nach einem Schlaganfall), eine weitere Forschungsperspektive in Zusammenhang mit dem Modell. Um es abschließend zusammenzufassen: Sprache und Altern wird sowohl aus anwendungsorientierter als auch aus theoretischer Sicht ein ebenso wichtiges wie interessantes Forschungsfeld bleiben.

\section{Literatur}

Arbuckle, T. Y. \& Gold, D. P. (1993). Aging, inhibition and verbosity. In: Journal of Gerontology: Psychological Sciences 48, 225-232.

Bäckman, L. \& Dixon, R. (1992). Psychological compensation: A theoretical framework. In: Psychological Bulletin 112, 259-283.

Baltes, M. M., Wahl, H.-W. \& Reichert, M. (1991). Sucessful aging in long-term care institutions. In: Annual Review of Gerontology and Geriatrics 11, 311-338.

Baltes, P. (1993). The aging mind: Potential and limits. In: The Gerontologist 33, 580-594.

Bayles, K. A. \& Kaszniak, A. W. (1987). Communication and cognition in normal aging and dementia. Boston: Little, Brown.

Bieman-Copland, S., Ryan, E. B., Ellis, C. H. \& Anas, A. P. (In preparation). „Getting old does that to your memory". Is age a good excuse?

Brownell, H. \& Joanette, Y. (eds.) (1993). Narrative discourse in neurologically impaired and normal aging adults. San Diego: Singular.

Coupland, N., Coupland, J. \& Giles, H. (1991). Language, society and the elderly. Oxford: Basil Blackwell.

de Wilde, I. \& de Bot, K. (1989). Taal van verzorgenden tegen ouderen in een psychogeriatrisch verpleeghuis [A simplified register in caregivers' speech to elderly demented patients]. In: Tijdschrift voor Gerontologie en Geriatrie 20, 97-100.

Erber, J. T., Szuchman, L. T. \& Rothberg, S. T. (1990). Everyday memory failure: Age differences in appraisal and attribution. In: Psychology and Aging 5, 236-241. 
Gold, D. P., Arbuckle, T. Y. \& Andres, D. (1994). Verbosity in older adults. In: Hummert, M. L., Wiemann, J. M. \& Nussbaum, J. F. (eds.), Interpersonal communication in older adulthood: Interdisciplinary theory and reserarch. Thousand Oaks, CA: Sage, 107-129.

Hummert, M. L. (1990). Multiple stereotypes of elderly and young adults: A comparison of structure and evaluations. In: Psychology and Aging 5, 182-193.

Hummert, M. L. (1994). Physiognomic cues to age and the activation of stereotypes of the elderly in interaction. In: International Journal of Aging and Human Development 39, 5-19.

Hummert, M. L. \& Ryan, E. B. (1996). Toward understanding variations in patronizing talk addressed to older adults: Psycholinguistic features of care and control. In: International Journal of Psycholinguistics 12 (2), 149-169.

Kite, M. E., \& Johnson, B. T. (1988). Attitudes toward older and younger adults: A meta-analysis. In: Psychology and Aging 3, 233-244.

Kemper, S. (1992). Language and aging. In: Craik, F. I. M. \& Salthouse, T. A. (eds.), The handbook of aging and cognition. Hillsdale, NJ: Lawrence Erlbaum, 213-270.

Kwong See, S. T. \& Ryan, E. B. (1996). Cognitive mediation of discourse processing in later life. In: Journal of Speech-Language Pathology and Audiology 20, 109-117.

Light, L. L. (1988). Language and aging: Competence versus performance. In: Birren, J. E. \& Bengtson, V. L. (eds.), Emergent theories of aging. New York: Springer, 177-213.

Light, L. L. \& Burke, D. M. (eds.) (1988). Language, memory and aging. New York: Cambridge University Press.

Rodin, J. \& Langer, E. J. (1980). Aging labels: The decline of control and the fall of self-esteem. In: Journal of Social Issues 36, 12-29.

Ryan, E. B., Boich, L. H. \& Klemenchuck-Politeski, L. (1994). Patronizing behavior in health care: Is ignoring the older, accented speaker excusable? Paper presented at the Second International Conference on Communication, Aging and Health, Hamilton, Canada.

Ryan, E. B., Bourhis, R. Y. \& Knops, U. (1991). Evaluative perceptions of patronizing speech addressed to elders. In: Psychology and Aging 6, 442-450.

Ryan, E. B., Giles, H., Bartolucci, G. \& Henwood, K. (1986). Psycholinguistic and social psychological components of communication by and with the elderly. In: Language and Communication 6, 124.

Ryan, E. B., Hamilton, J. M. \& Kwong See, S. (1994). Patronizing the old: How do younger and older adults respond to baby talk in the nursing home? In: International Journal of Aging and Human Development 39, 21-32.

Ryan, E. B., Hummert, M. L. \& Boich, L. H. (1995). Communication predicaments of aging: Patronizing behavior toward older adults. In: Journal of Language and Social Psychology 14, 144-166.

Ryan, E. B. \& Kwong See, S. (1993). Age-based beliefs about memory changes for self and other across adulthood. In: Journal of Gerontology: Psychological Sciences 48, 199-201.

Ryan, E. B., Kwong See, S., Meneer, W. B. \& Trovato, D. (1992). Age-based perceptions of language performance among younger and older adults. In: Communication Research 19, 423-443.

Ryan, E. B. \& Laurie, S. (1990). Evaluations of older and younger adult speakers: Influence of communication effectiveness and noise. In: Psychology and Aging 5, 514-519.

Ryan, E. B., Meredith, S., D., MacLean, M. J. \& Orange, J. B. (1995). Changing the way we talk with elders: Promoting health using the Communication Enhancement Model. In: International Journal of Aging and Human Development 41, 87-105.

Ryan, E. B., Wood, L. A., Sachweh, S. \& Kroger, R. O. (1995). A crosscultural examination of institutional talk to elders: Variations on a theme. Paper presented at the annual meeting of the Gerontological Society of Amerinca, Los Angeles, USA.

Stine, E. A. L., Soederberg, L. M. \& Morrow, D. G. (1996). Language and discourse processing through adulthood. In: Blanchard-Fields, F. \& Hess, T. M. (eds.), Perspectives on cognitive change in adulthood and aging. New York: McGraw-Hill, 255-290. 


\title{
Kommunikative Konstruktion der sozialen Kategorie 'Alter' im Gespräch
}

\author{
Caja Thimm
}

Die Frage nach dem Einfluß, den soziale Kategorien auf die konversationelle Konstruktion von Identität ausüben können, hat in den letzten Jahren aus verschiedenen Perspektiven linguistisches Interesse gefunden. Unterschieden wurden dabei besonders die Kategorien Geschlecht (Braun \& Pasero 1997), Jugend (Schwitalla \& Streeck 1989), Rollenkategorien (Kallmeyer \& Keim 1994) und nationale Identität (Czyzewski, Drescher, Gülich \& Hausendorf 1995). Obwohl 'Alter' unfraglich ebenfalls eine wichtige Variable ist, wurde dem Altsein einer Person in der deutschsprachigen Linguistik bisher wenig Aufmerksamkeit zuteil. ${ }^{1}$ Dies ist umso erstaunlicher, als die BRD einen bisher ungekannten demographischen Umbruch erlebt, der auch für die Kommunikationsverhältnisse relevant wird. Neben bekannten quantitativen Generationenveränderungen in der Gesellschaft gibt es nämlich Anzeichen für eine Veränderung kommunikativer Beziehungen, die nicht nur aus demographischer, sondern aus sprachwissenschaftlicher Sicht bemerkenswert sind. Ältere Menschen sind weniger, als dies etwa noch im vorigen Jahrhundert der Fall war, in den Kontext einer Mehrgenerationenfamilie eingebunden. In vielen Fällen besteht eine große geographische Distanz zwischen den Familienmitgliedern. Familie ist heute häufig 'multilokal', Kinder und Enkel(innen) stehen damit für alltägliche Bedürfnisse seltener zur Verfügung (Mayer \& Baltes 1996). In dem Maße, wie die Familie kleiner geworden ist und immer mehr Menschen es vorziehen, unverheiratet und/oder kinderlos zu bleiben, sind mehr und mehr ältere Menschen auf die extra-familiale Kommunikation angewiesen. Ältere Menschen verbringen ihren Alltag immer mehr in öffentlichen Settings, darunter auch zunehmend in solchen, die speziell für ältere konzipiert sind (wie z.B. Seniorentreffs, Seniorenuniversitäten oder andere spezielle Bildungs- und Freizeiteinrichtungen für Ältere). Auch zeigen Studien, daß ältere Menschen dem Kontakt mit Jüngeren durchaus skeptisch gegenüber stehen und einen hohen Bedarf an Austausch untereinander betonen (Daum 1982; Nussbaum 1983).

Im Mittelpunkt dieses Beitrages steht daher die Frage, welche Rolle dem Altsein von Älteren selbst zugewiesen wird und in welcher Art und Weise sie das Altsein (und Altersunterschiede) konversationell bearbeiten. Ziel ist es herauszuarbeiten, welche Rolle das Alter für Konversationen unter älteren Menschen spielt, bzw. ob und in welchen Formen sprachlich auf die Kategorie 'Alter' Bezug genommen wird. Ausgehend von der Annahme, daß Alter eine wichtige soziale Kategorie darstellt, möchte ich in diesem Beitrag versuchen, Alter als grundlegende Einflußvariable auf verbale Interaktionen zu erfassen, um damit die Frage nach 'Altersidentität' aus linguistischer Sicht aufzugreifen.

1 So z.B. haben Kallmeyer (1994) und Kallmeyer \& Keim (1994) die Gespräche einer Gruppe von älteren Frauen über Jahre hinweg dokumentiert und detailliert analysiert, ohne explizit auf die Kategorie Alter einzugehen (vgl. auch Fiehler 1996; Thimm 1996). 


\section{Soziale Kategorien}

Soziale Kategorien spielen in unserem Altag eine wichtige Rolle. Sie ermöglichen Zugehörigkeit und Solidarisierung mit einigen Personen und Personengruppen, aber auch Abgrenzung von anderen, die als 'fremd' oder 'anders' empfunden und einer Outgroup zugeordnet werden (Kallmeyer 1989). Um genauer bearbeiten zu können, in welcher Form sprachlich auf soziale Kategorien Bezug genommen werden kann, wie soziale Identität und Gruppenbezüge interaktiv hergestellt werden und wie sich intergenerationelle und intragenerationelle Konversationen bezüglich der Behandlung der Kategorie 'Alter' unterscheiden, ist es notwendig zu betrachten, welche Rolle sozialen Kategorien in Interaktionen zukommen kann.

Dazu ist zunächst anzuführen, daß Kategorien eine Form der Wissensstrukturierung und der sozialen Ordnung darstellen, sie sind kognitive Entitäten, die in enger Verbindung mit bestimmten Eigenschafts- bzw. Handlungszuschreibungen stehen. Lakoff $(1987,5)$ sieht die Fähigkeit zum Kategorisieren als Teil der kognitiven Grundausstattung an und stellt fest, daß „there is nothing more basic than categorization to our thought, perception, action, and speech“. Ausgegangen wird somit von einer grundlegenden Kategorisierungskompetenz, die uns befähigt, sowohl sprachliche Zeichen aus ihrem semiotischen Umfeld auf andere Zeichen und reale Gegebenheiten zurückzubeziehen, aber uns ebenfalls ermöglicht, Komplexität zu reduzieren und Begriffe innerhalb der Welt zuzuorden, wie dies in kognitiven Ansätzen der lexikalischen Semantik genauer ausgeführt ist. ${ }^{2}$

Kategorisierungen sind demnach letztlich eine Form der Denkstrukturierung, die beliebige Objekte umfassen, d.h. sowohl menschliche, als auch dingliche Gegenstände und Ordnungen betreffen kann. Soziale Kategorien stellen damit einen „Ausschnitt aus dem umfangreichen Repertoire an Kategorien dar, das uns zum Erfassen der Welt zur Verfügung steht“" (Drescher \& Dausendschön-Gay 1995, 85). Sie sind Kategorien, die zur Bezeichnung von Personen verwendet werden und dienen der personenbezogenen Kategorisierung. Soziales Kategorisieren beschreibt einen Zuordnungsprozeß von Personen zu Personengruppen, so daß soziales Kategorisieren als eine Form der „Typisierung innerhalb der menschlichen Welt“ (Schütz 1971) gelten kann.

Betrachtet man soziale Kategorien als Möglichkeit, die soziale Welt zu strukturieren, zu ordnen und - letztlich - sinnhaft zu deuten, so sind sie als Teil geteilter sozialer Wissensbestände natürlich auch kommunikativ wirksam. Beispielsweise sind sie mit Bewertungen verbunden, die den Umgang mit Mitgliedern der Gruppen, die mittels einer sozialen Kategorie bezeichnet werden, beeinflussen. Bereits der Kategorisierungsprozeß als solcher hat kommunikative Folgen, da die Charakterisierung, die ein Individuum bezüglich eines anderen durch direkte Beobachtung vornehmen kann, durch zwei fundamentale Formen der Identifikation gekennzeichnet ist. Einerseits die kategoriale Identifikation, die den Anderen in eine oder mehrere soziale Kategorien einordnet, andererseits die individuelle Identifikation, die von persönlichen Merkmalen über Auftreten und Stimme bis zum Namen reicht (Goffman 1992). Wir sind zwar als Mitglieder bestimmter sozialer Kategorien identifizierbar, die nicht

2 Hier sind besonders die Arbeiten von Rosch (1978) zu erwähnen. Roschs Neukonzeption des Kategorienbegriffs stützt sich im wesentlichen auf die empirisch ermittelte sogenannte 'interne Struktur' kategorialer Begriffe, die sich durch einen „prototypischen Kern“ und periphere Zonen des Übergangs zu angrenzenden Kategorien auszeichnet; vgl. auch Lakoff (1987, 112ff.). 
unserer Kontrolle unterliegen ${ }^{3}$, können aber durch eigenes Handeln den Stellenwert unserer Zugehörigkeit beeinflussen. So ist es Sprechern und Sprecherinnen beispielsweise möglich, durch die Themenwahl darauf Einfluß nehmen, ob einer sozialen Kategorie interaktiv Gewicht zugemessen wird oder nicht. Soziale Identität wird also nicht nur durch die Zugehörigkeit zu Altersgruppen, Geschlecht, sozialem Status oder nationalen, ethnischen oder kulturellen Gruppen bestimmt, sondern auch durch einen Prozeß der Relevantsetzung dieser Identität durch soziales Handeln im Austausch mit anderen.

'Alter' läßt sich demnach als eine soziale Kategorie verstehen, die als erkennbarer 'Identitätsaufhänger' (Goffman 1992) ein Beurteilungskriterium darstellt, ihren genauen Stellenwert aber erst durch die situativ flexible Definition der Handelnden erfährt: Nicht in jeder Situation wird das Alter der Beteiligten in gleicher Weise salient (Ward 1984).

\section{Mitgliedschaftskategorisierungen}

Während auch heute noch die Vorstellung von sozialer Gruppenzugehörigkeit als unveränderlicher Teil der sozialen Identität viele Arbeiten dominiert, ${ }^{4}$ konzipierte der Soziologe Harvey Sacks seine Vorstellung von Kategorienzugehörigkeit als flexible Mitgliedschaftskategorisierungen (membership categories) (1972a,b; 1992). Er hat damit vor allem auf den hohen Stellenwert des Kategorisierens für die alltägliche Interaktion hingewiesen und so einen bisher vernachlässigten Aspekt sozialer Organisation herausgestellt.

Sacks geht von Mitgliedschaftskategorien aus, die von unterschiedlicher Qualität sind. Einige lassen sich als äußerlich markant und nur begrenzt veränderbar klassifizieren (wie Geschlecht, Alter oder Hautfarbe), andere als veränderbar und weniger leicht dekodierbar (Status, nationale Zugehörigkeit). Kategorien werden in Kategorienkollektionen zusammengefaßt, die entweder aus mehreren Kategorien bestehen (wie Nation), oder aber als 'two-set-class' bipolar strukturiert sind und aus dichotomen Kategorien bestehen (Alte/Junge oder auch Frau/Mann). Als Bezeichnungsmittel fungieren die regelgeleiteten Kategorienkollektionsbezeichnungen ('member-ship category devices'), die mindestens eine Kategorie enthalten „which may be applied to some population containing at least a member, so as to provide, by the use of some rules of application, for the pairing of at least a population member and a categorization device member. A device is a collection plus rules of application" (1972b, 332).

Diejenigen Regeln, nach denen Kategorisierungsprozesse systematisiert werden können, sind nach Sacks die Regel der Ökonomie ('economy rule') und die Regel der Konsistenz ('consistency rule').

Die Ökonomieregel besagt, daß die Verwendung einer Kategorienbezeichnung referenziell ausreichend ist, d.h daß auf Personen mithilfe einer Kategorie aus einer Kategorienkollektion adäquat Bezug genommen werden kann: „It is adequate on

3 Dies wird durch die elektronischen Kommunikationsmedien allerdings zunehmend komplexer. So schuf sich beispielweise der Psychiater Sanford Lewin eine weibliche Identität im Internet und agierte jahrelang 'als Frau' in 'women discussion groups' (Bahl \& Beck 1996).

4 Dazu gehören auch die Studien, die Alterszugehörigkeit als unabhängige Variable verstehen, wie die meisten Untersuchungen zur Kommunikation im Alter, vgl. Emery (1986), Ryan et al. (1995), Hummert, Nussbaum \& Wieman (1994). 
many occasions to say of someone no more than that they are 'female' or 'old' or 'negro'"' (1972a, 34).

Die Konsistenzregel thematisiert die Zusammenhänge zwischen dem Gebrauch einer übereinstimmenden Kategorienkollektion für weitere Personen, d.h. wenn zur Kategorisierung einer Person eine Kategorie aus einer bestimmten Kategorienkollektion verwendet wird, so können weitere erwähnte Personen ebenfalls mit Kategorien aus dieser Kollektion belegt werden.

Neben der Möglichkeit, mit einer Kategorienbezeichnung auf Personen Bezug zu nehmen, hat Sacks einen Aspekt der Bestimmung einer Kategorie herausgearbeitet, der für die Kategorisierung von Personen als 'alt' besonders aussagekräftig ist: die kategoriengebundenen Aktivitäten ('category bound activities'). Diese gelten als Definitionskriterien für Kategorien, „sie gehören zur Kategorie und sind das, was man macht als Kategorien-Angehöriger" (Keim \& Schmitt 1993, 145). Neben den kategoriengebundenen Aktivitäten sind es außerdem kategoriengebundene Eigenschaften, die als zur Kategorie gehörende Wissensbestände die Identifizierung von Kategorienzugehörigkeit ermöglichen.

Wie jedoch in Interaktionen auf soziale Kategorien referiert wird bzw. welche Funktionen solchen Referenzen zukommen können, hängt von den kontextuellen Bedingungen ab. So betont Sacks die Notwendigkeit der Bezugnahme auf die Kategorien durch die Handelnden selbst: nicht der (externe) Blick auf (vermeintliche) soziale Zugehörigkeiten, sondern der faktische Gebrauch der Kategorien in der Interaktion bestimmt die Geltungskraft der Kategorie. Die Betonung dieser mutuellen Konstruktionen von Kategorien unterscheidet Sacks' Konzeption der Mitgliedschaftskategorien von den sozialpsychologischen oder soziologischen Ansätzen, die Kategorien als Form der Eigenschaftszuordnungen zu Personen oder Personengruppen ansehen. Sacks weist dem gemeinsamen 'gebrauchen' oder 'zusammenstellen' von Kategorienkollektionen eine entscheidende Funktion zu.

Individuen sind jedoch nicht nur Mitglieder in einer Kategorienkollektion, sondern in einer Vielzahl von Kategorienkollektionen. Es stellt sich somit die Frage, ob ältere Menschen ihr Alter als Identifikations- und Kategorisierungsmittel ansehen und ob und in welcher Form sie es sprachlich im Gespräch untereinander relevant setzen (Hausendorf 1994).

Im Zusammenhang mit der Fragestellung nach der sprachlichen Manifestation der Kategorie 'Alter' ist zu betonen, daß es nicht nur das 'objektive' Alter ist, das als Hintergrund kommunikativer Alltagsprozesse wirksam wird, sondern daß es vielmehr von Kategorisierungsprozessen innerhalb der Interaktion abhängt, ob und welche Rolle dem Alt-Sein zukommt. Coupland, Coupland \& Giles $(1991,70)$ betonen, daß auch die Zugehörigkeit zu einer höheren Altersgruppe nicht als 'natürlich salient' vorausgesetzt werden darf:

\footnotetext{
„And we might be tempted to think that age salience is a natural result of older and younger speakers coming into contact. We believe that this is an ageist assumption. In other intergroup contexts (talk between the sexes, ethnic groups, the social classes, and so on), we would assume that speakers could potentially align as group members and mark this in their talk, but we would not assume this was inevitable or even predictable. Why should we assume that elderly category membership is more 'naturally' salient?"
}

Folgt man dieser Argumentation, so heißt es, diejenigen kommunikativen Mechanismen und Muster zu identifizieren, die die sprachliche Realisierung und interaktive Konstituierung der sozialen Kategorie 'Alter' bewirken. Es ist eine Sache zu erken- 
nen, daß eine Person alt oder jung ist und sie als Kategorienmitglied zu identifizieren. Eine andere dagegen ist es, ob und wie sprachlich auf sie Bezug genommen wird, inwieweit also der sozialen Kategorie für die Interaktion Relevanz zugewiesen wird.

Sprachliche Bezugnahmen auf soziale Kategorien können in unterschiedlicher Form gestaltet werden. Entscheidend ist dabei, ob lexikalisch verfestigte Bezeichnungen für die Kategorien zur Verfügung stehen oder diese interaktiv hergestellt werden. So spricht Kallmeyer $(1994,29)$ von Kategorisierung „wenn ein fester Kategorienbestand existiert, der in sich systematisch geordnet ist, und wenn die betreffenden Kategorien mit festen sprachlichen Ausdrucksweisen verbunden sind (Kategorienbezeichnungen, Formeln).“

Auch wenn ein fester Kategorienbestand zugrunde gelegt wird, d.h. das Wissen um die soziale Relevanz bestimmter lexikalischer Bezeichnungsweisen für Personengruppen notwendig vorausgesetzt werden kann, so ist die sprachliche Repräsentation einer sozialen Kategorie innerhalb von Interaktionen als so variabel anzusehen, daß „auf dieselbe Person je nach Perspektive, unter der die Identität dieser Person gesprächsweise in den Blick kommt, unterschiedliche Kategorien angewendet werden [können]. Kategorisierung ist also immer perspektivisch, und sie ist einseitig, sofern sie die Komplexität der Definition von sozialen Identitäten und Beziehungen jeweils auf einen Aspekt reduziert" (Kallmeyer \& Keim 1994, 261). Dies verweist darauf, daß zwischen denjenigen Kategorien zu unterscheiden ist, auf die sich Personen mittels Aktivierung von Alltagswissen der jeweiligen Kulturgemeinschaft als vorhandene Kategorien beziehen können, und solchen, die gesprächsweise hergestellt werden und nicht als verfestigt gelten können (Keim \& Schmitt 1993). Da die Kategorie 'Alter' als verfestigte Kategorie anzusehen ist, stellt sich die Frage nach denjenigen kommunikativen Verfahren, die im konkreten Kontext für sprachliche Verweise auf das 'höhere Erwachsenenalter' Verwendung finden. Als methodische Annäherung wird im nächsten Abschnitt ein Konzept von Altersreferenz vorgeschlagen, das auf der Basis der sozialen Referenz und unter Ergänzung weiterer Referenzformen die Erfassung von Bezugnahmen auf das Altsein oder Jungsein ermöglicht.

\section{Soziale Kategorie und soziale Referenz}

Als wichtigste Form der Bezugnahme auf soziale Kategorien können 'soziale Referenzen' angeführt werden. Als soziale Referenz gelten Formen der Bezugnahme auf soziale Einheiten. Dadurch wird die Kategorie einerseits benannt, andererseits werden durch soziale Referenzen Eigenschaften dieser sozialen Einheiten verdeutlicht. Kallmeyer $(1994,25)$ bezeichnet als „grammatisches Kernstück der sozialen Referenz" die Verfahren der Deixis, primär der personalen Deixis (ich/wir - die anderen) sowie die lokale und temporale Deixis (hier-dort-früher). Sprachlich werden soziale Kategorisierungen also vor allem durch Personenbezeichnungen realisiert, aber durch andere Formen der Deixis ergänzt. Aus dieser Sicht hat der Gebrauch von Personenbezeichnungen, die als soziale Kategorien identifizierbar sind, 'primär referentielle Funktion' (Drescher \& Dausenschön-Gay 1995, 85). Die sprachlichen Mittel, die in Betracht kommen, um Personen als Vertreter sozialer Gruppen zu kategorisieren, sind entsprechend größtenteils als personale Referenz zu erfassen (Quasthoff 1984). 
Ohne an dieser Stelle eine genauere Diskussion führen zu können, seien einige Anmerkungen zur Referenzlinguistik angefügt. Referenzlinguistik befaßt sich, ganz allgemein zusammengefaßt, „mit den Bezügen sprachlicher Ausdrücke auf außersprachliches" (Vater 1992, 109). Daß es mit dieser Charakterisierung nicht getan ist, zeigt nicht nur die nahezu unüberschaubare Anzahl der Arbeiten zu Referenz und Referenz in Texten, ${ }^{5}$ sondern auch die „terminologische Unklarheit“ (v. Polenz 1985) in Bezug auf den Begriff der Referenz. Die terminologische Unklarheit betrifft die Tatsache, daß das Verb 'referieren' häufig nicht als Handlungsverb im Sinne der Beschreibung der Handlungen eines/r Sprecher/in verwendet wird, sondern als Aussage über sprachliche Ausdrücke, z.B. 'dieses Wort referiert auf $x$ '. Von mir wird referieren jedoch als sprachliches Handeln verstanden, durch das ein Sprecher/eine Sprecherin mithilfe eines oder mehrerer sprachlicher Ausdrücke auf einen bestimmten Gegenstand (bzw. Person) Bezug nimmt: „Wenn jemand referiert, vollzieht er oder sie eine sprachliche Handlung, die von andern verstanden, bewertet oder nachvollzogen werden kann. Aus dieser Sicht kann Referieren als Handlungsmuster aufgefasst werden" (Wimmer 1979, 9).

Die Frage nach Altersreferenzen, d.h in welcher Form auf Alter referiert werden kann, bildet den Schwerpunkt der nachstehenden Analysen. Besonders herausgehoben werden personale und temporale Referenzen, durch die explizite und implizite Verweise auf das eigene Alter, das der Partnerin und das Dritter vollzogen werden, die zu einer interaktiven Relevanzsetzung der Kategorie 'Alter' führen.

\section{Das Gesprächsmaterial}

Grundlage der Analysen sind Gesprächsmitschnitte von 14 Dialogen zwischen jeweils zwei älteren Frauen, die im Rahmen eines größeren Forschungsprojektes zu 'Partnerhypothesen und soziale Identität in Konversationen' erhoben wurden. ${ }^{6}$ Die Gespräche fanden in einer Volkshochschule mit einer angegliederten Bildungseinrichtung für Ältere statt. Die Angebote dieser Einrichtung sind für Personen über 60 Jahre kostenlos und erfreuen sich aufgrund ihres hohen Niveaus großer Beliebtheit. Die Teilnehmerinnnen waren über Aushänge und Anzeigen geworben worden und hatten die Information erhalten, daß der 'Alltag von Frauen' Gegenstand der Untersuchung sei. Das Alter der Sprecherinnen variierte zwischen 60 und 86 Jahren, sie erhielten keine spezifizierte Aufgabe, sondern nur die Aufforderung, 'einander kennenzulernen'. Die Versuchsleiterinnen informierten die Teilnehmerinnen über den Ablauf und betraten den Raum erst wieder, um das Gespräch nach ca. 10 Min. zu beenden.

Im Anschluß an das Gespräch wurde mit jeder Teilnehmerin ein Nachinterviewgeführt. Die Auswertung dieser Nachgespräche zeigt, daß die Aufnahmesituation von den meisten Beteiligten als unproblematisch empfunden wurde. Obwohl sich die Gespräche als 'inszeniert' bezeichnen lassen, verliefen sie zumeist in angeregter und lebhafter Atmosphäre. Die Gespräche wurden anhand einer speziell für die Er-

5 Genauer dazu Ehrich (1992), v. Polenz (1985), Vater (1992), Wiegand (1996), Wimmer (1979).

6 Ich danke der Deutschen Forschungsgemeinschaft für die Förderung unserer Arbeiten im Sonderforschungsbereich 245 'Sprache und Situation' (Heidelberg/Mannheim) und E. Hicks, I. Hub, R. Jakob, A. Kolz, S. Maier, U. Rademacher, A. Wagner \& C. Wagner für ihre Mithilfe bei Durchführung und Auswertung der Studie. 
fassung altersspezifischer Kommunikation entwickelten Transkriptionsmethode verschriftlicht (Neubauer, Hub \& Thimm 1994, s. Anhang).

\section{Altersreferenzen in dialogischer Interaktion unter Älteren}

In den nachstehenden Ausführungen werden diejenigen Bezugnahmen auf das höhere Erwachsenenalter (Altersreferenzen) besonders herausgearbeitet, die sich im Funktionszusammenhang der jeweiligen Dialoge als Selbstkategorisierung, Partnerkategorisierung oder Fremdkategorisierung bestimmen lassen. Neben der grammatisch-lexikalischen Ebene werden damit auch die interaktiven Funktionen angesprochen, die mit solchen Kategorisierungsverfahren verbunden sind. Es ist die Einbeziehung dieser funktionalen Aspekte, die einen Einblick in die kommunikativ vermittelten Identitätsprobleme im höheren Alter eröffnet.

\subsection{Personale Referenzen}

Personale Referenz kann mit Hilfe von Nomina und Pronomina, aber auch mit Hilfe von Namensnennungen erfolgen. Sacks \& Schegloff (1978) postulieren zwei Präferenzen in der Domäne der personalen Referenz, einerseits die Tendenz, personale Referenz möglichst mit Hilfe einer einzigen Referenzform zu realisieren ('Minimisierung'), andererseits eine Orientierung am Empfänger ('recipient design'), die den Gebrauch von erkennbaren Referenzformen ('recognitials') bedingt. Als erkennbare Referenzformen sind vor allem Namen zu nennen, da diese insofern prototypische Referenzformen sind, als sie gleichzeitig minimisierte Referenzen darstellen.

Pronominale Anredeformen für singuläre Adressaten unterscheiden sich im zweielementigen Anredesystem des Deutschen in 'du' und 'Sie'. Der Anrede mit 'du' kommt einerseits die Bedeutung von Vertrautheit oder Intimität zu und ist unter Jüngeren als Normalform der Anrede anzusehen. 'Du' kann in anderen sozialen Kontexten auch herablassend sein bzw. als Zeichen der Verachtung fungieren, ${ }^{7}$ 'Sie' gilt dagegen als Ausdruck von Distanz und Höflichkeit. Bemerkenswert ist, daß pronominale Anredeformen situativ variiert werden können, die Bedeutung kann also erst aus dem jeweiligen Kontext erschlossen werden (Hartmann 1973).

In der überwiegenden Anzahl der Gespräche herrscht als Anredeform das höfliche 'Sie' und die Nennung des Nachnamens vor. In einem Gespräch fand jedoch eine explizite Aushandlung über die Anredeformen statt, die in einer Einigung auf dem 'Du' endete. Der folgende Gesprächsausschnitt macht deutlich, daß es das Gefühl der Zugehörigkeit zu einer gemeinsamen sozialen Kategorie (der gleichen Altersgruppe) ist, das den Sprecherinnen das 'Du' nahelegt:

Ausschnitt 1 (Gespräch a21/22); [A=63 Jahre, B=62 Jahre $]$

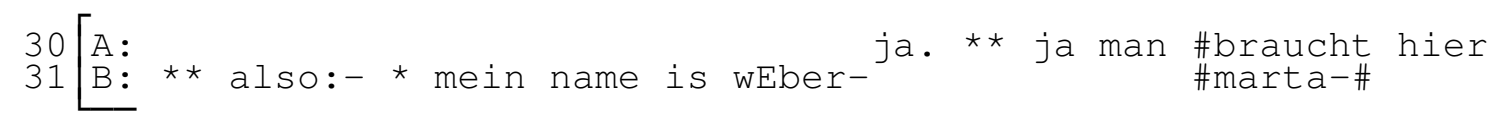

7 Wie z.B. beim 'foreigner talk' (Hinnenkamp 1989). 


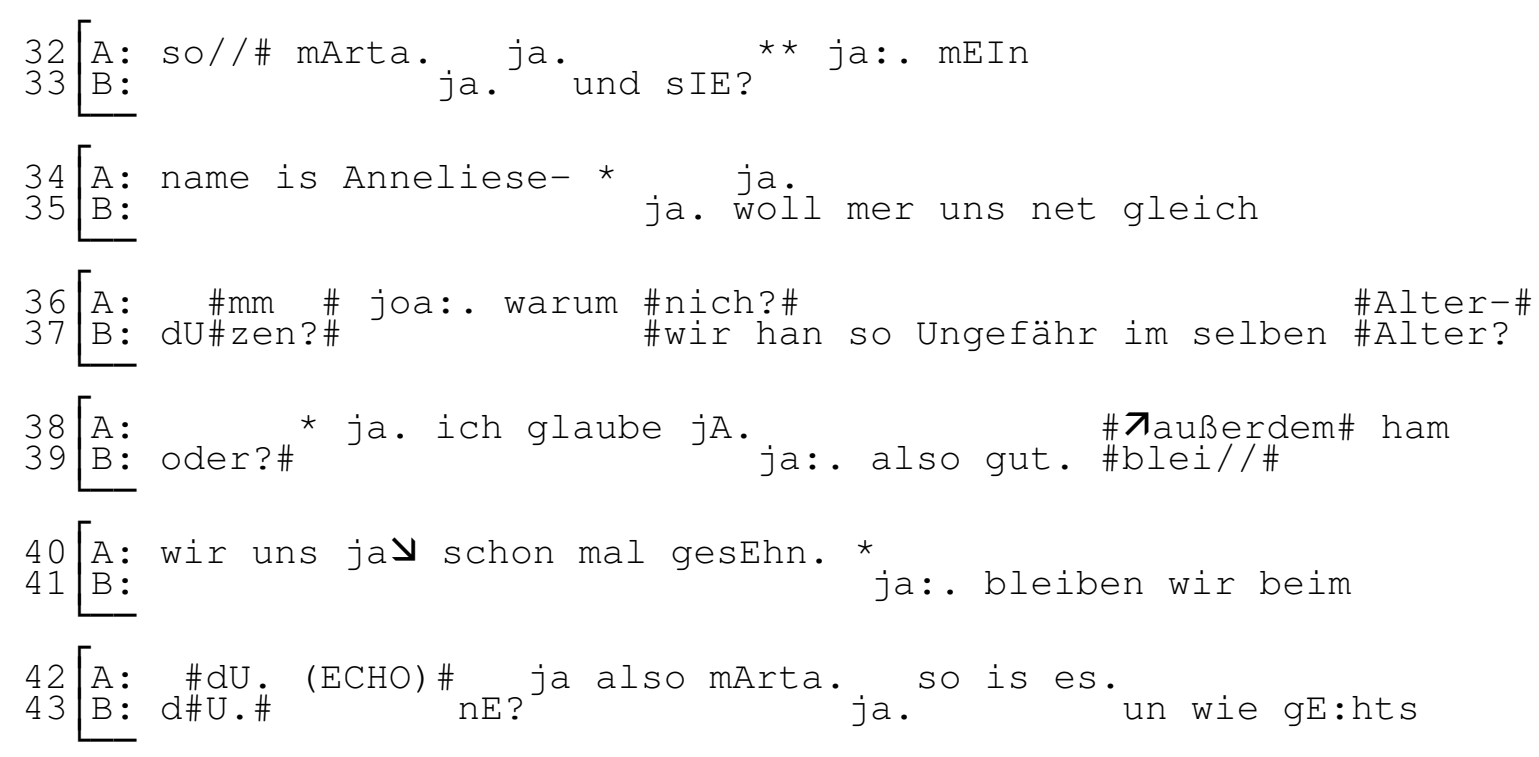

Dieser Gesprächsausschnitt zeigt auf sehr anschauliche Weise, wie einerseits zunächst die formale Anredeform und die Namensnennung eingehalten wird (wobei interessanterweise zuerst der Name und dann der Vorname genannt wird), dann aber die Erkenntnis, zur gleichen sozialen Kategorie zu gehören ('ungefähr im selben Alter') und sich zumindest schon einmal begegnet zu sein, zu einer durch die pronominale Anredeform sprachlich explizierten Symbolisierung von Nähe führt. Dieser Ausschnitt gibt einen ersten Hinweis auf die solidarisierende Funktion der Verwendung der Kategorienbezeichnung. Das Sprechen über Alter und der Bezug zum Altsein als Kategorie beinhaltet die Möglichkeit, Altsein als etwas Gemeinsames $\mathrm{zu}$ identifizieren und thematische Interessen daraus abzuleiten.

Einer vorbehaltslosen Identifizierung mit dem eigenen Altsein stehen jedoch verschiedene Hindernisse entgegen. Zu nennen sind hier sowohl das negative gesellschaftliche Bild vom Alter und stereotype Einstellungen zu älteren Menschen (Lehr \& Niederfranke 1991; Tews 1991), aber auch die negativen Einstellungen älterer Menschen selbst zum Alter: Alt sind immer nur die Andern, nie man selbst (Rothermund, Wentura \& Brandstädter 1995).

Die Komplexität der Identifizierung mit dem eigenen Alter wird in den Texten an zwei Verfahren ersichtlich. Einerseits solidarisiert man sich mit bestimmten Facetten des Altseins und konstituiert das Alter als eine Gemeinsamkeit, die thematische Anknüpfungspunkte eröffnet. Andererseits wird in vielen Gesprächen eine Outgroup 'Alte' etabliert, der devaluative Altersattribute zugeordnet werden. Bei der sprachlichen Realisierung dieser Identifikationen und Abgrenzungen kommt dem Personalpronomen 'wir' eine wichtige Funktion zu. Mit 'wir' wird nicht nur auf präsente Bezugspersonen, sondern auch auf Abwesende referiert, dies kann sich u.a. in der polarisierenden Form des 'wir und die anderen' ausdrücken (Kallmeyer 1989).

Zunächst ein Beispiel, in dem die gemeinsamkeitssymbolisierende Funktion des Personalpronomens 'wir' ersichtlich wird:

Ausschnitt 2 (Gespräch a41/42); [A=73 Jahre, B=65 Jahre $]$

237 A: was diel was die frau weber (=OBERBÜRGERMEISTERIN) hier 


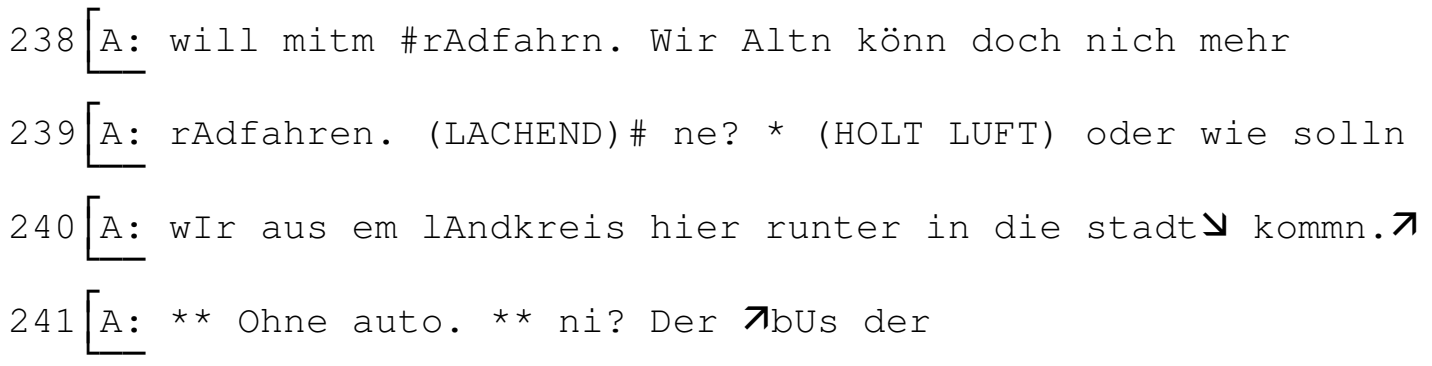

In diesem Ausschnitt wird das 'wir' durch die Kategorienbezeichnung ergänzt. Dabei wird das Gemeinsame des Alt-Seins anhand eines Defizites expliziert: 'wir Alten können doch nicht mehr radfahren'. Die Kategorie wird appellativ verwendet und fungiert als Teil der indirekten Aufforderung an die Gesprächspartnerin, dazu Stellung zu nehmen. Eindrücklich an dieser Altersreferenz ist die Aussage über den Verlust der Fähigkeit zum Radfahren, ein Defizit, das als typisches Charakteristikum der Gesamtgruppe 'Alte' formuliert wird. Die verbale Konstruktion mit einer Negation weist darauf hin, daß es nicht um die Zuweisung einer kategoriengebundenen Aktivität, sondern um die Zuweisung eines Aktivitätsdefizits geht. Eine solche Defizitperspektive erscheint bezüglich der linguistischen Beschreibung sozialen Kategorisierens als wichtige Ergänzung. Sollte sich nämlich zeigen, daß die soziale Kategorie Alter (oder auch andere soziale Kategorien) nicht über kategoriengebundene Aktivitäten, sondern über Aktivitätsdefizite ausgezeichnet ist, so könnte dies als Differenzierungsmerkmal zu anderen Kategorien herangezogen werden.

Eine weitere Form der Selbstkategorisierung kann durch Hinzufügen anderer Kategorien erfolgen. So z.B. im nächsten Ausschnitt, in dem die Kategorie 'Alter' durch die Ergänzung um die Geschlechterkategorie präzisiert wird:

Ausschnitt 3 (Gespräch a43/44); [A=60 Jahre, B=61 Jahre]

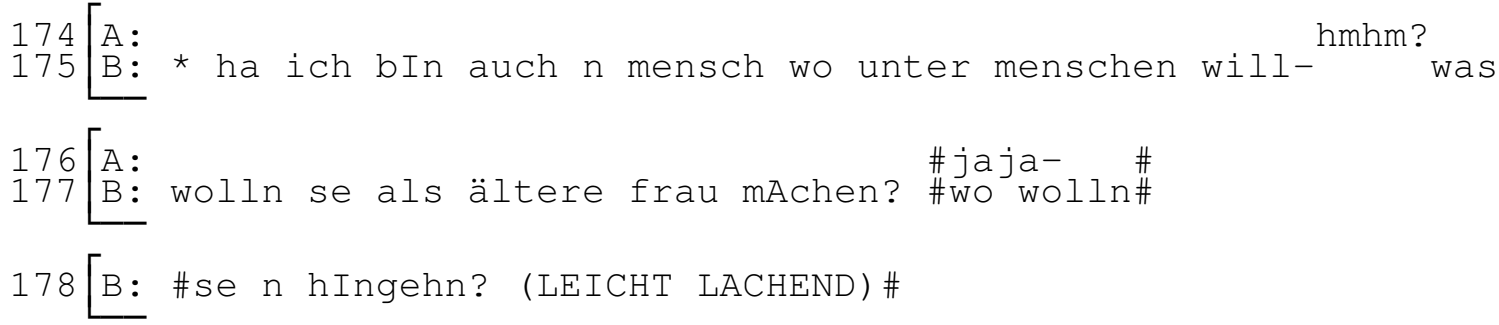

Hier findet eine doppelte Selbstkategorisierung statt. Argumentativ wird damit die zweifache Benachteiligung aufgrund der Zugehörigkeit zu zwei stigmatisierten sozialen Gruppen (alt und weiblich) angesprochen. Da ihre Gesprächspartnerin ebenfalls in die solchermaßen markierte Gruppe gehört, läßt sich die Solidarisierung hier als implizit realisiert ansehen.

Während bei Ausschnitt 2 und 3 trotz der Negation von Kompetenz bzw. der Unterstellung von Nachteilen eine solidarisierende Identifikation mit der 'Wir-Gruppe der Alten' ersichtlich wird, zeigen die nächsten Ausschnitte Beispiele für den großen Abgrenzungsbedarf vom Alter. Zunächst ein Beispiel, in dem die Distanz vor allem über den Gebrauch der Kategorienbezeichnungen realisiert wird: 
Ausschnitt 4 (Gespräch a59/60); [A=67 Jahre, B=60 Jahre]

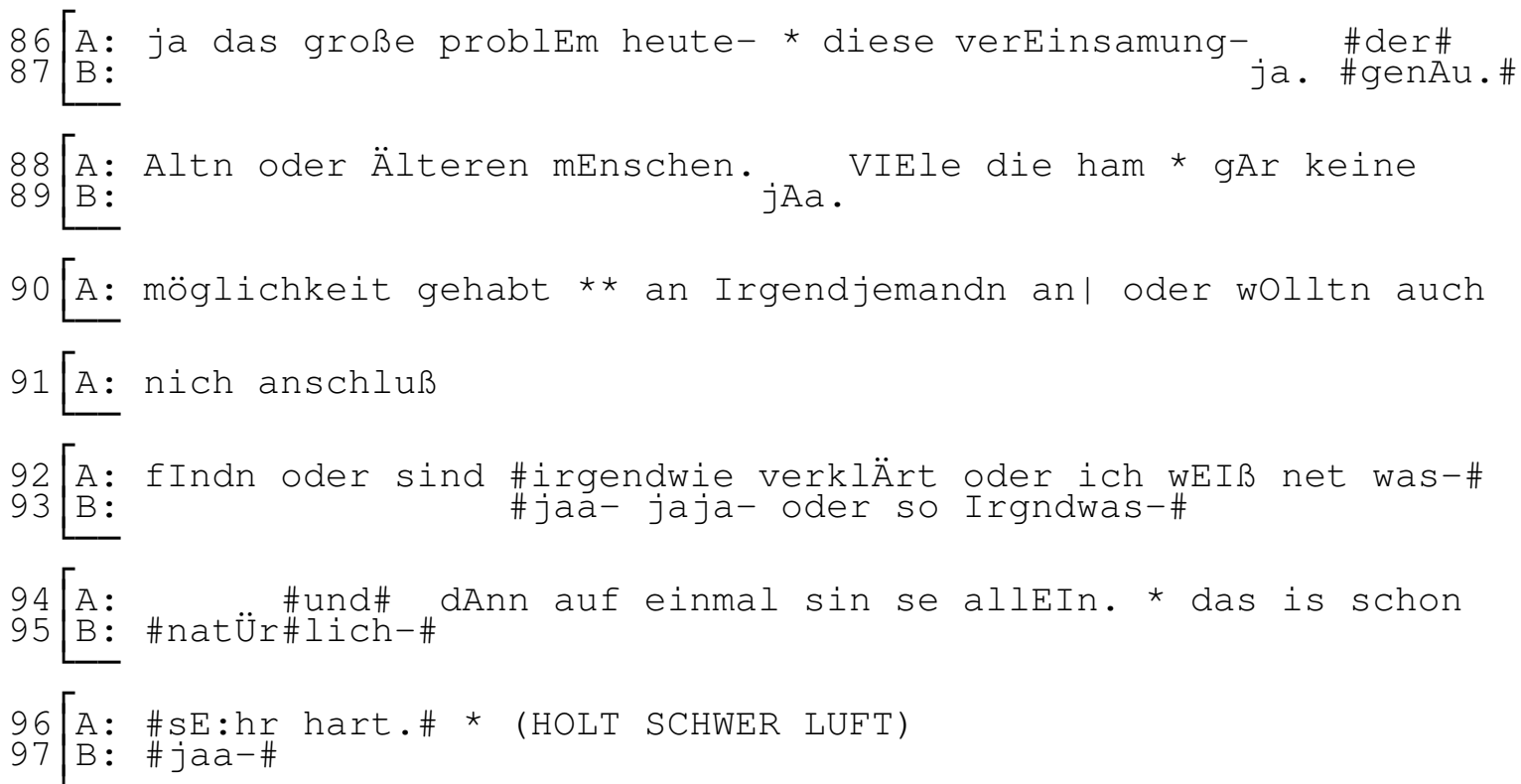

In diesem Text finden sich zwei adjektische Ergänzungen bei der Bezugnahme auf die Kategorie: die Kategorienbezeichnungen 'die alten Menschen' und die abgeschwächte Form 'ältere Menschen'. Nach der Relevanzsetzung durch den Gebrauch der Kategorienbezeichnungen erfolgt - wie im folgenden auch an anderen Textstellen zu zeigen sein wird - die Charakterisierung dieser Gruppe mithilfe kategoriengebundener Aktivitätsdefizite und altersstereotyper Eigenschaften. Sie weist ihnen ein 'großes Problem' ('diese Vereinsamung') und als Aktivitätsdefizit den Mangel an Kontakt zu. Zusätzlich wird diese Gruppe als 'irgendwie verklärt' charakterisiert und damit eine psychologisierende Abwertung realisiert. Ohne es mit einer expliziten Altersdistanzierung zu verbinden, gelingt es der Sprecherin durch dieses Verfahren, sich von den 'vereinsamten Alten' und sogar von den 'älteren Menschen' generell zu distanzieren. Ihre Gesprächspartnerin stimmt in diese Distanzierung ein, so daß durch die Abgrenzung von einer negativ beschriebenen Gruppe Gemeinsamkeit zwischen den Sprecherinnen hergestellt wird.

Solchermaßen positive Selbstkategorisierung mithilfe verschiedener Formen der Abgrenzung vom Alter bzw. von alten Personen ist eine der zentralen Funktionen der Altersreferenzen in diesen Dialogen. Die personale Referenz fungiert dabei als Fremdkategorisierung, d.h. es erfolgt eine sprachliche Etikettierung einer Gruppe als Outgroup, von der man sich dann positiv abgrenzen kann. Eine ähnliche Form der Distanzierung findet sich in Ausschnitt 5. Hier wird allerdings durch eine abweichende personale Referenz auf die 'Achzigjährigen' eine Binnendifferenzierung eingeführt:

Ausschnitt 5 (Gespräch a41/42); [A=73 Jahre, B=65 Jahre]

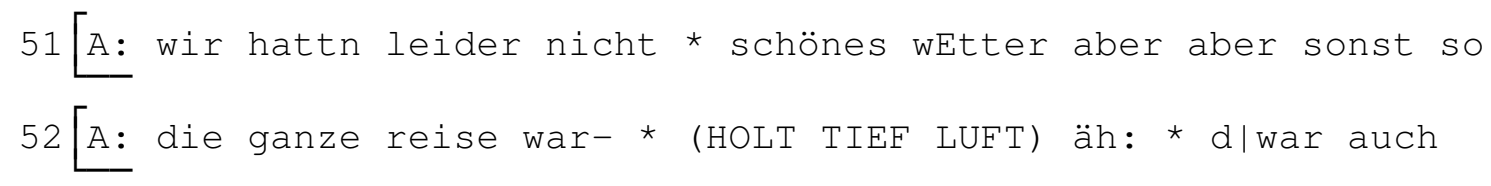




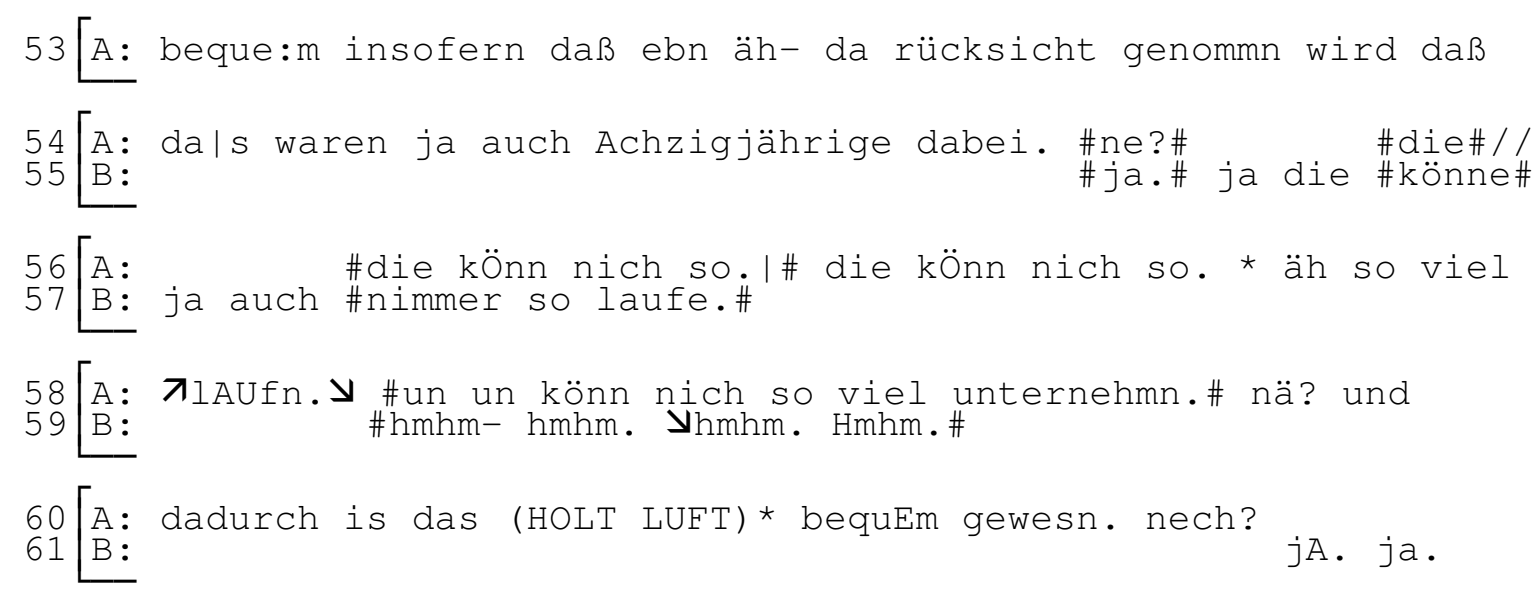

Die Beschreibung von 80-jährigen als generell in ihrer Bewegungsfähigkeit eingeschränkt reflektiert implizit auf die eigenen besseren Möglichkeiten der Fortbewegung und fungiert somit als Abgrenzung von der Gruppe der beeinträchtigten Älteren. Diese Form der Distanzierung erfolgt nach dem Muster 'wir und die anderen' und wird von B unterstützt. Sie ergänzt zustimmend anhand eines Einschubs (bei Z. 55) ein weiteres Defizit ('die könne ja auch nimmer so laufe'). Die Referenz auf die Kategorie wird über die referentielle Nominalphrase ('Achzigjährige') realisiert, die mittels der Altersangabe eine spezifische Untergruppe konstituiert. Diese Form der Bezugnahme möchte ich als Subkategorisierung bezeichnen. Durch die Benennung als 'Achzigjährige' wird eine fest umrissene Subgruppe innerhalb der Kategorie 'alte Menschen' gebildet und mithilfe von Aktivitätsdefiziten gekennzeichnet, die im Gespräch von beiden Sprecherinnen als 'typisch' für diese Subkategorie markiert werden.

Verschiedene Formen der Subkategorisierung bilden eine häufig gewählte Form der Distanzierung vom Altsein. Der folgende Ausschnitt zeigt, wie flexibel solche Kategorienbezüge zwischen 'wir' und 'die anderen' gehandhabt werden können:

Ausschnitt 6 (Gespräch a15/16); [A=66 Jahre, B= 67 Jahre]

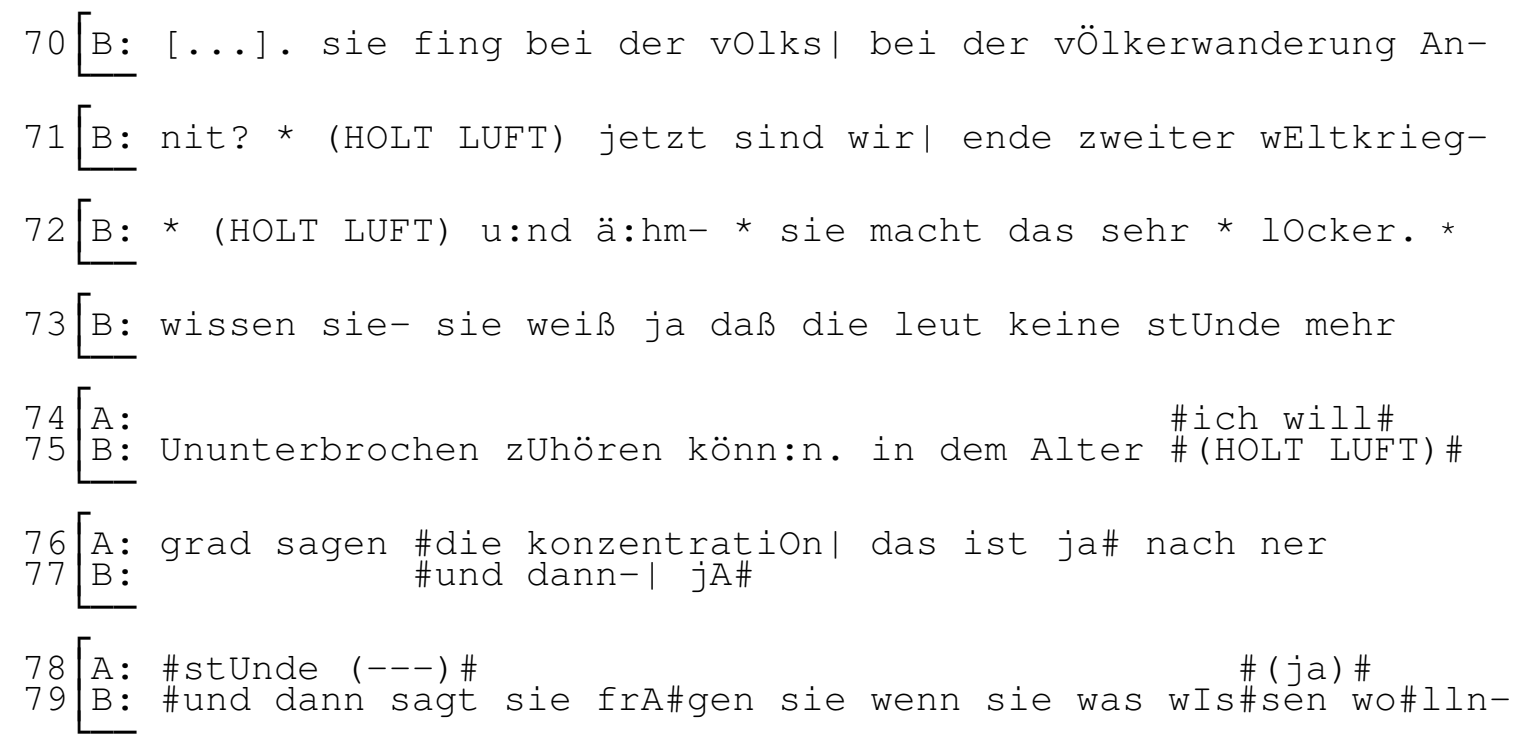




$$
\begin{aligned}
& 80[\mathrm{~B}: 0: \text { der- * Eigene erlEbnisse können jetzt grad in der } \\
& 81[\mathrm{~A}: \#(---) \# \\
& 82 \text { B: \#nEuern zeit mit\# Eingebracht werden-* (HOLT LUFT) עes Ufert } \\
& \text { 83 B: manchmal Aus gell? } \text { A A:ber sie versteht das dann immer wieder } \\
& 84 \text { B : ähm- * }
\end{aligned}
$$

Die Sprecherin B erzählt von einem Geschichtsseminar, das sie an der Altenakademie belegt hat. In die Schilderung der Kompetenzen der Seminarleiterin ('sie macht das sehr locker') fließt eine Darstellung der Teilnehmergruppe als eingeschränkt kompetent ein. Dabei wechselt Sprecherin B innerhalb eines einzigen Satzes die Perspektiven: Das auf die Gruppe der Teilnehmerlnnen an dem Geschichtskurs bezogene 'wir' steht kontrastiv neben der Gruppe der 'Alten', die mit einer distanzierenden Nominalphrase mit definitem Artikel ('die Leut') charakterisiert wird. Auch die Sprecherin selbst ist Mitglied der erstgenannten Gruppe (der TeilnehmerInnen an dem Geschichtskurs), kann sich aber trotzdem mithilfe der Kategorienbezeichnung 'die alten Leut' von diesen distanzieren. Der Gruppe der 'Leut in dem Alter' werden zwei Defizite zugewiesen. Sie können nicht mehr zuhören und sind daran beteiligt, daß es 'manchmal ausufert', eine Anspielung auf die Redseligkeit der Personen innerhalb der Referenzgruppe. Auch hier wird die Zuweisung der Defizite von beiden Sprecherinnen konsensuell vorgenommen. Die Gesprächspartnerin A setzt bei Z. 74 mit einer Ergänzung ein und führt mangelnde Konzentrationsfähigkeit als Defizit an. Dieser Textausschnitt bestätigt die These von Kallmeyer \& Keim (1994), daß es eine Frage der Perspektivität ist, wie die Bezugnahme auf die jeweilige Kategorie geregelt ist.

Neben den Abgrenzungen durch Subkategorisierungen finden sich auch Distanzierungen von der Altersgruppe der Jungen. Während die Subkategorie der 'inkompetenten Alten' dazu dient, sich von ihr positiv abzusetzen und damit eine positive Altersidentität aufzubauen, werden im selben Gespräch die 'Jungen' zum regelrechten Feindbild stilisiert:

Ausschnitt 7 (Gespräch a1516); [A=66 Jahre, B=67 Jahre]

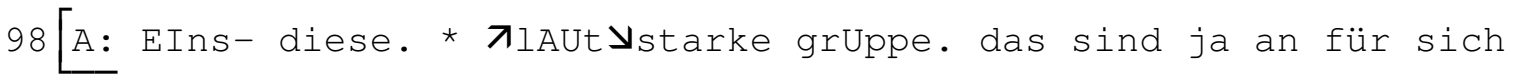

$$
\begin{aligned}
& \begin{aligned}
99 & {\left[\begin{array}{l}
\text { A: } \\
\text { B: }
\end{array}\right.} \\
& \text { denige. }
\end{aligned}
\end{aligned}
$$

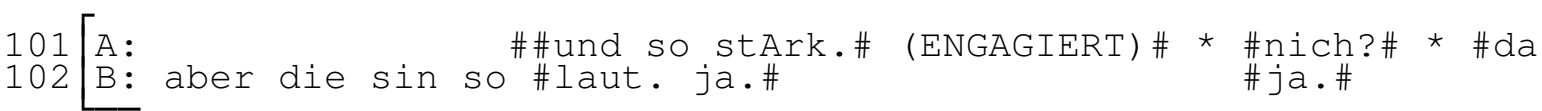

$$
\begin{aligned}
& 103 \text { A: wEIB ich nich ob des nich n fehler von Uns Ältren is:- * sich } \\
& 104[\mathrm{~A} \text { : so zurÜckzuziehn und zu sagn * wir mAchn nichts. nicht? }
\end{aligned}
$$

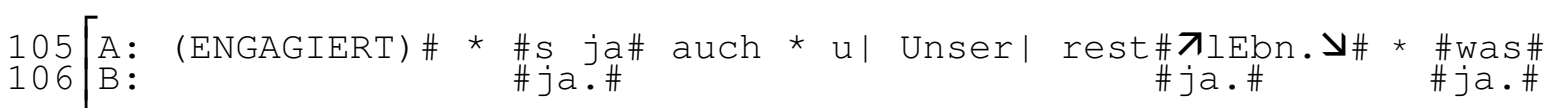




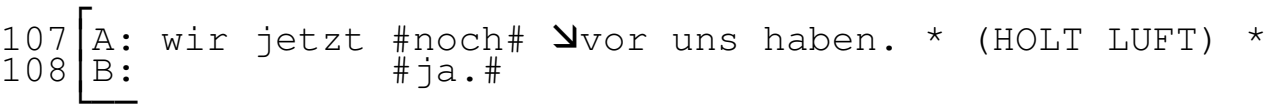

$109[$ A: \#Уnaja.\# wir kö\#nn| jetz//\#

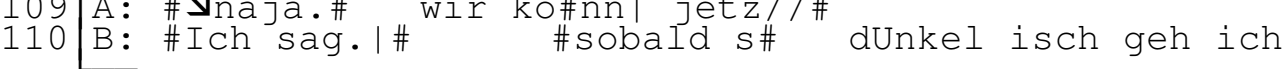

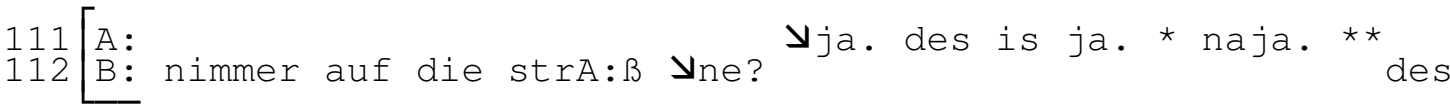

Die Outgroup wird hier zwar nicht explizit mit der Kategorienbezeichnung genannt, aber aus der Zuweisung der Aktivitäten und Eigenschaften wird deutlich, daß eine andere Altersgruppe gemeint ist. Die Gruppe der Älteren wird als Ingroup markiert ('uns Älteren', Z. 103), während die lautstarke Gruppe als bedrohliche Outgroup gekennzeichnet wird. Einhergehend mit dieser konversationellen Etablierung eines antagonistischen Verhältnisses zwischen Alt und Jung erfolgt eine explizite Selbstkritik als 'zu passiv'. Diese Kritik an 'uns Älteren' wird argumentativ über die lexikalisch ungewöhnliche Bezeichnung des 'Restlebens' untermauert. Zwar wird mithilfe dieser Äußerung ein Argument auf Teilhabe am Leben formuliert, andererseits macht diese Formulierung das Alter zu einem nicht vollwertigen Anhängsel an das 'richtige Leben' und reflektiert eine ambivalente Einstellung zum eigenen Alter.

Neben den angeführten Verfahren der expliziten Kategorisierung und Distanzierung von der Gesamtgruppe der Alten oder lexikalisch spezifizierten Subgruppen, lassen sich auch weniger explizite Möglichkeiten nachweisen, sich von einer als negativ charakterisierten Gruppe von Alten positiv abzusetzen. Wie über lexikalische Markiertheit eine implizite Abgrenzung von der Gruppe der Älteren realisiert werden kannn, zeigt sich in Beispiel 8 anhand der Verwendungsweise von 'Altenpflege' und 'Altersheim':

Ausschnitt 8 (Gespräch a43/44); [A=60 Jahre , B=61 Jahre]

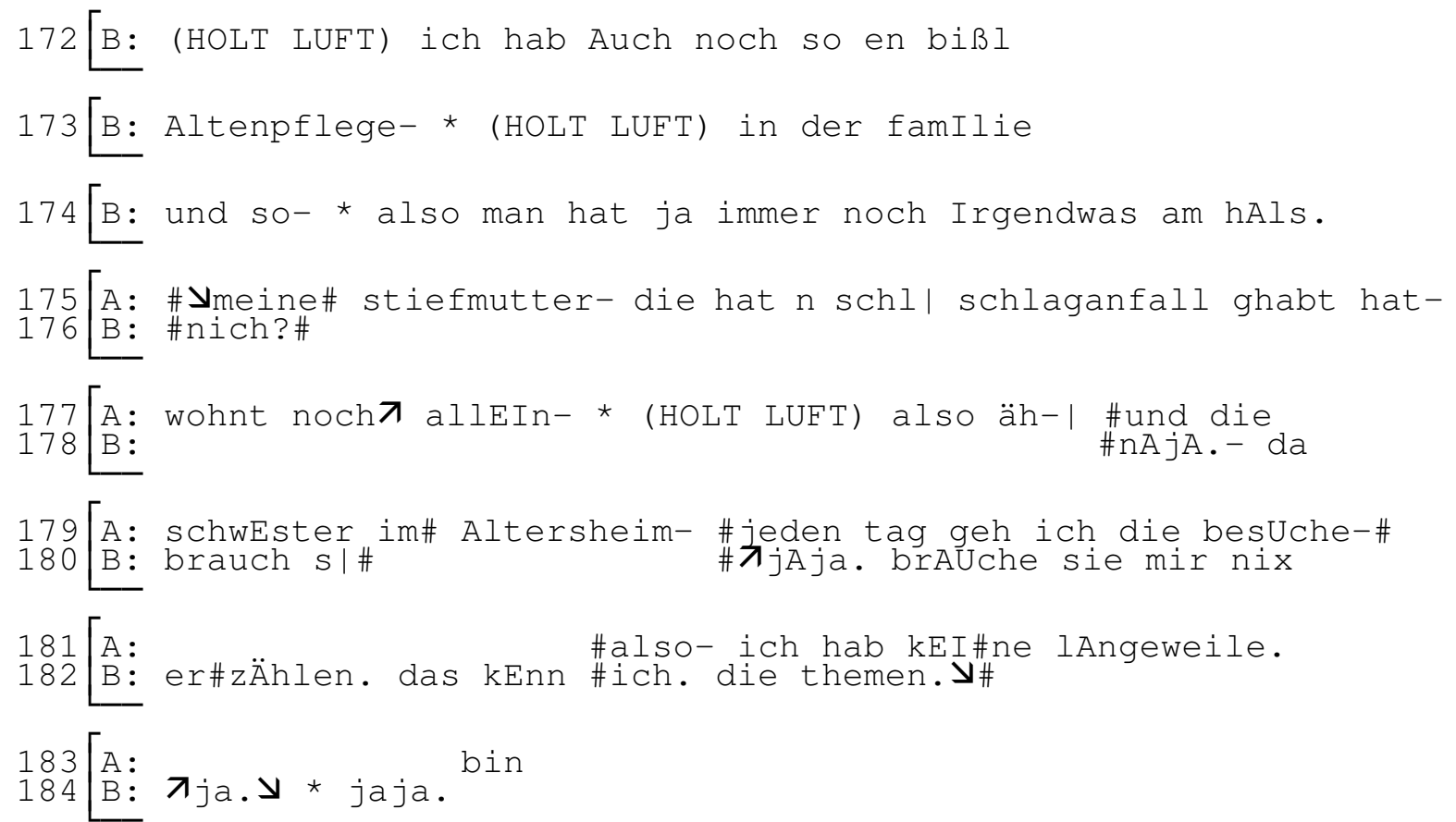


Als Distanzierung von 'den Alten' wird in diesem Ausschnitt keine explizite Markierung einer Subkategorie gewählt, sondern eine weniger explizite Form. Hatte sich die Sprecherin B mit ihrer Äußerung ('ich hab auch noch so en bißl Altenpflege') indirekt durch diese Aktivität von den pflegebedürftigen Alten distanziert, so kann Sprecherin A nicht zurückstehen und verweist ebenfalls auf weniger kompetente Personen in ihrem familiären Umfeld. Sie beginnt mit personalen Referenzen (Stiefmutter/Schwester) und präzisiert die Hinfälligkeit der Personen durch einen Hinweis auf eine Erkrankung (Schlaganfall) bzw. durch die Notwendigkeit eines Altersheimaufenthaltes. Dies geschieht bei gleichzeitiger Betonung der eigenen Aktivität ('jeden Tag geh ich die besuchen'). Beide Sprecherinnen grenzen sich von hinfälligen Älteren ab und geraten dabei in einen kompetitiven Vergleich der eigenen Leistungsfähigkeit, ohne dies jedoch explizit zu thematisieren. Solche durch lexikalische Referenzen realisierten Verweise auf die Kategorie Alter sind eine komplexe Möglichkeit der Distanzierung von der Subkategorie 'pflegebedürftige Alte'.

\subsection{Zeitreferenzen}

In verschiedenen Arbeiten wurde nachgewiesen, daß Bezugnahmen auf temporale Aspekte in Gesprächen zwischen Alt und Jung eine gewichtige Rolle spielen und als Hinweise auf 'age contextualisation' zu sehen sind (Coupland, Coupland, Giles, Henwood \& Wieman 1988; Coupland, Coupland \& Giles 1989; Fiehler 1997, Kruse \& Thimm 1997). Nicht nur im Gespräch mit Jüngeren, auch untereinander erweisen sich zeitliche Aspekte als wichtiges Charakteristikum für Gespräche von Älteren.

Um zunächst einen breiten Zugang zur Frage von Zeitbezügen in den Dialogen zu ermöglichen, werden Zeitreferenzen generell als diejenigen sprachlichen Handlungen verstanden, die explizit oder implizit einen zeitlichen Bezug herstellen. Zeitreferenz wird also nicht nur über Tempusmorpheme im Verb ausgedrückt, sondern es geht vielmehr um die thematisch ausgedrückte Referenz auf Zeitlichkeit. Schwerpunkt liegt auf denjenigen Bezugnahmen, die sich als vergangenheitsorientiert bezeichnen lassen. Folgende Formen der Zeitreferenz sollen unterschieden werden:

\section{Numerische Zeitreferenzen:}

- Nennen des numerischen Alters ('Ich werde siebzig').

- Nennen einer Zeitangabe im Kontext biographischen Erzählens ('1942 zogen wir nach H.').

- Nennen von Zeitangaben ohne Bezug zur eigenen Person. ('Im Mai 1945 mußten die alle aus ihren Häusern raus').

\section{Unbestimmte Zeitreferenzen:}

- Historisch-kontextuell determinierte Zeitreferenzen: ('Zur Kaiserzeit', 'während des Krieges').

- Persönlich-kontextualisierte Zeitreferenzen ('Als ich zur Schule ging').

Zeitreferenzen stellten für die älteren Sprecherinnen eine der wichtigsten Formen der Selbstvergewisserung ihrer personalen Identität dar. Besonders Referenzen auf die Vergangenheit ziehen sich wie ein roter Faden durch alle Gespräche. Welche 
Dimensionen der sozialen Kategorie Alter dabei anhand des numerischen Alters entwickelt werden können, zeigt der nachstehende Ausschnitt eines Gesprächsbeginns. Die Sprecherinnen ziehen als Methode der Relevanzsetzung von Alter eine Dichotomisierung heran: Altsein und Jungsein werden kontrastiv nebeneinander gesetzt:

Ausschnitt 9 (Gespräch a41/42); [A=65 Jahre, B=72 Jahre]

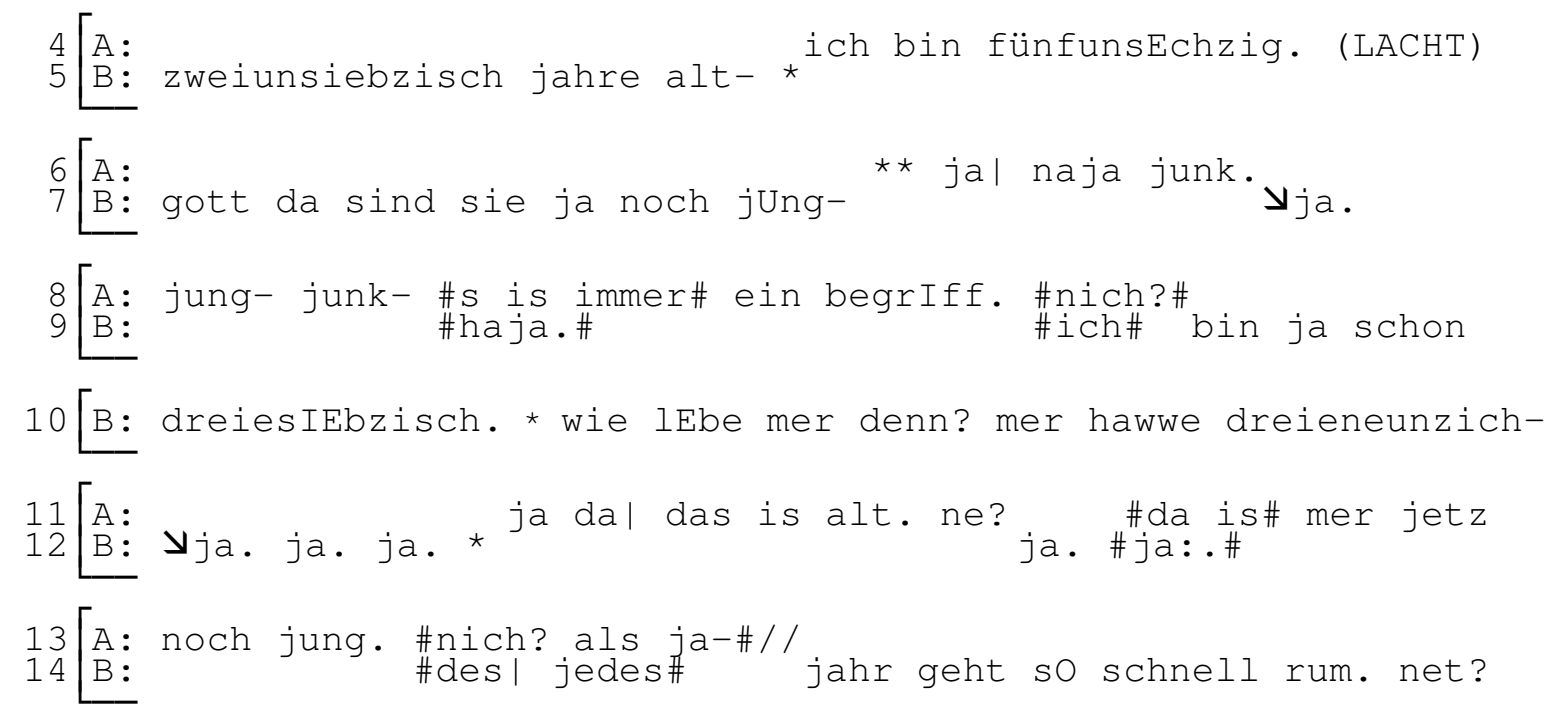

Der Austausch über das numerische Alter zeigt, daß die Altersdifferenz von sieben Jahren spontan als groß empfunden und sogar eine Intergruppensituation postuliert wird (Sie sind jung - ich bin alt), daß jedoch über das Indefinitpronomen 'man' ('da is mer jetz noch jung') wieder ein Ingroupbezug hergestellt wird. Die letzte Zeile (Z. 14) zeigt einen Konsens: die Sprecherinnen sind sich einig, daß die Zeit so schnell vorbeigeht, die Dichotomisierung wird aufgehoben. Das Repertoire an Zeitreferenzen wird in dichter Form gebraucht, es werden sowohl numerische Altersnennung, kalendarische Referenzen (Jahreszahl), als auch allgemeine Zeitreferenzen nebeneinandergestellt (durch das Temporaladverb 'jetzt'). Diese Zeitreferenzen bilden den argumentativen Hintergrund für den Konsens: Die Feststellung 'da is mer jetzt noch jung' verdeutlicht, daß die Kategorien von Altsein und Jungsein von den Sprecherinnen anhand von heute geltenden Altersvorstellungen relativiert werden.

Wie wichtig für die Sprecherinnen das numerische Alter ist, zeigt sich besonders dann, wenn Altersunterschiede relevant gesetzt werden. In Ausschnitt 10 wird deutlich, daß sich die Sprecherinnen nicht in gleichem Maße der Gruppe der Älteren zugehörig fühlen. Expliziert wird dies anhand der Einführung einer zweiten Kategorie ('meine Mutter'), die sich der Kategorienkollektion 'Familie' zurechnen läßt.

Ausschnitt 10 (Gespräch a51/52); [A=62 Jahre, B=86 Jahre]

$173[\mathrm{~B}:$ hm. * solange wie ich: aber meine wohnung hAlten kann möcht
$174[\mathrm{~B}:$ ich natürlich da blelbn. * \#ich bin ja sicher viel ̈̈lter als 


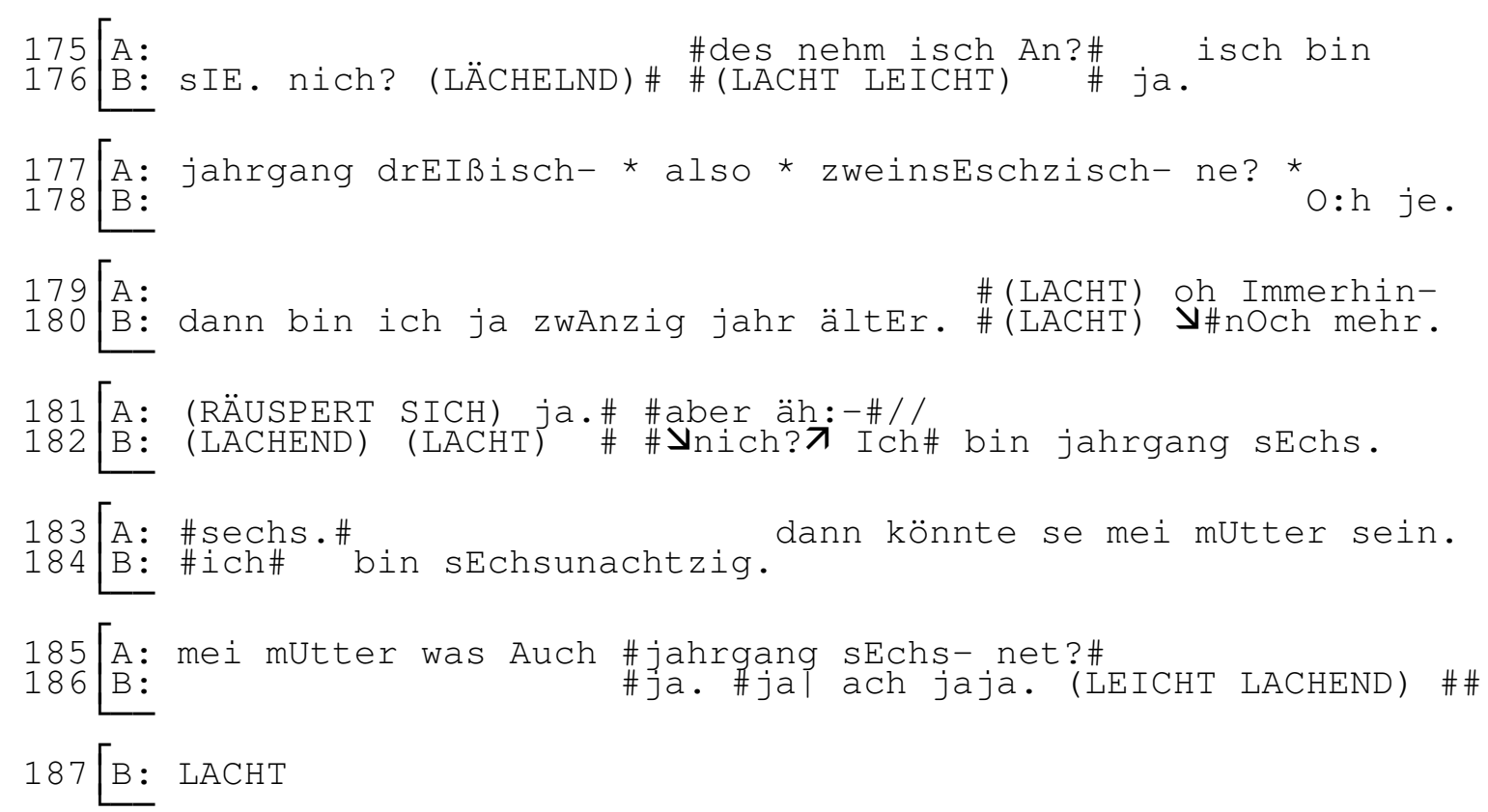

Auch in diesem Transkript findet sich die schon in Ausschnitt 9 nachgewiesene Verdichtung von Zeitreferenzen. Wird zunächst wieder ein genereller Unterschied genannt ('älter als Sie'), so erfolgen die Präzisierungen anhand einer Jahrgangsbezeichnung ('Jahrgang 30'). Es folgt dann, wie um der Partnerin die Rechentätigkeit zu ersparen, die Nennung des numerischen Alters ('also zweinsechzig') und eine vergleichende Äußerung, mit der unter Heranziehung einer Kategorie aus einer anderen Kategorienkollektion eine Distanzierung realisiert wird. Die Verknüpfung von verschiedenen Formen der Zeitreferenz zeigt anschaulich, wie innerhalb dieser Domäne wichtige interaktive Manifestationen des Kategorisierens erfolgen können.

Aufschlußreich ist die Formulierung 'da könnte se mei mutter sein', die explizit auf die hohe Sensibilität für verschiedene Altersgrupppen unter den Älteren selbst verweist. Dies wird auch an den Gesprächsthemen erkenntlich. So hatte die ältere Frau mit dem Verbleiben in der eigenen Wohnung ein Thema angesprochen, von dem sie nicht sicher ist, ob ihre (jüngere) Gesprächspartnerin es in gleicher Weise als Problem empfindet wie sie selbst. Betrachtet man den großen Altersunterschied zwischen $A$ und $B$ von über 20 Jahren, so ist der von B vorgenommene Vergleich mit der Generation ihrer Mutter durchaus zutreffend. Aufschlußreich ist aber, daß sich die Sprecherinnen trotz dieses großen Altersunterschiedes übereinstimmend der Gruppe der Älteren zuordnen und ihre Gesprächsthemen entlang entsprechender Interessengebiete auswählen.

An den Gesprächsausschnitten 9 und 10 wird einerseits ersichtlich, daß das genaue Alter von den Teilnehmerinnen höchst sensibel anhand von numerischen Altersbezügen differenziert wird. Auf der anderen Seite erscheint das Altsein trotz der von den Sprecherinnen thematisierten Unterschiede als eine so starke Gemeinsamkeit, daß sich beide darauf beziehen. Alter kommt in diesen Dialogen die Funktion einer übergeordneten Identitätskategorie zu, durch deren Relevanzsetzung man Gemeinsamkeit konstituieren kann. 


\section{Zusammenfassung}

Als wesentliches Ergebnis läßt sich festhalten, daß nicht nur in der Intergruppenbegegnung von jungen und alten Menschen die Kategorie 'höheres Erwachsenenalter' eine zentrale thematische Rolle spielt (Coupland, Coupland \& Giles 1991; Thimm 1995a,b; 1998), sondern auch unter den Älteren selbst. Referenzen auf das Alter erfolgen anhand unterschiedlicher Referenztypen. Vorherrschend sind Personenund Zeitreferenzen. Mit diesen Beispielen läßt sich eindrücklich belegen, daß die Identifizierung mit dem eigenen Alter flexibel gestaltet wird und nur als perspektivische Sichtweise auf ausgewählte Facetten des Altseins zu erfassen ist. Altsein (und Jungsein) wird in seiner spezifischen Ausprägung und Funktion - als Identifizierungs- oder Abgrenzungsmerkmal - nicht nur in jeder Interation zwischen den Beteiligten jeweils situationsspezifisch konstituiert, sondern es unterliegt perspektivischen Wechseln. So sprechen Coupland, Coupland \& Giles $(1991,68)$ von Alter als einem "token to be manipulated for immediate purposes in the discourse“. Auch betonen sie die Flexibilität bei der Attribuierung mit Alterszuschreibungen, sie gehen davon aus, daß Sprecher/innen nicht als „uniformly old or not old“ anzusehen sind, sondern sich bezüglich einiger Altersaspekte als 'alt' darstellen, um sich dann im nächsten Moment von ungewünschten Attributen zu distanzieren und als Nicht-Kategorienmitglied zu präsentieren. Alter wird also variabel entweder als Ingroupmarker mit dem Ziel einer gemeinsamen und solidarisierenden Kategorisierung gebraucht oder aber durch Subkategorisierungen als Distanzierungsobjekt relevant gesetzt. Dabei kommt der negativen Charakterisierung des Alters bzw. alter Menschen eine selbstwertschützende Funktion zu: Alt und inkompetent will - verständlicherweise - niemand sein. Abgrenzungen von defizitären Aspekten des Alters steht für diese älteren Frauen in direktem Bezug zu den 'wir'-Aussagen eines positiven Entwurfs von Altersidentität. Daß sie allerdings durch ihre offen devaluierenden Bewertungen nicht zu einem besseren Bild vom Alter in der Gesellschaft beitragen, sollte dabei nicht völlig aus dem Auge verloren werden. Wenn Mitglieder einer Kategorie sich solchermaßen negativ von anderen Mitgliedern absetzen müssen, steht die Werthaftigkeit der Gesamtgruppe zur Disposition.

Die Frage, wie die soziale Kategorie 'Alter' in Konversationen relevant gesetzt wird, wurde methodisch anhand von sozialen Referenzen untersucht, die unter der inhaltlich ausgerichteten Rubrik 'Altersreferenzen' zusammengefaßt wurden. Auch wenn dies sicherlich nur ein methodischer Ansatz ist, Kategorisierung und (Stereo-) Typisierung des Alters in ihrer linguistischen Dimension zu erfassen, so darf der Versuch, die sprachlich kommunizierte soziale Welt in ihrer komplexen Auswirkung auf Selbst- und Fremdbild, auf Ingroup- und Outgroupbeziehungen anhand von sprachlichen Bezügen auf soziale Kategorisierungen zu erfassen, als ein vielversprechender Weg angesehen werden.

\section{Literatur}

Bahl, Anke \& Beck, Stefan (1996). Technogene Nähe. Handlungsbedingungen und -optionen computermediierter Kommunikation. In: Tübinger Korrespondenzblatt 46, 38-52.

Braun, Friederike \& Pasero, Ulrike (Hrsg.) (1997). Die kommunikative Konstruktion von Geschlecht. Centaurus: Pfaffenhofen.

Coupland, Nikolas, Coupland, Justine \& Giles, Howard (1991). Language, society and the elderly. Discourse, identity and ageing. Cambridge, Mass.: Blackwell. 
Coupland, Nikolas, Coupland, Justine, Giles, Howard, Henwood, Karen \& Wiemann, John (1988). Elderly self-disclosure: Interactional and intergroup issues. In: Language and Communication 8(2), 109-133.

Coupland, Nikolas, Coupland, Justine \& Giles, Howard (1989). Telling age in later life: identity and face implications. In: Text, 9(2), 129-151.

Czyzewski, Marek, Drescher, Martina, Gülich, Elisabeth \& Hausendorf, Heiko (1995). Selbst- und Fremdbilder im Gespräch. Theoretische und methodologische Aspekte. In: Czyzewski, M., Gülich, E., Hausendorf, H. \& Kastner, M. (Hrsg.), Nationale Selbst- und Fremdbilder im Gespräch. Opladen: Westdeutscher Verlag, 11-84.

Daum, Martin (1982). The preference for age-homogeneous vs. age-heterogeneous social interaction. In: Journal of Gerontological Work 4, 247-262.

Drescher, Martina \& Dausendschön-Gay, Ulrich (1995). 'sin wer an son immobilienmakler da eh gekommen.' Zum sprachlichen Umgang mit sozialen Kategorien im Gespräch. In: Czyzewski, M., Gülich, E., Hausendorf, H. \& Kastner, M. (Hrsg.), Nationale Selbst- und Fremdbilder im Gespräch. Opladen: Westdeutscher Verlag, 85-119.

Ehrich, Veronika (1992). Hier und Jetzt. Studien zur propositionalen und temporalen Deixis. Niemeyer: Tübingen.

Emery, Olga B. (1986). Linguistic decreement in normal aging. In: Language and Communication 6(1/2), 47-64.

Fiehler, Reinhard (1997). Kommunikation im Alter und ihre sprachwissenschaftliche Analyse. Gibt es einen Kommunikationsstil des Alters? In: Selting, M. \& Sandig, B. (Hrsg.), Sprech- und Gesprächsstile. Berlin/New York: de Gruyter, 345-370.

Fiehler, Reinhard (1996). Die Linguistik und das Alter. In: Sprachreport 1, 1-3.

Goffman, Erving (1992). Stigma. Über die Techniken der Bewältigung beschädigter Identität. Frankfurt: Suhrkamp.

Gutfleisch-Rieck, Ingrid, Klein, Wolfgang, Speck, Agnes \& Spranz-Fogasy, Thomas (1989). Transkriptionsvereinbarungen für den Sonderforschungsbereich 245. Arbeiten aus dem Sonderforschungsbereich 245 'Sprechen und Sprachverstehen im sozialen Kontext', Heidelberg/Mannheim, Bericht Nr. 14. Heidelberg: Psychologisches Insitut.

Hartmann, Dietrich (1973). begrüssungen und begrüssungsrituale. In: Zeitschrift für germanistische Linguistik 1.2, 133-162.

Hausendorf, Heiko (1994). Das Eigene und das Fremde. Soziale Kategorisierungen unter Anwesenden. In: Zentrum für interdisziplinäre Forschung, Jahresbericht 92/93. Universität Bielefeld, 5589.

Hinnenkamp, Volker (1989). Interaktionale Soziolinguistik und interkulturelle Kommunikation. Gesprächsmanagement zwischen Deutschen und Türken. Tübingen: Niemeyer.

Hummert, Mary Lee, Nussbaum, John \& Wieman, John (eds.) (1994). Interpersonal communication in older adulthood. Tousand Oaks: Sage.

Kallmeyer, Werner (1989). Wir und die Anderen: Sprachliche Symbolisierung sozialer Identität und soziale Segmentierung. In: Nelde, P. H. (Hrsg.), Urban language conflict/Urbane Sprachkonflikte. Bonn: Dümmer, 31-46.

Kallmeyer, Werner (1994). Das Projekt 'Kommunikation in der Stadt'. In: Kallmeyer, W. (Hrsg.), Kommunikation in der Stadt. Teil 1: Exemplarische Analysen des Sprachverhaltens in Mannheim. New York: de Gruyter, 1-39.

Kallmeyer, Werner \& Keim, Inken (1994). Formelhaftes Sprechen in der Filsbachwelt. In: Kallmeyer, W. (Hrsg.), Kommunikation in der Stadt. Teil 1: Exemplarische Analysen des Sprachverhaltens in Mannheim. Berlin/New York: de Gruyter, 250-318.

Keim, Inken \& Schmitt, Reinhold (1993). Evangelisch, ne? Die interaktive Konstruktion der sozialen Kategorie 'Übersiedler'. In: Deutsche Sprache 2, 143-161.

Kruse, Lenelis \& Thimm, Caja (1997). Das Gespräch zwischen den Generationen. In: Krappmann, L. \& Lepenies, A. (Hrsg.), Alt und Jung. Kooperation und Konflikt zwischen den Generationen. Frankfurt: Campus, 112-136.

Lakoff, Georg (1987). Women, fire and dangerous things. What categories reveal about the mind. Chicago/London: University Press.

Lehr, Ursula \& Niederfranke, Annette (1991). Altersbilder und Altersstereotype. In: Oswald, W., Wettermann, L., Lehr, U. \& Thomae, H. (Hrsg.), Gerontologie. Stuttgart: Kohlhammer, 38-46. 
Mayer, Karl U. \& Baltes, Paul (1996). Die Berliner Altersstudie. Berlin: Akademie.

Neubauer, Marion, Hub, Ingrid \& Thimm, Caja (1994). Transkribieren mit LaTeX: Transkriptionsregeln, Eingabeverfahren und Auswertungsmöglichkeiten. Arbeiten aus dem Sonderforschungsbereich 245 'Sprache und Situation', 76. Heidelberg: Psychologisches Institut der Universität.

Nussbaum, John (1983). Relational closeness of elderly interaction: implications for life satisfaction. In: The Western Journal of Speech Communication 47, 229-243.

Polenz, Peter von (1985). Satzsemantik. New York/Frankfurt: de Gruyter.

Quasthoff, Uta (1984). On the ontogenesis of doing personal reference: syntactic, semantic and interactional aspects. In: Folia Linguistica, XVIII, 503-538.

Rosch, Elenor (1978). The principles of categorization. In: Rosch, E. \& Lloyd, B. (eds.), Cognition and categorization. Hillsdale: Lawrence Erlbaum, 30-49.

Rothermund, K., Wentura, D. \& Brandstädter, J. (1995). Selbstwertschützende Verschiebungen in der Semantik des Begriffs 'alt' im höheren Erwachsenenalter. In: Sprache und Kognition 14(2), 5263.

Ryan, Ellen, Hummert, Mary Lee \& Boich, Linda (1995). Communication predicaments of aging. Patronizing behavior toward older adults. In: Journal of Language and Social Psychology 14(1-2), 144-166.

Sacks, Harvey (1972a). An initial investigation of the usuability of conversational data for doing sociologogy. In Sudnow, D. (ed.), Studies in social interaction. New York: Free press, 31-74.

Sacks, Harvey (1972b). On the analyzability of stories by children. In: Gumperz, J. \& Hymes, J. (eds.), Directions in sociolinguistics. New York: Holt, 325-345.

Sacks, Harvey (1992). Lectures on conversation. Oxford/Cambridge: Blackwell.

Sacks, Harvey \& Schegloff (1978). Zwei Präferenzen in der Organisation personaler Referenz in der Konversation und ihre Wechselwirkungen. In: Quasthoff, U. (Hrsg.), SprachstrukturSozialstruktur. Königstein: Scriptor, 150-157.

Schütz, Alfred (1971). Gesammelte Aufsätze (1-3). Den Haag: Nijhoff.

Schwitalla, Johannes \& Streeck, Jürgen (1989). Subversive Interaktionen: Sprachliche Verfahren der sozialen Abgrenzung in einer Jugendlichengruppe. In: Hinnenkamp, V. \& Selting, M. (Hrsg.), Stil und Stilisierung: Arbeiten zur interpretativen Soziolinguistik. Tübingen: Niemeyer, 229-251.

Tews, Hans Peter (1991). Altersbilder. Über Wandel und Beeinflussung von Vorstellungen vom und Einstellungen zum Alter. (Forum 16) Herausgegeben vom Kuratorium Deutsche Altershilfe: Köln.

Thimm, Caja (1995a). Verständigungsprobleme in Gesprächen zwischen Alt und Jung. In: Spillner, B. (Hrsg.), Sprache: Verstehen und Verständlichkeit. Frankfurt/New York: Peter Lang, 89-95.

Thimm, Caja (1995b). Intergruppenkommunikation, soziales Vorurteil und konversationale Implikaturen: Alt und Jung im Dialog. In: Liedtke, F. (Hrsg.), Implikaturen: Grammatische und pragmatische Analysen. Tübingen: Niemeyer, 187-208.

Thimm, Caja (1996). Sprache und Kommunikation im Alter: Plädoyer für eine Gerontologische Linguistik. In: Sprachreport 1, 4-5.

Thimm, Caja (1998). Alter als Kommunikationsproblem. Eine exemplarische Analyse von Strategien in intergenerationeller Kommunikation. In: Fiehler, R. (Hrsg.), Verständigungsprobleme und gestörte Kommunikation. Opladen: Westdeutscher Verlag, 177-197.

Vater, Heinz (1992). Einführung in die Textlinguistik. Struktur, Thema und Referenz in Texten. München: Fink.

Ward, Richard A. (1984). The marginality and salience of being old: when is age relevant? In: The Gerontologist 24 (3), 227-232.

Wiegand, Herbert-Ernst (1996). Über usuelle und nicht-usuelle Benennungskontexte in Alltag und Wissenschaft. In: Knobloch, C. \& Schaeder, B. (Hrsg.), Nomination - fachsprachlich und gemeinsprachlich. Opladen: Westdeutscher Verlag, 55-103.

Wimmer, Reiner (1979). Referenzsemantik. Tübingen: Niemeyer. 


\section{Anhang: Transkriptionskonventionen}

Als Basis liegen die Transkriptionsvereinbarungen des SFB 245 zugrunde, die von Gutfleisch-Rieck, Klein, Speck \& Spranz-Fogasy (1989) erstellt wurden und die unter Berücksichtigung eigener Forschungsziele entsprechend erweitert bzw. modifiziert wurden. So wurden beispielsweise Lautstärke und prosodische Merkmale ergänzt, da wir aufgrund der Forschungslage bezüglich dieser Kategorien Unterschiede erwarteten.

Die Transkripte sind in Form der Partiturschreibweise abgefaßt. Die Äußerungen der Sprecherinnen werden in Kleinschreibung notiert. Großschreibung bleibt der Kennzeichnung besonderer sprachlicher Phänomene (s.u.) vorbehalten. Bei Sprecherwechseln bzw. bei Simultanpassagen der Sprecherinnen sind die Zeilen untereinander geschrieben und mit einer eckigen Klammer am Zeilenanfang zusammengefaßt.

Unverständliche Passagen: Vermuteter Wortlaut steht in runden Klammern. Bestehen zwei Alternativen des Wortverstehens, werden diese durch einen Schrägstrich getrennt.

Simultanpassagen: Gleichzeitiges Sprechen ist durch je ein 'Doppelkreuz' (\#) am Anfang und am Ende des gleichzeitig gesprochenen Textes gekennzeichnet.

Pausen werden ab einer Länge von 0,5 Sekunden transkribiert:

0,5 sek bis $<1$ sek *

1 sek bis $<2$ sek **

$>2$ sek Sekundenzahl in 0,5-Schritten zwischen den Sternchen angegeben

Unterbrechungen durch die andere Sprecherin sind durch einen Doppelschrägstrich (//) am Ende des Sprechakts der 'unterbrochenen' Sprecherin gekennzeichnet.

Wortabbrüche und Äußerungsabbrüche: Eine Markierung erfolgt durch einen senkrechten Strich (I) direkt hinter dem abgebrochenen Wort oder Satz.

Kommentare sind mit Großbuchstaben geschrieben und durch Klammern begrenzt. Bezieht sich ein Kommentar auf eine Texteinheit, ist diese am Anfang und Ende mit einem Doppelkreuz (\#) markiert.

Satzzeichen: Die Satzzeichen erfüllen in den Transkripten nicht ihre 'normale' Funktion, sondern sind wie folgt gesetzt:

Punkt (.): Bei einer Zäsur oder fallender Intonation

Fragezeichen (?): $\quad$ Bei Fragen

Gedankenstrich (-): $\quad$ Bei schwebender Intonation

Betonte Vokale: $\quad$ Auffällige Betonungen werden durch Großbuchstaben

hervorgehoben

Auffällige Dehnungen: Doppelpunkt hinter dem gedehnten Vokal/Konsonant

Rückmeldepartikel u.ä.: Diese Aktivitäten werden je nach der interpretierten Bedeutung transkribiert:

$\mathrm{hm}, \mathrm{hmhm} \quad=\quad$ bejahend, unterstützend

$\mathrm{mhm} \quad=\quad$ verneinend

hm-- $\quad$ = zögernd, zweifelnd

$\mathrm{mm} \quad=\quad$ überlegend

$\mathrm{hm}$ ? $\quad=\quad$ fragend 
Veränderungen der Lautstärke: Werden anhand subjektiver Wahrnehmung festgehalten. Dabei können sich die Pfeilmarkierungen sowohl auf einzelne Worte als auch auf ganze Textausschnitte beziehen, wenn diese deutlich lauter oder leiser gesprochen werden.

$(\boldsymbol{\lambda}=$ lauter, $\boldsymbol{y}=$ leiser $)$.

Prosodische Merkmale: Bei dezidiertem, abgesetztem Sprechen wird eine Kennzeichnung mit Bindestrichen zwischen den einzelnen Wörtern vorgenommen. 


\title{
Altersspezifisches Kommunikationsverhalten in Verkaufsgesprächen
}

\author{
Achim Pothmann
}

\section{Einleitung}

Auf der Grundlage einer diskursanalytischen Untersuchung von Verkaufsgesprächen im Schuheinzelhandel (vgl. Pothmann 1997) beschreibt dieser Beitrag das differierende Kommunikationsverhalten von Kunden unterschiedlicher Altersgruppen. Im Rahmen dieser Untersuchung wurden 81 Verkaufsgespräche in zwei Geschäftstypen aufgezeichnet, transkribiert und analysiert. Im Geschäftstyp 1 (Young-Fashion-Geschäft) werden ausschließlich modische - 'junge' - Schuhe angeboten. Das Alter der Kunden und Kundinnen in diesem Geschäft liegt zwischen 12 und 35 Jahren. Im Geschäftstyp 2 (Comfort-Geschäft) ist das Angebot auf komfortable, bequeme Schuhe konzentriert. Hier beträgt das Durchschnittsalter der Kunden etwa 65 bis 70 Jahre.

Im Rahmen der o.g. Untersuchung wurden die Verkaufsgespräche in beiden Geschäften u.a. unter der Fragestellung analysiert, inwieweit und wodurch sich das Kommunikationsverhalten der Kunden im Young-Fashion-Geschäft von dem im Comfort-Geschäft unterscheidet. Da mit den unterschiedlichen Verkaufskonzeptionen wie oben erwähnt verschiedene Zielgruppen angesprochen werden (YoungFashion: junge Leute, Comfort: ältere Leute), wurden die Divergenzen im Kommunikationsverhalten unter dem Aspekt „zielgruppenspezifisches Kommunikationsverhalten in Schuhverkaufsgesprächen" zusammengefaßt. Dies scheint mir ein geeigneter Ansatz, um Merkmale altersspezifischen Kommunikationsverhaltens in einer vergleichenden Perspektive bestimmen zu können.

Im folgenden Beitrag werden zwei Aspekte untersucht: Zum einen wird analysiert, inwieweit zielgruppenspezifisches Kommunikationsverhalten in den beiden $\mathrm{Ge}-$ schäftstypen tatsächlich identifizierbar ist (Abschnitt 1 bis 4). Zum anderen wird diskutiert, inwiefern dieses identifizierte Kommunikationsverhalten auch altersspezifisch ist (Abschnitt 5).

Zielgruppenspezifik wurde bei der Bearbeitung aller zentralen Aufgaben eines Verkaufsgesprächs identifiziert. ${ }^{1}$ Es handelt sich dabei um die folgenden Aufgaben:

- Kontaktherstellung

- Auswahlbearbeitung

- Entscheidungsbearbeitung

- Realisierung des Kaufs

- Beendigung des Verkaufsgespräches

Zu den zentralen Aufgaben, die in einem Verkaufsgespräch bearbeitet werden, vgl. Pothmann (1997). Dort werden die Aufgaben in einem Handlungsschema 'Verkaufen' zusammengefaßt und damit ein Beschreibungsmodell für Verkaufsgespräche entwickelt. 
Da es aber den Rahmen dieses Artikels sprengen würde, all diese Aspekte im Detail zu analysieren, konzentriere ich mich auf die Untersuchung zweier Phänomene, die m.E. für das Material und damit die Diskussion von Zielgruppen- bzw. Altersspezifik in Verkaufsgesprächen exemplarisch sind. Zum einen werden Nebensequenzen in Verkaufsgesprächen der unterschiedlichen Geschäftstypen analysiert (Abschnitt 2). Zum anderen werden Sequenzen untersucht, die unter der Bezeichnung 'Neindanke'-Sequenzen zusammengefaßt sind (Abschnitt 3).

\section{Nebensequenzen im Comfort-Geschäft}

Ein Beispiel soll in die Thematik einführen:

Gespräch C4-A4

Kontext des Verkaufsgesprächs C4-A2 in Zeile 15: ${ }^{2}$ Nach einer ersten Formulierung der Entscheidung und einer Sequenz der gemeinsamen Entscheidungsbestätigung produziert die Verkäuferin folgende $\ddot{A} u ß e r u n g:$

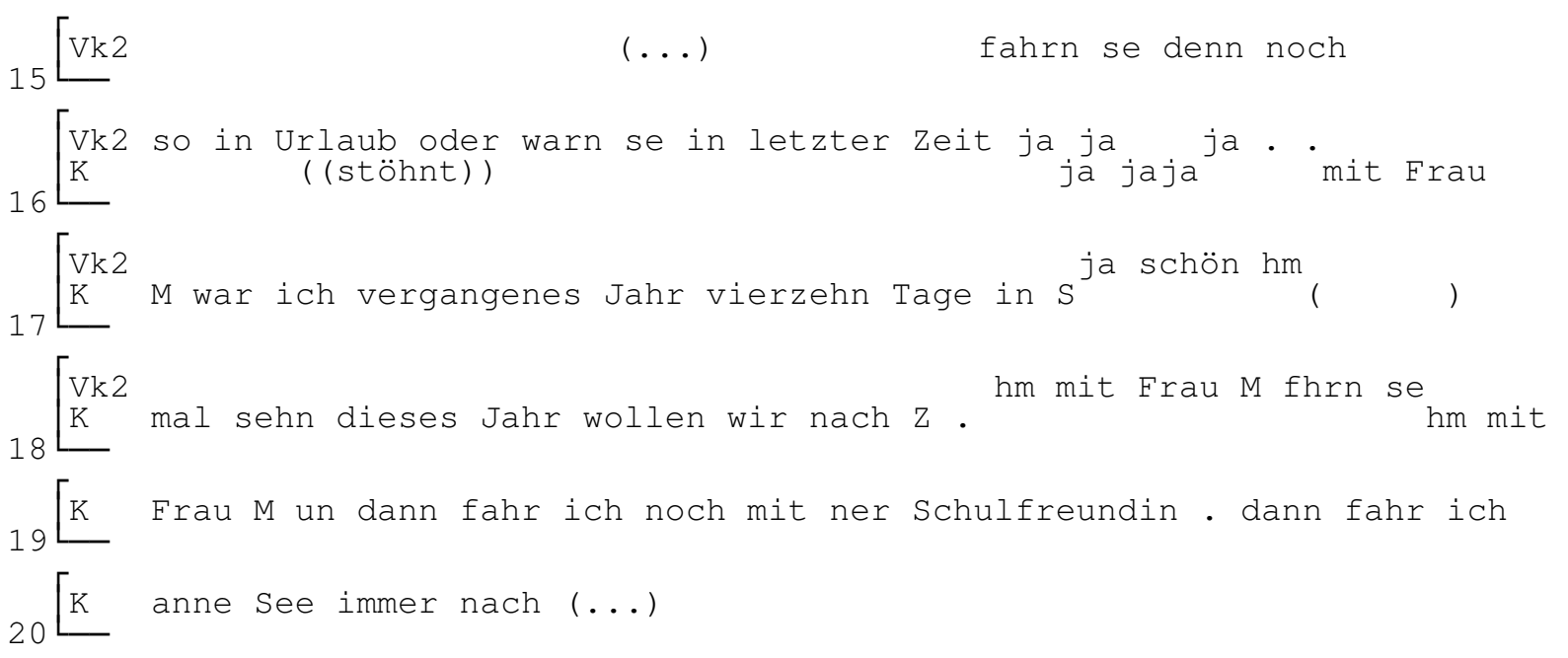

Nebensequenzen werden in diesem Beitrag verstanden als Sequenzen, die nicht direkt zur Bearbeitung der Aufgaben des Handlungsschemas 'Verkaufen' dienen. Bei der Analyse der Korpora Comfort und Young-Fashion fiel auf, daß zwar viele derartiger Nebensequenzen im Comfort zu finden sind, sie im Young-Fashion aber fast gänzlich fehlen. Um zu untersuchen, inwieweit sich anhand dieses Phänomens Zielgruppenspezifik zeigt, werden die Nebensequenzen im Comfort-Material zunächst beschrieben und anschließend deren Funktionen analysiert.

2 „C4-A2" ist ein Verkaufsgespräch des Comfort-Korpus („C"). Die Signatur von Young Fashion-Verkaufsgesprächen beginnt mit „YF". 
Die nachstehende Liste nennt häufige Themen dieser Nebensequenzen:

- Probleme in der Lebenssituation der Kundin

- Gesundheitsprobleme allgemein

- Fußprobleme

- Gesundheitsprobleme der Verwandten der Kundin

- Urlaub

- Klatsch/Lästereien

- Wetter

- Gemeinsame Bekannte

- Aktivitäten der Kundin im Anschluß an das Verkaufsgespräch

- Vergangenheitsrekonstruktion

- Resümee des Verkaufsgesprächs

Auffällig ist, daß nicht alle Themen von jedem Gesprächsteilnehmer initiiert werden. So dominiert die Verkäuferin in den Gesprächen z.B. das Thema Urlaub (s.o.). Auch erkundigt sie sich nach gemeinsamen Bekannten oder versucht, gemeinsame Bekannte herauszufinden. Des weiteren zeigt sie eine schon langfristige Beziehung zur Kundin auf (Rekonstruktion und Demonstration der gemeinsamen positiven Vergangenheit) und leistet damit für ihr Unternehmen Imagearbeit.

Die Kundin hingegen initiiert hauptsächlich Themen wie Fuß- bzw. Gesundheitsprobleme, Probleme ihrer Lebenssituation, Wetter und Erlebnisse des Tages. Themen, die von der Verkäuferin und der Kundin in das Gespräch eingebracht werden, sind u.a. die Aktivitäten der Kundin im Anschluß an das Verkaufsgespräch oder Klatsch über Bekannte wie z.B.:

\section{Gespräch C4-A2}

Kontext des Verkaufsgesprächs C4-A2 in Zeile 89: Die Kundin lästert über eine ihrer Bekannten.

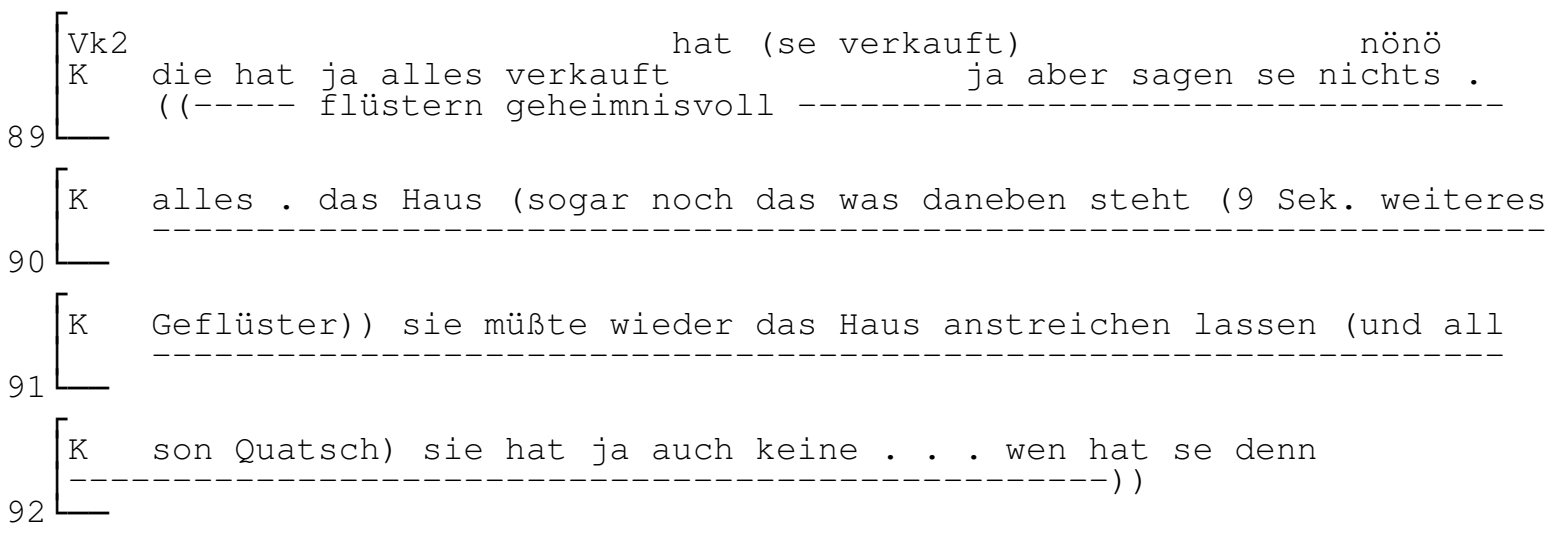

Bevor die Funktionen der Nebensequenzen diskutiert werden, stellt sich die Frage, in welchen Gesprächssituationen Nebensequenzen initiiert werden. ${ }^{3}$ Hilfreich hierbei

3 Wie Nebensequenzen initiiert und beendet werden, in welchem Zusammenhang sie mit den anderen Themen des Gesprächs stehen und wie die Kohärenz zwischen den Themen von den Gesprächsteilnehmern hergestellt wird, soll hier nicht untersucht werden, da dadurch keine weiteren zielgruppenspe- 
ist eine Einteilung der Gespräche in die Kategorien 'Gespräche mit positiven Kaufentscheidungen während des Verkaufsgesprächs', 'Abnahmeverkaufsgespräche' und 'Verkaufsgespräche mit negativer Kaufentscheidung'.

Es konnte festgestellt werden, daß nur in der Kategorie 'Gespräche mit positiver Kaufentscheidung während des Verkaufsgesprächs' Nebensequenzen produziert werden. In 'Abnahmeverkaufsgesprächen' oder 'Verkaufsgesprächen mit negativer Kaufentscheidung' finden sich keine Nebensequenzen.

Nebensequenzen treten nicht während der Bearbeitung der Aufgaben 'Kontaktherstellung' und 'Anliegenformulierung' auf. Selten werden sie im Rahmen der Auswahl initiiert. Fast ausschließlich werden Nebensequenzen während bzw. zwischen der Bearbeitung der Aufgaben 'Kaufentscheidung', 'Kaufrealisation' und 'Beendigung des Verkaufsgesprächs' bearbeitet.

Welche Funktionen haben nun die Nebensequenzen in Schuhverkaufsgesprächen? Gülich (1980) weist im Rahmen der Funktionsbestimmung bei Erzählungen auf das folgende zentrale Problem hin: Je genauer die übergeordneten Handlungsschemata in die Erzählungen (Nebensequenzen) ${ }^{4}$ eingebettet sind, bestimmt und beschrieben werden können, desto sicherer läßt sich angeben, ob eine Erzählung (Nebensequenz) für ein bestimmtes Handlungsschema funktional ist oder nicht $(1980,376)$. Nachfolgend benenne ich Funktionen der Nebensequenzen in Verkaufsgesprächen und illustriere sie zum Teil mit Beispielen:

\section{a) Beziehungsförderung /-konstituierung /-bestätigung}

Bei der Analyse der Nebensequenzen wird deutlich, daß sowohl Verkäuferin als auch Kundin zur Beziehungskonstituierung /-förderung beitragen. Der o.g. Gesprächsausschnitt (C4-A2-Z. 89-92) zeigt beispielhaft die Initiierung von Klatsch. ${ }^{5}$

Weiterhin wird die Förderung einer positiven Beziehung durch gemeinsames Lachen erkennbar, ${ }^{6}$ durch Thematisieren von Gesundheitsproblemen und durch das Thematisieren von Aktivitäten der Kundin nach dem Verkaufsgespräch. Auch wird die dauerhafte Bekanntschaft zwischen Verkäuferin und Kundin angesprochen, gewürdigt und dadurch bestätigt (Demonstration der gemeinsamen Vergangenheit).

\section{b) Bedenkzeit bekommen}

Ein anderer Grund für die Initiierung einer Nebensequenz ist es, Bedenkzeit zu bekommen. Die Kundin produziert eine Nebensequenz, um z.B. für ihre Entscheidungsfindung Zeit zu gewinnen.

\footnotetext{
zifischen Phänomene sichtbar werden. Gleichwohl ist bei der Analyse der Nebensequenzthemen und ihrer Funktionen deutlich geworden, daß die Übergänge unterschiedlich bearbeitet werden. So wurde z.B. deutlich, daß die Übergänge zwischen Nebensequenzen ohne Themenzusammenhang anders konstituiert werden als zwischen Nebensequenzen mit thematischem Bezug zur vorherigen Aufgabe bzw. zur vorangegangenen Nebensequenz. Sacks (1971) weist in diesem Zusammenhang darauf hin, daß Nebensequenzen (z.B. Erzählungen), sofern sie von längerer Dauer sein sollen, explizit als solche kenntlich gemacht werden (309). Nach der Beendigung der Nebensequenz wird dann nach Selting $(1987,71)$ das zuvor suspendierte Thema wiederaufgenommen bzw. oft auch auf eine noch nicht erfüllte konditionelle Relevanz eingegangen.

4 Erzählungen in Verkaufsgesprächen werden hier als eine Form der Nebensequenz angesehen.

5 Hinsichtlich der beziehungsfördernden Funktion von Klatsch vgl. Bergmann (1987).

6 Hinsichtlich der beziehungsfördernden Funktion von Lachen vgl. Schröder (1986).
} 
c) Entspannung einer Situation

Nebensequenzen werden auch zur Entspannung einer Situation produziert. Besonders nach der Formulierung einer Kaufentscheidung ist dies erkennbar, wenn die Verkäuferin von der Bearbeitung der Aufgabe 'Kaufentscheidung' auf ein anderes Thema (z.B. eine Nebensequenz) lenkt. Ein Beispiel zeigt Verkaufsgespräch C5-A3-Z. 41ff:

Kontext: Die Kundin hat sich für ein Paar Schuhe entschieden und formuliert daraufhin ihre Kaufentscheidung. Die dann entstehende Gesprächspause beendet die Verkäuferin durch die Initiierung einer Nebensequenz:

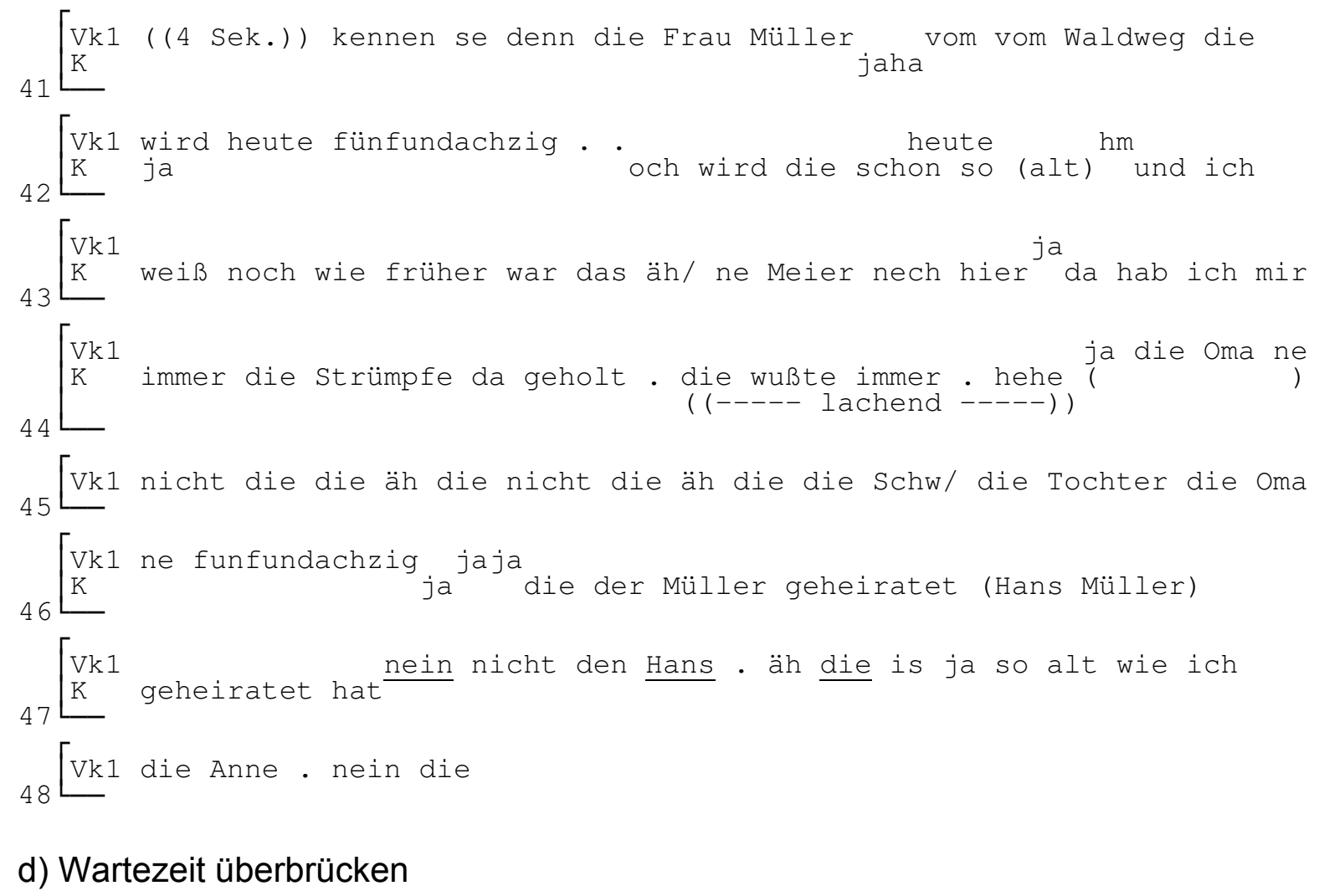

d) Wartezeit überbrücken

Während eine Verkäuferin die Schuhe im Lager sucht, entsteht eine Pause in der Kommunikation. Diese wird häufig von einer Kollegin der Verkäuferin durch die Initiierung eine Nebensequenz überbrückt. Aber auch während der Kaufrealisation entstehen potentielle Schweigephasen, da keine Aufgabe kommunikativ bearbeitet werden muß. Diese Phasen werden ebenso mit Nebensequenzen gefüllt.

e) Imageverbesserung

Mit Hilfe von Nebensequenzen kann die Verkäuferin positive Aspekte ihres Unternehmens herausstellen. 
f) Mitteilungsbedürfnis der Kundin befriedigen

Über die Beziehungspflege hinaus wird in einigen Nebensequenzen deutlich, daß die Kunden teilweise ein großes Mitteilungsbedürfnis haben. Dieses reicht von Klagen über eigene Gesundheitsprobleme bis hin zum Bericht über die Probleme ihrer Verwandten und Bekannten.

g) 'Seelsorge'

Ein beeindruckendes Beispiel, wie offen Kundinnen im Comfort-Geschäft die sie belastenden Probleme äußern, findet sich im Comfort-Verkaufsgespräch C5-B1. In der betreffenden Sequenz offenbart die Kundin ihre Probleme und beginnt dabei sogar zu weinen. Zuvor äußert sie folgendes:

Gespräch C5-B1

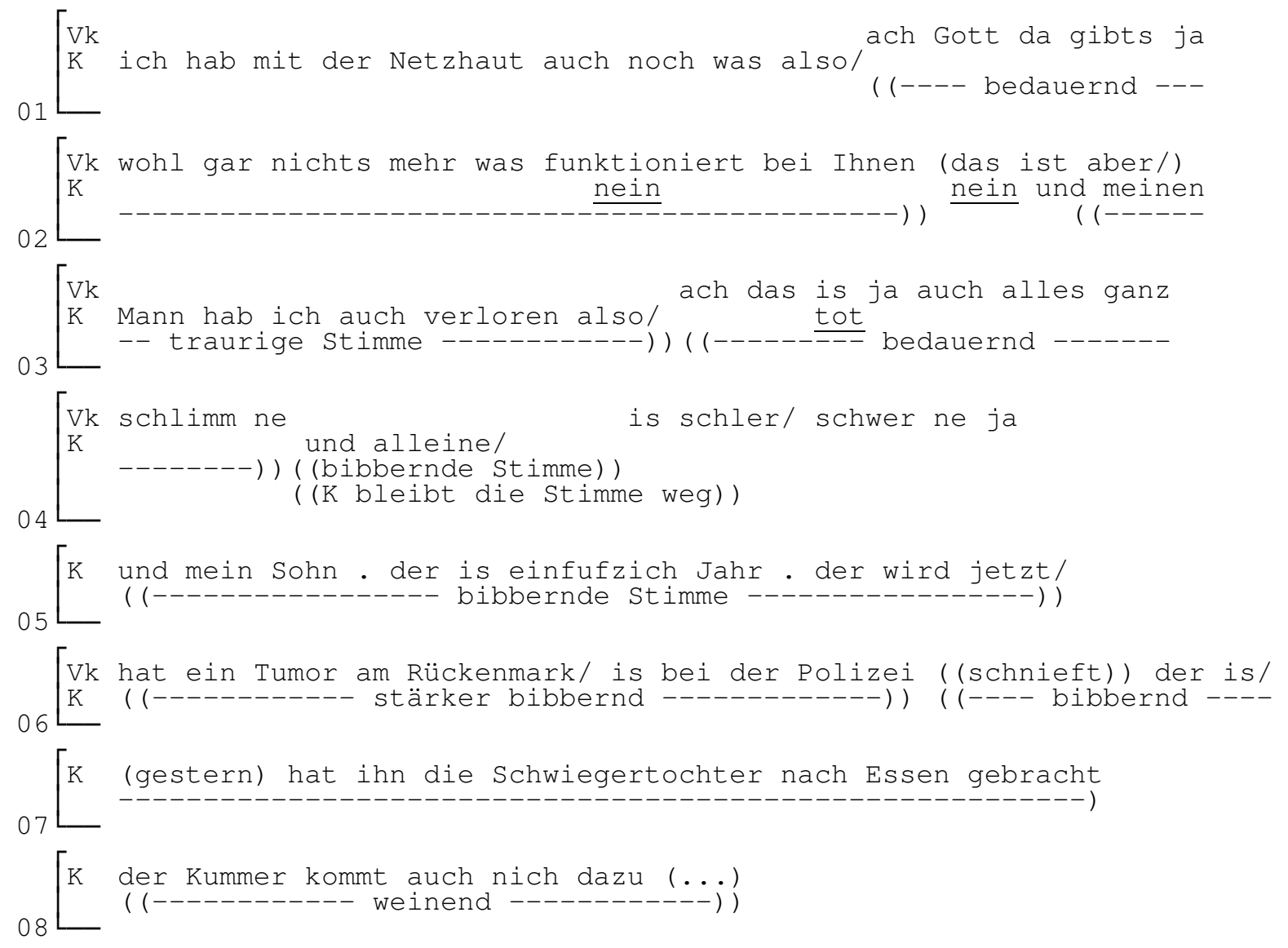

Coupland/Coupland/Giles (1991) haben die Neigung älterer Menschen, frühzeitig und ausführlich ihre Probleme zu offenbaren, näher untersucht. Sie bezeichnen diese 'Selbstentblößung' als „painful self-disclosure" (PSD) und verstehen darunter die Tatsache, daß ältere Menschen - im Vergleich zu jüngeren - schneller von persönlich intimen Schicksalsschlägen wie Krankheit, Tod, Mängel, Schwäche, Einsamkeit usw. berichten ((1991, 81); vgl. auch Coupland/Coupland/Giles/Wiemann 1988). Die Verkäuferin beschränkt im oben zitierten Fall ihre Äußerungen auf Bekundungen der Anteilnahme, wie z.B. ach das is ja alles ganz schlimm (C5-B1-Z. 3/4). 
h) Einleitung der Beendigung

Zudem kann durch Nebensequenzen eine Beendigungsinitiative bestätigt werden, indem die Kundin erzählt, was sie nach dem Verkaufsgespräch zu tun beabsichtigt oder indem die Gesprächsteilnehmer das Verkaufsgespräch als abgeschlossene, vergangene Aktivität behandeln.

Wichtig ist, darauf hinzuweisen, daß sich die aufgelisteten Funktionen nicht gegenseitig ausschließen. Die meisten Nebensequenzäußerungen sind multifunktional.

Darüber hinaus wird offenkundig, daß die Gesprächsteilnehmer nicht nur gemeinsam die für ein Verkaufsgespräch notwendigen Aufgaben bewältigen, sondern durch den Wechsel von der Verkaufsebene auf die persönliche Ebene auch die Entwicklung einer positiven Beziehung fördern. Die Verkäuferinnen manifestieren diese Beziehung durch Initiierung von Themen wie Urlaub, gemeinsame Bekannte oder durch Signalisieren des Interesses an der Person und den Problemen der Kundin. Sie schaffen auf diese Weise zur Kundin ein 'positives Feld'. Die Kundin wiederum nutzt die Gelegenheit, ihre kommunikativen Bedürfnisse zu befriedigen (Klatsch, Berichten von Gesundheitsproblemen usw.). In diesem Zusammenhang wird deutlich, daß die Kundin eine Erwartungshaltung an das Verkaufsgespräch hat, die über die reine Verkaufsinteraktion hinausgeht. Verkaufen bzw. Kaufen wird von den Gesprächsteilnehmern im Comfort zu einem für die Kundin offensichtlich bedeutsamen sozialen Ereignis. $^{7}$

Im Young-Fashion hingegen werden kaum Nebensequenzen produziert. Nur in Verkaufsgesprächen, die der Kategorie 'Gespräche, in denen eine positive Kaufentscheidung während des Verkaufsgesprächs getroffen wird' angehören, finden sich Nebensequenzen. Während die Nebensequenzen im Comfort oftmals expandiert werden, entsteht im Young-Fashion der Eindruck, daß sie von beiden Gesprächspartnerinnen eher vermieden bzw. deren Expansion verhindert wird.

\section{3. 'Nein-danke'-Sequenzen im Young-Fashion-Geschäft}

Im Comfort-Material ist die große Anzahl an Nebensequenzen und deren besondere Rolle in Verkaufsgesprächen aufgefallen. Im Young-Fashion-Material sticht dagegen ein anderes Phänomen hervor. In 35 der Young-Fashion-Verkaufssequenzen und somit in mehr als der Hälfte aller Young-Fashion-Interaktionen wünscht die Kundin zunächst keine Bedienung. Diese kurzen Sequenzen, in denen die Kundin im Rahmen der Anliegenformulierung einem Verkaufsgespräch abweist, werden im folgenden als 'Nein-danke'-Sequenzen bezeichnet. Dabei soll unberücksichtigt bleiben, ob später dennoch ein Verkaufsgespräch initiiert wird.

7 Bestätigt wird dieser Gedanke durch Berichte der Verkäuferinnen im Comfort. Sie erzählen von Kundinnen, die innen aus Freude und Dankbarkeit Eis, Kuchen oder ähnliches in den Laden bringen. Eine Verkäuferin berichtet außerdem, daß Kunden das Geschäft betreten, sich mit ihr ausgiebig unterhalten und abschließend eine Kleinigkeit, wie z.B. Pflegemittel für Schuhe, kaufen. Dies ist vielleicht nicht ungewöhnlich. Das wahre Motiv für das Betreten des Geschäftes ist jedoch nicht immer der Pflegemittelkauf, denn in einigen Fällen weisen die Kunden explizit darauf hin, daß sie nicht die Zeit der Verkäuferin in Anspruch nehmen können, ohne etwas zu kaufen - also kaufen sie. 
Die folgenden Beispiele vermitteln einen Eindruck, um welche Sequenzen es sich handelt:

\section{Gespräch YF4-A6}

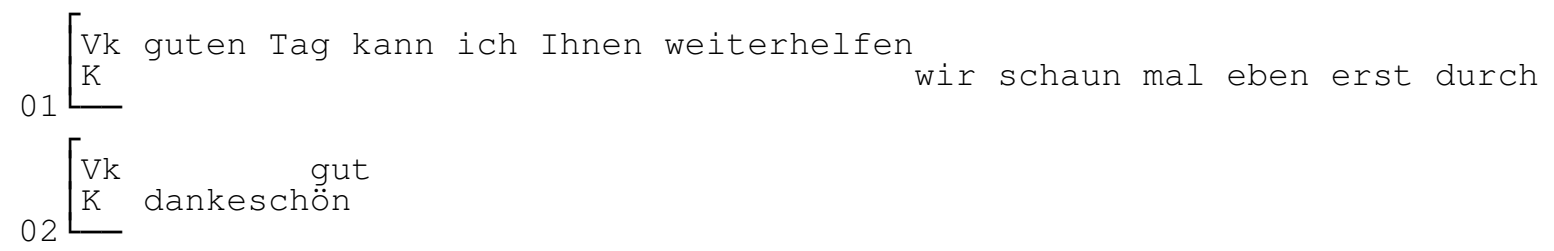

\section{YF5-B8}

$0_{01}^{\left[\begin{array}{l}\text { Vk kann ich Ihnen helfen ich komm zurecht } \\ K\end{array}\right.}$

Bevor die 'Nein-danke'-Sequenzen im Detail analysiert werden, wird zunächst deren grundlegende Struktur dargestellt. Aufgrund der leichten Abgrenzbarkeit der 'Neindanke'-Sequenzen zu anderen sowie ihrer einzelnen Elemente untereinander werden zur Veranschaulichung Häufigkeiten angegeben.

Die Anliegenformulierung ist ein konstitutives Element für Schuhverkaufsgespräche (vgl. Pothmann 1997). Auch bei den 'Nein-danke'-Sequenzen wird diese Aufgabe immer bearbeitet. Die Besonderheit liegt darin, daß die Young-Fashion-Kundin - direkt oder indirekt - das Anliegen benennt, kein Verkaufsgespräch führen zu wollen. Ferner sind alle 'Nein-danke'-Sequenzen verkäuferinitiiert. In der Hälfte der Fälle wird der Kontakt von der Verkäuferin durch eine Begrüßung hergestellt. Ansonsten beginnt das potentielle Verkaufsgespräch mit einer Aufforderung zur Anliegenformulierung. Auffällig ist, daß in der Hälfte der Sequenzen mit Begrüßung, die Verkäuferin keinen Gegengruß erhält. Dieses musterverletzende Verhalten der Kundin ist in allen anderen Verkaufsgesprächen nicht zu identifizieren. Als Regularität läßt sich daraus formulieren: Wenn die Verkäuferin die Kundin begrüßt und die Kundin nicht unmittelbar darauf den Gruß erwidert - meist entsteht dann eine kurze Pause -, dann wird die Kundin ein Verkaufsgespräch (zunächst) abweisen.

Das Nichterwidern des Gegengrußes kann offenbar als Signal verstanden werden, daß die Kundin kein Verkaufsgespräch führen möchte. Die Kundin möchte sich zunächst selbständig im Laden umschauen, was sie im Rahmen der Anliegenformulierung - wie im u.g. Beispiel - häufig auch explizit äußert:

\section{Gespräch YF4-A3}

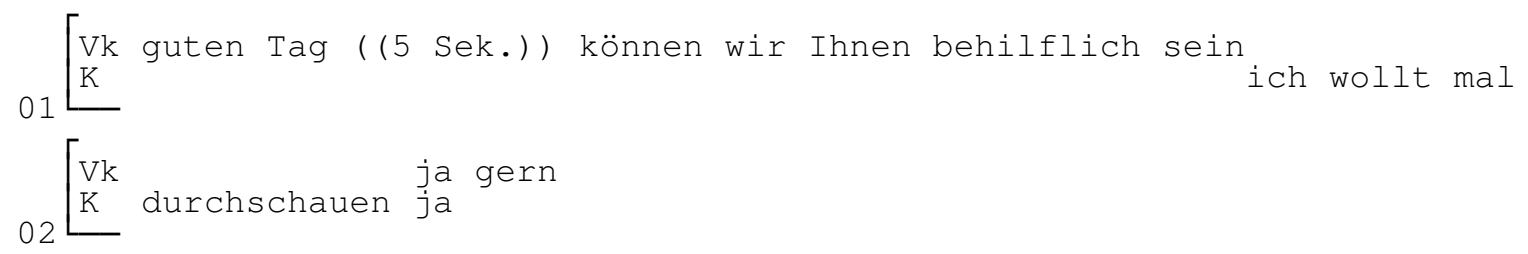


Um nun die 'Nein-danke'-Sequenzen auf einer detaillierteren Ebene zu untersuchen, sollen die Sequenzen in die beiden folgenden Kategorien untergliedert werden:

- Abweisen des Verkaufsgesprächs ohne explizite Benennung des Anliegens und ohne Rechtfertigung der Abweisung

- Abweisen des Verkaufsgesprächs mit expliziter Benennung des Anliegens oder Rechtfertigung der Abweisung

Formen der Abweisung des Verkäufers ohne explizite Anliegenbenennung oder Rechtfertigung sind z.B.
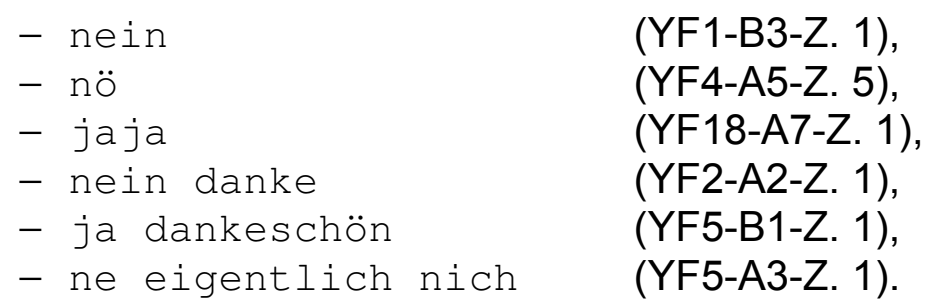

Ob die Kundin mit ja oder nein antwortet, hängt von der Aufforderung zur Anliegenformulierung $a b$.

Abweisungen des Verkaufsgesprächs durch explizite Anliegenbenennungen bzw. Rechtfertigungen lauten z.B.:

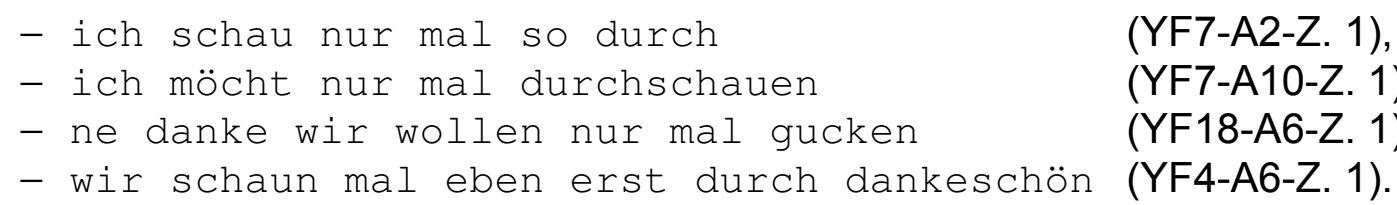

Die Reaktionen der Kundinnen auf die Aufforderungen der Verkäuferinnen sind verschieden. Eine Korrelation zwischen der Aufforderung zur Anliegenformulierung und bestimmten Anliegenbenennungen ist nicht festzustellen. Während in der ersten Kategorie die Reaktion der Kundin auf die Aufforderung zur Anliegenformulierung oft so zu interpretieren ist, daß sie die Aufforderung als Frage verstanden hat, auf die mit ja oder nein geantwortet werden kann, dominiert in 'Nein-danke'-Sequenzen der zweiten Kategorie die Lesart, daß die Kundin die Aufforderung zur Anliegenformulierung möglicherweise als tatsächliche Aufforderung verstanden hat. ${ }^{8}$ Eine reduzierte Antwort wie ja oder nein erscheint im letztgenannten Fall nicht ausreichend zu sein, so daß die Kundin ihr Anliegen äußert. Die Anliegenbenennung hat hier eher eine Rechtfertigungsfunktion.

Unabhängig von den Kategorien wird deutlich, daß die Kundin sich zunächst prinzipiell allein umschauen möchte.

8 Die unterschiedlichen Interpretationen schließen sich nicht gegenseitig aus. Hier geht es nur um die präferierte Interpretation. Daß auch die Aufforderungen zur Anliegenformulierung in der ersten Kategorie als Angebot bzw. Aufforderung interpretiert werden können, wird durch den Dank der Kundin deutlich. 
Was resultieren kann, wenn eine Verkäuferin trotz Abweisung des Verkaufsgesprächs durch die Kundin eine Verkaufsgesprächssituation aufrecht erhalten möchte, wird im Verkaufsgespräch YF7-A4 deutlich: Auf die Aufforderung zur Anliegenformulierung kann ich Dir weiterhelfen (Z. 1) antwortet die Kundin nö (Z. 1) und wehrt damit ein Verkaufsgespräch ab. Dies akzeptiert die Verkäuferin allerdings nicht und versucht weiter, auf die Kundin einzugehen. Diese weist die Aktivitäten der Verkäuferin wiederum zurück und äußert sogar explizit in Z. 2/3: (...) laß mich lieber selber (...), worauf die Verkäuferin nicht eingeht. Anschließend bringt die Verkäuferin Modellvorschläge ein, die erneut von der Kundin abgewiesen werden. In $Z$. 7 leitet die Kundin zur Beendigung mit $t j a$ über, weist einen weiteren Vorschlag der Verkäuferin ab und beendet dann die Interaktion mit na ja tschüs (Z. 8).

Die Verkäuferin ignoriert demnach alle Signale der Kundin, die darauf schließen lassen, daß diese sich allein (mit ihrer Begleiterin) umschauen möchte. Da die Verkäuferin selbst die explizite Aufforderung der Kundin laß mich lieber selber nicht beachtet, scheint es für die Kundin nur die Möglichkeit zu geben, das Gespräch durch Verlassen des Geschäftes zu beenden.

Es muß jedoch betont werden, daß es sich bei dem Verhalten der Verkäuferin in YF7-A4 um eine Ausnahme handelt. In der Regel reagieren die Verkäuferinnen auf die oft formlose Abweisung mit entsprechenden Akzeptanzbekundungen wie z.B. ja gerne, ja o.k., ja gut. Dadurch bleibt eine entspannte Atmosphäre erhalten, die es der Kundin ermöglicht, die Verkäuferin zu einem späteren Zeitpunkt zur Bearbeitung einer Aufgabe anzusprechen.

Das Comfort-Korpus beinhaltet lediglich eine 'Nein-danke'-Sequenz (C5-B3). Jedoch sprechen einige Aspekte dagegen, diese Sequenz derselben Kategorie zuzuordnen wie die 'Nein-danke'-Sequenzen des Young-Fashion-Korpus. So gibt es im YoungFashion keine Sequenz, in der ein Verkaufsgespräch abgewiesen wird, ohne daß eine Aufforderung zur Anliegenformulierung von der Verkäuferin produziert wurde. Darüber hinaus wird im Young-Fashion durchgängig ein Verkaufsgespräch abgewiesen, ohne daß die Kundin konkretisiert, was sie sich selbständig anschauen möchte. In dem o.g. Comfort-Gespräch expliziert die Kundin hingegen schon direkt im Anschluß an die Anliegenbenennung ihre Interessenlage (gucken was so Neues da ist (...) und zwar Bequemmode ham se ja (...)(Z. 2)). Besonders auffällig ist jedoch, daß die Kundin schon mit der Abweisung ich möcht an sich im Moment nur mal gucken (...) (Z. 1/2) ihr Anliegen mit an sich abschwächt bzw. relativiert. Dadurch entsteht bei dieser Sequenz der Eindruck, daß die Kundin mit ihrem relativierten Anliegen eher eine potentielle negative Kaufentscheidung antizipiert. Hierdurch wird es ihr möglich, zwar ein Verkaufsgespräch zu führen, jedoch auch ohne Face-Verletzung mit einer negativen Kaufentscheidung das Geschäft verlassen zu können.

Wenn sich in weiteren Analysen die o.g. Lesart bestätigen ließe, handelte es sich bei der Comfort-Sequenz nicht um eine 'Nein-danke'-Sequenz. Demnach wären 'Nein-danke'-Sequenzen ein nur für das Young-Fashion-Geschäft spezifisches Phänomen. 


\section{Weitere zielgruppenspezifische Phänomene im Kommunikationsverhalten}

Ein Unterschied prinzipieller Art ist die Tatsache, daß die Verkaufsgespräche im Comfort-Geschäft im Durchschnitt ca. fünf Minuten länger dauern als die Gespräche im Young-Fashion-Geschäft. Ein Grund für die kurzen Young-Fashion-Verkaufsgespräche ist die effiziente, zielgerichtete Aufgabenerfüllung. Während im Comfort-Geschäft 'vollständige' Verkaufsgespräche von der Begrüßung über die Auswahl bis hin zur Beendigung produziert werden, besteht ein Young-Fashion-Verkaufsgespräch eher aus unzusammenhängenden Gesprächsbruchstücken. Die Kundin bearbeitet die Aufgabe 'Auswahl' in der Regel zunächst selbständig, bis sie die Unterstützung der Verkäuferin benötigt. Ein Beispiel für die Aufnahme bzw. Wiederaufnahme einer Verkaufsinteraktion ist YF3-A10:

$01\left[\begin{array}{l}\text { Vk } \\ K\end{array}\right.$ ähm könn se mir hiervon den Zweiten geben ja Augenblick. ich hol ihn

Im Young-Fashion-Geschäft reduziert sich die Verkäuferrolle demnach auf unterstützende Maßnahmen zur Aufgabenbearbeitung des Handlungsschemas 'Verkaufen'. Dies wird gleichfalls bei der Analyse der Anliegenbenennung der Kundin im Young-Fashion-Geschäft deutlich: In der Regel weist die Kundin entweder ein Verkaufsgespräch ab, oder sie möchte eine konkrete Aufgabe bearbeiten, die sie allein nicht erfüllen kann.

In den Gesprächen im Comfort-Geschäft steht Formalität im Vordergrund, was sich schon in der Gesprächseröffnung zeigt. Kunden werden fast durchgängig gesiezt, und die Gesprächseröffnungen werden in einem etablierten Schema bestehend aus Gruß, Gegengruß, Aufforderung zur Anliegenformulierung und der Benennung des Anliegens realisiert. Dieses Schema wird im Young-Fashion nicht immer durchlaufen, da häufig von der Kundin kein Gegengruß produziert wird oder das Anliegen von der Kundin benannt wird, ohne daß sie zuvor von der Verkäuferin dazu aufgefordert worden ist. Verkaufsgespräch YF2-A11 ist ein Beispiel für den letztgenannten Fall:

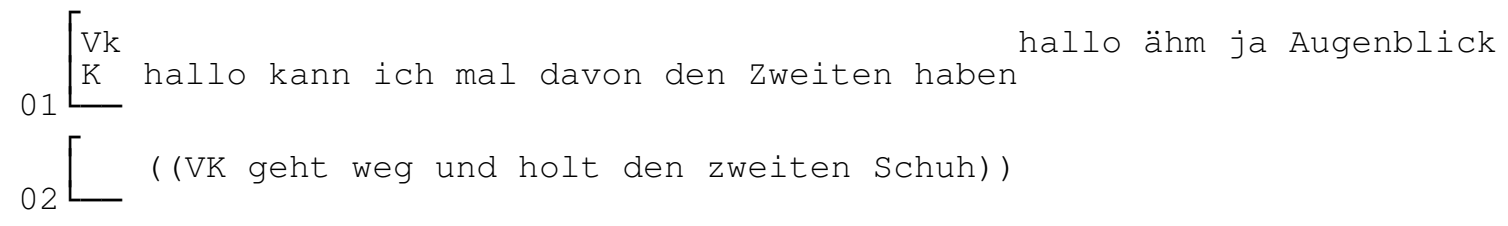

Die Analyse hat auch gezeigt, daß neben der ausführlichen Bearbeitung der Aufgaben des Handlungsschemas 'Verkaufen' vielfältige Aktivitäten auf der Beziehungsebene stattfinden. Diese beziehungskonstituierenden /-fördernden Sequenzen werden nicht nur von der Verkäuferin - motiviert durch berufliche Zwänge - produziert, sondern auch von der Kundin. Dies ist ein Phänomen, das nur im Comfort-Geschäft zu erkennen ist. Sowohl die Verkäuferinnen als auch die Kunden initiieren Nebensequenzen, die teilweise die Hälfte der gesamten Gesprächsdauer einnehmen. Comfort-Verkaufsgespräche weisen dadurch eine deutliche soziale Prägung auf. Das Ziel des käuflichen Erwerbs von Schuhen tritt zum Teil in den Hintergrund.

Im Young-Fashion hingegen wechseln die Gesprächsteilnehmer nur selten von der Verkaufs- auf die Beziehungsebene. Durch fehlende Nebensequenzen und häufiges 
Abweisen der Verkaufsgespräche wird erkennbar, daß nicht nur die Beziehungsebene einen erheblich geringeren Stellenwert in Young-Fashion-Kauf-/Verkaufinteraktionen einnimmt, sondern sich die gesamte Verkaufsinteraktion auf eine zielgerichtete, emotionsfreie, effiziente und partielle Bearbeitung derjenigen Aufgaben beschränkt, welche die Kundin nicht allein bewältigen kann.

Im Unterschied dazu, sind Comfort-Verkaufsgespräche stark sozial geprägte Gespräche bei denen teilweise das Ziel des käuflichen Erwerbs von Schuhen in den Hintergrund tritt.

\section{Begründungsversuch für zielgruppenspezifisches Kommunikationsverhalten}

Zur umfassenden Erklärung zielgruppenspezifischen Verhaltens sind Studien notwendig, die es ermöglichen, die Zielgruppe eines Geschäftstyps eindeutig hinsichtlich der Personen, ihrer psychologischen und sozialen Merkmale, Erwartungen usw. zu beschreiben. Im Rahmen solcher Marktstudien werden die relevanten Faktoren ermittelt, die für das zielgruppenspezifische Verhalten in den Geschäften verantwortlich sind, mit denen also Zielgruppenspezifik begründet werden kann. Hier soll lediglich durch Hinweis auf mögliche relevante Aspekte ein Versuch zur Begründung zielgruppenspezifischen Kommunikationsverhaltens geliefert werden.

Zunächst ist zur Begründung zielgruppenspezifischen Kommunikationsverhaltens der Einfluß der unterschiedlichen institutionellen Rahmen zu nennen. Vogt (1976) hat hierzu eine Untersuchung durchgeführt. Er vergleicht das Kommunikationsverhalten in einem Krämerladen und einem Supermarkt. Es werden dort gleiche Produkte verkauft, dennoch differieren in den unterschiedlichen Institutionen sowohl das Gesprächsverhalten als auch die Erwartungen der Gesprächsteilnehmer an ein Verkaufsgespräch. Im Krämerladen finden ausschließlich Bedienungsverkaufsgespräche statt, da aufgrund der Ladengestaltung keine Selbstbedienung möglich ist. Im Supermarkt hingegen ist das Gegenteil der Fall. Durch die besondere Form der Warenpräsentation wird Selbstbedienung unterstützt und gleichzeitig weniger Personal eingesetzt. Es überrascht daher kaum, daß Verkaufsgespräche weniger häufig stattfinden und sich in ihrer Bearbeitung von denen im Krämerladen unterscheiden. Zweifelsfrei ist dieser Aspekt auch ein Grund für das zielgruppenspezifische Verhalten in den Geschäften Comfort und Young-Fashion. Allerdings scheint der institutionsspezifische Einfluß hinsichtlich der Zielgruppenspezifik in den hier untersuchten Geschäftstypen geringer zu sein, da sich die Geschäfte z.B. in der Konzeption der Warenpräsentation nicht unterscheiden (Vorwahlverkauf). Entsprechend auffällige institutionelle Divergenzen wie in den von Vogt untersuchten Geschäftstypen sind nicht erkennbar. ${ }^{9}$

Ein weiterer möglicher Aspekt zur Begründung der Unterschiede ist in dem divergierenden Alter bzw. den unterschiedlichen Lebenssituationen der Zielgruppenmitglieder zu suchen. Auf die Begründung zielgruppenspezifischen Kommunikationsverhaltens durch unterschiedliche Generationszugehörigkeit wird deshalb im folgenden näher eingegangen.

9 Diesen Eindruck bestätigt das Verkaufsgespräch C11-A2, in dem eine Young Fashion-Kundin im Comfort einkauft und dabei das gleiche Kommunikationsverhalten wie Kundinnen im Young Fashion zeigt. 
Im Young-Fashion sind die Kunden in der Regel Schülerinnen/Schüler, Studentinnen und Studenten oder junge Berufstätige. Sie sind überwiegend ledig. Sie verfügen sowohl über Fernsehen, Radio, Zeitschriften und Informationsaustausch in ihrem sozialen Umfeld (Clique, Schule, Arbeitsplatz usw.) als auch über die Zeit, diese Informationen für sich auszuwerten, so daß für sie eine große Markttransparenz (Transparenz über angebotene Ware, Service und Dienstleistungen) besteht. Durch diesen hohen Grad an Information, Flexibilität und Mobilität nimmt die Bindung dieser Kunden an ein Geschäft ab. Im Comfort hingegen verkehren Kunden, die sich in der Regel im Rentenalter befinden und keiner beruflichen Tätigkeit nachgehen. Das berufliche soziale Umfeld entfällt oft mit dem Übergang in die Pensionierung. Zudem sind viele der Kundinnen Witwen. Ein Ergebnis solcher Entwicklungen ist häufig Vereinsamung. Dies hat wiederum oft zur Folge, daß „ältere Menschen, die geringe Kontaktmöglichkeiten haben, das Verkaufsgespräch verstärkt wegen der sozialen Kontaktmöglichkeiten suchen und weniger wegen der sachlichen Informationsvermittlung" (Kroeber-Riel 1984, 256). Hinzu kommt die Häufung von Gesundheitsproblemen wie z.B. Fußbeschwerden, die das Gehen erschweren, das Kaufen von Schuhen komplizieren und intensive fachliche Beratung erforderlichen. Diese Aspekte können die Expansion der Comfort-Verkaufsgespräche erklären.

Ein weiterer Gesichtspunkt, der für die Erklärung altersspezifischen Verhaltens eine Rolle spielt, ist die unterschiedliche Sozialisation der Mitglieder der beiden Zielgruppen. Das Comfort-Geschäft betreten hauptsächlich Frauen (nur ca. 15\% Männer), die ein oder sogar zwei Weltkriege und weitere wirtschaftliche Krisen miterleben mußten und die in einer Zeit des Unterangebots und Geldmangels aufgewachsen sind. Konsumverzicht war für diese Personengruppe demnach keine Seltenheit.

Im Young-Fashion hingegen kaufen in der Regel Jugendliche, die in der Zeit des Überangebots, der massiven Werbebeeinflussung sowie einer hohen Markttransparenz aufgewachsen sind. Sie leben in einer Zeit der Konsumfreude, da die Verfügungsmenge für Konsum in den letzten Jahrzehnten erheblich gestiegen ist. Das derzeit oftmals selbstverständliche Einkaufen Jugendlicher ohne Begleitung der Eltern war früher kaum denkbar. Kaufen war zu jener Zeit ein familiäres Ereignis; heute hat es eher den Charakter individueller Selbstverwirklichung.

Während die Comfort-Kunden also den Schuhkauf als soziales Ereignis und möglicherweise als Kompensation fehlender Kommunikation verstehen, verhalten sich Young-Fashion-Kunden gegenüber 'unnötigen' Ausweitungen des Verkaufsgesprächs in der Regel abweisend.

Alle bisher aufgeführten Aspekte weisen darauf hin, daß die Kunden beider Altersgruppen offensichtlich deutlich unterschiedliche Erwartungen mit einem Verkaufsgespräch verbinden, was zu den oben vorgestellten alters- bzw. zielgruppenspezifischen Phänomenen führt. 


\section{Literatur}

Bergmann, J.-R. (1987). Klatsch. Zur Sozialform der diskreten Indiskretion. Berlin: de Gruyter.

Coupland, N. (ed.) (1988). Style of Discourse. London/New York/Sidney: Croom Helm.

Coupland, N., Coupland, J. \& Giles, H. (1991). Language, Society and the elderly. Discourse, Identity and Aging. Oxford/Cambridge: Blackwell.

Coupland, N., Coupland, J., Giles, H. \& Wiemann, J. (1988). My life in your hands: processes of selfdisclosure in intergenerational talk. In: Coupland (1988), 201-253.

Gülich, E. (1980). Konventionelle Muster und kommunikative Funktionen von Altagserzählungen. In: Ehlich, K. (Hrsg), Erzählen im Alltag. Frankfurt a.M.: Suhrkamp, 335-384.

Kjolseth, R. \& Sack, F. (Hrsg.) (1971). Zur Soziologie der Sprache. In: Kölner Zeitschrift für Soziologie und Sozialpsychologie. Sonderheft 5/1971.

Kroeber-Riel, W. (1984). Konsumentenverhalten. München: Vahlen.

Pothmann, A. (1997). Diskursanalyse von Verkaufsgesprächen. Opladen: Westdeutscher Verlag.

Sacks, H. (1971). Das Erzählen von Geschichten innerhalb von Unterhaltungen. In: Kjolseth \& Sack (1971), 307-314.

Schröder, S. (1986). Lachen in Gesprächen: Formen und Funktionen der interaktionellen Organisation. Universität Bielefeld. Unveröffentlichte Staatsexamensarbeit.

Selting, M. (1987). Verständigungsprobleme: eine empirische Analyse am Beispiel der Bürger-Verwaltungs- Kommunikation. Tübingen: Niemeyer.

Vogt, R. (1976). Beschreibung und Erläuterung sprachlicher Kommunikation in Institutionen: Das Einkaufen. Universität Hamburg. Unveröffentlichte Staatsexamensarbeit. 


\title{
„Weil alte Leute übert Ohr hauen find ich wirklich nicht gut“"
}

\author{
Zur Funktion von altersthematisierenden Äußerungen im Diskurs
}

\author{
Guido Schnieders
}

Ausgehend vom aktuellen Interesse an altersspezifischer und altersbezüglicher Kommunikation (1) wird am Beispiel authentischer telefonischer Reklamationsgespräche (2) untersucht, welche Erwartungen die Beteiligten hinsichtlich des Alters von über 70jährigen KundInnen haben. Methodisch basiert die Untersuchung auf einer handlungstheoretischen Auffassung von pragmatischen Präsuppositionen (3), mit deren Hilfe herausgearbeitet wird, wie die Beteiligten bestimmte Vorstellungen über Alter im Diskurs aktualisieren und für ihre Zwecke funktionalisieren. Nach der Beschreibung des Korpus (4.1) werden zunächst Gespräche analysiert, die Dritte namens älterer Kundlnnen und für diese geführt haben (4.2). Die dort aufweisbaren Handlungspräsuppositionen werden bezüglich ihres Inhalts, ihrer handlungspraktischen Funktion und der Struktur bzw. Reichweite des innen zugrundeliegenden Wissens bestimmt. Sie unterscheiden sich in diesen Hinsichten von denen, die in Reklamationen vorkommen, die von älteren Kundlnnen selbst geführt werden (4.3). Die Analyse beschränkt sich aus methodischen Gründen auf Gespräche, in denen das Alter (bzw. das Altsein) von KundInnen explizit thematisiert wird.

\section{Einleitung}

In der öffentlichen Diskussion sind Alte und ist Alter vorwiegend als Problem präsent. Vor allem die absehbaren Folgen der bekannten demographischen Perspektiven - wie etwa die Krise der Rentenversicherungsträger - prägen das Bild vom Alter z.B. in den Medien. Von der „Überalterung der Gesellschaft“, der „Altenlast“ und der „Rentenlast“ ist die Rede, von „Krieg den Alten!“ gar. Der so inszenierte Verteilungskampf trägt dazu bei, daß vorwiegend negative Vorstellungen von Alten als handlungsmäßig eingeschränkt, hilfs- und pflegebedürftig, also abhängig, kommunikativ inkompetent, einsam usw. Konjunktur haben - nicht nur bei Jungen, sondern auch bei Alten selbst (vgl. Thimm 1995a).

Herabsetzende Vorstellungen über Alte und Alter sind nicht nur für die Situation in der BRD kennzeichnend. In den USA und in Großbritannien hat die Greifbarkeit solcher Vorurteile vor dem Hintergrund der Debatte über „political correctness“ schon vor einiger Zeit zu einer Intensivierung der Forschung über Kommunikation und Alter in Soziologie, Sozialpsychologie und Soziolinguistik geführt. ${ }^{1}$ Dabei ist die Untersu-

\footnotetext{
Wichtige Beiträge sind u.a. die Beschreibungen des „secondary baby talk“ in der Kommunikation zwischen Pflegepersonal und AltenheimbewohnerInnen (Caporael, Lukaszewski \& Culbertson 1983; Caporael \& Culbertson 1986); einflußreich für die Modellbildung im Forschungsbereich insgesamt ist die Akkommodationstheorie (Ryan et al. 1986; Coupland et al. 1988); den Forschungsstand im angelsächsischen Raum repräsentieren Coupland, Coupland \& Giles (1991), dort findet sich auch ein forschungsgeschichtlicher Überblick.
} 
chung von altersbezüglichen Vorurteilen (bzw. von Altenfeindlichkeit allgemein) ein zentraler Gegenstand.

Die Beschreibung von Stereotypen, ihren Manifestationsformen und ihrer Wirksamkeit macht aber nur einen Teil der im Forschungsbereich verfolgten Ziele aus. Beschreibungsgegenstand ist darüber hinaus generell die Veränderung sprachlicher und kommunikativer Fähigkeiten beim Übergang vom Erwachsenenalter zum Alter; so untersucht die Forschungsgruppe um Coupland, Coupland und Giles, wie sich diese Veränderungen in der Interaktion zwischen Alten und Jüngeren auswirken. ${ }^{2}$ Für den deutschen Sprachraum - in dem die wissenschaftliche Untersuchung von Kommunikation und Alter noch am Anfang steht - formuliert Fiehler (1996) ähnliche Forschungsdesiderate.

Hinsichtlich des Gegenstandsbezugs läßt sich in der internationalen Forschung erst spät - genauer: erst im Anschluß an die genannten Arbeiten von Coupland, Coupland und Giles - ein breiteres Interesse für die Untersuchung von Interaktionen bzw. Diskursen ausmachen. ${ }^{3}$ So ist nach wie vor ein Mangel an Analysen von authentischen altersspezifischen und altersbezüglichen Kommunikationen zu beklagen. Die wenigen Untersuchungen, die auf einer entsprechenden Grundlage basieren, verwenden zudem meist halbexperimentell erhobene Konversationen, deren Entstehung wesentlich durch die Aufgabenstellung und weniger durch die Bedürfnisse der an innen Beteiligten motiviert ist (so z.B. Coupland, Coupland \& Giles 1991; Coupland, Nussbaum \& Coupland 1991; Thimm 1995a, 1995b). Entsprechend werden mikroanalytische Untersuchungen von authentischen Diskursen dringend gefordert (vgl. Fiehler 1996; Thimm 1996).

Der vorliegende Beitrag leistet eine solche Untersuchung authentischer Diskurse am Beispiel von Reklamationsgesprächen. Für diese Diskurse ist das Alter der Kundlnnen normalerweise unerheblich. In bestimmten Konstellationen kommt es jedoch vor, daß das Alter älterer, d.h. über 70jähriger Kundlnnen thematisiert wird, weil es Beteiligten im Sinn ihrer Zielverfolgung geboten erscheint; die Kategorie "Alter" wird dann zweckfunktional eingesetzt. Konkret bilden dabei Erwartungen, die die Beteiligten in bezug auf Alte haben, die Voraussetzung für das Gelingen sprachlicher Handlungen, die für den Diskurszweck funktional sind. Diese Erwartungen werden nicht explizit. Sie sind stillschweigend geteilte Annahmen über Alte, die dem Bereich des Selbstverständlichen angehören, über das sich im Diskurs nicht eigens verständigt werden muß. Obwohl sie handlungsleitend sind, bleiben sie somit hintergründig und unauffällig. ${ }^{4} \mathrm{Da}$ sie aber für das sprachliche Handeln funktional sind, sind sie trotzdem analytisch rekonstruierbar.

Inhaltlich assoziieren diese Erwartungen Alter oft mit Kategorien wie „inkompetent“, „unmündig“, „handlungsmäßig eingeschränkt“ etc. Dabei weisen sie jedoch unterschiedliche Strukturen auf: Das ihnen zugrundeliegende Wissen hat je verschie-

2 Vgl. neben Coupland, Coupland \& Giles (1991) etwa Coupland et al. (1990) und Coupland, Nussbaum \& Coupland (1991).

3 Für frühere Arbeiten ist das Vorgehen der Untersuchungen von Caporael, Culbertson \& Lukaszewski (1983) und Caporael \& Culbertson (1986) typisch. Hier werden Aufnahmen von Kommunikationen zwischen Pflegepersonal und Altenheimbewohnerlnnen Versuchspersonen in Form einzelner, isolierter und dekontextualisierter Äußerungen paarweise dargeboten und von diesen in bezug auf vorgegebene inhaltliche Kategorien bewertet. Diskursanalytische Fragestellungen lassen sich so natürlich nicht bearbeiten; die sprachliche Wirklichkeit scheint in diesen experimentellen Settings nur auf äußerst vermittelte Weise auf.

4 Tatsächlich bin ich auch erst durch die Forschungen im Bereich „Kommunikation und Alter" auf diese Strukturen aufmerksam geworden. 
dene Reichweite und Geltungskraft. Es gibt z.B. Erwartungen der Form „Alte sind häufig nur eingeschränkt kompetent" wie auch solche der Form „Wie jeder weiß, sind Alte immer eingeschränkt kompetent". Welche Erwartungen mit welcher Struktur jeweils aktualisiert werden, ist abhängig davon, wer sie in den Gesprächen mit welchem Ziel in welchen Handlungen voraussetzt.

Ziel der folgenden Untersuchung ist die Rekonstruktion der Erwartungen und ihrer Strukturen in den genannten Hinsichten. Dabei werden die Erwartungen als Handlungspräsuppositionen analysiert (s. 3).

Die empirische Basis der Untersuchung bilden authentische telefonische Reklamationsgespräche, die von älteren Kundlnnen selbst oder von Dritten in deren Namen mit einem privatwirtschaftlichen Unternehmen geführt wurden. Analysiert werden Thematisierungen des Alters älterer - d.h. über 70jähriger - KundInnen. ${ }^{5}$

Im einzelnen wird in der Analyse für beide Anruferlnnengruppen vergleichend herausgearbeitet,

- welche Erwartungen bzw. Handlungspräsuppositionen die Beteiligten jeweils mit der Thematisierung des Alters verbinden,

- für welche Ziele und Zwecke die Beteiligten diese Präsuppositionen in den Reklamationsgesprächen jeweils funktionalisieren und

- welche Struktur das Wissen, das den Erwartungen bzw. Präsuppositionen zugrundeliegt, jeweils aufweist (d.h. auf was sich das präsupponierte Wissen jeweils bezieht und welche Geltungskraft ihm dabei unterstellt wird).

Die Analyse der Gespräche, die Dritte für und namens älterer Kundlnnen führen, hat sich als besonders fruchtbar erwiesen. Hier liegt deshalb der Schwerpunkt der vorliegenden Untersuchung.

Die Fragestellungen können nicht isoliert voneinander behandelt werden; die Analyse von Handlungspräsuppositionen kann insgesamt nur in bezug auf die Zwecke der Diskurse, in denen sie vorkommen, vorgenommen werden. Deshalb wird im folgenden zunächst auf die Zwecke von Reklamationsgesprächen eingegangen.

\section{Reklamationsgespräche}

Reklamationsgespräche ${ }^{6}$ sind Gespräche, in denen ein Kunde / eine Kundin die Befriedigung eines materiell bedeutsamen Anspruchs gegenüber einem Unternehmen einfordert. Reklamierende Kundlnnen sehen im Rahmen eines Kauf-VerkaufProzesses durch das Unternehmen ihre kaufvertraglich garantierten Interessen verletzt; der Zweck von Reklamationsgesprächen ist es, hier einen Interessenausgleich herbeizuführen.

5 Mit „Thematisierung des Alters älterer KundInnen“ ist hier nicht lediglich die Thematisierung des numerischen Alters gemeint, sondern allgemein die Thematisierung des Umstandes, daß ein Kunde / eine Kundin alt ist. Die Angabe des numerischen Alters ist also nur eines der möglichen Mittel, mit denen diese Thematisierung vorgenommen werden kann.

6 Linguistische Beschreibungen zu Reklamationsgesprächen finden sich bei Grießhaber (1985, 1987), Ohama (1987), Antos (1988, 1989), Fiehler \& Kindt (1994), Fiehler, Kindt \& Schnieders (demn.), Schnieders (demn.). 
Kennzeichnend für diesen Interessenausgleich ist das Aufeinandertreffen von unterschiedlichen Handlungsvoraussetzungen, -interessen und -formen. Reklamationsgespräche sind Diskurse, die die Grenze einer Institution überschreiten. Damit verbunden sind sie systematisch gekennzeichnet durch unterschiedliche Erwartungen und Orientierungen auf seiten der Beteiligten. So sind - ganz allgemein - die Kundlnnen eher an den Erfordernissen des eigenen Alltags orientiert, während die SachbearbeiterInnen sich von der Institution und ihren Routinen leiten lassen.

Dementsprechend unterscheidet sich das Wissen der Beteiligten bezüglich des reklamierten Sachverhalts, der zudem im Rahmen unterschiedlicher Handlungszusammenhänge wahrgenommen wird. Für die Kundlnnen stellt das reklamierte Problem eine meist ärgerliche Störung der normalen Handlungsabläufe des Alltags dar. Den Sachbearbeiterlnnen hingegen präsentiert sich der reklamierte Sachverhalt als ein professionell zu bearbeitender Fall, den sie zu behandeln haben, wie es durch die Arbeitsteiligkeit der Institution vorgegeben ist.

Verschieden sind entsprechend auch die Handlungsorientierungen bezüglich der Lösungsfindung; Kundlnnen und SachbearbeiterInnen verfolgen unterschiedliche und nicht immer miteinander zu vereinbarende Ziele. Die Kundlnnen erwarten sich von der Reklamation eine Problemlösung, die eine materielle Rekompensation beinhaltet und ihren konkreten alltagsbezogenen Bedürfnissen genügt. Die Sachbearbeiterlnnen haben eine Lösung zu wählen, die sich in die dafür vorgesehenen institutionellen Bearbeitungsprozeduren fügt.

Als Folge dieser Differenzen haben die Beteiligten im Diskurs unterschiedliche Aufgaben zu bearbeiten. Dabei sind Reklamationsgespräche - wie dies für professionelles Sprachhandeln in Institutionen typisch ist (vgl. Becker-Mrotzek 1991; Ehlich \& Rehbein 1994) - auf seiten der Institutionenvertreterlnnen vor allem von institutionellen Routinen bzw. entsprechenden Handlungsformen geprägt.

So müssen die Sachbearbeiterlnnen gezielt genau die Informationen erfragen, die für die institutionelle Kategorisierung der Sachverhalte relevant sind. Sie müssen institutionenspezifische Bearbeitungsverfahren wie das Erfragen von Auftragsnummern durchführen. Sie müssen schließlich eine Lösung durchsetzen, die der arbeitsteilig organisierten Zusammenarbeit innerhalb des Unternehmens entspricht, und sie müssen diese Lösung den KundInnen überdies als deren Bedürfnissen angemessen präsentieren. Dabei sind sie erheblich handlungserfahrener als die KundInnen: Die SachbearbeiterInnen sind sehr routiniert, führen die Gespräche professionell und werden für ihre Aufgaben geschult. Die Kundlnnen machen dagegen nur sporadisch Erfahrungen mit Reklamationsgesprächen.

Das Interesse der Beteiligten an der erfolgreichen Durchführung von Reklamationsgesprächen erklärt sich trotz dieser Differenzen aufgrund der Tatsache, daß diese Form der Problemlösung verglichen mit den Alternativen (z.B. einen Anwalt einschalten) für beide Seiten weniger aufwendig und damit vorteilhaft ist.

Insgesamt sind Reklamationen institutionalisierte Reparaturprozesse, die von Unternehmen eingerichtet und strukturiert werden, um im Konfliktfall im direkten Austausch mit den Kundlnnen einen Ausgleich herbeizuführen. ${ }^{7}$

7 Die Einrichtung von eigens mit der Reklamationsbearbeitung betrauten Abteilungen - und damit die Bündelung und Professionalisierung der entsprechenden Bemühungen - wird Unternehmen von betriebswirtschaftlicher Seite schon seit längerem empfohlen (vgl. Hansen \& Schoenheit 1979). Da diese Abteilungen gleich mehrere Funktionen im Rahmen des Marketing erfüllen, sind sie mittelfristig profitabel (zur Berechnung vgl. Hoffmann 1991); modernen Marketingkonzepten gelten sie als selbstverständlich (vgl. z.B. Bruhn 1995). 
Das Alter von Kundlnnen spielt bei Reklamationen im Regelfall keine Rolle - so wird etwa in Beispiel 1 (s. 4.2; FI. 29) deutlich, daß das Unternehmen, dem meine Aufnahmen entstammen, eine Altersangabe nicht routinemäßig erhebt. Die Thematisierung von Alter ist somit die Ausnahme. Sie dient der strategisch motivierten Verfolgung von Teilzielen, die in bezug auf den Gesamtzweck funktional sind. Wie unten gezeigt wird, sind es nur wenige und klar bestimmbare Teilziele, für die Verweise auf das Alter älterer Kundlnnen in Reklamationsgesprächen eingesetzt werden.

\section{Grundlagen der Analyse: Präsuppositionen}

Die folgende Analyse basiert auf der Funktionalen Pragmatik (vgl. Rehbein 1977; Ehlich \& Rehbein 1986; Ehlich 1991) und auf der entsprechenden Auffassung von Handlungspräsuppositionen (vgl. Ehlich \& Rehbein 1972). Die Funktionale Pragmatik begreift Diskurse als Abfolgen sprachlicher Handlungen, die im Rahmen gesellschaftlicher Zwecksetzungen zustandekommen; dabei schlägt sich ihre Zweckhaftigkeit in ihrer Musterstruktur nieder. Muster sind gesellschaftlich ausgearbeitete kommunikative Formen, die die innere Struktur von einfachen wie komplexen sprachlichen Handlungen angeben; sie spezifizieren die zweckbezogene Ordnung des Diskurses. Ihre Kenntnis, ihre Routinisierung entlastet die Interaktanten kognitiv und schafft damit Raum für die Planung und Durchführung etwa von diskursiven Strategien.

Präsuppositionen sind in diesem Rahmen diejenigen Voraussetzungen für das Gelingen einer sprachlichen Handlung, die die SprecherInnen bei der Ausführung der Handlung den Angesprochenen gegenüber als von beiden geteilt unterstellen und die bei Gelingen der Handlung vom Kommunikationspartner akzeptiert wurden. ${ }^{8}$ Die Präsuppositionen einer bestimmten Handlung konstituieren das gemeinsame Handlungssystem - bestehend aus gesellschaftlichem und womöglich nur den Handelnden gemeinsamem Wissen -, vor dessen Hintergrund die Handelnden die Handlung planen und das sie bei ihrer Ausführung wechselseitig voraussetzen. Präsuppositionen gehen in die Planung einer sprachlichen Handlung insofern als Erwartungen ein. ${ }^{9}$

8 In diesem Sinn unterstellt ein Sprecher A mit dem Vorwurf Du hast mich sehr enttäuscht, indem Du Dich so lange nicht gemeldet hast dem Angesprochenen B u.a., daß er berechtigterweise erwartet hatte, daß B sich meldet. A präsupponiert also, daß z.B. eine entsprechende Verabredung bestand oder die Art der sozialen Beziehung zwischen beiden so war, daß er erwarten durfte, daß $B$ sich meldet. Die Vorwurfshandlung setzt dabei voraus, daß diese Erwartung auf Wissen beruhte, das A und B gemeinsam ist, also auf einer gemeinsamen Handlungspräsupposition. Wenn B mit einer Entschuldigung reagiert (z.B. Ich hatte Deine Telefonnummer verloren) bestätigt er die Berechtigung des Vorwurfs und damit die gemeinsame Handlungspräsupposition. Eine Zurückweisung der Präsupposition müßte diese eigens zum Thema machen (z.B. Aber wieso denn, wir kennen uns doch kaum).

9 Der Bezug auf sprachliche Handlungen unterscheidet diese Auffassung von Präsuppositionen von sprachlichen Präsuppositionen, wie sie in der Linguistik im Anschluß an philosophische Präsuppositionstheorien (vgl. Frege 1962 [1892]; Strawson 1950) als wahrheitswertfunktionale Relationen zwischen Propositionen oder als kontextunabhängige Eigenschaften von Sätzen und Äußerungen diskutiert werden (vgl. Petöfi \& Franck 1973). Auch pragmatische Präsuppositionen im Sinn eines additiven Konzepts von Pragmatik sind hier nicht gemeint. Kennzeichnend für solche Konzepte ist, daß zunächst an isoliert betrachteten Sätzen mögliche äußerungsunabhängige Präsuppositionen bestimmt werden und anschließend deren Verhalten in vorgestellten Kontexten diskutiert wird (vgl. z.B. Gazdar 1979). Die hier analysierten Präsuppositionen von Handlungen sind grundsätzlich von 
Der Ausdruck „Präsupposition“ nimmt also Bezug auf Strukturen des Wissens und des Glaubens, die von den Beteiligten im Rahmen ihrer Kooperation wechselseitig als gemeinsame, als fraglose, als selbstverständlich gültige unterstellt werden. Gerade weil sie als selbstverständlich unterstellt werden, werden Präsuppositionen dabei nicht notwendig sprachlich expliziert. Da sie aber als Handlungsvoraussetzungen kommunikativ wirksam werden, sind sie analytisch, d.h. interpretativ-hermeneutisch rekonstruierbar.

Insgesamt erlauben Präsuppositionen es, über Aspekte gemeinsamen Wissens stillschweigend Einigung zu erzielen, d.h. geteilte Annahmen als Handlungsvoraussetzungen wirksam werden zu lassen, ohne sie zu thematisieren. Aufgrund dieser Charakteristik sind sie geeignet zum Transport dessen, was häufig als „Stereotyp“ oder „Vorurteil“ analysiert wird.

Allerdings äußert Redder (1995) grundsätzliche Zweifel an der analytischen Tragfähigkeit von Ausdrücken wie „Vorurteil“ oder „Stereotyp“. Sie kritisiert vor allem, daß etwa mit „Stereotyp“ nicht hinsichtlich der zugrundeliegenden Wissensstrukturen differenziert wird. Diese Kritik paßt zu den empirischen Befunden im hier analysierten Material: Die Präsuppositionen bezüglich des Alters von Kundlnnen in Reklamationsgesprächen weisen u.a. nicht immer dieselbe Bezugsdomäne und dieselbe Geltungskraft auf. Die Analyse faßt diese Präsuppositionen entsprechend nicht pauschal als „Vorurteile“ o.ä. auf, sondern differenziert sie - dem Vorschlag Redders folgend - mit Bezug auf die von Ehlich \& Rehbein (1977) entwickelte Unterscheidung verschiedener Typen von Wissensstrukturen. Damit lassen sich auch die jeweiligen Funktionen der Präsuppositionen genauer bestimmen.

Die Rekonstruktion von Handlungspräsuppositionen kann nicht für isolierte einzelne Äußerungen durchgeführt werden. Sprachliche Handlungen samt ihren Voraussetzungen bilden im Diskurs die Voraussetzungen für die jeweils folgenden Handlungen. Die Beschreibung von Präsuppositionen hat somit den Zweck und den Fortgang des gesamten Diskurses zu berücksichtigen. Entsprechend bezieht sich die Analyse altersbezüglicher Präsuppositionen auf die je aktuelle Ziel- und Zweckverfolgung der Beteiligten.

Konkret wird deshalb im folgenden jeweils ausgegangen von der Bestimmung der Musterposition, bei deren Realisierung die Thematisierung von Alter eine Rolle spielt. Ein solches Vorgehen liegt auch aufgrund der empirischen Befunde nahe: Thematisierungen von Alter treten im analysierten Material nur an ganz bestimmten Musterpositionen auf.

\section{Analyse}

\subsection{Das Korpus}

Die Materialbasis der Untersuchung bilden 100 transkribiert vorliegende Reklamationsgespräche (Gesamtdauer: 342 Minuten), die aus demselben Unternehmen stammen. In etwa 25 der Gespräche sind die Kundlnnen alt. ${ }^{10}$ Diese KundInnen-

zeichentheoretisch aufgefaßten Präsuppositionen (vgl. die Überblicke bei Seuren 1991 und Astroh 1996) zu unterscheiden.

10 Identifiziert wurden diese 25 Gespräche mit älteren Kundlnnen aufgrund allgemeiner intonatorischer und stimmlicher Merkmale oder weil in innen deren Alter explizit genannt wird. Es muß angenommen werden, daß das erstgenannte Verfahren nicht so exakt ist, wie das zu wünschen wäre 
gruppe spielt also eine quantitativ bedeutsame Rolle im Reklamationsaufkommen des Unternehmens. Dies läßt den Schluß zu, daß ältere Kundlnnen für die Firma wirtschaftlich relevant sind.

Thematisiert wird das Alter älterer Kundlnnen in 11 Gesprächen, also in etwas weniger als der Hälfte der Gespräche, die ältere Kundlnnen betreffen. Diese $11 \mathrm{Ge}-$ spräche bilden hier den zentralen Untersuchungsgegenstand. Die folgende Übersicht gibt an, wer in wieviel dieser Gespräche das Thema Alter initiiert und wer dabei jeweils anruft.

\begin{tabular}{|c|c|c||}
\hline $\begin{array}{c}\text { Thematisierung des Al- } \\
\text { ters der Kunden zuerst } \\
\text { durch... }\end{array}$ & Anruferln & Sachbearbeiterln \\
\hline \hline Dritte Person ruft an & 4 & 1 \\
\hline Kunde ruft selbst an & 6 & - \\
\hline
\end{tabular}

Wenn das Alter älterer Kundlnnen zum Thema wird, geht die Initiative fast immer von den Anruferlnnen aus - im wesentlichen sind es also die KlientInnen, die versuchen, das Alter für ihre Ziele zu funktionalisieren.

Deutlich ist weiter, daß SachbearbeiterInnen älteren Kundlnnen gegenüber nie deren Alter ansprechen. ${ }^{11}$

Wenn Dritte namens älterer Kundlnnen die Reklamation führen, kommt - das ist der Übersicht allein nicht zu entnehmen - deren Alter immer zur Sprache. Im folgenden Abschnitt wird verdeutlicht, warum das so ist.

\section{2 „Alter“ in Reklamationsgesprächen mit Dritten}

Thematisierungen des Alters der Kundlnnen finden sich in Reklamationsgesprächen, die Dritte namens älterer Kundlnnen führen, in außerordentlich systematischer Weise. Sie kommen in allen Gesprächen dieser Art vor und werden immer für die Verfolgung derselben Ziele eingesetzt, d.h. sie kommen immer an denselben Musterpositionen vor. Zudem wird in allen Gesprächen dieser Art derselbe Sachverhaltstyp (,nicht bedarfsgerechte Beratung“) reklamiert.

Um diesen Sachverhaltstyp zu illustrieren und zugleich anschaulich zu machen, wie altersbezügliche Präsuppositionen im Diskurs prozessiert werden, wird im folgenden zunächst ein kurzes Reklamationsgespräch vollständig wiedergegeben.

Für das Verständnis des Gesprächs ist wichtig, daß die Firma, der die Aufnahmen entstammen, im Direktvertrieb arbeitet - es gibt keinen Einzelhandel, verkauft wird durch Vertreterlnnen in der Wohnung der Kundlnnen, zugestellt wird per Post. Die Vertreterlnnen arbeiten auf Provisionsbasis; das Unternehmen kann Kaufverträge

- ein Grund, warum sich die Analyse auf die 11 Gespräche beschränkt, in denen das Alter explizit thematisiert wird.

11 Das entspricht Beobachtungen, die in bezug auf institutionell anders eingebettete Diskurse von Coupland, Coupland \& Giles (1991) und von Thimm (1995a, b) gemacht wurden. Diesen Beobachtungen zufolge sprechen in Gesprächen zwischen Alten und Jungen meistens die Alten selbst ihr Alter an. 
nicht ohne Begründung innen gegenüber stornieren oder aussetzen. In Beispiel 1 ruft eine Verwandte für eine 81jährige Kundin an und reklamiert, daß diese mit dem gekauften Produkt nichts anfangen kann und es eigentlich auch nicht haben wollte.

Beispiel $1^{12}$

${ }^{\mathrm{Tm}}[$ ( ) Müller und Co.

Aw

(Aufnahmebeginn bei Namensnennung Tms]

[ruft an]

Aw [ ten Tag, hier ist Rolff. . Und zwar hat meine Oma an der

Aw[ Türe hier von Müller son [PRODUKTBEZEICHNUNG] gekauft,

Aw $[$ ich sag Ihnen jetzt vorab mal die Geschichte. Und kann

Aw [ mit dem Ding nix machen, die ist einenachtzig, die hat

Aw[ sich wohl irgendwie überfahren jefühlt und hat das Ding

$\operatorname{Tm}^{>}[/$
Aw $[$per Nachnahme auch genommen. Jetzt, äh hat se mir dat

Aw [ nach Wochen jetzt gebeichtet, jetzt ne Bitte an Ihnen,

Aw[ wir ham alle Müller [PRODUKTBEZEICHNUNGEN] und so wei-

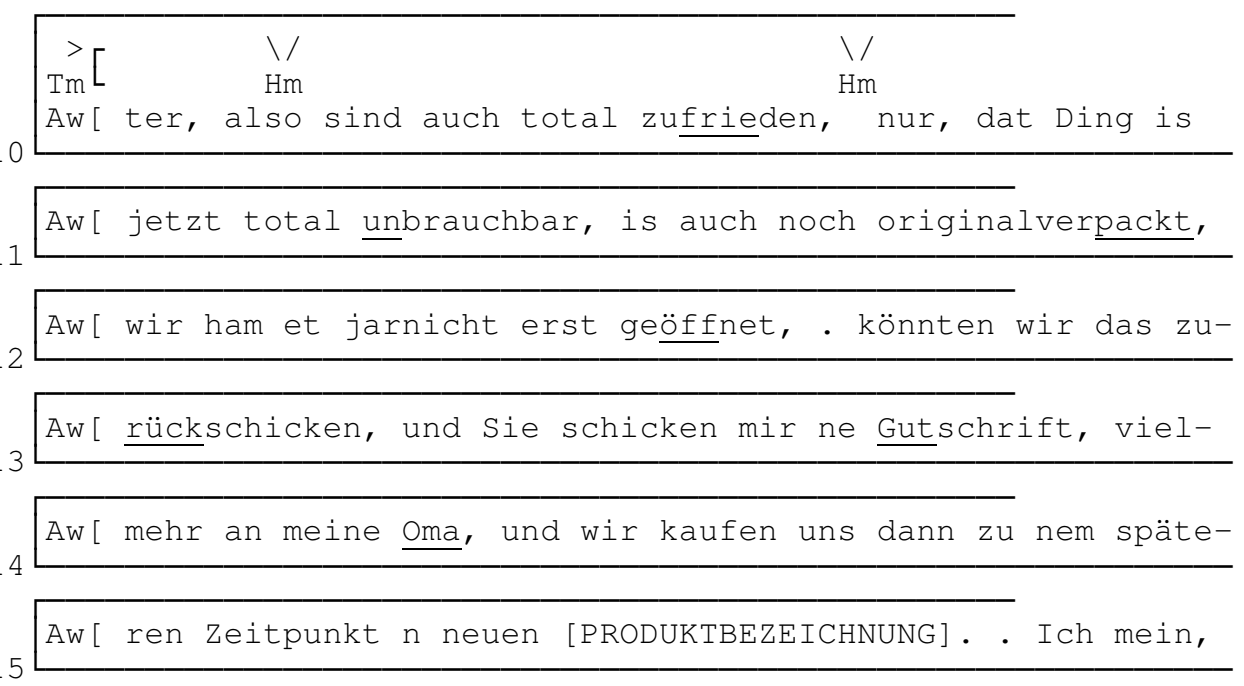

12 Alle Transkriptionen wurden mit dem PC-gestützten Transkriptionsprogramm HIAT-DOS 2.0 angefertigt (zu den Transkriptionskonventionen vgl. Ehlich \& Rehbein 1976; Ehlich \& Redder 1994). Die Siglen bezeichnen jeweils den Sachbearbeiter (,Tm“ für männlich, „Tw“ für weiblich), den Kunden („Km“ oder „Kw“) oder den Dritten, der namens eines Kunden anruft („Aw“ oder „Am“). Die Firmen- und Ortsnamen sowie Zahlenangaben sind durch Aliasnamen bzw. andere Zahlen ersetzt; die Größenordnungen der Geldbeträge blieben dabei erhalten. Produktbezeichnungen sind im Transkript durch „PRODUKT“, „PRODUKTNAME“ o.ä. wiedergegeben. 

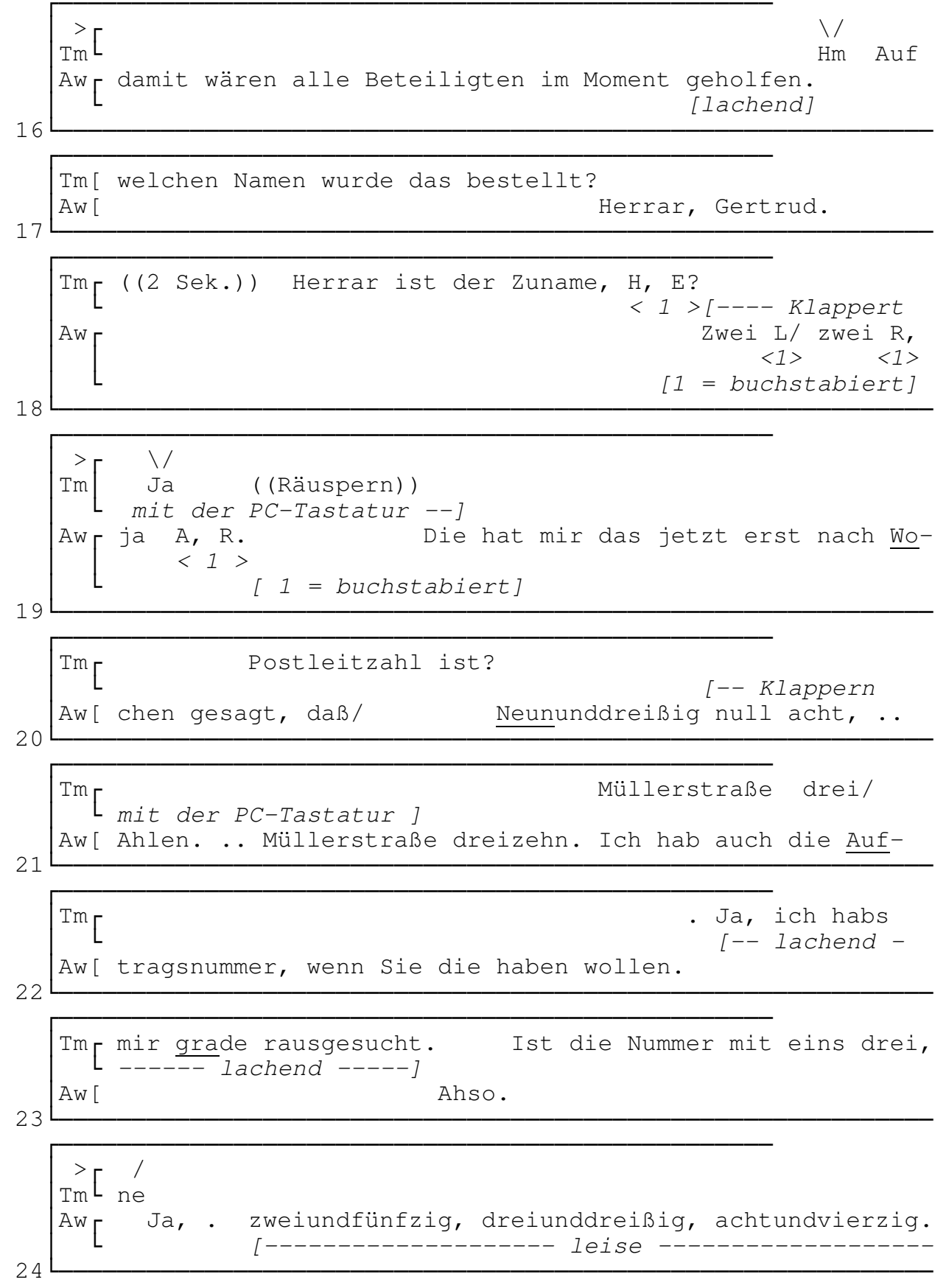

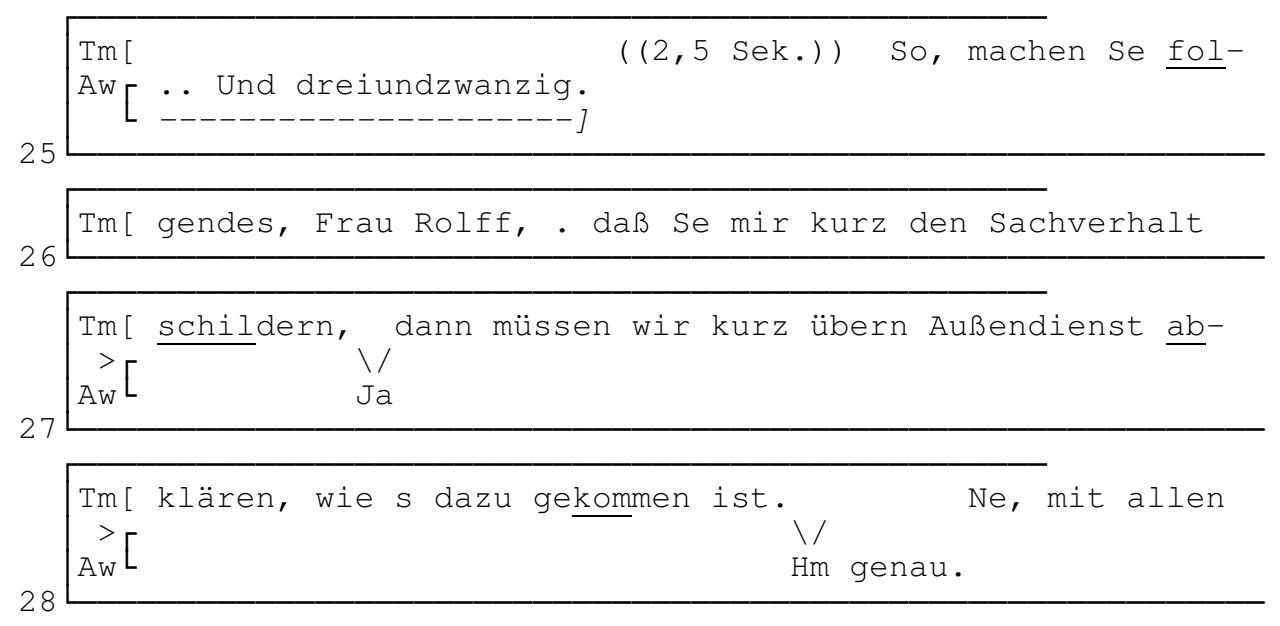




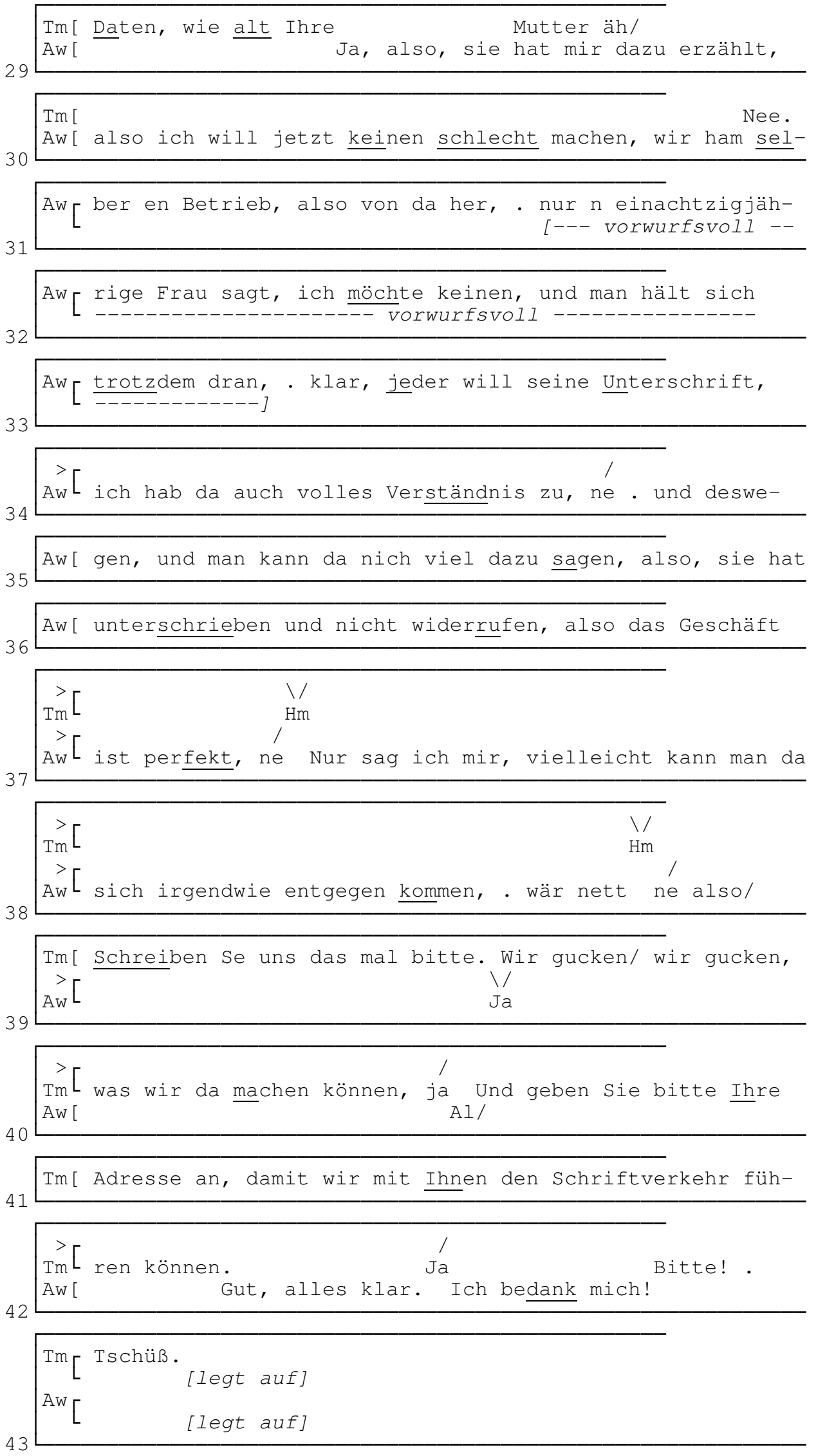


In diesem Gespräch wird ein Fall nicht bedarfsgerechter Beratung reklamiert: Die Kundin wollte das Gerät eigentlich gar nicht haben und kann es nicht gebrauchen; es wurde ihr, so die alltagssprachliche Ausdrucksweise vieler Kundlnnen, angedreht oder aufgeschwatzt. Sämtliche Gespräche im Korpus, in denen Dritte für ältere Kundlnnen anrufen, gehören zu diesem Typ. Den Kundlnnen werden - so die Vorwürfe im einzelnen - Geräte verkauft, auch wenn sie diese aufgrund eingeschränkter körperlicher Bewegungsfähigkeit nicht bedienen können oder die sie bereits haben; VertreterInnen - so andere Vorwürfe - fälschen oder erschleichen sich Unterschriften.

Womöglich deutet sich hier ein über mein Korpus hinaus verbreitetes Phänomen an: In etwa der Hälfte aller Fälle des Typs „nicht bedarfsgerechte Beratung“ sind ältere Kundlnnen betroffen; sie sind bezüglich dieses Typs damit überrepräsentiert. Es ist in diesem Zusammenhang wichtig zu betonen, daß es sich bei dem Unternehmen, dem die Aufnahmen entstammen, um ein traditionsreiches Haus mit gutem Ruf handelt, das sehr bemüht ist, sich von sogenannten „Drückerkolonnen“ abzusetzen. Tatsächlich wird - s. 4.2.4 - diesen Fällen firmenintern besondere Aufmerksamkeit zuteil.

\subsubsection{Präsuppositionen bei der Übernahme der geschäftlichen Zuständigkeit: Einschätzungen über Alte}

Die erste Thematisierung des Alters der Kundin findet gleich zu Beginn des Beispielgesprächs statt: In Fläche 2 (im folgenden abgekürzt Fl. 2) bezeichnet die Anruferin die Kundin als Oma, in FI. 5 nennt sie ihr numerisches Alter. Dieser Einstieg in den Diskurs ist für die Gespräche mit Dritten typisch. Beispiel 2 illustriert einen sehr ähnlichen Gesprächsanfang.

Beispiel 2
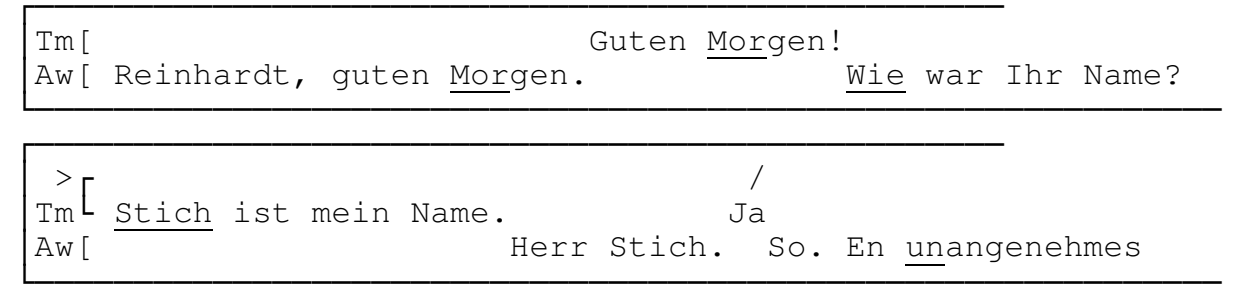

Aw[ Thema hier. . Also, . passen Se auf. Meine Mutter ist

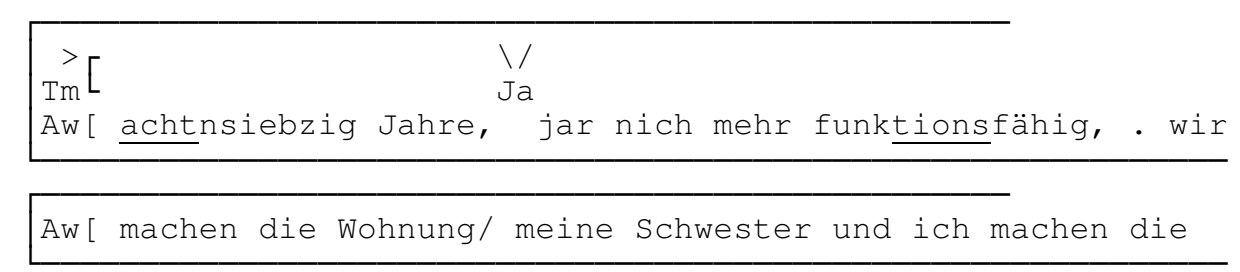

Die Thematisierung des Alters dient hier dazu, die jeweilige Anruferin als Gesprächspartnerin in Vertretung der Kundin zu etablieren und ihr die Übernahme der Geschäftskorrespondenz bis zur Erledigung des Falles zu sichern. Auffällig ist, daß diese Übernahme in beiden Beispielen nebensächlich und implizit abgehandelt wird. 
So fühlt sich die Anruferin in Beispiel 1 ganz selbstverständlich für die geschäftlichen Angelegenheiten der Kundin zuständig (vgl. etwa die Personaldeixeis in FI. 12$14^{13}$ ); einer sofortigen Ratifizierung durch den Sachbearbeiter bedarf es in beiden Beispielen nicht. In Beispiel 1 erfolgt eine solche Ratifizierung erst zum Ende des Diskurses und wird dann wiederum deutlich wie selbstverständlich abgehandelt (FI. 40-42). De facto wird die jeweilige Kundin und Vertragspartnerin damit von den Beteiligten als nur eingeschränkt geschäftsfähig - d.h. als partiell unmündig - behandelt.

An dieser Musterposition ${ }^{14}$ wird die Übernahme der geschäftlichen Zuständigkeit durch die AnruferInnen durchgeführt. Dabei wird grundsätzlich das numerische Alter der Kundlnnen angegeben - in dem einen Fall (s. die Tabelle in 4.1), in dem die Anruferin dies nicht von selbst tut, wird es vom Sachbearbeiter erfragt. Explizite Gründe für die Übernahme der geschäftlichen Zuständigkeit werden im allgemeinen nicht gegeben (vgl. Bsp. 1). Offensichtlich spielen an dieser Musterposition als Voraussetzung für die Zuständigkeitsübernahme Präsuppositionen eine Rolle, die es erlauben, Alten in Geschäftsdingen (partielle) Unmündigkeit zu unterstellen.

Allerdings sind diese Präsuppositionen allein für die Zuständigkeitsübernahme nicht hinreichend; die Analyse sämtlicher Gespräche dieses Typs ergibt ein weit genaueres Bild.

Demnach ist neben der Angabe des numerischen Alters der Kundlnnen noch die Angabe des Verwandtschaftsgrades der Anruferlnnen zu den Kundlnnen für die Übernahme der Zuständigkeit konstitutiv - wenn diese Angabe ausbleibt, wird von den SachbearbeiterInnen nachgefragt.

Nur, wenn die angegebene Verwandtschaft eine in direkter Linie ist, genügt - wie in den Beispielen 1 und 2 - pauschal die Angabe des Alters. Ist die Verwandtschaft weitläufiger oder die soziale Beziehung von anderer Natur, werden Angaben gemacht, die die eingeschränkte Geschäftsfähigkeit der Kundlnnen individuell begründen. Bleiben diese Angaben aus, so werden sie nachgefragt. Zudem wird in diesen Fällen die Übergabe der geschäftlichen Zuständigkeit explizit gemacht.

Insgesamt werden an dieser Musterposition mit der Thematisierung des Alters der Kundlnnen somit Präsuppositionen wirksam, die Alten in geschäftlichen Hinsichten (partielle) Unmündigkeit unterstellen. In Beispiel 1 und 2 wird deutlich, daß sich die Beteiligten dabei nicht der Gültigkeit dieser Inhalte erst wechselseitig versichern müssen; es handelt sich also um Elemente voraussetzbaren, mithin gesellschaftlichen Wissens.

Dieser Befund muß jedoch noch präzisiert werden. Die an der analysierten Musterposition aufgewiesenen Präsuppositionen sind nicht als pauschale Zuschreibun-

${ }^{13}$ Interessant ist, daß die Anruferin in diesem Abschnitt einmal zur juristisch korrekten Referenz zurückkehrt: Nachdem sie sich selbst mit und Sie schicken mir ne Gutschrift (Bsp. 1, Fl. 13) explizit als geschäftlich Handelnde eingesetzt hat, verbessert sie sich mit vielmehr meiner Oma (FI. 13-14). Auf der Gutschrift, die den Kaufvertrag ablösen soll, soll also der Name der Kundin stehen. Hier wird deutlich, daß die Übernahme der geschäftlichen Zuständigkeit zwar faktisch, nicht aber formell vollzogen wird - formell, d.h. juristisch abgesichert setzte das den komplizierten und konsequenzenreichen Akt der Entmündigung voraus.

14 Konkret handelt es sich bei dieser Position im Gesamthandlungsmuster „Reklamationsgespräch“ um die „beidseitige Klärung der Zuständigkeit“. Hier wird geklärt, ob die Sachbearbeiterlnnen für das Problem zuständig und die AnruferInnen bezüglich des Problems verhandlungs- und entscheidungskompetent sind. Die Realisierungsformen dieser Musterposition im Korpus sind sehr vielfältig. In Abhängigkeit von der Vorgeschichte kann die Klärung der Zuständigkeit sehr aufwendig sein; häufig wird sie allerdings auch eher implizit, d.h. durch Vollzug abgehandelt. 
gen aufzufassen, die allen Alten unterstellt werden. Sie sind hinsichtlich ihrer Geltungskraft vielmehr einzuschränken. Die Fälle, in denen keine direkte Verwandtschaft vorliegt, zeigen, daß die Präsupposition „nur eingeschränkt geschäftsfähig“ nicht generell mit der Angabe des Alters verbunden wird. Auch in den anderen Gesprächen ist immer nur von einzelnen, bestimmten Alten die Rede, nie von Alten generell.

Dem gesellschaftlichen Wissen, das den Präsuppositionen zugrundeliegt, kann hier lediglich die Reichweite einer Einschätzung ${ }^{15}$ (vgl. Ehlich \& Rehbein 1977; Redder 1995) zugesprochen werden. Die Beteiligten setzen an dieser Musterposition lediglich voraus, daß es häufiger Alte gibt, die nur eingeschränkt geschäftsfähig sind; sie haben entsprechend quantifizierte Erwartungen. Davon ausgehend genügt dann in Beispiel 1 und 2 die Relevantsetzung dieser Möglichkeit durch die Thematisierung des Alters, um die Übergabe der geschäftlichen Zuständigkeit in die Wege zu leiten.

Die konkrete handlungspraktische Wirksamkeit der Präsuppositionen hängt an der analysierten Musterposition - wie gesehen - auf komplexe Weise von weiteren Faktoren ab. Dabei sind wiederum die zweckbezogenen Interessen der Institution wichtig. So ist der Unterschied in der Behandlung direkt verwandter und anderer AnruferInnen auf den Umstand zurückzuführen, daß dem Unternehmen die ersteren in bezug auf die weitere Kooperation als zuverlässiger gelten können.

\subsubsection{Präsuppositionen bei der Reklamation von „nicht bedarfsgerechter Beratung“ I: Der Aufbau von Bildern über einzelne Kundlnnen}

Die Thematisierung des Alters der KundInnen ist in den Gesprächen mit Dritten nicht nur für die Übernahme der geschäftlichen Zuständigkeit, sondern auch für den Reklamationszweck im engeren Sinn funktional.

In Beispiel 1 und 2 erfolgt die Angabe des numerischen Alters der Kundin direkt nach der das Rederecht sichernden Ankündigung ich sag Ihnen jetzt vorab mal die Geschichte (Bsp. 1, Fl. 4) bzw. Also, . passen Se auf (Bsp. 2, Fl. 4). Damit werden die Sachverhaltsdarstellungen durch die Anruferinnen eingeleitet. Natürlich sind diese Darstellungen zielgeleitet: Die Anruferinnen versuchen, eine alltagsweltliche Sachverhaltspräsentation zu geben, die es nahelegt, den Fall als „nicht bedarfsgerechte Beratung“ zu kategorisieren und damit den Kaufvertrag für nichtig zu erklären. ${ }^{16}$ Die Thematisierung des Alters der Kundlnnen spielt dabei eine wichtige Rolle.

Die Bedingungen einer Reklamation von „nicht bedarfsgerechter Beratung“ lassen sich wiederum aus einer größeren Zahl von Gesprächen rekonstruieren. Auch hier gilt: Wenn eine der nachstehenden Begründungen nicht angeführt wird, wird in den

15 Wissensstrukturen vom Typ Einschätzung liegen nach Ehlich \& Rehbein (1977) vor, wenn ein Gewußtes über ein Wissensthema diesem nach Ansicht des Wissenden mehrfach zukommt. Einschätzungen stellen gegenüber rein partikularem Erlebniswissen zwar bereits eine synthetische Leistung dar. Da das Gewußte dem Thema des Wissens jedoch nicht immer zukommt, erlauben sie andererseits nur schwache Antizipationen zukünftiger Sachverhalte und bilden allein keine feste Ausgangsbasis für das Handeln.

16 In Beispiel 1 versucht die Anruferin lediglich, eine Umwidmung des Kaufvertrages mit nicht zeitlich limitiertem Aufschub zu erreichen. Meistens bestehen die Anruferlnnen jedoch auf der Nichtigkeit des Kaufvertrages. 
Gesprächen entsprechend nachgefragt oder die Angelegenheit nicht als „nicht bedarfsgerechte Beratung" kategorisiert und der Kaufvertrag nicht außer Kraft gesetzt.

Demnach ist für „nicht bedarfsgerechte Beratung“ zunächst konstitutiv, daß kein Bedarf besteht. Diese Voraussetzung ist z.B. gegeben, wenn die gekauften Produkte beim Kunden bereits in hinreichender Zahl vorhanden sind oder die KundInnen sie aufgrund eingeschränkter Handlungsfähigkeit nicht handhaben können. In Beispiel 1 verweist die Anruferin zweimal, in FI. 5 und 11, darauf, daß die Kundin mit dem Ding nix machen kann und dat Ding ... jetzt total unbrauchbar ist. Dabei wird diese Behauptung nicht durch Angaben über die möglicherweise eingeschränkte Mobilität der Kundin, sondern nur durch die Angabe ihres Alters (in FI. 5) gestützt.

Die zweite Bedingung ist, daß der Kaufwille zum Kaufzeitpunkt nicht wirklich vorhanden war bzw. sich nicht an den objektiven Gegebenheiten hat orientieren können. ${ }^{17}$ Diese Bedingung liegt z.B. vor, wenn dem Vertreter / der Vertreterin irreführende Angaben nachgewiesen werden können oder der Kunde nicht weiß, was er bestellt hat, weil aufgrund seiner schlechten Deutschkenntnisse im Verkaufsgespräch keine Verständigung zustande kam. In den Gesprächen, die Dritte namens älterer KundInnen führen, setzen die Anruferlnnen an dieser Stelle spezifische Präsuppositionen zu deren Alter für ihre Ziele ein.

Die Anruferin in Beispiel 1 verfolgt hier eine Doppelstrategie. Einerseits präsentiert sie gleich ihre ganze Familie als Stammkundlnnen (FI. 9/10) und macht dann den Vorschlag mit der Gutschrift (FI. 13-15). Sie zielt hier also eher auf eine Kulanzregelung ab als auf eine Reklamation von „nicht bedarfsgerechter Beratung“.

Zugleich aber teilt sie mit, die Kundin habe sich wohl irgendwie überfahren jefühlt (FI. 6). In dieser Phase des Gesprächs wird damit noch nicht direkt ein Fehlverhalten des Vertreters / der Vertreterin unterstellt. Mögliche Gründe, warum sich die Kundin wohl überfahren gefühlt hat, ergeben sich nur implizit, im Zusammenhang mit der Angabe ihres Alters (FI. 5). Diesen Zusammenhang unterstützt die Anruferin im weiteren, indem sie in ihrer Darstellung präsupponiert, die Oma sei unselbständig, abhängig, hilfs- und kontrollbedürftig (vgl. Fl. 7/8: Jetzt, äh hat se mir dat nach Wochen jetzt gebeichtet, FI. 19/20: das jetzt erst nach Wochen gesagt, daß). In Beispiel 2 finden sich inhaltlich und funktional vergleichbare Strukturen in Fl. 5 und 6 (jar nich mehr funktionsfähig, . wir machen die Wohnung/).

Die Anruferlnnen präsupponieren hier, daß die Kundlnnen gleich in mehreren Hinsichten - und darunter auch in solchen, die mit der Reklamation prima facie nichts zu tun zu haben scheinen - unselbständig, abhängig etc. sind. Indem sie das tun, bauen sie ein bestimmtes Bild (vgl. Ehlich \& Rehbein 1977; Redder 1995) von ihnen auf (anders als die Einschätzung in 4.2.1 bezieht sich das Bild hier jeweils auf eine individuelle Kundin).

Das Bild ist eine Wissensstruktur, die aus einer Reihe von - inhaltlich analogen Einschätzungen über einen Gegenstand zusammengesetzt ist. Es ist gegenüber der Einschätzung das Resultat einer weiteren Extrapolation: Das Gewußte trifft beim Bild nicht mehr nur häufig auf einen Gegenstand zu. Vielmehr hat sich gezeigt, daß das Gewußte wiederholt auf den Gegenstand zutrifft, so daß es sich zu verläßlichem

17 Diese - in den Reklamationsgesprächen alltagsbezogen vorgenommene - Angabe hat ein juristisches Korrelat: Im Privatrecht kann die Willenserklärung, die einem Rechtsgeschäft zugrundeliegt, wegen Irrtums, arglistiger Täuschung oder Drohung nichtig sein (vgl. Avenarius 1992). Das Alter einer Person ist rein juristisch natürlich kein Nichtigkeitsgrund. 
Wissen verdichtet, also immer für den Gegenstand gilt. Anders als die Einschätzung stellt das Bild damit sicheres Wissen über ein Thema dar. Es erlaubt gesicherte Antizipationen von Sachverhalten und bildet somit eine verläßliche Handlungsbasis.

Durch das präsupponierte Bild stellen die Anruferlnnen an dieser Musterposition die jeweilige individuelle Kundin generell als unselbständig, unmündig, mithin abhängig dar.

Die Anruferlnnen verfolgen mit der Strategie „Bild aufbauen“ das Ziel, zu illustrieren, daß der Kaufwille zum Zeitpunkt der Vertragsunterzeichnung nicht vorhanden war. Sie versuchen zu zeigen, daß es hier nicht darum geht, daß die jeweilige Kundin es sich im Nachhinein anders überlegt hat (das wäre kein Reklamationsgrund). Wenn die Kundin generell unselbständig und nur eingeschränkt geschäftsfähig ist, kann von einem entsprechenden Willen auch zum Kaufzeitpunkt nicht ausgegangen werden. ${ }^{18}$ Der Kaufvertrag wäre mithin - nicht im formalen, juristischen Sinn, sondern im Sinn der guten Sitten - als nichtig anzusehen.

Der aufgezeigte Übergang von der Einschätzung zum Bild in den analysierten Gesprächen ist eine Konsequenz der vorherigen Übernahme der geschäftlichen Zuständigkeit. Indem die Einschätzung „es gibt unmündige Alte“ neben anderen Faktoren dazu beiträgt, daß anschließend eine bestimmte ältere Kundin faktisch als unmündig behandelt wird, wird ein entsprechendes Bild von dieser bestimmten Kundin bereits handlungsleitend. Ebenso setzt die anschließende Strategie „Bild aufbauen“ die aufgewiesene Einschätzung voraus: Eine mögliche Übernahme des Bildes und der Konsequenzen durch die Sachbearbeiterlnnen, also ein möglicher Erfolg der Strategie wird durch die geteilte Einschätzung, daß es unmündige Alte gibt, wahrscheinlicher.

\subsubsection{Präsuppositionen bei der Reklamation von „nicht bedarfsgerechter Beratung" II: Allgemeine Sentenzen bezüglich aller Alten}

Das Verfahren „Bild aufbauen“ ist ein alltagsbezogenes Verfahren; im Alltag ist es vermutlich auch meist erfolgreich. Institutionen basieren indes auf anderen Handlungsformen - vor allem auf solchen, die die Verrechtlichung der Institution reflektieren. Rechtlich sind die Kundlnnen aber grundsätzlich geschäftsfähig.

Damit ist der Erfolg des Verfahrens „Bild aufbauen“ insgesamt fraglich; die Anruferin in Beispiel 1 macht in FI. 35-37 deutlich, daß sie das weiß. Entsprechend verwenden die Anruferlnnen in den Gesprächen mit Dritten weitere, auf den Bildern aufbauende Strategien. Für diese Strategien ist wiederum charakteristisch, daß die bisher präsupponierten Wissensstrukturen weiter verallgemeinert werden.

In Beispiel 1 reagiert der Sachbearbeiter auf das Verfahren „Bild aufbauen“ und den anschließenden Vorschlag der Anruferin, indem er die Entscheidung vertagen und den Sachverhalt intern prüfen lassen will (FI. 26-28). Das ist die seitens der Institution vorgesehene Bearbeitungsprozedur (s. 4.2.4). Daraufhin beginnt die Anruferin, von ihrer Bitte um eine Kulanzregelung abzurücken und ihre vorher verfolgte Strategie zu ergänzen. In FI. 31-33 formuliert sie mit nur n einachtzigjährige

18 Für den Aufbau des Bildes und für die Wirksamkeit der damit verbundenen Strategie ist es unerheblich, ob es sich hier um ein Trugbild handelt, ob eine der Anruferlnnen also versucht, sich bzw. der Kundin durch irreale Darstellungen Vorteile zu verschaffen. Das Bild bezieht sich hier jeweils auf eine individuelle Kundin; die SachbearbeiterInnen haben mithin während des Gesprächs keine Möglichkeit, die Angaben zu überprüfen. 
Frau sagt, ich möchte keinen, und man hält sich trotzdem dran einen Vorwurf (vgl. zu Vorwürfen im einzelnen Rehbein 1972), mit dem sie unterstellt, daß eine Fehlhandlung seitens des Vertreters / der Vertreterin vorliegt und sie mithin Anspruch auf Kompensation hat.

Vorwürfe dieser Art sind in den Gesprächen mit Dritten typischerweise anzutreffen. Beispiel 3 illustriert eine weit weniger zurückhaltende Formulierung.

\section{Beispiel 3}

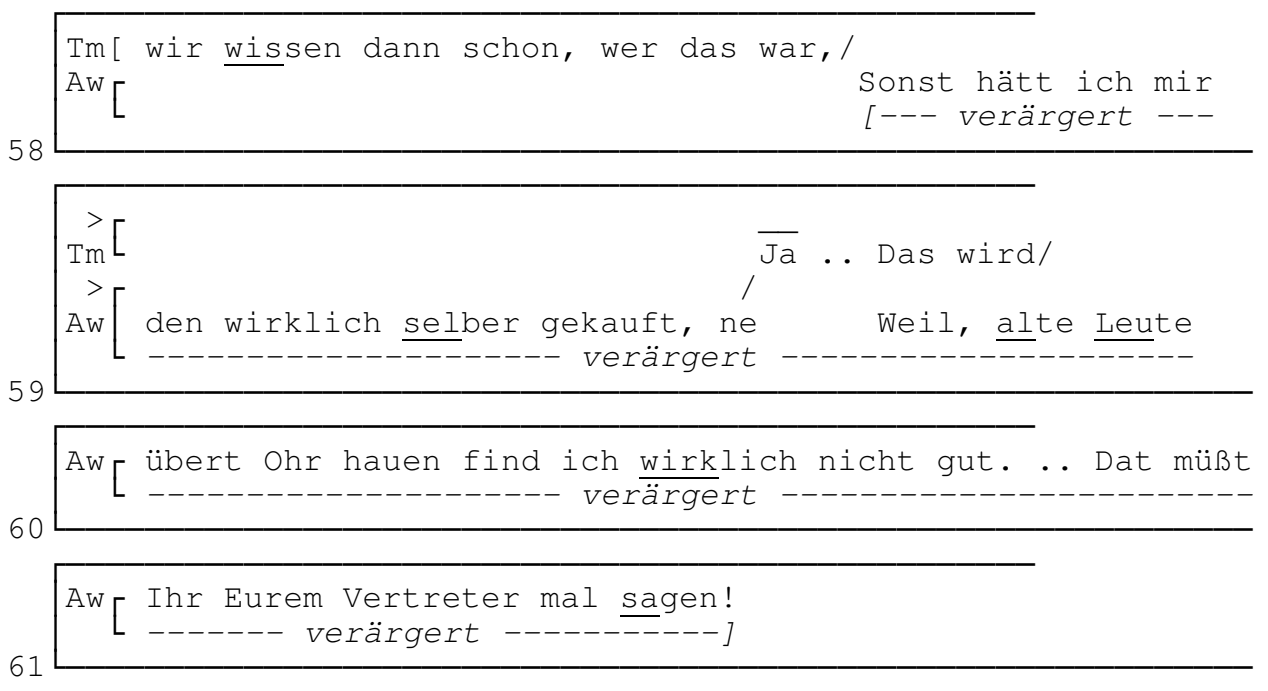

Gegenüber dem Bild setzen die Vorwurfsformulierungen in Beispiel 1 und 3 ein allgemeineres Wissen voraus. Offensichtlich ist hier nicht mehr nur von bestimmten einzelnen Alten die Rede, sondern von Alten generell. Mit den Vorwürfen wird präsupponiert, alte Leute bzw. einachtzigjährige Frauen wären allgemein unselbständig, d.h. hier: hilflos.

Diese Verallgemeinerungen sind funktional motiviert. Wenn als selbstverständlich vorausgesetzt werden kann, daß Alte generell unselbständig und hilfsbedürftig sind, dann gilt dieses Wissen auch für alle Wissenden. Das Wissen, das mit den Vorwürfen unterstellt wird, hat die Struktur einer Sentenz (vgl. Ehlich \& Rehbein 1977; Redder 1995); es gilt nicht nur immer, sondern auch für alle Subjekte des Wissens. ${ }^{19}$

Damit kann den Vertreterlnnen hier eine Fehlhandlung unterstellt werden: Da auch sie hätten wissen und erwarten müssen, daß Alte tendenziell unselbständig sind, wären sie zu besonderer Rücksicht auf die Kundlnnen verpflichtet gewesen. Da der Kaufwille der KundInnen im Nachhinein nicht mehr gegeben ist, haben sie diese Rücksicht offensichtlich nicht walten lassen.

19 Die Verwendung von immer, alle, mehrere u.a. quantifizierenden Ausdrücken ist hier - wie auch in bezug auf den Strukturtyp Bild in 4.2.2. - nicht im Sinn einer logischen Quantifizierung zu verstehen. Ehlich \& Rehbein $(1977,56)$ weisen in ihrer Diskussion der Sentenz darauf hin, daß „das in der Sentenz abgebundene Wissen (...) das Recht zur All-Quantifizierung also nicht aus einem überprüfbaren Rückbezug im Sinn der Logik auf alle bekannten Individuen usw.“ bezieht. Mentale Strukturen sind von anderer Natur. Sie unterliegen einer pragmatischen Quantifizierung und können auch im Falle der All-Quantifizierung nicht durch ein einziges Gegenbeispiel allein widerlegt werden. Die pragmatische Bestimmung der All-Aussage ist somit systematisch diffus. - Gewendet auf die Vorwürfe in Beispiel 1 und 3 meint das: Unterstellt wird hier nicht, es gäbe keine Alten, die selbständig, mündig, geschäftsfähig etc. sind, sondern lediglich, daß allgemein erwartet werden muß, daß Alte entsprechend eingeschränkt kompetent sind. 
Während das Verfahren „Bild aufbauen“ zu einer Sachverhaltsdarstellung geführt hat, gemäß der eine generell unselbständige Kundin ohne die Fähigkeit, ihr Tun richtig einzuschätzen, einen Kaufvertrag unterschrieben hat, wird durch die Verallgemeinerung des Bildes zur Sentenz jetzt das Vorliegen eines Verstoßes begründet (wiederum nicht im juristischen Sinn, aber gegen die guten Sitten). Folglich leiten die Anruferlnnen daraus einen Anspruch auf Reparatur ab.

Die Präsupponierung von Sentenzen wie „wie allgemein bekannt ist, sind Alte generell abhängig, hilfs- und kontrollbedürftig, nur eingeschränkt geschäftsfähig etc." in Vorwurfshandlungen wird in den analysierten Gesprächen durch die jeweils vorangehende Strategie „Bild aufbauen“ vorbereitet. Die Verwendung einer solchen Sentenz setzt voraus, daß Entsprechendes auch für die jeweilige individuelle Kundin angenommen wird - andernfalls wäre sie nicht funktional einsetzbar. Zugleich wird die Sentenz durch das vorher aufgebaute Bild von der Kundin gegen eine mögliche Zurückweisung abgesichert: Der Sentenz zu widersprechen wäre angesichts der Tatsache, daß die betroffene Kundin behindert ist, sehr unhöflich. Tatsächlich kommt eine solche Zurückweisung in meinem Korpus nur einmal vor.

4.2.4 Alter und die institutionenspezifische Bearbeitung von „nicht bedarfsgerechter Beratung"

Die bisherige Analyse hat kaum darauf Bezug genommen, ob die von den AnruferInnen unterstellten Wissensvoraussetzungen auch von den SachbearbeiterInnen (bzw. der Institution) geteilt werden. Gezeigt wurde lediglich, daß die Übernahme der geschäftlichen Zuständigkeit durch die AnruferInnen (s. 4.2.1) gelingt und daß die dabei unterstellten Präsuppositionen vom Typ Einschätzung als Teil des gemeinsamen Handlungssystems damit von der Institution - eben qua Handlungsvollzug - bestätigt werden.

In Beispiel 1 reagiert der Sachbearbeiter auf den Vorwurf der Anruferin (FI. 31-33) nicht bzw. nur mit einer Wiederholung der Aufforderung, den Sachverhalt schriftlich darzustellen (FI. 39/40). Diese indifferente Haltung wird durch die Bearbeitungsverfahren der Institution systematisch erzeugt.

Bei „nicht bedarfsgerechter Beratung“ wird die Sachlage grundsätzlich vom Unternehmen erst geprüft, und d.h. mit dem jeweiligen Vertreter abgeklärt. Das erfordert eine schriftliche Reklamation, weil die Vertreterlnnen bei einem vorliegenden rechtsgültigen Kaufvertrag juristisch verbrieften Anspruch auf ihre Provision haben. Die SachbearbeiterInnen sind hinsichtlich dieser Fälle also gar nicht entscheidungskompetent. Sie müssen sich indifferent verhalten, was die Übernahme der beschriebenen Präsuppositionen etwa vom Strukturtyp Sentenz angeht - andernfalls würden sie der Entscheidung vorgreifen.

Trotzdem spielt das Alter der Kundlnnen bei der Bearbeitung dieser Fälle eine Rolle. Es gibt eine - genau eine - Musterposition, an der die Sachbearbeiterlnnen deren Alter thematisieren. Diese Position ist die Aufforderung, den Sachverhalt schriftlich zu schildern. An dieser Position ergeht in allen Gesprächen dieser Art der Hinweis, dabei das Alter der Kundin / des Kunden anzugeben (in Bsp. 1 in FI. 29). Den Hintergrund bildet hier wiederum die erwähnte Sachverhaltsprüfung qua Rücksprache mit dem Vertreter / der Vertreterin: Die Firma erhebt an dieser Musterposition systematisch die Informationen, die für die anschließenden internen Auseinandersetzungen relevant sind. 
Offensichtlich gilt somit der Umstand, daß ein Kunde / eine Kundin alt ist, im Zusammenhang mit einer Reklamation wegen „nicht bedarfsgerechter Beratung“ firmenintern als bedenkenswert. Trotz der systematischen Indifferenz der Sachbearbeiterlnnen gegenüber den entsprechenden Strategien der AnruferInnen scheinen also Präsuppositionen über Alte in die institutionellen Routinen eingegangen zu sein. Da „nicht bedarfsgerechte Beratung“ in bezug auf Alte überproportional häufig reklamiert wird (s. 4.2), ist davon auszugehen, daß hier systematisch versucht wird, die Vertreterlnnen bezüglich dieser Fälle zu kontrollieren und abzuschrecken. Die nähere Bestimmung der institutionellen Präsuppositionen ist allein anhand der Transkripte allerdings nicht möglich.

Insgesamt ist damit für Reklamationsgespräche, die Dritte namens älterer KundInnen führen, typisch, daß die AnruferInnen Präsuppositionen, denen zufolge Alte abhängig, hilfs- und kontrollbedürftig, in geschäftlichen Hinsichten partiell unmündig etc. sind, für ihre Ziele einsetzen. Diese Präsuppositionen werden als - relativ unauffällige - Einschätzungen in das gemeinsame Handlungssystem eingeführt und bis zur Sentenz verallgemeinert; ihr Bezugsbereich und ihre Geltungskraft wird von den Anruferlnnen dabei differenziert auf das jeweils verfolgte Teilziel bezogen. Es ist somit eine systematisch aufgebaute und zweckfunktional abgestufte strategische Verwendung dieser Präsuppositionen zu erkennen. Auf seiten der Institution sind sie - mit allerdings noch unbestimmter Qualität - Bestandteil von Routinen.

\subsection{Thematisierungen des eigenen Alters durch die Kundlnnen}

In Reklamationsgesprächen, die von älteren Kundlnnen selbst geführt werden, werden Thematisierungen ihres Alters ausschließlich von ihnen selbst vorgenommen. Sie sind überwiegend an der Musterposition zu finden, an der die Problemlösung behandelt wird oder dort, wo das weitere Vorgehen (z.B. schriftliche Darstellung durch den Kunden / die Kundin und Prüfung seitens der Institution) besprochen wird, nur selten in den früheren Phasen der Diskurse. Die Kundlnnen verfolgen mit der Thematisierung ihres Alters im allgemeinen das Ziel, Lösungs- bzw. Verfahrensvorschläge der SachbearbeiterInnen zurückzuweisen, um für sie passendere Lösungen oder ein passenderes weiteres Vorgehen zu erstreiten. Sie thematisieren ihr Alter also gewöhnlich erst, wenn die Reklamation für sie unbefriedigend zu enden droht.

Damit werden mit Alter verbundene Präsuppositionen hier anders plaziert und funktional anders eingesetzt als in den Gesprächen, die Dritte namens älterer Kundlnnen führen. Zudem wird natürlich von den Alten selbst nie auch nur ansatzweise die eigene Geschäftsfähigkeit oder die eigene Mündigkeit in Frage gestellt.

Typische Illustrationen für Thematisierungen des eigenen Alters geben die folgenden Beispiele. Beiden Ausschnitten gehen Lösungsvorschläge durch die SachbearbeiterInnen voraus. 
Beispiel 4

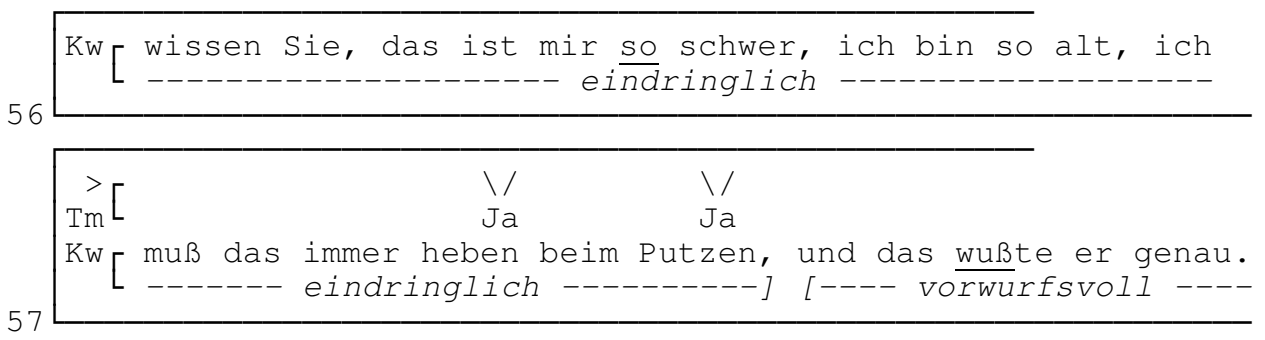

Beispiel 5

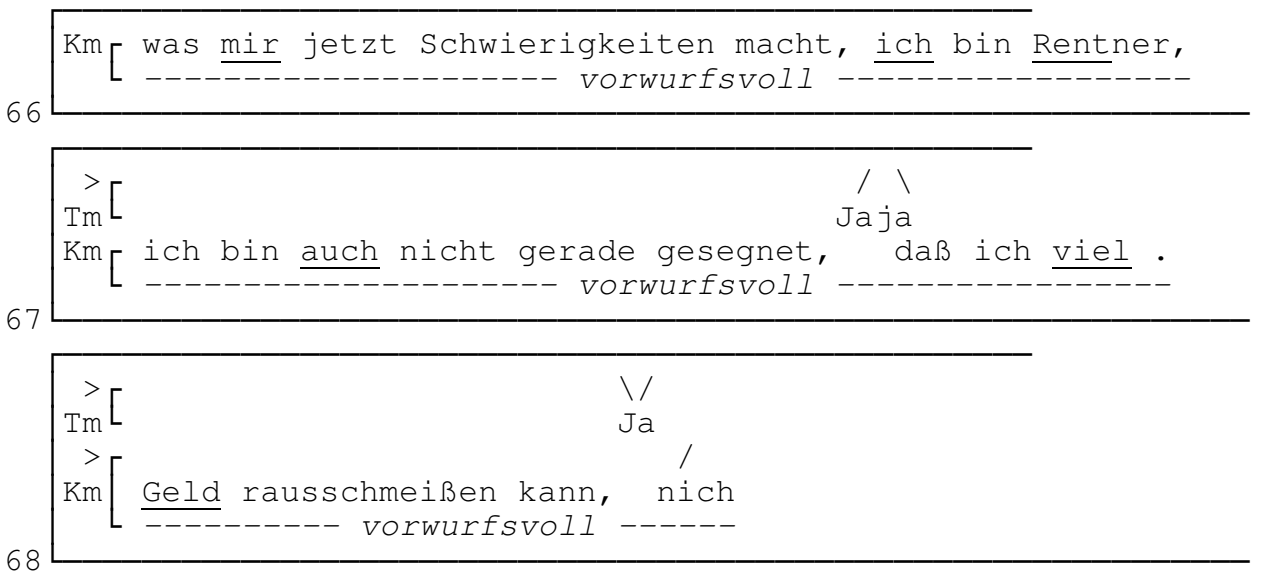

In beiden Fällen enthüllen die KundInnen im Zusammenhang mit der Thematisierung ihres Alters Informationen über eigene Handlungsbeschränkungen - in Beispiel 4 geht es um eingeschränkte Mobilität, in Beispiel 5 um finanzielle Beschränkungen. ${ }^{20}$ Sie geben damit an, daß sie bestimmte Fähigkeiten bzw. Möglichkeiten, die für die Umsetzung des vorhergehenden Lösungsvorschlags wichtig sind, nicht haben.

Die Verweise ich bin so alt und ich bin Rentner haben in diesem Rahmen die Funktion, diese Angaben zu plausibilisieren. Das ist insbesondere deshalb wichtig, weil mit den Angaben über eigene Handlungsbeschränkungen eine Zurückweisung der vorher angebotenen Lösung verbunden ist. Da die Institution mit dem Lösungsangebot ihren Aufgaben im Reklamationsprozeß zunächst einmal nachgekommen ist, bedarf die Zurückweisung einer besonderen Begründung. Zudem kann die Institution aufgrund ihrer arbeitsteiligen Organisationsform nur ein begrenztes Spektrum von Lösungen anbieten; Abweichungen von den jeweils vorgesehenen Verfahrensweisen sind immer aufwendig.

Mit den Verweisen auf das Altsein bzw. auf das alterstypische Rentnerdasein wird präsupponiert, daß Alte häufiger oder typischerweise in körperlichen und finanziellen Hinsichten eingeschränkt sind; die Präsuppositionen haben hier also die Struktur einer Einschätzung bzw. eines Bildes. ${ }^{21}$ Die Angaben über eigene Handlungsbe-

20 Coupland, Coupland \& Giles (1991) sprechen bei solchen Äußerungen von „painful selfdisclosures“ - von mehr oder weniger schmerzlichen und mehr oder weniger freiwilligen Enthüllungen eigenen Unvermögens.

21 Es ist an dieser Stelle schwierig, den Wissensstrukturtyp der Präsuppositionen eindeutig zu bestimmen. Um eine Sentenz, die für alle Alten gilt und allen Sprechern, also auch den Sachbearbeiterlnnen bekannt ist, handelt es sich hier nicht. Wenn die KundInnen eine solche Struktur unterstellen würden, könnten sie den vorhergehenden, ihrer Situation als Alte offensichtlich nicht an- 
schränkungen werden im Rahmen dieser Präsuppositionen somit durch ihre Übereinstimmung mit dem, was in bezug auf Alte zumindest als nicht unerwartet unterstellt wird, plausibilisiert und gestützt. Dabei ist angesichts der institutionellen und mithin verrechtlichten Beziehung zwischen KundInnen und Unternehmen auch wichtig, daß die Verweise auf das Alter bzw. den Status als Rentner im Zweifelsfall relativ leicht zu überprüfen sind.

Indem sie die eigenen Handlungsbeschränkungen durch die Präsuppositionen als nicht untypisch verallgemeinern, machen die Kundlnnen zugleich deutlich, daß sie eigentlich keine individuelle Lösung verlangen; die Problemkonstellation, in der sie sich befinden, ist als alterstypische ja nicht ungewöhnlich. Die Kundlnnen stellen durch die Thematisierung ihres Alters an dieser Stelle also ihren Lösungsanspruch implizit als vom Unternehmen erwartbar und damit als nicht unbillig dar.

Wie das nächste Beispiel illustriert, bleibt der Erfolg dieser Strategie aber davon abhängig, ob die verlangte Lösung zu den institutionenspezifischen Bearbeitungsprozeduren paßt.

Beispiel 6

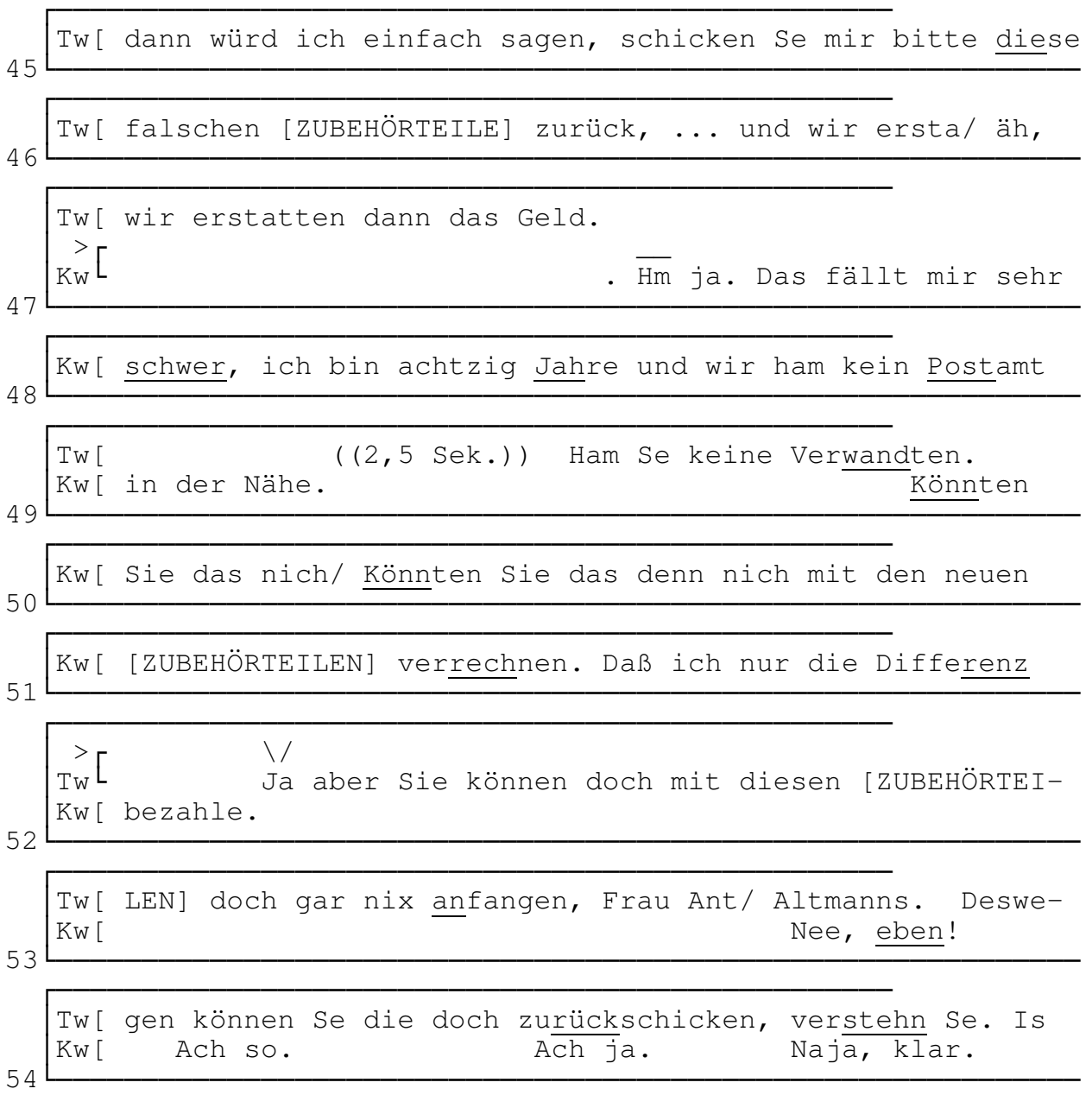

gemessenen Lösungsvorschlag als Zumutung wider besseres Wissen auffassen. Das würde sie berechtigen, mit weit pointierteren Vorwürfen zu reagieren, als sie es de facto tun. Es muß sich deshalb um eine Wissensstruktur handeln, derzufolge zwar durchaus erwartbar ist, daß Alte körperlich bzw. finanziell eingeschränkt sind - allerdings ohne daß unterstellt wird, daß jeder Sprecher das von jedem Alten erwartet. 


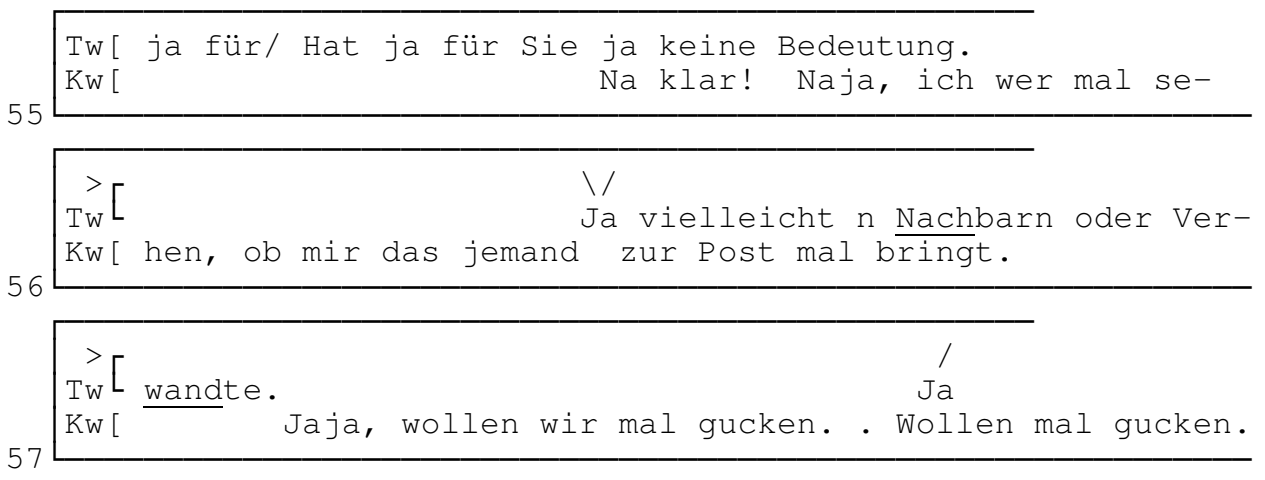

Die Kundin in diesem Beispiel hat Zubehörteile bestellt, bezahlt und falsche geschickt bekommen. Sie wird nun aufgefordert, diese falschen Teile zur Post zu tragen und zurückzuschicken - erst dann, so der Vorschlag der Sachbearbeiterin, bekommt sie ihr Geld zurück (FI. 45-47). Tatsächlich hat die Firma in einer Reihe von Fällen die Mitarbeit der KundInnen - hier: den Weg zur Post - in ihren Bearbeitungsverfahren eingeplant. Andere Lösungen wären für sie deshalb wesentlich aufwendiger.

Offensichtlich reflektieren die institutionellen Bearbeitungsverfahren ein firmeninternes Modell vom Kunden. Diesem Modell gemäß sind KundInnen in vielen Hinsichten kooperationswillig und -fähig. Die Kundin in Beispiel 6 entspricht diesem Modell nicht. Sie sieht sich gezwungen, Beschränkungen ihrer Mobilität zu thematisieren und verfährt dabei (s. FI. 47-49) wie die KundInnen in Beispiel 4 und 5.

Diese Strategie scheitert. Die Sachbearbeiterin, die hier nicht helfen kann, insistiert mit Ham Se keine Verwandten. (FI. 49, ähnlich nochmal FI. 56/57) weiterhin auf einer Lösung, die von der Kundin durchgeführt wird. Bevor sich die Kundin hier zu weiteren privaten Entblößungen etwa bezüglich eigener Einsamkeit nötigen läßt, akzeptiert sie die Übernahme der Handlungszuständigkeit, obwohl sie die Sachlage nicht verschuldet hat und obwohl sie offenbar noch nicht weiß, wie sie das Problem lösen soll (FI. 55-57). Trotz der oben erwähnten wirtschaftlichen Bedeutung, die ältere Kundlnnen für das Unternehmen haben, werden deren Bedürfnisse das zeigen auch andere Beispiele - sowohl diskursiv wie in den institutionell vorgesehenen Bearbeitungsverfahren offensichtlich nur unzureichend berücksichtigt.

\section{Resümee}

Die Analyse der Reklamationsgespräche, die Dritte namens älterer Kundlnnen geführt haben, zeigt, daß die Anruferlnnen bei einigen ihrer Handlungen von Erwartungen ausgehen, denen zufolge Alte in geschäftlichen Hinsichten partiell unmündig, abhängig, hilfs- und kontrollbedürftig etc. sind. Diese Erwartungen bzw. Handlungspräsuppositionen ähneln zum Teil den Strukturen, die in der Stereotypenforschung als Stereotypen analysiert werden. ${ }^{22}$ Von einer solchen Analyse wurde hier abgesehen. Vielmehr erweist es sich als fruchtbar, die Präsuppositionen bezüglich der

${ }^{22}$ Vgl. eine der klassischen Bestimmungen für linguistische Stereotypen: „Ein Stereotyp ist der verbale Ausdruck einer auf soziale Gruppen oder einzelne Personen als deren Mitglieder gerichteten Überzeugung. Es hat die logische Form eines Urteils, das in ungerechtfertigt vereinfachender und generalisierender Weise, mit emotional wertender Tendenz, einer Klasse von Personen bestimmte Verhaltensweisen zu- oder abspricht. Linguistisch ist es als Satz beschreibbar." (Quasthoff 1973, 28). 
innen zugrundeliegenden Wissensstrukturtypen, d.h. hinsichtlich ihres jeweiligen Bezugsbereichs und ihrer Geltungskraft zu differenzieren.

Damit kann das handlungsleitende Potential der aufgewiesenen Erwartungen an Alte genauer bestimmt werden. Zugleich geht diese Differenzierung einher mit einem detaillierteren Bezug der Präsuppositionen auf die Ziele und Zwecke, die mit den Handlungen, in die sie einfließen, verfolgt werden.

So ist für die Gespräche mit Dritten typisch, daß die Präsuppositionen über Alte von den Anruferlnnen als Einschätzungen (z.B. paraphrasierbar als „Es gibt häufiger Alte, die partiell unmündig etc. sind") in das gemeinsame Handlungssystem eingeführt und über Bilder der individuellen Kundlnnen („Diese Alte ist generell unmündig“) bis zur Sentenz („Wie jeder weiß, sind Alte immer unmündig“) verallgemeinert werden (s. 4.2.1 - 4.2.3). Dabei wird der strategische Einsatz der Präsuppositionen, die eine sichere Handlungsbasis bieten (wie die Sentenz) durch die weniger sicheren (wie die Einschätzung) vorbereitet. Es ist somit nicht nur eine zweckfunktional abgestufte, sondern auch eine systematisch aufgebaute Verwendung der Präsuppositionen zu erkennen. Damit zeigt sich, daß die Differenzierung der präsupponierten Wissensstrukturen es auch ermöglicht, im einzelnen zu rekonstruieren, wie Strukturen, die häufig pauschal als Stereotypen analysiert werden, im Diskurs aufgebaut werden.

Der Versuch der AnruferInnen, u.a. durch Präsuppositionen über Alte den jeweiligen Kaufvertrag als unrechtmäßig zu desavourieren, ist - wie gesehen - zumindest nicht unmittelbar erfolgreich. Zwar sind Erwartungen an Alte auch in die institutionellen Routinen eingeflossen (s. 4.2.4), doch im Diskurs müssen sich die Sachbearbeiterlnnen gegenüber den (z.B. in 4.2.3 analysierten) Vorwurfshandlungen indifferent verhalten: Die Sentenzen werden eindeutig nicht ratifiziert. Offensichtlich handelt es sich bei den Strategien, die die AnruferInnen anwenden, indem sie Präsuppositionen über Alte in ihre Handlungen einfließen lassen, um alltagsbezogene Verfahren, denen keine institutionellen Verfahren entsprechen. Darin liegen weitere Konfliktpotentiale verborgen: Aufgrund seiner Indifferenz gegenüber den Präsuppositionen bzw. den Vorwürfen riskiert das Unternehmen - vor allem, wenn es später eine einschlägige Reklamation zurückweist -, als altenfeindlich zu gelten.

Eine ähnliche Indifferenz seitens des Unternehmens konnte in den Gesprächen mit älteren Kundlnnen festgestellt werden (s. 4.3). Diese Kundlnnen thematisieren ihr Alter meistens erst, wenn die Reklamation zu einer für sie unpassenden Lösung zu führen droht. Wie in 4.3 illustriert wurde, sind Einwände unter Verweis auf das eigene Alter dabei höchstens dann erfolgreich, wenn es unter den institutionell vorgesehenen Bearbeitungsverfahren eine passende Lösung sowieso schon gibt. Hier führen die Routinisierung und Rationalisierung der Reklamationsbearbeitung im Unternehmen und vor allem die in diese Verfahren eingeflossene "vorurteilsfreie“ Gleichbehandlung aller KundInnen zu Unflexibilität. Gerade ein Unternehmen, das sich aufgrund seiner Vertriebsform (Vorführung und Bestellung der Ware zu und Lieferung nach Hause) für mobilitätsbeschränkte Kundlnnen geradezu anbietet und entsprechend viele solcher Kundlnnen zu seinen Stammkundlnnen zählt, sollte hier entsprechende Lösungen vorsehen. Die Gleichbehandlung von Kundlnnen ist nicht als Schematismus, sondern als Bearbeitung von Differenz zu verstehen. 


\section{Literatur}

Antos, G. (1988). Zwischen Kunde und Computer. Interaktionsprobleme bei telefonischen Reklamationsgesprächen. In: Gutenberg, N. (Hrsg.), Kann man Kommunikation lehren? Frankfurt a.M.: Scriptor, 9-17.

Antos, G. (1989). Optimales Telefonieren nach Script. Neue Formen des Mediengebrauchs in der Wirtschaftskommunikation. Ein Beitrag zu einer „Bedarfs-Linguistk“. In: Antos, G. \& Augst, G. (Hrsg.), Textoptimierung. Das Verständlichmachen von Texten als linguistisches, psychologisches und praktisches Problem. Frankfurt a.M. etc.: Lang, 125-161.

Astroh, M. (1996). Präsupposition und Implikatur. In: Dascal, M., Gerhardus, D., Lorenz, K. \& Meggle, G. (Hrsg.), Sprachphilosophie. = HSK, Bd. 7.2. Berlin, New York: de Gruyter, 1391-1407.

Avenarius, H. (1992). Kleines Rechtswörterbuch. 7. Auflage. Düsseldorf: Landeszentrale für politische Bildung.

Becker-Mrotzek, M. (1991). Professionelles Sprachhandeln in Institutionen. Duisburg: L.A.U.D.

Bruhn, M. (1995). Integrierte Unternehmenskommunikation. Ansatzpunkte für eine strategische und operative Umsetzung integrierter Kommunikationsarbeit. 2., überarb. und erw. Aufl. Stuttgart: Schäffer-Poeschel.

Caporael, L. R. \& Culbertson, G. H. (1986). Verbal response modes of baby talk and other speech at institutions for the aged. In: Language and Communication 6 (1/2), 99-112.

Caporael, L. R., Lukaszewski, M. P. \& Culbertson, G. H. (1983). Secondary baby talk: judgements by institutionalized elderly and their caregivers. In: Journal of Personality and Social Psychology, Vol. 44, No. 4, 746-754.

Coupland, J., Nussbaum, J. \& Coupland, N. (1991). The reproduction of aging and agism in intergenerational talk. In: Coupland, N., Giles, H. \& Wiemann, J. (eds.), Miscommunication and problematic talk. London: Sage, 85-192.

Coupland, N., Coupland, J. \& Giles, H. (1991). Language, society and the elderly. Oxford (U.K.), Cambridge (U.S.A.): Blackwell.

Coupland, N., Coupland, J., Giles, H. \& Henwood, K. (1988). Accommodating the elderly: Invoking and extending a theory. In: Language in society 17, 1-41.

Coupland, N., Henwood, K., Coupland, J. \& Giles, H. (1990). Accommodating trouble-talk: the management of elderly self-disclosure. In: McGregor, G. \& White, R. (eds.), Reception and Response. London: Croom Helm, 112-144.

Ehlich, K. (1991). Funktional-pragmatische Kommunikationsanalyse - Ziele und Verfahren. In: Flader, D. (Hrsg.), Verbale Interaktion. Studien zur Empirie und Methodologie der Pragmatik. Stuttgart: Metzler, 127-143.

Ehlich, K. \& Redder, A. (1994). Einleitung. In: Redder, A. \& Ehlich, K. (Hrsg.), Gesprochene Sprache: Transkripte und Tondokumente. Tübingen: Niemeyer, 1-18.

Ehlich, K. \& Rehbein, J. (1972). Erwarten. In: Wunderlich, D. (Hrsg.), Linguistische Pragmatik. Frankfurt a.M.: Suhrkamp, 99-114.

Ehlich, K. \& Rehbein, J. (1976). Halbinterpretative Arbeitstranskriptionen (HIAT). In: Linguistische Berichte 45, 21-41.

Ehlich, K. \& Rehbein, J. (1977). Wissen, kommunikatives Handeln und die Schule. In: Goeppert, H. C. (Hrsg.), Sprachverhalten im Unterricht. Zur Kommunikation von Lehrer und Schüler in der Unterrichtssituation. München: Wilhelm Fink, 36-114.

Ehlich, K. \& Rehbein J. (1986). Muster und Institution. Untersuchungen zur schulischen Kommunikation. Tübingen: Narr.

Ehlich, K. \& Rehbein, J. (1994). Institutionsanalyse. Prolegomena zur Untersuchung von Kommunikation in Institutionen. In: Brünner, G. \& Graefen, G. (Hrsg.), Texte und Diskurse. Methoden und Forschungsergebnisse der Funktionalen Pragmatik. Opladen: Westdeutscher Verlag, 287327.

Fiehler, R. (1996). Die Linguistik und das Alter. In: Sprachreport 1/96, 1-3.

Fiehler, R. \& Kindt, W. (1994). Reklamationsgespräche. Schulungsperspektiven auf der Basis von Ergebnissen diskursanalytischer Untersuchungen. In: Bartsch, E. (Hrsg.), Sprechen, Führen, Kooperieren in Betrieb und Verwaltung. Kommunikation in Unternehmen. München, Basel: Reinhardt, 255-269. 
Fiehler, R., Kindt, W. \& Schnieders, G. (demn.). Kommunikationsprobleme in Reklamationsgesprächen. In: Brünner, G., Fiehler, R. \& Kindt, W. (Hrsg.), Angewandte Diskursforschung: Kommunikation untersuchen und lehren. $35 \mathrm{~S}$.

Frege, G. (1962) [1892]. Über Sinn und Bedeutung. In: Frege, G.: Funktion, Begriff, Bedeutung. Hrsg. und eingel. von Günther Patzig. Göttingen: Vandenhoeck \& Ruprecht, 40-65 (Originalausgabe 1892)

Gazdar, G. (1979). Pragmatics. Implicature, Presupposition, and Logical Form. New York etc.: Academic Press.

Grießhaber, W. (1985). Zitieren von Handlungsmustern. - „Recht im Alltag“ im Unterricht für ausländische Arbeiter. In: Rehbein, J. (Hrsg.), Interkulturelle Kommunikation. Tübingen: Narr, 257275.

Grießhaber, W. (1987). Personalisierung von Sachkonflikten. Beschwerden auf dem Arbeitsamt beim interkulturellen Rollenspiel. In: OBST 38, 69-84.

Hansen, U. \& Schoenheit, I. (1979). Verbraucherabteilungen als Frühwarnsysteme. In: Zeitschrift für Betriebswirtschaft, Ergänzungsheft 2, 49. Jg., 120-134.

Hoffmann, A. (1991). Die Erfolgskontrolle von Beschwerdemanagement-Systemen: theoretische und empirische Erkenntnisse zum unternehmerischen Nutzen von Beschwerdeabteilungen. Frankfurt a.M. etc.: Lang.

Ohama, R. (1987). Eine Reklamation. In: OBST 38, 27-52.

Petöfi, J. S. \& Franck, D. (Hg.) (1973). Präsuppositionen in Philosophie und Linguistik. Frankfurt a.M.: Athenäum.

Quasthoff, U. M. (1973). Soziales Vorurteil und Kommunikation. Eine sprachwissenschaftliche Analyse des Stereotyps. Frankfurt a.M.: Fischer Athenäum.

Redder, A. (1995). „Stereotyp“ - eine sprachwissenschaftliche Kritik. In: Jahrbuch Deutsch als Fremdsprache 21, 311-329.

Rehbein, J. (1972). Entschuldigungen und Rechtfertigungen. Zur Sequenzierung von kommunikativen Handlungen. In: Wunderlich, D. (Hrsg.), Linguistische Pragmatik. Frankfurt a.M., 288-317.

Rehbein, J. (1977). Komplexes Handeln. Elemente zur Handlungstheorie der Sprache. Stuttgart: Metzler.

Ryan, E. B., Giles, H., Bartolucci, G. \& Henwood, K. (1986). Psycholinguistic and social components of communication by and with the elderly. In: Language and Communication 6 (1/2), 1-24.

Schnieders, G. (demn.). Authentische und simulierte Reklamationsgespräche - ein exemplarischer Vergleich. In: Rehbein, J. (Hrsg.), Spektrum der Funktionalen Pragmatik. 19 S.

Seuren, P. A. M. (1991). Präsuppositionen. In: Stechow, A. von \& Wunderlich, D. (Hrsg.), Semantik. = HSK, Bd. 6. Berlin/New York: de Gruyter, 286-319.

Strawson, P. F. (1950). On referring. In: Mind 67, 320-344.

Thimm, C. (1995a). Verständigungsprobleme in Gesprächen zwischen alt und jung. In: Spillner, B. (Hrsg.), Sprache: Verstehen und Verständlichkeit. Kongreßbeiträge zur 25. Jahrestagung der Gesellschaft für Angewandte Linguistik GAL e.V. Frankfurt a.M. etc: Lang, 89-94.

Thimm, C. (1995b). Intergruppenkommunikation, soziales Vorurteil und konversationelle Implikaturen: Alt und Jung im Dialog. In: Liedtke, F. (Hrsg.), Implikaturen: grammatische und pragmatische Analysen. Tübingen: Niemeyer, 187-208.

Thimm, C. (1996). Alter, Sprache, Kommunikation: Plädoyer für eine Gerontologische Linguistik. In: Sprachreport 1/96, 4-5. 


\title{
Ist 'Altersstil' in der Sprechsprache wissenschaftlich nachweisbar?
}

\author{
Überlegungen zu Interviews mit 70- bis 100jährigen Emigranten
}

Anne Betten

\section{Das Israelkorpus und seine syntaktisch-stilistischen Besonderheiten}

Um es vorweg zu sagen: eigentlich habe ich, wie es der Titel meines Beitrags schon anzeigt, hauptsächlich Fragen zu einem speziellen Datenkorpus und wenig Antworten - eher Vermutungen, Überlegungen. Bei diesem Korpus handelt es sich um rund 150 Gespräche von ein bis drei Stunden Dauer, die ich mit zwei Kolleginnen, Dr. Kristine Hecker (Universität Bologna) und Dr. Miryam Du-nour (Jerusalem), von 1989 bis 1994 in Israel mit deutsch-jüdischen Emigranten und Emigrantinnen der dreißiger Jahre aufgenommen habe. ${ }^{1}$ Zur Zeit der Aufnahme waren unsere Gesprächspartner/innen 70 bis 100 Jahre alt.

Im Verlauf des Projektes traten allgemein menschliche, historische und kultursoziologische Gesichtspunkte immer mehr in den Vordergrund. Ausgegangen war ich als Sprachwissenschaftlerin jedoch von der Beobachtung, daß sich in dieser Emigrantengruppe ein sehr gepflegtes, normorientiertes, d.h. weitgehend an der Schriftund Literatursprache orientiertes Bildungsbürgerdeutsch erhalten hat, das ich das „Deutsch der zwanziger Jahre“ genannt habe. Manchmal wird es, zum Teil von den Sprechern selbst, auch als „Weimarer Deutsch“ bezeichnet, also mit der Weimarer Republik in Verbindung gebracht, wobei jedoch Assoziationen an das Deutsch der Klassiker in Weimar durchaus willkommen und auch angebracht sind. ${ }^{2}$ Es gibt meines Wissens keine direkten Möglichkeiten eines Vergleichs mit ähnlichen spontanen Gesprächsaufnahmen aus den zwanziger Jahren selbst. Vieles spricht jedoch dafür - wie ich im weiteren zeigen werde -, daß sich in Israel die Sprache der Gebildeten des ersten Drittels unseres Jahrhunderts ziemlich unverändert erhalten hat. Zumindest theoretisch stellt sich angesichts des nunmehr hohen Alters der Sprecher jedoch auch die Frage, ob es, wenn schon nicht extern bzw. gesellschaftlich bedingte, so doch altersbedingte Veränderungen in ihrer Sprache geben könnte, auf Grund derer das Material als Quelle für das „Deutsch der zwanziger Jahre“ doch mit gewissen Vorbehalten zu betrachten wäre. In diesem Falle wäre es ebenso wichtig wie interessant zu wissen, welche spezifischen Veränderungen oder neuen Merkmale

\footnotetext{
Vgl. die Textpublikationen in Betten (1995) in gesprächsanalytischer wortwörtlicher Transkription und die leicht überarbeiteten Texte in Betten \& Du-nour (1996). Beide Bücher zusammen machen jedoch nur einen kleinen Teil der fast 300 Aufnahmestunden zugänglich. Die Publikation in der Phonai-Reihe (Betten 1995) wird durch einen zweiten Band mit weiteren Transkriptionstexten der Sprecher speziell zu ihrem Sprachgebrauch und einem linguistischen Analyseteil fortgesetzt werden. Dem Phonaiband ist eine CD mit 38 kurzen Sprecherbeiträgen beigegeben; die CD des Folgebandes wird nochmals Ausschnitte von insgesamt 70 Minuten enthalten. Der Großteil dieser Aufnahmen wird seit 1995 am Institut für deutsche Sprache in Mannheim digitalisiert und in Zukunft von dort ausleihbar sein.

2 Vgl. dazu, auch mit Kommentaren aus den Primärtexten der Interviewten, Betten (1996).
} 
durch den Faktor Alter hinzukommen und bei einer Analyse zu berücksichtigen wären.

Auf die Gründe, warum in Israel das Deutsche als die Muttersprache der Emigranten so besonders lang und kultiviert gepflegt wurde, kann ich hier nur kurz eingehen. Für den heutigen Betrachter, speziell aus Deutschland, ist es sehr bewegend, daß gerade die Emigranten, die ins "Land der Väter" gekommen sind, vor allem aufgrund der großen Sprachbarriere, die das Hebräische (Iwrit) für die meisten darstellte, besonders nachhaltig an die Sprache und Kultur ihrer Verfolger und Mörder gebunden blieben. Die 55.000 bis 85.000 Deutschsprachigen, die zwischen 1933 und 1945 ins Land kamen (die Zahlenangaben schwanken beträchtlich), waren die bis dahin größte Einwanderungswelle nach Palästina, das bis 1933 stärker von ostjüdischen Einwanderern geprägt war. Schon von daher ist es verständlich, daß sich das Deutsche als Familiensprache wie auch in vielen gesellschaftlichen Gruppen erhielt, so z.B. in dörflichen Ansiedlungen, die oft von geschlossenen Gruppen deutscher Einwanderer gegründet wurden. Sie waren von der Umstellung auf die meist ungewohnte landwirtschaftliche Arbeit so gefordert bzw. überfordert, daß sie jahre-, oft jahrzehntelang zum Erlernen des Hebräischen weder Kraft noch Zeit noch Motivation hatten. Es entfaltete sich dort oft spätabends ein reges Kulturleben in deutscher Sprache, wodurch die ehemaligen Akademiker ihren geistigen Bedürfnissen nachkamen. Ähnlich war es in gewissen Teilen der Städte, in denen überwiegend deutschsprachige Einwanderer lebten. So wurde z.B. der Norden Tel Avivs scherzhaft „Kanton Iwrit“ genannt, was in österreichischer Aussprache wie „kein Ton Iwrit“ lautet.

Interessant ist, daß sich nicht nur die älteren Einwanderer wegen ihrer Sprachprobleme weitgehend in deutschsprachigen Zirkeln bewegten. Auch unter den in jugendlichem Alter Eingewanderten gab es viele, die aufgrund besonderer Umstände noch lange in der deutschen Sprache blieben, sowohl im Alltag als auch manchmal in ihrer Lektüre und sonstigen kulturellen Orientierung. Dabei müssen Kinder, die erst 8 oder auch 13, 14 Jahre alt waren, als sie ins Land kamen, ihre Sprachkompetenz im Deutschen - auch parallel zum raschen Erlernen des Hebräischen für Schule oder Beruf - noch ausgebaut haben. Das heißt, daß die Sprachnormen und formen der tonangebenden Generation der Erwachsenen, unter denen überdurchschnittlich viele Akademiker waren - wenn auch jetzt zunächst oft in primitivsten Hilfsarbeiterjobs -, sehr stark prägend gewesen sein müssen. Hatte sich die Zugehörigkeit zu „besseren Kreisen“ in früherer Zeit allgemein nicht primär durch materiellen Besitz, sondern zunächst einmal durch den Besitz einer gepflegten, grammatisch absolut korrekten Sprache zu erweisen, so dürfte dies bei den Palästinaflüchtlingen um so mehr gegolten haben. Schon in Deutschland hatten die assimilierten Juden, traditionell von vielen Berufen ausgegrenzt, auf den Erwerb schulischer und akademischer Bildung besonderen Wert gelegt und sprachlich höchste Maßstäbe angelegt. Die Emigrantensituation dürfte diese Betonung von Bildung noch vertieft haben: Die meisten kamen mit bloßen Händen, hatten nichts vorzuweisen als ihre Bildung, und diese manifestierte sich zunächst einmal durch sprachliche Ausdrucksfähigkeit. Wahrscheinlich ist es dadurch zu erklären, daß gerade diejenigen, die ihre Ausbildung hatten abbrechen müssen - ob als Schüler, Studenten oder in einer Berufsausbildung -, besonders bestrebt waren, sich als "dazugehörig“ auszuweisen und um sprachliche Korrektheit und Ausdrucksfähigkeit besonders bemüht waren. Sie waren also motiviert, sich trotz der ganz neuen Lebensumstände in den noch wichtigen gesellschaftlichen Kreisen aus der alten Welt Achtung und Geltung zu 
verschaffen - via Sprache! Dazu paßt, daß wir mehrmals von Interviewpartnern beim Erheben biographischer Daten, wenn wir nachfragten, ob sie in Deutschland noch das Abitur gemacht hätten, hörten: „Nein, ich mußte vorher abbrechen - aber das brauchen Sie nicht zu schreiben, das braucht hier niemand zu wissen!" oder "Das habe ich niemals verwunden: ich bin der/die erste in meiner Familie ohne Abitur".

So kommt es, daß manche Jugendliche - wie etwa unser Interviewpartner Abraham Frank (geb. 1923 bei Diez), der bei der Einwanderung 13 Jahre alt war und in Palästina aufgrund schwieriger wirtschaftlicher Bedingungen im Elternhaus keine weiterführenden Schulen mehr besuchen konnte - sich im Deutschen offensichtlich noch weiterentwickelten, zum Teil durch Lektüre, besonders aber offensichtlich durch den Einfluß ihres mündlichen Umgangs. Frank, der in seiner weiteren Familie Rabbiner, Lehrer und andere Akademiker hatte, ist zwar selbst Autodidakt ${ }^{3}$, aber er spricht konsequent in jeder Situation ein quasi druckreifes, auf uns fast gestochen wirkendes Deutsch, das man in Deutschland heute auch bei Akademikern kaum hört. Die Konstruktionen seiner langen, komplexen Sätze entgleiten ihm fast nie, was in denkbar großem Kontrast zu spontanen Aufnahmen quer durch alle Altersgruppen und Bildungsschichten in deutschsprachigen Ländern heute steht.

Das Interview mit A. Frank, aus dem die beiden folgenden Ausschnitte stammen, wurde von mir 1991 beim Kaffeetrinken auf seiner Terrasse aufgenommen. Er war damals 68 Jahre alt. Ich habe inn später viele Male bei unterschiedlichen Anlässen wiedergetroffen und festgestellt, daß er immer gleich spricht. In Beispiel 1 erzählt er von seinem Vater aus der Anfangszeit.

\section{Beispiel $1^{4}$}

1 wir warn damals in diesem dorf * zwei oder drei * deutschjüdi02 sche familien * er konnte mit niemand sprechen $\uparrow$ hebräisch: *

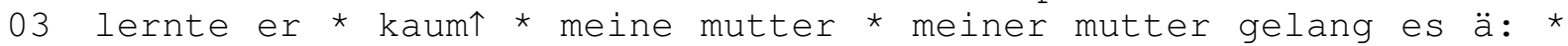
04 passables ä: * hebräisch ä zu erlernen $\uparrow$ mein vater obwohl er im 05 lehrhaus in * stuttgart und von zu hause her * ä: : die heilige 06 sprache der gebete kannte $\uparrow *$ es gelang ihm einfach nicht ä neu07 hebräisch zu lernen $\star \star$ und ä:m: * das klima * zweihundert * 08 meter unter dem meeresspiegel $\downarrow$ * die schwere harte landwirt09 schaftliche arbeit bananen ** tomaten*anbau * hühnerzucht * kuh10 wirtschaft $*$ bei manchmal ** vierzich grad * in der sonne $\star *$ 11 heißen langen * sommertagen ** war für ihn gesundheitlich sehr 12 sehr * zermürbend $\star \star$ und ä: menschlich und seelisch * ä:: ** 13 war die einordnung ** in diesen $* \star$ ersten jahren de:r arabi14 schen unruhen neunzehnhundertsechsundreißich neunundreißich * 15 und später neunundreißich bis fünfunvierzich während der 16 kriegsjahre als man von europa und dem schicksal * der jüdi17 schen mitmenschen * noch gar nich richtich * wußte aber * 18 jedenfalls völlich abgeschnitten war * auch kein leichtes $\downarrow$ * so 19 daß e:r ** wirtschaftlich ** völlig * ruiniert $\uparrow *$ und fast ** ä 20 brotlos * ä neunzehnhundertsechsunvierzich * als ich bereits 21 in tel aviv ansässich war ** ä:: die: siedlung: das haus ver22 kaufte * und ä: : die landwirtschaftliche arbeit aufgeben mußte 23 * nicht zuletzt: weil er bereits das sechuigste lebensjahr 24 erreicht hatte $\downarrow$

3 Er besuchte später Abendschulen und schreibt und spricht auch sehr gut Iwrit und Englisch.

4 Dieser Textausschnitt ist abgedruckt in Betten (1995, 308f.) und folgt den für diesen Band der neuen Phonai-Reihe ausgearbeiteten Transkriptionsregeln. 
Wenn man intonatorische Zeichen einbezieht, muß eigentlich die ganze Passage unter einem Bogen als eine Äußerungseinheit gesehen werden. Aber selbst wenn man, trotz fehlender Pausen und steigender Stimmführung, in Z. 4 den "Satz" erst mit me in vater anfangen ließe, bliebe er lang und komplex genug. Gleich hier am Anfang ist die einzige kleinere sprechsprachliche syntaktische Abweichung von schriftsprachlichen Regeln zu verzeichnen: me in vater, wohl erst als Subjekt geplant, wird nach Einschub des obwohl-Satzes zu einer Art Nominativus pendens, da der Satz nochmals neu begonnen wird: es gelang ihm einfach nicht (Z. 6.). Von hier an geht es jedoch trotz vielen Nebensätzen und Parenthesen ohne jede Konzession an die Mündlichkeit weiter: Man beachte die Fortsetzung des Hauptsatzes vom Subjekt das klima (Z. 7) mit war für ihn ... zermürbend (Z. 11f.); menschlich und seelisch war die Einordnung (Z. 12f.) wird fortgesetzt durch auch kein leichtes (Z. 18) sowie durch den folgenden so daß-Satz (Z. 18ff.), der zunächst durch eine Parenthese (wirtschaftlich ... brotlos, $Z$. 19f.), dann durch einen Nebensatz (als ich ... war, Z. 20f.) unterbrochen und am Ende noch durch einen Kausalsatz (nicht zuletzt weil ... hatte, $\boldsymbol{Z}$. 23f.) erweitert wird.

Die Konstruktionen im nächsten Beispiel von A. Frank sind nicht ganz so umfangreich, aber ebenso beeindruckend durch ihre - am schriftsprachlichen Standard gemessen - korrekte Durchführung bzw. Beibehaltung auch über lange Distanzen hinweg. Hier erzählt er von seiner Frau, die mit einer Kindergruppe nach England geschickt worden war.

\section{Beispiel 2}

01 aufgrund dieser garantien $\uparrow$ * die im grunde nichts anderes waren 02 als ein stück papier $\uparrow$ wurden vom bloomsburyhouse $\downarrow$ das war * 03 ä: : das zentrum dieser hilfsorganisation in london $\uparrow *$ privat-

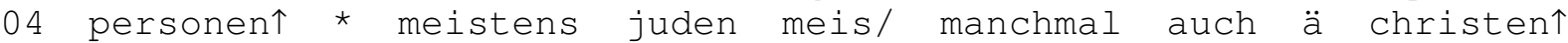
05 pfarrer erzieher sozialarbeiter und so weiter nach * deutschland 06 österreich und der tschechoslowakei geschickt * um nach vorheri07 ger * meistens nur sehr kurzer anmeldung $\downarrow$ daß wiederum * zehn $\uparrow$ 08 * siebenundzwanzig fünfzig garantien vorlägen $\uparrow * \star$ eine ent09 sprechende anzahl von kindern个 * auf dem bahnhof oder im 10 gemeindebüro oder im palästinaamt entgegenzunehmen $\uparrow$ von denen 11 sich die eltern die ihre kinder angemeldet hatten zur aus12 wanderung * manchmal * $*$ innerhalb von vierundzwanzig * bis 13 achtundvierzig stunden trennen mußten $\downarrow$ * $3 *$ ohne zu wissen ob 14 sie sich je wiedersehen würden $\downarrow \star \star$ ä:m $\star \star$ auf diese art und 15 weise $\uparrow$ wurden ** neuntausendachthundertsechsundfünfzig kinder 16 gerettet $\uparrow$ * fast zehntausend nach england gebracht eine humani17 täre * ä aktion großbritanniens $\downarrow$ die: jahre und jahrzehntelang 18 fast vergessen war die erst in den letzten jahren * ä: dokumen19 tarisch und auch schriftstellerisch und ä:ja: ä: durch 20 zeitungartikel ä: und wie gesagt auch durch einen film $\uparrow$ und 21 wie gesagt durch diese groß=angelegte reunion in london dem 22 breiten publikum=ä: ä bekannt wurde $\downarrow$

Diese Passage kann man ohne die sonst bei spontanem Sprechen oft auftretenden Segmentierungsprobleme in zwei umfangreiche, aber ganz klar gegliederte Satzgefüge auflösen. Der erste Satz von aufgrund bis wiedersehen würden (Z. 1-14) besteht zunächst aus dem Hauptsatz (Z. 1-6), in den ein Relativsatz (Z. 1f.), eine Parenthese (das war ... in Iondon, Z. 2f.) und eine Apposition (meistens 
juden ... und so weiter, Z. 4f.) eingebaut sind, und in seinem zweiten Teil aus einem umfangreichen Finalsatz (Z. 6-14), der weitere Nebensätze zweiten Grades enthält, die mit ebenso bewundernswerter Korrektheit wie Eleganz sowohl sequenziell gereiht wie hierarchisch gestaffelt ineinandergreifen. D.h. hier wird eine komplexe historische Zusatzinformation, eine ganze abgerundete "Geschichte“, in einem einzigen komplexen Satz wiedergegeben. Kommentar, Bemerkung und Zusatzinformationen folgen dann in einer parataktischen Satzreihe (Z. 14-22), die jedoch rhythmisch und intonatorisch auch eindeutig unter einen großen Satzbogen gefaßt wird.

Um deutlich zu machen, daß es sich bei Abraham Franks Sprechstil nicht um ein Einzelphänomen handelt, sei wenigstens noch ein weiteres Beispiel von einem halbwegs vergleichbaren Probanden aus dem österreichischen Sprachgebiet angefügt. Der Wiener $Y$ (er war einer der wenigen, der seinen Namen nicht genannt haben wollte), geb. 1920, kam mit 18 Jahren ins Land. Er war bei der Aufnahme 71 Jahre alt und ist ebenfalls kein Akademiker; in Wien hatte er vor der Emigration 1938 das Realgymnasium nicht mehr abschließen können. Wie die meisten begann er in Palästina mit Gelegenheitsarbeiten, war danach bei der britischen Mandatsregierung und schließlich als selbständiger Unternehmer tätig. Ähnlich wie A. Frank, der nach seiner Pensionierung - so auch noch zur Zeit unseres Interviews - als Kulturreferent für das deutschsprachige Mitteilungsblatt des 'Vereins der Einwanderer aus Mitteleuropa' (IOME) arbeitete, hatte Herr Y soeben eine neue Tätigkeit als Korrespondent einer deutschen Zeitung aufgenommen, worüber er im folgenden berichtet.

\title{
Beispiel $3^{5}$
}

\begin{abstract}
das war auch wie alles in meinem leben $* \star$ eine verkettung von zufällen $\downarrow * \star$ ich hatte * wie ich ihnen eingangs gesagt hatte ** oft * und viel leserbriefe an die frankfurter geschrieben $\downarrow$ * ein teil davon wurde veröffentlicht $\downarrow$ * als * die * zeitung in würzburg * sich an unsern presseattaché in bonn wandte mit der bitte ihm einen berichterstatter in israel vorzuschlagen $\uparrow$ ** hat dieser herr mehrere namen angegeben $\uparrow$ und eines tages vorigen * november oder dezember $\uparrow * \star \mathrm{kam}$ ein brief aus würzburg von einer zeitung die deutsche tagespost heißt und eine katholische abonnentenzeitung is sie erscheint dreimal in der woche $\uparrow$ und wird wohl auch frei verkauft aber im großen und ganzen stützt sie sich auf ihre zwanzichtausend abonnenten $\uparrow *$ daß sie einen mitarbeiter in israel suchen $\uparrow$ und ob ich daran interesse hätte $\downarrow$ no also selbstverständlich: * habe ich sofort * meine ** begeisterte zustimmung gegeben $\uparrow$ und dann sieben wochen von dem

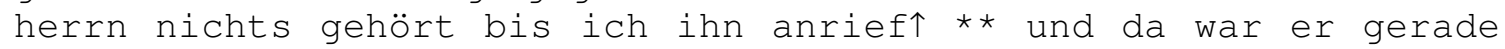
im SCHNAUFT * technischen umbruch seines betriebs computer installiert und so weiter und hatte keine zeit $\uparrow$ und seit dezember schreibe ich [...]
\end{abstract}

Auch Herr Y führt fast alle seine Sätze grammatisch penibel nach den schriftsprachlichen Normvorstellungen durch, und das ebenfalls bei zum Teil sehr umfangreichen Konstruktionen, wie etwa dem Satzgefüge als die zeitung ... interesse

5 Vgl. zu diesem Text, dort eingebettet in die Fragen und Kommentare der Interviewerin, wiederum Betten $(1995,368 f$.$) .$ 
hätte (Z. 4-13). Besonders erstaunlich ist auch hier u.a., daß der lange parenthetische Einschub sie erscheint dreimal in der woche ${ }^{*}$ und wird wohl auch frei verkauft aber im großen und ganzen stützt sie sich auf ihre zwanzichtausend abonnenten $\uparrow(Z$. 10-12) in den Trägersatz eingefügt ist, ohne dessen Konstruktionsablauf auch nur im geringsten zu beeinflussen, während wir im Mündlichen sonst in solchen Fällen zumindest eine stützende Wiederaufnahmeform am Ende der Parenthese und häufig im folgenden Konstruktionsänderungen, wenn nicht die vollständige Aufgabe des ursprünglichen Satzmusters zu erwarten haben. ${ }^{6}$

Die folgenden Interviewpartner, Dr. Josef Walk und Dr. Esriel Hildesheimer, haben im Gegensatz zu den beiden bisher besprochenen noch in Deutschland studiert. Walk (geb. 1914 in Breslau) wurde Volksschullehrer, Hildesheimer (geb. 1912 in Halberstadt) mußte sein Studium abbrechen. Beide gingen in Israel in fortgerücktem Alter an die Universität zurück. Walk wurde Pädagogikprofessor und war eine Zeitlang Direktor des Leo Baeck Instituts, seit seiner Pensionierung arbeitet er als freier Forscher. In den letzten 20 Jahren war er öfter nach Deutschland zu Vorträgen eingeladen und stellte dabei selbst interessante Überlegungen über den Unterschied zwischen seinem Deutsch und der Sprech- und Schriftsprache im heutigen Deutschland an. Daraus seien zwei kurze Ausschnitte wiedergegeben, die sowohl wegen ihres Inhalts interessant sind (so Bsp. 4 über seine "unmoderne“ VerbEndstellung im Nebensatz), vor allem aber als Belege seiner durchschnittlichen Satzlänge und Konstruktionsweise betrachtet werden sollen.

\section{Beispiel 4}

01 um auch da n gleich * gleich ein beispiel zu bringn $\uparrow$ ich bin 02 doch immer gewohnt und muß mir das abgewöhnen ich weiß es $\uparrow$ * ne-

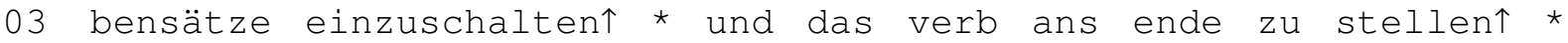
04 un:d ich weiß daß das heute nicht mehr üblich is $\uparrow$ und bemühe 05 mich * das zu umgehen $\uparrow$ aber ** bei manchn meiner aufsätze be06 ziehungsweise büchern * ist mir das jetzt schon passiert $\uparrow$ daß 07 man mich da verbessert hat $\uparrow$ und * ich gebe zu daß es für die: * 08 aufnahmefähigkeit * des lesers * durchaus erleichternd is wenn 09 man * die heutige form benutzt $\downarrow$

\section{Beispiel 5}

01 ich spreche noch heute * deutsch auch in vorträgen * eigent-

02 lich=ä: * ohne jede schwierichkeit个 vielleicht auch weil wir zu 03 hause miteinander * doch * wesentlich deutsch sprechen $\uparrow$ was ja 04 bei $n$ meisten der fall is wenn das ihre muttersprache ist $\uparrow *$ ä:

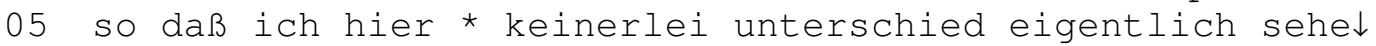

Es ließen sich weit komplexere Sätze von Walk anführen als in diesen Beispielen, von denen vor allem Beispiel 4 eher eine parataktische Satzreihung demonstriert. Aber auch hier läßt sich wieder beobachten, wie wenig erweiternde Einschübe die Konstruktion der Trägersätze bzw. deren „nahtlose“ Fortsetzung beeinflussen, man vgl. die Anschlüsse nach und muß mir das abgewöhnen ich weiß es $\uparrow$ (Bsp. 4, Z. 2) und vielleicht auch weil ... das ihre muttersprache ist $\uparrow$ (Bsp. 5, Z. 2-4).

6 Vgl. mit verschiedenartigen Beispielen Betten (1980, 191ff.). 
Esriel Hildesheimer besuchte nach seiner Einwanderung 1933 zunächst eine Talmudhochschule, war Mitbegründer eines religiösen Kibbuz', arbeitete danach u.a. als Buchantiquar, später im Verteidigungsministerium und beim Staatskontrolleur ( $\approx$ Rechnungshof). Im folgenden Abschnitt berichtet er, wie es dazu kam, daß er in fortgeschrittenem Alter noch Magister und Promotion in Geschichte ablegte.

\section{Beispiel 6}

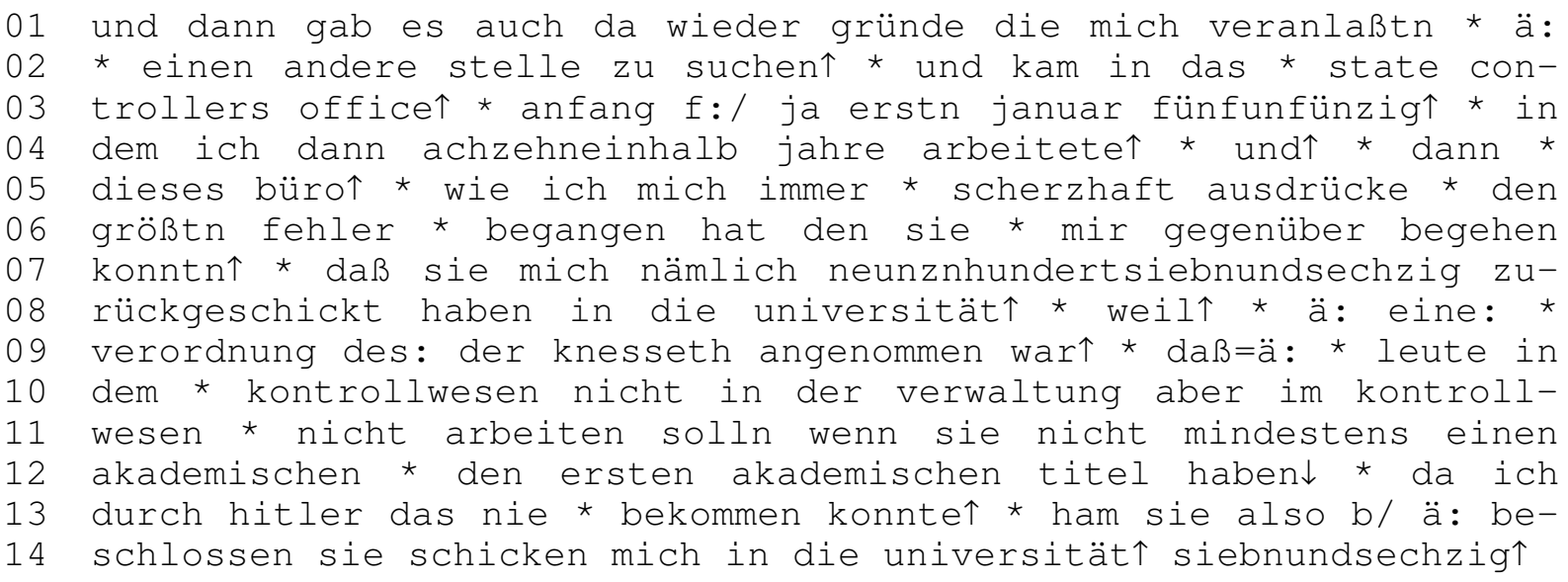

Von Z. 1 bis 14 liegt hier ein komplexer Satz vor, mit einer grammatischen "Irregularität": der mit und dann gereihte Satz (Z. 4ff.) hat das Verb in NebensatzStellung statt in Hauptsatz-Stellung (begangen hat, Z. 6). Darauf folgt eine Serie von Nebensätzen, und zwar nach dem Relativsatz den sie ... (Z. 6f.) die mit den Subjunktionen daß (Z. 7), weil (Z. 8), daß (Z. 9), wenn (Z. 11) eingeleiteten Nebensätze, die jeweils in hierarchischer Abhängigkeit voneinander stehen. Auch in diesem Satz findet sich wieder das Phänomen der „nahtlosen“ Fortsetzung nach Einschub, und zwar nach wie ich mich immer * scherzhaft ausdrücke (Z. $5)$ und nach der Präzisierung nicht in der verwaltung aber im kontrollwesen (Z. 10f.).

Zur angemessenen Beurteilung der hohen grammatischen und stilistischen Kompetenz im Deutschen sollte noch erwähnt werden, daß Walk und Hildesheimer während ihrer Berufstätigkeit viel bzw. nur Hebräisch oder Englisch gesprochen und geschrieben haben. Beide konnten schon ordentlich Hebräisch, als sie ins Land kamen. Daher waren beide besonders motiviert, ihre Kenntnisse des Hebräischen zu vervollkommnen; beide halten ihr Hebräisch für besser als ihr Deutsch. Allerdings arbeiten beide wissenschaftlich über die Tradition des deutschen Judentums und lesen daher deutschsprachige Fachliteratur, geben aber an, darüber hinaus fast nichts mehr auf deutsch gelesen zu haben.

J. Walk und E. Hildesheimer waren bei ihrer Emigration ca. 22 Jahre alt und zum Zeitpunkt der Aufnahme Ende 70. Während man bei einem Dreizehnjährigen wie A. Frank annehmen muß, daß sich seine Beherrschung der deutschen Sprache nach der Emigration noch weiterentwickelt hat, liegt bei dieser Altersgruppe eher die Vermutung nahe, daß sie ihre Sprachkompetenz bewahrt hat. Allerdings wäre auch bei innen von weiterer Sprachpflege allein durch den mündlichen Umgang mit einer gewissen - in den verschiedenen Phasen ihres Lebens durchaus wechselnden - Anzahl gebildeter Sprecher (in einer Art "Sprachinsel“-Situation) auszugehen. Es sei jedenfalls abschließend zu den Sprachbeispielen noch einmal angemerkt, daß es sich hier nicht um Einzelfälle handelt. Auch in der Gruppe der 80- bis 100jährigen 
läßt sich ein ähnlich kultiviertes und konzentriertes Sprechen in komplexen syntaktischen Strukturen vielfach belegen.

Im Verlaufe des Projekts war jedoch einige Male zu beobachten, daß durch altersbedingte Verschlechterungen des Gesamtbefindens von Personen, die wir mehrmals im Abstand von ein, zwei Jahren trafen, auch die sprachliche Darstellungsfähigkeit, speziell bei längeren monologischen Erzählungen, eklatant nachgelassen hatte. Das betraf vor allem das Sprechen während der Bandaufnahme, seltener das lockere private Gespräch. Es war in diesen Fällen nicht so, daß die Kompetenz, grammatisch korrekte syntaktische Strukturen zu bilden, beeinträchtigt gewesen wäre; die Formulierungsschwierigkeiten waren vielmehr eher gedächtnisbedingt. So führten vor allem beim Bemühen, chronologisch erzählen zu wollen, die plötzlichen Gedächtnisausfälle z.B. zu Pausen, Satzabbrüchen u.ä.m.

Einige wenige unserer über 80jährigen Gesprächspartner sprachen durchwegs mit sehr großen Pausen. Hier sind wir auf Vermutungen angewiesen, wie weit diese Sprechweise ganz oder nur teilweise altersbedingt war. Bei dieser kleinen Gruppe ist dann jedoch um so auffälliger, wie konsequent auch von innen die Satzbaupläne trotz der großen Pausen durchgeführt werden. Gelegentlich mögen diese Pausen auch mit der Suche nach den richtigen Wörtern und Formulierungen zusammenhängen: Manche versicherten uns, seit ihrer Einwanderung sehr wenig Deutsch gesprochen zu haben und z.B. über Details aus ihrem Beruf noch nie auf deutsch berichtet zu haben. Wieweit hier das Altersgedächtnis oder andere Phänomene beim Abrufen und Übersetzen lexikalischer Einheiten aus der Sprache, in der man einen Begriff kennengelernt hat, eine Rolle spielen bzw. sich beides gegenseitig beeinflußt, ist sehr schwer zu beurteilen, hier aber nicht das eigentliche Problem.

Desweiteren ließ sich noch beobachten, daß sich bei einigen wenigen Interviewten die Tendenz zum assoziativen Drauflossprechen (auch "off-topic-verbosity" genannt $^{7}$ ) mit zunehmendem Alter (z.B. zwischen 80 und 85 ) verstärkte, so daß sich etwa eine schon vorhandene Neigung zu Exkursen zu hemmungslosem Abschweifen von jeglichem Thema steigerte. Dies kann sich auch in der Zunahme entsprechender syntaktischer Phänomene äußern, und hier kommt es dann z.B. auch zu (dem sonst eben relativ selten zu beobachtenden) Konstruktionsumbau bzw. zu Anakoluthen nach Parenthesen oder Nebensätzen.

\section{Vergleich unserer Analyseergebnisse mit bisherigen Forschungen zu Komplexität und Veränderungen der Syntax im Alter}

Von besonderem Interesse angesichts dieser Befunde scheint mir die Frage zu sein, ob man bei der Mehrzahl der Interviewten, die geistig sehr rege und ganz „präsent“ sind und über ausgezeichnete erzählerische und sprachliche Fähigkeiten verfügen, davon ausgehen kann/muß, daß sich ihr Deutsch in den 60 Jahren, die sie jetzt schon in einer Sprachinselsituation leben, altersbedingt entwickelt und verändert hat, oder ob sie weitgehend noch so sprechen wie bei ihrer Einwanderung. Daran schließt sich dann im Hinblick auf diejenigen, die bei der Einwanderung noch sehr jung waren und deren sprachliche Bildung noch nicht abgeschlossen war, die Frage an, wie die Sprachgemeinschaft der deutschsprachigen Erwachsenen in bzw. seit dieser Zeit auch noch diese Jüngeren in ihre hochentwickelte, aber dann sozusagen

7 Vgl. dazu z.B. Gold et al. (1993) und in diesem Band den Beitrag von Ryan \& Kwong See. 
auf der Stufe der Einwanderungszeit stehengebliebene Sprachkultur integriert hat, ohne daß diese vom sonst üblichen generationsbedingten Sprachwandel berührt wurde.

Die von mir zu Rate gezogene Fachliteratur zur Sprache im Alter hat mir zur Beantwortung dieser Fragen noch nicht viel Hilfe gegeben. Als ganz unbrauchbar erwiesen sich die vorwiegend älteren literaturwissenschaftlichen Abhandlungen über den Altersstil großer Schriftsteller, die sich bevorzugt Goethe, Hölderlin oder Thomas Mann auswählten. Wenn hier überhaupt auf konkrete sprachliche Phänomene eingegangen wird, so bevorzugt auf Beobachtungen zur Lexik, wie z.B. Neologismen und neue Wortbildungen. Zu Goethes Stil in 'Faust II' macht Friese (1937, $606 \mathrm{u}$. 610) einige vage Anmerkungen, die auf syntaktische Eigenarten zu verweisen scheinen: "Goethes monumentaler Stil" sei charakterisiert durch „markige Kürze, Wucht und Gedrungenheit“, und damit, laut Friese, eben kein Altersstil, sondern „ein Beweis für die ungeschwächte Dichterkraft des alten Goethe“. ${ }^{8}$ D.h. weder der Befund noch die Analysemethode bieten einen Ansatzpunkt für einen Vergleich mit meinem Material.

Etwas erwägenswertere Hinweise und Thesen finden sich in der neueren sozialpsychologischen Forschung zum Thema 'Kommunikation und Alter'. Coupland, Coupland \& Giles (1991) bieten zwar für meine syntaktischen Fragen auch nicht viel, aber immerhin Informationen über Arbeiten, die das „deficit paradigm“ nicht nur auf der Ebene des Sprachverstehens, sondern auch auf der der Sprachproduktion nachzuweisen versuchen, u.a. indem sie von einem direkten Verhältnis zwischen "language deficits and linguistic complexity“ ausgehen (S. 12). Demgegenüber stehen jedoch Studien, die - zumindest bei nicht chronisch kranken alten Menschen keine Abnahme der Sprachfähigkeit erkennen lassen, ja sogar auf größeres kommunikatives Geschick hinweisen: „elderly subjects have sometimes been shown to 'outperform' young communicators" (S. 13f.).

Überlegenswerte Anregungen für eine syntaktische Bewertung meiner IsraelDaten geben insbesondere die Untersuchungen von Susan Kemper, die sich vielfach speziell der Frage gewidmet hat, ob die Produktion syntaktisch komplexer Sätze im Alter zurückgeht. Wurde manchmal bemängelt, daß Kemper in ihren früheren Arbeiten nur schriftliches Material analysierte, wertet sie später (Kemper 1988) auch mündliche Belege aus und vergleicht sie mit den schriftlichen. Ihre Ergebnisse sind u.a., daß sich die Durchschnittslänge der Äußerungen und auch die Flüssigkeit beim Sprechen mit dem Alter nicht verändern. Wohl aber weisen ihre Daten bei der jüngeren Probandengruppe von 50- bis 60jährigen eine größere Zahl komplexer Strukturen mit Mehrfacheinbettungen und Kombinationen von Einbettungen und Koordinationen auf als die der älteren Gruppe der 70- bis 80jährigen (S. 61). Unter den von den 70- bis 80jährigen nicht oder eklatant weniger benutzten Strukturen seien vor allem linksverzweigende Strukturen; stattdessen würden sie Rechtsverzweigungen nutzen, was sie in die Lage versetze, die Satzlänge ihrer Äußerungen aufrecht zu

8 Bei der genaueren Beschreibung dieses Stils geht es jedoch wiederum vor allem um „das Wort", das „sinnfällig, plastisch, lapidar wirken“ könne (Friese 1937, 606). Ein einziger Satz in diesem Aufsatz gibt einige konkretere Hinweise, mit welchen sprachlichen Mitteln diese stilistische „Konzentration und Gedrungenheit“ erreicht wird: „Durch Weglassung des Artikels und der Pro-

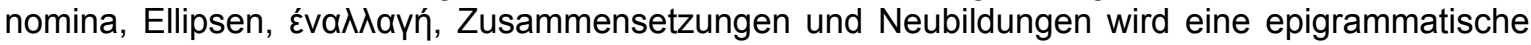
Kürze und Schlagkraft von michelangelesker Wucht erreicht" (S. 610). 
erhalten. ${ }^{9}$ Dies an meinem Material zu überprüfen, wäre interessant, aber Kemper (1988, 67ff.) erwägt selbst den entscheidenden Einwand, ob die hier beobachteten Unterschiede nicht denen „between informal, spoken, and formal written language“ entsprechen. Durch die Analyse von zwölf Tagebuchschreibern über eine Spanne von 70 Lebensjahren hält sie jedoch ihre Ergebnisse zur altersbedingten syntaktischen Entwicklung im Mündlichen auch für das Schriftliche für bestätigt und bleibt daher für beide sprachlichen Realisationsformen bei dem generalisierenden Resümee: „There is an overall decline in adults' production and imitation of complex, multiply-embedded sentences with age, and this age-related decline appears to be more precipitous for left-branching constructions than for right-branching ones." (S. 73) ${ }^{10}$

Leah L. Light (1993, 908ff.) stützt sich im Kapitel 'Production of Discourse' ihres Handbuchartikels über 'Language Change in Old Age' auf diese Untersuchungen Kempers, relativiert aber speziell die Annahme von der Abnahme syntaktischer Komplexität durch das statement: „The evidence on this point suggests that this may be true but is not altogether consistent". So lege etwa eine Studie von L. K. Obler (1980) nahe, daß ältere Erwachsene eine elaboriertere Sprache haben als junge. Auch P. V. Cooper (1990) habe weder eine Abnahme der Satzlänge noch der Satzkomplexität feststellen können. Light hält allerdings Kempers Untersuchungen für die differenzierteren und daher derzeit überzeugenderen.

Bedenkenswert sind ergänzende Forschungen Kempers und anderer zur Diskurskohärenz $^{11}$, die zu ergeben scheinen, daß bei alten Erwachsenen schriftliche wie auch mündliche Erzählungen strukturell komplexer sind als bei jüngeren, indem sie mehr Episoden (und zwar sowohl „multiple“ wie „embedded“) und häufiger eine Koda mit Evaluation des Erzählten enthalten. Andererseits wird auf der syntaktischen Ebene eine Abnahme von Kohäsionsmitteln wie Anaphern und Konjunktionen, aber auch Kataphern, Ellipsen etc. festgestellt. Diesen Befund hält Light $(1993,909)$ fest mit dem Satz: „Decreased cohesiveness was associated with increased structural complexity." - Während es in unserem Material aus Israel eine unglaubliche Fülle von Beispielen für die strukturelle Komplexität von Erzählungen gibt, dürfte sich jedoch die Behauptung, gleichzeitig nähmen die Kohäsionsmittel ab, hier nicht bestätigen.

Interessant für einen Vergleich sind schließlich noch die Ergebnisse einer Studie von Walker, Roberts \& Hedrick von $1988^{12}$, daß die Älteren mehr Interjektionen (erläutert als Füllwörter und gefüllte Pausen) benützen. Auch hier zeigt sich in meinem Material überwiegend anderes: Selbst bei langsam und mit langen Pausen $\mathrm{Re}-$ denden sind - außer vielen Ähs - viel weniger Gliederungssignale und andere mit der Sprachproduktion oder der Interaktion häufig gekoppelte Gesprächswörter zu finden als in Texten wesentlich jüngerer Sprecher in den deutschsprachigen Län-

9 Kemper $(1988,61)$ gibt als Beispiele für diese beiden in der Linguistik unterschiedenen Stellungsmöglichkeiten eingebetteter Strukturen u.a. die folgenden Nebensätze (subordinate clauses): Because Bill left the party without his coat, John was upset (= linksverzweigend); John was upset because Bill left the party without his coat (= rechtsverzweigend).

10 In weiteren Untersuchungen, z.B. Cheung \& Kemper (1992), wird versucht, diese Ergebnisse durch Heranziehung weiterer Merkmale für syntaktische Komplexität und weitere Tests zu erhärten und die sich nach diesen Experimenten für sie erwiesene These "that the complexity of adults' speech declines with advancing age" als Reflex einer "reduction in the capacity of working memory" zu sehen (S. 72).

11 Referiert bei L. L. Light $(1993,909 f$.$) .$

12 Referiert bei L. L. Light $(1993,910)$. 
dern heute. ${ }^{13}$ Es bestätigen sich eher die jüngst auch von Schu \& Stein (1994) z.T. in Weiterführung von G. Antos formulierten Beobachtungen an dem wieder aufgerollten Material der Freiburger 'Texte gesprochener deutscher Standardsprache, ${ }^{\text {, }}$, daß es eine Korrelation zwischen schriftsprachlich orientiertem, grammatisch "korrektem“ Sprechen und dem weitgehenden Fehlen von Gliederungssignalen gibt, und umgekehrt. Fast alle unsere Interviews gehören diesem stark schriftsprachlich orientierten Typus an.

\section{Spezifische Probleme unseres Materials und offene Fragen}

Nach dieser Sichtung der augenblicklich zur Verfügung stehenden Einzelforschungsergebnisse, die zum Teil in Kontrast zu unserem Befund zu stehen scheinen, würde ich an unser Material eher die folgenden Fragen stellen:

- Haben sich die zu beobachtenden stilistischen und grammatischen Verhaltensweisen/Vorlieben mit dem Alter verstärkt oder vermindert?

- Ist das Alter zur Erklärung der Konservierung des Normbewußtseins einer früheren Epoche der deutschen Sprachkultur mehr oder weniger relevant als die Kommunikation in einer Sprachinselsituation, ohne Nachwuchs junger Sprecher und größeren kommunikativen Austausch mit anderen gesprochenen und geschriebenen Varietäten des deutschen Sprachgebiets?

- Hat sich dieses Normbewußtsein eventuell im Laufe der Jahre automatisch oder in Abhängigkeit vom Alter der Sprecher verstärkt und/oder auch qualitativ verengt durch das Fehlen von Anpassungsprozessen und Diskussionen der Norm?

Ich kann diese Fragen u.a. deswegen nicht beantworten, weil ich keine Aufnahmen derselben Sprechergruppe von früher habe und mir bislang auch kein vergeichbares Korpus mit Aufnahmen aus den 20er Jahren bekannt ist. Als einziges ist mir derzeit klar, daß eine frühe Orientierung an sprachlichen Normen, erworben über alltäglichen Sprachgebrauch und Spracherziehung durch Elternhaus, Schule und Orientierung am prestigehaltigsten gesellschaftlichen Umfeld, unterstützt durch viel Lektüre etc. diese (schriftsprachlichen) Normen offenbar früh und vor allem unauslöschlich verankert, so daß die damit verbundenen Sprachstrukturen vollständig internalisiert sind und automatisch in jeder Situation reproduziert werden. Das dürfte bei unseren Sprechern z.B. die Folge haben, daß weder das Altersgedächtnis noch Zerstreutheit oder sonstige Ablenkungen die korrekte Wiederaufnahme und Weiterführung einer komplexen syntaktischen Konstruktion nach längerer Unterbrechung beeinträchigen können. Wenn es so ist, daß eine Reihe früh erworbener Verhaltensnormen (wie etwa das Vorhalten der Hand beim Gähnen) selbst bei sonst hochgradig gestörten Personen meist noch automatisch funktionieren, könnte Ähnliches vielleicht auch für den Erwerb syntaktischer Strukturen durch frühen Drill gelten (von Gehirnstörungen, die das Sprachzentrum mitbetreffen, einmal abgesehen), und zwar speziell, wenn das Prestige der dahinterstehenden Normen von den Sprechern restlos anerkannt wurde und wird.

13 Vgl. dazu mit Beispieltexten Betten (1994, 394f.) und (1995a, 271ff.).

14 Z.T. korrektiv zu R. Raths auf diesen Texten aufbauenden generalisierenden Thesen über den Charakter gesprochener Sprache, vor allem in der einflußreichen Buchversion von 1979, wo suggeriert wurde, eine hohe Zahl von Gliederungssignalen sei konstitutiv für jeden spontan gesprochenen Text. 
Mehr als alle augenblicklich in der Forschung zur Sprache im Alter diskutierten Thesen, die meist aus relativ kleinen und speziellen Datenmengen abgeleitet sind, scheinen mir daher für unsere Daten einige Anmerkungen der Psychologin Hede Helfrich $(1979,73)$ zuzutreffen. Sie nämlich kommt bei der Erörterung wiederum anderer, etwas älterer Forschungsergebnisse zu folgendem, durch unser Projekt wie mir scheint voll bestätigtem Schluß: „[...] we may assume that older people tend to define more situations as formal and therefore prefer a more qualitative style." ${ }^{15}$ Und ferner: „Moreover, it is likely that the historical trend or Zeitgeist has shifted from more formality to more informality."

\section{Literatur}

Betten, Anne (1980). Fehler und Kommunikationsstrategien. Zur funktionalen Erklärung einiger häufig vorkommender syntaktischer Wiederaufnahme-Formen in der gesprochenen deutschen Gegenwartssprache. In: Cherubim, D. (Hrsg.), Fehlerlinguistik. Beiträge zum Problem der sprachlichen Abweichung. Tübingen, 188-208.

Betten, Anne (1994). Normenwandel im gesprochenen Deutsch des 20. Jahrhunderts. In: Čmejrková, S., Daneš, F. \& Havlová, E. (eds.), Writing vs Speaking. Language, Text, Discourse, Communication. Proceedings of the Conference [...] Prague, October 14-16, 1992, Tübingen, 391-396.

Betten, Anne (Hrsg.) (1995). Sprachbewahrung nach der Emigration - Das Deutsch der 20er Jahre in Israel. Teil l: Transkripte und Tondokumente, Tübingen.

Betten, Anne (1995a). Stilphänomene der Mündlichkeit und Schriftlichkeit im Wandel. In: Stickel, G. (Hrsg.), Stilfragen. Berlin/New York, 257-279.

Betten, Anne (1996). Das Deutsch der 20er Jahre in Israel. Bericht über ein Forschungsprojekt. In: Sprachreport. Informationen und Meinungen zur deutschen Sprache. hg. vom Institut für deutsche Sprache, H. 4, 5-10.

Betten, Anne \& Du-nour, Miryam (1996). 'Wir sind die Letzten. Fragt uns aus'. Gespräche mit den Emigranten der dreißiger Jahre in Israel. 2. verb. Aufl., Gerlingen.

Cheung, Hintat \& Kemper, Susan (1992). Competing complexity metrics and adults' production of complex sentences. In: Applied Psycholinguistics 13, 53-76.

Coupland, Nikolas, Coupland, Justine \& Giles, Howard (1991). Language, Society and the Elderly. Discourse, Identity and Ageing. Oxford/Cambridge.

Friese, Hans (1937). Goethes monumentaler Stil. In: Zeitschrift für Deutschkunde 51, 605-617.

Gold, Dolores., Andres, David., Arbuckle, Tannis \& Zieren, C. (1993). Off-target verbosity and talkativeness in elderly people. In: Canadian Journal on Aging 12, 67-77.

Helfrich, Hede (1979). Age markers in speech. In: Scherer, K. R. \& Giles, H., Social markers in speech. Cambridge etc., 63-107.

Kemper, Susan (1988). Geriatric psycholinguistics: Syntactic limitations of oral and written language. In: Light, L. L. \& Burke, D. M. (eds.), Language, memory, and aging. Cambridge/New York, 5876.

Light, Leah L. (1993). Language Changes in Old Age. In: Blanken, G. et al. (eds.), Linguistic Disorders and Pathologies. An International Handbook, Berlin/NewYork (HSK 8), 900-918.

Rath, Rainer (1979). Kommunikationspraxis. Analysen zur Textbildung und Textgliederung im gesprochenen Deutsch. Göttingen.

Schu, Josef \& Stein, Stephan (1994). Lexikalische Gliederungssignale in spontan gesprochener Sprache: mehr Fragen als Antworten? In: Deutsche Sprache 22, 241-260.

15 Zu dessen Definition vgl. die Forschungsdiskussion bei Helfrich. 


\title{
„so frau adams $\downarrow$ guck mal $\downarrow$ ein feines bac-spray $\downarrow$ gut $\uparrow$ \\ Charakteristische Merkmale der Kommunikation zwischen Pflegepersonal und BewohnerInnen in der Altenpflege
}

\author{
Svenja Sachweh
}

\section{Einleitung}

Thema dieses Beitrages ist die Kommunikation zwischen Pflegepersonal und BewohnerInnen im Altenpflegeheim. Ziel dieser Ausführungen ist es, auf der Basis der Gesprächsanalyse einen Eindruck von institutionell eingebetteter Kommunikation zwischen den Generationen zu vermitteln: wer spricht mit wem, und vor allem, wie wird gesprochen? Die Untersuchung als solche soll letzten Endes der Verbesserung der Altenpflege-Ausbildung dienen: Es ist geplant, im Rahmen eines Kommunikationstrainings konkrete Beispiele aus dem Heimalltag dazu zu nutzen, die zukünftigen Altenpflegerlnnen für die möglichen Schwierigkeiten zu sensibilisieren, die beim Sprechen mit pflegebedürftigen alten Menschen auftreten können.

Die verbale Kommunikation zwischen Personal und PatientInnen im Krankenhaus, und hier vor allem das Gespräch zwischen Arzt und Patient, ist mittlerweile linguistisch recht gut erforscht (Fehlenberg 1987; Fiehler 1990; Lalouschek 1995; Löning \& Rehbein 1993; Lörcher 1983; Redder \& Wiese 1994; Weinhold 1991). Gesprächsanalytische Forschung zum Thema Sprache und Altenpflege aber ist bis zum heutigen Tage, und vor allem in Deutschland, nicht existent.

Aufgrund der unterschiedlichen Ziele und Strukturen der beiden medizinischen Institutionen sind die Ergebnisse aus der einen Forschungsrichtung nicht ohne weiteres auf die andere übertragbar. Die Grundlage für die vorliegende Untersuchung bilden daher zwei sozialpsychologische Ansätze: einerseits die umfassenden Arbeiten von Ryan zum patronisierenden Sprechen junger gegenüber alten Menschen, und andererseits die Untersuchungen von Caporael, die erstmalig die Verwendung von Babysprache in amerikanischen Alteneinrichtungen beschrieb.

Das Kernstück von Ryans Arbeit ist ein Modell von mißlingender Kommunikation zwischen den Generationen (Ryan, Hummert, \& Boich 1995; Ryan, Meredith, MacLean \& Orange 1995). Es geht davon aus, daß jüngere Menschen aufgrund stereotyper bzw. klischeehafter Erwartungen in bezug auf eine reduzierte kommunikative Kompetenz alter Menschen ihr Gesprächsverhalten dahingehend ändern, daß sie beispielsweise nur wenige Themen ansprechen, lauter reden und direktive, vereinfachte, oder eben Baby Talk-Äußerungen wählen, wenn sie sich mit alten Menschen unterhalten (Ryan \& Hummert 1993). In ihrer neuesten Arbeit, in der Hummert und Ryan (1996) die unterschiedlichen Arten patronisierenden Sprechens darstellen, heißt es hierzu:

„Patronizing communication directed to older adults has been conceptualized as inappropriate modifications based on age stereotypes of incompetence and dependence rather than on the actual communication needs of older persons." (149) 
Patronisierendes Sprechen führe einerseits zu einer Einschränkung der Chancen für eine erfolgreiche Kommunikation zwischen Jung und Alt, und andererseits zu einer Verstärkung altersstereotyper Verhaltensweisen bei den Alten. In einer Abwärtsspirale würden sowohl die Vorurteile der Jungen als auch die Frustration der Alten verstärkt. Ryan hat dafür den Begriff Communication Predicament of Aging geprägt.

Caporael (1981) hat demgegenüber speziell das Kommunikationsverhalten von Pflegekräften in Altenpflegeheimen untersucht und dabei herausgefunden, daß die PflegerInnen mindestens drei verschiedene Stile verwenden: die normale Erwachsenensprache im Umgang mit ihren KollegInnen und zwei unterschiedliche Stile zum Sprechen mit den BewohnerInnen. Alle Äußerungen, die die für Baby-Talk typischen prosodischen Merkmale aufweisen, hat sie als Secondary-Baby-Talk (SBT) klassifiziert. Ihren Untersuchungen zufolge vermittelt SBT Zuneigung. Alle anderen, prosodisch unauffälligen an die BewohnerInnen gerichteten Worte bezeichnet sie als Nicht-Baby-Talk. Im Gegensatz zu Secondary-Baby-Talk liege hierin ein institutionenspezifisches Register vor, welches Abhängigkeit signalisiere und gleichzeitig fördere.

Im folgenden soll untersucht werden, ob und inwiefern das Pflegepersonal gegenüber den AltenheimbewohnerInnen patronisierend spricht bzw. Baby-Talk verwendet, und ob darüber hinaus noch andere Gesprächsstrategien nachzuweisen sind.

\section{Datenerhebung}

Alle meine Daten verdanke ich einem Pflegeheim aus dem Freiburger Umland. Nach der Vorstellung der geplanten Untersuchung bei Heimleitung und Stationsschwestern habe ich in 5 Stationen bis zu zwei Wochen beobachtend am Heimalltag teilgenommen. Das Ziel war, erste Einblicke in die zu untersuchenden institutionellen Vorgänge zu gewinnen und die Mitarbeiterlnnen und Bewohnerlnnen an meine Anwesenheit zu gewöhnen. Insgesamt 33 PflegerInnen und 71 BewohnerInnen haben sich mit Tonbandaufnahmen ihrer Gespräche während der Morgenpflege einverstanden erklärt. Die Aufnahmen wurden in einem zeitlichen Rahmen von 2 bis 3 Wochen je Station gemacht und anschließend transkribiert. Das Korpus besteht aus 196 Interaktionen mit einer Gesamtlänge von ca. 44 Stunden. Die Analyse des Materials, das die Grundlage meiner Dissertation bildet, ist noch nicht abgeschlossen.

\section{Voraussetzungen für die Analyse der Kommunikation im Altenpflegeheim}

\subsection{Kontextgebundenheit}

Das Verhältnis von Kommunikation und nichtsprachlichen Handlungen im Altenpflegeheim ist empraktisch. Ein Großteil der pflegerischen Äußerungen ist handlungsorientiert. Das bedeutet, daß der primäre Zweck des Sprechens - wie etwa auch bei ärztlichen Untersuchungen oder bei kooperativen praktischen Arbeiten (Fiehler 1993) - in der Begleitung und Durchführung der Pflegeaktivitäten besteht. Eine Interpretation der Gespräche ist ohne Kenntnis des Kontextes nicht denkbar. 


\subsection{Asymmetrie}

Kommunikation im Altenpflegeheim ist institutionelle Kommunikation. Ein wesentliches Merkmal institutioneller Kommunikation ist nun die grundsätzliche Asymmetrie, die zwischen den Beteiligten besteht (Wodak 1987). Für das Verständnis meines Materials ist es entscheidend, sich bewußt zu machen, auf wievielen Ebenen hier Asymmetrien bestehen:

- auf der Ebene des Lebensalters: Die PflegerInnen sind jung, die Bewohnerlnnen sind alt;

- auf der physischen Ebene: Die Pflegerlnnen sind gesund und aktiv, die Bewohnerlnnen sind - meistens - sehr krank und passiv. Sie verfügen nur noch über eingeschränkte Handlungs- und Sprachfähigkeiten;

- auf der psychischen Ebene: Die PflegerInnen haben, salopp gesprochen, das Leben noch vor sich, während die alten Menschen nur noch dem Tod entgegensehen;

- auf der Sachebene: Die PflegerInnen sind ExpertInnen in Sachen Pflege, die Bewohnerlnnen hingegen sind im allgemeinen medizinische Laien;

- schließlich auf der institutionellen Ebene, denn die PflegerInnen haben die institutionelle Sanktionsmacht inne, während die Bewohnerlnnen, überspitzt formuliert, hilf- und machtlose Dienstleistungsempfängerlnnen sind.

Mit anderen Worten: Wie auch immer die verbale Kommunikation zwischen Personal und alten Menschen im einzelnen funktionieren mag, sie erfolgt sicher nicht immer nach den Regeln, die uns von unseren alltäglichen Kommunikationserfahrungen mit weniger weitreichenden Asymmetrien zwischen gesunden Gesprächspartnern her vertraut sind.

\section{Das Gesprächsverhalten der Bewohnerlnnen}

Das Gesprächsverhalten von Altenheimbewohnerlnnen ist meines Wissens bislang nicht linguistisch beschrieben worden. Es kann auf der Grundlage der vorliegenden Datenbasis folgendermaßen charakterisiert werden: Die allgemeine Beteiligung am Gespräch ist gering. Je kränker die alten Menschen sind, desto schweigsamer sind sie auch. Sie sind eher reaktiv als aktiv: Es gibt kaum Fragen oder andere Eigeninitiativen. Während das Verhältnis zwischen aktivem und reaktivem Sprechen bei den geistig gesunden Bewohnerlnnen beispielsweise in der Regel noch recht ausgeglichen ist, wird der Anteil der Eigeninitiativen je nach der Schwere der Erkrankung immer geringer. In extremen Fällen steuern die Bewohnerlnnen überhaupt keine Beiträge mehr zum Gespräch bei, ohne vom Pflegepersonal dazu angeregt worden zu sein. Vor allem bei BewohnerInnen, die sich im fortgeschrittenen Stadium der Demenz befinden, liegt das Verhältnis von aktiven zu reaktiven Äußerungen im vorliegenden Material bei bis zu 1:47. Einerseits ist das Gesprächsverhalten der institutionalisierten alten Menschen als minimal responsiv zu bezeichnen, wenn sie beispielsweise auf geschlossene Fragen antworten. Im folgenden Textausschnitt reagiert die Bewohnerin (B) lediglich mit Ein-Wort-Antworten auf die Fragen des Pflegers $(P)(Z .02,05,08,13,29)$ : 
Beispiel 1: Ausschnitt aus Text 125: P18 - B42 ${ }^{1}$

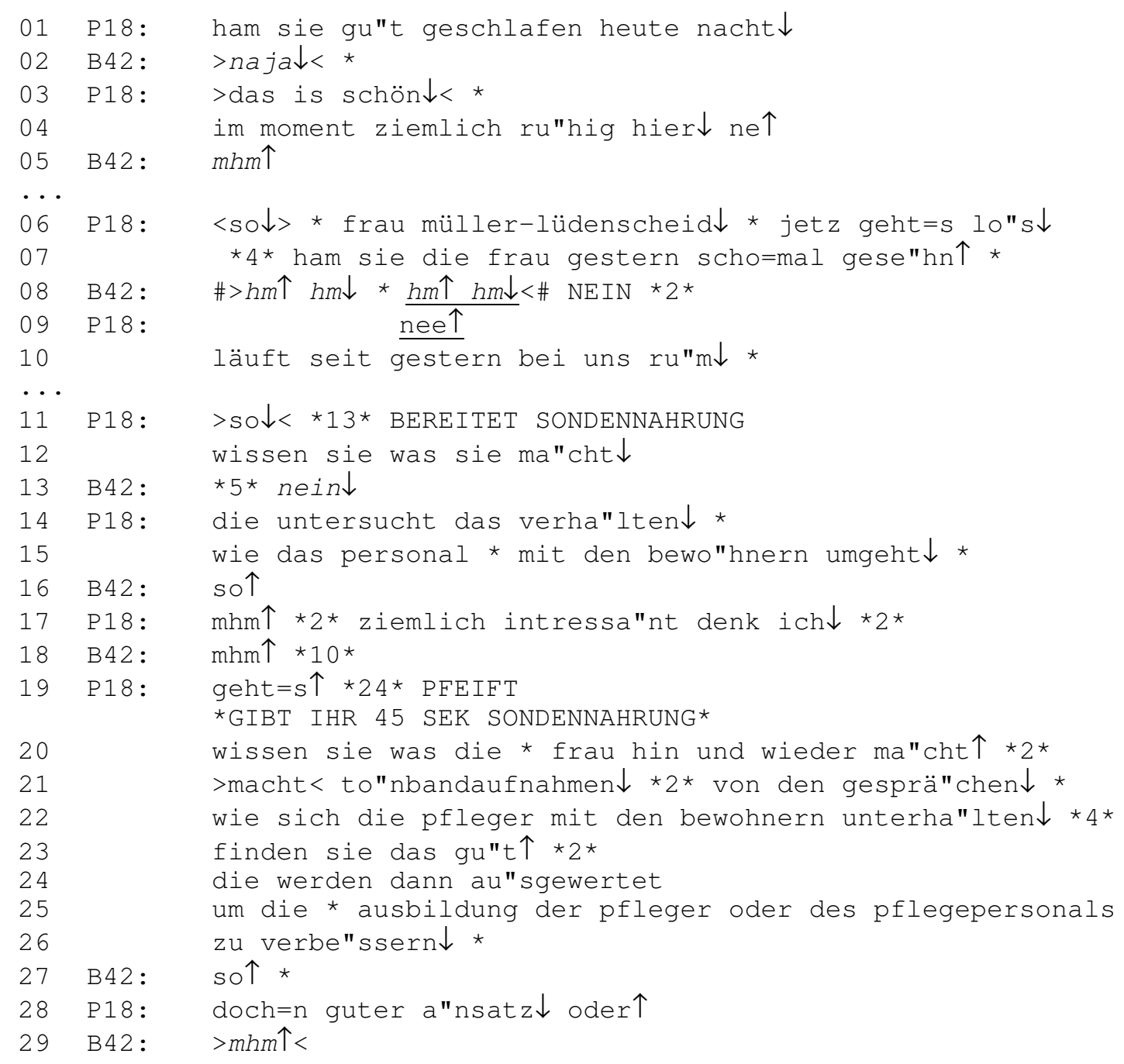

Andererseits werden Fragen des Personals wie in den Zeilen 19 und 23 nicht, zumindest nicht verbal, oder erst nach einer Wiederholung beantwortet. Je nach der geistigen Regheit greifen sie angebotene Small-Talk-Themen auf. Relativ häufig

1 Die jeweils interessierenden Phänomene sind hier und im folgenden zur Verdeutlichung kursiv gedruckt. Transkribiert wurde nach den Konventionen des Instituts für deutsche Sprache in Mannheim. Es bedeuten:

$\begin{array}{clll}\text { B } & \text { Sigle für Bewohnerln } & * & \text { kurze Pause } \\ \mathrm{P} & \text { Sigle für Pflegerln } & { }^{*} 3^{*} & \text { 3 Sekunden lange Pause } \\ U & \text { Sigle für Untersucherin } & <\text { lauter } & \text { lauter gesprochen } \\ \downarrow & \text { fallende Intonation } & >\text { leiser } & \text { leiser gesprochen } \\ \uparrow & \text { steigende Intonation } & (\ldots) & \text { unverständliche Passage } \\ " & \text { Betonung } & \ldots & \text { Auslassung } \\ : & \text { Dehnung } & \underline{\text { ich }} & \\ = & \text { Verschleifung } & \underline{\text { aber }} & \text { gleichzeitiges Sprechen } \\ \rightarrow \text { schnell } \leftarrow & \text { schneller gesprochen } & \# \# & \text { Erstreckung des Kommentars }\end{array}$

$\leftarrow$ langsam $\rightarrow$ langsamer gesprochen

LACHEN Kommentar der Transkribendin 
fehlt der von innen erwartbare zweite Teil einer Paarsequenz, wie etwa im Fall von Gruß und Gegengruß. Es erfolgen nur wenige Rückmeldehandlungen, d.h. die gewohnten, ratifizierenden Hörersignale fehlen häufig. Im obenstehenden Beispiel setzt die Bewohnerin sie nur dann ein, wenn eine Pause entsteht (Z. 16, 18, 27); niemals spricht sie von sich aus zur gleichen Zeit wie der Pfleger, wie es in normaler Altagskommunikation bei Hörersignalen häufig der Fall ist. Das passive Gesprächsverhalten bewirkt, daß es wie im ersten Beispiel kaum simultane Sequenzen oder einen Kampf ums Rederecht gibt. Je nach Art und Schwere der Pflegebedürftigkeit kommunizieren die BewohnerInnen nur noch nonverbal. Einige reagieren auf die Gesprächsbemühungen und handlungsbezogenen Äußerungen der Pflegerlnnen lediglich mit einem multifunktionalen Schreien. Die Bewohnerin im folgenden Beispiel, die außer diesem Schreien in seltenen Fällen noch Worte wie ja, nein und oh sagt, beachtet dabei jedoch zumeist noch die Regeln des Turn-Taking: Ihr Schreien erfolgt meist im Sinne einer Antwort oder Reaktion nach den Äußerungen des Pflegepersonals, wie hier in den Zeilen 05, 08, und 10:

Beispiel 2: Ausschnitt aus Text 134, P23 - B51

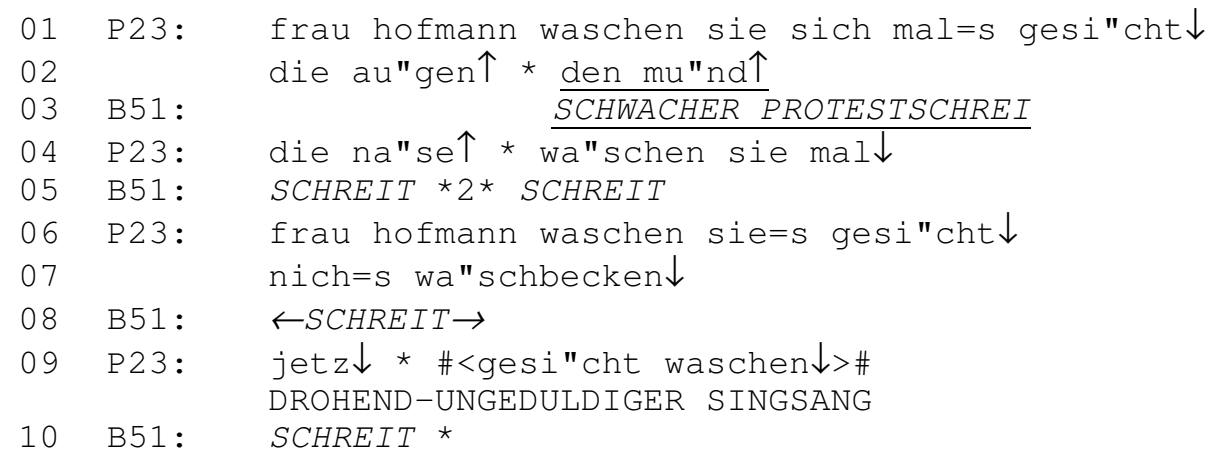

Andere wiederum monologisieren unverständlich vor sich hin, ohne wirklich Bezug auf die Sprechaktivitäten des Personals zu nehmen, und ohne zu begreifen, daß ihre eigenen Äußerungen für andere, wie hier im dritten Beispiel ab Zeile 07, unverständlich sind:

Beispiel 3: Ausschnitt aus Text 130, P21 - B47

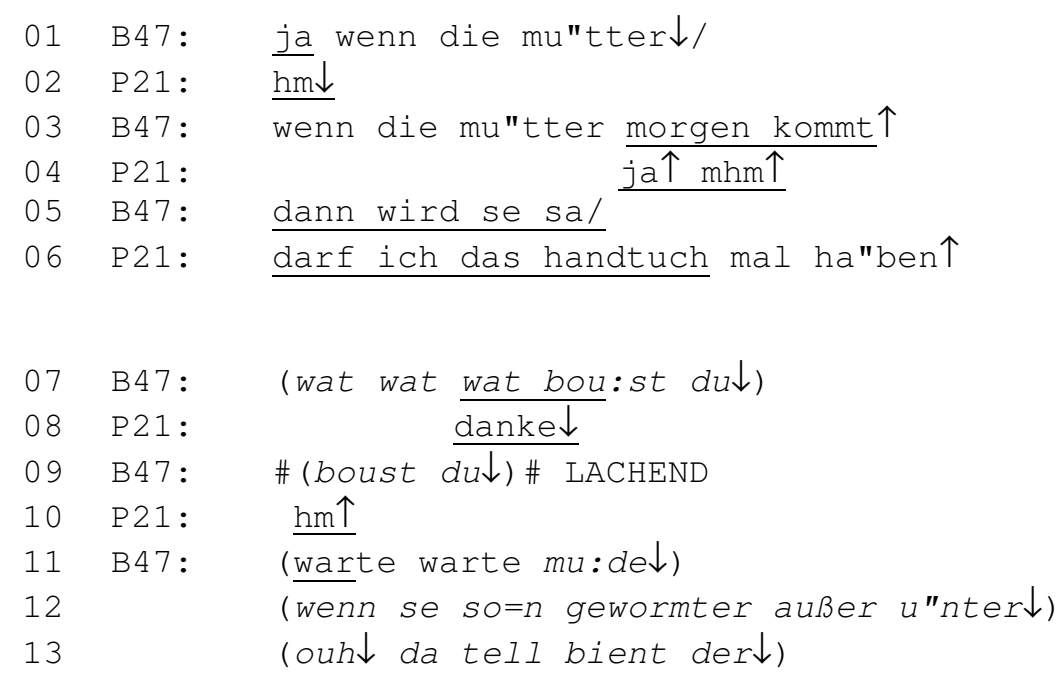




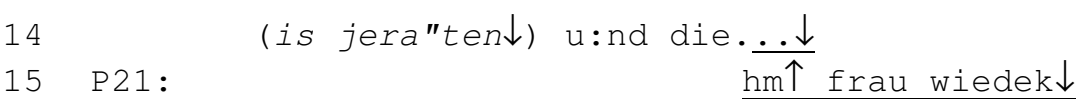

Angesichts dieser Liste an kommunikativen Verhaltensweisen, die mehr oder weniger nicht den uns vertrauten Grice'schen Gesprächsmaximen entsprechen, lautet meine zentrale Hypothese: Um erfolgreich mit den kranken alten Menschen im Pflegeheim kommunizieren zu können, bedarf es im Hinblick auf die Beziehungsebene gesichtsschonender und im Hinblick auf die Zweckorientierung der Gespräche vor allem verständnissichernder Gesprächsstrategien von seiten der PflegerInnen.

\section{Das Gesprächsverhalten des Pflegepersonals}

In den Ansätzen der Erforschung pflegerischen Gesprächsverhaltens in der Altenpflege wird teils implizit, teils explizit verallgemeinernd davon ausgegangen, daß das Sprechen der Pflegerlnnen respektlos ist (Grainger 1990; Whitbourne, Culgin \& Cassidy 1995). Schon die Bezeichnung des pflegerischen Gesprächsverhaltens als patronisierend ist negativ konnotiert und somit abwertend. Meiner Ansicht nach ist dies einer unvoreingenommenen linguistischen Betrachtung des facettenreichen empirischen Materials nicht dienlich. Aus diesem Grunde möchte ich in den nächsten Abschnitten versuchen, die folgenden vier Aspekte eines denkbaren Kontinuums möglichst deskriptiv darzustellen: Gesichtsschonende Strategien (5.1), Verständnissichernde Strategien (5.2), Baby-Talk (5.3) und Gesichtsbedrohendes Gesprächsverhalten (5.4).

Wie bewältigen nun die PflegerInnen die Kommunikation mit den Bewohnerlnnen im einzelnen? Ein wesentliches Kennzeichen der Kommunikation in der Altenpflege ist die sehr unterschiedlich große Redemenge der Beteiligten. Die BewohnerInnen sprechen nicht nur, wie in den meisten Institutionen, weniger als die Pflegerlnnen, sondern teilweise überhaupt nicht. Der folgende Textausschnitt verdeutlicht den häufig monologischen Charakter der Kommunikation während der Pflege. Er besteht zum größten Teil aus Handlungsaufforderungen. Die Bewohnerin B06 reagiert hier lediglich nonverbal, nämlich mit einem Stöhnen (Z. 12, 14), auf die Worte der Pflegerin. Es ist noch nicht einmal klar, ob sie damit überhaupt kommunikative Absichten verfolgt:

Beispiel 4: Ausschnitt aus Text 013, P02 - B06

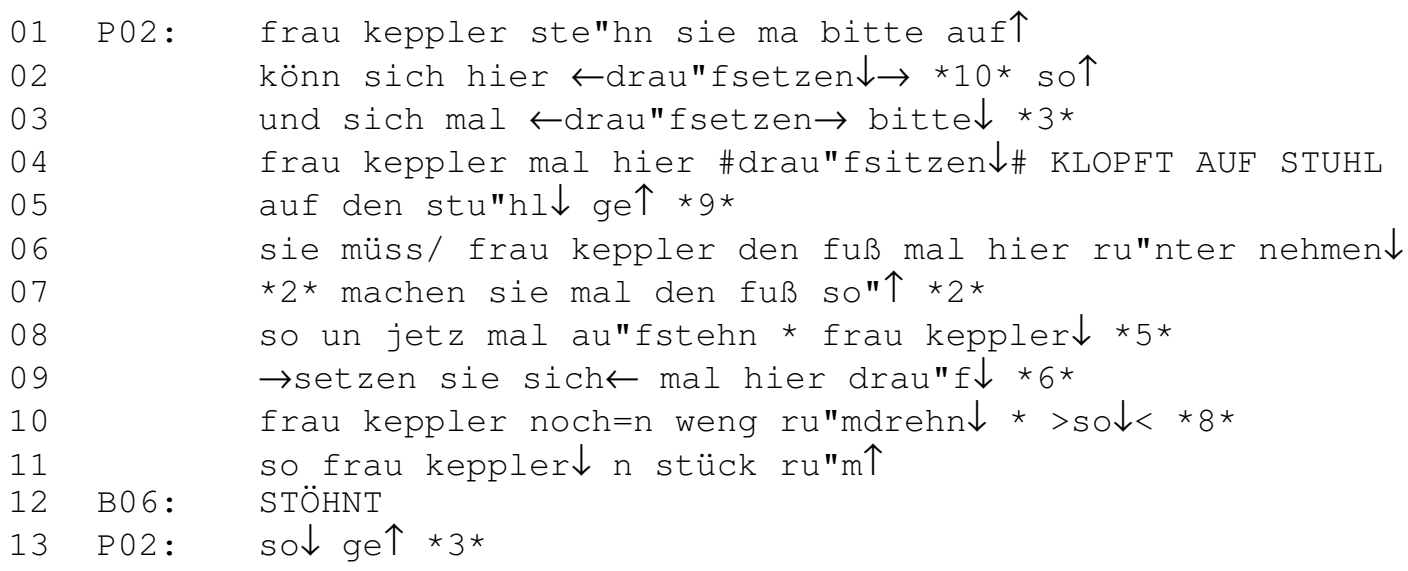




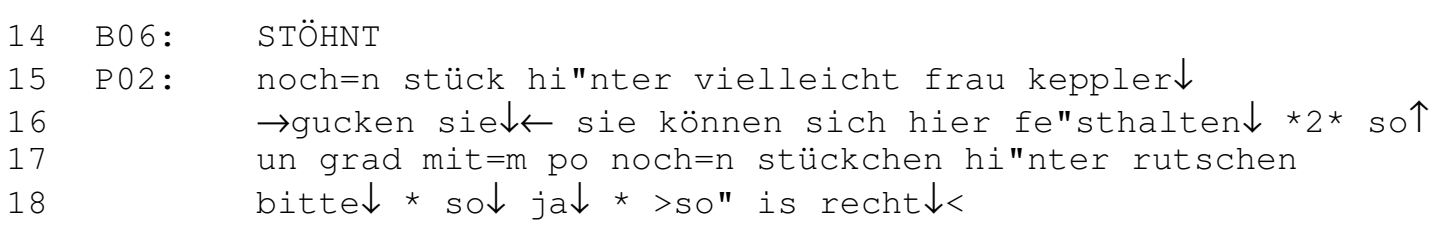

\subsection{Gesichtsschonende Strategien}

Im Gegensatz zu den Ergebnissen anderer Untersuchungen verhält sich das Personal in dem von mir untersuchten Altenpflegeheim nicht immer patronisierend, wie Ryan und KollegInnen es nennen würden, sondern in vielen Fällen auch dezidiert und über das gewohnte Maß hinaus respektvoll und höflich. Als gesichtsschonend im Sinne von Brown und Levinson (1987) habe ich daher die folgenden Merkmale klassifiziert: Die Bewohnerlnnen werden im allgemeinen gesiezt und mit ihrem Nachnamen angesprochen. Manche Aufforderungen werden wie in Beispiel 5 nicht imperativisch $(Z .13,16)$, sondern mithilfe von Infinitiv- $(Z$. 03, 05), Modalverbkonstruktionen $(Z$. 01, 11) und Ellipsen $(Z$. 03, 05) formuliert. Darüber hinaus werden sie in vielen Fällen durch Konjunktiv und Modalpartikeln (Z. 16) abgeschwächt. Auch gehen sie häufig mit bitte (Z. 03) und danke einher.

Beispiel 5: Ausschnitt aus Text 070: P05 - B06

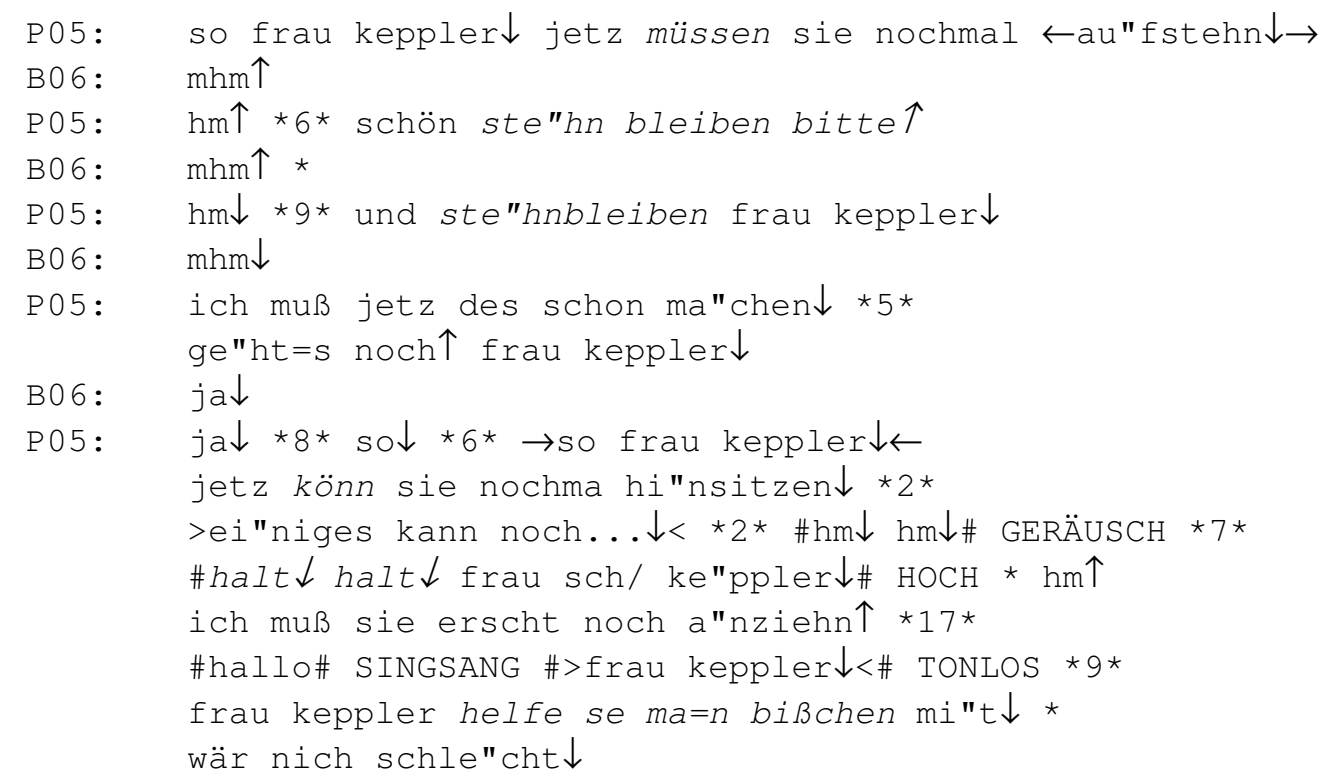

Übermäßiges Loben oder Komplimente gleichen die durch die direktive Situation bedingten Angriffe auf das "negative face" aus, wie das Verhalten von P25 in Beispiel 6 besonders in den Zeilen 04 und 05 zeigt: Nachdem die Pflegerin der Bewohnerin deutlich gemacht hat, wie diese sich während des Anziehens richtig zu verhalten hat, macht sie ihr ein Kompliment in Bezug auf das soeben angezogene Kleidungsstück, um die in ihren Anweisungen (Z. 01, 02) enthaltene Kritik wett- oder vielleicht sogar vergessen zu machen. 
Beispiel 6: Ausschnitt aus Text 138, P25 - B51

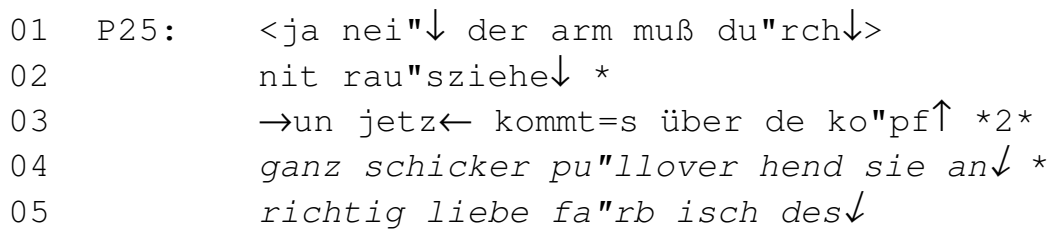

Auffällig sind auch die folgenden drei Verhaltensweisen. Ihnen ist gemeinsam, daß sie darauf abzielen, die vielen Asymmetrien zwischen den Beteiligten auszugleichen. Ihr Zweck ist es darüber hinaus, eine objektiv nicht gegebene Normalität der Kommunikation vorzuspiegeln.

Erstens übernehmen die PflegerInnen bei der Pflege von Bewohnerlnnen, die nicht mehr sprechen können, oftmals beide Gesprächsrollen. ${ }^{2}$ Das Personal repariert gewissermaßen die mangelnde Dialogizität des Gesprächs, wie deutlich am nächsten Beispiel zu sehen ist: Die Pflegerin übernimmt in den Zeilen 02, 08 und 13 die Perspektive der Bewohnerin und formuliert deren mögliche Empfindungen bzw. Reaktionen auf das Pflegegeschehen und auf ihre Äußerungen und Fragen. In Zeile 08 beispielsweise beantwortet sie die Frage, die sie B35 gerade gestellt hat, selbst. Damit signalisiert sie, daß sie die Bewohnerin zwar als sprachlosen, nicht aber als empfindungslosen Menschen betrachtet, auf dessen Gefühle sie, wenn möglich, Rücksicht nehmen will.

Beispiel 7: Ausschnitt aus Text 105, P13 - B35

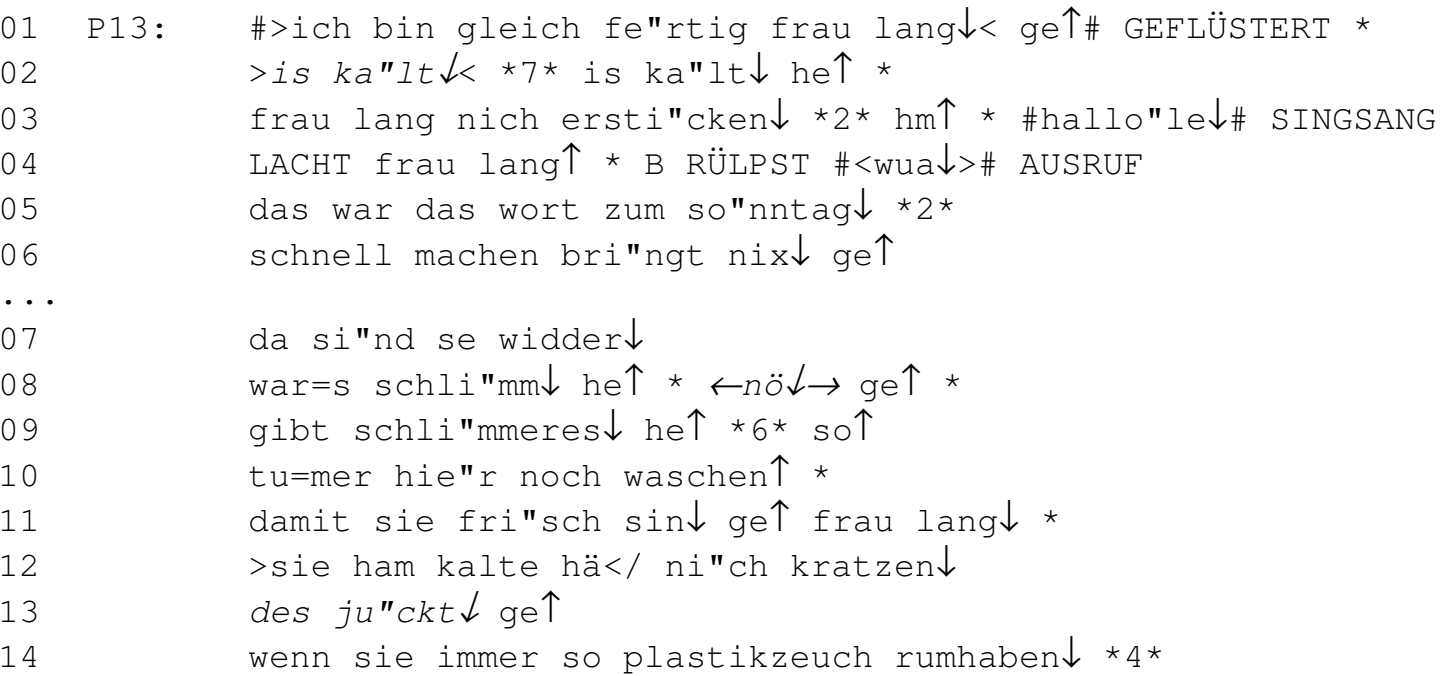

Zweitens werden normales Verstehen sowie ein normaler Gesprächsverlauf mithilfe von ratifizierenden Hörersignalen wie mhm oder ach so auch dann signalisiert, wenn BewohnerInnen nur noch unverständliche Äußerungen produzieren, wie im nachstehenden Beispiel 8. Auch das von P21 in Zeile 07 gebrauchte Lachen hat den Zweck, Solidarität und Verständnis zu demonstrieren:

2 Dieses Phänomen ist auch in der Mutter-Kind-Kommunikation beobachtet worden (Ochs 1992). 
Beispiel 8: Ausschnitt aus Text 130, P21 - B47

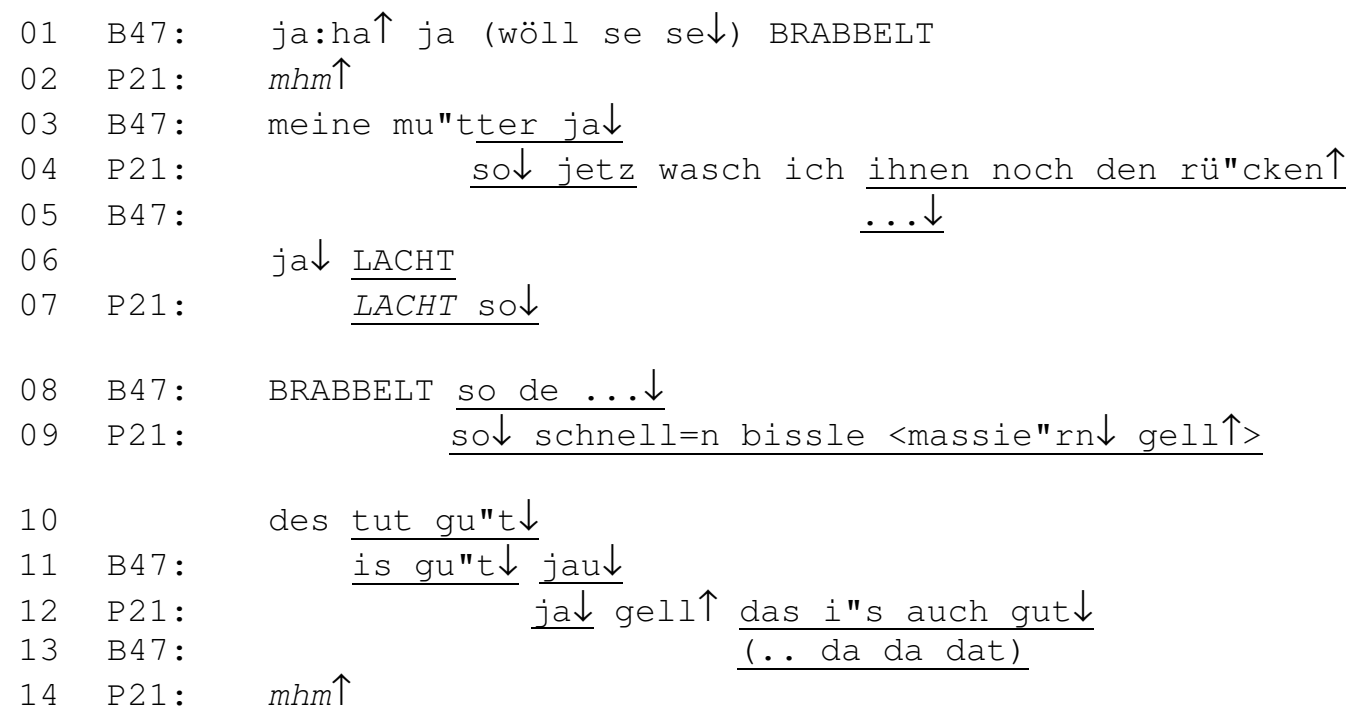

Drittens und letztens schließlich fordern die PflegerInnen verbal auch diejenigen BewohnerInnen höflich zur Mithilfe auf, die dazu aus Krankheitsgründen nicht mehr in der Lage sind. So sagt etwa eine Pflegerin zu einer spastisch gelähmten Frau, die

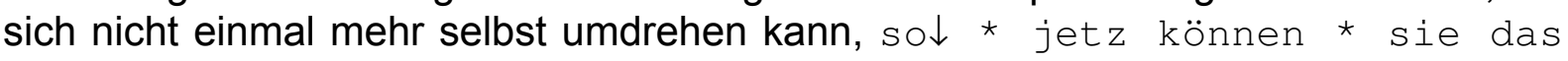
na"chthemd wieder anlegen $\uparrow$. Eine Aufforderung zum Umdrehen geht häufig damit einher, daß die Pflegekraft die Bewohnerin im Moment des Sprechens dreht, wie im folgenden Beispiel:

Beispiel 9: Ausschnitt aus Text 120, P14 - B35

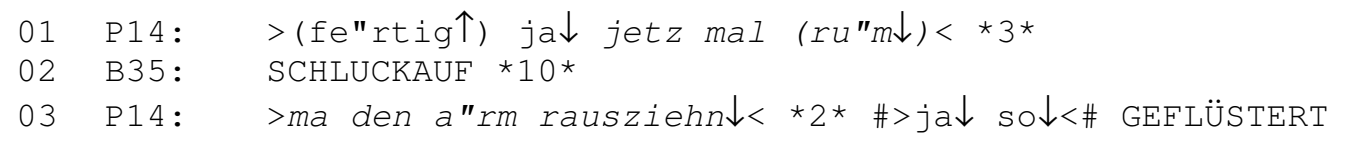

Zusammenfassend ist festzuhalten, daß die dezidierten und zum Teil ungewöhnlichen Bemühungen, den pflegebedürftigen Alten Respekt zu erweisen, deutlich zeigen, daß neben der Handlungs- und Kommunikationssteuerung (Fiehler 1993) auch die Image- und Beziehungsarbeit ein zentraler Bestandteil der Pflegekommunikation ist.

\subsection{Verständnissichernde Strategien}

Angesichts der vielfältigen Beschränkungen, denen das rezeptive wie auch das produktive Gesprächsverhalten einer großen Anzahl der schwer pflegebedürftigen HeimbewohnerInnen - etwa bedingt durch Aphasien, durch eine Verringerung der Kapazität des Kurzzeitgedächtnisses oder durch Schwerhörigkeit - unterliegt, ist ein, wenn nicht das zentrale Anliegen der Pflegekräfte, sich bzw. das Pflegegeschehen den BewohnerInnen verständlich zu machen. Als in erster Linie verständnissichernd verstehe ich entsprechend die im folgenden genannten Aspekte:

Es fällt auf, daß gemäß der primär empraktischen und direktiven Funktion der Gespräche auf der lexikalischen Ebene immer dieselben Handlungsverben wie etwa 
hinsetzen, aufstehen, oder umdrehen sowie immer gleiche Richtungsanzeiger wie hoch, rum, drauf, oder zurück gebraucht werden. Auch werden Pronomen vereindeutigend durch Nomen ersetzt.

Im Hinblick auf den Satzbau ist festzustellen, daß die Äußerungen des Personals meist kurz und einfach strukturiert sind. Ellipsen werden dazu genutzt, die Bewohnerlnnen sowohl höflich als auch sprachökonomisch zu bestimmten Handlungen aufzufordern. Beispiel 10 illustriert, wie eine Schwester angesichts des Nichtverstehens der angesprochenen Bewohnerin ihre Aufforderung immer mehr verkürzt, indem sie zunächst sowohl die dialektale pronominale ehr (entspricht hochdt. Sie) als auch die namentliche Anrede (maria) sowie das vermutlich modal gebrauchte, dialektale Verb den (entspricht hochdt. tun) ausläßt und die Äußerung schließlich auch um die abschwächende Modalpartikel mal reduziert:

Beispiel 10: Ausschnitt aus Text 190, P27 - B70

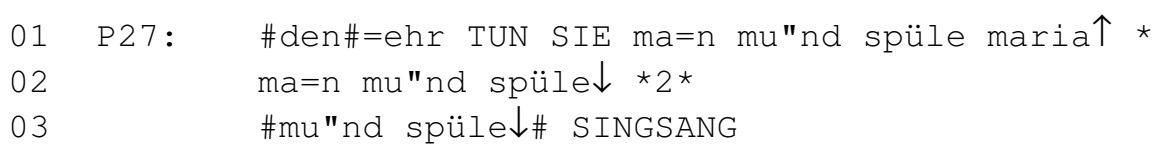

Vor allem auf der Ebene der Gesprächssteuerung finden sich viele verständnissichernde Strategien: Anfang und Ende der Morgenpflege werden mithilfe von rituellen Gesprächsanfängen und -beendigungen deutlich markiert. Der Ablauf folgt einem festen Schema. Die Pflegerlnnen sprechen sehr formelhaft. Gliederungssignale strukturieren nicht nur das Gespräch, sondern auch die Pflegeaktivitäten: Sie kündigen jeweils neue Handlungen an. Das Gliederungssignal so etwa wird im Beispiel 4 in dieser Art verwendet. Vergewissernde Nachfragen wie ne $\uparrow$, gell $\uparrow$ usw. dienen nicht nur zur Verständnissicherung, sondern gleichzeitig zur Aufforderung an die BewohnerInnen, sich am Gespräch zu beteiligen. Sie bieten den BewohnerInnen explizit das Rederecht an, wie in den Zeilen 02-04, 06-08, 10, 11, und 14 des folgenden Beispiels: ${ }^{3}$

Beispiel 11: Ausschnitt aus Text 101, P10 - B34

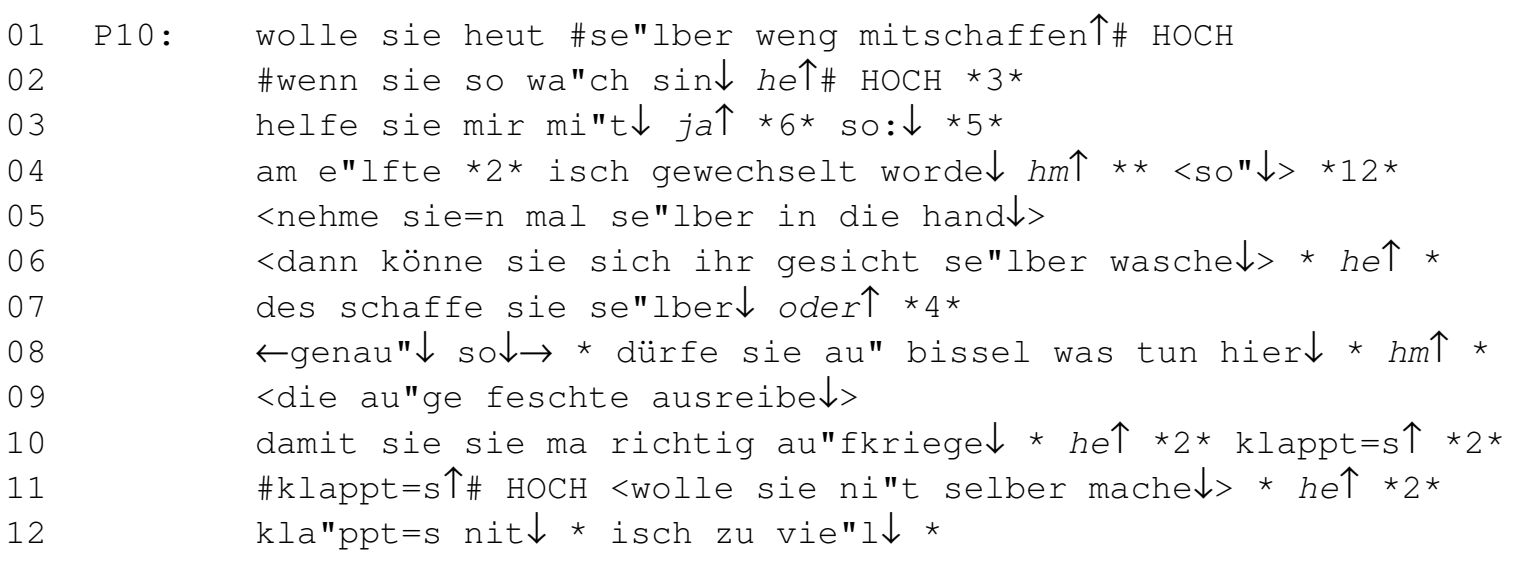

3 Interessanterweise werden diese tag-questions umso häufiger und hartnäckiger eingesetzt, je weniger der/die Angesprochene von sich selbst aus spricht bzw. zu sprechen in der Lage ist. Dies gilt auch und sogar für Fälle, in denen die angesprochenen Bewohnerlnnen gar nicht mehr sprechen können. 
Die mit vielen Äußerungen einhergehende namentliche Anrede wird zum Erhalt der Aufmerksamkeit der BewohnerInnen gebraucht. Auch dies läßt sich gut in den Beispielen 4, 5, und 7 beobachten. An Gesprächsausschnitt 12 ist zu sehen, daß die namentliche Anrede sowohl ein- $(Z .01,10)$ als auch ausleitend $(Z$. 05, 08, 09) verwendet wird:

Beispiel 12: Ausschnitt aus Text 190, P27 - B70

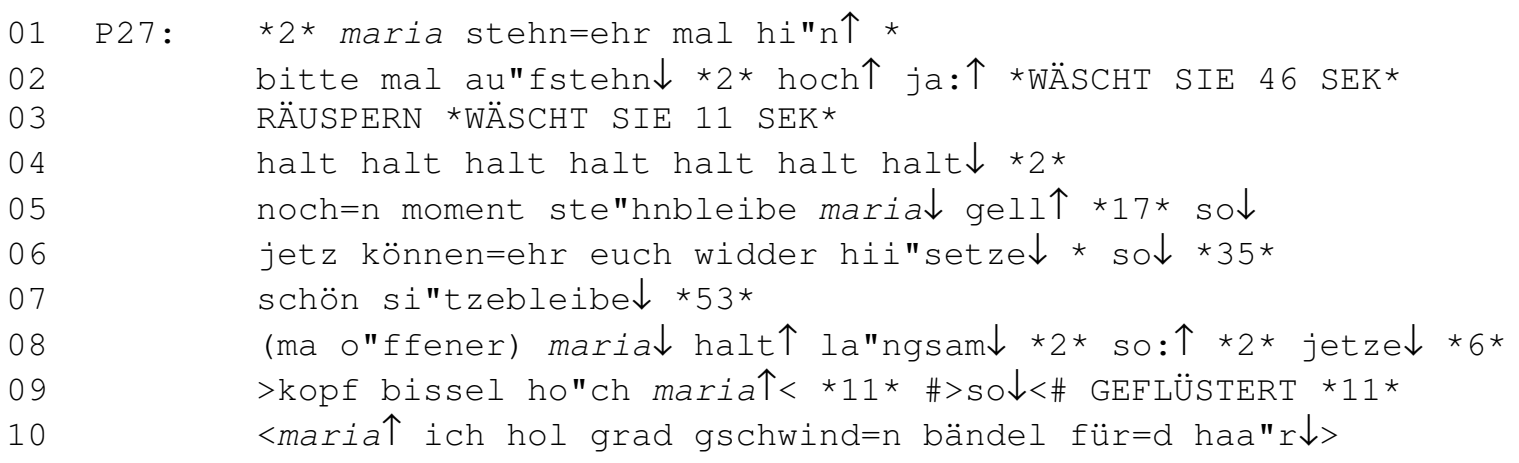

Die PflegerInnen wiederholen häufig bestätigend ihre eigenen Äußerungen und fragend die der BewohnerInnen. Im folgenden Beispiel wiederholt der Zivildienstleistende die Worte der Bewohnerin in den Zeilen 08, 12, 16 und 21 sowohl in verständnissichernder als auch in spaßhafter Absicht:

Beispiel 13: Ausschnitt aus Text 073, P05 - B14

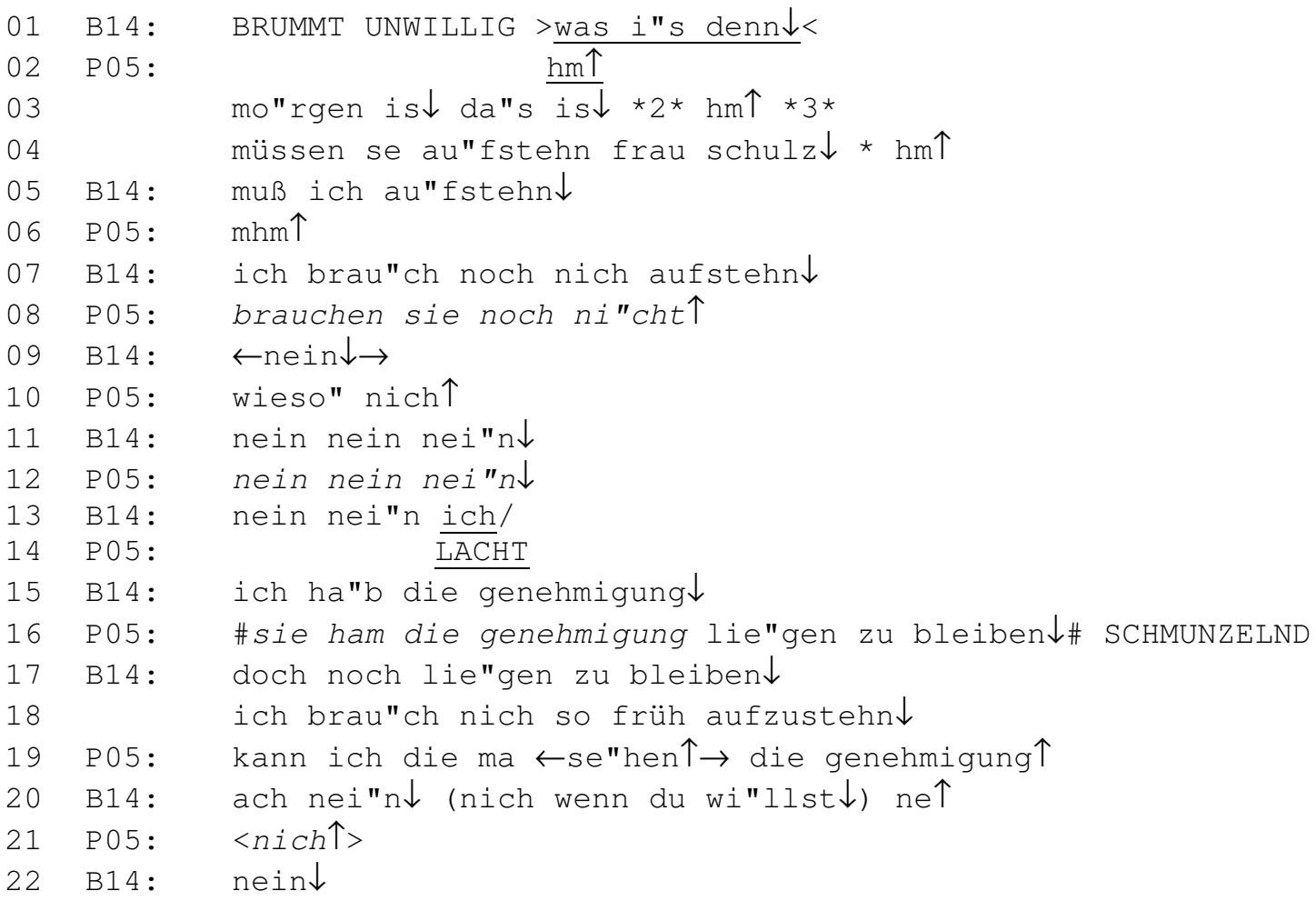


Die Initiierung von Paarsequenzen wie etwa Gruß-Gegengruß, Frage-Antwort etc. lädt wiederum zu mehr Dialogizität ein. Es werden im wesentlichen geschlossene Fragen gestellt, die auf eine einfache ja- oder nein-Antwort zielen und so für die Bewohnerlnnen leicht $\mathrm{zu}$ verstehen und zu verarbeiten sind. ${ }^{4} \mathrm{Im}$ vorhergehenden Beispiel 13 ist dies in den Zeilen 08, 19 und 21 der Fall.

Alles in allem ist das Gesprächsverhalten der Pflegerlnnen also in hohem Maße funktional, denn es gewährleistet vor allem durch die vielen Mittel der Verständnissicherung eine für die alten Menschen durchschaubare und effektive Durchführung der Pflege.

\subsection{Baby-Talk}

Der Begriff Baby-Talk bezeichnet primär das Sprachregister, das Mütter zur Kommunikation mit ihren Kindern verwenden (Ferguson 1977; Szagun 1991). Neben Kindern können aber auch Ausländer, Kranke und eben wie im vorliegenden Fall alte Menschen Adressatlnnen von bestimmten Elementen der Babysprache sein. Eine wesentliche Funktion von primärer Babysprache ist die Verständnissicherung, oder, wie Ferguson (1977) dies formuliert hat, das Aufrechterhalten bzw. Vereinfachen der Kommunikation. Eine zweite Funktion ist das Übermitteln einer positiven emotionalen Botschaft. Beides gilt auch für die Verwendung von Baby-Talk in der Altenpflege.

Neben der geringen Komplexität und der großen Redundanz mancher Äußerungen sind es vor allem Prosodie und Wortschatz, die einer eingehenderen Betrachtung bedürfen. Auf der Ebene der Prosodie fällt auf, daß die Pflegerlnnen mit manchen Bewohnerlnnen nicht nur deutlich langsamer, sondern auch in einer viel höheren, schrillen Tonlage und mit großen Tonhöhenunterschieden sprechen - eben wie Mütter mit ihren Babies. Auch verwenden sie teilweise Intonationsmuster, die eindeutig von denen der normalen Erwachsenensprache abweichen (Garnica 1977); so sprechen sie beispielsweise auch einige auffordernde Äußerungen mit fragender Betonung, wie im folgenden Textausschnitt:

Beispiel 14: Ausschnitt aus Text 120, P14 - B35

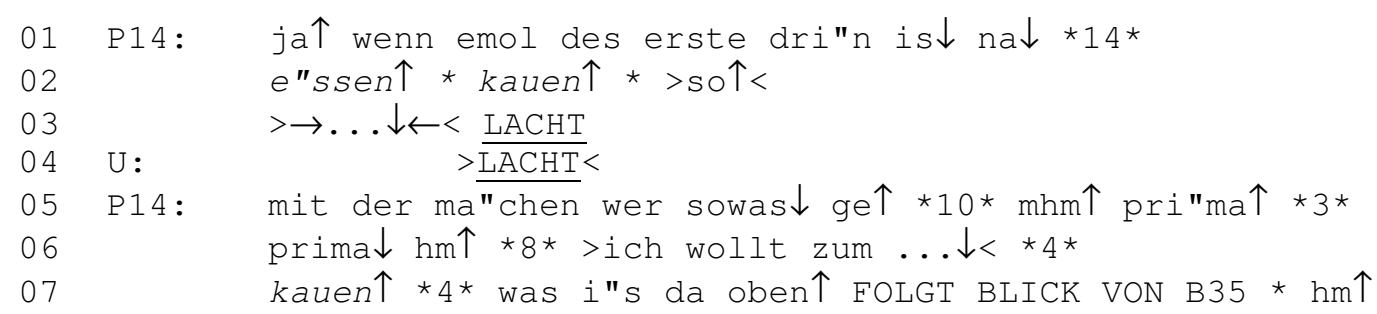

Desgleichen flüstern sie manchmal, wenn sie mit den Bewohnerlnnen sprechen. So redet etwa $\mathrm{P} 13$ beruhigend flüsternd auf eine spastisch gelähmte Bewohnerin ein: >ich bin gleich fe"rtig frau lang $\downarrow<$ ge $\uparrow$. Laut Garnica (1977) ist auch dies ein typisches Kennzeichen von primärem Baby-Talk. Im folgenden Ausschnitt

4 Vgl. hierzu auch das Frageverhalten in den Beispielen 1 und 11. 
ist die Verknüpfung der hohen Stimme (Z. 01-03) mit beruhigendem Flüstern (Z. 03) zu sehen:

Beispiel 15: Ausschnitt aus Text 196: P30 - B68

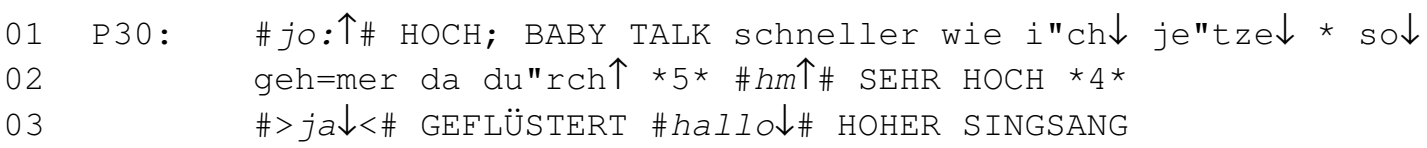

Laut Szagun (1991) bewirken die intonatorischen Eigenheiten des Baby-Talk, daß die Aufmerksamkeit kindlicher AdressatInnen auf die Sprache gelenkt wird und die sprachlichen Elemente besser analysiert werden können. Daß dies auch für alte Adressatlnnen gilt, haben Cohen und Faulkner (1986) in einer experimentellen Studie bewiesen.

Auf der Ebene der Lexik ist das Sprechen der Pflegerlnnen dadurch charakterisiert, daß nur ein kleiner, spezifischer Wortschatz sowie Diminutive und Kosenamen verwendet werden. Auffällig ist etwa, daß die BewohnerInnen oft aufgefordert werden, etwas schön zu machen, oder Dinge als fein bezeichnet werden. So auch das im Titel genannte Deodorant. Manche PflegerInnen reden die alten Damen mit den Kosenamen Schätzle, Mäuschen, Frolleinchen oder meine Süße an. Zusammenfassend kann also gesagt werden, daß Tonhöhe, Anredevarianten und Wortwahl auch in der Altenpflege die oben genannten Funktionen der Verständnissicherung und der Signalisierung von Zuneigung und Fürsorglichkeit erfüllen. Sie verdeutlichen jedoch auch, daß die PflegerInnen die so Angesprochenen nicht mehr uneingeschränkt als gleichwertige Erwachsene betrachten. In einigen Fällen wird so zu Unrecht von körperlicher Hilfsbedürftigkeit auch auf eine geistige und sprachliche Behinderung geschlossen. Entsprechend wird die Verwendung von Babysprache von manchen alten Menschen als unangemessen oder respektlos empfunden, oder wie dies eine Bewohnerin während einer Pflegeinteraktion formulierte:

Beispiel 16: Ausschnitt aus Text 179, P30 - B68

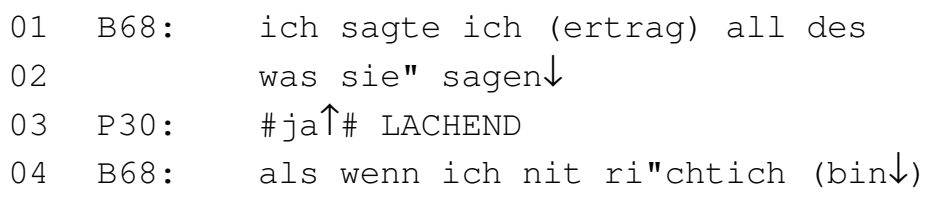

Dies ist allerdings nur die eine Seite der Medaille. Ich möchte an dieser Stelle eine Lanze für diejenigen brechen, die die schwierige Aufgabe übernommen haben, alte Menschen bis zu ihrem Tod zu pflegen: Angesichts der großen Ähnlichkeiten der Säuglings- und Altenpflege, die sich u.a. auf den Ebenen der Intimpflege und der oft eingeschränkten Verbalisierungsfähigkeiten der Gepflegten manifestieren, ist eine Übertragung mütterlichen Sprachverhaltens auf die Pflegeinteraktion im Altenheim wenn auch nicht uneingeschränkt wünschenswert, so doch verständlich. Die PflegerInnen haben sicher nicht die Absicht, die BewohnerInnen durch den Gebrauch von Babysprache zu erniedrigen. Im Gegenteil: sie möchten ihnen Nähe, Geborgenheit und Trost vermitteln. Das wird auch in vielen, nur eben nicht allen Fällen so verstanden. Einigen BewohnerInnen scheint es ausgesprochen gut zu tun, auf diese Art bemuttert zu werden. Das Dilemma ist meines Erachtens, daß es im Deutschen kei- 
ne Sprachvariante gibt, die gleichermaßen Respekt und Fürsorglichkeit auszudrücken in der Lage wäre.

\subsection{Gesichtsbedrohendes Gesprächsverhalten}

Daß Pflegekommunikation (wenigstens nach meinem Verständnis) nicht immer gelingt, und sicher für manche Pflegerin zuweilen auch eine Überforderung darstellt, möchte ich abschließend an den von mir so genannten gesichtsbedrohenden $\mathrm{Ge}-$ sprächsstrategien demonstrieren. Im Gegensatz zum Baby-Talk sind ihre Auswirkungen vermutlich ausschließlich negativer Art. Gemeinsam ist innen allen, daß sie den BewohnerInnen nicht den Status eines Erwachsenen, sondern den eines Kindes zuschreiben.

Besonders auffällig ist dies im Fall der Referenz und der Anrede: Manchmal wird auf die BewohnerInnen nicht pronominal, sondern namentlich referiert - d.h. als hätten sie wie ein Kleinkind das Konzept „ich“ noch nicht begriffen. Dies wird in Beispiel 17 deutlich:

Beispiel 17: Ausschnitt aus Text 131, P21 - B48

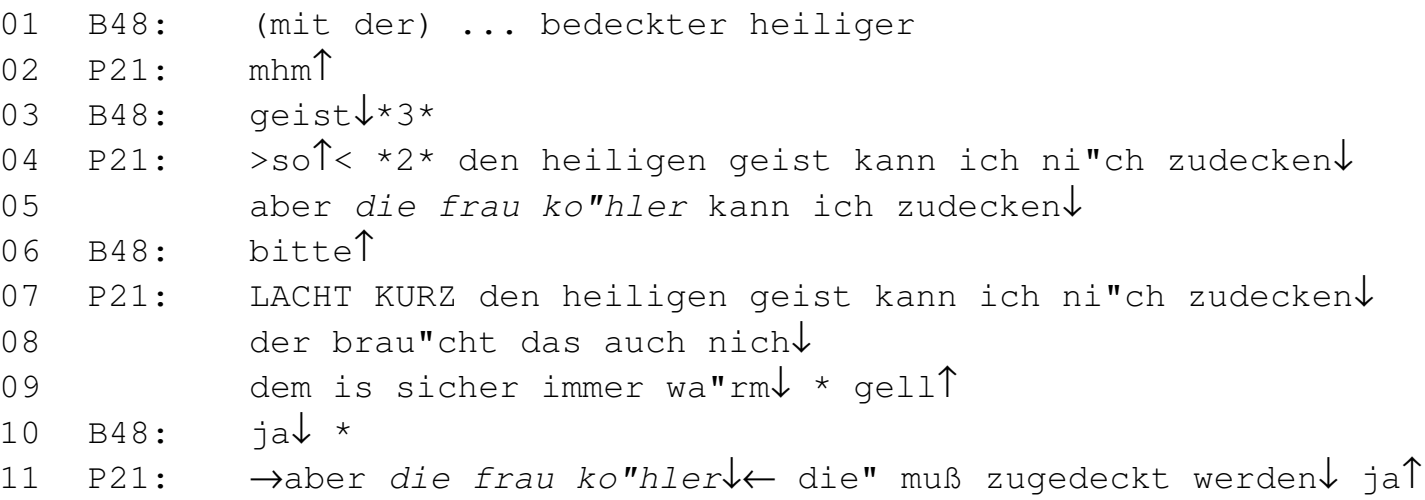

Manche Schwestern kombinieren imperativische Verbformen der 2. Person Singular mit der höflichen namentlichen Anrede. Auf diese Art und Weise entstehen ambivalente Botschaften, die nur oberflächlich respektvoll erscheinen. Ein treffliches Beispiel hierfür ist das Zitat, das ich für den Titel dieses Aufsatzes gewählt habe: so frau adams $\downarrow$ guck mal $\downarrow$ ein feines bac-spray $\downarrow$ gut $\uparrow$.

Es kommt vor, daß im Falle eines Konfliktes vom Siezen zum Duzen übergegangen und den Bewohnerlnnen somit die einem (nicht verwandten oder befreundeten) Erwachsenen gebührende höfliche Anrede mit dem Nachnamen verweigert wird. Beispiel 18 verdeutlicht dies:

Beispiel 18: Ausschnitt aus Text 180, P27 - B69

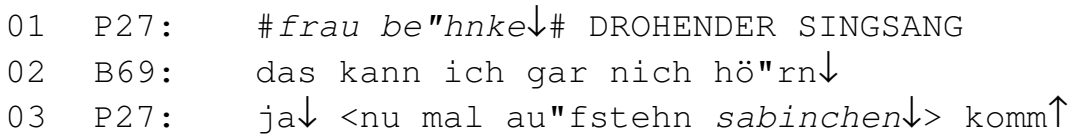

Hier demonstriert die Schwester der Bewohnerin durch den Wechsel von der förmlichen bzw. höflichen Anrede mit dem Nachnamen zu einer diminuierten Anrede mit 
dem Vornamen erstens deren Kinderstatus und zweitens ihre eigene, institutionell abgesicherte Macht. Mit anderen Worten: Die Wahl der Anrede verdeutlicht in diesem Fall die grundlegende Asymmetrie zwischen den Beteiligten, die die Pflegekräfte normalerweise ja mit den verschiedensten Mitteln unsichtbar zu machen bestrebt sind. ${ }^{5}$

Ferner wird das von Brown und Levinson so genannte "negative face“ der Bewohnerlnnen nicht beachtet, indem in ihrer Anwesenheit über sie gesprochen wird (was, nebenbei bemerkt, Erwachsene tagtäglich auch bei kleinen Kindern tun). Im folgenden Beispiel wird nicht nur über die Bewohnerin gesprochen, sondern sie wird auch durch den Gebrauch der reduplizierten Baby-Talk Form popo (Z. 01) einerseits zum Kind degradiert und andererseits durch die Verwendung des pejorativen Begriffes stinken (Z. 03) beleidigt.

Beispiel 19: Ausschnitt aus Text 180, P27 - P30 - B69

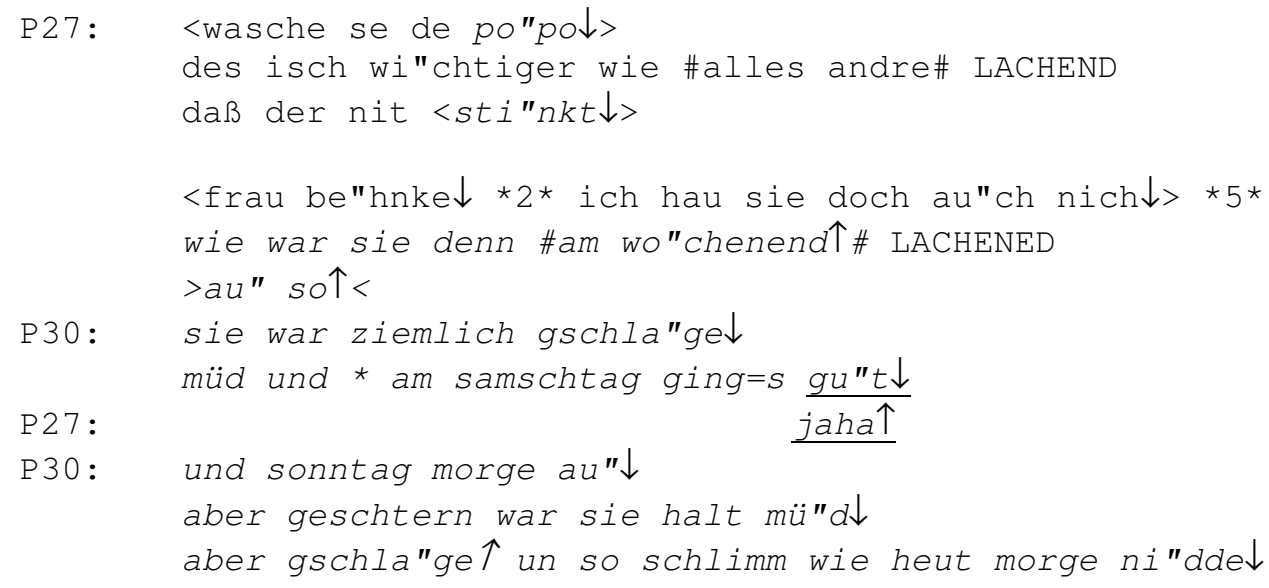

Das "negative face“ der Bewohnerlnnen wird ebenfalls mißachtet, indem sie unterbrochen werden, wenn sie nicht schnell genug reagieren oder formulieren. In Beispiel 20 etwa beendet der Pfleger die Äußerungen der amnestischen Aphasikerin B45 (Z. 05, 09) in der (wenn auch gutgemeinten) Absicht, ihr weitere Wortfindungsprobleme zu ersparen:

Beispiel 20: Ausschnitt aus Text 129, P18 - B45

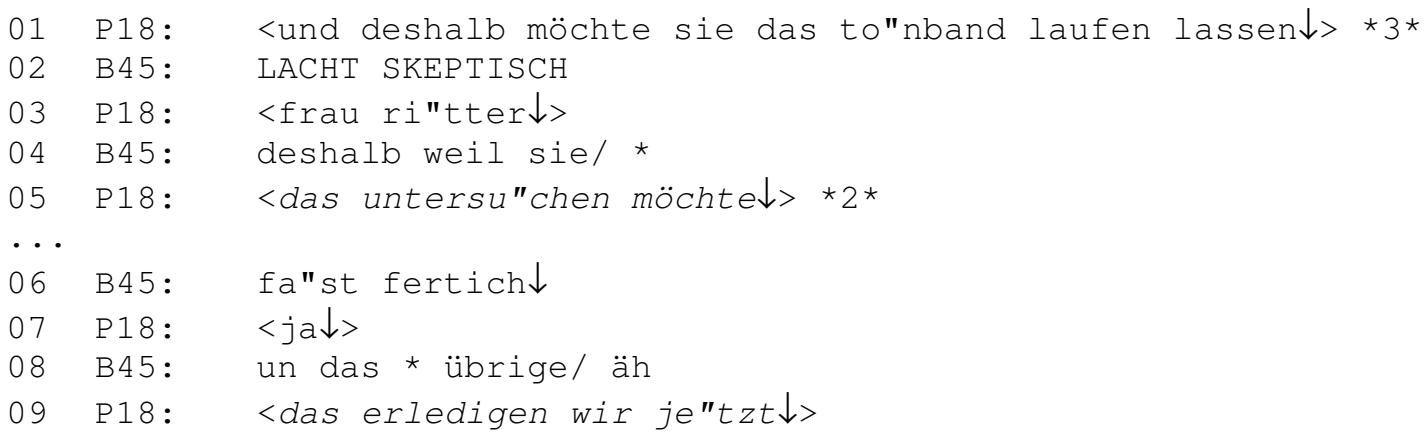

5 Vgl. Abschnitt 5.1. 
Angriffe auf das "positive face“ können darin bestehen, daß die Bewohnerlnnen so unverblümt und drastisch kritisiert werden wie Kinder. In Beispiel 21 zeigt sich das in den Zeilen 05 und 07, in denen ein Zivildienstleistender das Verhalten des Bewohners gegenüber dessen Frau rügt:

Beispiel 21: Ausschnitt aus Text 086, P09 - B30

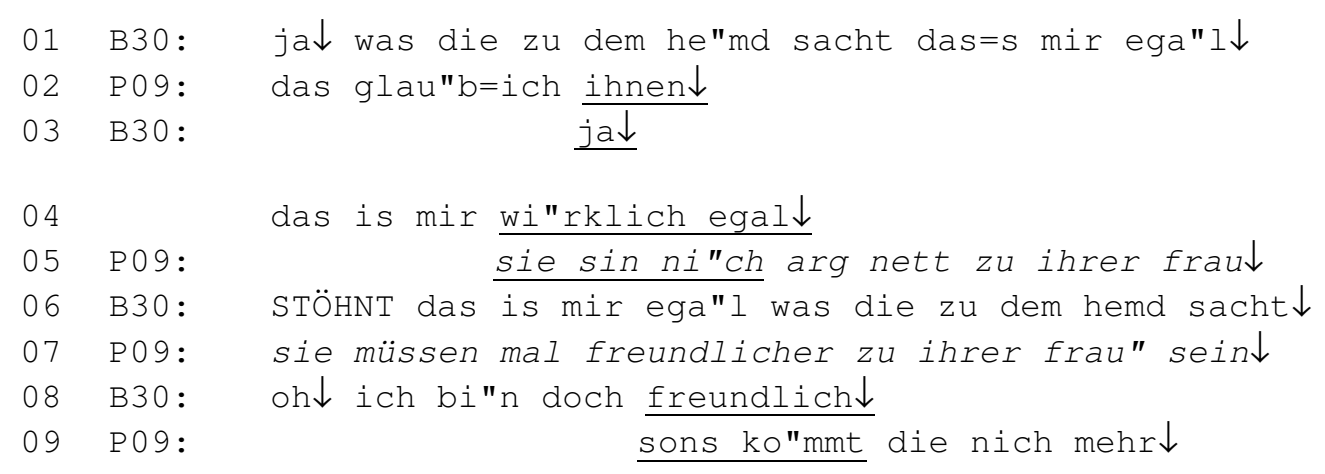

Ähnliches gilt auch für das Imitieren der sprachlichen Eigenheiten der Bewohnerlnnen (also etwa deren Schreien oder Sprachautomatismen) sowie für das Ignorieren oder Abtun mißliebiger Äußerungen. Im folgenden Textausschnitt imitiert ein Zivildienstleistender sowohl die gerade klagend geäußerte Aufforderung der Bewohnerin (Z. 02) als auch deren Sprachautomatismus (Z. 10, 14, 16), den sie mit geringfügigen Abwandlungen immer dann produziert, wenn sie nicht direkt auf ein Gespräch fokussiert ist:

Beispiel 22: Ausschnitt aus Text 073, P05 - B14

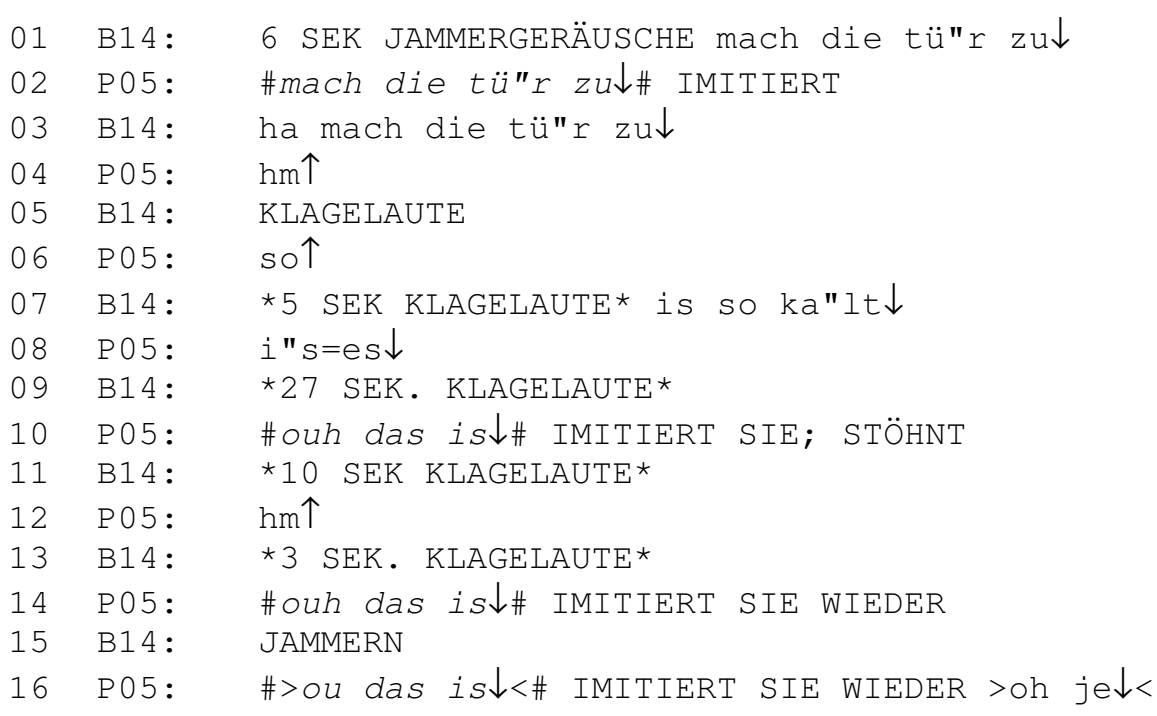

\section{Schlußfolgerungen}

Detaillierte gesprächsanalytische Untersuchungen haben gezeigt, daß das Gesprächsverhalten der BewohnerInnen in einem Altenpflegeheim bedingt durch sowohl deren Rolle als KlientInnen der Institution als auch durch verschiedenste psychophysische Erkrankungen als vorwiegend passiv zu bezeichnen ist. Entsprechend 
hat sich die anfangs aufgestellte Hypothese bestätigt: Die Kommunikation mit den Bewohnerlnnen, deren Hauptzweck ja die Durchführung der Pflegeaktivitäten ist, ist durch gesichtsschonende und verständnissichernde Ausgleichsstrategien geprägt. Charakteristisch ist ferner, daß die PflegerInnen mögliche Verständnisschwierigkeiten oder Kommunikationsstörungen in vielen Fällen nicht erst abwarten, sondern diese antizipieren und entsprechend präventiv auf sie reagieren. Darüber hinaus weist das Gesprächsverhalten des Pflegepersonals widersprüchliche Tendenzen auf: während die Pflegerlnnen sich auf der einen Seite sehr bemühen, den BewohnerInnen höflich und respektvoll zu begegnen, behandeln sie diese auf der anderen Seite, wenn auch oft in gutmeinender Absicht, wie im Falle des Baby-Talk, gleichermaßen wie Kinder und laufen somit Gefahr, deren Selbstwertgefühl zu untergraben.

Ein Kommunikationstraining auf der Basis dieser Ergebnisse könnte meines Erachtens hilfreich sein, um die AltenpflegerInnen für den eigenen Sprachgebrauch zu sensibilisieren. Es könnte verdeutlichen, daß manche Kommunikationsstrategien sowohl positive als auch negative Auswirkungen haben können. Es könnte vor allem aber auch helfen, ein Bewußtsein dafür zu schaffen, daß Erfolg wie Bewertung bestimmter Kommunikationsstrategien, wie etwa Baby-Talk, nicht allein von der sprachlichen Oberfläche, sondern ganz entscheidend von der Akzeptanz der individuellen AdressatInnen abhängt.

\section{Literatur}

Brown, P. \& Levinson, S. (1987). Politeness: Some universals in language usage. Cambridge.

Caporael, L. R. (1981). The paralanguage of caregiving: Baby talk to the institutionalized aged. In: Journal of Personality \& Social Psychology 40, 876-884.

Caporael, L. R., Lukazewski, M. \& Culbertson, G. (1983). Secondary baby talk: Judgements by institutionalized elderly and their caregivers. In: Journal of Personality \& Social Psychology 44, 746754.

Cohen, G. \& Faulkner, D. (1986). Does "elderspeak" work? The effect of intonation and stress on comprehension and recall of spoken discourse in old age. In: Language \& Communiation 6, 9198.

Fehlenberg, D. (1987). Kommunikation zwischen Arzt und Patient: Gesprächsstrukturen der psychosomatischen Krankenvisite. Bochum.

Ferguson, C. (1977). Baby Talk as simplified register. In: Snow, C. E. \& Ferguson, C. A. (eds.), Talking to children. New York, 209-235.

Fiehler, R. (1990). Erleben und Emotionalität als Problem der Arzt-Patienten-Kommunikation. In: Ehlich, K., Koerfer, A., Redder, A. \& Weingarten, R. (Hrsg.), Medizinische und therapeutische Kommunikation. Opladen, 41-65.

Fiehler, R. (1993). Spezifika der Kommunikation in Kooperationen. In: Schröder, H. (Hrsg.), Fachtextpragmatik. Tübingen, 343-357.

Garnica, O. (1977). Some prosodic and paralinguistic features of speech to young children. In: Snow, C. \& Ferguson, Ch. (eds.), Talking to children: Language input and acquisition. Cambridge, 6388.

Grainger, K. (1990). Care and control: Interactional management in nursing the elderly. In: Clark, R., Fairclough, N., Ivanic, R., McLeod, N., Thomas, J. \& Meara, P. (eds.), Language and power. Papers from the Twenty-Second Annual Meeting of the British Association for Applied Linguistics held at Lancaster University, September 1989. (British Studies in Applied Linguistics 5). 
Hummert, M. L. \& Ryan, E. (1996). Toward understanding variations in patronizing talk addressed to older adults: Psycholinguistic features of care and control. In: International Journal of Psycholinguistics 12(2), 149-169.

Lalouschek, J. (1995). Ärztliche Gesprächsausbildung. Eine diskursanalytische Studie zu Formen des ärztlichen Gesprächs. Opladen.

Löning, P. \& Rehbein, J. (Hrsg.) (1993). Arzt-Patienten-Kommunikation. Analysen zu interdisziplinären Problemen des medizinischen Diskurses. Berlin.

Lörcher, H. (1983). Gesprächsanalytische Untersuchungen zur Arzt-Patienten-Kommunikation. Tübingen.

Ochs, E. (1992). Indexing gender. In: Duranti, A. \& Goodwin, C. (eds.), Rethinking context: Language as an interactive phenomenon. Cambridge, 335-358.

Redder, A. \& Wiese, J. (Hrsg.) (1994). Medizinische Kommunikation: Diskurspraxis, Diskursethik, Diskursanalyse. Opladen.

Ryan, E. \& Hummert, M. L. (1993). Negative stereotypes and patronizing talk to institutionalized elders. Paper presented at the Symposium on Perceptions and Misperceptions in Intergenerational Caregiving Relationships, Gerontological Society of America, New Orleans, November 1993.

Ryan, E., Hummert, M. L., \& Boich, L. H. (1995). Communication Predicaments of aging: Patronizing behavior toward older adults. In: Journal of Language and Social Psychology 14, 144-166.

Ryan, E., Meredith, S. D., MacLean, M. J. \& Orange, J. B. (1995). Changing the way we talk with elders: Promoting health using the Communication Enhancement Model. In: The International Journal of Aging and Human Development 41, 87-105.

Szagun, G. ${ }^{4}(1991)$. Sprachentwicklung beim Kind: Eine Einführung. München.

Weinhold, C. (1991). Kommunikation in Krankenhäusern. Ein Forschungsbericht über deutschsprachige Analysen der Gespräche zwischen Arzt und Patient und das Gesprächsverhalten des Pflegepersonals. In: Zeitschrift für Germanistik NF 1, 674-684.

Whitbourne, S. K., Culgin, S. \& Cassidy, E. (1995). Evaluation of infantilizing intonation and content of speech directed at the aged. In: International Journal of Aging and Human Development 41(2), 109-116.

Wodak, R. (1987). Kommunikation in Institutionen. In: Ammon, U., Dittmar, N. \& Mattheier, K. J. (Hrsg.), Sociolinguistics-Soziolinguistik. Berlin, 799-820. 


\title{
Zu unterschiedlichen Realisierungen des Komplimentmusters in Altentagesstätten- bzw. Altenheimkommunikation ${ }^{1}$
}

\author{
Margitta Lambert
}

\section{Einleitung}

Nach meiner fast zehnjährigen Forschungsarbeit zur Altenkommunikation, die rückblickend als dornenreiches Betreten von Neuland (schwierige Datenerhebung, defizitäre Forschungslage etc.) zu charakterisieren ist, freue ich mich, daß mit diesem Sammelband dem Kommunikationsverhalten alter Menschen endlich auch in Deutschland erstmals zu einer sprachwissenschaftlichen Öffentlichkeit verholfen wird. Auch die Sprachwissenschaft sollte dazu beitragen, Antworten auf drängende gesellschaftliche Probleme zu finden. Denn trotz der für viele Menschen sogar bedrohlichen Zunahme des Bevölkerungsanteils alter Menschen in unserer Gesellschaft, der sogenannten „Vergreisung“, mit ihren weitreichenden sozialen und sozioökonomischen Implikationen führt erstaunlicherweise gerade diese Bevölkerungsgruppe ein gesellschaftliches wie auch linguistisches Schattendasein. Im Gegensatz zur Altenkommunikation sind Jugend- und Kindersprache, Erwachsenensprache in Alltags- und institutioneller Kommunikation oder im Fremd- und Fachsprachenkontext gut bearbeitete linguistische Forschungsfelder.

Mein Hauptforschungsziel innerhalb der Altenkommunikation ist seit meiner Magisterarbeit das komplizierte wie komplexe Phänomen dialogischer Nähe bzw. einige seiner Dimensionen wie zum Beispiel Aufmerksamkeit, Zuwendung, Wertschätzung materialorientiert zu beschreiben und zu analysieren. In diesem Beitrag werde ich am Beispiel des teilweise gegensätzlichen Komplimentverhaltens in zwei alterstypischen Lebensumwelten, nämlich Altentagesstätte und Heim, zu belegen versuchen, daß neben den allgemeinen, vielfältig restriktiven Alter( $n$ )sbedingungen auch unaushandelbare räumlich-soziale Nähe (= Heim) gegenüber den relativ frei entscheidbaren Begegnungsbedingungen (= Altentagesstätte) beträchtliche Folgen für die verbale Manifestation von Nähe qua Kompliment haben können.

Mein Beitrag ist folgendermaßen aufgebaut: Nach Hinweisen zu Nähekonzeptualisierung und Näherealität(en) alter Menschen folgen Skizzen zum linguistischen Phänomen Kompliment und Angaben zur Datenerhebung. Danach werde ich meine Annahmen anhand der Analyse von insgesamt vier exemplarischen Gesprächsausschnitten aus Tagesstätten- und Heimkommunikation zu belegen versuchen. Den Schluß bildet ein Kurzresümee.

\footnotetext{
1 Der vorliegende Beitrag ist die leicht erweiterte Fassung meines Vortrages im Rahmen der Arbeitsgruppe "Sprache und Kommunikation im Alter" innerhalb der Jahrestagung der Deutschen Gesellschaft für Sprachwissenschaft vom 28.2 - 1.3.1996 in Freiburg. Er präsentiert Teilergebnisse meiner Dissertation („Die kommunikative Etablierung von Nähe. Etholinguistische Untersuchungen der Kommunikation alter Frauen in Altentagesstätte und Heim“, Frankfurt a.M.: Lang 1997).
} 


\section{Zur Nähekonzeptualisierung}

Meine Nähekonzeptualisierung orientiert sich vor allem an dem von Sager entwickelten etholinguistischen Ansatz. Zentrales Anliegen der interdisziplinär arbeitenden Etholinguistik ist es, konstitutionell-anthropologische Dimensionen in verbaler Interaktion zu erfassen. ${ }^{2}$ Sager (1991) stellt relevante Zusammenhänge zwischen Raum in einem sehr weit gefaßten Sinn, Kommunikation, Konstitution und Kultur her. Raum ist danach verbunden mit Dimensionen wie etwa Schutz, Ruhe und Geborgenheit. Raumansprüche gelten als grundlegende, zu respektierende Umweltansprüche, entsprechend werden Raumverletzungen vermieden bzw. sanktioniert. Bereits diese grobe Skizzierung verweist auf vielfältige Interdependenzen zwischen räumlicher, sozialer und emotionaler Nähe. Sager definiert „Nähe" (oder Distanz) als

„kommunikative Konstrukte (...), die von den Gesprächspartnern durch unterschiedliche Verhaltensformen hervorgebracht, gesichert bzw. wiederhergestellt werden, wobei durch das Konstrukt NÄHE ein Eindringen in die Endosphäre der Intimität manifestiert wird, durch das Konstrukt DISTANZ ein Zurückziehen aus dieser Distanzzone erreicht wird. “3

Daß der Mensch als soziales Lebewesen außerdem auf nahe, verläßliche und dauerhafte Bindungen und Nähe angewiesen ist, ist eine fast triviale Erkenntnis. Sie scheint jedoch angesichts der steigenden Therapiebedürftigkeit vieler Menschen in unserer von „Coolness“ geprägten Zeit ins Hintertreffen geraten zu sein. Als - unentbehrliche/s - Fähigkeit/Bedürfnis ist Nähe im etholinguistischen Verständnis ein existentielles Artmerkmal des Menschen. Es ist, wie zuvor angedeutet, umweltkorreliert und von weiteren Eigenschaften wie zum Beispiel Alter und Geschlecht sowie der ambivalenten Haltung zum Sozialpartner geprägt. Nähe ist definiert durch zentrale Kriterien wie Zuwendung, Vertrauen, Wertschätzung sowie Gemeinsamkeit und Harmonie.

In der Kommunikation als wechselseitig ausgerichtetem Prozeß der Konstitution des gemeinsam akzeptierten sozialen Sinns NÄHE sind Komplimente diesbezüglich wichtige indikative Ereignisse, um spezifische Sinnmomente von Nähe zu realisieren.

\section{Zur Näherealität alter Menschen}

Vor dem Hintergrund des existentiellen Stellenwerts von räumlicher wie auch sozialer Nähe sind hinsichtlich der Näherealität betagter Frauen vielfältige Defizite zu beobachten. Wesentliche Einflußkomplexe werde ich im folgenden nachzeichnen.

In einer Gesellschaft, die nach Leistung, Verwertbarkeit und Jugendlichkeit strebt, gelten alte Menschen leicht als überflüssige Fürsorgeempfänger, deren Bestimmung es zu sein scheint, in Altenheimen aufbewahrt zu werden. Schlagworte aus Politik und Medien wie "ergrauende Gesellschaft", „Altenlast" und "Generationenkampf“ sind geläufige diskriminierende Begleiter des Altenalltags. Negative Alterskonnotationen manifestieren sich neben jugendsprachlichen Ausdrücken wie "Grufti“ und „Mumie“ auch in gängigen Redensarten wie dem abfälligen „Mensch Opa!“ oder der

2 Da eine genauere (sprach)theoretische Begründung meiner Forschungen den hier gesetzten Rahmen sprengen würde, begnüge ich mich mit diesen kurzen Hinweisen. Vgl. z.B. Sager (1988) und (1995); Eibl-Eibesfeldt (1984).

3 Sager (1991, 16); vgl. Lambert (1997). 
Invektive „alte Schachtel“. Für solche meist inadäquaten, negativ-stereotypen sprachlichen Darstellungen verwendet die anglo-amerikanische Forschung (z.B. Coupland et al. 1991) den Terminus „Ageismus“ (vgl. Kramer i.d.Bd.).

Diese stark handlungsleitenden Negativklischees dürften zu einem nicht unwesentlichen Teil auch auf das zwar veraltete, dennoch weiterwirkende gerontologische Schlüsselkonzept des Defizit-Modells rekurrieren. Es wurde inzwischen von anderen, vor allem Birrens sogenanntem Kompetenz-Modell (Birren \& Cunningham 1985) abgelöst, das Alter nicht länger ausschließlich als Problem, sondern als Phänomen betrachtet und damit den verzerrt-negativen deutlich positivere Identifikationsmuster entgegensetzt. Dieser auch für meine Forschung bevorzugte Ansatz stellt einen geeigneten wissenschaftlichen Ausgangspunkt dar, um alltagsweltliche wie wissenschaftliche Konzepte zu überdenken und sowohl Altenfremd- wie -selbstbilder als auch den intergenerationalen Dialog günstig zu beeinflussen.

An dem aktuell vorherrschenden negativen Altenbild, in dem Hinfälligkeit und Kompetenzeinschränkung dominieren, orientiert sich in sehr hohem Maße das Altenselbstbild. Unsicherheit und mangelndes Selbstwertgefühl, überwiegend bereits internalisierte Elemente generationsspezifischer weiblicher Sozialisation, lassen auf diese Weise Resignation, Berührungsangst oder sogar Bedrohung bei den sich oft abgeschoben Fühlenden wachsen.

Neben der skizzierten öffentlichen Diskriminierung fühlen sich alte Menschen darüber hinaus vielfach auch im privaten Umgang einer Nichtbeachtung ausgesetzt oder „zum Schweigen“ gebracht. Waren früher alte Menschen bei uns Teil oder sogar Zentrum eines meist Mehrgenerationenhaushalts und hatten dort das Sagen, so nimmt diese Art des intergenerativen Zusammenlebens, besonders in den Städten, ständig ab. Hinzu kommt, daß im Zuge des modernen sozialen Wandels das für intime Beziehungen zentrale Netzwerk Familie selbst einem komplexen Funktionswandel unterworfen ist. Es entfallen für Alte lebenslang ausgeübte familiäre Aufgaben und Kontakte, nicht zuletzt verkümmern auch die ausgeprägten weiblichen Empathietalente. Ferner reduziert sich mit der zunehmenden Mobilisierung und Individualisierung auch der wenig interessante interne Diskurs mit den (Groß-)Eltern und führt zu Abstrichen bzw. zum Abbau räumlicher, sozialer und emotionaler Nähe überwiegend zu Lasten der Alten.

Zum üblichen Lebenskontext alter Menschen, ganz besonders hochaltriger Frauen, gehört es heute, allein zu leben. Gemäß Erstem Altenbericht (1993) geht mit der vor allem kriegsbedingten „Feminisierung" des Alters die Tendenz zur Singularisierung einher. Partnerverlust und Weggang der Kinder sind weitere Ursachen für ein Singledasein im Alter, das - im Gegensatz zu jungen Menschen - kaum als gewählte und veränderbare Lebensform anzusehen ist. Obgleich das Verbleiben in der gewohnten Umgebung den Erhalt lebenslang gewachsener Kontakte und die soziale Eingebundenheit begünstigt, beschränkt neben gravierenden Verlusterfahrungen der altersbedingt kleiner werdende Aktionsradius die Möglichkeiten und vielleicht auch die Fähigkeit, im Alter Beziehungen zu pflegen oder gar neue Beziehungen einzugehen.

Die hier nur kursorisch erfaßbare lebenslaufbezogene Näherealität alter Menschen läßt sich mithin insgesamt als defizitär charakterisieren. Diese unzureichende soziale Einbindung Betagter läßt vermuten, daß diesbezüglich Kompensation angestrebt und verstärkt nach Bindung gesucht wird. Vor diesem Hintergrund zeichnet sich zugleich der hohe Stellenwert des Kompliments als wesentliches Instrument der Kontaktherstellung und -konsolidierung innerhalb der Altenkommunikation ab. 


\subsection{Zwei Lebensumfelder alter Menschen}

Heim wie Altentagesstätte sind zunächst sehr allgemein als Institutionen definierbar, die „eo ipso Kommunikation zwischen Aktanten“4 verlangen. Dennoch gibt es gravierende, Kommunikation wie Nähe determinierende Faktoren, die zu nennen sind.

Innerhalb der Institution Altenheim reflektiert die Betreuungsskala (von Altenwohn- bis Altenpflegeheim) die jeweilige Hilfsbedürftigkeit des familiär nicht versorgbaren alten Menschen. Die oft unfreiwillige Übersiedlung in ein Heim bedeutet Aufgeben der gewohnten Umgebung, zu der lebenslange, auch emotionale Bindungen bestanden, und ist verbunden mit Gefühlen von Unsicherheit und Angst. Diese „Entwurzelung" geht ferner einher mit dem Nachlassen bzw. dem Abreißen der noch verbliebenen Kontakte zu Freunden und Nachbarn.

Der vielfältig vororganisierte Heimalltag und seine beschränkten räumlichen und sozialen Bewegungsfreiheiten führen den teilweise hochsensiblen Alterspersönlichkeiten die „neue“ Fremdabhängigkeit und ihr endgültiges „Nicht-Dazugehören“ nur allzu deutlich vor Augen. Das oft knappe und unzureichend ausgebildete Personal versorgt die vielfach als hilflos Wahrgenommenen mit dem Notwendigsten; emotionale Bedürfnisse der Alten bleiben meist auf der Strecke.

Aus dem räumlich engeren Zusammenleben resultieren zudem eine zum Teil ungewollte erhöhte Kontaktfrequenz und - aufgrund der meist nicht wählbaren Unterbringung in Mehrpersonenzimmern - für manche Bewohner eine Art aufgezwungener Intimität. Gesellige alte Frauen werden hier eine tendenziell zufriedenstellende Situation vorfinden, die sich wiederum in lebhafter und zugewandter Kommunikation ausdrückt. Für schüchterne oder einzelgängerisch veranlagte alte Menschen können diese veränderten Bedingungen erhebliche Belastungen darstellen. Hinsichtlich der kommunikativen Näheetablierung können daraus resultieren: Vermeidung sozialer Kontakte, Rückzug oder auch Aggression. ${ }^{5}$ Als zusätzlich nähehemmend sind auch die wenig einladenden Räumlichkeiten einzuschätzen, in denen die Unterhaltungen innerhalb sogenannter Freizeiten stattfinden. Ort der von mir untersuchten Plaudereien ist beispielsweise die „Sitzecke“ eines Flures. Dort sind die Sprecherinnen zum Teil erheblichen akustischen und visuellen Beeinträchtigungen durch Personal, Mitbewohner und Besucher ausgesetzt.

Altentagesstätten, deren Vorläufer in Hamburg die Wärmestuben der Nachkriegszeit waren, dienen mit ihren zum Teil breitgefächerten Angeboten (Sport, Ausflüge, kulturelle Aktivitäten etc.) dem regelmäßigen, werktäglichen Treffen alter, vor allem alleinstehender Menschen aus dem Stadtviertel. Lebenskontinuität, Alltagskompetenz und Kontakte dieser alten Menschen werden unter anderem dadurch aufrechterhalten, daß sie zum Beispiel ihren Einpersonenhaushalt noch eigenständig bewältigen. Ihre oft jahrzehntealte soziale und räumliche Eingebundenheit kann im $\mathrm{Ge}-$ gensatz zu den Heimbewohnern als relativ bewahrt bezeichnet werden, wenngleich auch diese Sprecherinnen in erheblichem Umfang von der modernen familialen EntBindung ge- bzw. betroffen sind.

Die generell freiwilligen und zeitlich begrenzten Begegnungen mit gleichaltrigen Frauen finden regelmäßig zu festen Terminen und aushäusig statt. Die Frauen nutzen die institutionellen Kontaktangebote, um sich innerhalb ansprechend gestalteter, gruppeneigener Räume in der Altentagesstätte ungestört ihren Plaudereien zu wid-

\footnotetext{
Ehlich \& Rehbein $(1980,338)$.
}

5 Vgl. z.B. Goffman (1972). 
men. Anders als die zuvor skizzierten ungünstigeren Heimbedingungen lassen diese von Autonomie geprägten Voraussetzungen ein tendenziell bereitwilliges und freundliches sprachliches Näheverhalten erwarten.

\section{Zum Untersuchungsgegenstand Kompliment und zur Materialbasis}

Mittels eines hier nicht zu explizierenden, kombinierten linguistischen Ansatzes aus Gesprächsanalyse, Pragmalinguistik und Etholinguistik werde ich die kommunikative Etablierung von Nähe in Altenplaudereien zweier altersspezifischer Lebenswelten, Heim und Altentagesstätte, untersuchen. Dabei konzentriere ich mich auf ein zentrales konversationelles Instrument dialogisch realisierter Nähe, auf das Kompliment. Es ist mit einigen Hinweisen zu Wesen, Funktion und Struktur darzustellen.

Das Aussprechen wie auch das Annehmen von Komplimenten sind, obgleich weitgehend ritualisiert, gleichermaßen diffizile nähedefinierende Interaktionsaufgaben. Ob und wie Gesprächsteilnehmer mit dem Muster umgehen, indem sie in unterschiedlicher Weise den kommunikativen Obligationen Folge leisten, läßt auf soziale und kommunikative Kompetenz, insbesondere auf spezifische Näheintentionen und dimensionen schließen. Die zuvor erörterten umfeldbedingt unterschiedlichen Näherealitäten alter Menschen lassen neben den üblichen, vor allem im ein- und ausgegrenzten Heimbereich, abweichende Musterrealisierungen vermuten.

Der Umgang mit Komplimenten ist beeinflußt von Kultur, Gesellschaft, Sozialisation und Erfahrung. Abhängig von situativen und personellen Varianten werden diese Kommunikationsaufgaben mit Hilfe eines breitgefächerten vokalisch-lexikalisch-syntaktischen Handlungsrepertoires von den Interaktanten gelöst. Allgemein bevorzugte Form im Deutschen ist der aktiv bestätigende Aussagesatz des Musters „Ihr Kleid ist chic", „Sie sehen gut aus“; als jugendsprachliche Beispiele sind Exklamationen wie „Wow!“, „Geil ey!“ zu ergänzen.

Die Gesprächsanalyse geht davon aus, daß ein Kompliment eine konversationelle Aktivität ist, die eine Reaktion erfordert. So gehört das Kompliment zunächst einmal zum Komplex der Sequenzen. Eine Sequenz ist mit Werlen der „systematische Zusammenhang zweier oder mehrerer Äußerungen, die aufeinander zu folgen haben“. Das heißt: mit dem ersten Sequenzglied werden Obligationen erzeugt, "die durch Äußerung eines zweiten Sequenzgliedes erfülltt“ ${ }^{\star 6}$ werden. Frage/Antwort und Gruß/Gegengruß sind bekannte Beispiele. Als "implizites Ideal“ in unserer Gesellschaft gilt, als Hörer ein Kompliment dankend anzunehmen und Übereinstimmung mit dem Sprecher herzustellen.

Holly zählt Komplimente zu den sympathiebekundenden bestätigenden Sequenzen, für die prinzipiell „eine symmetrische Verteilung der rituellen Schritte“7 gilt. Das geäußerte Kompliment würde in einer Minimalsequenz etwa mit Dank oder Ablenkung quittiert.

Leisi, der in „Paar und Sprache“ vor allem auf das heterosexuelle verbale Annäherungsverhalten eingeht, definiert das Kompliment als "ein Verbalisieren und Ansprechen von Vorzügen (...) des Partners“8. Die Wurzeln des Kompliments gehen seiner Meinung nach zurück auf Werberituale. Hauptkomponenten des Kompliments sind: interaktive selbstbewußt machende Aufwertung (Einzigartigkeits-/Relevanz-

\footnotetext{
6 Werlen $(1979,171)$

7 Holly $(1979,48)$.

8 Leisi $(1978,60)$.
} 
betonung) sowie neben dem Dank komplementäre Relevanz- bzw. Dominanzrelativierung durch Abwiegeln/Ablenkung/submissive Beschwichtigung.

Ähnlich zählen auch neuere Arbeiten (z.B. Herbert \& Straight (1989), Holmes (1988), Chen (1993), Holmes (1993)) Komplimente zu den Höflichkeitsstrategien. Komplimente seien positiv auf andere hin orientiert und dienen vor allem der Verringerung der sozialen Distanz und der Erhöhung bzw. Festigung der Solidarität. Holmes $(1993,107)$ bezeichnet in ihrer Studie zum geschlechtstypischen Gebrauch von Komplimenten diese als „affektive Sprechakte“ und „soziale Gleitmittel“. Frauentypisch sind Holmes (1988 und 1993) zufolge der persönlichere Stil, die vergleichsweise erhöhte Frequenz im Geben wie Empfangen von Komplimenten sowie die Inhalte von Komplimenten. So beziehen sich $61 \%$ der weiblichen Komplimente auf die äußere Erscheinung der Partnerin.

Daß Komplimentverhalten durchaus auch zwanghafte und gesichtsbedrohende Züge tragen kann, ist sehr wahrscheinlich mit dem verpflichtenden Charakter und dem Dilemma der möglichst selbstlobvermeidenden Komplimentannahme (,indepting nature of compliments (...) double bind of having to agree with the complimenter and to avoid self-praise“99) zu begründen. Dem Umgang mit diesem vielfältig bedingten Dilemma widmen sich einige neuere Arbeiten zum Kompliment, in denen es vorrangig um die Untersuchung der zweiten konstitutiven Musterposition, der Komplimentreaktion, geht. Die nicht wesentlich differierenden Antworttypen der einzelnen Autoren lassen sich zu drei Hauptstrategien mit jeweils ca. drei bis fünf Substrategien subsummieren. Für meine Analyse habe ich die von Holmes (1989 und 1993) vorgestellten Haupttypen zugrunde gelegt: A. Annehmen (ACCEPT), B. Zurückweisen (REJECT) und C. Abtönen/Ausweichen (DEFLECT/EVADE).

Diese vorbereitenden Erörterungen schließen mit einem Blick auf die Datenerhebung und leiten über zum Analyseteil. Mein Datenmaterial besteht aus zwei verschriftlichten Korpora von sogenannten Klönrunden in den beiden genannten Institutionen. Es handelt sich dabei zum einen um ca. 9 Stunden fremderhobenen Heimmaterials aus dem Jahr 1984 und zum anderen um ca. 21 Stunden selbsterhobener Tondokumente aus zwei Tagesstätten von 1992. Letztere stellen auch die Materialbasis meiner Dissertation dar.

Die Heimgesprächsgruppe besteht aus drei, die insgesamt vier Tagesstättengruppen ${ }^{10}$ aus jeweils drei bis acht 74- bis 88jährigen Frauen in nahezu festen Konstellationen. Eine relative Vertrautheit untereinander aufgrund einer 3- bis 20jährigen Bekanntschaft kann bei allen Sprecherinnen vorausgesetzt werden. Es kann, auch bei den Altenheimbewohnerinnen, vom sogenannten „normalen Alter" ausgegangen werden. Alle Frauen sind kompetente Sprecherinnen aus dem eher unteren Mittelstand. Fast alle Frauen sind verwitwet. Ehemalige Berufstätigkeit ist eine seltene Ausnahme in diesem Personenkreis.

9 Chen (1993, 58/60), vgl. Herbert \& Straight (1989).

10 Benannt habe ich die Tagesstättengruppen nach ihren Trefftagen (Versalienabkürzung plus Erhebungsdatum innerhalb der von mir gewählten inhaltsbezogenen Transkripttitel); ähnlich tragen die Heimausschnitte Titel ohne weitere Zusätze. 


\section{Analysen zum Komplimentverhalten in der Altenkommunikation}

\subsection{Komplimentverhalten in der Tagesstätte}

In Übereinstimmung mit Holmes (1988 und 1993) läßt sich als allgemeine Beobachtung vorausschicken, daß in der Frauenkommunikation der Tagesstätten eine aufgeschlossene, freundlich-heitere und vertrauensvolle Atmosphäre vorherrscht. Entsprechend folgt ein zugewandtes und aufmerksames Auditorium den musterbedingten Obligationen eigentlich immer und offensichtlich gern. Dies illustriert das erste kleine Beispiel aus einem Gespräch, in dem Haarprobleme und die anstehende Dauerwelle der Sprecherin JO zuvor im Fokus standen. Im aktuellen Ausschnitt geht GR auf $\mathrm{CHs}$ gutsitzende Frisur ein. $\mathrm{CH}$ kann sich besonders glücklich schätzen, da ihre sogenannte „Naturkrause“ nicht nur ein gutes Aussehen beschert, sondern ihr auch aus Sicht der Frauen erhebliche Kosten und Mühen erspart.

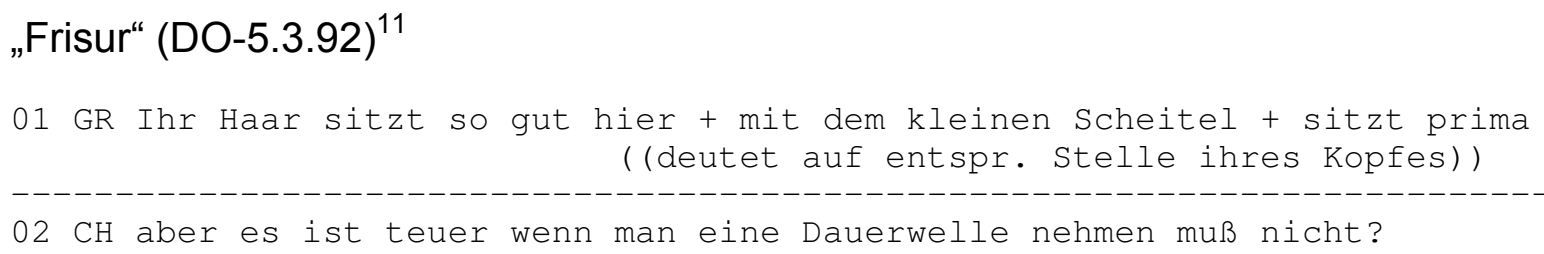

GRs Hinweis in 01 auf $\mathrm{CHs}$ Frisur ist unschwer als Kompliment zu identifizieren. Darin hebt GR CHs hübsch aussehendes und gepflegtes Haar hervor (steigernde Partikel so, sympathievermittelnde positive Adjektive gut, prima). Die Komplimentannahme vollzieht $\mathrm{CH}$ mit einer Art indirektem Gegenkompliment, bei Holmes die Annahme-Substrategie A.4. („Return compliment“). Darin lenkt $\mathrm{CH}$ zunächst deutlich von sich ab (adversatives aber). Hierin kann auch eine Bescheidenheitsgeste gesehen werden (im Sinne von „das ist nicht mein persönliches Verdienst“), die mögliche Neidgefühle besänftigen und Konflikte im Vorfeld eliminieren soll. $\mathrm{CH}$ fährt fort mit einer erkundigenden (nicht?), vielleicht sogar rhetorischen und damit kontaktverstärkenden, Frage (02). Neben der (Rollen-)Vorrang einräumenden Fragehandlung assoziiert teuer so etwas wie „gut situiert“ und ist damit zusätzliches Indiz der Wertschätzung bzw. Anerkennung der Partnerin.

Es handelt sich hier also um ein für ein Frauenleben - ganz besonders dieser Generation - typisches, reziprok partnerbestätigendes bzw. -aufwertendes Verhalten. Geschlechtstypisch ist mit der äußeren Erscheinung der Inhalt; das Aussehen stellt zugleich eine zentrale Komponente des weiblichen Selbstbildes dar. Bemerkenswert erscheint mir, daß entgegen gängigen Negativklischees Alter und physische Attraktivität in dieser Kommunikation sehr wohl vereinbar sind.

In der Tagesstättenkommunikation habe ich generell beobachtet, daß Komplimentgelegenheiten sehr intensiv gesucht und genutzt wurden; dies illustriert das

11 Es werden folgende Transkriptionssymbole verwandt:

$\begin{array}{ll}+++ & \text { Pause, ca. 3 Sek. } \\ : & \text { Dehnung } \\ \text { (Unterstr.) } & \text { Emphase } \\ ! ? & \text { Exklamations- bzw. Frageintonation } \\ (\quad) & \text { unverständliche Passage } \\ ((\quad)) & \text { Kommentar }\end{array}$


Beispiel „Schöne Beine“. Der Episode geht eine ausführliche Darstellung voraus, in der die Sprecherin $\mathrm{CH}$ von ihrer geliebten Katze berichtet, deren schönes Fell durchaus auch sichtbar - „haarige“ Nachteile hat (01).

"Schöne Beine“ (DO-12.3.92)

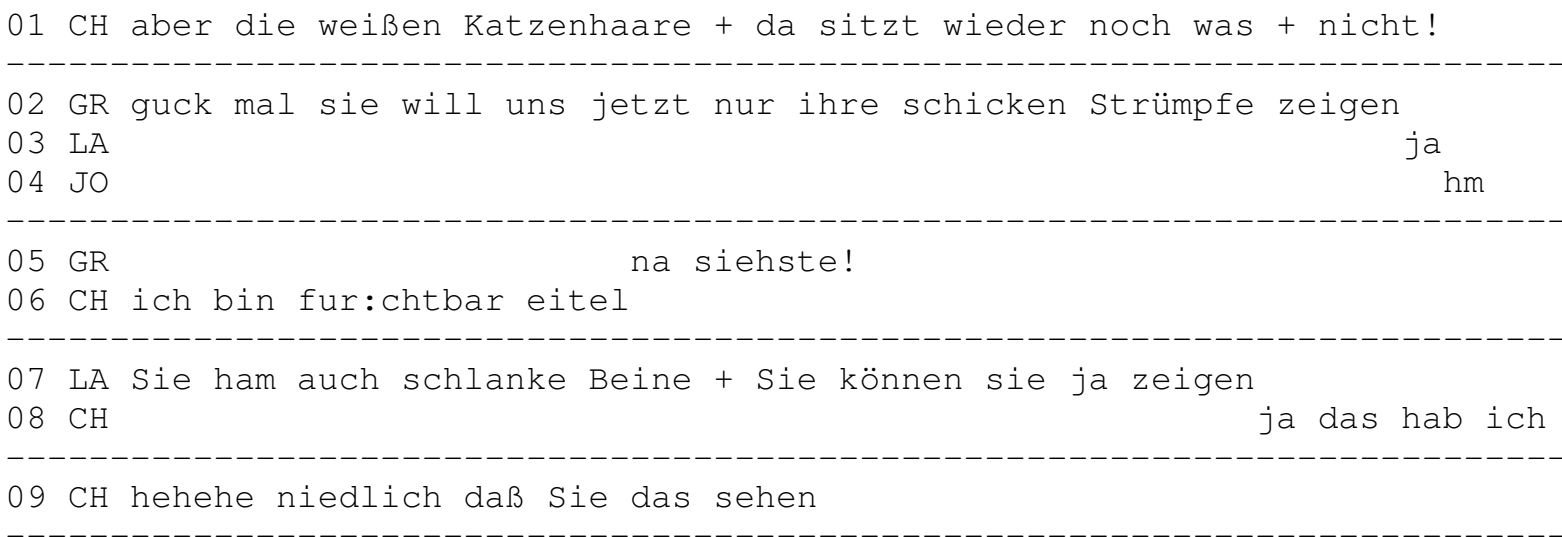

CHs Hinweis auf die an der Kleidung haftenden Katzenhaare lenkt die Zuhörerinnen unmittelbar auf ihre äußere Erscheinung. CHs Selbsthinweis honoriert GR mit einer zweifach (03/04) gestützten komplimentähnlichen, frotzelnden Äußerung (positives, sympathieerzeugendes Adjektiv schick) in 02. Indirekt gibt GR CH darin zwar auch zu verstehen, daß sie CHs Eingangsäußerung als „koketten Trick“ durchschaut hat. $\mathrm{CH}$ quittiert GRs Kompliment (02) in 06 zunächst mit einem weiteren Selbsthinweis. Mit dieser Feststellung bestätigt $\mathrm{CH}$ deutlich (vgl. GRs Reaktion in 05) GRs Anspielung (02). Hierin sind Holmes Annahme-Substrategie A.2. (Beipflichtung, „Agreeing utterance"), wie auch die Type A.3. (Abschwächung, „Downgrading“) zu erkennen. $\mathrm{CHs}$ Äußerung, mit dem Geständnis zugleich eine selbstverkleinernde Geste, fungiert hinsichtlich der Sprecherin LA als "fishing for compliments": in 07 erweitert (Strümpfe ... auch Beine) und „vertieft“ (unterhalb der Strumpfoberfläche) LA liebenswürdig und schmeichelnd ihre Partneraufwertung. Zudem fügt LA ihrem Kompliment eine legitimierend-ermunternde Komponente (Sie können sie ja zeigen) hinzu. Freundlich lachend und fast überschwenglich (09) quittiert $\mathrm{CH}$ dieses umfassende Kompliment mit Freude und Dank (Annahmetyp A.1., Würdigung/Zeichen der Übereinstimmung, „Appreciation/agreement token“). Ich möchte darauf hinweisen, daß ich solche expliziten, sehr selbstbewußten Bestätigungen der eigenen Vorzüge (08) nur selten beobachtet habe.

Dieses Beispiel zeigt vor allem, daß deutliche Neigungen bestehen, Komplimentgelegenheiten nach Kräften zu schaffen, zu (be)nutzen und damit kommunikativ die gewünschte Zuwendung und Aufwertung bzw. Nähe zu erbitten und zu gewähren.

Neben solchen leicht zu identifizierenden, gewitzten Aufmerksamkeitsappellen sind auch subtile wie vage Komplimentveranlassungen zu verzeichnen. Gemeint ist damit ein Verhalten, in dem verhüllte Selbsthinweise (allgemein gehaltene Anekdoten, beiläufig erwähnte Erlebnisse etc.) wie selbstverständlich als Komplimentauslöser fungieren. 


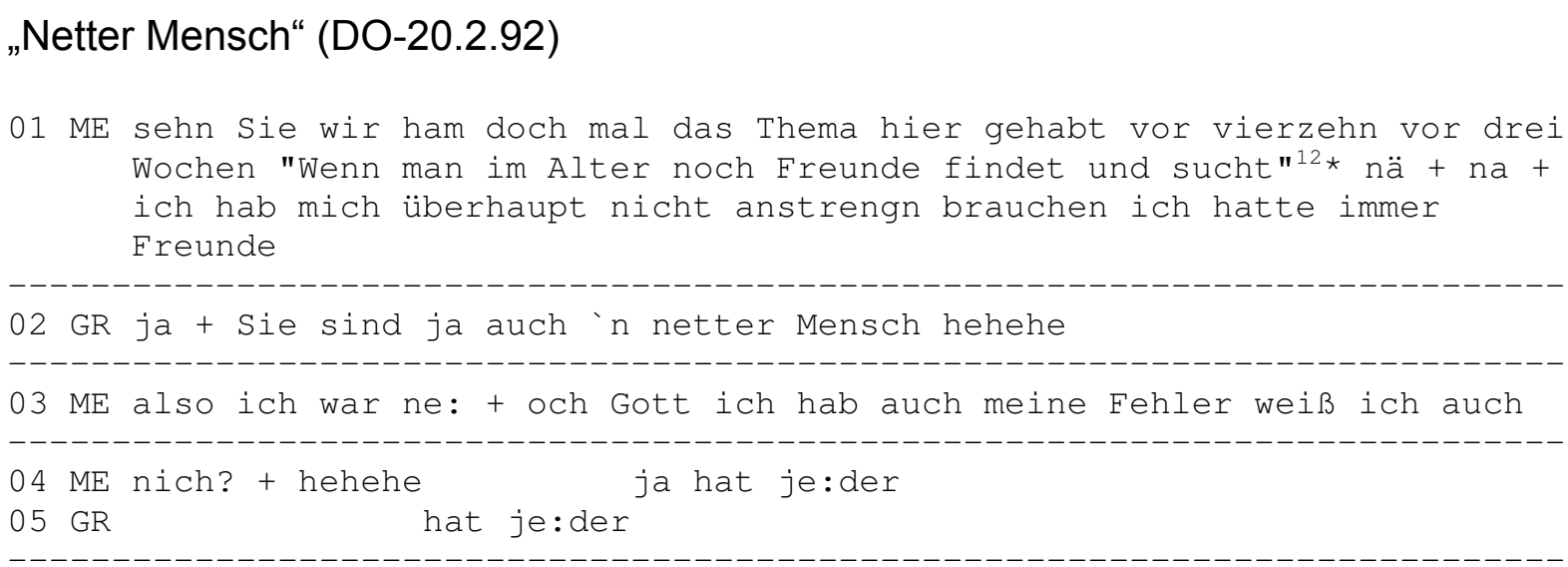

Eine gemeinsam besuchte Veranstaltung ist gewissermaßen „Eintrittskarte“ für MEs verdeckte überaus positive Selbsteinschätzung in 01: nich anstrengn ... immer Freunde konnotiert "langwährende, hohe Beliebtheit aufgrund des angenehmen Charakters MEs“. Die Sprecherin GR reagiert unmittelbar mit Bestätigung ( ja) und Kompliment in 02 (netter Mensch). Das nachfolgende Lachen GRs scheint zugleich das möglicherweise als „abverlangt“ und prahlerisch empfundene Kompliment schwebend zu halten bzw. es sogar zu ironisieren. Trotz möglicher inhaltlicher Differenz und/oder aufgrund eines nachvollziehbaren Vorbehalts - die Frauen trafen erstmalig aufeinander - signalisiert GRs nicht ganz eindeutiges Kompliment zumindest an der Oberfläche eine zuwendungsbetonte und Wertschätzung bezeugende Haltung.

MEs vergleichsweise (zu 01) devoter Quittierungsschritt in 03/04 kann als Kombination aus relativierender Akzeptanzstrategie A.3. (Abschwächung, „Downgrading“) und Ausweichreaktion C.5. (Bitte um nochmalige Bestätigung, „Request reassurance") interpretiert werden. Hier scheint sich auch GRs Verhaltensambivalenz widerzuspiegeln: leicht stockende Redeweise, Negationspartikel mit Frageintonation sowie inhaltliches Zugeständnis (Fehler) indizieren Unsicherheit und Submission. Nach dieser wohl auch kompensatorischen verbalen „Selbstverkleinerung" MEs „repariert“ GR in 05 beschwichtigend (Dehnung) MEs selbstproduzierte Peinlichkeit („Angeben“ in 01, Geständnis in 03). Mit dem zugleich von MEs Person wegführenden Normalitätshinweis jeder hilft GR ME in 05 aus der Klemme. Dankbar (Bestätigung ja und Konstruktionsübernahme hat jeder) und vermutlich erleichtert über die gerettete Situation schließt sich ME in 04 an.

Die Beispiele aus der Tagesstättenkommunikation belegen, daß die alten Sprecherinnen sowohl den „versteckten“ als auch den ein wenig "nachgeholfenen“ bis fordernden konversationellen Musterverpflichtungen bereitwillig nachkommen. Generationstypisch "gehorsam" sowie geschlechtstypisch vorausempfindend-überkompensierend sind reziproke Mustererfüllungen bzw. -übererfüllungen zu verzeichnen. Protektiver Imageschutz, Aufwertung, Partnerbestätigung und Kommunikationsharmonie sind wesentliche Ergebnisse dieser auf die Bedürfnisse anderer hin orientierten Frauenkomplimente. Nicht von ungefähr spricht die feministische Linguistik von erhöhter weiblicher Erwartungsanpassung und Beziehungsarbeit und sieht in Frauen ideale Kommunikationspartner. ${ }^{13}$

12 Diskussionsthema innerhalb des einmal wöchentlich stattfindenden „Gesamtaltenkreises“.

13 Z.B. Trömel-Plötz (1984), Kotthoff (1988), Holmes (1993), Trömel-Plötz (1996). 
Die beobachteten Elizitierungs- und Ausweitungstendenzen im Komplimentverhalten dieser Sprecherinnen lassen sich meines Erachtens außer mit individuellen vor allem mit dem eingangs erörterten gruppenspezifischen Zuwendungs- und Aufmerksamkeitsmanko in Einklang bringen. Auf sprachlicher Sequentialität aufbauende Strategien werden zum Teil subtil eingesetzt, um sozusagen mit sanfter Gewalt zum gegenseitigen, ausgiebigen „Streicheln mit Worten“ (Leisi 1978) anzuleiten. Sie können so den alterskorrelierten Nähemangel interaktiv in gewissem Umfang ausgleichen. Allem Anschein nach kann also in der Tagesstättenkommunikation eine gesellschaftlich wie familial verweigerte bzw. nur defizitär geleistete Aufmerksamkeit, Zuwendung bzw. Nähe zumindest teilkompensiert werden. Holly spricht von „sekundäre Bedürfnisbefriedigung versprechend(en) (...) 'Notlösungen' in heiklen Situationen (...), wo unmittelbare und positive Bestätigungen des eigenen oder fremden Images wegen systematischer Unterdrückungsverhältnisse (...) nicht erreichbar oder nicht akzeptabel erscheinen“"14.

Die weitgehende Konventionalisiertheit des Kompliments kommt den alten Sprecherinnen bei der Näheetablierung hilfreich entgegen. Das lebenslang geübte, vertraute Verhaltensmuster ist mühelos - und das heißt im Alterskontext vor allem kraftschonend - abruf- wie handhabbar und ermöglicht bzw. erleichtert ein flüssiges, kompetentes und erfolgreiches interaktives Etablieren von Nähe. Allerdings entsteht bei den Beobachtungen zum Komplimentverhalten auch der Eindruck, daß „überkompensierende" Komplimente eine Art künstlicher oder Gefälligkeitsnähe produzieren. Ein Schlüssel hierfür mag in Unterwürfigkeitsattitüden aus weiblichem Rollenverhalten heraus liegen; sie dürften sich unter dem (Ein-)Druck zeitlich begrenzter Beziehungen im Alter verstärken. Eine weitere Ursache ist in alterstypisch verlustgeprägten Bindungsängsten zu vermuten.

\subsection{Zum Komplimentverhalten im Altenheim}

Einem dem Gesamteindruck nach tendenziell kooperativen bzw. affiliativen Sequenzverhalten in den Tagesstätten und im Heim stehen punktuelle, aggressiv orientierte ${ }^{15}$ Zuspitzungen in der beobachteten Heimgruppe (KA/KL/ME) gegenüber. Im Komplimentzusammenhang wird eine solche aggressive Orientierung an spezifischen Musterrealisierungen ablesbar sein.

Besonders zwischen KA und $\mathrm{KL}$, die ein gemeinsames Zimmer bewohnen, kommt es zu heftigen Kontroversen. Sie werden jedoch meist erfolgreich von der sozial sehr gewandten und aufgeschlossenen ME geschlichtet. Aus der Kenntnis des Gesamtmaterials heraus ist anzumerken, daß im Gegensatz zu KA und ME es für die Sprecherin KL schwieriger zu sein scheint, die aktuelle (Alters-/Heim-)Situation zu akzeptieren. Diese Schwierigkeiten äußern sich unter anderem darin, daß sich KL dem gemeinsamen Klönen physisch oder verbal (z.B. Aufforderungen wie <lassen Sie mich in Ruhe!>, Einsilbigkeit) zu entziehen versucht.

Vorauszuschicken ist, daß Komplimente in dieser Dreiergruppe relativ selten auftreten. Sie gehen primär von der gesprächigen und redegewandten Sprecherin ME aus. Die im folgenden „belobte“ Sprecherin KL kann, wie erwähnt, als kommunikati-

14 Holly (1979, 82).

15 Unter „aggressiver Orientierung im rituellen Handeln“ soll mit Holly die einseitige kooperationsverweigernde Imageorientierung verstanden werden, vgl. Holly $(1979,82)$. 
onsscheu charakterisiert werden. Der ausgewählten Passage „Buntes Kleid“ war eine längere mit Stimmen und Geräuschen angefüllte Pause vorausgegangen.

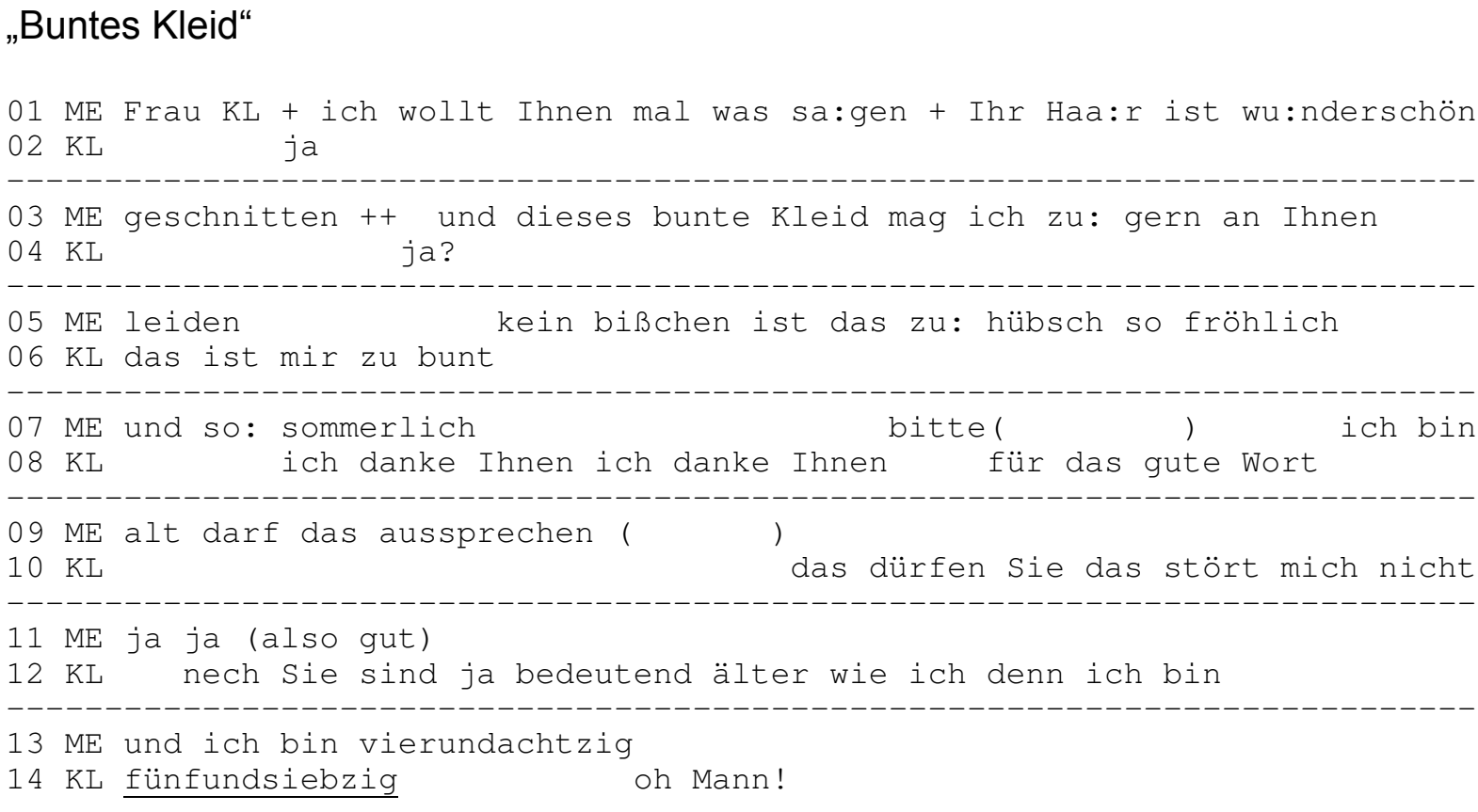

MEs relativ aufwendiges Haarkompliment in 01/03 (höfliche namentliche Anrede, auffordernd-kontaktverstärkendes Vorlaufelement ich wollt..., gesteigertes Adjektiv) quittiert die sprachlich ungewandtere $\mathrm{KL}$ mit einer Minimalreaktion in 04. Das verlegen klingende ja läßt mindestens zwei Interpretationen zu. Es kann sich um den Typ B.2. (Genauigkeit in Frage stellen, "Question accuracy“) oder den Typ C.5. (Um nochmalige Bestätigung bitten, „Request reassurance“) handeln. Offensichtlich transportiert KL mit ihrer Reaktion eine Art von Unsicherheit, welche wiederum vermehrte Bemühungen, das sogenannte „Nachdoppeln“ (Holmes 1988), seitens der Komplimentgeberin erfordert.

So setzt ME in 03/05 ein zweites emphatisches (gedehnter Steigerungspartikel) Kompliment nach, in dem sie Bewunderung für KLs hübsches Kleid ausdrückt. KL weist in 06 dieses zweite Kompliment zurück. Diese Reaktion ist als Typ B.1. (Ablehnung äußern, „Disagreeing utterance“) einzuordnen. Inhaltlich stellt KL sowohl die Interpretationskompetenz als auch die Geschmacksauffassung MEs in Frage. KL geht mit diesem antagonistisch getönten Kommentar deutlich auf Distanz zu ME; als besonders ruppig ist im Komplimentkontext die Unterbrechung einzuschätzen. Auf diese wiederholte Zurückweisung doppelt ME erneut noch intensiver nach, um ihr Kompliment in Kraft zu setzen: aktives Ignorieren des Widerspruchs (kein bißchen) und Komplimentintensivierung (variierte, partikelverstärkte Adjektivanhäufung in 05/07).

Wie um schnell und endgültig diese ihr offenbar unangenehme oder auch ungewohnte Liebenswürdigkeit zu beenden, fällt KL ME in 08 erneut (vgl. 06), nun mit einem Dank, ins Wort. Diese Reaktion kann zunächst als Akzeptanztyp A.1. (Würdigung/Zeichen der Übereinkunft, „Appreciation/agreement token“) klassifiziert werden. Dennoch scheint sie ungewöhnlich, ganz besonders vor dem Hintergrund des anschließenden Wortwechsels. Denn erstens ist der Dank der üblicherweise kommunikationsscheuen KL (vgl. 04) relativ umfangreich. Er wirkt zudem hölzern 
und "gestelzt" (für das gute Wort, 08), inm scheint die echte Freude bzw. Dankbarkeit zu fehlen. Zweitens erscheint MEs betontes und leicht schroff klingendes bitte (07) hier ungewöhnlich. Möglicherweise will sie damit signalisieren, daß auch KLs zweite Unterbrechung (Anfang 08) sie keineswegs zum Schweigen gebracht hat. Auch MEs anschließende selbstaufwertende Komplimentrechtfertigung (07/09) scheint mir außergewöhnlich. Mit dem belehrenden Unterton in darf das konstituiert ME eine auf ihrem Altersvorsprung basierende Handlungs- bzw. Komplimentlegitimierung. Drittens fällt KLs diesbezügliche Reaktion in 10/14 auf, vielleicht ein ungeschickt formulierter erneuter Dank. Das leicht gönnerhaft wirkende das dürfen sie darin kann weitergehend interpretiert werden als erlaubniserteilende und damit indirekte dominanzorientierte Direktive. Das anschließende kommentierende stört mich nicht verweist zusätzlich darauf, daß KL auf MEs Freundlichkeit bzw. Annäherung keinen gesteigerten Wert legt und ist, beispielsweise nach zweimaligem Inswortfallen, als weitere implizite Abwehr- und Überlegenheitsdemonstration KLs gegenüber ME deutbar. Daß hier Dominanzansprüche verbal manifestiert werden, indiziert schließlich auch der exklamative, eher abfällige Kommentar (entmutigend klingendes oh Mann!) KLs in 14. KL scheint damit den zuvor (07/09) von ME reklamierten, altersbegründeten superioren Status MEs anzuzweifeln.

Insgesamt kann hier von einer beiderseitig unkooperativen bzw. aggressiven Verwendung ritueller Muster gesprochen werden. Sie besteht einerseits darin, daß ME ihre rhetorische Überlegenheit und die sequenz-inhärenten Obligationen mehr oder weniger bewußt (aus)nutzt, um - in gewissem Maß erwartbar - die weniger mitteilsame $\mathrm{KL}$ mit einer eher unerwünschten Annäherung bzw. Liebenswürdigkeit „aus der Reserve“ zu locken. Mit ihrer übertreibend-imponierenden Schmeichelei bzw. ihrer, wie Holly (1979) sagen würde, auf „rituellen Profit“ gerichteten „Inszenierung" scheint ME KLs individuelles Distanz- bzW. Differenzbedürfnis nicht wahrzunehmen bzw. nicht wirklich zu respektieren.

Andererseits kommt KL zwar ihrer musterinhärenten kommunikativen Verpflichtung nach, reagiert auf das wohl ungebetene Zunahetreten jedoch zugleich offensiv und strafend-verweigernd (z.B. wiederholte Simultaneität in 06/08, Demonstration ihrer „rituellen Kompetenz“ durch förmlich-hyperkorrekte Form in 08). Mithin demonstriert auch sie verbal Kompetenz und Überlegenheit. Sie versucht damit, MEs als dominanzorientiert und zudringlich empfundenes Verhalten in seine Schranken zu weisen und eigene Distanzansprüche durchzusetzen.

Dieses zwar nicht heimtypische, jedoch keineswegs singuläre Beispiel zeigt, daß ein genuin beziehungskultivierendes Interaktionsinstrument unter bestimmten Voraussetzungen durchaus zu gegenseitigen Imageattacken bzw. Statusduellen gebzw. mißbraucht werden kann. Es ergeben sich meiner Ansicht nach damit durchaus Belege für die oben genannte Annahme, daß außer Einflußfaktoren wie Persönlichkeit, Beziehungsproblematik, Kommunikationsgewohnheiten etc. für dieses abweichende Kommunikationsverhalten die zuvor erörterten ungewohnten und zusätzlich erschwerten komplexen restriktiven Alter(n)sbedingungen ursächlich sind. Vor allem die ausweglose wie unausweichliche, nicht aushandelbare räumlich-soziale Nähe im Heim fördert meines Erachtens das Nichtrespektieren von persönlicher Distanz und komplementär das aggressive Verteidigen und Durchsetzen von existentiell relevanten Raumansprüchen und Grenzen in nähezerstörender Weise. Allzu geringe räumlich-soziale Entfernung, wie im „ghettoisierten Zwangsverband“ Heim, wird vielfach als Belästigung und sozialer Streß erlebt und kompensiert durch das Vermeiden in- 
timer Verhaltensweisen bzw. sogar durch das Zeigen aggressiven Verhaltens. Wissenschaftliche Belege hierfür beziehe ich aus meinem interdisziplinären Ansatz. ${ }^{16}$ Ich gewinne zusätzliche Stützung für meine Annahme erstens aus der Tatsache, daß ich ähnliche oder vergleichbare Musterentfaltungen in der Tagesstättenkommunikation nicht beobachtet habe und zweitens aus Holmes' (1993) Ergebnissen, nach denen Formen der Komplimentzurückweisung für weibliche Kommunikation höchst ungewöhnlich sind.

\section{Resümee}

Als Fazit der kurzen Ausführungen läßt sich folgendes festhalten:

- Meine vergleichende Untersuchung von Altenkommunikation in zwei alterstypischen Lebensumwelten, Altenheim und Altentagesstätte, liefert Belege dafür, daß Komplimente bedeutsame linguistische Instrumente sind, um dialogisch Nähe zu etablieren, sei es, daß gegenseitig großzügig Aufmerksamkeit und Anerkennung geschenkt oder rücksichtsvoll Images geschützt werden. Auffallend in der Frauenkommunikation dieser beiden Bereiche sind die z.T. unüblichen Verläufe des Komplimentmusters im Heim.

- Mangelnde Sensibilität, Unterstützungsverweigerung und Aufbau von Machtgefälle kennzeichnen den temporär aggressiven Umgang mit dem „Zuvorkommenheitsritual“ Kompliment in der Heimkommunikation. Die imagebedrohenden "Grenzverletzungen“ wie auch die „Abstands- bzw. Grenzverteidigungen“ reflektieren in hohem Maße die dort zugespitzte Auseinandersetzung mit Aufgaben und Belastungen im Alter. Offensichtlich besteht innerhalb extrem restriktiver Bedingungen die Neigung bzw. Notwendigkeit, nicht respektierte Abstandsansprüche aggressiv durchzusetzen. Die unangemessen scheinenden, näheverhindernden Reaktionen sind so gesehen durchaus sinnvolle Mechanismen in der Auseinandersetzung mit und der Bewältigung von Umwelt, eine Art „Streß- bzw. Krisenmanagement" gewissermaßen.

- In der Tagesstättenkommunikation ist eine überwiegend reziprok-kooperative bis überangepaßte Musterrealisierung zu beobachten. Engagiert wie großzügig signalisieren sich die Frauen Solidarität und versichern sich gegenseitig ihrer Relevanz und Attraktivität. Indem sie Wünsche und Ansprüche anderer berücksichtigen bzw. vorempfinden, tragen sie wesentlich dazu bei, Befangenheit ab- und Wohlgefühl und Selbstwert aufzubauen und damit in gewissem Umfang elementare Nähebedürfnisse zu erfüllen. Die Analyse liefert damit auch überzeugende Argumente für die Annahme, daß vielfältig bedingte Aufmerksamkeits- und Zuwendungsdefizite alter Menschen auf der Mikroebene der face-to-face-Interaktion, besonders innerhalb des selbstgewählten und vertrauten Netzwerkes Tagesstätte, kompensiert werden können.

16 Z.B. Goffman (1972), Rexilius-Grubitzsch (1981), Eibl-Eibesfeldt (1984). 


\section{Literatur}

Birren, J. E. \& Cunningham, W. (1985). Research on the Psychology of Aging: Principles, Concepts and Theory. In: Birren, J. E. \& Schaie, K. W. (Hrsg.), Handbook of the Psychology of Aging. 2. Aufl. New York, 3-34.

Carmichael, C. W. \& Knapp, M. L. (1988). Nonverbal Aspects of Communication and Aging. In: Carmichael, C. W., Botan, C. H. \& Hawkins, R., Human Communication and the Aging Process. Prospect Heights/lllinois, 111-128.

Chen, R. (1993). Responding to compliments. A contrastive study of politeness strategies between American English and Chinese speakers. In: Journal of Pragmatics 20, 49-75.

Coupland, N., Coupland, J. \& Giles, H. (1991). Language, Society and the Elderly. Oxford, Cambridge.

Ehlich, K. \& Rehbein, J. (1980). Sprache in Institutionen. In: Althaus, H. P., Henne, H. \& Wiegand, H. E. (Hrsg.), Lexikon der Germanistischen Linguistik. 2. Aufl. Tübingen, 338-346.

Eibl-Eibesfeldt, I. (1984). Die Biologie des Menschen. Grundriß der Humanethologie. München/Zürich.

Erster Altenbericht (1993). Die Lebenssituation älterer Menschen in Deutschland. Bundesministerium für Familie und Senioren, Drucksache 12/5897, 28.9.93.

Goffman, E. (1972). Asyle. Über die soziale Situation psychiatrischer Patienten und anderer Insassen. Frankfurt a.M.

Goffman, E. (1978). Interaktionsrituale. Über Verhalten in direkter Kommunikation. Frankfurt a.M.

Herbert, R. K. \& Straight, H. S. (1989). Compliment-rejection versus compliment-avoidance: Listenerbased versus speaker-based pragmatic strategies. In: Language \& Communication Vol. 9, No. $1,35-47$.

Holly, W. (1979). Imagearbeit in Gesprächen. Zur linguistischen Beschreibung des Beziehungsaspekts. Tübingen.

Holmes, J. (1988). Paying compliments: A sex-preferential politeness strategy. In: Journal of Pragmatics $12,445-465$.

Holmes, J. (1993). New Zealand woman are good to talk to: An analysis of politeness strategies in interaction. In: Journal of Pragmatics 20, 91-116.

Kotthoff, H. (1988). Vom Lächeln der Mona Lisa zum Lachen der Hyänen. Über geschlechtsspezifische Heiterkeit. In: Kotthoff, H. (Hrsg.), Das Gelächter der Geschlechter. Humor und Macht in Gesprächen von Frauen und Männern. Frankfurt a.M., 123-153.

Lambert, M. (1997). Die kommunikative Etablierung von Nähe. Etholinguistische Untersuchungen der Kommunikation alter Frauen in Altentagesstätte und Heim. Frankfurt a.M./Berlin/Bern/New York/Paris/Wien.

Leisi, E. (1978). Paar und Sprache. Linguistische Aspekte der Zweierbeziehung. Heidelberg.

Rexilius, G. \& Grubitzsch, S. (1981). Handbuch psychologischer Grundbegriffe. Reinbek.

Sager, S. F. (1988). Reflexionen zu einer linguistischen Ethologie. Hamburg.

Sager, S. F. (1991). Formen des Zugangsmanagements. Kommunikationsanthropologische Überlegungen zu einer Semantik des Raumes. (Unveröff. Vortragsmanuskript [Univ. Essen]).

Sager, S. F. (1995). Verbales Verhalten. Eine semiotische Studie zur linguistischen Ethologie. Tübingen.

Trömel-Plötz, S. (Hrsg.) (1984). Gewalt durch Sprache. Die Vergewaltigung von Frauen in Gesprächen. Frankfurt a.M.

Trömel-Plötz, S. (Hrsg.) (1996). Frauengespräche: Sprache der Verständigung. Frankfurt a.M.

Werlen, I. (1979). Interaktionsrituale. In: Dittmann, J. (Hrsg.), Arbeiten zur Konversationsanalyse.

Tübingen, 144-175. 


\title{
Alter, Familienhierarchie und Kommunikationsstatus
}

\author{
Daniela Heidtmann
}

\section{Einleitung}

Obwohl aus statistischen Untersuchungen hervorgeht, daß es heutzutage immer mehr ältere Menschen gibt, ist von deren Existenz oft wenig zu bemerken. Medien als bedeutende öffentliche Instanzen transportieren überwiegend das Bild der ewig jungen und mobilen Gesellschaft. Einst wichtige, gerade dem alten Menschen zugeschriebene Werte, wie beispielsweise 'Weisheit', also durch Lebenserfahrung gewonnene Reife, scheinen zunehmend in Vergessenheit zu geraten. Aber nicht nur das Bild in der Öffentlichkeit wird von der Jugend geprägt und dominiert, auch die private Sphäre der Familie unterliegt seit geraumer Zeit einem Wandlungsprozeß hin zur Kleinfamilie, in der für die ältere Generation oft wenig oder gar kein Raum bleibt. In seinen Beobachtungen zu Dominanzverlust im Generationenwechsel bemerkt Fiehler (1997, 359):

\begin{abstract}
„Geht man von drei koexistierenden Generationen aus, also Großeltern, Eltern und Kindern, so zeigt schon die begriffliche Konstruktion dieser Reihe, daß das Primat bei der Elterngeneration liegt. Sie hat die gesellschaftliche Macht inne, sie besetzt alle relevanten Positionen und hält die Fäden der Erziehung und Altenbetreuung in der Hand. Entsprechend ist in unserer Gesellschaft der Übergang in die Altenrolle im Zuge des Generationenwechsels mit einem einschneidenden Macht- bzw. Dominanzverlust verbunden."
\end{abstract}

Diese Aussage mag zwar in den allermeisten Fällen zutreffen, jedoch sind in bestimmten Kontexten auch Ausnahmen denkbar, was ich im folgenden anhand einiger Auszüge familiären Gesprächsmaterials aufzeigen möchte. ${ }^{1}$

Mein ethnographischer ${ }^{2}$ Beitrag beschäftigt sich mit der Frage, welche familienhierarchische Position eine ältere Frau in einem bestimmten, eher mit dem 'klassischen großfamiliären Familienmodell' korrespondierenden, Rahmen einnimmt und wie sich ihr Interaktionsstatus in der Familie darstellt.

Gegenstand der Untersuchung ist eine matriarchal geprägte Viergenerationenfamilie, die aus 24 Mitgliedern besteht. Die einzelnen Angehörigen sind nicht, wie beispielsweise im bäuerlichen Kontext, über gemeinsame Arbeit oder gemeinsame Berufe (z.B. Führen eines Familienbetriebes) verbunden. ${ }^{3}$ Vielmehr besteht der Zusammenhalt darin, daß alle Gruppenmitglieder, auf fünf Häuser mit separaten Woh-

1 Dabei stütze ich mich auf Tonbandaufnahmen, die ich im Rahmen meiner Magisterarbeit (1997) angefertigt und analysiert habe.

2 In wenigen Sätzen läßt sich Ethnographie als Form der Beobachtung und Darstellung von Gruppen unter möglichst genauer Rekonstruktion ihrer Lebensform darstellen. Ein klassisches ethnographisches Erhebungsverfahren ist die 'teilnehmende Beobachtung'. Forscherlnnen haben dabei über einen gewissen Zeitraum hinweg Zugang zum sozialen Leben einer Gemeinschaft, um so ein authentisches Bild von ihr zu erhalten. Neben teilnehmender Beobachtung sind heute auch Tonoder Videoaufzeichnungen von natürlichen Gesprächen und narrativen Interviews eine wichtige Datenquelle. Zur Ethnographie und ethnographischen Erhebungsverfahren siehe z.B. Kallmeyer (1995); Spradley (1979 u. 1980).

3 Zu Untersuchungen bäuerlicher Familien siehe z.B. Hildenbrand et al. (1992). 
nungen verteilt, die meist weniger als $500 \mathrm{~m}$ auseinander liegen, in einem kleinen Dorf leben und dort täglich Kontakt miteinander haben. So existieren Formen der Alltagsgestaltung und Kooperation, die generationsübergreifend sind, wie beispielsweise gemeinsame sportliche Aktivitäten, Hilfe bei Renovierungen, Hilfe bei Finanzund Rechtsfragen, Babysitting, Großeinkäufe bestimmter Lebensmittel und Waren, die anschließend unter den Familien aufgeteilt werden, Treffen einzelner Mitglieder zwecks Geselligkeit, gemeinsame Urlaube - auch mit der gesamten Großfamilie. Außerdem finden durchschnittlich zwei Mal pro Monat Geburtstagsfeiern von Familienmitgliedern statt, zu denen sich jeweils die Gesamtfamilie trifft.

Einige Transkriptausschnitte von Tonbandaufnahmen, die ich an einem Geburtstagsfest eines männlichen Familienmitgliedes gemacht habe, ethnographische Einzelinterviews mit verschiedenen Angehörigen sowie ein ethnographisches Gruppeninterview mit drei Personen, werden die Grundlage der folgenden Analysen bilden. Ausgewählt wurden verschiedene Gespräche, an denen das älteste Familienmitglied (Irmgard) beteiligt ist bzw. Interviews, in denen über sie und ihre kommunikativen Verhaltensweisen berichtet wird. ${ }^{4}$

Dabei werde ich als Einführung unterschiedliche Interviewzitate zusammenstellen, die eine Beschreibung und Charakterisierung der Familienältesten vornehmen und ihre Position in der Familienhierarchie verdeutlichen. Anschließend soll der Fokus auf bestimmte interaktive Verhaltensweisen Irmgards gerichtet werden, die man in einer alltagsweltlichen Terminologie als 'Hineinplatzen in ein Gespräch' bezeichnen könnte. Mehrere Auszüge aus Gesprächen im Kontext der Geburtstagsfeier werden analysiert und in Hinblick auf Irmgards Verhalten und der Reaktion anderer Beteiligter darauf beschrieben, um Aussagen über das Selbst- und Fremdbild ihres interfamiliären Kommunikationsstatus machen zu können. Die aus den Transkriptanalysen herausgearbeiteten kommunikativen Verhaltensweisen werden anschließend mit Darstellungen aus dem Gruppeninterview kontrastiert.

\section{Charakterisierung, Beschreibung und soziale Kategorisierung Irmgards}

Irmgard (ID) ist Mutter eines Sohnes und zweier Töchter, siebenfache Großmutter und vierfache Urgroßmutter. Aber nicht nur ihren direkten Nachkommen, sondern auch allen (Ehe-)Partnern ihrer Kinder und Enkel begegnet sie, als seien es ihre eigenen Kinder. Damit sind für sie, wie für alle anderen, bestimmte Rechte und Pflichten verbunden, die Irmgard vorgibt: „Oma [ID] versucht die Familie mit Regeln zusammenzuhalten. [...] Sie gibt ihre Norm vor, sie sagt ganz klipp und klar, was ihr nicht gefällt. [...] Wie sie erzogen wurde, ihre Werte versucht sie jetzt noch rüber zu retten in diese Zeit." (Interview Schwiegersohn). Irmgard ist diejenige, die "das Sagen“ hat und auf die man hört. „Sie hat ihre Kinder relativ autoritär erzogen ${ }^{5}$ und dul-

4 Die Tonbandaufnahmen und Feldbeobachtungen sind zwischen 1995 und 1997 entstanden, die Familienälteste war in diesem Zeitraum zwischen 73 und 75 Jahre alt.

5 Daß der Prozeß der Erziehung aller Familienangehörigen durch Irmgard noch nicht abgeschlossen ist, sondern bis in die Gegenwart hinein wirkt, wird an unterschiedlichen Gesprächspassagen deutlich. Beispielsweise weist sie einen Familienangehörigen während der Geburtstagsfeier zurecht, weil er zur Begrüßung der anderen Gäste auf den Tisch klopft:

ID: nei:n $\downarrow$ in der familie $\rightarrow$ also das mag ich nich $\downarrow \leftarrow$ nein $\downarrow$ in der

ID: familie muß man sich die hand geben $\downarrow$

Über weitere Erziehungsversuche berichtet auch Nina in den folgenden Interviews (Abschnitt 5). 
det keinen Widerspruch [...] man muß sich fügen." (Interview Schwiegersohn). Irmgars Schwiegersohn resümiert seine Aussagen in einer sehr anschaulichen Kategorie zur Beschreibung der Familienältesten und ihres 'Anhanges': „Das ist die Gluk$\boldsymbol{k e}^{6}$, das ist die Glucke und Küken, sie hat alle Kinder und Kindeskinder um sich gescharrt und wehe es widerspricht einer oder es macht einer was, was außer ihrer Norm ist. [...] Eine alte Glucke, hat alle an sich gebunden".

Ein illustratives Beispiel für Irmgards Stellung und Funktion in der Familie ist der folgende Gesprächsausschnitt, an dem Irmgard, ihre Tochter Melina und ihre Enkelinnen Johanna und Nina beteiligt sind. Es geht darum, daß der Hund der Familie Meyer normalerweise nicht auf Betten springen oder sich gar hineinlegen darf. Als aber Melina krank ist und sich aus Schwäche gegen den Hund nicht durchsetzen kann, nimmt dieser die Gelegenheit wahr und legt sich zu ihr. Erst als Irmgard die Wohnung betritt, verläßt er sofort das Bett.

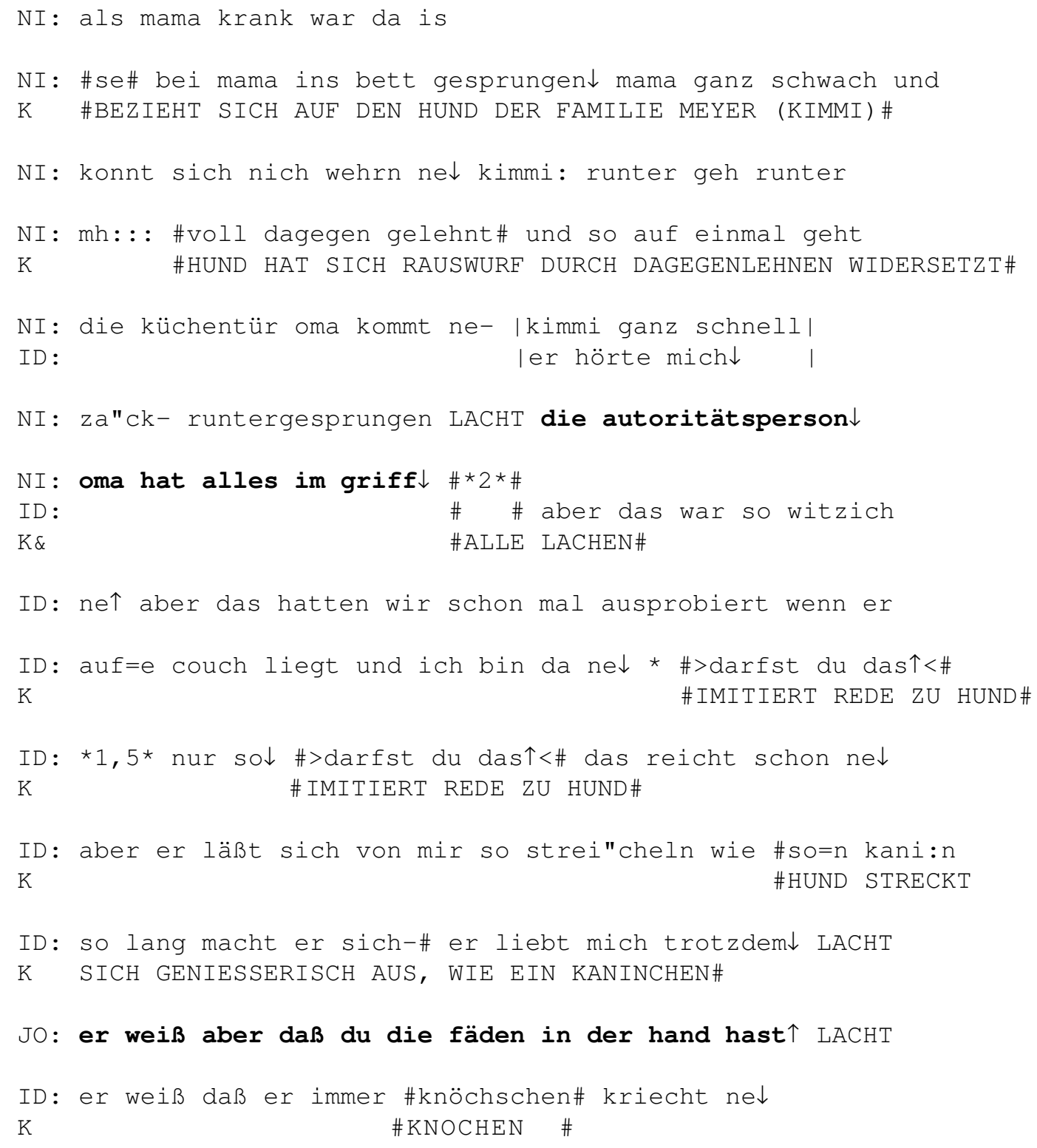

6 Explizite Kategorienbezeichnungen werden im folgenden fett gedruckt. 
In dieser kurzen Erzählung wird deutlich, daß Irmgards Regeln wirklich von allen Familienangehörigen, selbst vom Hund, befolgt werden. In dem Gespräch über den Hund werden von den Enkelinnen Typisierungen zur Beschreibung von Irmgards Rolle entwickelt: Nina verwendet die Kategorie Autoritätsperson, die [...] alles im Griff [hat] und - laut Johanna - die Fäden in der Hand hält.

Bemerkenswert ist Irmgards eigene Interpretation des Gehorsams. Auf die Kategorie „Autoritätsperson“, oder „Person, die die Fäden in der Hand hält“ bzw. „Person, die alles im Griff hat" geht sie nicht weiter ein, sondern erzählt, daß sie den Hund quasi als Gegenleistung für seinen Gehorsam - ausgiebig streichelt oder ihm Knochen zu fressen gibt. Hier wird ein wichtiger Aspekt offenkundig, nämlich die Belohnung. Natürlich muß es Gründe dafür geben, daß so viele unterschiedliche - auch erwachsene - Menschen, sich den Vorgaben einer über siebzig Jahre alten Person unterwerfen. Nach Melinas Urteil ist es bequem, Irmgards Regeln zu befolgen. Die Familienälteste ist eine sehr großzügige Person, und man kann durch sie sehr viele Vorteile haben: Sie näht beispielsweise Kleidung für die Familienmitglieder, macht oft Geschenke und kleine Überraschungen oder Aufmerksamkeiten, sie kocht täglich und wenn jemand einmal keine Lust oder Zeit hat, sein Essen selbst zuzubereiten, kann er oder sie sich relativ kurzfristig bei ihr zum Essen einladen. Sie hütet die Urenkel, sie hat sehr gute Kontakte zu vielen Dorfbewohnern und kann sogar behilflich sein beim Beschaffen von Wohnungen/Bauplätzen im Ort, sie bügelt ihren Enkeln auch mal die Wäsche, wenn diese keine Zeit haben, und sie verfügt über Informationen. ${ }^{7}$ Irmgard ist die wichtigste Person für den 'Umschlag von Neuigkeiten' aus den einzelnen Kleinfamilien oder aus dem Dorf. Von ihrem Schwiegersohn wird sie im Interview deshalb wie folgt typisiert: „Oma ist die Schaltzentrale, da laufen alle Fäden zusammen." Ihr werden Informationen zugetragen, sie sorgt dafür, diese weiterzugeben, hat damit einen kontinuierlichen Überblick über aktuelle Geschehnisse und als Folge dessen diverse Kontrollgelegenheiten. Möglich wird die Funktion der Schaltzentrale, „weil sie zu allen Kontakt hat. Fast täglich. Zu ihren Kindern, zu ihren Enkeln, wenn die nicht kommen, dann wird telefoniert oder bei Oma geben sie sich die Klinke in die Hand. Und das Telefon schellt auch ständig. Schon morgens früh und abends noch spät" (Interview Tochter). Neben täglichen Kontakten dienen auch die Geburtstagsfeiern sowie die Treffen vor und nach einem Urlaub dem Informationsaustausch. Irmgard und ihr Ehemann Otto unternehmen häufig kürzere und längere Nah- und Fernreisen, wobei der Tag vor der Abreise und der Tag nach der Ankunft zur allgemeinen Verabschiedung bzw. Begrüßung benutzt wird: „Dann geht's hier wie auf dem Taubenschlag, da gibt einer dem anderen die Klinke in die Hand. Auch, bevor sie fährt, wird erst gegessen zusammen nochmal, Kaffee getrunken, Waffeln gegessen, Abschied genommen“ (Interview Schwiegersohn) [...] "Und dann ist hier die Wohnung voll bis oben hin" (Interview Tochter).

Offensichtlich ist Irmgard auch in persönlichen Angelegenheiten eine wichtige Ansprechpartnerin, wovon folgende Äußerung zeugt: „Oma ist immer informiert darüber, was in den anderen Familien passiert, bei Oma weint man sich aus, sie bohrt nach" (Interview Schwiegersohn). Meines Erachtens befindet sich Irmgard durch ihr aktuelles Wissen in einer Schlüsselstellung („Oma ist absolutes Zentrum“; Interview Enkelin), weil ohne sie der Informationsfluß eingeschränkt wäre. Es liegt in ihren Händen, welche Informationen überhaupt weitergegeben werden und wie diese

7 Natürlich spielen neben all den aufgezählten Gründen auch persönliche emotionale Bindungen eine große Rolle. 
weitergegeben werden. Über ihre Position kann sie Wertmaßstäbe verdeutlichen und auch Familienmitglieder positiv oder negativ darstellen: „Entweder müßten die [Familienmitglieder] irgendwas machen, was Oma sehr verärgert oder sehr erfreut hat, dann wird mir das unmittelbar sofort danach mitgeteilt, wenn sich sowas ereignet hat" (Interview Tochter). Die Informationsweitergabe ist auch ein Mittel, um Verhalten zu kontrollieren bzw. zu sanktionieren: „Gestraft wird mit Verachtung oder mit 'schlecht machen', also Dinge an andere Familienmitglieder weitergeben, die dann auch böse auf einen sind" (Interview Schwiegersohn).

Irmgards Urteile über andere und deren Fähigkeiten sind dabei vorrangig an den eigenen Maßstäben orientiert. „Ilka [Tochter] ist [zum Beispiel] die kulinarische Queen, weil sie so kocht wie Oma. Das Lob wird dann im ganzen Clan verbreitet" (Interview Schwiegersohn). Aufgrund dieser Wertorientierung kommt ihre Tochter zu einem sehr deutlichen Urteil, mit dem sie eine weitere Kategorisierung Irmgards vornimmt: „Oma gehört zu den zwanghaften Typen ${ }^{9}$ das sind die zwanghaften Persönlichkeiten [...] immer ihre Meinung muß auch die Meinung der anderen sein, die lassen keine andere Meinung zu oder auch sie hat immer den besten Kuchen und alles andre wird nicht so akzeptiert. Ihres, immer ihres ist das beste. Das sind diese zwanghaften Typen, die auf der anderen Seite aber auch sehr großzügig und zuvorkommend und so sind."

Irmgards Schwiegersohn ergänzt die Aussage: „Sie muß immer sofort im Mittelpunkt stehen, dieses Mittelpunktdenken. Sie nimmt sich zu wichtig“. Auch Irmgard selbst ist von ihrer Wichtigkeit und Bedeutung für den Zusammenhalt der Gemeinschaft überzeugt und gibt an, daß der Verband ihrer Meinung nach ohne sie nicht funktionieren würde.

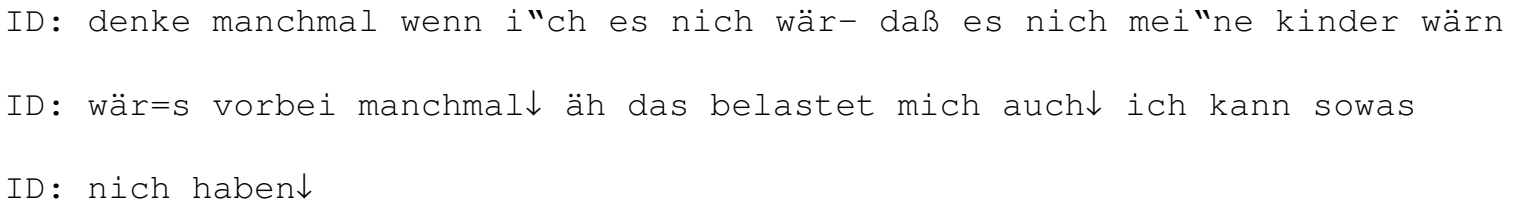

Ihrer Auffassung nach könnte die enge Bindung der Gruppenmitglieder untereinander ohne sie nicht aufrecht erhalten werden. Die Gedanken daran, daß sich die Familienstruktur ändern oder auflösen könnte, ist für sie belastend, denn „Oma legt Wert darauf, daß die Familie 'eins' ist" (Interview Enkelin), also insgesamt geschlossen und miteinander 'im Reinen'. Dafür setzt sie sich tagtäglich ein, indem sie, als Chefin (Interview „Schwieger-Enkel“) ihrer „Funktion des Nicht-Loslassens. Alle, alles unter Kontrolle zu haben." (Interview Tochter) nachgeht.

In ihrer Position als Schaltzentrale und absolutes Zentrum zeichnet sie sich durch ihr reges kommunikatives Verhalten aus: „Omas Lieblingsbeschäftigung ist reden, reden, reden“ [...] „Von 100 Prozent der gesprochenen Worte spricht Oma sowieso 95 in jeder Veranstaltung ... über früher, Kochen, Nähen, dann wieder wie sie aus 'ner Jacke 'ne Hose und aus 'ner Hose 'n Schlüpfer und aus 'm Schlüpfer 'n paar

8 Ihre Tochter ist oft Irmgards allererste Ansprechpartnerin, da sie im selben Haus wohnt und daher schnell erreichbar ist.

9 Die Kategorie „Zwanghafter Typ“ ist einem Kategoriensystem von Persönlichkeiten entlehnt, das Fritz Riemann in seiner psychoanalytischen Arbeit „Grundformen der Angst“ entwickelt. Mit dieser Arbeit hatte sich Irmgards Tochter zum Zeitpunkt der Aufnahmen auseinandergesetzt. Ihre Aussage im Interview ordnet Irmgard also in eine von Riemann vorgegebene Kategorie ein. 
Schuhe macht LACHEN [...] Die Themen bei den Frauen ${ }^{10}$ [auf einer Geburtstagsfeier] sind meist von Oma beherrscht, es geht um das Nähen oder die Nachbarin" (Interview Schwiegersohn).

Insgesamt geht aus den Fremddarstellungen der Familiengründerin deutlich hervor, daß sie über einen hohen Status in der Familienhierarchie verfügt. Davon zeugen nicht nur Typisierungen wie Chefin, Glucke, absolutes Zentrum oder Autoritätsperson, die alle in gewisser Weise mit Macht und Dominanz verbunden sind, sondern auch Beschreibungen wie "Fäden in der Hand halten" oder "Themen beherrschen". Inwiefern sich diese allgemeinen Zuschreibungen auch bezogen auf Irmgards Interaktionsstatus halten lassen, soll im folgenden untersucht werden.

\section{Interaktives Verhalten Irmgards und die Reaktionen anderer Familienmitglieder}

Die folgenden Gesprächsausschnitte aus dem Kontext der Geburtstagsfeier werden über das alltagsweltlich als 'Hineinplatzen in ein Gespräch' charakterisierte kommunikative Verhalten Irmgards Aufschluß geben. Zum einen wird die Struktur und der sequentielle Verlauf der Gespräche, zum anderen aber auch die thematische Ausrichtung analysiert, um durch Irmgards Selbstdarstellung Aussagen über ihren familiären Interaktionsstatus, also über ihre Rechte und Möglichkeiten der Gesprächsstrukturierung, thematischen Bearbeitung und Situationsdefinition, machen zu können. Dabei gehe ich davon aus, daß

„... the ways in which discourse is structured reveal how power is acquired, negotiated, consolidated or lost among family members. It is through discourse that individuals are able to project a self-image and identify the terms for in-group membership. It is thus through discourse that the web of interpersonal relationships among the members is constructed and affirmed. And it is through the study of discourse that these factors become manifest to the researcher" (Watts 1991, 23).

\subsection{Irmgards Verhalten gegenüber ihrer Enkelin und ihrer Schwiegertochter}

Die Familienmitglieder Otto (OT; Ehemann), Karl (KL; Sohn), Jost (JJ; „SchwiegerEnkel"), Marietta (MA; Enkelin) und Mona (MO; Schwiegertochter) sitzen nach dem Abendessen im Wohnzimmer und planen eine anläßlich der Goldenen Hochzeit von Irmgard und Otto stattfindende Reise nach Dänemark. Irmgard hat drei große Ferienbauernhäuser gemietet, in denen die Großfamilie eine Woche lang auf Kosten des "Goldbrautpaares“ leben, entspannen, essen, trinken und feiern soll. Zuerst wird kurz darüber geredet, welcher Ort genau das Ziel der Reise sein wird, danach werden organisatorische Fragen, u.a. Preise für Lebensmittel, geklärt: Nachdem erörtert wurde, daß Fleisch in Dänemark teurer als in Deutschland ist, macht Jost die gleiche Rechnung für Tuborg-Bier auf. Während seiner Ausführungen betritt die Familienälteste Irmgard das Wohnzimmer - mit einem selbstgenähten Kleid für Mariettas Tochter in der Hand.

10 Die Formulierung 'bei den Frauen' verweist auf eine familientypische Unterteilung bei allen Geburtstagsfeiern. Es gibt sowohl Phasen, zu denen sich alle Teilnehmenden in einem Raum aufhalten, als auch solche, in denen die Gruppe nach Geschlechtern getrennt ist. 
Transkriptausschnitt: Nähen 1

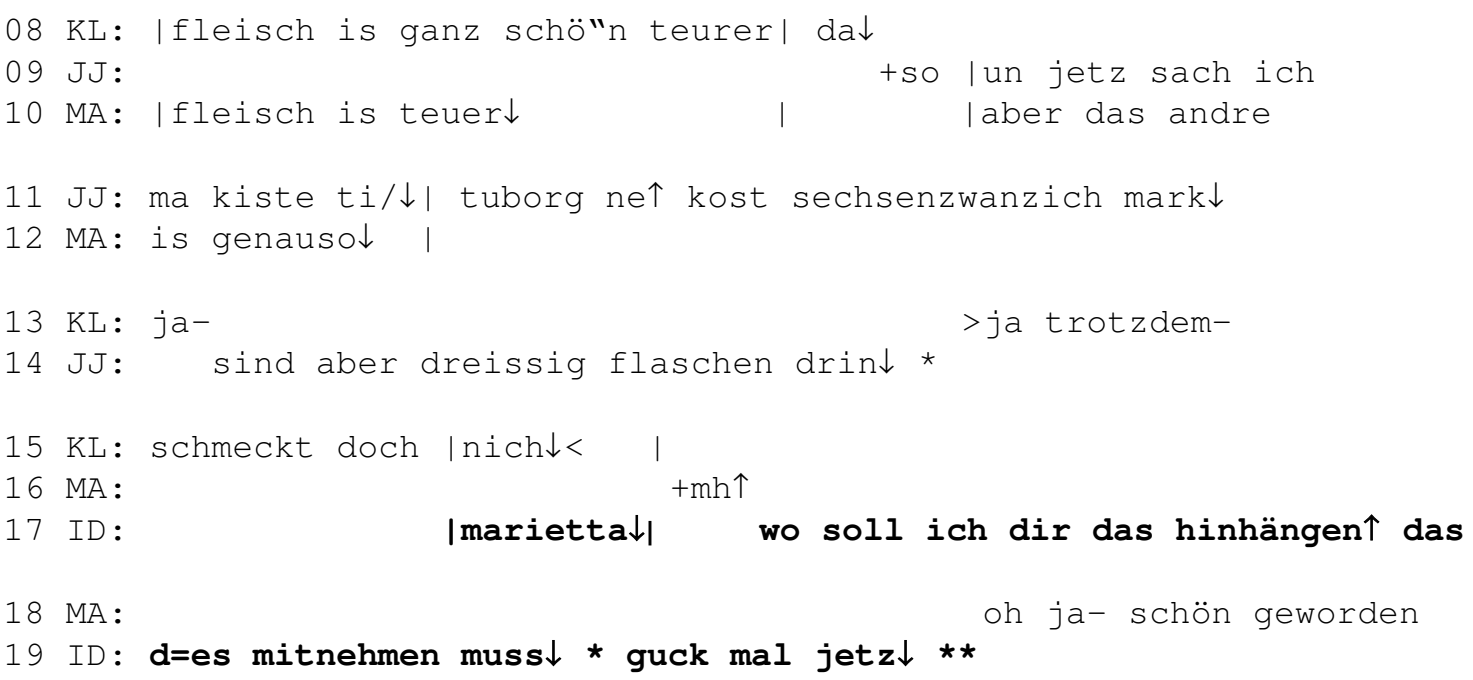

Irmgard spricht ihre Enkelin Marietta namentlich an (Z. 17). Sie beginnt eine Aktivität, die in direkter Konkurrenz zu dem bereits über weite Strecken etablierten Kommunikationszusammenhang und dem gerade von Jost und Karl bearbeiteten Thema "Tuborg-Bier" steht, indem sie ein Mitglied der Gruppe adressiert. Auf dem ersten Blick scheint es, als würde Irmgard durch die spezielle Orientierung auf eine Person die laufende Interaktion nicht beeinträchtigen, da sie nicht mit Karl oder Jost um den floor konkurriert, sondern lediglich eine Zuhörerin für ihre Belange unaufwendig 'abwirbt'.

Dennoch gibt diese selbstverständliche Handlung Aufschlüsse über Irmgards Vorstellung bezüglich ihrer Relevanz auf dem Schauplatz. Ohne auch nur andeutungsweise zu wissen, um was es in der Gesprächsrunde bisher gegangen ist, denn das konnte sie durch ihre Abwesenheit und auch während des zügigen Zugehens auf die Gruppe nicht erfassen, stuft sie die Relevanz des Themas für Marietta zurück und nimmt gleichzeitig an, daß Marietta als Teilnehmerin an dem bisherigen Gespräch für die anderen nicht wichtig ist. Die Familienälteste geht nicht davon aus, daß sie warten muß, bis es einen geeigneten Gesprächszeitpunkt für ihr Anliegen gibt und daß sie austarieren muß, wann sie am günstigsten in die Interaktion integriert werden kann.

Obwohl man diese kurze Adressierungssequenz nicht überbewerten sollte, da bei einem Familienfest die Toleranzgrenze für kurzzeitige Störungen oder 'Zweiergespräche' wohl höher ist als beispielsweise in einem institutionalisierteren Rahmen, möchte ich einen Deutungsaspekt nicht außer Acht lassen: Irmgard verhält sich den anderen gegenüber ignorant und nimmt sich ohne Warten oder Zögern Raum für ihre Interessen. Dies könnte erste vorsichtige Hinweise auf ihr Selbstbild geben.

Doch selbst wenn diese Handlung angesichts der Tatsache, daß die Oma ${ }^{11}$ auch alle hätte ansprechen können und somit das Gespräch vollkommen gestört hätte, nicht so gravierend ist, wie sie hätte sein können, werden die anderen zumindest kurzzeitig 'aus dem Konzept gebracht'. Nach Karls Äußerung, dessen Ende simultan zu Irmgards Adressierung ist, entsteht eine zweisekündige Pause und Karl redet im

11 'Oma' verweist im folgenden nicht auf eine Verwandtschaftsbeziehung, sondern entspricht der Bezeichnung durch die Familienangehörigen, die mit 'Oma' stets die Familienälteste meinen. 
folgenden wesentlich leiser weiter als Irmgard. Vermutlich resultiert die Pause aus der kurzzeitigen Orientierung aller SprecherInnen auf Irmgard. Diese Sequenz hat damit ambivalente Potentiale, da das auf dem ersten Blick nicht sehr folgenreiche 'Herausholen' einer Sprecherin aus der etablierten Interaktion insgesamt doch gravierende Folgen für das Gespräch hat und meines Erachtens als Unterbrechung einstufbar ist. Dies wiederum kann auf den übergeordneten Status verweisen, den sich Irmgard in dieser Gesprächssequenz selbst zuschreibt:

„Not only does an interruption prevent the participant from completing whatever social activity s/he has begun, but it also implies that the interrupter considers that whatever s/he proceeds to do in some sense has priority over what the interrupted was doing. It is thus a denial of participant rights, on the one hand, and a negation of the validity of the interrupted activity, on the other" (Watts 1991, 92).

Indem Irmgard sowohl nonverbal, durch das auffällige Hochhalten des Kleides, als auch verbal, durch die laute Adressierung Mariettas, den etablierten Interaktionsfluß unterbricht, bedroht sie das Face ${ }^{12}$ des derzeitigen Sprechers (Karl), da er darin eingeschränkt wird, seine kommunikativen Handlungen/Ziele weiter zu verfolgen. Ihr Verhalten ist jedoch so angelegt, daß es nicht an Karl gebunden, sondern auf alle Anwesenden übertragbar ist. Diese Deutung wird durch die Tatsache nahegelegt, daß sie in der kurzen Zeit ihres 'Szenenauftrittes' nicht ausmachen konnte, wer das Rederecht hatte und die Face-Bedrohung somit alle hätte betreffen können.

Doch nicht nur, daß die Oma ihre Enkelin aus dem Gespräch über das TuborgBier herausholt, sondern auch, wie unaufwendig dies geschieht, fällt auf. Nachdem Irmgard Marietta angesprochen hat, steht diese sofort zur Verfügung (+mh, Z. 16). Durch die Namensnennung, die deutlich fokussierende Qualität hat, eröffnet Irmgard den Diskurs mit ihrer Enkelin.

Schon der Einstieg in das Gespräch kann erste Hinweise auf die selbstzugeschriebene Bedeutung Irmgards in der Familienhierarchie geben: Ihre Präsenz evoziert weitreichende Veränderungen des laufenden Diskurses, denn Marietta ist sofort bereit, sich auf sie zu orientieren und die Nicht-Angesprochenen wenden sich ihr ebenfalls kurz zu, protestieren in keiner Weise gegen die Störung, sondern setzen als deutlich ist, daß sie nicht angesprochen wurden - ihr Thema in reduzierter Lautstärke fort. Insofern wird Irmgards Selbstbild hier durch ein korrelierendes Fremdbild bestätigt.

Nachdem sich Irmgard der Aufmerksamkeit ihrer Adressatin sicher ist, fragt sie, das Kleid vor sich haltend: wo soll ich dir das hinhängen $\uparrow$ das d=es mitnehmen muss $\downarrow$ (Z. 17-19). Auf der Ebene der Gesprächsstruktur zeigt sich, daß Irmgard eine Frage stellt und damit konditionelle Relevanzen ${ }^{13}$ in bezug auf die Folgeaktivität Mariettas setzt. Marietta kann nicht schnell wieder in das Gespräch über das Tuborg-Bier zurück, sondern muß den von Irmgard aufgebauten Reaktionsverpflichtungen in Form einer Antwort nachkommen und sich entsprechend stärker auf

12 Zum Face-Konzept siehe: Goffman (1971); Brown \& Levinson (1978).

13 Bei der sequenziellen Organisation verbaler Interaktion spielen Verknüpfungen und Abfolgen von (Handlungs-)Aktivitäten eine wichtige Rolle. Das Konzept der konditionellen Relevanz beschreibt die Beziehung zwischen Initiativen und den darauf folgenden Reaktionen. „In einer Folge von Aktivitäten, von denen die erste relativ starke und eindeutige Reaktionsverpflichtungen aufbaut (...), wird ein bestimmter Aktivitätstyp für die Folgeaktivität relevant gesetzt, und die Folgeaktivität zeigt durch die Art der Realisierung ihre Relevanz im Verhältnis zur voraufgehenden Bezugsaktivität“ (Kallmeyer 1988, 1099). 
sie orientieren. ${ }^{14}$ An dieser Verpflichtung der Enkelin sieht man noch deutlicher, welche Rechte sich die Familienälteste selbst zuschreibt.

Nachdem Marietta auf die erste Frage und den begründenden Nachtrag - im Gegensatz zu der anfänglich schnellen Orientierung auf ihre Oma - nicht reagiert hat, und den Übergabepunkt, der durch fallende Intonation und anschließende Pause

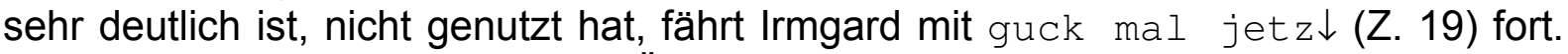
Mit diesem dritten Segment ihrer Äußerung klagt sie deutlich eine Reaktion Mariettas auf das Kleid ein.

Das Ausbleiben von Reaktionen zeigt, daß Marietta an dieser Stelle den Kommunikationsstatus, den sich Irmgard selbst zugewiesen hat, nicht bestätigt. Es existiert ein Ungleichgewicht zwischen der Selbstverständlichkeit von Irmgards Handlungen und dem angedeuteten 'Widerstand' Mariettas. Die Aufforderung guck mal jetz $\downarrow$ (Z. 19) könnte als Reaktion der Oma darauf verstanden werden. Irmgard muß an dieser Stelle damit beginnen, an dem Gespräch und ihrem Kommunikationsstatus zu arbeiten, um ihre Enkelin in das Gespräch einzubinden und um so die Selbstzuschreibungen zu realisieren. Es gelingt ihr jedoch und Marietta löst die konditionellen Relevanzen ein (oh ja- schön geworden). In den folgenden - hier nicht wiedergegebenen Sequenzen - baut die Familienälteste mit ihrer Enkelin ihr konkurrierendes Thema aus und bezieht dabei auch ihre Schwiegertochter Mona immer wieder in das Gespräch ein. Mona steht der Oma aber im Gegensatz zu Marietta nur für formale Rückmeldungen ( $\mathrm{mhm}$ ) zur Verfügung und scheint immer noch auf die Urlaubsplanung, die leise im Hintergrund weiterläuft, konzentriert.

\subsection{Irmgards Verhalten gegenüber ihrem Sohn und ihrem Schwiegersohn}

Dieses explizite Herausgreifen eines Sprechers bzw. einer Sprecherin aus einem Kommunikationszusammenhang wird von Irmgard oft praktiziert und im folgenden an weiteren Beispielen - in kürzerer Form - demonstriert.

Im gleichen Gespräch über das Kleid, versucht sie an späterer Stelle, nachdem sie Gelegenheit hatte, ihre textilverarbeitenden Kompetenzen für Marietta detailliert darzustellen, ihren Sohn Karl in das Thema einzubeziehen.

Transkriptausschnitt: Nähen 2

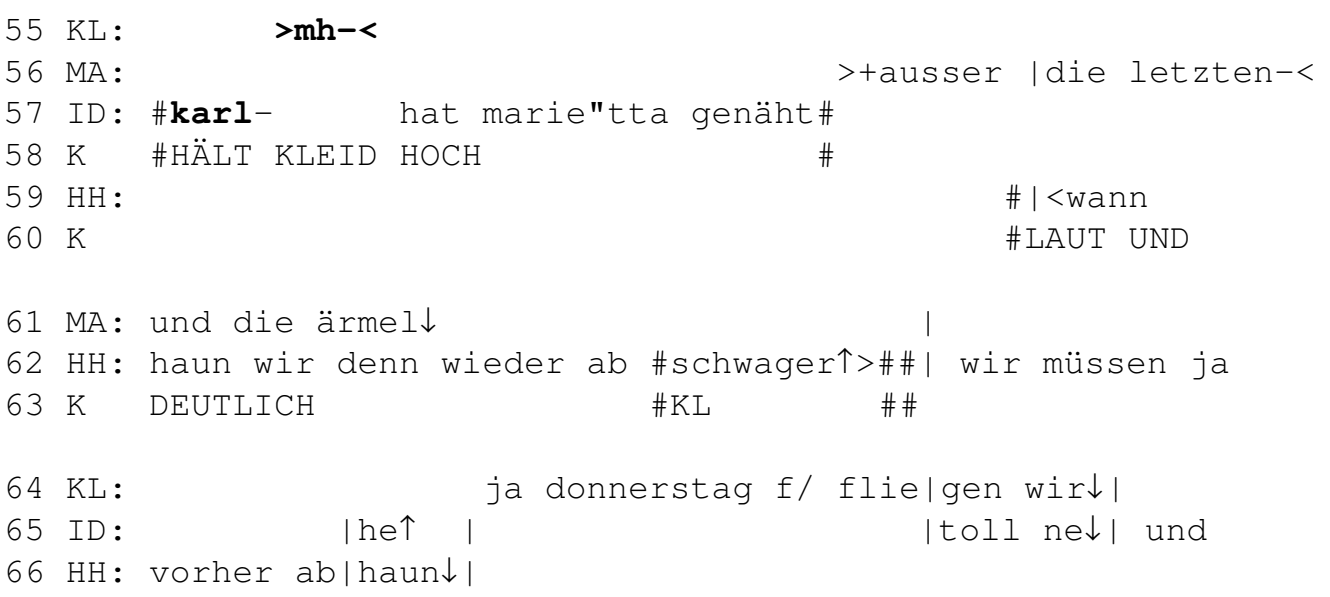

14 Hätte Irmgard lediglich gesagt, sie hänge das Kleid an diesen oder jenen Platz, hätte für ihre Enkelin die Möglichkeit bestanden, sich schnell wieder in die alte Gesprächsrunde zu re-integrieren. 


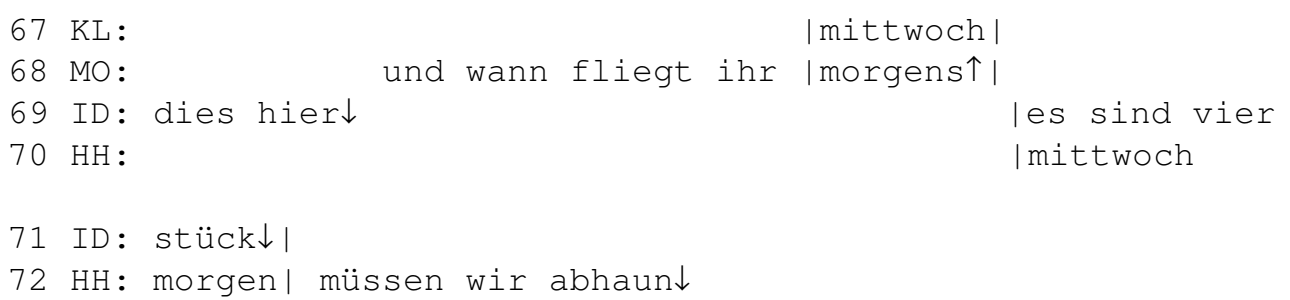

Zum zweiten Mal seit ihrer Anwesenheit auf dem Schauplatz adressiert sie ungeachtet irgendwelcher Regeln einen Sprecher und greift diesen somit aus seinem 'laufenden' Interaktionszusammenhang heraus. Nicht nur dieses Verhalten ist mit dem zuvor praktizierten und beschriebenen identisch, auch strukturell gibt es deutliche Parallelen. Karl orientiert sich nämlich, wie zuvor Marietta, sofort auf seine Mutter (>mh-<; Z. 55):

Diese hält das Kleid mit den Worten hat marie"tta genäht (Z. 57) vor sich. $\mathrm{Da}$ sie es durch die aufwendige vorherige Selbstdarstellung, die in Konkurrenz zu dem Gespräch der Männer und dabei deutlich lauter war, nicht geschafft hat, Aufmerksamkeit von einem der Männer zu bekommen, wendet sie sich nun explizit an ihren Sohn und redet dabei über ihre Enkelin (seine Tochter). Damit hat sie zumindest die Möglichkeit, über einen 'Umweg', nämlich Lehrerin Mariettas zu sein, Anerkennung von ihrem Sohn zu erhalten.

Karl orientiert sich aber nicht weiter auf seine Mutter oder seine Tochter, sondern auf Hannes (IDs Schwiegersohn), der ihn solidarisch wieder in das Männergespräch 'zurückholt': <wann haun wir denn wieder ab schwager $\uparrow$ wir müssen ja vorher abhaun $\downarrow$ (Z. 59-66). Während also zuvor die beiden Frauen, Marietta und - später auch - Mona, ohne Widerstände aus dem Gespräch über die Urlaubsplanung entlassen wurden, wird das männliche Familienmitglied Karl von Hannes mit Irmgards Mitteln (erhöhte Lautstärke, Setzen von konditionellen Relevanzen) in das Gespräch re-integriert.

Trotz Irmgards einforderndem he个 (Z. 65), das simultan zu Hannes abhaun gesprochen wird und ihre Erwartung einer Gratifikation von Seiten Karls ausdrückt, beantwortet Karl die Frage seines Schwagers, macht also deutlich, zu welchem Interaktionszusammenhang er gehört: ja donnerstag f/ fliegen wir (...) mittwoch (Z. 64-67). Auch Mona nutzt an dieser Stelle die Gelegenheit, wieder vollständig in das Urlaubsgespräch einzusteigen durch ihre Nachfrage: und wann fliegt ihr morgens $\uparrow($ Z. 68).

Über mehrere Äußerungen hinweg sind die zwei Kommunikationsgruppen in direkter Konkurrenz, wobei es zu einigen Überlappungen von Gesprächsbeiträgen kommt. Obwohl es offensichtlich ist, daß Irmgard ihren Sohn nicht für das Gespräch über das Kleid gewinnen kann, redet sie trotzdem zu ihm gewandt weiter. Mit ihrer

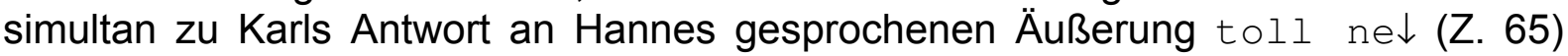
formuliert sie nun selbst die von ihrem Sohn geforderte Bewertung. Somit erfüllt sie sich zunächst selbst ihre Erwartungen, gibt sich jedoch nicht vollständig der 'Niederlage' hin, sondern versucht noch ein weiteres Mal, Karls Aufmerksamkeit zu gewinnen, indem sie nun von dem ganzen Kleid abläßt und die Knöpfe fokussiert: und dies hier $\downarrow$ (...) es sind vier stück $\downarrow$ (Z. 66-71). Doch auch dieses Fortführen ihres Themas, ungeachtet des Desinteresses der anderen, bringt keinen weiteren Erfolg und somit greift sie wieder auf ihre 'bewährte' Gesprächspartnerin Marietta zurück und etabliert mit ihr nun nochmals den Diskurs über das Kleid. 


\subsection{Irmgards Verhalten gegenüber ihrem Ehemann Otto}

Ein weiteres Beispiel für Unterbrechungen einer etablierten Interaktion durch die Familienälteste, das sehr gut ihren selbst zugeschriebenen hohen Kommunikationsstatus spiegelt, ist das Gespräch mit Otto. An der Interaktion sind Heinrich (HE; Schwiegersohn), Hannes (HH; Schwiegersohn), Otto (OT; Ehemann) und Ilka (IL; Tochter) beteiligt. Hannes erörtert die Vor- und Nachteile wasserdurchlässiger Pflastersteine für seine Garagenauffahrt.

Transkriptausschnitt: Steine

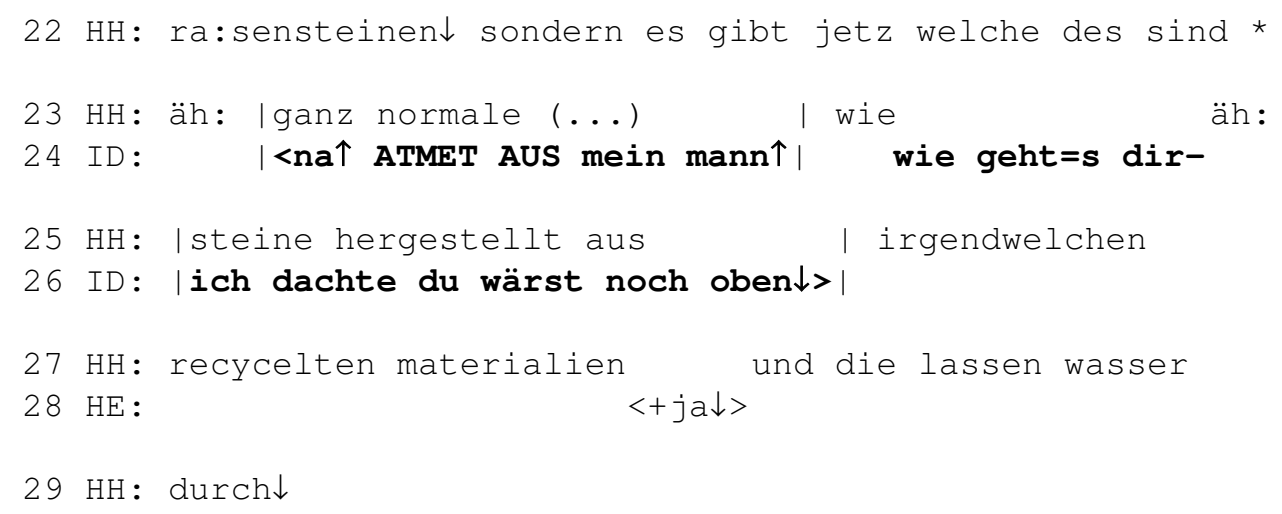

Irmgard betritt den Raum. Wie bei den Transkriptausschnitten „Nähen1“ und „Nähen 2" geht sie auch hier davon aus, nicht auf eine geeignete Gelegenheit warten zu müssen, um 'sanft' in das Gespräch integriert zu werden. Eine weitere Parallele liegt in der lauten Adressierung einer bestimmten Person, hier ihres Ehemanns Otto ( $<$ na- ATMET AUS mein mann- wie geht=s dir-; Z. 24). Und auch von der Gesprächsstruktur gibt es eine auffällige Entsprechung, nämlich daß die Familienälteste direkt nach der Frage über Ottos Befinden eine weitere Äußerung anschließt (ich dachte du wärst noch oben $\downarrow>;$ Z. 26) und damit ihre Initiative dehnt. Im Gegensatz zu Karl oder Marietta, die sehr spontan und direkt nach der Adressierung durch eine Rückmeldung $(+m h)$ auf Irmgards Äußerung reagierten, orientiert sich Otto weder verbal noch nonverbal auf seine Frau, sondern blickt weiter in die Richtung des aktuellen Sprechers Hannes. Meines Erachtens demonstriert er somit deutlich, daß er Irmgards selbstzugeschriebene Rechte mißachtet und den von ihr suggerierten hohen Kommunikationsstatus zurückweist. ${ }^{15}$

Betrachtet man Hannes, den Sprecher, der zur Zeit der Störung dabei war, die Besonderheiten wasserdurchlässiger Steine in Abgrenzung zu Rasensteinen für llka darzulegen, so sieht man, daß er zunächst durch Irmgard 'aus dem Konzept gebracht wird' (äh:; Z. 23), seine Äußerung aber dennoch zu Ende führt: >nein nein< nich mit den ra:sensteinen $\downarrow$ sondern es gibt jetz welche des sind * äh: ganz normale (..) wie äh: steine hergestellt

15 Wie alle anderen Familienmitglieder bearbeitet Otto Irmgards Störung nicht explizit, indem er sie thematisiert, sie bewertet oder darüber diskutiert. Jedoch ist seine Nicht-Reaktion bisher die deutlichste Ablehnung von Irmgards Verhaltensweise. Eine mögliche Deutung, die erklärt, weshalb es für Otto unter Umständen leichter als für alle anderen ist, sich eindeutig zu verhalten, könnte sein, daß er als Irmgards Ehemann ihren erzieherischen Maßnahmen nicht so ausgesetzt ist, wie die jüngeren Familienmitglieder - also ausnahmslos alle anderen. Eventuell hat er mehr Freiraum und wird nicht so hart sanktioniert. 
aus irgendwelchen recycelten materialien und die lassen wasser und die lassen wasser durch $\downarrow$ (Z. 18-29).

\subsection{Irmgards Verhalten gegenüber ihrem Schwiegersohn Heinrich}

Nach Ottos deutlicher Vermeidung einer Kommunikation mit seiner Frau beginnt Irmgard nicht, wie bei ihrer Schwiegertochter und ihrer Enkelin, an ihrem Kommunikationsstaus zu arbeiten, das Gespräch zu dehnen und in Gang zu halten, sondern sie wendet sich direkt im Anschluß an Hannes Äußerungsbeendigung zu Heinrich, ebenfalls durch namentliche Adressierung:

Transkriptausschnitt: Schlafen

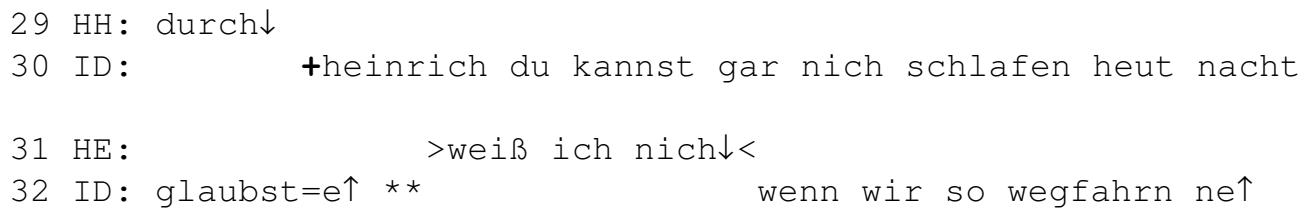

Inhaltlich spielt sie darauf an, daß Heinrich am folgenden Morgen eine mehrwöchige Urlaubsreise in die USA antreten wird. Auf Irmgards Feststellung, Heinrich könne nachts nicht schlafen, die auf Bestätigung zielt (glaubst=e $\uparrow$; Z. 32), erfolgt von dem Angesprochenen erst nach kurzer Gesprächspause eine Antwort. Diese ist leise gesprochen und sehr unbestimmt; weder bestätigt, noch revidiert sie die Vermutung der Familienältesten (>weiß ich nich $\downarrow<;$ Z. 31). Heinrich drückt aus, daß er sich bisher über den Schlaf vor der Reise keine Gedanken gemacht hat und stuft meines Erachtens damit die Relevanz der Äußerung zurück. Auch die vorangegangene kurze Pause, die vage Reaktion und die reduzierte Lautstärke könnten ein Hinweis darauf sein, daß Heinrich noch leichten 'Widerstand' leistet bzw. nicht vollständig auf Irmgard orientiert ist. Insgesamt gibt sein Verhalten der Oma allerdings bessere Möglichkeiten, das Gespräch mit ihm weiter auszubauen, als dies beispielsweise bei Otto oder auch bei Karl der Fall war. Irmgard fährt mit einer knappen Schilderung eigener Erfahrungen fort:

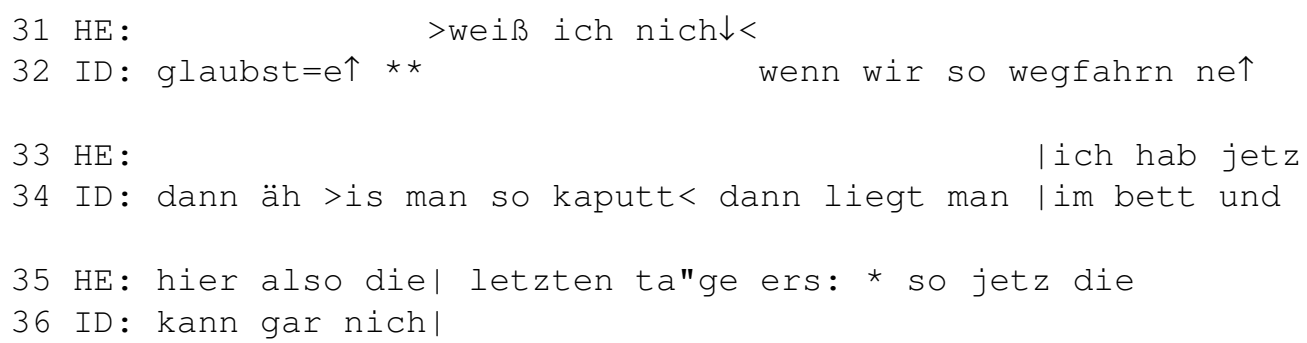

Im weiteren Verlauf unterscheidet sich dieses Gespräch deutlich von den zuvor betrachteten Transkripten „Nähen“ und "Steine“. Noch bevor Irmgard mit der Begründung, weshalb sie vor Urlauben nicht schlafen kann, abschließt, bringt sich Heinrich simultan in das Gespräch ein. Er bearbeitet nun ebenfalls das Thema "Schlafen“. Interessant ist, daß Irmgard zu Heinrichs Gunsten auf ihre Äußerungsschließung verzichtet (und kann gar nich [schlafen; D.H.]; Z. 34-36), die Simultansequenz 
durch Aufgabe ihres 'turns' beendet und ihrem Schwiegersohn so die Möglichkeit gibt, seinen Beitrag, der ja offensichtlich noch als weitere Bearbeitung ihrer Anfangsfrage interpretiert werden kann, zu expandieren.

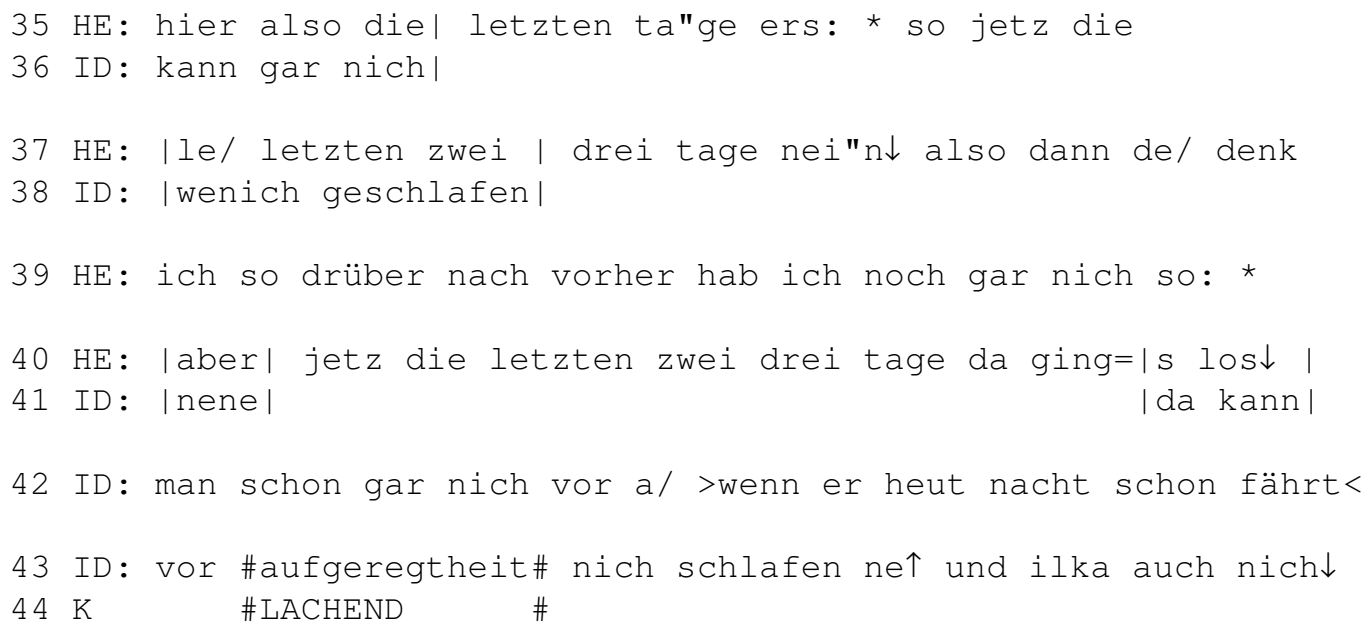

Heinrich schildert, daß er in den letzten Tagen überhaupt erst angefangen habe, über die Tatsache zu reflektieren, bald eine große Reise anzutreten. Inhaltlich deckt seine Fokussierung des Nachdenkens über die Reise nicht voll die in Irmgards Frage nahegelegte Problematik heut nacht nicht schlafen zu können. Die unterschiedlichen Nuancen bei der Bearbeitung des Themas manifestieren sich beispielsweise in Irmgards Einwurf wenich geschlafen (Z. 38) und Heinrichs Reak-

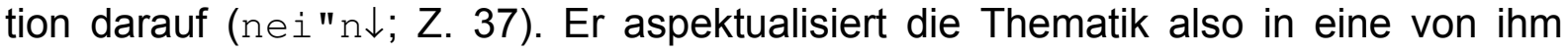
gewünschte Richtung.

Heinrichs Verhalten bei der Reaktion auf die Familienälteste unterscheidet sich strukturell gesehen - vom vorherigen Verhalten der anderen Familienmitglieder. Er bringt sich in das Gespräch ein, erhält sogar nach kurzer Simultaneität das Rederecht und verhält sich aktiv, indem er im weiteren Verlauf auch neue Punkte in das Gespräch einführt. Es entwickelt sich vom Thema „Schlafen“ zur Besprechung des geplanten Ablaufes am Flugtag (Ilka fährt Heinrich zum Bahnhof):

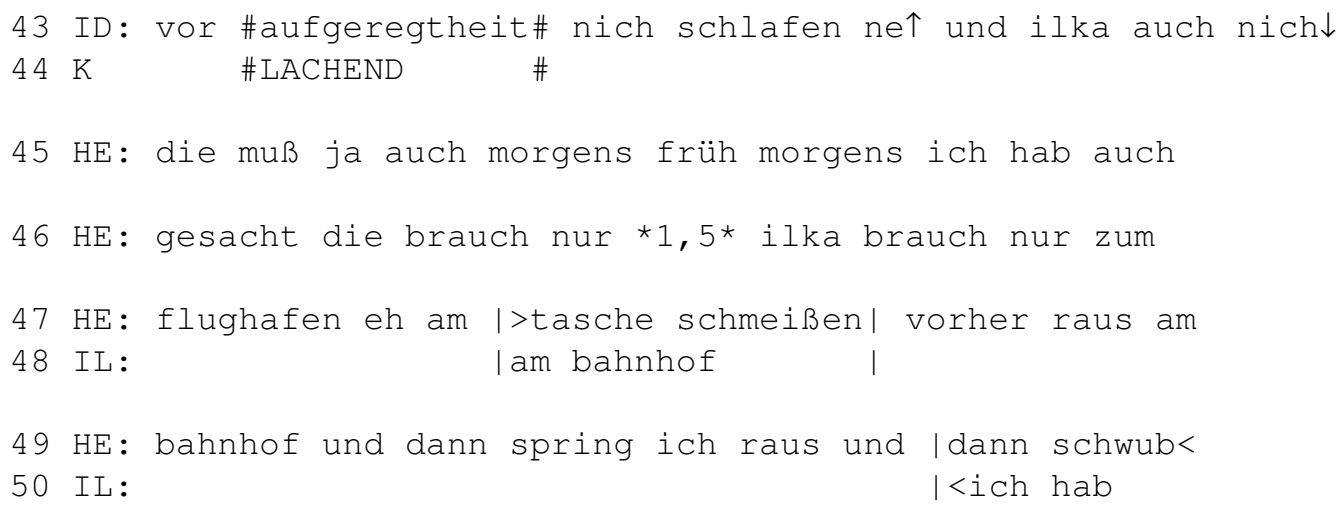

Dies schafft natürlich - im Gegensatz zu den Chancen der passiveren Familienmitglieder - eine Möglichkeit für Heinrich, an der Kommunikation, sowohl thematisch als auch an deren Ablauf, zu arbeiten. Auf diese Weise kann er Irmgards Störung konstruktiv für sich und seine Interessen nutzen und gleichzeitig Irmgards Status, den sie sich durch die Störung zugeschrieben hat, bestätigen. 


\section{4. Überblick über die interaktiven Verhaltensweisen}

Irmgards Unterbrechungen, die immer geduldet werden, tangieren generell alle anwesenden Familienmitglieder. Insofern kann man sie generell als Demonstration ihrer selbstzugeschriebenen familieninternen Machtposition sehen.

Die Folgereaktionen gliedern sich allerdings personenbezogen auf: Marietta und Mona stehen Irmgard für das Gespräch zur Verfügung. Monas Funktion erschöpft sich lediglich in formalen Rückmeldungen, die ein Minimun an Responsivität und Orientierung auf Irmgard ausdrücken. Marietta zeigt sich etwas involvierter, ist aber, verglichen mit der vorausgegangenen 'Urlaubssequenz', bedeutend inaktiver.

So wird der von Irmgard durch ihre ersten Aktivitäten präsupponierte hohe Kommunikationsstatus zunächst nur oberflächlich von den Frauen bestätigt. Gegenüber ihrer Enkelin gelingt es ihr im Verlaufe des Gespräches aber, eine deutliche Machtposition aufzubauen und sie als Kommunikationspartnerin zu verpflichten, während inre Schwiegertochter eine Gelegenheit, in der Irmgard nicht auf sie orientiert ist, nutzt, um sich wieder in das Gespräch über die Urlaubsplanung zu integrieren.

Bei ihrem Sohn Karl gestalten sich Irmgards 'Zugriffmöglichkeiten' schwieriger. Es gelingt der Oma im Transkript „Nähen“ nicht, ihn für ihr Thema zu gewinnen. Im Gegenteil: Karl, der zunächst formal ihren Wunsch nach Aufmerksamkeit durch eine schnelle Rückmeldung erfüllte, wird solidarisch von seinem Schwager wieder zum Thema Urlaubsplanung zurückgeholt. So praktizieren die Männer eine Art 'defensiven Widerstand'. Diesem begegnet die Familienälteste - anders als bei Marietta, die sie an das Gespräch gebunden hat - indem sie ungeachtet ihres Mißerfolges weiter zu ihrem Adressaten redet, als sei er aufmerksam und ihm, wie bei einem Vortrag, kurz verschiedene Aspekte des Kleides vorführt.

In der Sequenz mit ihrem Ehemann Otto wird ihr Selbstbild von inm überhaupt nicht bestätigt. Seine Mißachtung ist die einzige totale Verweigerung einer Kommunikation. Irmgard wird durch sie dazu veranlaßt, nicht weiter an dem Gespräch zu arbeiten, sondern sich ein anderes Familienmitglied für ihre Zwecke aus dem etablierten Diskussionskontext 'herauszugreifen'.

Ihr Schwiegersohn Heinrich steigt relativ schnell in das Gespräch mit ihr ein, orientiert sich also formal an Irmgards Vorgaben, nutzt sie aber gleichzeitig, um die inn interessierenden thematischen Aspekte zu bearbeiten.

Die verschiedenen Reaktionsmöglichkeiten zeigen, daß Irmgard ihr Selbstbild nicht umstandslos durchsetzen kann, sondern daß es in der Interaktion bestätigt, revidiert, in jedem Fall aber bearbeitet wird. Die Präsentation ihrer familienhierarchischen Position in der Kommunikation ist also in einen dynamischen Prozeß eingebunden und steht darüber hinaus in einem Wechselverhältnis zu den anderen Gesprächsbeteiligten, die sich auf bestimmte Weisen Irmgard gegenüber verhalten. Sowohl die Männer als auch die Frauen haben Mechanismen entwickelt, auf die Familiengründerin und ihre Wünsche zu reagieren und gleichzeitig eigene Interessen zu wahren. Bezüglich der analysierten Gesprächsstellen könnte man hier salopp von 'Irmgards interaktivem Management der anderen' oder dem 'interaktiven Management der Familienältesten durch die Männer und Frauen' sprechen.

$\mathrm{Zu}$ vermuten ist, daß sich die Familienälteste sehr oft in der oben analysierten Weise verhält. Nicht zuletzt dies ist der Grund, weshalb die Familienangehörigen so 'reibungslos' mit der Situation umgehen können. 


\section{Darstellung von Irmgards interaktiven Verhaltensweisen im Interview}

Um die oben durchgeführte Analyse weiter zu verdichten, möchte ich komplettierend zu der bisherigen Arbeit mit den transkribierten Tonaufnahmen aus dem Kontext der Geburtstagsfeier einen weiteren Materialtyp heranziehen, nämlich das Gruppeninterview mit drei Personen. Die Anwesenden hatten von mir die 'Aufgabe' bekommen, sich über Irmgard zu unterhalten. Dabei entwickelte sich eine lebhafte gemeinsame Reflexion über ihr Kommunikationsverhalten. Die erste Aussage stammt von ihrem Schwiegersohn, der ausführt:

„Oma lebt nach dem Motto 'Wo ich bin, ist vorne und hinter mir gibt's nichts'. Oma hat ' $n$ großes Geltungsbedürfnis. Wir können uns unterhalten, die kommt rein und gibt ihr Thema vor. Wenn du dann nicht zuhörst, sofort Dein Gespräch aufgibst, wird se sauer." Diese Beschreibung paßt sehr gut zu allen bisher analysierten Unterbrechungen. Interessant ist aber darüber hinaus, daß Irmgards Selbstverständnis mit dem Fremdbild ihres Schwiegersohnes übereinstimmt.

Die Aussage bestätigt die geäußerte Vermutung, daß derartige Störungen eines etablierten Kommunikationszusammenhanges durch Irmgard häufig stattfinden.

Auch ihre Enkelin Nina berichtet über interaktive Erfahrungen mit Irmgard: „Wenn wir hier unten sitzen und Fernsehen gucken und is was is was wichtiges dran, das wir auch unbedingt sehen möchten - Oma kommt runter, sofort kann man's nich mehr kucken. Kommt man aber hingegen nach oben und die wolln was sehen: Sofort 'psssst!', Finger auf den Mund, zack. Ist ganz wichtig, nichts sagen und dann kann man sofort wieder abhaun."

In Ninas Beschreibung deutet sich an, daß Irmgard sich das Recht nimmt, die anderen zu stören, ggf. sogar durch 'Handgreiflichkeiten' („Dann schubst se dich an und sacht 'hey, ich, jetz sach ich was, ich bin grade reingekommen"), aber nicht duldet, selbst gestört zu werden. Die Information, die sich auf das Fernsehen bezieht, ist hier sehr aufschlußreich: „Kommt man aber hingegen hoch“, begibt sich also in die Wohnung von Irmgard und Otto, ist es nicht einmal möglich, sein Anliegen in irgendeiner Form zu äußern („,pssst!, Finger auf den Mund zack").

Hier könnte es interessant sein, sich noch einmal an die ganz zu Anfang des Transkriptes „Nähen 1“ entworfene Lesart zu erinnern, welche die Adressierung Mariettas und die folgende Frage nach dem Aufbewahrungsort für das Kleid reflektierte. Meines Erachtens konnten diese Sequenzen, da sie in einem privaten, nicht-institutionalisierten Rahmen stattfinden, noch legitimiert und als kurze Störung toleriert werden. Sie allein müssen noch nicht unbedingt Irmgards selbstzugeschriebene höhere Position in der Familienhierarchie spiegeln. Die Art der Situation ist in der beschriebenen Fernseh-Szene ähnlich und eine kurze Störung müßte auch dort akzeptabel sein. Jedoch erklärt Nina, daß es Familienmitgliedern nicht einmal möglich ist, ein Anliegen zu formulieren („Sofort psssst!“), solange Irmgard fernsieht. Dies gilt aber nicht nur im Fernsehkontext, sondern wird von ihrem Schwiegersohn bezogen auf andere Gespräche verallgemeinert: „Wenn sie [Irmgard] sich unterhält und du kommst denn sacht se: 'Stör ma nich'."

Diese Interviewsequenzen deuten an, daß es eine ungleiche Machtverteilung gibt zwischen Irmgard, die bestimmte Rechte hat und ausnutzt, und den übrigen, die gleiche Rechte Irmgard gegenüber nicht beanspruchen können (Enkelin: „Ich hab das mal gemacht. Ich bin mal in ihr Gespräch reingeplatzt und hab mich da so einfach reingedrängt. Da hab ich aber von ihr [Irmgard] voll einen auf den Deckel gekriegt."). Das im Interview erkennbare Fremdbild zeigt Irmgards hohen Kommunika- 
tionsstatus, der recht starr und unerschütterlich scheint sowie das deutlich subalterne Verhalten der anderen, das darauf bezogen ist.

Deutlich wird hier eine Diskrepanz zwischen dem im Interview geschilderten Kommunikationsverhalten und dem zuvor mit Hilfe verschiedener Transkriptausschnitte erarbeiteten Kommunikationsstatus der Familienältesten. Letzterer ist flexibler und wird in einem Prozeß ausgehandelt. Er impliziert zwei komplettierende Perspektiven, nämlich Irmgards Verhalten bezogen auf die anderen und das Verhalten der anderen bezogen auf Irmgard.

Aus dem Interview geht aber nicht nur hervor, welche Rechte sich Irmgard nimmt, welche Rechte demgegenüber andere Familienmitglieder haben und in welchen Situationen es zu der beschriebenen Kommunikationsform 'Hereinplatzen in ein Gespräch' kommt, sondern auch, wie die anderen Familienmitglieder darauf reagieren bzw. damit umgehen.

Eine Möglichkeit, die beispielhaft zitiert wird, ist, mit anderen Betroffenen in Abwesenheit der Familienältesten über ihr störendes Verhalten zu reden: „Fandst $D u$ das nicht auch wieder unmöglich von Mutti [Irmgard], wir unterhalten uns, sie kommt einfach rein und erzählt was von ihrem Vanillepudding oder sowas". Zwei Aspekte werden hier deutlich. Zum einen wird eine negative Bewertung des Verhaltens vorgenommen (unmöglich), zum anderen wird Irmgards Thema (Vanillepudding oder sowas) bezüglich seiner Relevanz rückgestuft. Auch in der Analyse des Transkriptes konnte durch das Verhalten der Angesprochenen gezeigt werden, wie unattraktiv beispielsweise das Thema „Nähen“ im Vergleich zur Urlaubsplanung war.

Desweiteren gibt das Interview Aufschlüsse über den Umgang der Familienangehörigen mit der aktuellen Störungssituation: „Ich schweige, damit wir keinen Ärger kriegen. Ich sach nichts dazu" (Interview Schwiegersohn). Auf meine Nachfrage, wie sich die anderen verhalten, wurde erläutert: „Die schweigen. Die sind so erzogen zu schweigen" (Interview Schwiegersohn). So können mit dieser Interviewäußerung ebenfalls Parallelen gezogen werden zu dem, was direkt an dem transkribierten Gespräch beobachtbar war, nämlich daß niemand die Störung verbal thematisierte bzw. bewertete. Interessant ist die Begründung, die Familienmitglieder seien zum Schweigen erzogen. Damit wird Irmgard als eine Person dargestellt, die selbst dafür gesorgt hat, ${ }^{16}$ daß ihr Verhalten kritik- und kommentarlos hingenommen wird.

Verstöße gegen das von Irmgard auferlegte Verhalten werden sanktioniert. Davon zeugen Formulierungen, wie beispielsweise „dann wird se sauer", „damit wir keinen Ärger kriegen“, „von ihr voll einen auf den Deckel kriegen“, „das traut sich keiner". Die Familienälteste wird als sehr mächtig und dominant dargestellt. Alle anderen fügen sich ihren Wünschen und bemühen sich darum, Irmgards Mißfallen nicht auf sich zu lenken. Die Konsequenzen, die sich aus Verhaltensweisen ergeben, welche nicht mit Irmgards Wünschen konform gehen, werden im folgenden aufgeführt:

Tochter: „Jeder weiß, wie beleidigt sie dann is und weil sie ja immer so viel für alle tut, hat niemand den Mut, sie zu beleidigen."

Schwiegersohn: "Und beleidigt sein, wenn sie beleidigt is, dann bedeutet das, denn bist du in der Verwandtschaft durch. Dann beschwert sie sich bei jedem über dich und das will keiner in Kauf nehmen."

16 Als Familiengründerin hat Irmgard auf jeden Fall die zweite Generation direkt erzogen. Aber ihr Einfluß wirkt weit bis in die vierte Generation, da sie sich oft als Expertin in Sachen Erziehung darstellt und oft Tips, Ratschläge usw. gibt, die auch angenommen werden. Darüber hinaus hat sie auch fast täglich Kontakt zu allen, selbst zu den Allerjüngsten. 
Enkelin: „Hält sie einem dann vor, was sie schon jahrelang, hat sie alles noch im Kopf, was sie überhaupt schon alles für dich getan hat. Und dann kriegt man so 'n schlechtes Gewissen und so."

Diese Aussagen bereichern die oben durchgeführte Interpretation. Denn ergänzend zu den herausgearbeiteten Verhaltensmechanismen in der konkreten Situation, erfährt man nun die Begründungen und die Wichtigkeit der Umgehensweise mit Irmgard. In erster Linie liegen die Ursachen in einer Abhängigkeitsbeziehung: Irmgard ist eine sehr hilfsbereite, wohltätige und zuvorkommende Person. Alle Familienangehörigen nehmen ihre Hilfeleistungen oft und gerne in Anspruch. Dies funktioniert aber nur, solange sie ein entspanntes und gutes Verhältnis zur Oma haben. Irmgard hält durch ihre freigiebige Art große Macht in ihren Händen: 'Funktioniert' die Familie nach ihrem Dafürhalten, wird sie durch Leistungen und Annehmlichkeiten belohnt, widersetzt sie sich, werden alle Vorteile, die man durch Irmgard erhalten könnte, zurückgezogen. Desweiteren dienen ihre freiwilligen Wohltätigkeiten auch der Erzeugung psychischen Drucks (schlechtes Gewissen; Interview Nina).

Eine wesentlich härtere Sanktion liegt aber in Irmgards Möglichkeiten, sich bei allen anderen über jemanden zu beschweren (Interview Schwiegersohn). In ihrer Funktion als „Schaltzentrale“, die für die Verbreitung von Neuigkeiten zuständig ist, liegt es an ihr, Stimmungen und Meinungen weiterzuvermitteln. So ist jedem daran gelegen, möglichst in ihrer Gunst zu stehen, fast wie bei einem Politiker, für dessen Vorankommen positive Medienberichte förderlich sind. Irmgards Beschwerde in der ganzen Familie hätte wesentliche Nachteile für den Betroffenen. In einem so eng verwobenen Familienkontext, in dem man nahezu täglich mit fast allen Angehörigen zu tun hat, ist ein schlechtes Dastehen oder angespanntes Verhältnis zu den anderen zermürbend und frustrierend.

Die kommunikativen Mechanismen, die in der Transkriptanalyse herausgearbeitet wurden, können eine Möglichkeit sein, eigene Interessen zu wahren und gleichzeitig innerhalb von Irmgards 'Norm' zu agieren. Sie sind ein Kompromiß, der in der aktuellen Störungssituation möglicherweise unbefriedigend für die einzelnen sein kann, jedoch auf Dauer ein konflikt- und sorgenfreieres Leben in der Großfamilie ermöglicht.

Ein Punkt, in dem man die Ergebnisse der analysierten Gesprächssequenzen mit den Interviewaussagen direkt kontrastieren kann, liegt in der konkreten Art und Weise, mit Irmgards Störungen umzugehen. Ihre Enkelin Nina berichtet über eine Situation, in der Irmgard das Zimmer betreten hat, während Nina selbst in einem Gespräch den floor hatte: "Ich hab schon mal einfach weitergeredet und zwar schon mehrfach. Aber bei mir, mich packt se dann jedes Mal an 'Hey, mal Ruhe hier, ich bin reingekommen, ich wollt was sagen, deine Großmutter wollt was sagen". Das Ignorieren der Familienältesten veranlaßt die Oma auf distanzlose und direkte Weise ihre Interessen durchzusetzen und ihre Enkelin zu unterbrechen. Meines Erachtens hat dies auch erzieherische Qualität. Irmgard macht Nina sehr deutlich darauf aufmerksam, daß ihre Erwartungen, man müsse sich sofort auf sie konzentrieren, sobald sie den Raum betritt, nicht erfüllt wurden. ${ }^{17}$

17 Daß Irmgard im Zitat nicht nur zweimal mit ich auf sich verweist, sondern im dritten Schritt auch die typisierende Bezeichnung Großmutter verwendet, verweist deutlich auf die superiore Position, die sie sich selbst zuschreibt. 
Die Möglichkeit, einfach weiter zu reden und Irmgard zu ignorieren, erwähnt auch ihr Schwiegersohn Hannes. Für ihn ist sie aber mit anderen Konsequenzen verbunden, als für die Enkelin: „Das mach ich immer. Ich rede durch, aber du hast keine Chance. Wenn du weiter sprichst, dann gelingt es ihr [Irmgard] einfach, deinen Gesprächspartner so abzulenken, daß er gezwungen wird, ihr zu zuhören und nicht mehr dir. Indem sie einfach weiter spricht und einen anfaßt oder was zeigt oder 'riech mal', oder 'schmeck mal', 'guck mal'."

Bei Hannes wählt die Familienälteste nicht den direkten Weg der Zurechtweisung, sondern die Ablenkung der Gesprächspartner. ${ }^{18}$ Offensichtlich sind ihre Erziehungsmöglichkeiten nicht bei allen Familienmitgliedern gleich. Ihre Enkelin kann sie direkter zurechtweisen als ihren Schwiegersohn. Jedoch verweist allein die Tatsache, daß sie in irgendeiner Form ihr 'Recht', Gespräche zu dominieren, in allen Situationen ausdrückt, auch darauf, daß sie es sich - unabhängig von der Personenkonstellation - generell zuschreibt.

\section{Fazit}

Die unterschiedlichen Datenquellen, die Grundlage dieser Arbeit sind, haben dazu beigetragen, ein differenziertes Bild von Irmgards interaktivem Status unter Berücksichtigung von Fremd- und Selbstdarstellungen zu liefern. Interessant ist vor allem, daß aus den verschiedenen Materialtypen teilweise widersprüchliche Informationen hervorgehen.

Die transkribierten Geburtstagsgespräche weisen auf eine wechselseitige Dynamik der Interaktanten und Schwankungen in Irmgards Interaktionsstatus hin, die Einzel- und Gruppeninterviews beschreiben inn als starr, gleichbleibend hoch und als fixen Orientierungspunkt für das Handeln der Familienmitglieder. Dies ist ein interessanter Befund, der zwar beschreibbar, aber - zumindest im Rahmen dieses Beitrags - nicht unbedingt erklärbar ist. Eine interessante Hypothese könnte m.E. jedoch sein, daß sich die Interviewten ihres flexiblen interaktiven Umgangs mit der Familienältesten nicht 'bewußt' sind. Vielmehr scheint innen lediglich das dominante verbale Verhalten präsent, das sie nicht hinterfragen oder anzweifeln, vielleicht weil es 'schon immer so war' und das Bild der 'dominanten Oma' regelrecht tradiert wurde. Dies würde erklären, weshalb sich niemand aktiv gegen Irmgards ignorantes Kommunikationsverhalten zur Wehr setzt. Da die Familienälteste mit Hilfe ihrer Verhaltensweisen klassische Hierarchieformen transportiert, die niemand zu hinterfragen wagt, kann sie ihre superiore Stellung regelrecht konservieren.

Doch neben den herausgearbeiteten Diskrepanzen der Ergebnisse aus den Interviews und den transkribierten Geburtstagsgesprächen scheint mir ein letzter Punkt wichtig: Während die Darstellung des interaktiven Status materialabhängige Nuancierungen aufwies, scheint der 'allgemeine' Status Irmgards in der Familienhierarchie unveränderbar. Typisierungen wie Schaltzentrale, Autoritätsperson usw. weisen auf eine unbestritten hohe Machtposition hin. Diese wird sowohl von den Familienmitgliedern im Interview als auch von Irmgard selbst in ihrer kurzen Reflexion über ihre eigene Wichtigkeit für die Existenz der Großfamilie verdeutlicht (vgl. Abschnitt 2). Mit diesem Befund korrespondieren auch die ethnographischen Beob-

18 Auch Mariettas Aufmerksamkeit wurde zu Beginn des Transkriptausschnittes „Nähen 1“ durch die Aufforderung guck mal jetz auf das Kleid und die Oma gelenkt. 
achtungen im Feld, beispielsweise wenn sie ihre Kontrollfunktion auf Geburtstagen ausübt, indem sie als erste den Schauplatz betritt und als letzte wieder verläßt.

Daraus wird deutlich, daß von ihrer Person für die Großfamilie sehr viel abhängt. Schließlich hat sie die Familie jahrzehntelang geführt bzw. organisiert und zwar ausnahmslos straff und mit festverankerten Strukturen, in die regelmäßige Treffen und enge Bindungen, die von allen Angehörigen mitgetragen werden, fraglos eingebaut sind. Sie hat als älteste Person des Verbandes die familiäre Macht inne, besetzt die relevanten Koordinations- und Kontrollpositionen und hält darüber hinaus immer noch, bis in die vierte Generation, die Fäden der Erziehung in der Hand. Im familiären Kontext ist die Familienälteste omnipräsent.

Eine solche Machtverteilung entspricht heutzutage sicher nicht mehr dem Regelfall, sondern ist eher als Ausnahme zu charakterisieren, die eng mit den spezifischen großfamiliären Lebensbedingungen verbunden ist. Verantwortlich für die langjährige Existenz und das Fortbestehen dieser klassisch-matriarchalen Familienform sind u.U. ein bestimmtes Bewußtsein, in dem verwandtschaftliche Bindungen und emotionale Beziehungen eine große Rolle spielen. Auch könnten Faktoren der Lebensorganisation von Bedeutung sein, denn das Fortführen tradierter und bewährter Konzepte alltäglicher Problemlösungen bietet den einzelnen Sicherheit und Erleichterung. Desweiteren sorgt möglicherweise auch die räumliche Konzentration auf ein bestimmtes örtliches Gebiet durch die vielen Kontakte für Zusammenschluß und Konservierung bestimmter Lebensformen. Beeinflussung durch außerfamiliäre Freundschaften bilden eher die Ausnahme und somit bleiben alle auf die Familie konzentriert. Neue Impulse, die zu einer Strukturveränderung führen könnten, sind zumindest bislang - nahezu ausgeschlossen.

\section{Literatur}

Brown, Penelope \& Levinson, Stephen (1978). Politeness. Some universals in language usage. London/New York.

Fiehler, Reinhard (1997). Kommunikation im Alter und ihre sprachwissenschaftliche Analyse. Gibt es einen Kommunikationsstil des Alters? In: Selting, Margret \& Sandig, Barbara (Hrsg.), Sprechund Gesprächsstile. Berlin/New York, 345-370.

Goffman, Erving (1971). Interaktionsrituale. Über Verhalten in direkter Kommunikation. Frankfurt a.M.

Heidtmann, Daniela (1997). Kommunikation in einer Großfamilie. Magisterarbeit. Mannheim.

Hildenbrand, Bruno, Bohler, Karl Friedrich, Jahn, Walter \& Schmitt, Reinhold (1992). Bauernfamilien im Modernisierungsprozeß. Frankfurt/New York.

Kallmeyer, Werner (1988). Konversationsanalytische Beschreibung. In: Ammon, U., Dittmar, N. \& Mattheier, K. J. (Hrsg.), Soziolinguistik. Ein internationales Handbuch zur Wissenschaft von Sprache und Gesellschaft. 2. Halbband. Berlin/New York, 1095-1108.

Kallmeyer, Werner (1995). Ethnographie städtischen Lebens. Zur Einführung in die Stadtteilbeschreibungen. In: Kallmeyer, Werner (Hrsg.), Kommunikation in der Stadt. Ethnographien von Mannheimer Stadtteilen. Berlin/New York.

Spradley, James P. (1979). The ethnographic interview. New York.

Spradley, James P. (1980). Participant observation. New York.

Watts, Richard J. (1991). Power in family discourse. New York. 


\section{Anhang}

\section{Transkriptionskonventionen}

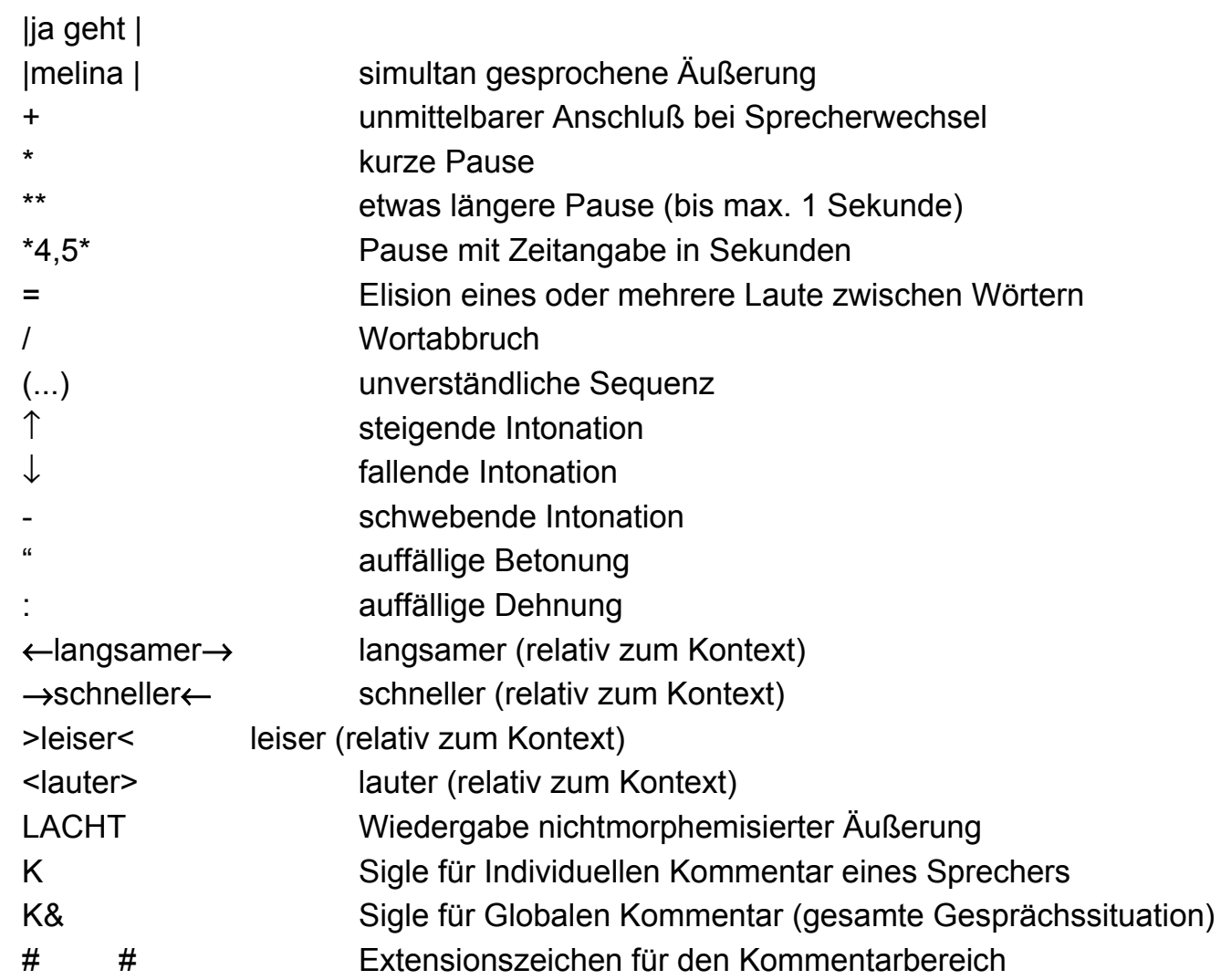




\title{
Der Einfluß von Altersstereotypen auf sprachliche Instruktionen
}

\author{
Stefanie Maier
}

\section{Einleitung: Theoretische Schwerpunkte}

Einstellungen und Meinungen über Andere bestimmen im alltäglichen Leben ganz wesentlich unsere Art und Weise des (sprachlichen) Umgangs mit Menschen. So führen beispielsweise negative Einstellungen zu Ausländern zu ausländerfeindlichem, diskriminierendem Verhalten dieser sozialen Gruppe gegenüber. In gleicher Weise, nur häufig wesentlich subtiler, wirken sich Einstellungen und Meinungen über ältere Menschen auf die Interaktion und Kommunikation mit innen aus. Diese Altersstereotypen standen inhaltlich im Mittelpunkt der hier berichteten Untersuchung, die im Projekt „Partnerhypothesen und Soziale Identität in Konversationen“ des Sonderforschungsbereichs "Sprache und Situation“ der Universitäten Heidelberg und Mannheim entstanden ist. Sie beschäftigt sich mit der Frage, wie spezifische Erwartungen über unsere GesprächspartnerInnen - sogenannte Partnerhypothesen - die sprachliche Interaktion mit diesen beeinflussen.

Die Beschäftigung mit Altersstereotypen wurde zum einen vor dem gesellschaftlichen Hintergrund der immer größer werdenden Gruppe älterer Menschen als auch aufgrund der wenigen Untersuchungen im deutschsprachigen Raum zu diesem Thema gewählt. Gerade die mit den Einstellungen gegenüber Älteren bzw. der mit der Partnerhypothese „alt“ verbundenen negativen Erwartungen bezüglich der Kompetenz und Leistungsfähigkeit älterer Menschen und deren sprachlicher Auswirkungen prägen das Selbstbild Älterer und auch das der Älteren in unserer Gesellschaft allgemein ganz wesentlich.

In der hier berichteten Untersuchung standen neben der Partnerhypothese „alt“ auch Annahmen über die „technische Kompetenz bzw. Inkompetenz“ im Mittelpunkt des Forschungsinteresses. Diese zusätzliche Eigenschaft wurde ausgewählt, um sowohl eine "typische“ Situation Älterer, im Sinne des negativen Stereotyps zu schaffen aber auch eine „untypische“, die den Erwartungen des Altersstereotyps widerspricht.

Untersucht wurde in einer experimentellen Versuchsanordnung, wie die Vorgabe dieser Partnerhypothesen sich auf die mündliche Instruktion für ein technisches Gerät auswirken. Hierfür wurden 60 männliche und weibliche Versuchspersonen gebeten, einer Zielperson, über die in Form einer Instruktion vier unterschiedliche Partnerhypothesen gebildet worden waren, spezifische Funktionen eines Radioweckers zu erklären.

Für die Klärung des theoretischen Hintergrundes können zwei Teilbereiche der Psychologie und Linguistik herangezogen werden:

- Sozialpsychologische Aspekte der Stereotypisierung und kategorialen Behandlung

- Allgemeinpsychologische und sprachliche Merkmale von Instruktionen 


\section{Sozialpsychologisches Verständnis von Stereotypen}

Bedeutsames Merkmal des Stereotypisierungsprozesses ist, daß eine Person lediglich aufgrund ihrer Zugehörigkeit zu einer spezifischen sozialen Kategorie (z.B. Geschlecht, Hautfarbe, Berufsgruppe oder Alter) und deren (vermeintlichen) Charakteristika und nicht als Individuum wahrgenommen und beurteilt wird. Dabei geht man davon aus, daß dieses Stereotyp durch Lernerfahrung erworben wurde. Es hat vereinfachende und übergeneralisierende Funktion und dient damit dem rationellen Wissensmanagement, um schnelle (Grob-)Entscheidungen zu ermöglichen. Aufgrund ihrer langen Entstehungsgeschichte und zunächst unausweichlichen kognitiven Aktivierung sind Stereotypen gegenüber Änderungen sehr resistent.

In der kognitiven Sozialpsychologie werden Stereotypen als mentale Repräsentationen verstanden, die in einem semantischen (kognitiven) Netzwerk vorliegen. Der Prozeß der Stereotypisierung umfaßt dabei die folgenden drei Komponenten, die entsprechend ihrer Chronologie beschrieben werden:

Die automatische Komponente

Sie umfaßt den Aspekt des Stereotypisierungsprozesses, der durch die bloße Wahrnehmung eines gruppenspezifischen Merkmals, wie z.B. graue Haare für die soziale Kategorie älterer Menschen, zur automatischen kognitiven Aktivierung damit assoziierter weiterer Eigenschaften älterer Menschen (z.B. krank, schwerhörig, etc.) führt. Das Entscheidende dabei ist, daß diese Assoziationen unbewußt und unwillkürlich ablaufen und abhängig von Sozialisation und Lernerfahrung des jeweiligen Individuums sind.

Diese automatische Aktivierung eines Stereotyps ist die Voraussetzung dafür, daß der Prozeß die weiteren beiden Komponenten durchlaufen kann.

\section{Die kontrollierte Komponente}

Erst in einem weiteren Schritt ist das bereits aktivierte Stereotyp für kontrollierte kognitive Prozesse zugänglich, wie z.B. das Ablehnen der meist negativen Assoziationen oder andere Effekte sozialer Erwünschtheit (d.h. Reaktionstendenzen im gesellschaftlich erwarteten Sinne, obwohl sie den eigenen Einstellungen widersprechen). Dieser Aspekt kann als „Vorurteil“ bezeichnet werden, da hier die normativen und auch individuellen Bewertungen des jeweiligen Stereotyps hinzukommen.

Bedeutsam für diese Prozeßkomponente ist, daß diese aktiven Bewertungsvorgänge nur dann einsetzen können, wenn genügend Zeit zur Verfügung steht und nicht unter Zeitdruck reagiert werden muß. Aktive kognitive Prozesse benötigen mehr Zeit als die automatische Aktivierung der ersten Komponente.

\section{Die behaviorale Komponente}

Im weiteren kann dieser Prozeß der „Stereotypaktivierung“ in spezifisches Verhalten gegenüber Mitgliedern der jeweiligen sozialen Gruppe münden. Die behaviorale Komponente des Stereotypisierens wird als kategoriale Behandlung oder, bei entsprechend negativem Verhalten auch als Diskriminierung bezeichnet. 


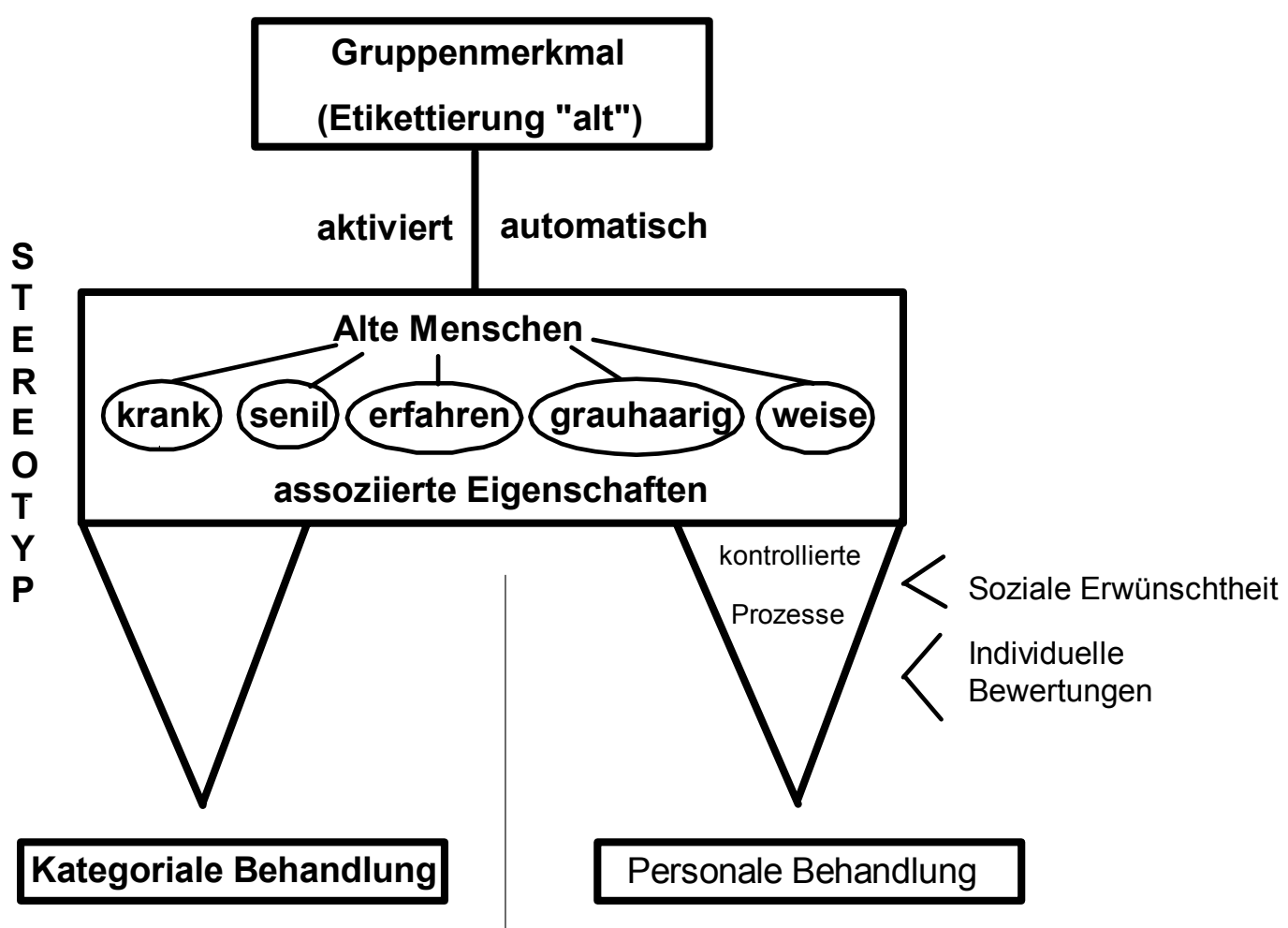

Abb. 1: Prozeßmodell sozialer Kategorisierung

Die dritte, behaviorale Komponente kann sich nun in unterschiedlicher Art und Weise äußern. Nicht immer ist explizites diskriminierendes Verhalten, wie z.B. bei der Fremdenfeindlichkeit der Ausdruck des aktivierten Stereotyps. Vielmehr finden sich im Alltag wesentlich subtilere Formen des „stereotyp-geleiteten“ Handelns gegenüber Mitgliedern unterschiedlicher sozialer Kategorien. Für das hier berichtete Experiment interessierten die sprachlichen Konsequenzen des aktivierten Stereotyps über die technische Kompetenz älterer Menschen.

\section{Abgrenzung des sozialpsychologischen zum linguistischen Verständnis des Stereotyp-Begriffs}

In der Linguistik findet der Begriff „Stereotyp“ seine häufigste Verwendung im Zusammenhang mit Einstellungen gegenüber Sprache bzw. Sprechern, die anhand spezifischer Sprachstile identifiziert werden können, und wird zumeist unter dem Begriff der Spracheinstellung untersucht. Sprache wird hier als wesentlicher Vermittler von Gruppenidentität verstanden. Der vorige Abschnitt beschreibt das, was Gülich (1978) als „Denkstereotyp“ bezeichnet. Dieses ist abzugrenzen vom „Sprechstereotyp“, das neben pragmatischen Idiomen, die an spezifische Typen von Kommunikationssituationen gebunden sind, vor allem formelhaften Gebrauch von Sprache meint, wie beispielsweise in Allgemeinplätzen oder Redewendungen.

Gegenstand der hier beschriebenen Untersuchung ist die Abbildung des aktivierten „Denk“ -Stereotyps an der sprachlichen Oberfläche, d.h. die Analyse sprachlicher Indikatoren als Folge der Aktivierung des Stereotyps über „Alter und technische Kompetenz". Dies heißt jedoch nicht, daß das Stereotyp tatsächlich auch im- 
mer explizit sprachlich geäußert wird. Vielmehr zeigen viele empirische Befunde, daß Stereotypen gegenüber spezifischen sozialen Kategorien, so auch älteren Menschen, eher implizit zum Ausdruck kommen.

Ein Ziel der Untersuchung war es daher, einen sensiblen Kontext zu schaffen, der die Analyse auch feiner sprachlicher Nuancen des Ausdruckes von Stereotypen und Vorurteilen zuläßt.

\section{Alter und technische (In-)Kompetenz}

Das Stereotyp über den Zusammenhang von Alter und geringer technischer Kompetenz schien besonders zur Untersuchung stereotypgeleiteten Sprechens geeignet. Trotz vieler neuer Forschungsergebnisse, die eindeutige Belege für unterschiedlichste Kompetenzen im Alter liefern (vgl. Lehr 1989; Baltes \& Baltes 1989), halten sich negative Vorurteile und Stereotypen dennoch hartnäckig in unserer Gesellschaft.

Neben den vermeintlichen körperlichen Defiziten herrschen häufig auch Erwartungen über kognitive und intellektuelle Defizite in den Vorstellungen über die Kompetenz älterer Menschen vor. Insbesondere im Bereich des Umgangs mit und der Einstellung Älterer zu neueren Techniken finden sich diese Vorstellungen ausgeprägt (Maier, Wagner \& Rademacher 1996). So wird beispielsweise ein Fotoapparat als handhabbar für jüngere Menschen, nicht jedoch für ältere eingeschätzt. In zahlreich erarbeiteten Vorschlägen, wie der technische Fortschritt ins Alltagsleben der älteren Erwachsenen integriert werden könnte, kommen die stark eingeschränkten, von Abbau und Defizit geprägten Vorstellungen über den Alternsprozeß und das Älterwerden zum Ausdruck (vgl. Ramm \& Gianturco 1973). Kerschner und Hart (1984) und Krauss und Hoyer (1983) konnten zeigen, daß sowohl die positive Einstellung gegenüber neuen Technologien als auch deren Gebrauch mit steigendem Alter abnimmt. Wobei hier soziokulturelle Faktoren wie Geschlecht, Schulbildung und Wohnort als Differenzierungsmerkmal angesehen werden müssen.

Für das im Folgenden beschriebene Experiment „Radiowecker“ wurden daher die beiden Partnerhypothesen „alt und technisch inkompetent“ bzw. „alt und technisch kompetent" für die experimentelle Manipulation verwendet. Die erste ist dabei konsistent mit dem herrschenden Stereotyp bzw. Vorurteil und läßt entsprechend eine stereotypgeleitete Form verbaler Interaktion erwarten. Die zweite Partnerhypothese widerspricht diesem Stereotyp indem sie das Gegenteil beschreibt, nämlich den kompetenten Umgang mit einem technischen Gerät und damit eine inkonsistente Personenbeschreibung vermittelt. Ziel diese Vorgehens war es zu überprüfen, inwieweit inkonsistente Informationen, die den ursprünglichen Erwartungen widersprechen, einen Einfluß auf den verbalen Umgang mit der betreffenden Person haben und in welchen sprachlichen Einheiten sie sich dann äußern.

\section{HörerInnen-Orientierung in Instruktionen}

Um die sehr subtilen sprachlichen Ausdrucksformen des aktivierten Stereotyps über alte Menschen und deren technische Kompetenz erfassen zu können, wurde eine Textsorte gewählt, die als sensibel für Effekte kategorialer Behandlung gilt: die Instruktion oder Anweisung (vgl. Speck 1993). 
Der Begriff der Instruktion beschreibt die sprachliche Vermittlung von (technischem) Wissen, die sowohl mündlich als auch schriftlich geschehen kann. Hierbei unterrichtet eine Person (Experte) eine andere (Novize) mit dem Ziel, daß diese beispielsweise ein technisches Gerät selbständig bedienen kann. Das dabei zu vermittelnde Wissen kann in drei Bereich eingeteilt werden (vgl. Wintermantel \& Laier 1994), die in eine Instruktion in Abhängigkeit von der jeweiligen Partnerorientierung (i.e. Hörerrepräsentation; Herrmann 1985) gewichtet eingehen (vgl. Abb. 2):

Theoretischer Anteil

Dieser Teil umfaßt auf einer kognitiv abstrakteren Ebene Erklärungen: Was geschieht bei den jeweiligen technischen Abläufen und warum?

\section{Instrumenteller Anteil}

Dieser beschreibt den zu instruierenden Sachverhalt und wird im weiteren mit dem Begriff der Objektreferenz bezeichnet: Welche Werkzeuge bzw. welche Teile des Gerätes sind notwendig für den sachgemäßen Ablauf des Verfahrens?

Hier kommt der kommunikativen Aufgabe des Sprechers, die durch den jeweiligen Kontext der Interaktion mitbestimmt wird, eine wesentliche Rolle zu. Die kommunikative Zielsetzung, mit der ein Text produziert wird, wirkt sich auf die Wahl der Objektbenennungen im Diskurs aus (vgl. Koelbing, Mangold-Allwinn, Baratelli, Kohlmann \& von Stutterheim 1994). Bei einer Instruktion wie in der hier vorliegenden Untersuchung, ist es für den Hörer bedeutsam, das benannte Objekt eindeutig unter diversen anderen identifizieren zu können. D.h. die Instruktion muß sprachlich so formuliert sein, daß der Hörer das jeweilige Objekt eindeutig von möglichen Alternativobjekten unterscheiden kann. Dies gilt besonders dann, wenn wie in dieser Untersuchung realisiert der Instruktionskontext so gestaltet ist, daß der Partner der Instruktion nicht anwesend ist und daher durch Rückfragen keine weiteren Objektspezifikationen durch den Sprecher initiieren kann (siehe Abschnitt 6.2).

\section{Praktischer Anteil}

Dieser Anteil beschreibt die zur Bedienung des technischen Gerätes notwendigen Handlungsschritte, d.h. die Handlungsreferenz einer Instruktion: Was muß man tun, um das Verfahren sachgerecht durchzuführen?

Grundsätzlich gilt, daß dasselbe Wissen in unterschiedlicher Weise in einer Instruktion dargestellt werden kann. Diese ist stark abhängig von den Bedingungen der jeweiligen Instruktionssituation. Die DIN-Norm für technische Erzeugnisse (1974) sieht sogar explizit vor, daß Bedienungsanleitungen ihre Zielgruppe jeweils flexibel berücksichtigen. Es sollten „Form und Ausführlichkeit [der Bedienungsanleitung] auf die Eigenart des Erzeugnisses und die voraussetzbare Sachkunde des Verwenders [Parnterhypothese] abgestimmt sein“ (DIN 8418; 1974, 234, Ergänzungen durch die Autorin).

Dies zeigt auch eine Reihe sprachpsychologischer und textlinguistischer Arbeiten, die Zusammenhänge zwischen kontextueller Einbettung und beispielsweise der Produktion von Objektreferenzen bei mündlichen Instruktion aufzeigen konnten (vgl. Herrmann 1985; im Überblick Herrmann \& Grabowski 1994; Ariel 1990). Zu den Bedingungen einer Instruktionssituation zählt jedoch neben Merkmalen des perzeptuellen Kontextes, in den das zu erklärende Objekt eingebettet ist, als wesentlicher Faktor die jeweilige Zielperson der Instruktion und deren Einschätzung durch den Instruierenden, d.h. also dessen Erwartungen und Annahmen - kurz: Partnerhypo- 
thesen - über sie. Diese Partnerhypothesen beeinflussen an spezifischen Punkten die Sprachproduktion im Rahmen einer Instruktion und führen damit zu partnerhypothesen- bzw. stereotypgeleitetem Sprechen. Im folgenden Abschnitt ist ein Sprachproduktionsmodell dargestellt, das den Einfluß von Partnerhypothesen bei Instruktionen näher erläutert.

\subsection{Instruktionen im Rahmen eines Sprachproduktionsmodells}

Gängige Sprachproduktionsmodelle (Herrmann 1985; Herrmann \& Hoppe-Graff 1988) unterscheiden drei Prozeßstufen der Sprachproduktion, die im Rahmen einer Instruktion oder Anleitung relevant sind:

- Wissensaktualisierung: Fokussierung und (kognitive) Aktivierung des Wissens über den zu instruierenden Sachverhalt;

- Selektion und Linearisierung: Auswahl spezifischer Sachverhaltsmerkmale und deren Translation in eine für sinnvoll erachtete Reihenfolge;

- Verbale Enkodierung: Sprachliche Realisierung.

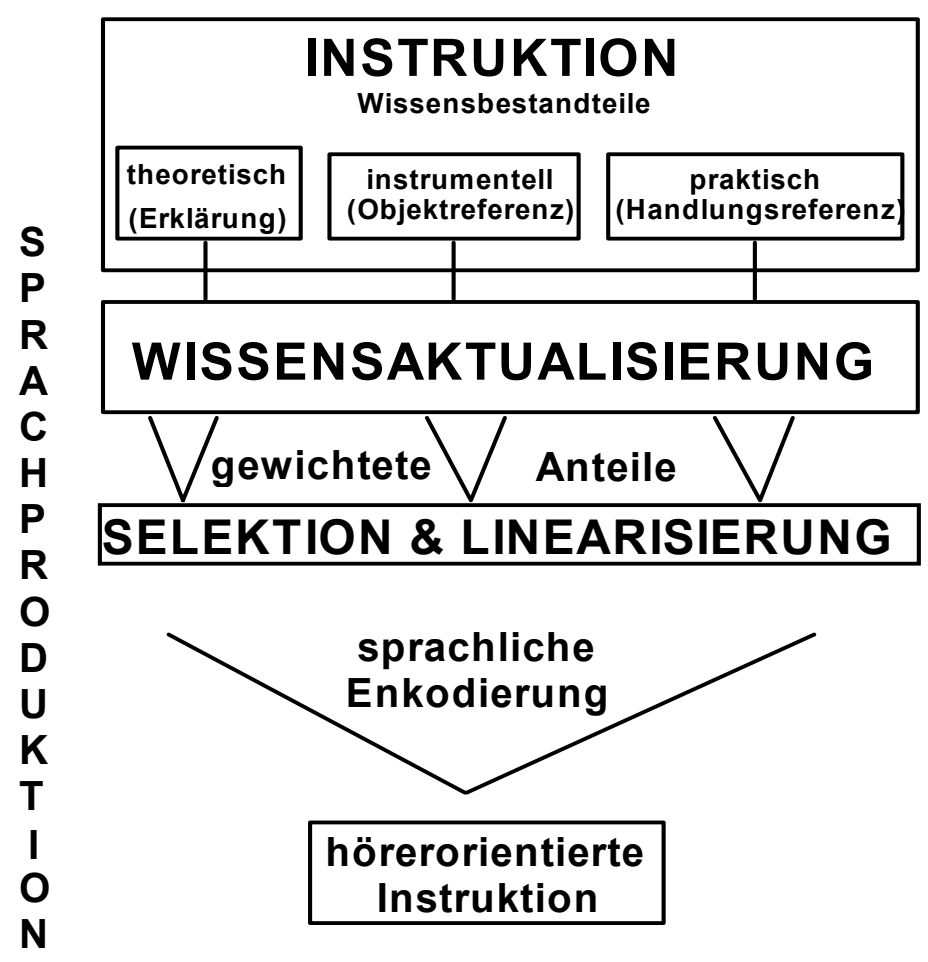

Abb. 2: Instruktionen im Rahmen eines Sprachproduktionsmodells (vgl. Wintermantel \& Laier 1994)

Dabei wird angenommen, daß die Produktion sprachlicher Instruktionen nicht das Resultat des bloßen Abrufs und der "automatisierten“ Versprachlichung von bereitliegendem Wissen ist, sondern daß im Zuge der Konzeptualisierung und der Enkodierung kontextorientierte Such- und Auswahlprozesse stattfinden, die wiederum an 
den Bedingungen der Sprechsituation bzw. dem jeweiligen Interaktionspartnern orientiert sind. An diesem Punkt der Sprachproduktion wird also erwartet, daß spezifische Partnereigenschaften oder -erwartungen, wie sie auch in Stereotypen und Vorurteilen repräsentiert sind, Einfluß auf die Art und Weise und den Verlauf der Kommunikation nehmen. Dies bildet den Ansatzpunkt der experimentellen Manipulation der im folgenden Abschnitt beschriebenen Untersuchung innerhalb des Sprachproduktionsprozesses.

\section{Das Experiment „Radiowecker“}

Zur Auswahl eines geeigneten technischen Gerätes wurden zunächst in einer Voruntersuchung unterschiedliche technische Geräte bezüglich ihrer Handhabbarkeit für ältere Menschen evaluiert (Maier et al. 1996). Dabei erwies sich der Radiowecker als geeignet, da seine funktionsgerechte Bedienung einen mittleren Schwierigkeitsgrad aufweist und damit gute Differenzierungsmöglichkeiten der sozialen Kategorien älterer und jüngerer Menschen hinsichtlich ihrer technischen Kompetenz bietet.

\subsection{Soziale Kategorisierung als unabhängige Variable: Die Partnerhypothese „alt"}

Im Experiment „Radiowecker" wurden vier verschiedene Partnerhypothesen in Form von Personenbeschreibungen über potentielle Zielpersonen konstruiert, denen dann Funktionen eines handelsüblichen Radioweckers durch die Versuchspersonen erklärt werden sollten. Dabei war die Interaktionssituation so gewählt worden, daß den Versuchspersonen nur die jeweilige Partnerbeschreibung vorgelegt wurde, jedoch eine reale Zielperson für ihre Instruktionen nicht anwesend war. Untersuchungen zum experimentellen Faktor "Kommunikationspartner“ mit den Ausprägungen abwesend/vorgestellt und anwesend/handelnd (Koelbing et al. 1994) haben gezeigt, daß die Anwesenheit eines spezifischen Kommunikationspartners wesentlichen Einfluß auf die Form der Interaktion hat. Hier besteht für die Zielperson die Möglichkeit, eigenes Vorwissen einzubringen oder durch gezieltes Nachfragen den Inhalt der Instruktion im Gespräch zu steuern.

Ziel der vorliegenden Untersuchung war es jedoch, ausschließlich das stereotypgeleitete Sprechen der Versuchspersonen in Abhängigkeit von der jeweiligen Partnerhypothese zu analysieren. Daher wurde für das Experiment „Radiowecker“ eine Versuchsanordnung mit abwesender Zielperson gewählt. Dieses Vorgehen entspricht dem stark evaluativen Charakter der Studie. Es gilt dies im Folgenden bei der Interpretation der Ergebnisse zu beachten. Sie können nicht im Sinne von Interaktion bzw. dialogischem Sprechen verallgemeinert werden. Sie liefern jedoch erste wichtige experimentelle Hinweise darauf, ob und wenn ja wie das Altersstereotyp sich an der sprachlichen Oberfläche des Stereotyphalters ausdrückt. Ausgehend hiervon können weitere Hypothesen formuliert werden, die schlußendlich auch in „realen“ Situationen, d.h. im Dialog zweier Personen untersucht werden müssen.

\subsubsection{Operationalisierung der Partnerhypothesen}

In vier verschiedenen Partnerbeschreibungen wurden Informationen bezüglich des Alters und der technischen Kompetenz der jeweiligen Zielperson variiert, für die der 
Radiowecker erklärt werden sollte (siehe Anhang A). Aus forschungsökonomischen Gründen wurde das Geschlecht der Zielperson konstant gehalten. Beschrieben wurde jeweils eine Frau (Else Berger) mit den entsprechenden Altersangaben und Eigenschaften. Jede Partnerhypothese bildete eine experimentelle Bedingung:

\section{Partnerhypothese "alt und technisch inkompetent"}

Diese Partnerhypothese entspricht dem negativen Stereotyp über Alter und technische Kompetenz, wobei die ausführliche Beschreibung der Zielperson die jeweiligen negativen Erwartungen quasi apriori bestätigt. Es wurde erwartet, daß sich diese konfirmierten Erwartungen auch in der sprachlichen Umsetzung der Instruktion des Radioweckers im Sinne stereotypgeleiteten Sprechens nachweisen lassen.

\section{Partnerhypothese "alt und technisch kompetent"}

Diese Partnerhypothese widerspricht den negativen Erwartungen bezüglich des Zusammenhangs von Alter und technischer Kompetenz. Hier sollte der Einfluß dieser mit dem Stereotyp inkonsistenten Information über die technische Kompetenz der Zielperson im Hinblick auf stereotypgeleitetes Sprechen überprüft werden. Erwartet wurde hier im Vergleich zur ersten Partnerhypothese, daß sich weniger Indikatoren für stereotypgeleitetes Sprechen finden.

\section{Partnerhypothese ,alt"}

Bei dieser Partnerhypothese wurde die Zielperson lediglich mit einer Altersangabe (82 Jahre) beschrieben. Durch diese alleinige Altersangabe kann angenommen werden, daß das „unbeeinflußte“ Stereotyp über ältere Menschen und deren technische Kompetenz aktiviert wird. Die Art der sprachlichen Äußerungen im Rahmen der Instruktion des Radioweckers für diese Zielperson, können daher als Vergleichsbasis für die beiden oben beschriebenen Bedingungen herangezogen werden. Somit kann die Bedingung dieser Partnerhypothese als Kontrollgruppe gesehen werden.

\section{Partnerhypothese ,jung "}

Diese letzte Bedingung diente dem Vergleich zwischen den Alterskategorien alt und jung. Als Partnerhypothese wurde, analog zur Partnerhypothese „alt“, lediglich die Altersangabe der Zielperson (32 Jahre) vermittelt. Auch diese Bedingung erfüllt die Funktion einer Kontrollgruppe.

\subsection{Durchführung}

Versuchspersonen: Insgesamt nahmen 120 studentische Versuchspersonen im Alter von 23 bis 29 Jahren an der Untersuchung teil. Jeweils 15 männliche und weibliche Versuchspersonen pro Bedingung.

Die Versuchspersonen wurden zufällig, jedoch nach ihrer Geschlechtszugehörigkeit ausbalanciert, einer der vier Bedingungen zugeordnet. Ihnen wurde mitgeteilt, daß es sich um eine Untersuchung zu Verbesserungsmöglichkeiten von Gebrauchsanweisungen handle. Sie sollten Frau Berger fünf Funktionen eines Radioweckers, den sie bei einer Tombola gewonnen hatte, erklären (siehe Anhang B). Die Wahl dieser Rahmengeschichte hatte den Vorteil, daß sie nicht, wie beispielsweise beim eigeninitiativen Kauf des Radioweckers durch Frau Berger, gerichtete Erwartungen über die Motivation, und damit möglicherweise auch über die Kompetenz von Frau Berger im Umgang mit diesem Radiowecker, nahelegt. 
Zunächst konnten sich die Versuchspersonen anhand der Originalgebrauchsanweisung des Herstellers mit den fünf vorgegebenen Funktionen des Geräts vertraut machen. Nachdem sie nach eigener Einschätzung glaubten diese verstanden zu haben und auch erklären zu können, sollten sie nun die Handhabung des Gerätes für die jeweilige (nicht anwesende) Zielperson erläutern. Ihre Äußerungen wurden mit einem Tonbandgerät aufgenommen und später transkribiert.

\subsection{Auswertungsvariablen}

Als wichtigste Variable jeglicher Instruktion oder Anleitung gilt deren Verständlichkeit. Diese ist jedoch keine Einzelvariable, sondern setzt sich aus verschiedenen Merkmalen wie z.B. dem Auflösungsgrad, Präzisionsgrad, der Kohärenz der Instruktion oder der Konsistenz der Objektbenennungen (vgl. Ehlich 1994) zusammen. Eine Variable, die besonders geeignet scheint, hörerorientierte bzw. partnerhypothesengeleitete Unterschiede in der Gewichtung der einzelnen Wissensanteile einer Instruktion nachzuweisen, ist der Präzisionsgrad, also die Genauigkeit mit der die Handhabung des Gerätes vermittelt wird. Im folgenden werden die Definition dieser Variable, ihre Auswertung und die hierzu gefundenen Ergebnisse dargestellt.

\subsection{Die Variable „Präzisionsgrad“}

Definition: Unter Präzisionsgrad wird die Art und Weise verstanden, wie ausführlich und genau

- apparative Teile des Gerätes (i.e. instrumentelle Wissensanteile oder Objektreferenzen) und

- die zur Bedienung notwendigen Schritte (i.e. praktische Wissensanteile oder Handlungsreferenzen)

beschrieben werden.

Die Auswertung dieser Variable erfolgte in drei Teilschritten:

- Grundlage für die Konstruktion eines Auswertungsschemas bildete die Originalgebrauchsanweisung des Herstellers. Aus dieser wurden dann für jede zu erklärende Funktion die für eine vollständige Instruktion mindestens notwendigen Teilhandlungen extrahiert.

- Diese wurden in einem zweiten Schritt in Objekt- und Handlungsreferenzen differenziert.

- Im dritten Schritt wurden nun für jede Objekt- und Handlungsreferenz drei Stufen des Präzisionsgrades definiert.

Die theoretischen Wissensanteile wurden für diese Untersuchung so operationalisiert, daß für jede Objekt- und Handlungsreferenz zusätzlich festgehalten wurde, ob die Versuchsperson zusätzlich eine Erklärung für die potentielle Hörerin liefert.

Stufe 1 ist dabei die eher unpräzise, nahe an der Minimaldefinition der notwendigen Teilhandlung orientierte Form der Instruktion. Mit steigendem Präzisionsgrad, 
der für die statistische Auswertung quantifiziert wurde, enthalten die Äußerungen genauere, beispielsweise mehr adjektivische Beschreibungen, die die Identifikation des Objektes bzw. die Ausführung der Handlung eindeutiger machen.

Beispiel: Stunden einstellen

1. Objektreferenz: Erste Taste identifizieren

Stufe 1: ,... vierter Knopf von links/zweiter von rechts ..."

Stufe 2: „... Taste mit der Uhr drauf; kleiner, runder Knopf ...."

Stufe $3:, \ldots$ kleiner, runder Knopf über dem eine Uhr ist ..."

2. Handlungsreferenz: Erste Taste drücken und festhalten

Stufe $1:$,... Knopf drücken und festhalten/... drauf bleiben ..."

Stufe 2: „... Knopf drücken und (ganz) lang drauf bleiben ..."

Stufe 3: „... mit der einen Hand/dem Zeigefinger der rechten Hand drücken und festhalten...“

3. Objektreferenz: Zweite Taste identifizieren

Stufe 1: ,... erste Knopf von links ..."

Stufe 2: „... Knopf über dem HOUR steht ..." , ...kleiner/schwarzer Knopf links ...“

Stufe 3: „... kleiner, runder, schwarzer Knopf, links, über dem HOUR steht ...“

4. Handlungsreferenz: Zweite Taste drücken bis ...

Stufe 1: „...Uhrzeit/Stunden einstellen ...."

Stufe 2: „... Taste solange drücken, bis die Uhrzeit erscheint ..."

Stufe 3: ,... solange drücken, bzw. sooft drücken, bis die gewünschte Uhrzeit, z.B. $11.00 \mathrm{Uhr}$ erscheint ..."

5. Handlungsreferenz: Beide Tasten loslassen

Stufe 1: „... beide Tasten loslassen ..."

Stufe $2:$,... zuerst ..., dann loslassen/gleichzeitig loslassen ..."

Stufe $3:, \ldots$ erst wenn die Uhrzeit eingestellt ist ..." ; ,... sicher sein, daß ..."

\subsection{Hypothesen}

Für die partnerhypothesenabhänige Sprachproduktion lassen sich für den Präzisionsgrad folgende Hypothesen formulieren:

(1) Für die technisch inkompetente Zielperson sollte die Instruktion präziser sein als für die übrigen Bedingungen.

(2) Für die lediglich als „alt” beschriebene Zielperson, bei der die Aktivierung des unbeeinflußten Stereotyps angenommen wird, wurde erwartet, daß hier kontrollierte Prozesse wie solche sozialer Erwünschtheit (d.h. gesellschaftlich erwartetes Verhalten zu zeigen, auch wenn es den eigenen Einstellungen widerspricht) Einfluß auf die Sprachproduktion nehmen und daher die Instruktion weniger präzise als für die inkompetente alte Frau Berger ausfällt.

(3) Für die Bedingung der technisch kompetenten und der jungen Zielperson wurde erwartet, daß im Vergleich zu den beiden anderen Bedingungen der Radiowecker weniger präzise erklärt wird.

Hinsichtlich der theoretischen Wissensanteile wurden keine spezifischen Hypothesen formuliert, da nicht grundsätzlich davon ausgegangen werden kann, daß die zu- 
sätzliche Erklärung einzelner Instruktionsschritte einen Sachverhalt verständlicher macht. Ebenso hat die Differenzierung praktischer und instrumenteller Wissensanteile und des Geschlechts der Versuchspersonen evaluativen Charakter.

\section{Ergebnisse}

Insgesamt gingen 118 von 120 Instruktionen in die Auswertung mit ein. Die beiden übrigen Gespräche mußten aufgrund schlechter Tonbandaufnahmen ausgeschlossen werden.

Da die Variable „Präzisionsgrad“ ordinalskaliert ist, wurden die Unterschiede in der Instruktion in Abhängigkeit von der Partnerhypothese mit Hilfe von KruskalWallis-H-Tests untersucht. Dabei gingen die Geschlechtszugehörigkeit der Versuchsperson (weiblich bzw. männlich), Referenzart (Objekt- oder Handlungsreferenz und die Bedingung (Partnerhypothese 1-4) als unabhängige Variablen ein.

Signifikante Unterschiede über alle Versuchspersonen konnten für den Faktor Bedingung gefunden werden $\left(\mathrm{Chi}^{2}=19,15, \mathrm{p}<.0003\right)$. Wobei die Bedingung „alt/inkompetent" den höchsten Präzisionsgrad erreichte und für die Bedingung ,jung“ am wenigsten präzise instruiert wurde.

Im folgenden wurde eine Differenzierung nach den Variablen Referenzart und Geschlechtszugehörigkeit der Versuchspersonen vorgenommen.

Instrumentelle Wissensanteile (Objektreferenzen)

Über alle Versuchspersonen hinweg konnten keine signifikanten Unterschiede im Präzisionsgrad in Abhängigkeit von der Partnerhypothese gefunden werden. Eine Differenzierung nach Geschlechtszugehörigkeit der Versuchsperson ergab für die Frauen $(n=59)$ signifikante Unterschiede zwischen den Bedingungen:

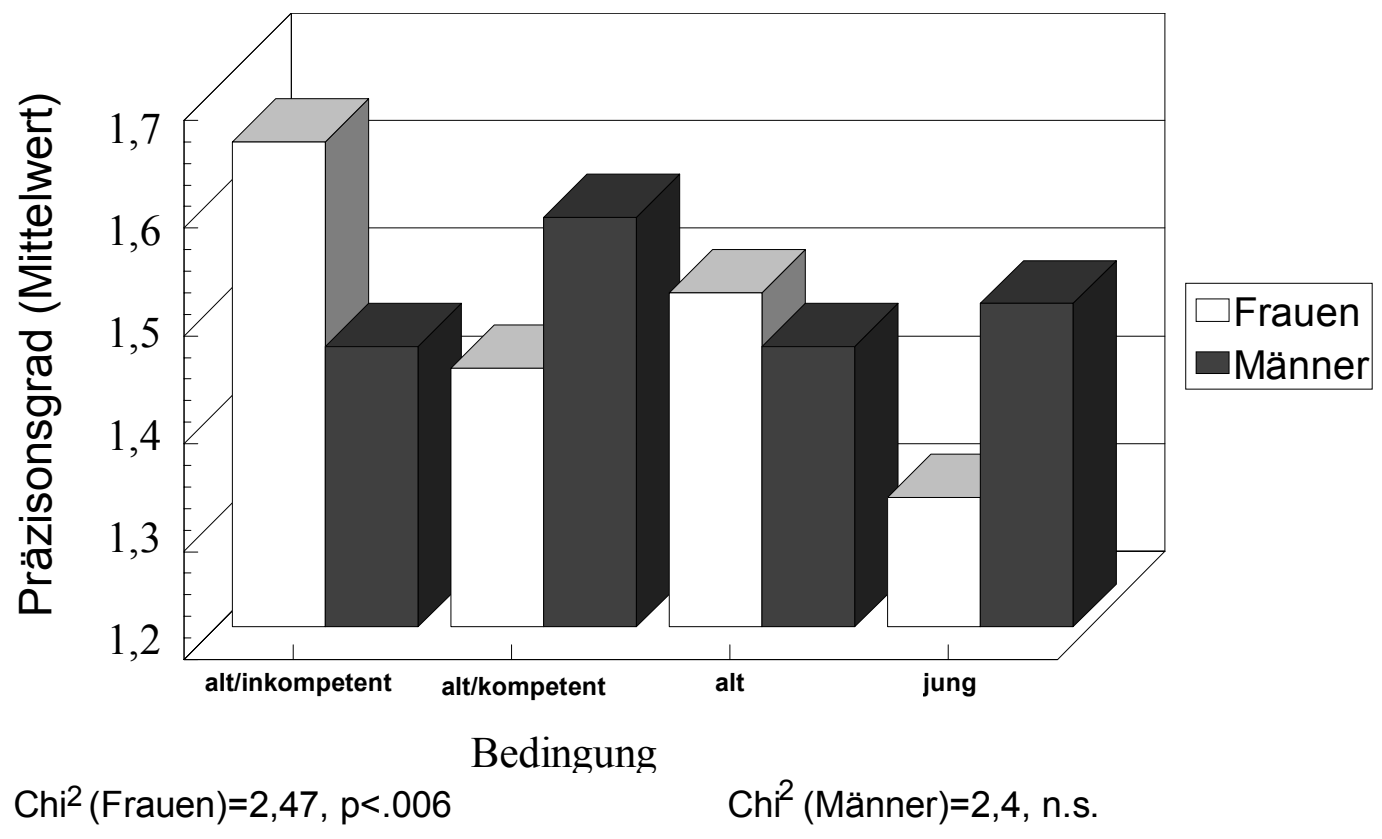

Abb. 3: Unterschiede im Präzisionsgrad der instrumentellen Objektreferenzen in Abhängigkeit von der Bedingung für beide Geschlechtskategorien 
In der stereotyp-konsistenten Bedingung (,alt/inkompetent“) wurde der Radiowecker mit dem höchsten Präzisionsgrad erklärt. Ebenso zeigt der Vergleich der beiden Kontrollgruppen, daß der Präzisionsgrad für die Bedingung „alt" höher ist als für die Bedingung ,jung“.

Für die Männer $(n=59)$ konnten jedoch keine Unterschiede in Abhängigkeit von der Partnerhypothese nachgewiesen werden.

Praktische Wissensanteile (Handlungsreferenzen)

Für die (Handlungsreferenzen) zeigten sich über alle Versuchspersonen hinweg signifikante Unterschiede im Präzisionsgrad zwischen den Bedingungen $\left(\mathrm{Chi}^{2}=15,3\right.$, p<.0016).

Auch hier wurden Einzeleffekte bezüglich der Geschlechtszugehörigkeit der Versuchspersonen überprüft:

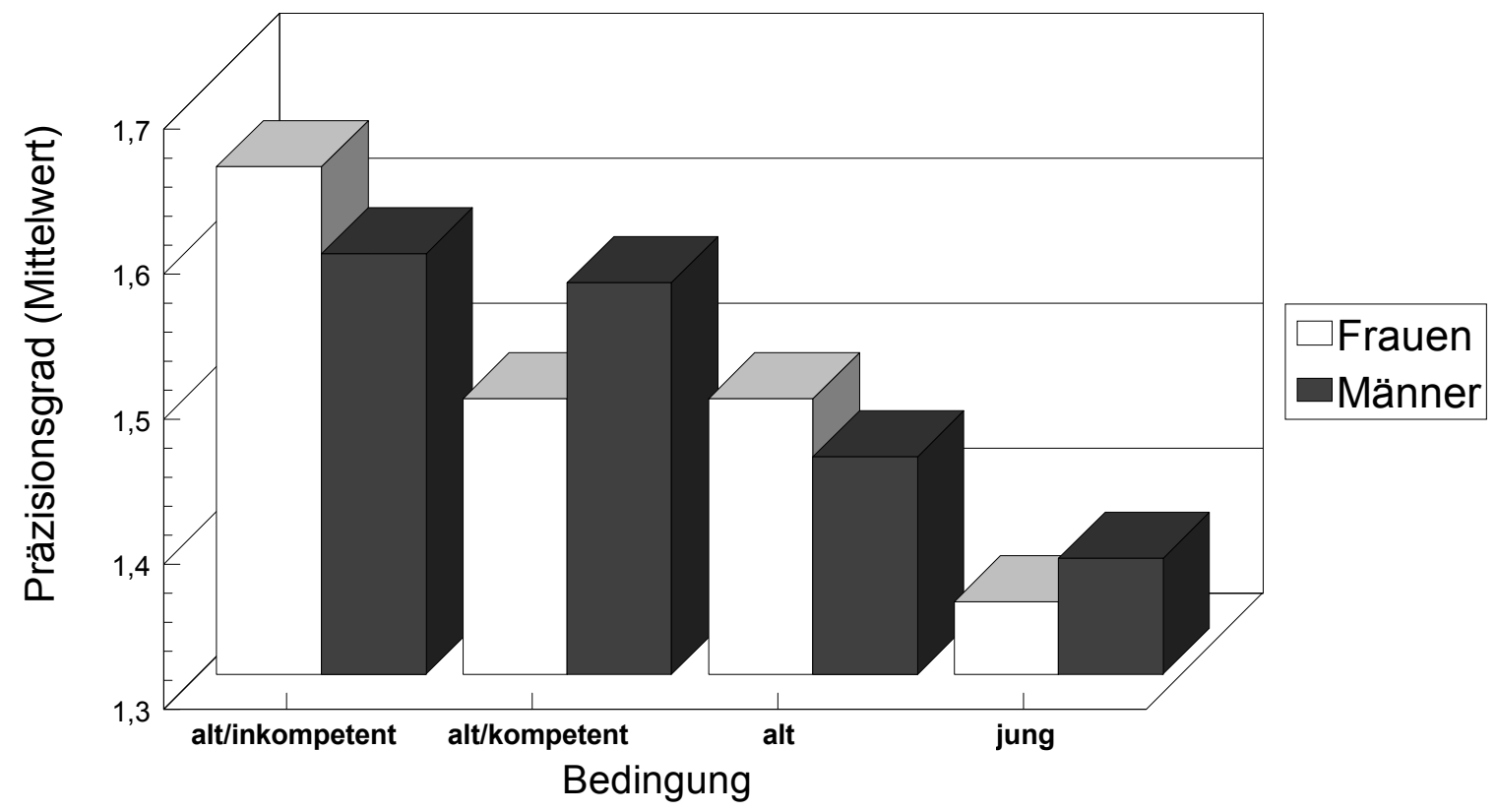

$\mathrm{Chi}^{2}$ (Frauen) $=9,88, \mathrm{p}<.019 \quad \mathrm{Chi}^{2}$ (Männer) $=6,6$, n.s.

Abb. 4: Unterschiede im Präzisionsgrad der praktischen Wissensanteile (Handlungsreferenzen) in Abhängigkeit von der Bedingung für beide Geschlechtskategorien

Während sich hier ebenfalls nur für die Frauen ein signifikanter Unterschied im Präzisionsgrad in Abhängigkeit von der Partnerhypothese zeigt $\left(\mathrm{Chi}^{2}=9,88, \mathrm{p}<.019\right)$, unterscheiden sich die Männer hinsichtlich des Präzisionsgrads ihrer Instruktion zwischen den Bedingungen nicht. Auch hier instruierten die Frauen in der Bedingung „alt/inkompetent“ mit dem höchsten Präzisionsgrad, hingegen in der Kontrollbedingung ,jung“ erwartungsgemäß mit dem geringsten.

Theoretische Wissensanteile (Erklärungen)

Die Unterschiede in der partnerhypothesenabhängigen Gewichtung der theoretischen Wissensanteile (Erklärungen) wurden anhand von $\mathrm{Chi}^{2}$-Tests überprüft. 
(1) Auch hier ist der Geschlechtsunterschied in Abhängigkeit von der jeweiligen Partnerhypothese das auffälligste Ergebnis ( $n=118)$ :

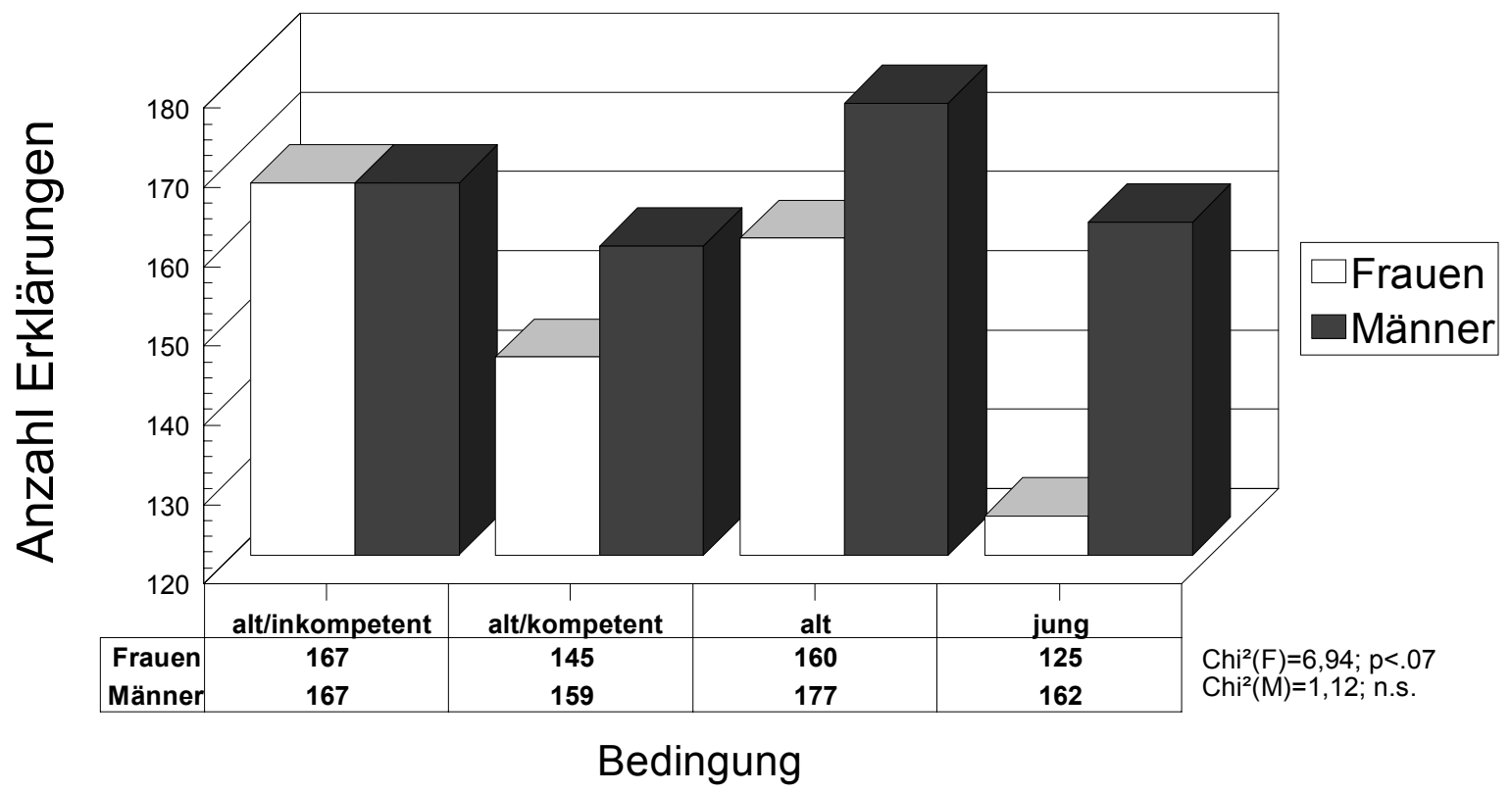

Abb. 5: Häufigkeitsvergleich gegebener Erklärungen (theoretische Wissensanteile) in Abhängigkeit von der Bedingung für beide Geschlechtskategorien

Die Ergebnisse zeigen einen tendenziell signifikanten Unterschied in der Häufigkeit der Erklärungen in Abhängigkeit von der Bedingung für die Frauen $\left(\mathrm{Chi}^{2}=6,94\right.$, p<.06). Auch hier zeigt sich, daß für die Bedingungen „alt/inkompetent" und „alt“ die meisten Erklärungen abgegeben wurden. Die Unterschiede wurden für die Männer statistisch nicht bedeutsam.

(2) Eine Differenzierung nach Objekt- und Handlungsreferenz bezüglich der Häufigkeit der für jede Kategorie abgegebenen Erklärungen zeigt signifikante Unterschiede in Abhängigkeit von der jeweiligen Partnerhypothese lediglich für die Handlungsreferenzen $\left(\mathrm{Chi}^{2}=11,04, \mathrm{p}<.011\right)$.

Auch hier finden sich Geschlechtsunterschiede: Die Unterschiede in der Häufigkeit der Erklärungen für die einzelnen Bedingungen sind nur für die Frauen statistisch signifikant $\left(\mathrm{Chi}^{2}=10,8, \mathrm{p}<.013\right)$ und weisen das gleiche Bild auf wie die obigen. 


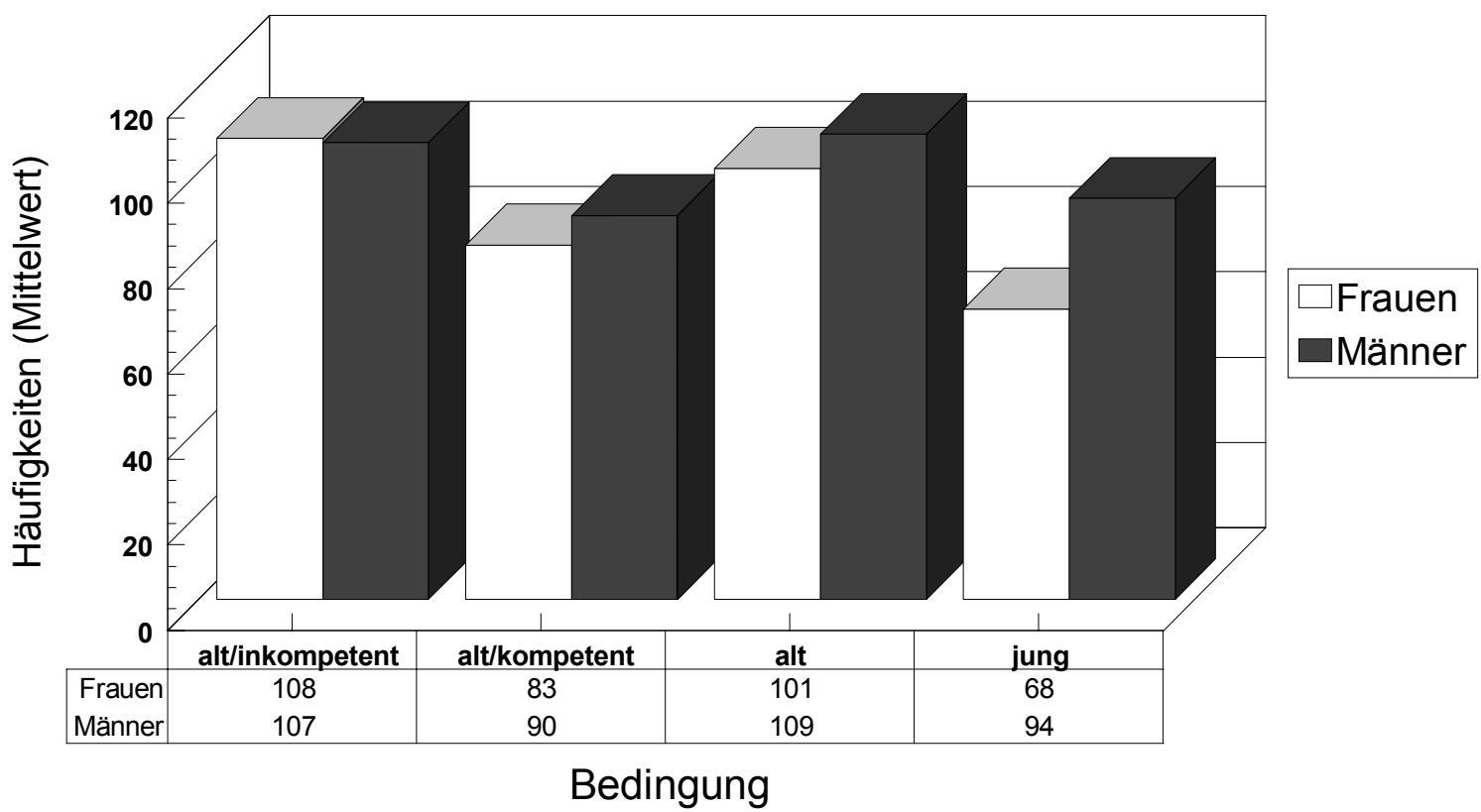

$\mathrm{Chi}^{2}$ (Frauen) $=10,80, \mathrm{p}<.0125 \quad \mathrm{Chi}^{2}$ (Männer) $=2,6$, n.s.

Abb. 6: Häufigkeitsvergleich gegebener Erklärungen (theoretischer Wissensanteile) zu Handlungsreferenzen in Abhängigkeit von der Bedingung für beide Geschlechtskategorien

Ebenfalls für die stereotyp-konsistente Bedingung und die Kontrollbedingung „alt“, bei der das unbeeinflußte Altersstereotyp aktiviert werden sollte, wurden die meisten Erklärungen gegeben. Die wenigsten finden sich wiederum in der Kontrollbedingung ,jung“.

\section{Diskussion}

Die Ergebnisse zum Präzisionsgrad zeigen, daß diese Variable geeignet ist, die Experimentalbedingungen voneinander zu trennen. Dabei zeigte sich, daß die stereotyp-konsistente Bedingung und die des unbeeinflußten Stereotyps sich in erwarteter Richtung von den beiden anderen Bedingungen unterscheiden. Die zusätzliche stereotyp-inkonsistente Information über die technische Kompetenz einer älteren Frau widerspricht dem negativen Stereotyp. Dieser Widerspruch zeigt sich in einem geringeren Präzisionsgrad der Instruktionen für diese Zielpersonen. Für die Bedingung des unbeeinflußten Stereotyps konnte gezeigt werden, daß das negative Stereotyp in Form der präziseren Instruktion seinen Niederschlag findet. Dabei ist jedoch als bedeutsames Ergebnis festzustellen, daß der Präzisionsgrad der Instruktionen zum einen eindeutig von der Partnerhypothese der jeweiligen Bedingung und zum anderen ganz wesentlich von der Geschlechtszugehörigkeit der Sprecherlnnen bestimmt wird. Zusätzlich finden sich Einflüsse der Referenzart (Handlungs- vs. Objektreferenz).

Weiterhin kann festgestellt werden, daß die Wahl der Textsorte „Instruktion“ sich als sensibles Instrument zur Erfassung sprachlicher Marker stereotypgeleiteten Sprechens erwiesen hat. 


\subsection{Geschlechtsunterschiede}

Insgesamt kann für die Frauen festgestellt werden, daß diese stark personenorientiert instruieren, d.h. sie passen die Genauigkeit und Ausführlichkeit ihrer Instruktion dem "vermeintlichen" Kompetenzgrad der Zielperson an. So instruieren sie erwartungsgemäß sowohl in der stereotyp-konsistenten Bedingung für die „alt/inkompetente" Zielperson als auch in der Bedingung des unbeeinflußten Stereotyps für die "alte" Zielperson präziser als sie dies in den beiden anderen Bedingungen tun.

Folgende Beispiele verdeutlichen Unterschiede in der Instruktion zweier Sprecherinnen für die erste Funktion: „Stecker einstecken“. (Die Transkriptionsregeln richten sich nach den Transkriptionsvereinbarungen des Sonderforschungsbereiches 245 (Neubauer, Hub \& Thimm 1994)).

Bedingung „alt/inkompetent“ ( $A=43 / 1 ;$ Z. 8-16)

"... dieser radiowecker hat so $\mathrm{n}$ | * schwarzes kabel was hintn raus geht $\star *$ (KLOPFT) (K) aus dem gerät rausgeht ** (KLOPFT) das ist der * stecker- * $*$ der muß also in die steckdOse.* (HL) wenn sie jetzt angst habn solltn daß zum beispiel (KLOPFT) während eines gewitters hm * die ** der strom ausfällt- * und sie aber auf jedm fall geweckt werdn (KLOPFT) müssen gibt es hier unten noch ein * batteriefach. *2,5* das könnn sie Aufmachen in dem sie..."

Bedingung ,jung“ ( $A=34 / 4 ;$ Z. 1-5)

"... diesen radiowecker (KLOPFT) frau berger. * (HL) den setzn in betrieb- indem sie als erstes den stecker (KLOPFT) in die steckdose steckn. ganz normal ..."

Für die dem Stereotyp widersprechende Bedingung dagegen fallen die Instruktionen von der Tendenz für die ,junge“ Zielperson deutlich weniger präzise aus. Dieser Einfluß der Partnerhypothese findet sich bei den Frauen sowohl für die instrumentellen als auch für die praktischen Wissensanteile.

Für die Männer konnten keine signifikanten Unterschiede zwischen den Bedingungen, weder im Gesamtvergleich noch bei Differenzierung der Referenzarten gefunden werden. Dies läßt im Gegensatz zu den Frauen auf eine stark sachorientierte Art und Weise des Instruierens schließen.

Auch hier verdeutlichen die folgenden beiden Gesprächsausschnitte jeweils aus der stereotyp-konsistenten Bedingung „alt/inkompetent“ den gefundenen Geschlechtsunterschied am Beispiel der Funktion „Lautstärke einstellen“:

Männliche Versuchsperson (A=M41/1; Z. 80-83)

"...* wenn sie das dann etwas lauter habn wolln dann nehmn sie einfach das Andere rad- *2,5* (RADIO EIN) und drehn und dann werdn sie feststellen lAUter und leiser."

Weibliche Versuchsperson ( $A=43 / 1 ; Z$. 79-88; 121-134)

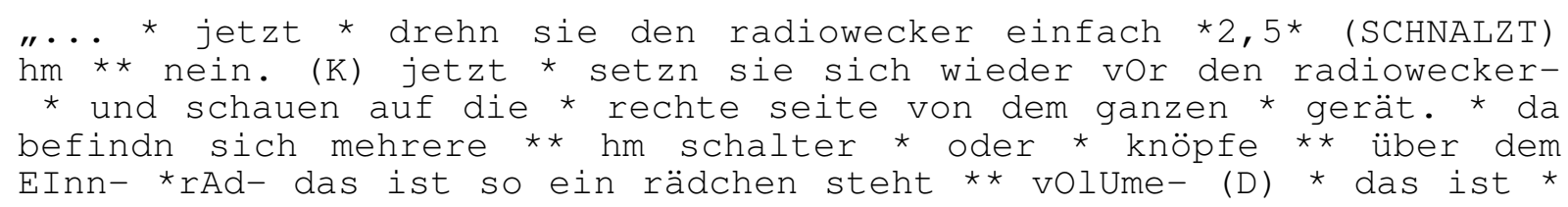


voljum (E) da heißt hm ist das die bedeutung für lautsprecher- * (K) also für lautstärke-"... [] "...die lAUtstärke- wenn sie die lautstärke verändern wolln- von dem was sie hörn dann * gehn sie auf $* 3,5 *$ (KLOPFT) hm $(K)$ um wieder von vorne anzufangen wenn sie vor dem gerät sitzn- mit der * mit der zeitanzeige schauen sie wieder nach rechts- *2,5* auf diese * drei *hab die ich ihnn vorhin beschrieben hab- und * gucken das * klEIne * rädchen - * auf der rechtn (K) hm der linkn seite an- ** wo ** hm über dem rädchen * volUme (D) * geschriebn ist. * $3 *$ (SCHNALZT) wenn sie * dAs ausprobiern- einmal ein bißchen nach rEchts einmal ein bißchen nach Links drehn dann verändert sich die lautstärke- und könnn einstelln wie sie * sie gerade habn wolln ..."

Eine weitere Interpretationsmöglichkeit lassen die gefundenen Ergebnisse ebenfalls zu. Für die männlichen Versuchspersonen kann der mögliche Einfluß der Altersvariable durch das vorherrschend negative Stereotyp über die technische Kompetenz von Frauen im allgemeinen überlagert worden sein. Somit konnten keine Unterschiede zwischen den Bedingungen gefunden werden. Durch die Beschränkung auf eine weibliche Zielperson (Else Berger) kann nicht eindeutig zwischen dem Altersund dem Frauenstereotyp differenziert werden. In nachfolgenden Untersuchungen wird dieser Frage nachgegangen werden müssen.

\subsection{Theoretische Wissensanteile}

Auch für die theoretischen Wissensanteile konnte ein deutlicher Einfluß der Partnerhypothese in Abhängigkeit vom Geschlecht der Versuchspersonen nachgewiesen werden. Frauen geben in der stereotyp-konsistenten Bedingung und der des unbeeinflußten Stereotyps tendenziell mehr Erklärungen als in den beiden anderen Bedingungen (vgl. Abb. 5). Auch hier konnten für die Männer keine Unterschiede zwischen den Bedingungen gefunden werden. Die Männer geben insgesamt mehr Erklärungen als die Frauen. Dieses Ergebnis scheint die Vermutung zu stützen, daß das Stereotyp der Männer über die technische Inkompetenz von Frauen bei den vorliegenden Instruktionen stärker zu Tragen kam. Dennoch ist dieser Befund durch zusätzliche Untersuchungen mit männlichen Zielpersonen zu validieren.

Eine Differenzierung der Häufigkeiten der Erklärungen nach instrumentellen und praktischen Wissensanteilen ergab lediglich für die Handlungsreferenzen Unterschiede in Abhängigkeit von der Bedingung (vgl. Abb. 6). Hier werden wiederum nur von Frauen für die stereotyp-konsistente Bedingung und für die der lediglich als „alt“ beschriebenen Person mehr Erklärungen gegeben als für die beiden anderen. Dieses Ergebnis deutet darauf hin, daß Erklärungen grundsätzlich als hilfreich für die Empfänger der Instruktion empfunden werden und daher insbesondere in den Bedingungen, bei denen stereotypgemäß geringe Kompetenzen der Zielperson erwartet werden, zusätzlich gegeben werden.

\section{Zusammenfassung und Ausblick}

Insgesamt konnte gezeigt werden, daß das negative Stereotyp über die technische Kompetenz älterer Menschen in der Art und Weise, wie innen ein technischer Sachverhalt erläutert wird, seinen Niederschlag in der Sprache findet. Die Variable 
„Präzisionsgrad“, d.h. also die Genauigkeit der Instruktion, hat sich dabei als guter sprachlicher Indikator für stereotypabhängiges Sprechen erwiesen. Ebenso zeigte sich die gewählte Kommunikationssituation der nicht anwesenden Hörerin für die Fragestellung geeignet. Die gefundenen Geschlechtsunterschiede bestätigen die Ergebnisse der Geschlechterforschung, die auf eine personenorientierte weibliche Interaktion einerseits, bei der das Alter und die damit verbundenen (positiven wie negativen) Assoziationen Berücksichtigung finden, und eine eher sachorientierte männliche Interaktion andererseits hinweisen. Zusätzlich zeigte sich, daß Erklärungen im Kontext einer Instruktionssituation als hilfreich gelten können.

Zusammenfassend machen die Ergebnisse dieser Untersuchung deutlich, daß Sprache als Vermittler von Einstellungen und Meinungen insbesondere auch auf indirekte Weise funktioniert. Sprachliche Indikatoren wie z.B. der Präzisionsgrad zeigen, wie kognitiv fest verankerte Strukturen sprachlich umgesetzt werden. Für das Experiment "Radiowecker" wurden, wie in Abschnitt 7 kurz erwähnt, weitere SprachVariablen erhoben. Die zum Präzisionsgrad gefundenen Hinweise auf stereotypgeleitetes Sprechen werden im Rahmen der Gesamtschau der Ergebnisse erneut betrachtet werden. Hierdurch kann ein differenzierteres Bild über mögliche sprachliche Einflüsse sozialer Stereotypen gezeichnet werden, das zum einen Rückschlüsse auf das Stereotyp selbst, und zum anderen auf die Funktion der Sprache zuläßt.

Im weiteren wird zu überprüfen sein, inwieweit solche Ergebnisse auf Interaktionssituationen, insbesondere auch dialogische, d.h. solche mit zwei "real" kommunizierenden Versuchspersonen, zu übertragen sind. 


\section{Literatur}

Ariel, M. (1990). Accessing Noun-Phrase Antecedents. London/New York: Routledge.

Baltes, P. B. \& Baltes, M. M. (1989). Erfolgreiches Altern: Mehr Jahre und mehr Leben. In: Baltes, M. M., Kohli, M. \& Sames, K. (Hrsg.), Erfolgreiches Altern: Bedingungen und Variationen. Bern, Stuttgart: Hans Huber.

DIN-Norm (1974). DIN 8418: Technische Erzeugnisse. Angaben in Gebrauchsanleitungen und Betriebsanleitungen.

Ehlich, K. (1994). Verweisungen und Kohärenz in Bedienungsanleitungen. Einige Aspekte der Verständlichkeit von Texten. In: Ehlich, K., Noack, C. \& Scheiter, S. (Hrsg.), Instruktion durch Text und Diskurs. Zur Linguistik technischer Texte. Opladen: Westdeutscher Verlag, 116-149.

Gülich, E. (1978). Was sein muß, muß sein. Überlegungen zum Gemeinplatz und seiner Verwendung. Bielefelder Papiere zur Linguistik und Literaturwissenschaft 7.

Herrmann, Th. (1985). Allgemeine Sprachpsychologie. München: Urban \& Schwarzenberg.

Herrman, Th. \& Grabowski, J. (1994). Sprechen: Psychologie der Sprachproduktion. Heidelberg: Spektrum Akademischer Verlag.

Herrmann, Th. \& Hoppe-Graff, S. (1988). Textproduktion. In: Mandl, H. \& Spada, H. (Hrsg.), Wissenspsychologie. München: Psychologie-Verlags-Union, 283-298.

Kerschner, P. A. \& Hart, K. (1984). The Aged User and Technology. In: Dunkle, R. E., Haug, M. R. \& Rosenberg, M. (eds.), Communications Technology and the Elderly. Issues and Forecasts. New York: Springer, 135-144.

Koelbing, H. G., Mangold-Allwin, R., Baratelli, S., Kohlmann, U. \& von Stutterheim, C. (1994). Wie beeinflußt der Ausführende den Instruierenden? Zum Einfluß eines anwesenden Partners auf die Wahl von Objektreferenzen in Instruktionstexten. Arbeiten aus dem Sonderforschungsbereich 245 „Sprache und Situation“, Heidelberg/Mannheim, Bericht Nr. 85. Institut für Deutsch als Fremdsprachenphilologie.

Krauss, I. K. \& Hoyer, W. J. (1983). Technology and the Older Person: Age, Sex and Experience as Moderators of Attitudes Towards computers. In: Robinson, P. K., Livingston, J. \& Birren, J. E. (eds.), Aging and Technological Advances. New York/London: Plenum Press, 349-350.

Lehr, U. (1989). Psychologie des Alterns. 7. Auflage. Heidelberg: Quelle und Meyer.

Maier, S., Wagner, A. \& Rademacher U. (1996). Altersstereotype. Arbeitspapier aus dem Sonderforschungsbereich 245 „Sprache und Situation“, Heidelberg/Mannheim.

Neubauer, M., Hub, I. \& Thimm, C. (1994). Transkribieren mit Latex: Transkriptionsregeln, Eingabeverfahren und Auswertungsmöglichkeiten. Arbeiten aus dem Sonderforschungsbereich 245 „Sprache und Situation“ Heidelberg/Mannheim. Bericht Nr. 76.

Ramm, D. \& Gianturco, D. (1973). Computers and Technology: Aiding tomorrow's aged. In: Gerontologist 13, 322-325.

Pelka, R. (1982). Sprachliche Aspekte von Bedienungsanleitungen technischer Geräte und Maschinen. In: Grosse, S. \& Mentrup, W. (Hrsg.), Anweisungstexte. Forschungsberichte des Instituts für Deutsche Sprache, Mannheim. Tübingen: Gunter Narr Verlag. 321 -323.

Speck, A. (1993). Instruieren im Dialog. Arbeiten aus dem Sonderforschungsbereich 245 „Sprache und Situation", Heidelberg/Mannheim, Bericht Nr. 60.

Wintermantel, M. \& Laier, R. (1994). Hörer-Orientierung in technischen Instruktionen. In: Ehlich, K., Noack, C. \& Scheiter, S. (Hrsg.), Instruktion durch Text und Diskurs. Zur Linguistik technischer Texte. Opladen: Westdeutscher Verlag, 100-115. 


\section{Anhang}

\section{A: Zielpersonenbeschreibung/Partnerhypothesen}

Bedingung „alt/inkompetent“

Frau Else Berger ist 82 Jahre alt. Sie lebt recht zurückgezogen, da sie gerne ihre Ruhe hat und konzentriert sich auf ihre Hobbies Spazierengehen, Lesen, Handarbeiten. Dem Angebot an Freizeitaktivitäten, das z.B. in der Akademie der Älteren angeboten wird, steht sie eher skeptisch gegenüber und bezweifelt, sich mit solch fremden Sachen wie Theaterspielen oder Photographieren noch anfreunden zu können. Technische Neuerungen hat sie auch in ihrem Haushalt bisher eher gemieden oder die Bedienung anderen überlassen, da sie glaubt, da „zwei linke Hände“ zu haben und mit der Bedienung nicht zurecht zu kommen. Einiges traut sie sich aufgrund ihrer Vergeßlichkeit auch nicht mehr zu. Zudem ist sie häufiger krank und kann an regelmäßigen Veranstaltungen nur sporadisch teilnehmen. Alles in allem führt sie ein recht ruhiges und häusliches Leben.

Bedingung „alt/kompetent“

Frau Else Berger ist 82 Jahre alt. Sie ist ein recht geselliger Mensch und pflegt ihre Kontakte mit Freundinnen und Nachbarn. Auch ihren Hobbies - Schwimmen, Gymnastik und Photographieren geht sie gerne und ausgiebig nach. Sie greift zudem ab und an auf das Freizeitangebot, das bei der Akademie der Älteren angeboten wird, zurück und hat dort gerade an einem Kurs über Photographieren und Entwickeln teilgenommen. Besonders begeistert sie die Möglichkeit, jetzt ihre Fotos selbst entwickeln und vergrößern zu können. Auch wenn sie noch nicht mit allen Rafinessen vertraut ist, ist sie recht neugierig frei nach dem Motto "Was nicht ist, kann ja noch werden“.

Bedingung „alt"

Frau Else Berger ist 82 Jahre alt.

Bedingung ,jung“

Frau Else Berger ist 32 Jahre alt.

\section{B: Anweisung an die Versuchspersonen}

Bitte erklären Sie Frau Berger zumindest die folgenden Funktionen:

1.) Inbetriebnahme des Gerätes: An das Stromnetz anschließen.

2.) Wie stellt man die momentane Uhrzeit ein?

3.) Wie wählt man einen Sender?

4.) Wie kann man die Lautstärke verändern?

5.) Wie kann man sich wecken lassen? 


\title{
Lebenssituation und Sprache
}

\author{
Roselore Brose
}

\section{Einleitung}

Immer mehr Menschen werden heute immer älter. Daher ist es nicht verwunderlich, daß sich neben Medizin, Psychologie und Soziologie seit geraumer Zeit auch die Sprachwissenschaft in zunehmendem Maße mit dem alternden Menschen befaßt. Bereits seit mehr als zwanzig Jahren beschäftigt sich die empirische Forschung der englischsprachigen Länder, insbesondere der USA, mit dem Sprach- und Kommunikationsverhalten älterer Menschen. Ein nicht unbeträchtlicher Teil der empirischen Wissenschaft konzentriert sich dabei mit Hilfe experimenteller Methoden auf psycholinguistische Phänomene der Sprachverarbeitung. Dabei zeigt sich, daß in vielen Bereichen die älteren Menschen den jüngeren in ihren Leistungen unterlegen sind. In einigen wenigen, wie zum Beispiel im semantischen Bereich, weisen sie allerdings mindestens gleichwertige Ergebnisse auf (für eine Übersicht vgl. Kemper 1992). Etwas jünger sind die Forschungen, die sich mehr auf das Sprachverhalten älterer Menschen beziehen. Hier wird vornehmlich mit qualitativen Methoden der Diskursanalyse gearbeitet. Auch diese Forschungen fanden zunächst im englischsprachigen Bereich statt (Coupland, Coupland \& Giles 1991; Kemper 1994; Ryan, Meredith, MacLean \& Orange 1995). In Deutschland befassen sich Linguistik und Psychologie leider erst seit kurzem und auch nur in sehr geringem Ausmaß mit dem Zusammenhang von Sprache und Altern (Fiehler 1997; Thimm 1995). Selbst in der erst kürzlich veröffentlichten Berliner Altersstudie (Mayer \& Baltes 1996) wird Sprache nur implizit - als Medium zur Messung von Intelligenzleistungen (Wortflüssigkeit und Wissen) - untersucht (Reischies \& Lindenberger 1996).

Im folgenden möchte ich mich mit diesen Forschungen zu dem - angenommenen Zusammenhang auseinandersetzen. Was all diesen Studien zum Sprachverhalten älterer Menschen gemeinsam ist, ist die Tatsache, daß fast immer nur das kalendarische Alter, das heißt die Anzahl der gelebten Jahre, als Hauptfaktor für die Veränderung von Sprachverhalten zugrunde gelegt wird. An diesem Punkt möchte ich ansetzen und eine alternative These zum Sprachverhalten älterer Menschen aufstellen. Ich werde mich dabei auf die empirische Erforschung von authentischer Sprache in natürlichen Settings beschränken.

Alter ist keine objektive Größe. Ob ein Mensch als alt angesehen wird, hängt wie wir leicht nachvollziehen können - zunächst von der Perspektive der beurteilenden Person ab. Für ein Grundschulkind sind bereits Zwanzigjährige alt, und junge Erwachsene sehen Vierzig- bis Fünfzigjährige als alt an. Alt sind für uns meistens diejenigen, die älter als wir selbst sind, und mit dem eigenen Älterwerden verschiebt sich auch der Maßstab in bezug auf das Alter. Alter lediglich anhand einer bestimmten Anzahl von gelebten Lebensjahren zu definieren erweist sich also als wenig sinnvoll, wie auch in jüngsten Untersuchungen betont wird (Maas \& Staudinger 1996). Üblicherweise wird der Zeitpunkt, zu dem ein Mensch die Berufstätigkeit beendet, mit dem Beginn des Alters gleichgesetzt, das heißt mit etwa sechzig bis fünf- 
undsechzig Jahren. In der heutigen Zeit, da ein nicht unerheblicher Teil aufgrund der Arbeitsmarktlage schon frühzeitig in Rente geschickt wird, dürfte diese Definition jedoch bereits Probleme aufwerfen. Ein anderer Ansatz unterscheidet zwischen jungen Alten - den Sechzig- bis Fünfundsiebzigjährigen - und alten Alten - den über Fünfundsiebzigjährigen - und in jüngster Zeit zusätzlich den Hochbetagten - den über Fünfundachtzigjährigen. Eine noch andere Sichtweise liegt dem Vorschlag zugrunde, mit jungen Alten diejenigen zu bezeichnen, die körperlich und vor allem geistig noch rüstig sind, und als alte Alte alle diejenigen, auf die diese Charakterisierung nicht mehr zutrifft (Lehr 1986). Hier wird offensichtlich, daß Alter nicht nur ein biologisches, sondern vor allem auch ein soziales Phänomen ist, und ich denke, daß wir uns bei den vielen Gesichtern des Alters und des Alterns von einer nur die Lebensjahre zählenden Definition lösen und eine differenziertere Sichtweise einnehmen müssen.

\section{Sprache und Altern: Gibt es einen Zusammenhang?}

Bei der Untersuchung der Frage, ob es einen erkennbaren Zusammenhang zwischen Sprache und Altern gibt, beziehe ich mich insbesondere auf die Forschungen zum Sprachverhalten älterer Menschen, die mit qualitativen, vor allem diskursanalytischen Methoden durchgeführt werden. Viele ältere Personen lassen den Eindruck entstehen, daß sie ein anderes Sprach- und Kommunikationsverhalten haben als jüngere. Aber hängt dies wirklich mit dem Ältersein oder gar Älterwerden zusammen? Beruht dieses Verhalten tatsächlich allein auf dem höheren Lebensalter? Ich möchte die alternative These aufstellen, daß die meisten der Phänomene, mit denen sich die Sprachwissenschaft bisher befaßt hat, nicht auf das kalendarische Alter der Sprecher und Sprecherinnen zurückzuführen sind, sondern vielmehr auf eine Vielzahl von Faktoren, die weniger altersbedingt als vielmehr strukturbedingt sind.

In der empirischen Forschung zum Sprachverhalten älterer Menschen gibt es eine Reihe von unterschiedlichen und sogar widersprüchlichen Ergebnissen. Einige Untersuchungen, wie die von Coupland, Coupland und Giles (1991), haben beispielsweise ergeben, daß ältere Menschen eher über schmerzvolle Ereignisse sprechen als jüngere. Bei einer ähnlichen Untersuchung von Collins und Gould (1994) zeigte sich dagegen, daß es eher die jüngeren Personen waren, die negative Äußerungen machten, als die älteren; häufig fühlten sie sich sogar weniger wohl bei positiven Äußerungen von Älteren.

Auch bei Untersuchungen zu der Art, wie Jüngere mit Älteren oder Ältere mit Jüngeren umgehen, wird einerseits festgestellt, daß die Älteren den Jüngeren gegenüber sogenannte „Patronizing Speech“ verwenden (Giles \& Williams 1994), und andererseits, daß es genau umgekehrt ist (Ryan, Hamilton \& Kwong See 1994).

Diese recht unterschiedlichen, ja teilweise geradezu konträren Ergebnisse lassen doch starke Zweifel aufkommen und legen nahe, andere Faktoren als das höhere Lebensalter für das entsprechende Sprach- und Kommunikationsverhalten in Betracht zu ziehen. Um dieser Frage nachzugehen, möchte ich zunächst auf einige relevante Forschungsergebnisse aus verwandten Disziplinen zurückgreifen, die sich teilweise schon seit Jahrzehnten mit dem Themenkomplex Alter und Altern befassen. Hierbei handelt es sich vor allem um die Soziologie und die Psychologie, insbesondere die Entwicklungspsychologie, die Kognitive Psychologie und die Ökologische Psychologie. 
Vor der eigentlichen Darstellung dieser Forschungsergebnisse werde ich in einem Exkurs auf ein Spezifikum eingehen, das gerade in bezug auf ältere Menschen viele negative Auswirkungen hat und das mir im Zusammenhang mit unserem Thema sehr wichtig erscheint, nämlich auf Stereotype und Vorurteile.

\section{Exkurs: Stereotype und Vorurteile}

„Elderspeak“, ein dem „Baby Talk" oder auch dem „Foreigner Talk“ verwandtes Sprachverhalten gegenüber älteren Menschen, wird bekanntlich vor allem im Pflegeund Betreuungsbereich von - meist jüngeren - Pflegepersonen gegenüber den älteren Patienten oder Bewohnern verwendet in der Annahme, daß diese Art zu sprechen die Verständigung erleichtere. Ausgelöst wird dieses Sprachverhalten durch sogenannte „Alterscues“ wie die körperliche Erscheinung, langsamere Bewegungen, Schwerhörigkeit oder Stimmqualität, wodurch dann stereotype Erwartungen ausgelöst werden. Aufgrund ihrer Vorstellung, daß ältere Menschen nicht nur körperlich, sondern auch in ihrer geistigen Wahrnehmungsleistung eingeschränkt sind, verhalten sich die Pflegepersonen diesen gegenüber in einer besonderen Weise und drängen sie damit in die Rolle von Hilfsbedürftigen und Unselbständigen. „Elderspeak" ist vor allem gekennzeichnet durch ein vereinfachtes Sprachregister mit folgenden Charakteristika (Kemper 1994):

- kürzere Äußerungen mit einer geringeren Anzahl von einfach konstruierten Sätzen,

- mehr Füllwörter, mehr Satzfragmente und weniger lange Wörter,

- langsameres Sprechen, längere Sprechpausen,

- besonders starke Betonung und erhöhte Lautstärke,

- häufige Verwendung der ersten Person Plural oder Ansprechen der Älteren mit Vornamen.

Die Vorurteilsforschung hat deutlich gezeigt, welche geradezu dramatischen Folgen mit bestimmten Stereotypen und dem daraus folgenden Verhalten verbunden sind. Die besondere Gefahr, die von dieser Art der Kommunikation ausgeht, liegt darin, daß die älteren Menschen die innen gegenüber bestehenden Vorstellungen und Vorurteile - daß sie nicht nur körperlich, sondern auch geistig eingeschränkt und hilfsbedürftig sind - schließlich internalisieren und die innen zugeschriebenen Charakteristika annehmen (Feezel \& Hawkins 1988). So schließt sich der Kreis im Sinne einer „self-fulfilling prophecy“. Die ältere Person, der ständig signalisiert wird, daß sie nicht mehr dazugehört oder nur in einer ganz bestimmten Rolle anerkannt wird und mit der in einer anderen Sprache gesprochen wird, ergibt sich schließlich in diese Rolle, und ihr Kommunikationsverhalten ändert sich (Hummert 1994). Ryan stellt dies sehr deutlich in ihrem Communication Predicament Model dar (Ryan, Meredith, MacLean \& Orange 1995; Ryan \& Kwong See i.d.Bd.).

Es ist offensichtlich, daß dadurch die Möglichkeiten einer adäquaten Kommunikation immer mehr eingeschränkt werden. Da ihnen entsprechende Kompetenzen abgesprochen werden, ziehen die älteren Menschen sich von kommunikativen Kontakten mit Jüngeren und sogar mit Gleichaltrigen zurück. Was dies für die Kommunikation im allgemeinen und die Sprachfähigkeiten im besonderen bedeuten kann, läßt sich leicht vorstellen. In diesem Zusammenhang sollte auch kritisch hinterfragt werden, ob denn das häufig angesprochene nachlassende gesellschaftliche Engage- 
ment vieler alter Menschen überhaupt auf eine mit dem Alter zunehmende Tendenz des Sich-Zurückziehens aus sozialen Verbindungen und Verpflichtungen zurückzuführen ist oder doch eher mit der Stellung und dem Ansehen der Älteren in der Gesellschaft zusammenhängt, die sie ausgrenzt, wodurch ihnen oft befriedigende Kontakte und soziale Betätigungen erschwert oder gar verweigert werden. Daß eine geistige Stabilität auf Dauer nicht ohne Kommunikation mit anderen Menschen und die dadurch erzielte Bestätigung der eigenen Person aufrechtzuerhalten ist, wurde bereits vor dreißig Jahren betont (Watzlawick, Beavin \& Jackson 1967).

Gerade älteren Menschen gegenüber gibt es eine ganze Reihe von Vorurteilen, von denen viele bewiesenermaßen unzutreffend sind. Dazu gehören vor allem die Vorurteile bezüglich der kognitiven Fähigkeiten Älterer und hier ganz besonders solche hinsichtlich Intelligenz und Lernfähigkeit. Im folgenden Abschnitt werde ich dazu einige Forschungsergebnisse etwas ausführlicher referieren.

\subsection{Intelligenzentwicklung über die Lebensspanne: Vom Defizitmodell zum Kompetenzmodell}

Lange Zeit wurde von der Wissenschaft die Ansicht vertreten - und im Alltagsverständnis herrscht noch heute die Annahme vor -, daß die kognitiven Fähigkeiten eines Menschen im Laufe des Lebens zunächst zunehmen und ab einem bestimmten Zeitpunkt - der zudem schon im relativ jungen Erwachsenenalter liegt - wieder abnehmen, was sich dann darin äußert, daß die Leistungsfähigkeit älterer Menschen im kognitiven Bereich - wie auch generell im körperlichen Bereich - nachläßt. Bereits die Bonner Längsschnittuntersuchung älterer Menschen, die über mehrere Jahrzehnte hinweg mit verschiedenen Kohorten durchgeführt wurde (Lehr \& Thomae 1987), hat jedoch gezeigt, daß dieses Defizitmodell der Intelligenzentwicklung nicht aufrechtzuerhalten und abzulösen ist durch ein Kompetenzmodell. Es stellte sich heraus, daß die kognitiven Leistungen älterer Menschen keinesfalls in dem Maße abnehmen, wie man das früher angenommen hat. Sowohl physiologische als auch psychologische Parameter verwiesen auf ein hohes Maß an interindividueller Variabilität, die über die zum Teil neunzehnjährige Beobachtung konstant blieb. Der objektive Gesundheitszustand zeigte enge Zusammenhänge mit kognitiver und psychomotorischer Leistungsfähigkeit. Dabei zeigte sich eine hohe Korrelation zwischen dem sozialen Status und unterschiedlichen Qualitäten der Gesundheit, der kognitiven und sozialen Kompetenz sowie "Lang-“ und "Kurzlebigen“. Außerdem wurde ein starker Zusammenhang zwischen besseren Leistungen in kognitiven Tests und weiterführender Schulbildung, günstigerem sozio-ökonomischem Status sowie höherer Aktivität festgestellt (Thomae 1993). Diese Ergebnisse weisen deutlich auf die Komplexität des Alternsprozesses hin und die daraus sich ergebende Notwendigkeit einer mehrdimensionalen Betrachtungsweise. Auch Weinert (1992) stellt aufgrund seiner Untersuchungen fest, daß der größte Teil kognitiver Leistungen in ihrer manifesten Unterschiedlichkeit nicht durch das Lebensalter als Indikator biologischer Veränderungen, sondern vielmehr durch verschiedene individuelle und soziale Lebensbedingungen beeinflußt wird.

Besonders interessant ist in diesem Zusammenhang das Zwei-KomponentenModell der kognitiven Entwicklung über die Lebensspanne (Baltes \& Baltes 1990a, b), das heuristisch zwischen der Mechanik und der Pragmatik der Intelligenz unterscheidet. Nach Baltes umfaßt die Mechanik die sogenannten "fluiden" und die Pragmatik die „kristallinen“ Anteile der Intelligenz (Cattell 1971). Während die Me- 
chanik der Intelligenz die grundlegende Informationsverarbeitung beinhaltet, umfaßt die Pragmatik das faktische und prozedurale Wissen. Die grundlegende Informationsverarbeitungsfähigkeit gilt als inhaltsfrei, universal und biologisch angelegt und weist genetische Differenzen auf, wogegen das Wissen inhaltsreich, kulturabhängig und auf Erfahrungen zurückzuführen ist.

Die Entwicklung der Intelligenz stellt sich als dynamisches Wechselspiel zwischen Wachstum und Abbau, Gewinn und Verlust dar - und zwar über die gesamte Lebensspanne hinweg. Im Alter allerdings wird die Gewichtung zwischen Gewinnen und Verlusten weniger positiv oder verschiebt sich sogar eher zum Negativen. Besonders zwei Eigenarten kennzeichnen dabei das kognitive Altern: Die Kapazitätsreserven der fluiden Intelligenz für Maximalleistungen vermindern sich. Dennoch läßt sich in manchen Wissenssystemen eine Weiterentwicklung und Erhaltung von Höchstleistungen beobachten. Wenn nun im Prozeß des Alterns bei einer Person bestimmte Kapazitätsschwellen überschritten werden, hat dies für ihre Entwicklung bestimmte Konsequenzen. Durch Selektion der besonders gut ausgebildeten Kompetenzen ergibt sich eine Verminderung der Anzahl von Hochleistungsbereichen; gleichzeitig werden kompensatorische und/oder substitutive Mechanismen entwikkelt (Baltes \& Baltes 1989; Baltes, Staudinger, Maercker \& Smith 1995; Baltes \& Carstensen 1996; siehe auch den Abschnitt „Erfolgreiches Altern“).

Das von Rott (1993) aufgrund einer Faktorenanalyse der bereits erwähnten Bonner Gerontologischen Längsschnittstudie entwickelte Drei-Komponenten-Modell der Intelligenzentwicklung beinhaltet kristalline, visuelle und verbale Gedächtniskomponenten, die zugleich unterschiedliche kognitive Strategien repräsentieren. Am stabilsten im Verlauf des Alterns sind die kristallinen Komponenten, jedoch zeigen sich bis zu einem Alter von etwa siebzig bis fünfundsiebzig Jahren auch bei den anderen beiden Komponenten keine nennenswerten Leistungsrückgänge. Erst ab etwa achtzig Jahren erfolgt eine Reduzierung auf zwei Faktoren, was als Fähigkeitskonzentration interpretiert wird. Dabei werden visuelle und verbale Strategien gebündelt, um Leistungsrückgänge zu kompensieren.

Aus diesen Befunden zeigt sich ganz deutlich, daß Ältere den biologischen und physiologischen Alternsprozessen, die zu strukturellen Veränderungen - meist im Sinne des Abbaus der Intelligenzstruktur - führen, nicht nur passiv ausgeliefert sind. Neben der Auswirkung von zahlreichen Umwelt- und Situationseinflüssen auf den Alternsprozeß wird die Entwicklung intellektueller Leistungen im Alter vor allem durch eine aktive, selbstverantwortliche Lebensgestaltung beeinflußt (Lehr 1986).

\subsection{Der Kompetenzbegriff}

Ein wichtiger Begriff in diesem Zusammenhang ist der der Kompetenz. Mit dem Kompetenzmodell wird versucht, den Veränderungen, die das höhere Lebensalter mit sich bringt, gerecht zu werden (Olbrich 1987). Es versteht Verhalten im Alter genau wie in jedem anderen Abschnitt des Lebens - als eine Funktion von Anforderungen an die Person und deren Ressourcen zur Bewältigung. Das Modell ist weniger orientiert an bestimmten, verbindlich von außen gesetzten Normen, sondern betont vielmehr die in einer je gegebenen Lebenssituation mit ihren personen- und umweltspezifischen Komponenten ablaufenden Prozesse des Verhaltens und Erlebens.

Im Alter sind besonders zwei psychische Komponenten für die Kompetenz wich tig: Intelligenz und Kontrolle. Intelligenz ist eine wesentliche Voraussetzung für er- 
folgreiche Transaktionen der alternden Personen mit ihrer sozialen und sachlichen Umwelt. In den letzten Jahrzehnten haben sich bei älteren Menschen nicht nur die intellektuellen Voraussetzungen für eine aktive Bewältigung von Anforderungen aus der Umwelt verbessert, sondern auch die Möglichkeiten zur Steigerung kognitiver Fähigkeiten und Fertigkeiten. Aufgrund von Untersuchungen an verschiedenen Alterskohorten zeigen sich dabei vor allem die Auswirkungen der inzwischen allgemein längeren Schul- und Ausbildung.

In vielen Forschungen zur Intelligenz konnte zudem bewiesen werden, daß selbst im höheren Lebensalter noch Kapazitätsreserven im kognitiven Bereich vorhanden sind, die durch entsprechendes Training aktiviert werden können. So wurde in einer neueren Untersuchung durch die Methode des Testing-the-Limits aufgezeigt, daß trainierte ältere Erwachsene sogar die Leistungen jüngerer, untrainierter Erwachsener übertreffen können (Staudinger \& Baltes 1995).

Bei einer anderen Studie zur kognitiven Leistungsfähigkeit (Shimamura et al. 1995) wurde gezeigt, daß ältere Professoren sogar höhere Leistungen erbrachten als eine jüngere Kontrollgruppe von Standardpersonen. Das bedeutet, daß nicht allein das Lebensalter, sondern insbesondere Faktoren wie Sozialisation, Bildungsniveau und vor allem Lebensführung maßgeblich sind für die Leistungsfähigkeit der Menschen - und ganz besonders der älteren Menschen.

Die zweite wichtige Komponente der Alterskompetenz ist Kontrolle. Kontrollüberzeugungen sind besonders wichtig für die Erhaltung von Kompetenz im Alter. Forschungen innerhalb der Ökologischen Psychologie haben bereits vor mehr als zwanzig Jahren deutliche Korrelationen zwischen erlebter Unveränderlichkeit der eigenen Situation und anderen Erlebens- und Verhaltensvariablen gezeigt. Möglichkeiten, die eigene Situation aktiv zu verändern, wirkten sich signifikant positiv auf den physischen und psychischen Zustand der untersuchten älteren Personen aus (Langer \& Rodin 1976).

Es war auch vor allem die Ökologische Psychologie, in deren Rahmen die theoretischen Aspekte des Kompetenzmodells herausgestellt wurden. So entwickelte Lawton (1982) ein Modell, bei dem er Kompetenz als die theoretisch oberste Kapazitätsgrenze der Person sieht, um in den Bereichen biologische Gesundheit, Sinneswahrnehmung, motorisches Verhalten und Kognition zu funktionieren. In seinem ökologischen Alternsmodell wird Verhalten als eine Funktion der Kompetenz des Individuums und des Aufforderungscharakters oder Drucks der Situation gesehen. Lawton geht davon aus, daß eine Person dazu tendiert, sich an jeglichen Stimulationslevel anzupassen, und zwar in der Weise, daß das Bewußtsein des Stimulus mit der Zeit nachläßt. Gleichzeitig besagt seine Hypothese, daß eine Person um so relativ unabhängiger von Verhaltensauswirkungen durch Umweltdruck ist, je höher ihre Kompetenz ist, während bei einer niedrigen Kompetenz die Empfindlichkeit gegenüber Umweltbelastungen höher wird. Bei einer leichten Überforderung des aktuellen Adaptationslevels entsteht ein Bereich maximalen Verhaltenspotentials (zone of maximum performance potential), bei leichter Unterforderung ein Bereich maximalen Komforts (zone of maximum comfort). Wird die Über- oder Unterforderung zu groß, hat dies schlecht angepaßtes Verhalten zur Folge. In Erweiterung dieses Ansatzes durch den Begriff der Proaktivität betont Lawton (1989), daß alte Menschen durchaus nicht nur auf eine vorhandene Umwelt reagieren können, sondern sogar in der Lage sind, Umwelten aktiv derart zu verändern, daß auch selbst gewünschtes Verhalten (wieder) möglich wird. 


\subsection{Erfolgreiches Altern}

Schon seit längerem hat die Forschungsgruppe um Paul und Margret Baltes nachweisen können, daß Altern - wie bereits erwähnt - nicht nur Verlust, sondern auch Gewinn bedeutet, das heißt, daß der Alternsprozeß vor allem als ein komplexes, dynamisches Geschehen zu sehen ist. In diesem Zusammenhang wurde der Begriff des „erfolgreichen Alterns" eingeführt. Wichtig dabei ist, daß erfolgreiches Altern sich nicht an von außen festgesetzten Normen orientiert, sondern vor allem als aktive Leistung des jeweiligen Menschen anzusehen ist und abhängt von seinen oder ihren Fähigkeitsbereichen und Zielen (Baltes \& Carstensen 1996).

Eine Strategie erfolgreichen Alterns wird in dem Modell der Optimierung durch Selektion und Kompensation als Antwort auf diese Problematik dargestellt (Baltes \& Baltes 1989; 1990a,b). Entwicklung und Altern werden dabei als ein Spezialisierungsprozeß angesehen, in dem sich vor allem bei biologischen Kapazitätsreserven alternsbedingte Verluste ergeben, in der Pragmatik der Intelligenz dagegen, das heißt dem im Laufe des Lebens erworbenen Wissen, auch alternsabhängige Fortschritte auftreten. Selektion resultiert aus der Annahme, daß eine verringerte Kapazitätsreserve und der alternsbedingte Anstieg von Verlusten eine Reduzierung von verschiedenen Hochleistungsbereichen erforderlich machen. Optimierung läßt sich aus der Annahme ableiten, daß es trotz höheren Alters möglich ist, in diversen Bereichen einen hohen Funktionsgrad aufrechtzuerhalten, zum einen durch ständige Praxis, zum anderen durch den Erwerb neuen Wissens und neuer Praktiken. Kompensation wird entscheidend, wenn die Lebensaufgaben einen Kapazitätsgrad erfordern, der außerhalb des aktuellen Fähigkeitsgrades liegt. Besonders in Situationen hoher geistiger oder physischer Anforderungen wird Kompensation erforderlich.

Zwar beschreiben Selektion, Kompensation und Optimierung einen allgemeinen Vorgang der Anpassung, der wahrscheinlich prinzipiell auf die meisten Lebensvorgänge zutrifft, im Alter erhalten diese Prozesse jedoch aufgrund des bereits erwähnten Verlustes an biologischen, mentalen und sozialen Kapazitätsreserven eine neue Gewichtung und Dynamik. Selektion bedeutet dann, daß sich die alternde Person auf Bereiche von besonders hoher Priorität konzentriert, wo Umweltanforderungen, persönliche Motive, Fertigkeiten sowie biologische Leistungsfähigkeit in einem Gleichgewicht stehen. Dadurch wird mit ansteigendem Alter eine immer ausgeprägtere Spezialisierung sowohl im Inhalt als auch in der Form von Lebenswelt und Handlungsräumen notwendig. Durch Optimierung suchen Menschen die von innen eingeschlagenen Lebenswege in Quantität und Qualität zu verbessern. Ein besonders anschauliches Beispiel von Optimierung durch Selektion und Kompensation ist Artur Rubinstein, der im Alter von über achtzig Jahren seine hohe Leistung als Pianist dadurch aufrechterhielt, daß er sein Repertoire reduzierte, verstärkt übte und spezielle Strategien entwickelte, wie beispielsweise das Verlangsamen seines Klavierspiels vor schnelleren Passagen, um so den Eindruck größerer Schnelligkeit zu erwecken.

Erfolgreiches Altern im Sinne einer Lebenszufriedenheit im Alter wird auch erreicht durch die kompetente Bewältigung von schwierigen sozialen Situationen. Der ältere Mensch, der es geschafft hat, für inn schwerwiegende Probleme zu lösen oder besondere Widrigkeiten zu bewältigen, wird dadurch ein psychisches und möglicherweise auch physisches Wohlbefinden erlangen. Erfolgreiches Altern hängt eng mit dieser Fähigkeit zusammen, mit Schwierigkeiten fertig zu werden und auch sozialen Rollenanforderungen gerecht zu werden (Lehr 1989). Die Forschungsarbeiten 
zu Coping - einem Bewältigungsverhalten, das die kognitiven, emotionalen und verhaltensmäßigen Reaktionen einer Person im Rahmen der Konfrontation und unmittelbaren Auseinandersetzung mit Altagsproblemen, Dauerbelastungen oder kritischen Lebensereignissen umfaßt - haben hier wichtige Erkenntnisse erbracht (Filipp 1990; Lazarus 1990; Saup 1990). So wird deutlich, daß etwa gerade diejenigen Personen, die im Laufe ihres Lebens mit kritischen Lebensereignissen konfrontiert worden waren und diese bewältigen konnten, hierbei Ressourcen entwickelt hatten, die ihnen dann auch noch im Alter zur Streßbewältigung zur Verfügung standen.

Ein weiterer Begriff, der mir im Zusammenhang mit dem vorliegenden Thema wichtig erscheint, ist "Weisheit“. Weisheit hängt eng mit Lebenswissen zusammen und umfaßt Einsichten in die eigenen Stärken und Schwächen, Wünsche und Reaktionsweisen, beinhaltet aber auch Kenntnisse über die Stärken und Schwächen, Wünsche und Reaktionsweisen der anderen. Wenn diese Kenntnisse und Fähigkeiten in grundlegenden Lebensfragen in sehr hohem Maße und in hoher Qualität vorliegen, wird von Weisheit gesprochen: Sie manifestiert sich insbesondere in einem reifen Urteil und guten Ratschlägen bei schwierigen und ungewissen Lebensproblemen. Allerdings ist längeres Leben allein keine ausreichende Bedingung, um lebenserfahren oder gar weise zu werden. Auch zu diesem Thema hat die BaltesGruppe beachtliche Forschungsergebnisse aufzuweisen (Baltes, Staudinger, Maercker \& Smith 1995; Staudinger \& Baltes 1996).

Diese verschiedenen dargestellten Forschungsergebnisse werden in ihrem Stellenwert deutlich, wenn wir uns klar machen, daß Altern ein lebenslanger Prozeß ist, der mit der Geburt einsetzt und mit dem Tod endet und in dessen Verlauf sich die Person sowohl körperlich als auch geistig entwickelt. Entwicklung bedeutet Lernen; sie bedeutet sowohl Wachstum als auch Verlust, vom Anfang bis zum Ende. Es gibt keinen Punkt im Laufe eines Lebens und keinen Bereich, wo es nicht prinzipiell möglich wäre, sich weiterzuentwickeln.

Der Bereich, der im Zusammenhang mit dem vorliegenden Thema besonders interessiert, betrifft Kommunikation und Sprache. Sprach- und Kommunikationsverhalten hängen eng mit der kognitiven Entwicklung beziehungsweise den kognitiven Fähigkeiten zusammen. Und wie die kognitiven Fähigkeiten das Resultat des Zusammenspiels von Biologie und Kultur sind (Staudinger \& Baltes 1995), erscheint es plausibel, daß dies auch auf das Sprach- und Kommunikationsverhalten zutrifft. Warum sollte, wenn bei normal alternden, gesunden Menschen die kognitiven Fähigkeiten erwiesenermaßen bis in die späten Lebensjahre erhalten bleiben können, nicht auch die Kommunikations- und Sprachfähigkeit erhalten bleiben? Warum sollte ein geistig gesunder älterer Mensch plötzlich anders sprechen als in jüngeren Jahren?

\section{Sprache und Kommunikation im Alter}

Diese Fragen führen wieder zurück zu meiner Anfangsthese. Bekanntlich ist Verhalten eine Funktion von Person und Umwelt. Das bedeutet, daß eine Änderung in der Umwelt einer Person, die sowohl räumliche als auch soziale und psychische Komponenten enthält, auch eine Änderung ihres Verhaltens bewirkt und damit auch ihres Sprachverhaltens. 


\subsection{Untersuchungsgegenstand}

Um meinen Gedankengang genauer darzulegen, möchte ich auf eine Untersuchung zurückgreifen, die ich 1994 über Teilnehmer eines Studienprogramms für Ältere durchgeführt habe. Mich interessierte die Frage, warum ältere Menschen sich noch einmal der Anstrengung eines Studiums unterwerfen, und ich bin dabei ebenfalls darauf gestoßen, daß die Biographie eines Menschen maßgeblich verantwortlich dafür ist, wie er oder sie sich auch im Erwachsenenalter noch entwickeln kann (Brose 1994). Es stellte sich heraus, daß bei Menschen, die durch die Widrigkeiten der Kriegs- und der Nachkriegszeit daran gehindert worden waren, ein bestimmtes Lern- und Lebensziel zu erreichen, dieser Wunsch nach wie vor so stark war, daß sie sich nach Beendigung der Berufs- oder Familienphase für eine Wiederaufnahme intensiven und gezielten Lernens entschieden. Durch die errungenen Lernerfolge fühlen sie heute eine tiefe Befriedigung.

Aufgrund dieser Ergebnisse meiner Untersuchung und unter Berücksichtigung der oben dargestellten Forschungsergebnisse zur kognitiven Entwicklung stelle ich die These auf, daß - ebenso wie für die kognitive Entwicklung und Leistungsfähigkeit auch für die Sprachentwicklung und die kommunikativen Fähigkeiten älterer Menschen vergleichbare Erklärungsmuster greifen. Nicht das Lebensalter eines Menschen ist bestimmend für die Art, wie er oder sie kommuniziert, sondern vor allem, wie er oder sie bereits als junger Mensch zu kommunizieren gelernt hat, welche Möglichkeiten er oder sie hatte, diese Kommunikation zu pflegen, und besonders, wie seine oder ihre jetzige Lebenssituation aussieht. Ich könnte auch sagen: Sprach- und Kommunikationsverhalten hängen nicht von einem bestimmten Lebensalter ab, sondern stellen eine Funktion von Sozialisation, Bildung, Erfahrung, Lebensführung und ganz besonders von der aktuellen Lebenssituation dar - und damit vor allem von sozialen Faktoren. Dabei muß selbstverständlich auch der Gesundheitszustand berücksichtigt werden.

\subsection{Vorgehensweise der Untersuchung}

Auf der Basis dieser Hypothese habe ich die Transkripte der Interviews aus meiner Untersuchung der älteren Studierenden - nunmehr aus linguistischer Perspektive erneut einer Analyse unterzogen. Da die damals Untersuchten jedoch maximal Mitte sechzig Jahre alt waren, habe ich zusätzlich Interviews mit über siebzigjährigen Personen gemacht - drei davon um die achtzig -, um eventuelle Unterschiede festzustellen. Zwei dieser zusätzlich interviewten Personen gehören nicht zu der Gruppe der älteren Studierenden.

Bei den genannten Interviews handelt es sich um narrative Interviews (vgl. Schütze 1983). Ich habe meinen Gesprächspartnerinnen und Gesprächspartnern zunächst ein wenig von meinem Forschungsinteresse und meinem eigenen späten Studium erzählt und sie dann gebeten, mir über ihr Leben zu berichten. Daraus ergaben sich zusammenhängende Texte mit kontinuierlichem Erzählfluß. Erst nachdem eine offensichtliche Koda, das heißt ein deutlicher Erzählabschluß, erreicht worden war, ergab sich durch Nachfragen ein mehr dialogischer Text.

Im Gegensatz zu meiner ursprünglichen Untersuchung, bei der die Texte mit hermeneutischen und psychoanalytischen Methoden untersucht wurden, habe ich sie nunmehr einer linguistischen Sequenzanalyse unterzogen. Dabei habe ich vor allem 
auf den Erzählfluß, die Erzählweise und eventuelle Auffälligkeiten geachtet. Insbesondere wollte ich herausfinden, ob die älteren Menschen oft zugeschriebenen Sprachcharakteristika wie Wortfindungsstörungen, häufige Themensprünge, veraltete Lexik und ähnliches tatsächlich zutreffen. Ich habe mich dabei weitgehend orientiert an Kategorien und Merkmalslisten, die in einigen Veröffentlichungen als mögliche Vorgehensweise angesehen werden, Alter im Sinne von höherem Lebensalter anhand des kommunikativen Verhaltens zu erkennen. Unter anderem werden folgende Merkmale aufgeführt (Coupland, Coupland \& Giles 1991; Fiehler 1997):

- Nennen des kalendarischen Alters,

- qualitative Altersbestimmungen und Nennung altersgebundener Kategorien und Rollen,

- Thematisierung altersbezogener Phänomene wie Abbau, Krankheit, Tod,

- Hinzufügen einer Vergangenheitsperspektive,

- Thematisierung von kulturellem und gesellschaftlichem Wandel,

- Identifikation mit der Vergangenheit.

Bei der sequenzanalytischen Untersuchung habe ich versucht, einige dieser Merkmale aufzufinden, um festzustellen, inwieweit sich eine solche Liste als heuristisches Instrument verwerten läßt.

Bei allen Texten fällt auf, daß die Erzählung lebhaft und ausführlich dargeboten wird. Bei den Teilnehmerinnen und Teilnehmern des Programms "Studieren ab 50“ steht verständlicherweise die Studienaktivität im Vordergrund und alles, was mit Wissen und Lernen zusammenhängt. Sie alle stehen sozusagen mitten im Leben, auch wenn sie inzwischen längst über das Alter einer normalen Berufstätigkeit hinaus sind: So ist beispielsweise eine Teilnehmerin inzwischen achtzig Jahre alt, und ihr Tag ist ausgefüllt mit Studieren, sozialen Aktivitäten und vielen anderen Interessensgebieten.

- Nennen des kalendarischen Alters

Bei der Durchsicht der verschiedenen Transkripte bin ich jeweils höchstens einmal auf eher implizites Erwähnen des Alters gestoßen, das dann jedoch wie im folgenden Beispiel im Zusammenhang mit Studienaktivitäten thematisiert wurde.

Ich würde nie sagen, also die ... eh die die lehnt mich ab oder so, die mag mich nicht, daß wir Älteren hier studieren, nein, gar nicht. (U.L., 79 J.)

- Thematisieren von Abbau, Krankheit, Tod

Über Krankheit oder Tod wurde überhaupt nicht gesprochen - mit einer Ausnahme, wo eine Frau über lang zurückliegende Herzprobleme berichtet, die sich im nachhinein als psychosomatisch bedingt herausstellten und die durch ihre heutigen Aktivitäten längst überwunden sind.

Und ich war vor einigen Jahren zur Kur. [...] ich hatte durch diese. ja Hemmungen und durch dies ganze. Durcheinander, als mein Mann wegging undsoweiter, so Herzbeschwerden. Und da hat man mich doch tatsächlich in so 'ne Herzklinik zur Kur geschickt . [...] (H.B., 61 J.) 
Über das Gedächtnis wird schon einmal geklagt, aber meines Erachtens ist dies kein Spezifikum von Älteren, sondern trifft auch auf Jüngere zu, nur wird dies hier anders interpretiert.

Also das Gedächtnis läßt doch nach, muß ich sagen, man man ich muß ganz intensiv. lernen, um zu begreifen und das immer wieder lesen und erinnern [...] (U.L., 79 J.)

- Nennung altersbezogener Rollen

Altersbezogene Rollen werden nur insofern erwähnt, als etwa - am Rande - die Betreuung von Enkelkindern neben der eigenen Studientätigkeit zur Sprache kommt.

[...] und dann. muß ich spurten und schnell sehen, daß ich in mein Auto komme, weil mein Enkelsohn. vom Kindergarten um zwölf abgeholt werden muß (Lachen). Ich hab nämlich meine Enkelkinder auch noch zu versorgen zu Hause [neben dem eigenen Studium, R.B.]. (M.Z., $66 \mathrm{~J}$.

- Hinzufügen einer Vergangenheitsperspektive

Alle Personen weisen noch eine starke Zukunftsorientierung auf. Ganz besonders deutlich wird dies im folgenden Beispiel:

Sagen wir mal, mein ziel ist, fertig zu sein [mit dem studium, R.B.], wenn mein Mann in Ruhestand geht, und. dann würd ich Ruhe geben. [...] Vielleicht. mach ich dann weiter, vielleicht hab ich dann große Projekte. Ich hab keine Ahnung, aber wie gesagt, das ist, das ist Zukunftsmusik, und darüber denk ich heut noch nicht nach. (B.R., 58 J.)

Zwar wird auch von der Vergangenheit gesprochen, was beim Sprechen über den eigenen Lebenslauf nicht zu vermeiden ist. Dies ist aber keinesfalls mit der Einnahme einer Vergangenheitsperspektive zu verwechseln.

- Wortfindungsstörungen, veraltete Lexik

Wortfindungsstörungen treten höchst selten auf, auf keinen Fall in einem von Jüngeren abweichenden Grad. Veraltete Lexik war ebenfalls nicht nachweisbar.

Besonders interessant in bezug auf die Lernfähigkeit älterer Menschen erscheinen mir folgende Aussagen:

Also, ich will damit sagen, ich bin eine von den studierenden, die wirklich alles erlernen mußte . alles, nicht.

[...] und dann hab ich ja auch sehr viel Latein lernen müssen, nicht, eh erstensmal in der Theologie und in der Geographie

Ich mußte mir eben Wörterbücher anschaffen, um die Begriffe kennenzulernen, nicht [...] Das hab ich dann gemacht, und wie ich alles gelöst hab, ja. ich hab mich hin in die Bücher gekniet, und ich habe eben auch mit Frau B. oft zusammengearbeitet, und wir haben dann eben so lange eben daran gearbeitet, bis wir es verstanden haben und bis wir's erklären konnten (U.L., 79 J.) 
Das andere. Probleme . äh hatte ich zu Anfang . mit den Fremdwörtern, weil da doch in Soziologie oder in Theologie, Geschichte und so äh dann doch sehr viele Fremdwörter vorkommen, ob aus dem Lateinischen oder Englischen, Französischen . und da hab ich dann eben das so gemacht, daß ich dann. äh ja, genau gelöst, indem ich mir die Fremdwörter so, wie ich sie verstanden hab, einfach aufgeschrieben hab und zu Hause dann im wörterbuch nachgeschaut.

[...] ich will es, solange ich kann, eben weitermachen. Und ich lerne so viel, und je mehr ich lerne, desto mehr sehe und merke ich, daß ich noch sehr viel zulernen müßte. (H.B., 61 J.)

Während es in den vorgenannten Beispielen viele Gemeinsamkeiten gab, zeigte sich allerdings ein bemerkenswerter Unterschied zwischen den Interviews mit den zwei Personen, die nicht an dem Studienprogramm teilnehmen. Ihre heutigen Lebensbedingungen sind sehr ähnlich. Beide Frauen leben seit einigen Monaten in einer Seniorenwohnanlage, jeweils in einer eigenen Zwei-Zimmer-Wohnung. Beide Frauen sind verwitwet, gesund, geistig sehr rege und sehr aktiv, die eine ist dreiundachtzig, die andere achtundsiebzig. Unterschiedlich bei diesen Frauen ist allerdings der frühere Lebensweg. Die Achtundsiebzigjährige, mit einer mittleren Schulausbildung sowie einer Berufsausbildung, war bis zu einer späten Wiederverheiratung vor fünfundzwanzig Jahren immer berufstätig und hat sich im Laufe ihres Lebens mit vielen Schwierigkeiten auseinandersetzen müssen. Die Dreiundachtzigjährige stammt aus einer Akademikerfamilie und hat Abitur, verspürte aber entgegen dem Wunsch des Vaters keinerlei Neigung zum Studium und übte nur, nachdem sie eine Zeitlang - wie sie selbst sagt - überhaupt nichts getan hatte, für eine kurze Zeit bis zu inrer Heirat eine angelernte Bürotätigkeit aus. Sie betont, daß sie es immer gut gehabt habe.

Ja nun also, und dann hab ich/ eh da hat mein Vater gesagt, ich soll studieren, das wollt ich aber nicht.. Jura, das war mir zu dumm alles. Weil mein Vater Jurist und mit'n Akten darum arbeitete, war mir zu trocken. Ja, da hab ich erst mal gar nichts gemacht. (H.S. -83 J.)

Während sich die Art des Erzählens und die sprachliche Darbietung bei der Achtundsiebzigjährigen nur minimal von der der Studienteilnehmerinnen und teilnehmer unterscheidet, zeigt sich bei der Dreiundachtzigjährigen ein auffälliges Sprachbild. Sie springt in ihrem Erzählen von einem Thema zum andern. Das heißt, sie fängt eine Erzählung an, schiebt einen neuen Gedankengang ein, findet aber trotz allem zu ihrer alten Erzählung zurück. Für die Zuhörerin ist es allerdings schwierig, mit dem Gang der Dinge Schritt zu halten. Es findet sich keine Kontinuität der Erzählung, wie dies bei allen anderen Interviewten der Fall war. Außerdem schweift die Erzählerin häufig in Klatschgeschichten ab. Folgende Passage ist nur ein Beispiel von vielen; die gesamte Erzählung ist entsprechend gestaltet.

Ja, also geboren bin ich in Thorn, ja. . Sie werden ja wissen, wo das liegt wahrscheinlich (Lachen) manche wissen's nämlich komischerweise nicht. Ja, und . da hab ich zwei Jahre verbracht, die weiß ich natürlich von gar nichts mehr, ist ja logisch. Und . eh da war mein Vater Amts . richter am am am Amtsgericht. Und im übrigen hab ich das vor fünf Jahren oder sechs Jahren besucht. Ich wollte gerne mein Geburtshaus sehen, ja. Und das Geburtshaus steht, ganz 
toll ist. vorne eh denkmalgeschützt, aber es . da warn wir vorne eine Fassade, hinten. Durchgang dürfen Sie nicht schauen. . Ja . und es war lustig, ich bin... eh deswegen auch nochmal hin, weil. von meiner Tochter eine frühere studentin, die jetzt Juristin ist, die stammte aus Thorn, und die hat uns zusammengebracht auch, ja, daß wir uns. irgendwie mal treffen und so. Die war auch bei meinem Geburtstag. Und eh der Vater von ihr der ist Professor in Thorn. Historiker. Und . die haben mich dann auch in Thorn rumgefahren. • Und es war eigentlich ganz nett, war ich bei denen auch zu Hause, nicht. Ja, also jedenfalls mein Vater war da, bis bis ich denn zwei Jahre war, dann waren wir denn in Berlin, und dann hab ich in Berlin meine Kindheit erlebt. Zwischendurch war mein Vater als Reserveoffizier aber auch mal in Polen, in Ostrowo, das liegt also irgendwie südlich auch. (H.S., 83 J.)

Meinem Verständnis nach zeigt sich hier deutlich, wie sehr das Verhalten eines Menschen von der durchlaufenen Entwicklung abhängt und wie wichtig dabei ganz besonders die tätige sowie ständige Auseinandersetzung und Bewältigung von auftretenden Problemen oder Entwicklungsaufgaben ist.

\section{Schlußfolgerungen}

Natürlich können diese wenigen Interviews noch nicht schlüssig Auskunft über den Zusammenhang von Sprache und Kommunikation mit den verschiedenen aufgeführten Faktoren geben. Bei Betrachtung der Transkripte aus dem Textkorpus von Anne Bettens Erhebung in Israel (Betten 1995 und i.d.Bd.) fühle ich mich jedoch ebenfalls in meiner Annahme gestützt. Auch hier sind es Menschen, die sich trotz ihres hohen Alters und trotz oder vielmehr gerade wegen der vielen Anforderungen, die an sie gestellt wurden, einen hohen Grad an Sprachfähigkeit bewahrt haben. Auch sie sind, wie die von mir interviewten Teilnehmer und Teilnehmerinnen des Studienprogramms „Studieren ab 50“, immer aktiv gewesen und sind es noch heute. Diese ständige Möglichkeit zur Kommunikation trägt ganz sicher bedeutsam zur Aufrechterhaltung des hohen Sprachniveaus bei.

So wie Intelligenzunterschiede zwischen Personen verschiedener Altersgruppen nur in geringem Maße auf das kalendarische Alter zurückgehen, sondern vor allem auf unterschiedliche Sozialisationsprozesse und Bildungsniveaus sowie die heutige Lebenssituation, so wird dies auch auf das Kommunikations- und Sprachverhalten zutreffen. Damit wird auch vor allem ein Kohorteneffekt wirksam.

Um in der Folge zu einer exakteren Aussage bezüglich des Zusammenhangs zwischen Lebenssituation und Sprache zu gelangen, müßten zunächst entsprechende Untersuchungen auch mit jüngeren Menschen durchgeführt werden, die in vergleichbaren Lebenssituationen wie die untersuchten Älteren leben. Es ist mir bewußt, daß dies keine leichte Aufgabe ist.

Wünschenswert wäre auch, daß authentische Gespräche sowohl zwischen Älteren als auch zwischen Älteren und Jüngeren sowie zwischen Jüngeren aufgezeichnet würden, um sie auf bestimmte Kriterien hin untersuchen zu können. Dies könnte dazu beitragen, die Vielschichtigkeit von Kommunikation und Sprache - wie sie sich während des gesamten Lebens und im besonderen im Alter zeigt - zu erkennen und entsprechende Konsequenzen daraus zu ziehen.

Hinzu kommt, daß alle bisherigen Untersuchungen vor allem Querschnittsuntersuchungen gewesen sind. Um jedoch überhaupt zu exakten Aussagen über mögli- 
che Alternseffekte zu kommen, müßten Längsschnittuntersuchungen über einen längeren Zeitraum hinweg durchgeführt werden, um das Zusammenwirken der vertikalen Einflußkomponenten wie Sozialisation, erreichtem Bildungsniveau sowie durchlebten Ereignissen und der horizontalen Einflußkomponenten wie aktueller Lebenssituation sowie Sprechsituation aufzuweisen.

Wenn Sprache und Kommunikation im Alter - wie von mir behauptet - eine Funktion aus Sozialisation, Bildungsgrad, Erfahrung, bisheriger Lebensführung und aktueller Lebenssituation darstellen, so wäre die Konsequenz aus einer solchen Erkenntnis, daß bereits in jungen Jahren durch entsprechende Erziehung frühzeitig Bildungsinteressen geweckt und damit Entwicklungsmöglichkeiten gefördert werden müßten. Eine gute Kommunikation ist wichtig, um Gesundheit über die gesamte Lebensspanne zu erreichen. Das heißt für eine zukunftsorientierte Gesellschaft, daß bereits in Kindheit und Jugend die Grundlagen für ein erfolgreiches Altern gelegt werden müssen, indem durch eine qualifizierte Bildung vor allem die Entwicklung kognitiver und kommunikativer Kompetenzen gefördert wird. Auf dieser Grundlage wird es möglich, daß auch im Alter neuartige kognitive Probleme gelöst werden können und weiterhin Interesse an neuen Wissensinhalten sowie an kognitiver Weiterentwicklung besteht. Dies ist die Voraussetzung für die Erhaltung der Kommunikations- und Sprachfähigkeit bis zum Lebensende. Auf diese Weise wird erfolgreiches Altern im Sinne von mehr Lebensjahren mit mehr Lebensqualität ermöglicht.

\section{Literatur}

Baltes, Margret M. \& Carstensen, Laura L. (1996). The process of successful aging. In: Ageing and Society 16, 397-422.

Baltes, Paul B. \& Baltes, Margret M. (1989). Optimierung durch Selektion und Kompensation. Ein psychologisches Modell erfolgreichen Alterns. In: Zeitschrift für Pädagogik 35, 85-105.

Baltes, Paul B. \& Baltes, Margret M. (1990a). Successful Aging. Perspectives from the Behavioral Sciences. Cambridge.

Baltes, Paul B. \& Baltes, Margret M. (1990b). Psychological perspectives on successful aging: The model of selective optimization with compensation. In: Baltes, P. B \& Baltes, M. M.(eds.), Successful Aging. Perspectives from the Behavioral Sciences. Cambridge, 1-34.

Baltes, Paul B., Staudinger, Ursula M., Maercker, Andreas \& Smith, Jacqui (1995). People nominated as wise: A comparative study of wisdom-related knowledge. In: Psychology and Aging 10 (2), 155-166.

Betten, Anne (Hrsg.) (1995). Sprachbewahrung nach der Emigration: Das Deutsch der 20er Jahre in Israel. Teil I: Transkripte und Tondokumente. Unter Mitarbeit von Sigrid Graßl. Tübingen: Niemeyer.

Brose, Roselore (1994). Lebensschicksal und Weiterbildung älterer Menschen: Eine qualitative Analyse am Beispiel von Teilnehmerinnen und Teilnehmern des Programms STUDIEREN AB 50. Bielefeld: AUE.

Cattell, Raymond B. (1971). Abilities: Their structure, growth, and action. Boston.

Collins, Caroline L. \& Gould, Odette N. (1994). Getting to know you: How own age and other's age relate to self-disclosure. In: International Journal of Aging and Human Development 39, 55-66.

Coupland, Nikolas, Coupland, Justine \& Giles, Howard (1991). Language, society and the elderly: Discourse, identity and ageing. Oxford/Cambridge: Blackwell.

Feezel, Jerry \& Hawkins, Robert (1988). Myths and stereotypes: Communication breakdowns. In: Carmichael, C. W., Botan, C. H. \& Hawkins, R.(eds.), Human communication and the aging process. Prospect Heights, IL: Waveland Press, 81-94. 
Fiehler, Reinhard (1997). Kommunikation im Alter und ihre sprachwissenschaftliche Analyse: Gibt es einen Kommunikationsstil des Alters? In: Selting, M. \& Sandig, B. (Hrsg.), Sprech- und Gesprächsstile. Berlin/New York: de Gruyter, 345-370.

Filipp, Sigrun-Heide (1990): Lebensereignisse. In: Filipp, S.-H. (Hrsg.), Kritische Lebensereignisse. 2. erw. Auflage. München, 3-52.

Giles, Howard \& Williams, Angie (1994). Patronizing the young: Forms and evaluations. In: International Journal of Aging and Human Development 39, 33-53.

Hummert, Mary Lee (1994). Physiognomic cues to age and the activation of stereotypes of the elderly in interaction. In: International Journal of Aging and Human Development 39, 5-19.

Kemper, Susan (1992). Language and aging. In: Craik, F. I. M. \& Salthouse, T. A. (eds.), The Handbook of Aging and Cognition. Hillsdale, NJ: Erlbaum, 213-270.

Kemper, Susan (1994). Elderspeak: Speech accommodations to older adults. In: Aging and Cognition, $1,17-28$.

Langer, Ellen J. \& Rodin, Judith (1976). The effects of choice and enhanced personal responsibility for the aged: A field experiment in an institutional setting. In: Journal of Personality and Social Psychology 34, 191-198.

Lawton, M. Powell (1982). Competence, environmental press, and the adaptation of older people. In: Lawton, M. P., Windley, P. G. \& Byerts, T. O. (eds.), Aging and the Environment: Theoretical Approaches. New York, 33-59.

Lawton, M. Powell (1989). Behavior-relevant ecological factors. In: Schaie, K. W. \& Schooler, C. (eds.), Social Structure and Aging: Psycho-logical Processes, Hillsdale, N.J. 57-78.

Lazarus, Richard S. (1990). Streß und Streßbewältigung - Ein Paradigma. In: Filipp, S.-H. (Hrsg.), Kritische Lebensereignisse. 2. erw. Auflage. München, 198-232.

Lehr, Ursula (1986). Senioren morgen - Probleme und Chancen. In: Massow, M., Neu anfangen: Ein Ratgeber für ein aktives Leben nach dem Beruf. Mit Beiträgen von Ursula Lehr, Ulrich Beer und Sigrund von Hasseln. München, 15-31.

Lehr, Ursula (1989). Kompetenz im Alter - Beiträge aus gerontologischer Forschung und Praxis. In: Rott, Chr. \& Oswald, F. (Hrsg.), Kompetenz im Alter. Vaduz, 1-14.

Lehr, Ursula \& Thomae, Hans (Hrsg.) (1987). Formen seelischen Alterns. Ergebnisse der Bonner Gerontologischen Längsschnittstudie (BOLSA). Stuttgart.

Maas, Ineke \& Staudinger, Ursula M. (1996). Lebensverlauf und Altern: Kontinuität und Diskontinuität der gesellschaftlichen Beteiligung des Lebensinvestments und ökonomischer Ressourcen. In: Mayer, K. U. \& Baltes, P. B.(Hrsg.), Die Berliner Altersstudie. Berlin: Akademie Verlag, 543572.

Mayer, Karl Ulrich \& Baltes, Paul B. (Hrsg.) (1996). Die Berliner Altersstudie. Berlin: Akademie Verlag.

Olbrich, Erhard (1987). Kompetenz im Alter. In: Zeitschrift für Gerontologie 20, 319-330.

Reischies, Friedel M. \& Lindenberger, Ulman (1996). Grenzen und Potentiale kognitiver Leistungsfähigkeit im Alter. In: Mayer, K. U. \& Baltes, P. B. (Hrsg.), Die Berliner Altersstudie. Berlin: Akademie Verlag, 351-377.

Rott, Christoph (1993). Ein Drei-Komponenten-Modell der Intelligenzentwicklung im Alter. Ergebnisse aus der Bonner Gerontologischen Längsschnittstudie. In: Zeitschrift für Gerontologie 26, $184-$ 190.

Ryan, Ellen Bouchard, Meredith, Sheree D., MacLean, Michael J. \& Orange, J. B. (1995). Changing the way we talk with elders: Promoting health using the communication enhancement model. In: International Journal of Aging and Human Development 41 (2), 89-107.

Ryan, Ellen Bouchard, Hamilton, J. M. \& Kwong See, S. T. (1994). Patronizing the old: How do younger and older adults respond to baby talk in the nursing home? In: International Journal of Aging and Human Development 39, 21-32.

Saup, Winfried (1990). Formen der Lebensbewältigung im Alter. In: Mayring, P. \& Saup, W. (Hrsg.), Entwicklungsprozesse im Alter. Stuttgart, 185-200.

Schütze, Fritz (1983): Biographieforschung und narratives Interview. In: Neue Praxis 13, 283-293.

Shimamura, Arthur P., Berry, Jane M., Mangels, Jennifer A., Rusting, Cheryl L. \& Jurica, Paul J. (1995). Memory and cognitive abilities in university professors: Evidence for successful aging. In: Psychological Science 6 (5), 271-277. 
Staudinger, Ursula M. \& Baltes, Paul B. (1995). Gedächtnis, Weisheit und Lebenserfahrung im Alter: Zur Ontogenese als Zusammenwirken von Biologie und Kultur. In: Dörner, D. \& van der Meer, E. (Hrsg.), Das Gedächtnis: Probleme - Trends - Perspektiven. Göttingen: Hogrefe, 433-484.

Staudinger, Ursula M. \& Baltes, Paul B. (1996). Weisheit als Gegenstand psychologischer Forschung. In: Psychologische Rundschau 47, 57-77.

Thimm, Caja (1995). Intergruppenkommunikation, soziales Vorurteil und konversationale Implikaturen: Alt und Jung im Dialog. In: Liedtke, F. (Hrsg.), Implikaturen. Tübingen: Niemeyer, 187-208.

Thomae, Hans (1993). Die Bonner Gerontologische Längsschnittstudie (BOLSA). In: Zeitschrift für Gerontologie 26, 142-150.

Watzlawick, Paul, Beavin, Janet H. \& Jackson, Don D. (1967). Human communication: A study of interactional patterns, pathologies, and paradoxes. New York: Norton.

Weinert, Franz E. (1992). Altern in psychologischer Perspektive. In: Akademie der Wissenschaften zu Berlin, Zukunft des Alterns und gesellschaftliche Entwicklung. Hrsg. von Paul B. Baltes und Jürgen Mittelstraß. Forschungsbericht Nr. 5. Berlin, 180-203. 


\title{
Sprachverhalten im Alter
}

\section{Beobachtungen und Diskussionen zum Begriff des Altersstils}

\author{
Dieter Cherubim / Suzanne Hilgendorf
}

\section{Einleitung}

Das Alter des Menschen in seinen unterschiedlichen Erscheinungsformen und der komplexe Prozeß des Alterns sind schon seit langem Gegenstände alltagsweltlichen Nachdenkens und wissenschaftlicher Reflexion. Alte oder sogar hochbetagte Menschen kommen z.B. relativ häufig in Märchen oder Sagen ${ }^{1}$ vor, und philosophische Diskussionen über das Glück oder Unglück des Alters reichen bis weit in die Antike zurück. ${ }^{2}$ Alter und Altern werden dabei oft als ambivalent empfunden: Sie können Auslöser von Bewunderung oder Faszination, häufiger jedoch von Angst, Ablehnung oder Verachtung sein. ${ }^{3}$ Ein hohes Alter zu erreichen war früher nur wenigen, vom Glück der Umstände Begünstigten vergönnt. Die Angaben über ein unvorstellbar hohes Alter der ersten Menschen (über 900 Jahre, heißt es) im Alten Testament ${ }^{4}$, können wir sicher nicht wörtlich nehmen; historisch-anthropologische Befunde über das tatsächlich erreichte Lebensalter in früheren Zeiten liefern uns eher ein anderes Bild. $^{5}$

Heute erreichen jedoch in bestimmten Regionen und unter bestimmten Lebensbedingungen immer mehr Menschen ein gleichsam „biblisches“ Alter. Meldungen in den Regionalzeitungen, daß die „Traumgrenze“ von 100 Jahren überschritten wird, sind nicht mehr selten. ${ }^{6}$ Aktuelle Spitzenwerte sind 121 Jahre für eine Frau (in

\footnotetext{
Vgl. die Hinweise z.B. bei Schenda (1977).
}

2 Als Klassiker gilt M.T. Ciceros berühmter Dialog Cato maior. De senectute liber, der 44 v.Chr. entstanden ist, seinerseits auf ältere (griechische) Arbeiten zu diesem Thema verweist (z.B. die vorbildhafte Szene zu Beginn von Platons Dialog Politeia : 328 c 8ff.) und von Jacob Grimm in seiner Rede über das Alter (1860/1984) wiederaufgegriffen wird. Vgl. dazu auch Schneidewin (1893).

3 Einzelheiten dazu bei Schenda (1977), vgl. auch Borscheid (1987).

4 Die bekannteste Stelle ist 1 . Mos. 5.

5 Nach Freye $(1986,146)$ ist die durchschnittliche menschliche Lebensdauer seit der Bronzezeit von etwa 18 auf mehr als 70 Jahre in Europa und Nordamerika gestiegen. Vgl. auch die Grafiken bei Hassan (1981) 122. Die mittlere Lebenserwartung stieg ebenfalls seit der Bronzezeit von etwa 18 Jahren auf über 70 Jahre heute, wobei zunächst ein sehr langsamer Anstieg, dann eine Verdoppelung der Lebenserwartung in den letzten 100 Jahren zu beobachten ist. Hinweise auf diese Daten und deren (hier nicht thematisierte) Problematik verdanken wir Frau Angelika Burkhardt (Braunschweig).

6 Nach einer Meldung der „Braunschweiger Zeitung“ vom 22.2.1995 gab es im Jahre 1993339000 Deutsche, die ihren 90. oder einen noch höheren Geburtstag feiern konnten. Davon waren 264000 weiblichen Geschlechts. Auch der Zuwachs war beträchtlich: Wurden 1950 nur 20000 Menschen 90 oder älter, so hatte sich deren Zahl 1960 verdoppelt, 1980 versiebenfacht und 1990 verzwölffacht. China oder der Balkan gelten traditionell als Regionen, wo viele Menschen ein hohes oder sogar sehr hohes Alter erreichen, obwohl man darüber kaum sichere Daten haben dürfte. Die „Braunschweigischen Landes-Zeitung“ vom 6.9.1896 meldete bereits, daß er in diesem Jahr in Irland bei 5 Mill. Einwohnern 576 Hundertjährige gab, in anderen Ländern mit einer wesentlich gröBeren Bevölkerung hingegen viel weniger (z.B. Spanien nur 401, Frankreich 213, Deutschland 
Frankreich) und 114 Jahre für einen Mann (in den USA). Altersforscher wie George Roth vom National Institute on Aging (Baltimore, Maryland/USA) untersuchen Faktoren, die ein hohes Alter begünstigen sollen, und halten in diesem Zusammenhang sogar eine Steigerung des menschlichen Alters bis zu 150 Jahren oder mehr für möglich. ${ }^{7}$ Entscheidend sind jedoch nicht die Spitzen-, sondern Durchschnittswerte bzw. die Streuung (Varianz). Auf eine einfache Formel gebracht läßt sich dennoch sagen, daß - zumindest in einigen Ländern Europas und Nordamerikas, aber auch in bestimmten Ländern Asiens - immer mehr Menschen immer älter werden. Diese Zunahme in der Population der alten Menschen führte nun nicht nur zu einer Reihe von gravierenden Problemen (z.B. ökonomischer, politischer und sozialer Art), sondern notwendigerweise auch dazu, daß das Interesse an Alter und Altersforschung in den letzten Jahren ständig gewachsen ist. Dabei standen naturgemäß die sozialen und psychologischen Probleme im Vordergrund. ${ }^{8}$ Umso erstaunlicher ist jedoch, daß ein damit zusammenhängender Aspekt bisher wenig oder kaum erforscht wurde: das Sprachverhalten von und mit alten Menschen. Obwohl Sprache als ein zentrales Mittel sozialer Organisation und individueller Selbstbestimmung angesehen wird, scheint doch das Thema „Sprache im Alter“ noch kein Gegenstand mit so klaren Konturen zu sein, daß eine systematische Erforschung im Rahmen eines einheitlichen Modells möglich wäre. Was bisher dominierte, war eher die Unterschiedlichkeit von Fragestellungen, Ausgangsbegriffen und Untersuchungsmethoden, so daß auch die bisher erarbeiteten Ergebnisse nur bedingt vergleichbar erscheinen.

Wir wollen daher im folgenden zunächst (2.) einige vorgreifliche Überlegungen zu einem Begriff von Sprache anstellen, der für eine solche Untersuchung tragfähig sein könnte, dann (3.) auf unsystematische Beobachtungen zum literarischen Altersstil einzelner Personen eingehen und (4.) einen Blick auf die aktuelle englischsprachige Forschung werfen, bevor wir (5.) an einem exemplarisch herausgegriffenen Brieftext einer über hundertjährigen Frau Merkmale von Sprachverhalten im Alter diskutieren, die uns besonders interessant erscheinen. Mit einigen Hinweisen wollen wir schließlich (6.) unseren ersten Annäherungsversuch an das Problem der Alterssprache beenden.

\section{Sprache im Alter}

Wir gehen davon aus, daß menschliche Sprachen sozial ausgehandelte und historisch tradierte Techniken kommunikativer Verständigung mittels komplexer semiotischer Systeme sind. Dabei umfaßt die übergreifende Verständigungsfunktion dieser Systeme ${ }^{9}$ verschiedene speziellere Funktionen wie z.B. die Erfassung und Strukturie-

78). Und in diesem Jahr geht eine Modellrechnung des Verbandes deutscher Rentenversicherungsträger davon aus, daß sich zwischen 1995 und 2040 die Anzahl der Personen in Deutschland, die 65 Jahre und älter sind, von 15\% auf 30\% verdoppeln werde (Braunschweiger Zeitung vom 17.9.1996).

7 Nach einer Meldung der Braunschweiger Zeitung vom 24.7.1996. Daß das nicht ganz abwegig ist, zeigt eine andere Meldung der gleichen Zeitung vom 31.3.1995: In diesem Jahr (1995) starb in China ein Mann mit 147 Jahren, der offiziell von den chinesischen Behörden als ältester männlicher Bürger der Volksrepublik anerkannt worden war.

8 Vgl. z.B. Schneider (1974), Lehr (1991).

9 W.v. Humboldt $(1827 / 1963,138)$ hat in diesem Zusammenhang von einem „unabänderlichen Dualismus" der Sprachen gesprochen. Soziologen wie Max Weber gehen beim sozialen Handeln, zu dem auch das Sprachhandeln gehört, prinzipiell von einer Gerichtetheit auf ein Gegenüber aus, 
rung von Wirklichkeit, die Organisation von materiellem und sozialem Handeln, die Orientierung in unterschiedlichen (räumlichen, zeitlichen, situativen, sozialen, epistemischen oder evaluativen) Bezugssystemen sowie die Selbstdarstellung und Einstellung auf andere in kommunikativen Akten. ${ }^{10}$ Die semiotischen Systeme, die in den einzelnen Sprachen unterschiedlich gestaltet (,parametrisiert“) sind, leisten die materielle Repräsentation und Distinktion der Zeichen selbst (Phonik/Graphik), die Ausbildung und Differenzierung elementarer Zeichenkonzepte (Lexik), die Konstruktion und Gliederung von funktionalen Zusammenhängen zwischen den elementaren Konzepten (Grammatik) und die Abstimmung der komplexen sprachlichen Äußerungen auf ko- und kontextuelle Bedingungen in kommunikativen Zusammenhängen (Pragmatik). ${ }^{11}$

Eine derartige Explikation von Sprache läuft freilich leicht Gefahr, ihren Gegenstand als etwas fest Umrissenes, Unveränderliches zu unterstellen; deswegen muß die Sprachtechnik, von der eben die Rede war, noch unter drei Aspekten stärker "dynamisiert" werden: ${ }^{12}$

(1) Jede historische Sprache stellt eine Technik, d.h. ein Verfahren dar, das auf Regeln beruht, die zwar die Effizienz des Verfahrens sicherstellen sollen, aber die Durchführung des Verfahrens keineswegs determinieren. Zur Phänotypik historischer Sprachen gehört also auch die prinzipielle Möglichkeit der Regelabweichung oder der Abwandlung im Gebrauch (Flexibilität). ${ }^{13}$

(2) Jede historische Sprache ist eine Technik, die unterschiedlichen „gewachsenen" Anforderungen gerecht werden muß. Welche Anforderungen jeweils gestellt werden, welche Bedürfnisse kommunikativer Verständigung zu erfüllen sind, hängt von bestimmten außersprachlichen Bedingungen (z.B. materiellen Voraussetzungen, sozialen Konstellationen, kulturellen Traditionen) und den entsprechenden psychischen Dispositionen ab; doch nicht alle außersprachlichen Bedingungen müssen dabei in sprachliche Differenzierungen übersetzt werden. Jede historische Sprache ist also durch eine eingeschränkte zweckgebundene Variation ausgezeichnet (Variabilität).

(3) Jede historische Sprache unterliegt dem beständigen Wandel in der Zeit, der sich aus dem Zusammenwirken unterschiedlicher Faktoren (z.B. der Heterogenität und Ungleichmäßigkeit der Systematik, der permanenten Reproduktion und Anpassung bei Erwerb und Gebrauch, den unterschiedlichen und z.T. gegensätzlichen kommunikativen Bedürfnissen, dem Zusammenhang mit anderen sozialen Erscheinungen) ergibt. Zur Qualität historischer Sprachen gehört also auch die permanente

und der gesamte linguistische Interaktionismus beruht auf Annahmen über die Intersubjektivität, die Austauschbarkeit der Standpunkte, Kooperationsprinzipien, Responsivitätsforderungen etc. Vgl. z.B. Pinxt (1981).

10 Die Liste der möglichen Sprachfunktionen ließe sich leicht noch erweitern oder weiter spezifizieren, wir beschränken uns hier jedoch auf die u.E. wichtigsten Leistungen. Vgl. auch Halliday (1973).

11 Die Verschiedenheit oder auch Gleichheit der Sprachen in technischer Hinsicht ist Thema der typologischen Forschung, aber auch der sog. Universalgrammatiken. Wie etwa das Beispiel der Wortbildung zeigt, sind selbst innerhalb einzelner Sprachen unterschiedliche Lösungen (z.B. Abgrenzung/Übergänge zwischen Lexik und Grammatik) möglich.

12 Wir greifen hier einen alten terminologischen Vorschlag von Hans Sperber (1914) auf, der seine Abhandlung über die Affektwirkung in den Sprachen als „Versuch einer dynamologischen Betrachtung des Sprachlebens" charakterisierte.

13 Vgl. dazu auch Cherubim (1980a, 126ff.). 
Restrukturierung ihres funktionellen Systems, das „Werden der Sprache im Sprechen" (Historizität). ${ }^{14}$

Eine angemessene Darstellung der Technik menschlicher Sprachen hat diese dynamischen Qualitäten (Flexibilität, Variabilität, Historizität) zu berücksichtigen. Das gilt ebenso für die Beschreibung dessen, was mit der Formulierung „Sprache im Alter" in den Blick genommen wird. Es betrifft zunächst die auf die Lebenszeit bezogene Entwicklung individueller Sprachkompetenzen, d.h. des persönlichen Verfügens über Anteile einer Sprachtechnik, die insgesamt die "Sprache“ einer bestimmten (historischen) Sprachgemeinschaft definiert; dann aber auch den Einfluß eines Faktors „Alter“ auf das Sprachverhalten. Was das Alter als Entwicklungsphase menschlichen Lebens oder Einflußgröße sprachlichen Verhaltens ist, läßt sich offenkundig unterschiedlich sehen. Rein zeitlich betrachtet gilt das Alter als letzte Phase des Lebens vor dem Tod, sofern dieser nach einer „normalen“ Lebensdauer, d.h. nicht vorzeitig eintritt. Biologisch wird das Alter mit dem Einsetzen bestimmter organischer Prozesse (z.B. Verminderung der Regenerationsfähigkeit) verbunden. Sozial läßt sich das Alter mit dem Ausscheiden aus dem aktiven Berufsleben, einer bestimmten Stellung in der generationalen Abfolge (z.B. der Großelternrolle) oder einer zurückgezogenen (eingeschränkten) Lebensweise zusammenbringen. Psychologisch alt ist man, wenn man sich alt fühlt, sagt ein bekanntes Klischee. Meist wird jedoch das Alter numerisch an der Zahl der Lebensjahre festgemacht, die keineswegs unbedeutend ist: Die Magie der sog. runden Zahlen rückt den Alterungsprozeß sozial relevant und unübersehbar ins Bewußtsein der Betroffenen. ${ }^{15}$

Auf diese numerischen Skalen sind auch die traditionellen Phaseneinteilungen menschlichen Lebens und ihre bildlichen Darstellungen als Treppenmodelle bezogen. ${ }^{16}$ Sprachwissenschaftlich interessant ist, daß den unterschiedenen Phasen nicht in gleicher Weise auch sprachliche (z.B. lexikalisch differenzierte) Konzepte entsprechen. Denn sowohl den klassischen 7er-Modellen (z.B. Säugling, Kleinkind, Kind, Jugendliche, Erwachsene, Ältere, Alte) wie auch denen, die in Zehnerschritten bis zur Obergrenze von 100 Jahren aufsteigen, stehen oft nur wenige originäre Altersgruppenbezeichnungen als simplicia (z.B. Kind, Mann/Frau, Greis/Greisin) gegenüber, und wenn überhaupt weitere Differenzierungen vorgenommen werden, so beziehen sich diese eher auf das Kindes- und Jugendalter als auf die späteren Phasen. ${ }^{17}$ Auch hierin zeigt sich ein geringeres Interesse am Alter.

Noch schwieriger als die Bestimmung der Altersphase ist der Versuch zu klären, inwiefern der Faktor Alter sprachliches Verhalten beeinflussen kann. Denn daß das keineswegs zur Deckung zu bringende biologische, soziale und psychische Alter irgendeinen Einfluß auch auf das Sprachverhalten, mittelbar sogar auf die dahinter stehenden Sprachkompetenzen ausübt, ist wohl anzunehmen. Aber wie wirkt sich das jeweils konkret aus? Und kann man die Wirkung dieses Einflußfaktors überhaupt von der Wirkung anderer Faktoren (z.B. der Gesundheit, der sozialen Her-

14 Für alle drei Aspekte, insbesondere den letzten, sei hier auf den sprachtheoretischen Ansatz E. Coserius verwiesen, z.B. Coseriu (1980).

15 Außer diesen „runden“ Zahlen, die Zehnerschritten entsprechen, gibt es andere (wie z.B. die Hochzeitsjubiläen), die ähnliche Funktionen erfüllen können.

16 Vgl. dazu auch Grimm $(1860 / 1984,217)$. Abbildungen solcher Treppenmodelle gibt es getrennt für Männer oder Frauen oder auch für beide zusammen. Meist sind sie mit entsprechenden Merkversen für jede Altersstufe verbunden.

17 Material dazu bei Grimm (1860/1984, 217ff.) und Hermanns (1994, 40ff.). Eine größere Materialsammlung dazu, von der J. Grimm a.a.O. spricht, ist leider nicht erhalten. 
kunft und Bildung, des Berufs und der Lebensumstände oder der Einstellungen) trennen $?^{18}$ Mehr oder weniger versteckt wird oft mit einem Regressions- oder Defizitmodell gearbeitet: Nach dem Aufbau der Sprache in der Phase der Kindheit (primärer Spracherwerb) und ihrem Ausbau in Jugend- und Erwachsenenzeit ${ }^{19}$ folgt im Alter, je nach Umständen, ein größerer oder geringerer Abbau der sprachlichen Leistungsfähigkeit, der alle systematischen Aspekte (von der Phonik/Graphik bis zur Pragmatik) betreffen kann. Das äußert sich z.B. im Nachlassen der Stimme, einer unsicheren (zitterigen) Schreibung, lexikalischen Lücken und zunehmenden Schwächen bei der Herstellung von grammatischer Konsistenz oder pragmatischer Stimmigkeit. ${ }^{20}$ Zweifellos kann hier nicht einfach das Gegenmodell einer linearen Weiterentwicklung von Sprache bis ins hohe Alter propagiert werden. Zu prüfen ist jedoch, ob trotz aller unvermeidbaren, biologisch, sozial oder psychisch begründeten Regressionen nicht auch bestimmte positive Sprachveränderungen im Alter beobachtbar sind. Sie könnten u.a. in bestimmten Verdichtungsleistungen (Steigerung der Komplexität), ${ }^{21}$ in einer Ausweitung der Verfügung über sprachliche Varianten oder in der Herstellung von Kontinuität zwischen unterschiedlichen generationalen Sprachmöglichkeiten liegen. ${ }^{22}$

Eine wesentlich anspruchsvollere, hypostasierende Vorstellung verbindet sich mit dem Ausdruck Alterssprache, der bisher jedoch bewußt vermieden wurde. Selbst wenn man gewisse Differenzen zwischen dem Sprachverhalten älterer und jüngerer Menschen überbetont, ließe sich dennoch daraus noch keine "Sondersprache" der Alten gewinnen, was aber im Falle von anderen Generationengruppen plausibler erscheinen mag, zumal sie ihrer Funktion nach deutlich auf Unterscheidung und Profilierung zielen. So hat man etwa für die speziellen Sprachformen der sozial Ausgestoßenen (Gaunersprache) oder der in Korporationen organisierten Studenten des 18./19. Jahrhunderts (Studentensprache) den Status einer Gruppensprache reklamiert. ${ }^{23}$ Aber sieht man einmal von den durchaus relevanten Wortschatzdifferenzen zwischen einer nur als Projektion vorstellbaren Gemeinsprache und diesen Spezialsprachen ab, so lassen sich die kommunikativ bedeutsamen Unterschiede eher in bestimmten Verfahren der Wirklichkeitsverarbeitung und Selbstdarstellung festmachen, z.B. in der größeren oder geringeren Nähe zu den ausgedrückten Sprachobjekten (Konkretheit vs. Abstraktheit) oder im höheren oder niedrigeren Anteil von Emotionalität (Expressivität vs. Sachlichkeit) bei den Sprachsubjekten. Daher hat

18 Nach bestimmten Schätzungen (vgl. dazu Lehr 1991) wirkt sich das Alter als Einflußfaktor nur etwa zu $4-4,5 \%$, die Gesundheit zu $8-10 \%$, die berufliche Tätigkeit zu $20 \%$ aus. Zum schwer kontrollierbaren Einfluß verschiedener Faktoren in Verbindung mit dem Alter vgl. auch Mattheier $(1987,81)$, Cheshire $(1987,767)$.

19 Vgl. dazu die verschiedenen Beiträge in Augst (1978).

20 Vgl. Gerritsen (1985), Cheshire (1987). In krassester Form geht man sogar von einer Art ReInfantilisierung im Alter aus: der geschwätzige Alte (senex loquax) vermag sich ebenso wenig auf seine Umgebung einzustellen wie das Gegenbild des mürrischen Alten (senex morosus). Doch manche unterscheiden hier zwischen kindlichem und kindischem Verhalten.

21 Lehr $(1991,79)$ spricht $z . B$. von der "cristallized intelligence“ alter Menschen.

22 Zu letzterem kann man die bekannte Beobachtung stellen, daß sich viele Menschen im Alter zunehmend wieder an Ausdrücke ihrer Jugendzeit (z.B. dialektale Varianten) erinnern und sie wieder reaktivieren; ferner, daß bestimmte "modische" oder in Phraseologismen fixierte Ausdrücke auch über größere zeitliche Distanzen beibehalten und damit (zumindest als Angebot) an die nächsten Generationen weitergereicht werden (Fossilisierung, age grading). Vgl. dazu auch Helfrich (1979), Mattheier (1987), Cheshire (1987).

23 Zu letzterem vgl. die Überlegungen bei Objartel (1985). 
man für die sog. Jugendsprache nur den Status eines "Jugendtons“ beansprucht, d.h. eine Neigung zu bestimmten semiotischen Verfahren, die die Abgrenzung zur Gegenwelt der Erwachsenen und die Identifizierung in der Gruppe zu signalisieren vermögen, die aber auch nur sekundär auf der Basis von Gemeinsprachen fungieren. ${ }^{24}$ Auf diesem Hintergrund könnte man die Frage nach der Qualität einer Alterssprache neu stellen: Welches könnten hier die besonderen Funktionen und die entsprechenden semiotischen Verfahren sein, die für die Sprachform dieser Altersgruppe prägend sind und wodurch unterscheiden sie sich von den Sprachformen, die man anderen Altersgruppen zuordnet? So mögen für die Kindersprache bestimmte Formen der Unfertigkeit und des kreativen Erprobens der sprachlichen Systematik symptomatisch sein; für die Jugendsprache die spielerisch-provokative Kontrastierung und Ausreizung; für die Erwachsenensprache die pragmatische Einpassung und die persönliche Profilierung, doch was bleibt dann für die Alten? Gibt es neben dem ja nicht zu leugnenden, wenn auch unterschiedlich wirksamen systematischen Abbau, einer gewissen Entpragmatisierung oder Erstarrung auch die Entfaltung neuer Qualitäten in der Sprache von alten Menschen? Geeignete Beschreibungsparameter fehlen hier noch ganz. Erste Hinweise finden sich jedoch in Untersuchungen, die in unterschiedlichen Kontexten und eher unsystematisch zum Sprachstil von einzelnen, meist herausragenden Personen im Alter durchgeführt wurden. Ihnen wenden wir uns jetzt zu.

\section{Beobachtungen zum literarischen Altersstil}

Traditioneller Gegenstand der Sprachwissenschaft war lange und fast ausschließlich die geschriebene Sprache literarisch ambitionierter und/oder als vorbildlich eingeschätzter Autoren. Noch die erste Geschichte der gesprochenen deutschen Sprache von Irmgard Weithase, die 1961 erschien, behandelte Texte, die zunächst schriftlich konzipiert und dann erst mündlich realisiert wurden (z.B. Predigten, Reden). Systematische Aufzeichnungen von gesprochener Sprache waren technisch allerdings auch erst relativ spät (nämlich gegen Ende des 19. Jahrhunderts) möglich. ${ }^{25}$ Einzelne Beobachtungen zum literarischen Altersstil einzelner Autoren sind hingegen nicht selten, verdanken sich aber durchaus unterschiedlichen Motiven. Ein frühes Beispiel für systematische Untersuchungen stellten sprachstatistische Analysen des 19. Jahrhunderts zum philosophischen Werk von Platon (ca. 428 - 347 v. Chr.) dar. Sie wurden zur Kontrolle von entwicklungsgeschichtlichen Hypothesen (Periodisierung seines Werks) benutzt und beschäftigten sich mit der Distribution von dialogischen Partikeln in den Schriften dieses Autors. ${ }^{26}$ Andere Beobachtungen zu Platons Altersstil gehen von einem vermutlich letzten Werk, den „Nomoi“, aus, sehen aber im Stil dieses Werkes auch die Vollendung einer Entwicklung, ,die sich in den späteren Werken [sc. Platons; d. Verf.] abzeichnet" (Lesky 1963, 584). Merkmale des Altersstils seien hier (freilich noch ohne Generalisierungsanspruch): der Abbau von Zügen einer zwar kunstvollen, aber höchst lebendigen Mündlichkeit (szenische Dialoge)

\footnotetext{
24 Vgl. Henne (1984, 70f.), Objartel (1985), Cherubim (1986). Die Vorstellung von einer homogenen Jugendsprache wird allerdings bei Henne ausdrücklich zurückgewiesen. Wenn von Jugendsprache gesprochen wird, so ist das nur ein Kurzname für ein wissenschaftliches Objekt, dessen Status und Struktur allererst zu klären ist; vgl. Kohrt \& Kucharczik (i.d.Bd.).

25 Vgl. dazu Cherubim (1989).

${ }^{26}$ Vgl. dazu die Hinweise bei Lesky $(1963,561)$, ferner Dittenberger (1881).
} 
zugunsten einer immer stärkeren lehrhaften Argumentation; Erstarrung im Satzbau, der kompliziert und schwierig erscheine, daneben auch eine Neigung zur „Verkünstelung“ zeige (a.a.O.). Stöcklein (1949, 211), der - einer Anregung von UIrich von Wilamowitz folgend - Platons Spätstil mit dem des alten Goethe verglich, wagte dann schon den Schritt zur Verallgemeinerung: „Es ist, als ob in großen Persönlichkeiten das Alter ähnliche Züge ausreife" (sic!). Und er überschritt dabei auch die Grenzen der künstlerischen Gattungen, wenn er den Altersstil von Dichtern wie Goethe mit der Malerei des alten Tizian und den späten Quartetten Beethovens zusammenbringt. Gemeinsame Alterszüge, die seiner Meinung nach auch in ähnlichen Gedanken gründen, faßte Stöcklein (a.a.O., 234) schließlich in folgenden Stichworten zusammen:

„Reflexion, Abstraktheit, Distanz, die lehrhaft genaue und zeremonielle Haltung - nicht ohne spielerische Entspannungen und Lässigkeiten; eine hoch überschauende und ordnende Geistigkeit, Verschwiegenheit und Geheimnis verbunden mit Abgeklärtheit [...]."

Goethes Altersstil ist wohl der am meisten behandelte Gegenstand dieser Art. Häufig wird hier von einer Abhandlung Paul Knauths (1898) ausgegangen, deren Ansatz allerdings schon im Jahr ihres Erscheinens von Konrad Burdach grundsätzlich infragegestellt wurde. ${ }^{27}$ Knauth hatte bestimmte lexikalische, morphologische und syntaktische Züge im Stil des Alterswerkes (seit 1814) als Ausdruck einer bestimmten Stilhaltung Goethes, des „kompressiven Stils“ (vgl. Burdach 1926, 71) interpretiert. Burdachs Kritik richtete sich vor allem gegen das selektive Vorgehen Knauths, das durch eine systematische Analyse ersetzt werden müsse (a.a.O., 62), gegen die vorschnellen psychologischen Deutungen, die zumindest durch eine systematische sprachhistorische Überprüfung zu ergänzen seien (a.a.O., 63f.), und schließlich gegen den Versuch, das eigene, zeitgebundene Sprachgefühl naiv für die Deutung früherer stilistischer Verfahren einzusetzen (a.a.O., 70f.). Dennoch folgt er Knauth in dem Befund, Goethes Altersstil sei kompressiv (a.a.O., 71).

Mehr vom Inhaltlichen als von konkreten sprachlichen Zügen ausgehend hatte dann Hans Friese (1937) Goethes Stil im Alter als "monumentalen Stil“ charakterisiert. Damit wandte er sich gegen den Beiklang des Negativen, Schwachen, der mit dem naturalistischen Konzept des Altersstil verbunden werden könne $(1937,606)$. Die „Monumentalität“ von Goethes Stil in seinem Spätwerk findet er u.a. im „Reichtum an sinnlichen Vorstellungen“ (a.a.O., 607) und der enormen Breite der Wortwahl und in der "Erhabenheit über Zeit und Raum" (608), in der "Gedrungen-heit" des Stils und der "Erhebung ins Überlebensgroße“ (610), im Humor als einer Technik der Distanzierung vom Altäglichen und Realen (611), in der starken persönlichen Färbung (612), im „Ausdruck einer strengen und herben Männlichkeit“ (sic!), im Gedankenreichtum und der Lehrhaftigkeit (612), in der Bändigung des Emotionalen und der Gelassenheit (614), in der Komprimiertheit und (größeren) Schwerverständlichkeit (615), schließlich in der Gedankentiefe und in seinem „nor-dischen, deutschen Gepräge“" (616)!

Diese letztlich rassistische Deutung ${ }^{28}$ steht freilich in ihrer Tendenz durchaus in der Nachfolge, inhaltlich aber in starkem Kontrast zu einer anderen charakterologi-

\footnotetext{
27 Wir zitieren die Besprechung von Burdach, die zuerst im Literarischen Zentralblatt 1898, Nr. 37 , Sp. 1517 - 1524 erschien, hier nach einer späteren Sammlung der kleinen Schriften Burdachs (1926). Dort findet sich auch eine Skizze früherer Arbeiten zu Goethes Altersstil.

28 Man bedenke Ort und Zeit der Publikation!
} 
schen Deutung von Goethes Altersstil, die wir dem Finnougristen und Vertreter der Allgemeinen Sprachwissenschaft Ernst Lewy verdanken. ${ }^{29}$ Lewy hatte bereits 1913 einen „Versuch“ über die Sprache des alten Goethe publiziert, der vielseitigen Widerspruch erfuhr ${ }^{30}$, aber dennoch von ihm weiter ausgebaut wurde. Ausgehend von einer Darstellung der z.T. schon von Knauth und anderen hervorgebenen Merkmale (z.B. Komposita-Bildung, Abstraktbildungen, Artikellosigkeit, Nominalstil, Neigung zu partizipialen Perioden, asyndetischen Konstruktionen, Vorliebe für unterschiedliche Intensivierungen) sieht er in Goethes Altersstil eine Neigung zum „Typischen“, zur Kontemplativität und Beschaulichkeit und bringt sie mit dem Sprachtypus der "schwertemperamentigen" Völker Nordosteuropas in Verbindung. ${ }^{31}$ Diese an die Lehre von den "Charaktertypen des Sprachbaus“ (Franz Nikolaus Finck) anschließende Deutung ${ }^{32}$ führt inn dazu, bei Goethe eine biographische Entwicklung im Stilverhalten von den germanisch-romanischen Anfängen bis hin zum „osteuropäischen" Alter zu sehen:

„[...] die größte geistige Persönlichkeit des modernen Europa würde sich als eine Zusammensetzung der drei ethnischen Hauptbestandteile Europas herausstellen [...] Das Leben dieser Persönlichkeit ist das Heraustreten dieser drei Schichten aus dem Kerne der Persönlichkeit: die Altersperiode des Stils ist der leibhaftig gewordene Geist versunkener Ahnen aus fernem Nordosten“ (1961b, 112).

Auch wenn Lewy sich der Problematik derartiger Konstruktionen sehr wohl bewußt ist $(1961 \mathrm{~b}, 112)$ und eigens darauf hinweist, daß vergleichende Untersuchungen zum Altersstil anderer Literaten zur Überprüfung herangezogen werden müßten (a.a.O., 110), stehen seine Arbeiten doch klar in der Tradition der spekulativen geistesgeschichtlichen Analysen des Altersstils, die erst durch moderne empirische Untersuchungen wie Lehr (1991) auf ein sicheres Fundament gestellt werden konnten.

Dies gilt auch noch für Erich Trunz (1954/1955), der Goethes Altersstil mit seiner "Altersweltanschauung" verbindet und inn daher als "symbolischen Stil" deutet (a.a.O. 134). Auch hier erfolgt die Beschreibung dieses Stils nur in der Weise, daß Trunz auf dazu passende sprachliche Züge (Lexik, Wortbildung, Syntax) hinweist und zusammenfassend konstatiert, Goethe habe im Alter mit all dem, was er sich im Laufe seines Lebens sprachlich erschlossen habe, „in freiester und eigenster Weise“ (a.a.O., 137) geschaltet. Schließlich schreckt er auch nicht vor fragwürdigen biographischen Verallgemeinerungen zurück:

„Der Stil der Goetheschen Jugend stand im Zusammenhang mit dem allgemeinen Stil der Zeit, sei es mit dem Sturm und Drang im Drama, sei es mit der Empfindsamkeit im Briefstil. Der Stil der Goetheschen Mannesjahre hatte Beziehungen zu den großen Meistern der Weltiteratur [...]. Der Altersstil aber ist völlig einzig in seiner Art. Er steht fast ohne Beziehung zur zeitgenössischen Dichtung und hat auch keine Vorbilder in dem weiten Felde der Weltliteratur, das der Dichter da-

${ }^{29}$ Wir zitieren hier ebenfalls nach den später (1961) von der Deutschen Akademie der Wissenschaften zu Berlin (Veröffentlichungen der Sprachwissenschaftlichen Kommission. 1) herausgegebenen Kleinen Schriften dieses Autors.

30 Vgl. dazu Lewys eigenen Bericht im Vorwort (1961a, 91ff.).

31 An anderer Stelle (1961b, 108f.) parallelisiert er Goethes Stil konkreter mit den ural-altaischen Sprachen.

32 Vgl. Finck (1910). Einen frühen Hinweis auf solche Gedanken findet Lewy schon bei G. v. d. Gabelentz (Lewy 1961a, 92, Anm. 1). 
mals überblickte. Er ist nur aus inm selbst heraus entwickelt. Er ist sein eigenstes Gebilde und sagt darum über inn und sein Wesen besonders viel aus." ${ }^{33}$

Man könnte in diesem Zusammenhang noch eine Reihe weiterer Arbeiten älterer und neuerer Provenienz anführen ${ }^{34}$, doch wir brechen die exemplarische Betrachtung an dieser Stelle ab. Geistesgeschichtliche Spekulationen dieser Art finden sich ja lange auch in der deutschen Psychologie, die sich durchaus an den referierten literarischen Untersuchungen orientierte (vgl. Salber 1959, 467ff.). Charakteristisch ist hier eine Arbeit Adolf Busemanns (1948). Auch Busemann sieht den Altersstil als Ergebnis bestimmter entwicklungspsychologischer Prozesse, grenzt aber die pathologischen Erscheinungen dieses Stils (z.B. Sprachabbau, Enthemmung des Sprechens) von Merkmalen des "gesunden" Stils ab und verbindet unbekümmert die schon aus den literarischen Untersuchungen bekannten Merkmale (z.B. Nominalstil, Sparsamkeit im Ausdruck, allegorisches Sprechen, Komplexität im Satzbau) mit psychologischen Faktoren (z.B. Sinndrängung, Steifheit, Würde, Abstand zu den Dingen, Reserviertheit, Bewußtsein) (1948, 148f.). Wie sehen dagegen die Ergebnisse neuerer psychologischer, psycholinguistischer oder linguistischer Untersuchungen aus? Wir können auch hier nur auf weniges eingehen.

\section{Einige Ergebnisse neuerer Untersuchungen}

Innerhalb der letzten 15 Jahre sind viele Forschungsbeiträge zum Thema des Zusammenhangs von Sprache und Alter in Großbritannien, Kanada und den Vereinigten Staaten erschienen. Von diesen Studien gehören einige Disziplinen wie Medizin, Psychologie und Soziologie an. Einige sind naturwissenschaftliche Untersuchungen, die z.B. die akustischen Merkmale der älteren Stimme analysieren. Daneben gibt es natürlich auch sprachwissenschaftlich relevante Recherchen. Nur auf diese wollen wir im folgenden eingehen.

\subsection{Alterskrankheiten und Sprache}

Ein Hauptinteresse der anglo-amerikanischen Alterssprachforschung gilt Sprachveränderungen, die durch Alterskrankheiten bedingt sind. Albert (1980) und Hutchinson \& Jensen (1980) erforschten z.B. Sprachunterschiede zwischen gesunden Älteren und solchen, die an Senilität leiden. Albert stellte fest, daß der Bildungsgrad der Patienten und die Art der normalen altersbedingten Gehirnatrophie einen entscheidenden Einfluß auf die Sprache haben; ebenso, welche Teile des Gehirns von Senilität betroffen sind. Hutchinson \& Jensen fanden eine Art Egozentrismus in der Sprache seniler Älterer, der erklären könnte, warum sich solche Menschen in ihren Untersuchungen weniger äußerten, aber gleichzeitig öfter mit neuen Themen anfingen als gesunde Vergleichspersonen. In diesem Zusammenhang gibt es andere Studien, die das Kommunikationsverhalten zwischen älteren Menschen und ihren Ärzten er-

33 Interessant sind in diesem Zusammenhang die Selbstdeutungen Goethes, die Trunz hier (a.a.O., 137f.) anführt und die die Stilentwicklung vom Kind (= Realist), über den Jüngling (= Idealist) und Mann (= Skeptiker) bis zum Greis (= Mystiker) entwicklungspsychologisch deuten.

34 Hinzuweisen wäre etwa auf die bekannten Untersuchungen zur Sprache Jacob Grimms (z.B. Andresen 1869; Simon 1929; Wyss 1979, bes. 182ff.), die aber speziell für etwaige Eigentümlichkeiten des Altersstils wenig erbringen. 
forschten (Adelman, Greene \& Charon 1991; Greene et al. 1986), ferner das Phänomen des baby talk und die care-giving-Sprache, d.h. wie Personal mit Bewohnern von Pflege- und Altersheimen umgeht (Caporael 1981; Caporael \& Culbertson 1986; Caporael, Lukaszewski \& Culbertson 1983; Sachweh i.d.Bd.). Weiterhin haben Wissenschaftler die geistigen Fähigkeiten von älteren Leuten untersucht, um Unterschiede bei der Sprachverarbeitung bzw. -produktion festzustellen (Barrett \& Wright 1981; Belmore 1981; Hess et al. 1993; Salthouse 1993; Zelinski \& Miura 1990). Die Ergebnisse zeigten u.a., daß es keine wesentlichen Unterschiede zwischen Älteren und Jüngeren in Bezug auf Sprachverarbeitung und -verständnis gibt, daß aber ältere Menschen häufiger Probleme bei der Speicherung von Informationen, vor allem nach längeren Zeitabständen, haben. Barrett \& Wright beobachteten aber auch, daß ältere Menschen sich gut an altertümliche Wörter erinnern.

Insgesamt widmeten sich die erwähnten Forschungen eher Ausnahme- oder Randfällen und ermöglichen deshalb nur eine begrenzte Sicht auf das allgemeine Problem des Verhältnisses von Sprache und Alter. Da nämlich heute viele ältere Leute gesund sind und ein weitgehend normales Leben führen, können solche Untersuchungen nicht viel über ihr spezifisches Sprachvermögen mitteilen und darüber, wie dieses sich eventuell von dem Sprachverhalten jüngerer Altersgruppen unterscheidet.

\subsection{Soziopsychologische Untersuchungen}

Es sind jedoch zwei ausschlaggebende Werke erschienen, die sich allgemein mit dem Verhältnis von Sprache und Alter beschäftigten und die im Rahmen soziopsychologischer Untersuchungsansätze grundlegende Beiträge zum Thema darstellen. Das erste ist eine 1986 veröffentlichte Sonderausgabe der Zeitschrift Language and Communication, herausgegeben von Howard Giles und Ellen B. Ryan, die dem Hauptthema „Kommunikation mit und von Älteren“ gewidmet ist. Da der Sammelband sehr unterschiedliche thematische Bereiche wie Diskursanalyse, literarische Darstellung, Eigenschaften der Stimme, Sprachverlust und baby talk aufgreift, geben die zehn Beiträge einen guten Eindruck von der Breite und dem Umfang des Forschungsgebietes heute. Beachtlich ist vor allem der Aufsatz von Ryan, Giles, Bartolucci \& Henwood, der den damaligen Forschungsstand zusammenfaßt und die Richtung für künftige Bemühungen angibt. Als Schlußfolgerung wird u.a. ein communication framework für den Umgang mit Älteren formuliert, das ein interaktives Modell für die problematische Situation älterer Leute im Gespräch beinhaltet.

Das Modell wird in einer graphischen Darstellung präsentiert, die eine Art Teufelskreis in der Kommunikation mit Älteren sichtbar macht (vgl. die ausführliche Darstellung dieses Modells in Ryan \& Kwong See (i.d.Bd.)). Noch vor der ersten Wort-äußerung können schon Beeinträchtigungen auftreten: Die visuelle Wahrnehmung des älteren Gesprächspartners weckt bei Jüngeren häufig die Vorstellung von dessen begrenztem kommunikativen Vermögen. Stimmt dieser Eindruck, so tritt bereits hier im Gespräch eine kommunikative Beeinträchtigung ein; aber auch wenn dieser Eindruck falsch ist, kann eine solche Einschätzung die folgende Kommunikation für beide Gesprächspartner erschweren. Zum Teil merkt dann die ältere Person, daß sie so eingeschätzt wird, und zieht sich aufgrund dessen zurück - was wiederum nur die Vorurteile auf Seiten des Gesprächspartners bestätigt und eventuell verstärkt. Der ganze Vorgang funktioniert gleichsam im Sinne einer self-fulfilling pro- 
phecy, da beide Partner aufgrund bestimmter Erwartungen ihre Verhaltensweisen wahrnehmen und steuern. Der größte Nachteil ist dabei für die älteren Personen, daß sie durch solche Erfahrungen an Selbstachtung verlieren und in psychologischer und sozialer Hinsicht passiver werden können. Erschwerend kommt hinzu, daß die physiologischen, psychologischen und soziokulturellen Folgen des Älterwerdens immer mehr zunehmen, so daß eine abwärts führende Spirale entsteht, aus der der ältere Mensch nur schwer herauskommt.

Fünf Jahre später erschien das Buch Language, Society and the Elderly von Nikolas Coupland, Justine Coupland und Howard Giles, ein umfassender Bericht über den Forschungsstand bis 1991, der vor allem die bedeutende mehrjährige For schung zusammenfaßt, die die Autoren, z.T. gemeinsam mit weiteren Kollegen, geleistet haben. Als Zentralthema gilt das Älterwerden und seine Bedeutung im gesellschaftlichen Diskurs, wobei das kaum artikulierte und noch weniger diskutierte Phänomen des ageism, ein auf das Alter bezogenes Äquivalent zum Rassismus, identifiziert und in seiner sehr weitreichenden Bedeutung für die Kommunikation herausgearbeitet wird (vgl. Kramer (i.d.Bd.)). Aus den verschiedenen Kapiteln, die sich u.a. mit Kommunikation zwischen den Generationen und dem Problem der Altersidentität befassen, geht hervor, daß ältere Personen häufiger vergangene Erfahrungen, ihren Gesundheitszustand und ihr numerisches Alter thematisieren, ein Vorgehen, das von wichtiger funktionaler Bedeutung für beide Gesprächspartner ist.

Bemerkenswert ist weiterhin eine communication accommodation theory für die Einigung bzw. Übereinkunft der Gesprächsteilnehmer bei der Kommunikation. Diese allgemeine Theorie wird auf ältere Leute angewendet, und es werden die unterschiedlichen soziolinguistischen Strategien je nach Gesprächsziel erforscht. Grundlage dieser Theorie sind Erkenntnisse darüber, wie sich Gesprächspartner einander anpassen bzw. gegenseitig einschätzen, was nicht nur Hinweise auf den Erfolg der Kommunikation vermitteln kann, sondern auch Erklärungen für kommunikative Mißverständnisse ermöglicht. Weiter wird analysiert, wie Menschen beim Gespräch ihre Sprache modifizieren, um mit ihrem Gesprächspartner zu konvergieren bzw. zu divergieren. Auch hier werden die Strategien junger Leute in der Unterhaltung mit Älteren skizziert. Daneben wird auch, gleichsam aus einer anderen Perspektive, eine Typologie der strategischen Methoden Älterer beim Gespräch mit Jüngeren präsentiert.

Coupland, Coupland, Giles \& Wiemann (1988) und Coupland, Coupland, Giles \& Henwood (1991) arbeiteten außerdem heraus, wie ältere Leute durch ihre Sprache ihr Alter anzeigen, wie sie also ihre Identität linguistisch markieren. Bei dieser Gruppe zeigte sich ferner eine hohe Frequenz desjenigen Verhaltens, das die Autoren als $P S D$ oder Painful Self-Disclosure, als schmerzhafte Selbstenthüllung, bezeichnet haben. Man stellte fest, daß ältere Leute in ihren Gesprächen sowohl mit Jüngeren als auch mit Gleichaltrigen verstärkt z.B. von körperlichen Gebrechen und Krankheit, von Trauer, Einsamkeit, von allgemeiner Schwäche und Tod reden. Ein anderes Merkmal im Diskurs von Älteren ist die Verwendung bestimmter Tempusausdrücke und Referenztechniken, die vor allem Bezug auf die Vergangenheit nehmen. Als erstes stellten Coupland und die anderen fest, daß ältere Menschen häufiger Vergangenheitstempora benutzten und dazu neigten, Geschehnisse in der Vergangenheit zeitlich genau einzuordnen bzw. den Abstand zur Gegenwart quantativ auszudrükken. Zweitens kommt es häufiger vor, daß Ältere sich im Gespräch vorwiegend mit der Vergangenheit assoziieren, was manchmal dazu führte, daß sie sich von der Gegenwart dissoziieren. Ein drittes Merkmal war die Diskussion von historischen 
bzw. kulturellen Veränderungen, häufig verbunden mit einem Vergleich zwischen Vergangenheit und Gegenwart.

\subsection{Gesprächsmerkmale und Stiltechniken bei Alten}

1983 publizierten Boden und Bielby eine vorläufige diskursanalytische Studie, in der sie Gespräche unter Älteren mit solchen zwischen Studenten vergleichen. Während beide Gruppen in ihren Gesprächen ähnliche strukturelle Merkmale aufzeigen, gibt es Unterschiede hinsichtlich der Themenentwicklung und -führung. Die älteren Menschen erinnerten sich z.B. in ihren Gesprächen mehr an die Vergangenheit. In der von Giles und Ryan herausgegebenen Zeitschrift Language and Communication stellen Kynette \& Kemper (1986) die Ergebnisse einer Untersuchung über den altersbedingten Verlust grammatischer Formen vor. 32 gesunde Erwachsenen mit Englisch als Muttersprache nahmen an der Studie teil, die nach Geschlecht und vier gleich starken Altersgruppen zwischen 50 und 90 Jahren differenziert war. Die Ergebnisse zeigen, daß mit steigendem Alter eine Verringerung der Flexibilität und Genauigkeit der syntaktischen Strukturen, Verbzeitformen und Formklassen stattfindet. Die 50- und 60jährigen als jüngste Gruppe verwendeten einfache syntaktische Strukturen wie auch grammatische Formen häufiger und korrekter, und sie benutzten gleichzeitig mehr komplexe Strukturen als alle anderen. Die richtige Verwendung von Satzstrukturen und Verbzeitformen nahm mit dem Alter ab, obwohl die Menge der letzteren gleich blieb. Mit steigendem Alter vergrößerte sich weder der Unterschied in der Durchschnittslänge von Äußerungen noch nahm die Häufigkeit von Satzfragmenten zu. Kynette \& Kemper stellen fest, daß vor allem grammatische Formen und syntaktische Strukturen, die hohe Anforderungen an das Gedächtnis stellen, von älteren Menschen nicht verwendet werden. 1992 veröffentlichten Glosser \& Deser eine Untersuchung zum Gesprächsverhalten älterer Menschen, die die Gespräche von 14 Menschen im Durchschnittsalter von 51,9 Jahren mit denen von 13 Älteren mit dem Durchschnittsalter von 76,2 Jahren vergleicht. Während es zwischen den zwei Gruppen keine wesentlichen Unterschiede in Bezug auf phonologische, lexikalische und syntaktische Merkmale gab, war dies hinsichtlich der thematischen Kohärenz des Gesprächs anders. Obwohl die älteren Teilnehmer in der Lage waren, einzelne Sätze sinnvoll miteinander zu verknüpfen, konnten sie dies nicht für das übergeordnete Thema des gesamten Diskurses leisten.

\section{Analyse eines Beispieltextes}

Im folgenden sollen am Beispiel eines Brieftextes einer hochbetagten Frau (Text 1) mögliche Merkmale des Altersstils diskutiert werden. Wir gehen dabei von drei Aspekten aus: Defektivität, Alterität und Kommunikabilität. Unter dem Aspekt der Defektivität ist danach zu fragen, ob sich im vorliegenden Text altersbedingte Merkmale eines Nachlassens der Sprachtechnik, über die sie ehemals verfügte, erkennen lassen. Unter dem Aspekt der Alterität ist zu prüfen, was aus heutiger Sicht am Text als andersartig, möglicherweise altertümlich oder obsolet, also generational bestimmt, anmutet (vgl. Turk 1990). Schließlich bezieht sich der Aspekt der Kommunikabilität auf das Problem der Verständlichkeit dieses Textes in Situationen intergenerationaler Diskurse, wie sie u.a. Lütjen (1978) untersucht hat. 
Text $1^{35}$

\section{TEXT}

Liebe Frau Cheru/bim

Sie sehen das es bei/mir nicht mehr so ganz stimmt.

Zuerst danke ich Ihnen von

05 ganzem Herzen für das schöne Paket!

Ich bin nun wieder gut versorgt!

Ich muß Ihnen leider nur so

ungutes berichten, Ich bin geistig

durcheinander gekommen, plötzlich

10 war der Ton weg, ich konnte nicht

mehr hören, ich sah alles hörte

aber keinen Ton, ich sah die

Menschen sprechen, konnte aber nichts

hören, wurde auch geistig unklar

15 und die Ärzte fingen an zu räzeln

wo kommt das her! Ich konnte alle meine

Obliegenheiten verrichten war aber nicht

klar. Gestern früh war plötzlich der

Ton wieder da, ich konnte wieder

20 hören sehen und alles war wieder in Ordnung, ein gräßlicher Zustand! Ich war paar Tage geistig krank ein gräßlicher Zustand zu sehen zu hören und nicht zu wissen wo her das

25 kommt, sie suchen hin und her, sie wollen heraus finden woher die geistige umnachtung kommt, ob vom Gehirn oder von äußeren Einflüssen.

Ich bin vollkommen normal wie

30 immer. Keine Medizin, die 3 Sachen die ich nahm sind gleich abgesetzt und ich lebe ganz normal die Ohren= Klinik im Krankenhaus soll nun untersuchen ob da alles in Ordnung

35 ist, sie wollen durchaus herausfinden ob mein Zustand durch äußere Ein= flüsse hervor gerufen worden ist! Ich lebe wie immer esse trinke wie immer und bin ganz mobil!

40 Ich danke Ihnen nochmal von ganzem Herzen und so wie etwas mit mir geschieht berichte ich Ihnen alles!

\section{ERLÄUTERUNGEN}

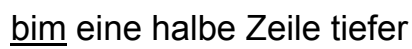

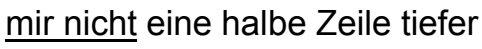

$\underline{\mathrm{mm}}$ durch $\underline{\mathrm{m}}$ mit Nasalstrich

$\underline{\mathrm{mm}}$ wie oben

$\underline{\mathrm{nn}}$ durch $\underline{\mathrm{n}}$ mit Nasalstrich

nn wie oben

$\underline{\mathrm{mm}}$ und $\underline{\mathrm{nn}}$ wie oben

$\underline{\text { nn }}$ wie oben

$\underline{\mathrm{mm}}$ wie oben

$\underline{\mathrm{mm}}$ wie oben

$\underline{\mathrm{mm}}$ wie oben

$\underline{\mathrm{mm}}$ wie oben

Trennungszeichen vertikal

Trenungszeichen wie oben

$\underline{\mathrm{mm}}$ wie oben

$\underline{\mathrm{mm}}$ wie oben

${ }^{35}$ Vgl. die Kopie des Originals im Anhang. 
S Sie schreiben mir bitte mal ein paar Zeilen ob Sie mein

45

Geschreibsel lesen können und wie

Sie es aufnehmen!

bis dahin nochmal tausend Dank

Ihre Tati

50

Ich fühle mich

vollkommen

gesund! $\underline{\text { S verschrieben }}$

nn wie oben

$\underline{\mathrm{mm}}$ wie oben

Einige Erläuterungen zu den Personen und zur Situation sind notwendig. Es handelt sich bei Text 1 um den Brief einer sehr alten Frau (101 Jahre), den sie unmittelbar nach einer Art Hörsturz (möglicherweise infolge eines Schlaganfalls) an eine andere Frau, die damals 75 Jahre alt war, schrieb. Die Briefschreiberin, die aus einfachen (bäuerlichen) Verhältnissen stammte, hatte nach kurzem Schulbesuch (Volksschule) und einer Ausbildung zur Krankenschwester einen großen Teil ihrer Berufszeit nicht in Krankenhäusern, sondern in sog. freien Anstellungen, meist in gutbürgerlichen Haushalten, verbracht. Von daher kannte sie auch die Adressatin, bei der sie mehrere Jahre als "Kinderfrau“ tätig und gleichsam in die Familie hineingewachsen war. ${ }^{36}$ Die daraus folgende gegenseitige Vertrautheit und Wertschätzung hatte nach dem letzten Krieg trotz räumlicher Trennung (Ost/West) zur Fortsetzung des Kontakts in Form von regelmäßigen Besuchen im Hause der Adressatin geführt, wobei die soziale Situation des Erstkontakts (soziales Gefälle) in gewissem Umfang erhalten blieb. Später war die Briefschreiberin, die unverheiratet war und keine Kinder hatte, als Rentnerin in den Westen gezogen und hatte dort zunächst mit ihrer Freundin, nach deren Tod dann alleine in verschiedenen Heimen gelebt. Die Adressatin hatte sie dort regelmäßig besucht, sich intensiv um sie gekümmert und ihr sogar (wegen der geringen Rente) materiell geholfen. Für die Briefschreiberin war die Adressatin daher nicht nur eine Respekts-, sondern auch eine Vertrauensperson, der sie zudem für ihre Fürsorge stets dankbar war. ${ }^{37}$ Unter denen, die sie kannten, galt die Briefschreiberin auch noch im hohen Alter als äußerst lebhaft, neugierig, selbständig und unerschrocken. Ein Zeitungsbericht über den obligaten Besuch des Bürgermeisters ihres Wohnortes zum 100. Geburtstag berichtete von „Selbstbewußtsein, Humor (und sogar) Frechheit" der Jubilarin.

\subsection{Defektivität}

Das sehr hohe Alter (101 Jahre) und die besondere Situation der Briefschreiberin (Hörsturz) lassen erwarten, daß der Brieftext eine Reihe von Ausfällen in den verschiedenen Bereichen der Sprachtechnik aufweist. Das ist jedoch kaum oder gar nicht der Fall. Es gibt insgesamt nur wenige Stellen, die eventuell als „abweichend“

${ }^{36}$ Daher unterzeichnet sie auch im Briefwechsel mit der Adressatin noch mit dem Kindernamen Tati (dim. zu Tata für Tante).

37 Die Adressatin ist Mutter eines der Autoren dieses Beitrags (D.Ch.), der die Briefschreiberin, die inzwischen verstorben ist, ebenfalls sehr gut kannte. 
in Bezug auf unterschiedliche Normen oder heutige Maßstäbe der Sprach- und Textgestaltung markiert werden können. ${ }^{38}$

In Anbetracht der besonderen Situation zeigt die Schreiberin von Text 1 eine sehr ruhige und klare Handschrift, dies im Unterschied etwa zur Handschrift eines 81jährigen Mannes, dessen Frau zu der Zeit, als er den Brief schrieb, erst einige Monate vorher gestorben war (vgl. Text $2 \mathrm{im}$ Anhang). Im Originalbrief finden sich darüber hinaus nur einige Wasserflecken, die von Tränen oder Speichel herrühren könnten. ${ }^{39}$ Die Schreiberin verwendet im vorliegenden Text eine unkonsequente Mischung von deutscher (Sütterlin) und lateinischer Schreibschrift, wobei letztere seit etwa 1942 in den deutschen Schulen verlangt wurde. ${ }^{40}$ Auffällig sind die sog. Nasalstriche bei $<m m>$ und $<n n>$ sowie die fast senkrecht geschriebenen doppelten Silbentrennstriche. $^{41}$ Insgesamt sind im Text nur ein Zeilenbruch (Z. 2), eine nicht erkennbar motivierte Durchstreichung (Z. 4) und eine offenkundige Verschreibung ( $Z$. 43) zu sehen. Bei der Rechtschreibung fallen wenige Schwächen in der Groß/Kleinschreibung $(Z$. 8, 28) und nur zwei wirkliche Falschschreibungen (Z. 2: das statt $d a ß$, Z. 15: räzeln für rätseln) auf. In anderen Briefen derselben Schreiberin findet man noch die hyperkorrekten Schreibungen feierlig und heimlig anstelle von feierlich und heimlich. ${ }^{42}$ Die Zeichensetzung weicht von den heutigen Regeln teilweise ab, etwa bei der Absetzung konjunktional oder relativ eingeleiteter Nebensätze, bei parataktischen Fügungen und Konstruktionen mit erweiterten Infinitivgruppen, die eben nicht durch Komma abgesetzt werden. Sie scheint insgesamt eher sprechsprachlich motiviert zu sein, was dem Charakter (Privatbrief) und der Funktion des Textes (lebhafter Bericht) entspricht. Auffällig ist schließlich die Getrenntschreibung bei Verbkomposita mit Richtungsadverbien (Z. 9: durcheinander kommen, Z. 26 und 35: heraus finden, Z. 37: hervor rufen). ${ }^{43}$

Flexionsmorphologie, Valenzsyntax und Wortstellung des Textes sind ohne Befund. Nur an einer Stelle (Z. 16) wechselt die Schreiberin von der zu erwartenden Nebensatzform mit Verbendstellung zur Form des Hauptsatzes mit Verbzweitstellung, allerdings ein übliches Verfahren lebhaften Erzählstils. Der Satzbau ist durchaus komplex. Zwar herrschen parataktische Fügungen vor, aber die Schreiberin gliedert lebhaft durch adverbiale Angaben temporaler Art (zuerst, plötzlich, gestern früh, paar Tage ${ }^{44}$ usw.), durch Konjunktionen und Modalpartikeln und verfügt auch über verschiedene Typen von Satzeinbettungen (z.B. Objektsatz, indirekter Fragesatz, Temporalsatz, Attributsatz, verkürzter Vergleichsatz). Einige eher sprechsprachliche emphatische Reduktionen (Z. 21 und 23: ein gräßlicher Zustand!, Z. 30:

38 Zur Problematik des Abweichungsbegriffs vgl. Cherubim (1980a).

39 Tatsächlich hatte die Schreiberin aufgrund einer mißglückten Zahnoperation nur bedingt Kontrolle über die Muskulatur ihres Mundes.

40 Man sieht diese Inkonsequenz etwa bei den verschiedenen $s$-Graphen, während $\langle h\rangle$ und $\langle d\rangle$ konsequent deutsch geschrieben werden.

41 Nach Auskunft der Adressatin wurden sie in der Schule nicht zugelassen, waren aber in Alltagsbriefen üblich.

42 Insgesamt stand uns ein kleines Korpus von 25 Briefen aus der Zeit von 1987 - 1990 (96 - 101 Jahre) zur Verfügung.

43 In anderen Briefen findet man noch wunder schön, auf hören und Lieblings Neffe. In Text 1, Z. 41 liest man so wie statt heute üblichem sowie.

44 Die Artikelauslassung paar Tage (Z. 22) mag auf einen Flüchtigkeitsfehler zurückgehen, in Z. 44 heißt es richtig ein paar Tage. 
keine Medizin) sowie eine Herausstellungskonstruktion (Z. 27f.) gehören ebenfalls zum normalen Stil lebhaften Erzählens.

Auch die Lexik des Brieftextes zeigt keinerlei Defekte oder Schwächen, sondern die Verfügung über einen differenzierten Wortschatz. Die Schreiberin beherrscht offenkundig anspruchsvolle lexikalische Varianten, Z.B. situativ-evaluativer Art (Z. 15: räzeln, Z. 21: gräßlicher Zustand, Z. 27: geistige Umnachtung, Z. 45: Geschreibsel) oder fachlich-spezieller Art (Z. 10: Ton, Z. 17: Obliegenheiten, Z. 31: absetzen, Z. 46: aufnehmen). Und sie geht sicher mit Kollokationen und phraseologischen Fügungen um (Z. 3: nicht mehr ganz stimmen, Z. 4f.: gut versorgt, Z. 8f.: geistig durcheinander, Z. 18: Obliegenheiten verrichten, Z. 25: hin und her suchen).

Ein ähnlich positiver Befund ergibt sich, wenn man die pragmatischen Fähigkeiten der Briefschreiberin in den Blick nimmt. Der Texttyp „persönlicher Brief“ kann von Aufbau und inhaltlicher Gestaltung her als gelungen angesehen werden, die personen-, raum- und zeitdeiktischen Bezüge erscheinen stimmig, die Adressatin wird nicht nur hinreichend angesprochen (Anreden, Dank- und Grußformeln: Z. 1, 40ff.), sondern auch in der Darstellung der Ereignisse immer wieder perspektivisch berücksichtigt (Z. 7f.: Ich muß Ihnen leider nur so ungutes berichten). Der Stil ist durch viele emotionale Bewertungen angereichert und daher als lebhaft zu charakterisieren. Die Schreiberin ist offenkundig in der Lage, eine Reihe unterschiedlicher Sprachhandlungen (Danken, Berichten, Entschuldigen, Auffordern, Grüßen, Versprechen, Versichern) typgerecht auszuführen.

Insgesamt kann man den Text auf allen Ebenen der Sprachtechnik nicht nur als gelungen, sondern auch als anspruchsvoll beschreiben. Weder das hohe Alter noch die besondere Situation (Hörsturz) scheinen sich negativ auf die Fähigkeit der Schreiberin ausgewirkt zu haben, Briefe dieses Typs zu verfassen bzw. persönliche Briefkontakte erfolgreich fortzuführen. Dies mag keineswegs selbstverständlich sein, wie etwa das Beispiel eines "nur" 77jährigen Sprachwissenschaftlers an seinen jungen Kollegen (Text $3 \mathrm{im}$ Anhang) zeigt, wo etwa der (möglicherweise generational begründete Telegrammstil) und die unflexible pragmatische Situierung größere Verständnisschwierigkeiten bereitet. ${ }^{45}$ Aber auch die Schreiberin von Text 1 reflektiert selbst über mögliche Beeinträchtigungen durch das Alter (Z. 2f.: Sie sehen das es bei mir nicht mehr so ganz stimmt; Z. 43ff.: Schreiben Sie mir bitte mal ein paar Zeilen, ob Sie mein Geschreibsel lesen können und wie Sie es aufnehmen!). Und wenn man sich andere Briefe von ihr ansieht, so findet man hier ein durchgängiges Motiv (Texte 4-6 im Anhang), das allerdings unterschwellig auch auf die nie ganz aufgehobene soziale Distanz zwischen „einfacher" Krankenschwester und der „Tochter aus höherem (d.h. gutbürgerlichen) Hause" verweist, bei der sie einst angestellt war. Auf diesen sozialen Hintergrund könnten dann ebenfalls die stilistischen Überanpassungen, die in allen Briefen zu finden sind, zurückgehen.

\subsection{Alterität}

Jenny Cheshire (1987, 760f.) unterscheidet an der Sprache alter Menschen altersspezifische (unterdifferenziert in altersexklusive und alterspräferente) Merkmale und generationsspezifische Merkmale. Der Aspekt der Alterität betrifft nur letztere. Gene-

45 Es geht dabei um dialektologische Probleme im Zusammenhang mit Forschungen im sog. Deutschen Sprachatlas, Marburg. Marbach ist ein Stadtviertel von Marburg, das für den Schreiber mit bestimmten biographischen Konnotationen verbunden war. 
rationsspezifik ist nun aber nicht so zu verstehen, daß die Sprache alter Menschen auf nur eine Generation, sprachlich also auf den Stand der Schul- und Jugendzeit dieser Menschen, festzulegen wäre. Vielmehr müssen wir mit einer Altersschichtung (age-grading) rechnen, die rückwärts gewandt weit über die einzelne Biographie hinausreichen kann. Solche Kontinuitätsphänomene in der Sprache von Individuen sind bisher wenig behandelt worden, dürften aber auch für sprachhistorische Untersuchungen im größeren Maßstab interessant sein. ${ }^{46}$

Die Briefschreiberin von Text 1 wurde 1889 geboren, erhielt also ihre sprachliche Prägung vorwiegend in der „guten alten Zeit“, wie sie von den Angehörigen dieser Generation gerne charakterisiert wurde. Sprachhistorisch läßt sich diese Zeit auch als Umbruchszeit verstehen (vgl. Cherubim 1998): Die starke Orientierung an der durch eine klassische Literatursprache repräsentierten Standardsprache war brüchig geworden, die mediale Diglossie von geschriebenem Standard und gesprochener Mundart löste sich langsam auf bzw. wurde zunehmend in Richtung auf eine Kompromißsprache, die gegen Ende des 19. Jahrhunderts als Umgangssprache thematisiert wurde und verschiedene Erscheinungsformen zeigte, verschoben. Dazu kam eine gewaltige Ausdifferenzierung in der Lexik, die besonders mit der rasanten Entwicklung in Technik und Wissenschaften, deren Popularisierung durch Massenmedien (Zeitungen und Zeitschriften, Konversationslexika, Kataloge, Werbung usw.) und der verbesserten Ausbildung der Menschen in dieser Zeit (z.B. durch Schulen und Universitäten, das Vereinswesen, Bibliotheken und Museen) verbunden war. Ebenfalls charakteristisch für diese Zeit war der Umbruch in der sprachlichen Orientierung an kulturell bedeutsamen Fremdsprachen: Das lange als höhere Gesellschaftssprache akzeptierte Französisch trat deutlich zurück, die alte europäische Bildungssprache Latein war ohnehin schon zum akademischen Jargon verkümmert, und die neue Weltwirtschaftssprache Englisch warf bereits ihre Schatten voraus, wurde aber gerade in dieser Zeit unter nationalistischer Flagge von einigen heftig bekämpft. Dazu kommt, daß - einem allgemeinen Trend folgend - auch historisierende Rückgriffe bis in die frühbürgerliche Zeit (Lutherdeutsch) als Bestandteil eines puristischen Programms (Sprachbereicherung) propagiert wurden. ${ }^{47}$ Schließlich kann man noch auf die erhöhte soziale Mobilität dieser Zeit verweisen, deren Verarbeitung im Sprachlichen sich auch in den vielfachen Brechungen und Veränderungen des „Sprachmodischen“ zeigte. ${ }^{48}$

Texte alter Menschen, die in dieser Zeit sprachlich sozialisiert wurden, können daher auf Spuren der hier nur angedeuteten sprachhistorischen Bewegungen abgesucht werden, zumal dann, wenn sie auch thematisch (z.B. in Erzählungen über die Jugendzeit) darauf fokussiert sind. Lexikalisch wären solche Spuren u.a. an Dialektund Fremdwörtern (Typ: dufte, knorke; Trottoir, Perron), die heute nicht mehr verwendet und/oder verstanden werden, ${ }^{49}$ an aktuellen Modewörtern (Typ: kolossal, Backfisch) oder Historismen (Typ: Vertiko, Beletage, Sommerfrische), an damals

46 Vgl. dazu jetzt auch Cherubim (1998) mit weiteren Hinweisen.

47 Hier ist nur auf das bekannte Wirken des Allgemeinen Deutschen Sprachvereins (gegründet 1885) hinzuweisen. Einen guten Eindruck von der „sprachlichen Szene“ dieser Zeit vermittelt Theodor Fontanes Roman Frau Jenny Treibel (erschienen 1892).

48 Vgl. dazu die Essays von Brennert (1898); auch die sehr lebendige Sprachkritik am Ende des 19. Jahrhunderts transportiert, mehr ungewollt, einiges von diesen Bewegungen.

49 Hier wäre auch an Spuren von Soziolekten zu erinnern, die heute weitgehend aus dem Bewußtsein entschwunden sind, damals aber noch in der Umgangssprache relativ verbreitet waren: das Jiddische, das Rotwelsche, die Schüler- und Studentensprache, der Militärjargon u.a. 
aktuellen Fachwörtern oder fachlichen Umschreibungen (Typ: Kinematograph, Elektrische, Benzinkutsche, Kraftomnibus), an Ideologiewörtern oder -phrasen (Typ: schneidig, judenzen, besserer Herr, höhere Tochter) und an Sprachspielereien (Typ: nichtsdestotrotz, Bruderflosse, letzteres in Anspielung auf Bruderhand) ${ }^{50}$ festzumachen. Im vorliegenden Text 1 gehören zu diesen Merkmalen der Alterität die schon behandelte deutsche Schreibschrift, bestimmte Erscheinungen der Rechtschreibung und Zeichensetzung, auf die ebenfalls bereits hingewiesen wurde, die weitgehend fremdwortfreie Diktion (z.B. Z. 34: in Ordnung sein statt heutigem o.k. sein), bestimmte formelle Kollokationen (z.B. Z. 4f.: von ganzem Herzen danken, Z. 47: tausend Dank) ${ }^{51}$, altertümlich gestelzte Phrasen (Z. 17: Obliegenheiten verrichten), spezifische Umschreibungen oder Euphemismen (Z. 8f.: geistig durcheinander, Z. 14: geistig unklar sein, Z. 22: geistig krank, Z. 27: geistige Umnachtung). Aufschlußreich erscheint uns in diesem Zusammenhang auch die Selbstcharakterisierung der Briefschreiberin als ganz mobil (Z. 39), die heute zu anderen Möglichkeiten wie beweglich, rüstig, munter, fit im Kontrast steht. ${ }^{52}$

\subsection{Kommunikabilität}

Zur Charakteristik von Texten alter Menschen gehört auch, wie in ihnen die besondere Lebenssituation des Alters bzw. die entsprechenden Wahrnehmungs- und Verarbeitungsresultate ausgedrückt sind. Solche Merkmale beeinflussen dann, so kann man annehmen, nicht unwesentlich das Gelingen von Kommunikation in unterschiedlichen Konstellationen. Lütjen (1978) hat hierzu einige Aspekte diskutiert, die die Richtung weisen. Sprachkommunikativ wirken sich z.B. in intergenerationalen Diskursen Faktoren wie Selbst- und Fremdeinschätzung (z.B. Egozentrik vs. Offenheit, positive oder negative Einschätzung des Alters, der jüngeren Generationen), Werthaltungen und Einstellungen (z.B. Patriotismus, Selbstbeherrschung, Disziplin) sowie allgemeine Verhaltens- und Sprachnormen (z.B. für Höflichkeitsverhalten) aus. Da es sich jedoch hier um die Analyse eines geschriebenen Textes handelt, können entsprechende Merkmale meist nur indirekt ermittelt werden. ${ }^{53}$ Anhaltspunkte dafür sind in Text 1 gewisse Züge von Egozentrik und die thematische Konzentration auf das eigene Befinden, die nur zu begreiflich ist und die sich sprachlich durch Wiederholungen und Redundanzen ausdrückt; ferner das zwar persönlich gemeinte, aber auch konventionell formulierte Höflichkeitsverhalten sowie die in den Text eingearbeitete Berücksichtigung der Perspektive der Adressatin, von der oben schon die Rede war.

50 Dazu kämen noch Abkürzungen, wie sie sich z.B. auch in den Briefen der Schreiberin von Text 1 finden: la als Qualitätsbewertung, vermutlich im Anschluß an die Berliner Autonummern, $M$ für Mark statt des heutigen DM, aber auch mit der Zwischenstufe der Mark der DDR, das alte Zeichen für Pfund usw.

51 Nicht in diesem Text kommen altertümliche Titel, Anreden oder Grußformeln (Typ: Geheimrat, gnädige Frau, wie befehlen? Ihr Diener, mit vorzüglicher Hochachtung usw.) vor.

52 Vgl. dazu die Belege im Deutschen Fremdwörterbuch s.v. mobil und generell Kuhlmann (1997).

53 Eine sinnvolle Ergänzung stellte daher die Analyse von Briefwechseln dar. 


\section{Schlußbemerkung}

Für die Erforschung der Einwirkungen, die das menschliche Alter in seinen verschiedenen (physischen, psychischen, sozialen) Dimensionen auf das Sprachverhalten und Sprachvermögen von Individuen ausübt, gibt es noch viel zu tun. Uns lag daran, hier einige Aspekte eines vielschichtigen Problems sichtbar zu machen und exemplarisch zu diskutieren. Briefwechsel alter Menschen, die relativ gut zugänglich sind, können dafür nach unseren Erfahrungen ein geeignetes Material sein, vor allem wenn man über Briefe aus einem längeren Zeitraum, biographische Hintergrundinformationen und geeignete Vergleichstexte verfügt. Gut bekannte Briefkorpora literarisch hervorgetretener Persönlichkeiten könnten hier erste Ansatzpunkte für heuristische Kategorisierungen liefern. Ebenso brauchbar erscheint Material, das z.B. im Rahmen von Oral-History-Studien von alten Menschen erhoben wurde. ${ }^{54}$ Auch die im Rahmen der Bonner Gerontologischen Längsschnittstudie (BOLSA) in halbstrukturierten Interviews erhobenen Daten könnten hier ausgewertet werden (vgl. Lehr \& Thomae 1987). Eine Hauptschwierigkeit stellt die Kontrolle des Faktors Alter dar: Konkretes Sprachverhalten ist meist komplex gesteuert, und der Faktor Alter wirkt sich je nach Qualität anderer (z.B. psychischer oder sozialer) Bedingungen sehr unterschiedlich aus. Ausdrücke wie Alterssprache oder Altersstil verdecken daher mit ihrer Faktizitätsunterstellung mehr Probleme als sie zeigen.

\section{Literatur}

Adelmann, Ronald D., Greene, Michele G. \& Charon, Rita (1991). Issues in the Physician-Elderly Patient Interaction. In: Ageing and Society 11, 127-148.

Albert, Martin K. (1980). Language in Normal and Dementing Elderly. In: Obler, Loraine K. \& Albert, Martin L. (eds.), Language and Communication in the Elderly. Lexington, Mass., 145-150.

Andresen, Karl Gustaf (1869). Über die Sprache Jacob Grimms. Leipzig: Teubner (reprograf. Nachdruck Wiesbaden: Sändig, 1968).

Augst, Gerhard (Hrsg.) (1978). Spracherwerb von 6 bis 16. Linguistische, psychologische, soziologische Grundlagen. Düsseldorf: Schwann.

Barrett, Terry R. \& Wright, Mavis (1981). Age-Related Facilitation in Recall Following Semantic Processing. In: Journal of Gerontology 36.2, 194-199.

Belmore, Susan M. (1981). Age-Related Changes in Processing Explicit versus Implicit Language. In: Journal of Gerontology 36.3, 316-322.

Boden, Deirde \& del Vento Bielby, Denise (1983). The Past as Resource: A Conversational Analysis of Elderly Talk. In: Human Development 26, 308-319.

Borscheid, Peter (1987). Geschichte des Alters, 16.-18. Jahrhundert (Studien zur Geschichte des Alltags. 7). Münster: F. Coppenrath.

Brennert, Hans (1898). Mode Worte. Aus dem Mitteleuropäischen. Berlin: F. Fontane \& Co.

Burdach, Konrad (1926). Goethes Sprache und Stil im Alter. In: ders., Vorspiel. Gesammelte Schriften zur Geschichte des deutschen Geistes. Bd. II: Goethe und sein Zeitalter [...]. Halle/S.: M. Niemeyer, 61-72.

Busemann, Adolf (1948). Stil und Charakter. Meisenheim/Glan: Westkulturverlag.

Caporael, Linnda R. (1981). The Paralanguage of Caregiving: Baby Talk to the Institutionalized Aged. In: Journal of Personality and Social Psychology 40.5, 876-884.

54 Vgl. etwa die Braunschweiger Studie von Roloff (1985). 
Caporael, Linnda R., Lukaszweski, Marlene P. \& Culbertson, Glen H. (1983). Secondary Baby Talk: Judgements by Institutionalized Elderly and Their Caregivers. In: Journal of Personality and Social Psychology 44.4, 746-754.

Caporael, Linnda R. \& Culbertson, Glen H. (1986). Verbal Response Modes of Baby Talk and Other Speech at Institutions for the Aged. In: Giles \& Ryan, 99-112.

Cherubim, Dieter (1980a). Fehlerlinguistik. Sprachliche Abweichungen als Gegenstand einer germanistischen Linguistik. In: Zeitschrift für germanistische Linguistik 8, 1-22.

Cherubim, Dieter (1980b). Abweichung und Sprachwandel. In: Cherubim, Dieter (Hrsg.), Fehlerlinguistik. Beiträge zum Problem der sprachlichen Abweichung. Tübingen: M. Niemeyer, 124-152.

Cherubim, Dieter (1986). Jugendsprache und Soziolinguistik. In: Neue Entwicklungen der Angewandten Linguistik. Kongreßbeiträge zur 15. Jahrestagung der Gesellschaft für Angewandte Linguistik, GAL e.V., Berlin 1984. Tübingen: Narr, 87-89.

Cherubim, Dieter (1989). Gesprochene Sprache - ein Lehrstück vom Umgang der Sprachwissenschaft mit ihren Gegenständen? In: Addison, Anthony \& Vogel, Klaus (Hrsg.), Gesprochene Fremdsprache. Beschreibung - Vermittlung - Bewertung. Bochum: ASK-Verlag, 12-36.

Cherubim, Dieter (1998). Kontinuität und Diskontinuität in der deutschen Sprache des 20. Jahrhunderts. In: Schmidt, Hartmut (Hrsg.), Das 20. Jahrhundert: Sprachgeschichte - Zeitgeschichte. (Jahrbuch des Instituts für deutsche Sprache 1997). Berlin, New York: W. de Gruyter \& Co. [im Druck].

Cheshire, Jenny (1987). Age and generation-specific use of language. In: Ammon, Ulrich, Dittmar, Norbert \& Mattheier, Klaus J. (Hrsg.), Soziolinguistik. Ein internationales Handbuch zur Wissenschaft von Sprache und Gesellschaft. 1. Halbband. Berlin, New York: W. de Gruyter \& Co., 760767.

Coseriu, Eugenio (1980). Vom Primat der Geschichte. In: Sprachwissenschaft 5, 125-145.

Coupland, Justine, Coupland, Nikolas, Giles, Howard \& Wiemann, John (1988). 'My life in Your Hands': Processes of Self-Disclosure in Intergenerational Talk. In: Coupland, Nikolas (ed.), Styles of Discourse. London, 201-253.

Coupland, Justine, Coupland, Nikolas, Giles, Howard \& Henwood, Karen (1991). Formulating Age: Dimensions of Age Identity in Elderly Talk. In: Discourse Processes: A Multidisciplinary Journal $14,87-106$.

Coupland, Nikolas, Coupland, Justine \& Giles, Howard (1991). Language, Society and the Elderly. Discourse, Identity and Ageing. Oxford, Cambridge.

Dittenberger, Wilhelm (1881). Sprachliche Kriterien für die Chronologie der platonischen Dialoge. In: Hermes 16, 321-345.

Finck, Franz Nikolaus (1910). Die Haupttypen des Sprachbaus. Leipzig: Teubner.

Freye, Hans-Albrecht (1986). Einführung in die Humanökologie für Mediziner und Biologen. Heidelberg: Quelle \& Meyer.

Friese, Hans (1937). Goethes monumentaler Stil. In: Zeitschrift für Deutschkunde 51, 605-617.

Gerritsen, Marinel (1985). Alters- und geschlechtsspezifische Sprachverwendung. In: Besch, Werner \& Mattheier, Klaus J. (Hrsg.), Ortssprachenforschung. Beiträge zu einem Bonner Kolloquium. Berlin: E. Schmidt, 79-108.

Giles, Howard \& Ryan, Ellen B. (eds.) (1986). Language, Communication and the Elderly = Language and Communication: An Interdisciplinary Journal 6.1/2.

Glosser, Guila \& Deser, Toni (1992). A Comparison of Changes in Macrolinguistic and Microlinguistic Aspects of Discourse Production in Normal Aginng. In: Journal of Gerontology: Psychological Sciences 47.4, 266-272.

Greene, Michele G., Adelman, Ronald, Charon, Rita \& Hoffmann, Susie (1986). Ageism in the Medical Encounter: An Exploratory Study of the Doctor-Elderly Patient Relationship. In: Giles \& Ryan, 113-124.

Grimm, Jacob (1860/1984). Rede über das Alter (1860). In: Wyss, Ulrich (Hrsg.), Jacob Grimm. Selbstbiographie. Ausgewählte Schriften, Reden und Abhandlungen. München: dtv, 216-234.

Halliday, Michael Alexander K. (1973). Explorations in the Functions of Language. London: E. Arnold.

Hassan, Fekri A. (1981). Demographic Archeology. New York: Academic Press.

Helfrich, Hede (1979). Age markers in speech. In: Scherer, K. R. \& Giles, H. (eds.), Social Markers in Speech. Cambridge. 
Henne, Helmut (1984). Jugend und ihre Sprache. In: Die deutche Sprache der Gegenwart. Vorträge gehalten auf der Tagung der Joachim Jungius-Gesellschaft der Wissenschaften, Hamburg am 4. und 5. November 1983. Göttingen: Vandenhoeck \& Ruprecht, 59-72.

Hermanns, Fritz (1994). Linguistische Anthropologie. Skizze eines Gegenstandsbereiches linguistischer Mentalitätsgeschichte. In: Busse, Dietrich, Hermanns, Fritz \& Teubert, Wolfgang (Hrsg.), Begriffsgeschichte und Diskursgeschichte. Methodenfragen und Forschungsergebnisse der historischen Semantik. Opladen: Westdeutscher Verlag, 29-59.

Hess, Thomas M. et al. (1993). Aging and Memory for Schematically vs. Taxonomically Organized Verbal Materials. In: Journal of Gerontology: Psychological Sciences 48.1, 37-44.

Humboldt, Wilhelm von (1827/1963). Über den Dualis. In: Flitner, Andreas \& Giel, Klaus (Hrsg.), Wilhelm von Humboldt. Werke in fünf Bänden. Bd. III: Schriften zur Sprachphilosophie. Darmstadt: Wissenschaftliche Buchgesellschaft, 113-143.

Hutchinson, John M. \& Jensen, Mary (1980). A Pragmatic Evaluation of Discourse Communication in Normal and Senile Elderly in a Nursing Home. In: Obler, Loraine K. \& Albert, Martin L. (eds.), Language and Communication in the Elderly. Lexington, Mass., 59-73.

Knauth, Paul (1898). Goethes Sprache und Stil im Alter. Leipzig: Avenarius.

Kuhlmann, Kathrin (1997). „Fit mit 50 - Jung mit 70“. Adressatenspezifische Sprach- und Textgestaltung in Werbung für alte Menschen. Masch. Magisterarbeit. Göttingen.

Kynette, Donna \& Kemper, Susan (1986). Aging and the Loss of Grammatical Forms: A CrossSectional Study of Language Performance. In: Giles \& Ryan, 65-72.

Lehr, Ursula (1991). Psychologie des Alterns. 7. ergänzte und erweiterte Aufl. Heidelberg: Quelle \& Meyer.

Lehr, Ursula \& Thomae, Hans (Hrsg.) (1987). Formen seelischen Alterns. Stuttgart: Enke.

Lesky, Albin (1963). Geschichte der griechischen Literatur. 2. neubearb. und erw. Aufl. Bern, München: Francke.

Lewy, Ernst (1961a). Zur Sprache des alten Goethe. Ein Versuch über die Sprache des Einzelnen. In: Lewy, Ernst, Kleine Schriften. Berlin: Akademie Verlag, 91-113.

Lewy, Ernst (1961b): Die Sprache des alten Goethe und die Möglichkeit ihrer biologischen Fundamentierung. In: Lewy, Ernst, Kleine Schriften. Berlin: Akademie Verlag, 106-113.

Lütjen, Hans Peter (1978). Intergenerationale Kommunikationskonflikte. In: Grazer Linguistische Studien 8, 114-135.

Mattheier, Klaus J. (1987). Alter, Generation. In: Ammon, Ulrich, Dittmar, Norbert \& Mattheier, Klaus J. (Hrsg.), Soziolinguistik. Ein internationales Handbuch zur Wissenschaft von Sprache und Gesellschaft. 1. Halbband. Berlin, New York: W. de Gruyter \& Co., 78-82.

Nentwig, Wolfgang (1995). Humanökologie. Fakten, Argumente, Ausblicke. Berlin: Springer 1995.

Objartel, Georg (1985). Studentische Kommunikationsstile im späten 18. Jahrhundert. In: Kimpel, Dieter (Hrsg.), Mehrsprachigkeit in der deutschen Aufklärung. Hamburg: Meiner, 28-41.

Pinxt, Stef (1981). Zur Theorie des Linguistischen Interaktionismus. In: Pragmatik. Theorie und Praxis. Amsterdam: Rodopi, 93-134.

Roloff, Ernst-August (1985). 100 Jahre Bürgertum in Braunschweig. Teil I: Von der Jasperallee zur Kaiser-Wilhelm-Straße. Braunschweig: Oeding.

Ryan, Ellen B., Giles, Howard, Bartolucci, Giampiero \& Henwood, Karen (1986). Psycholinguistics and Social Psychological Components of Communication by and with the Elderly. In: Giles \& Ryan, 1-24.

Salber, Wilhelm (1959). Die Entwicklung der Sprache. In: Lersch, Philipp u.a. (Hrsg.), Handbuch der Psychologie. Bd. III: Entwicklungspsychologie. 2. Aufl. Göttingen: Hogrefe, 442-476.

Salthouse, Timothy A. (1993). Speed and Knowledge as Determinants of Adult Age Differences in Verbal Tasks. In: Journal of Gerontology: Psychological Sciences 48.1, 29-36.

Schenda, Rudolf (1977). [Artikel] Alte Leute. In: Ranke, Kurt u.a. (Hrsg.), Enzyklopädie des Märchens. Handwörterbuch zur historischen und vergleichenden Erzähllforschung. Bd. 1. Berlin/New York: W. de Gruyter, Sp. 373-380.

Schneider, Hans-Dieter (1974) Aspekte des Alterns. Ergebnisse sozialpsychologischer Forschung. Frankfurt a.M.: Athenäum-Fischer.

Schneidewin, Max (1893). Cicero und Jacob Grimm über das Alter. Hamburg: Verlagsanstalt und Druckerei. 
Simon, Ernst (1929). Zu Jacob Grimms Sprache, Stil und Persönlichkeit. In: Deutsche Vierteljahresschrift für Literaturwissenschaft und Geistesgeschichte (DVjS) 7, 515-559.

Sperber, Hans (1914). Über den Affekt als Ursache der Sprachveränderung. Versuch einer dynamologischen Betrachtung des Sprachlebens. Halle/S.: M. Niemeyer.

Stöcklein, Paul (1949). Wege zum späten Goethe. Dichtung. Gedanke. Zeichnung. Interpretationen. Hamburg: Marion von Schröder.

Turk, Horst (1990). Alienität und Alterität als Schlüsselbegriffe einer Kultursemantik. In: Jahrbuch für Internationale Germanistik 22/1, 8-31.

Trunz, Erich (1954/1955). Goethes Altersstil. In: Wirkendes Wort 5, 134-139.

Weithase, Irmgard (1961). Zur Geschichte der gesprochenen deutschen Sprache. 2 Bde. Tübingen: Niemeyer.

Wyss, Ulrich (1979). Die wilde Philologie. Jacob Grimm und der Historismus. München: Beck.

Zelinski, Elizabeth M. \& Miura, Shari A. (1990). Anaphor Comprehension in Younger and Older Adults. In: International Journal of Aging and Human Development 31/2, 111-134. 
Cherubim/Hilgendorf: Sprachverhalten im Alter

252

Anhang

Text 1

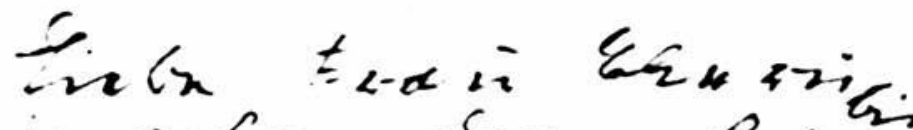

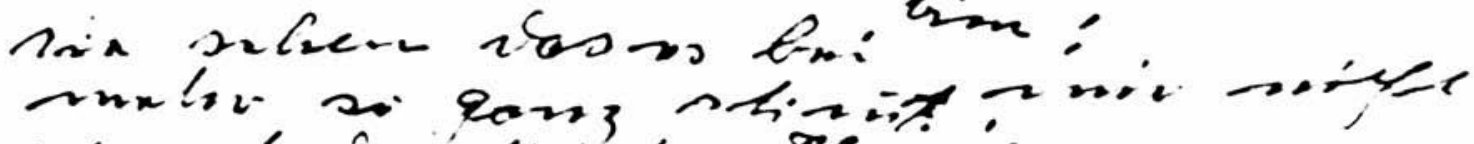

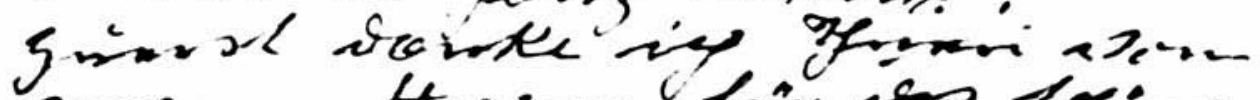

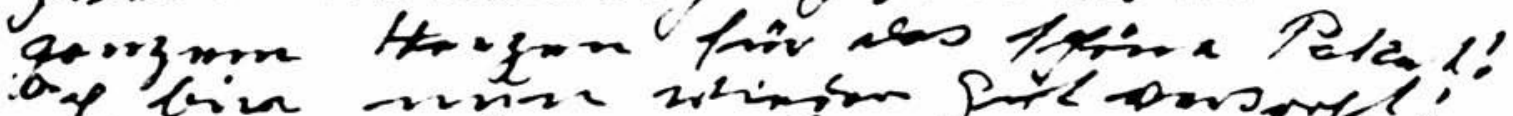

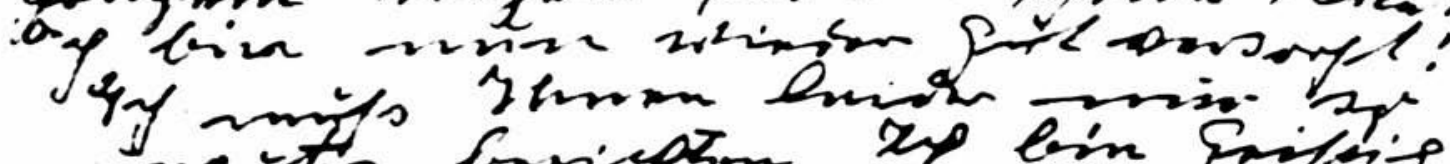

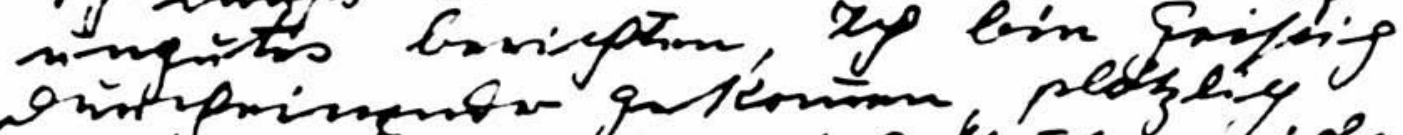

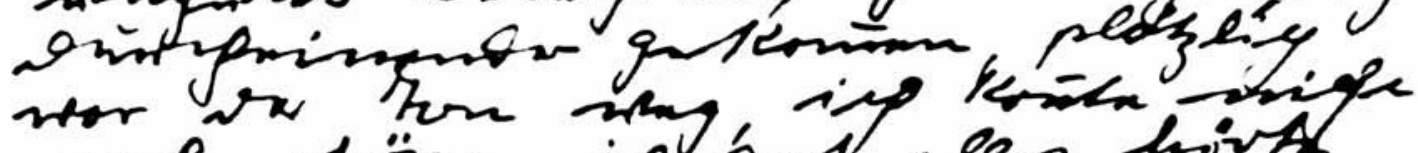

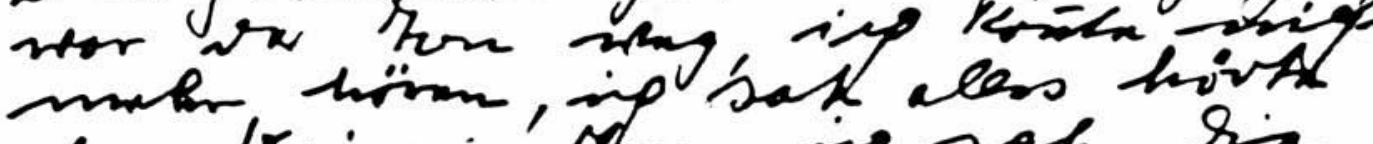
obor lcinimin' Mon, ig seh hix

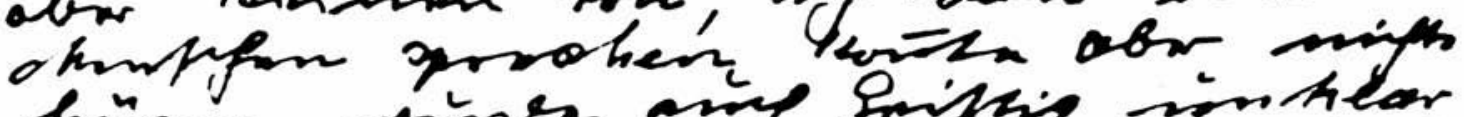

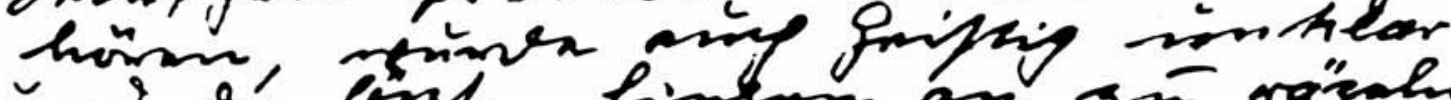
inni trin eingh fing

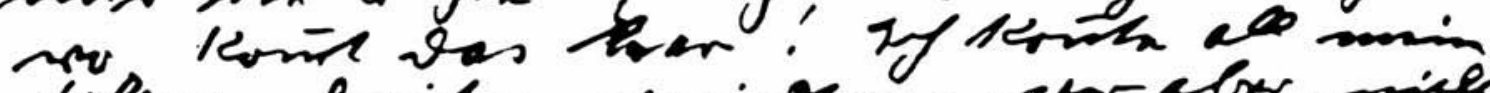

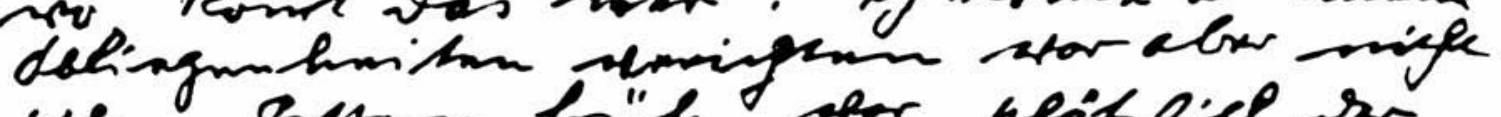

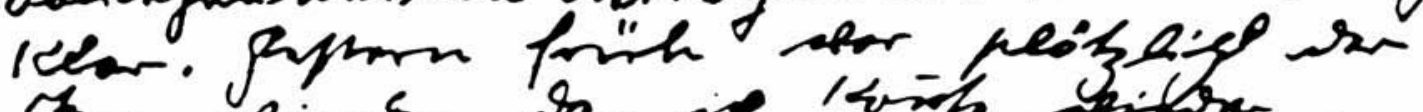

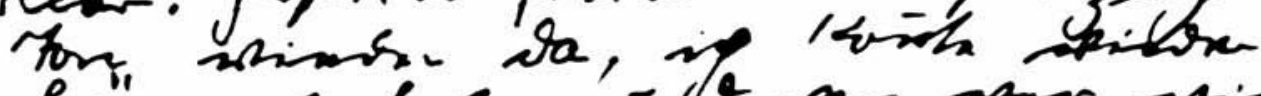

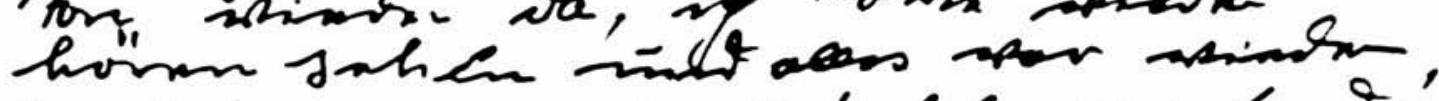

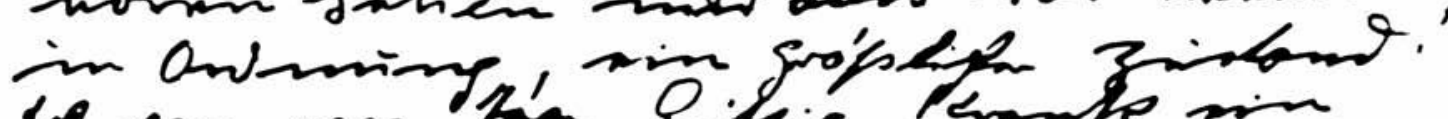

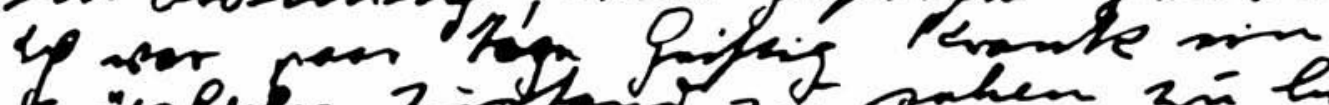

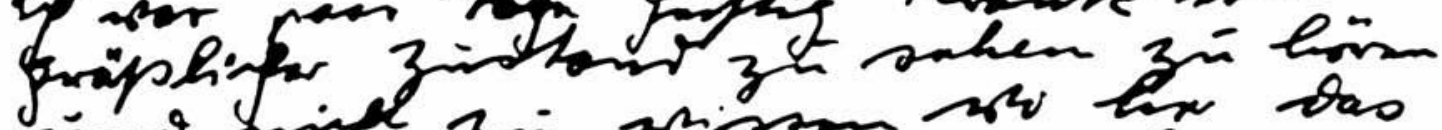
mino minge zis anizson ose ba tas lcomst, In finfon fir imot har, lir

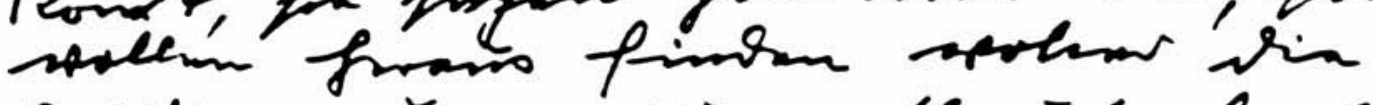
griftign simmoyeing thorit, ob zarm 
Cherubim/Hilgendorf: Sprachverhalten im Alter

253

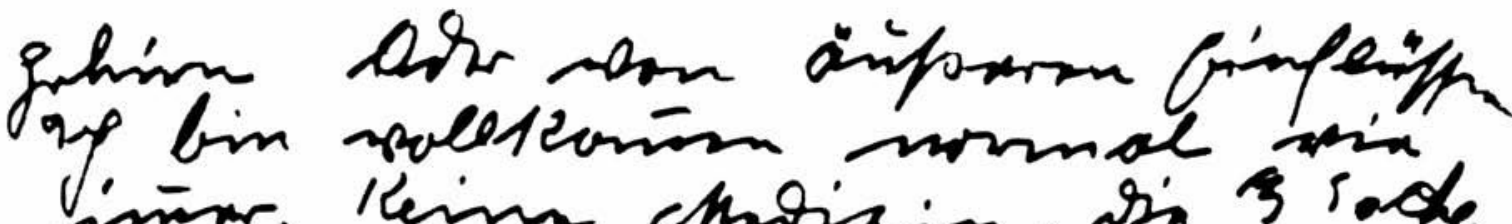

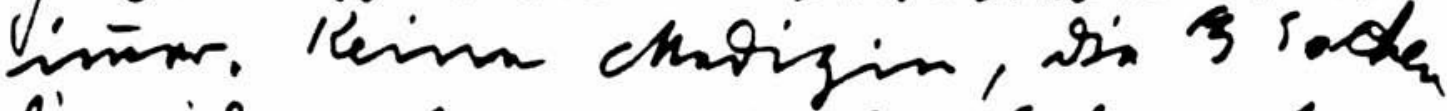
in inf nalum zing ghinf abgose

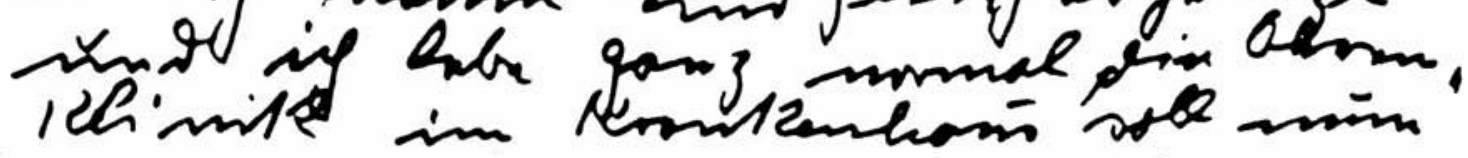
imsmainfm wh do deles in ariming

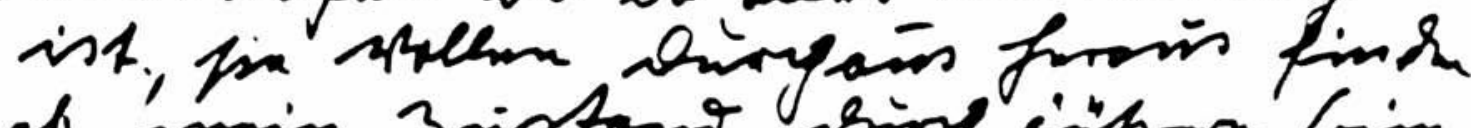
ob union zistowo aring infp-ra fin.

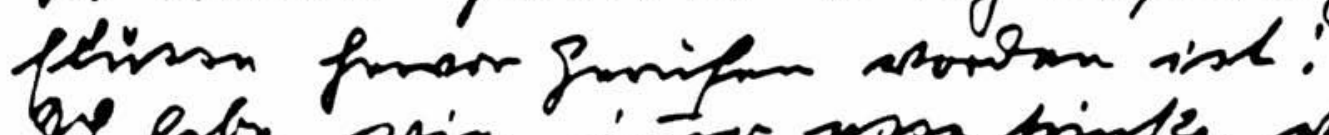

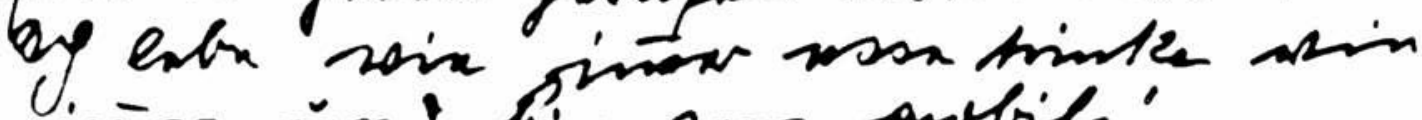
inim ind bin porz anbil.

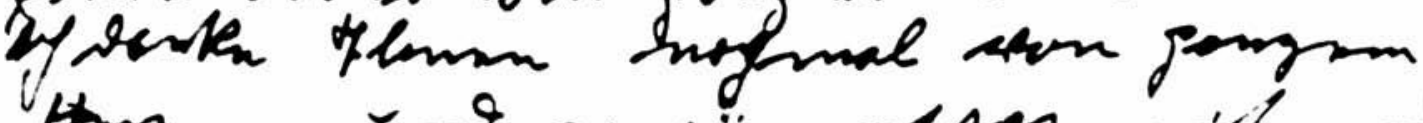

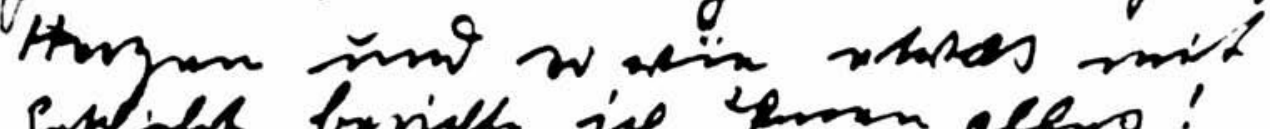

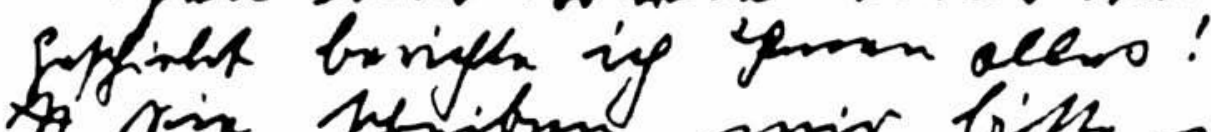

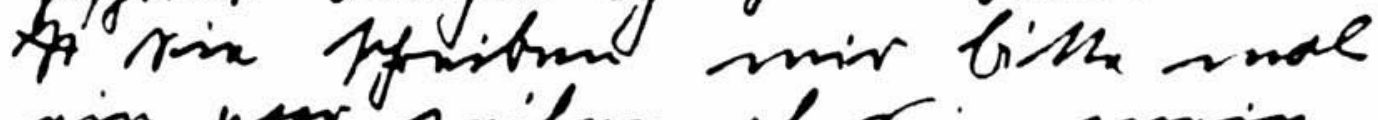
nin poor zrilmo of Tin samin

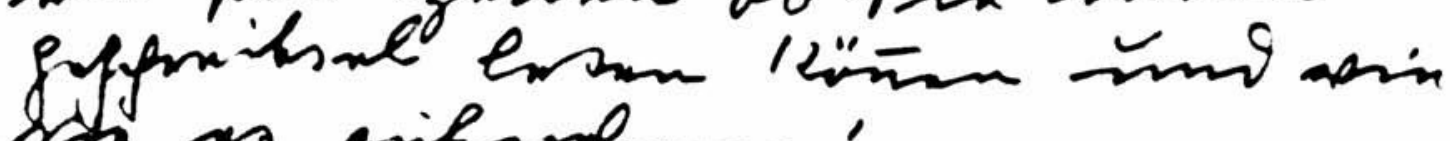

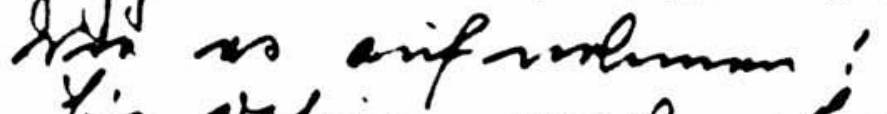

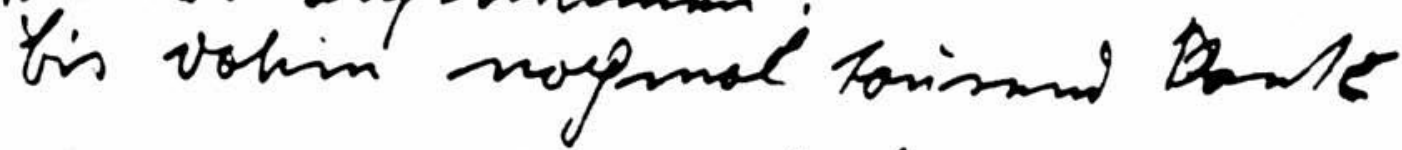
Iforn Iati! ap finhle ming gurint: 
Text 2

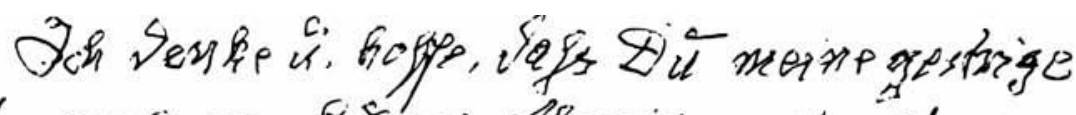

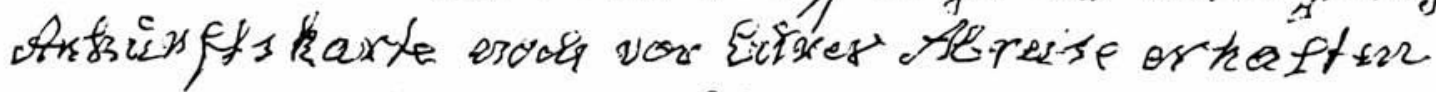

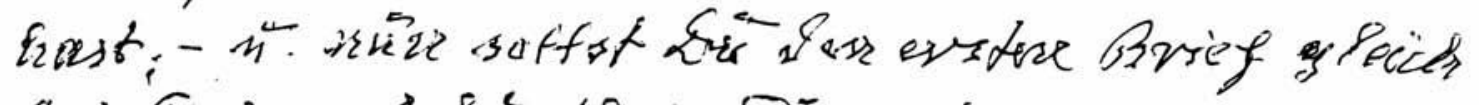

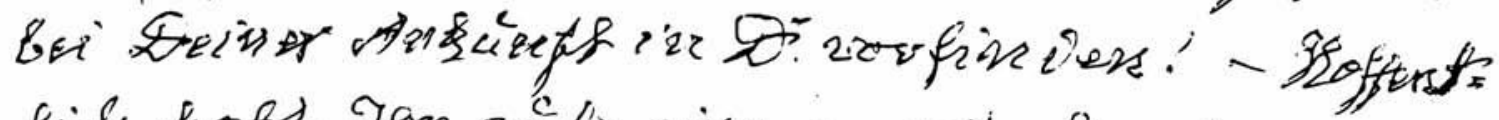

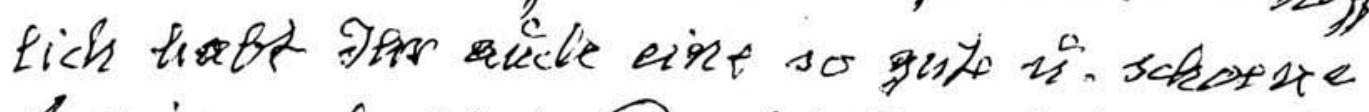

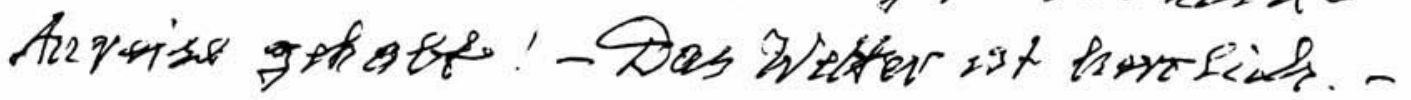

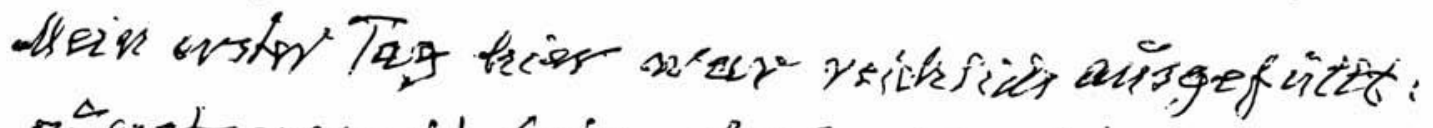

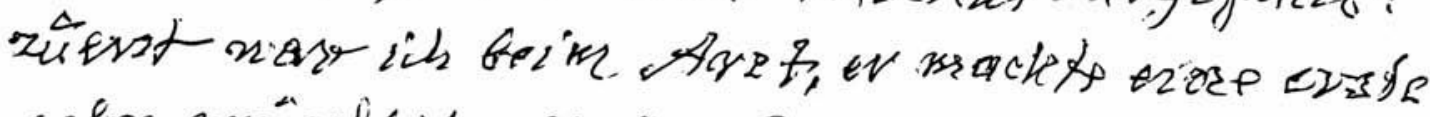

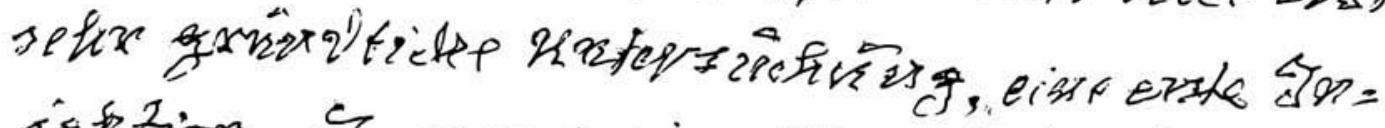

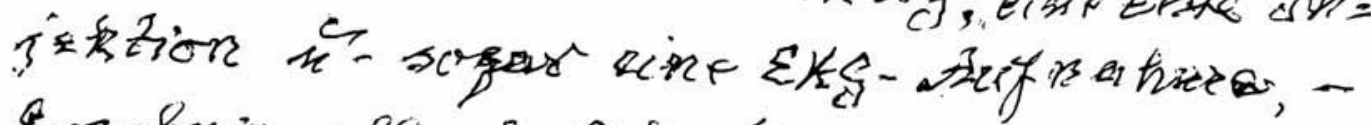

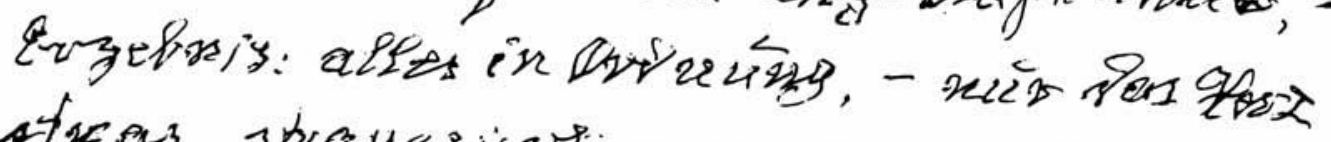

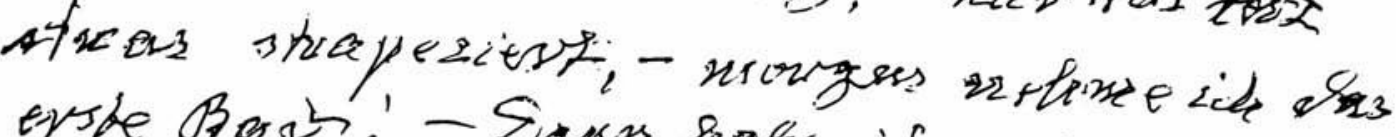

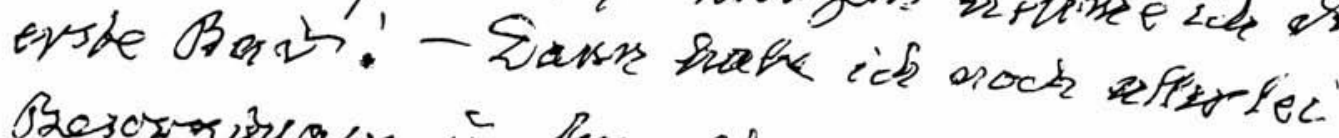

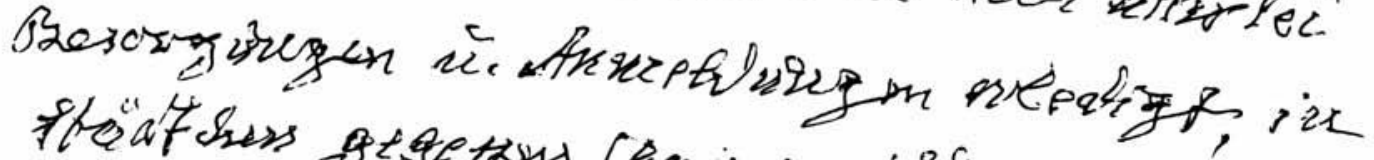

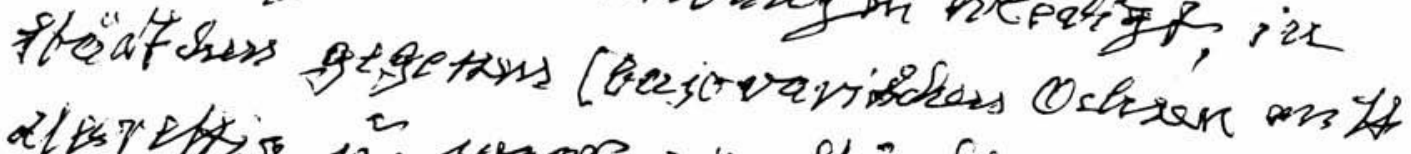

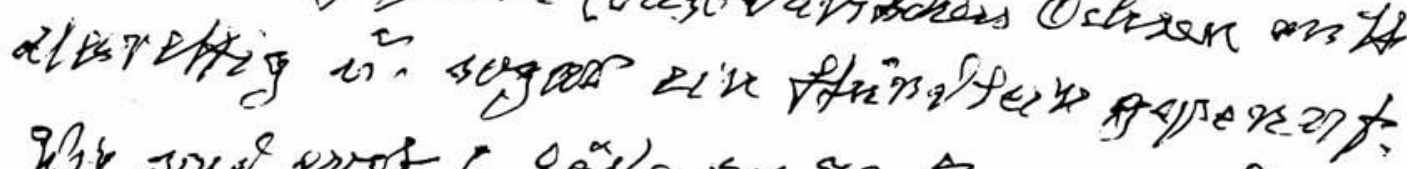

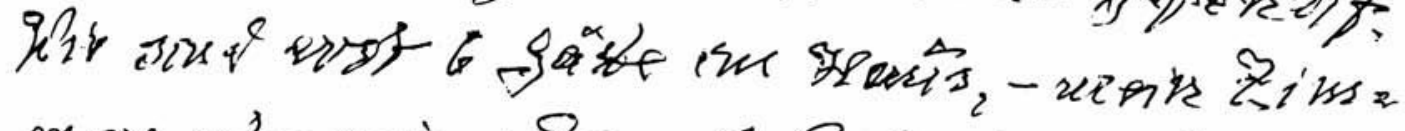

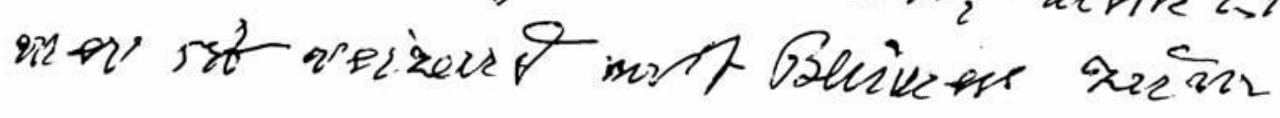


Cherubim/Hilgendorf: Sprachverhalten im Alter

255

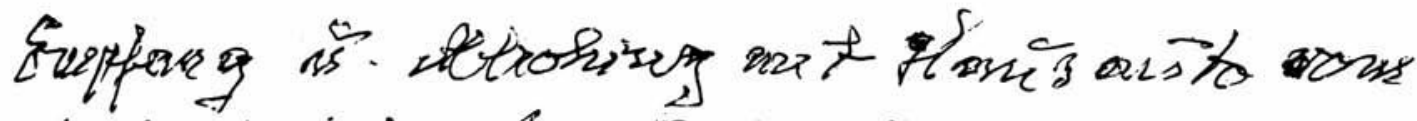

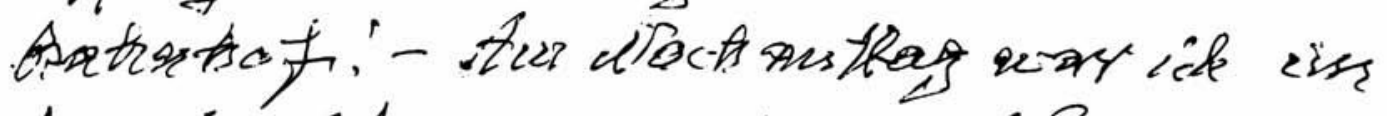

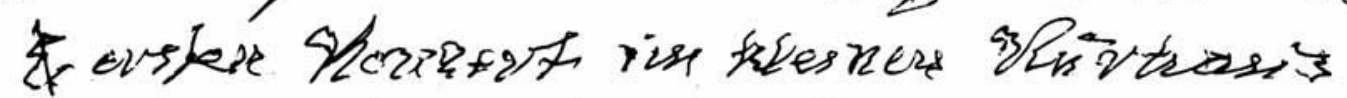

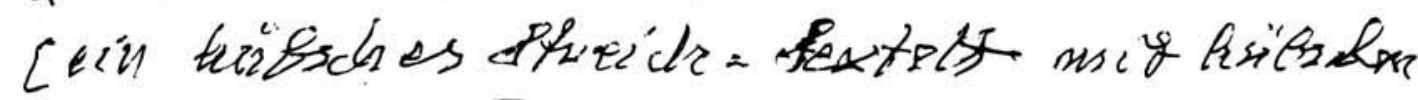

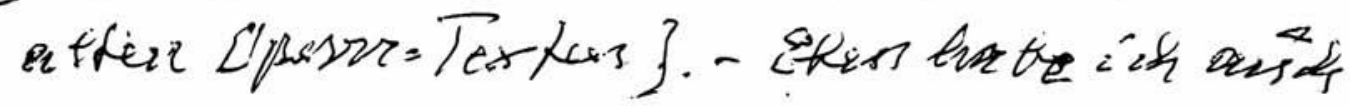

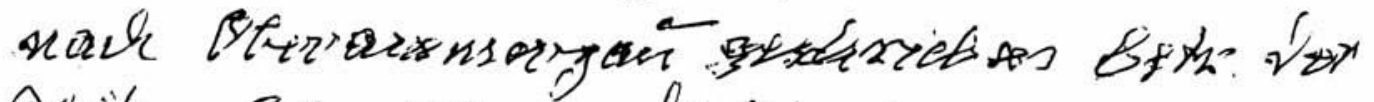

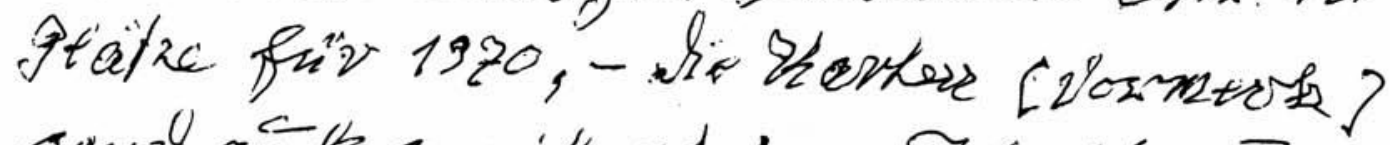

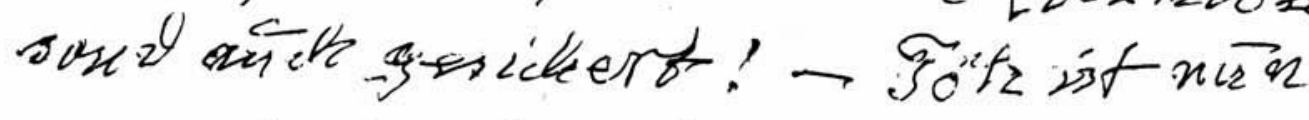

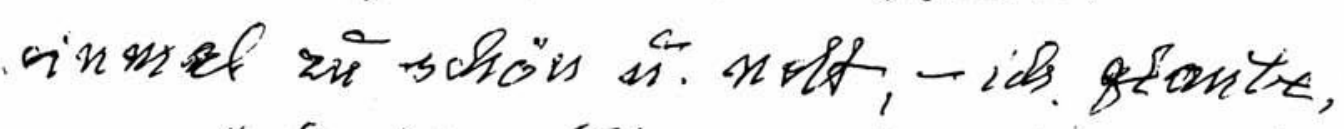

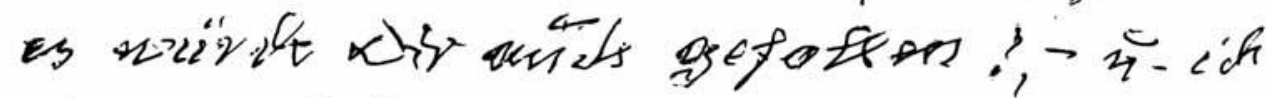

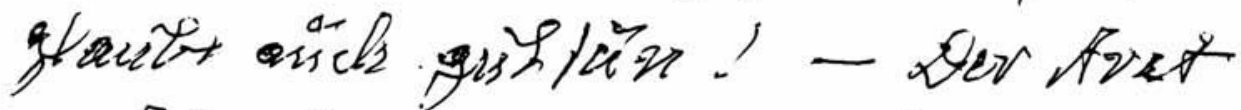

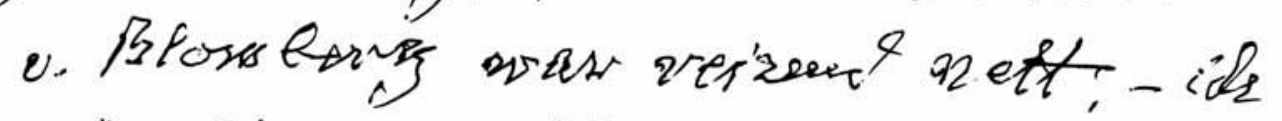

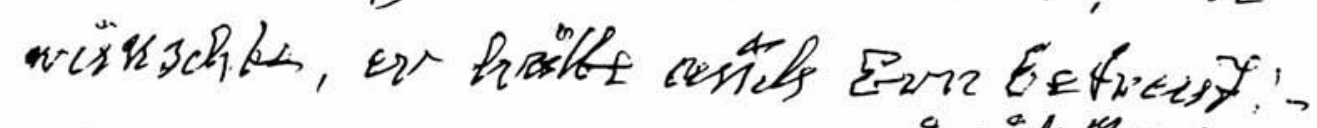

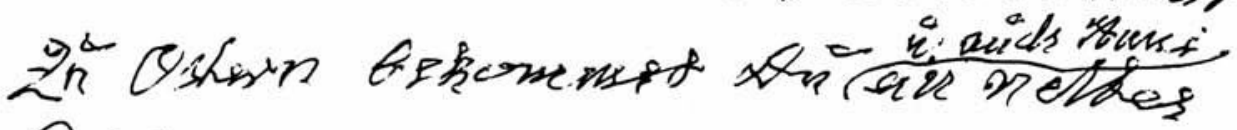

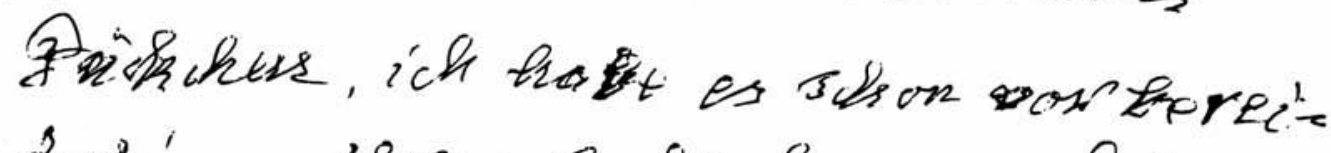

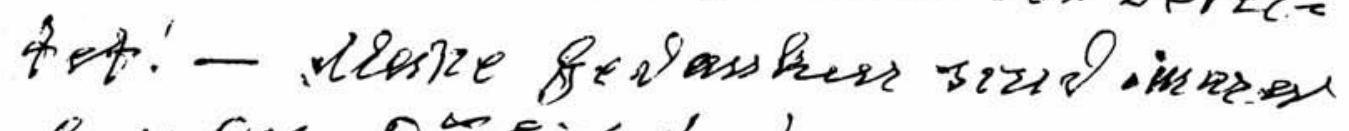
lari Nis, tor nipt thes.' -

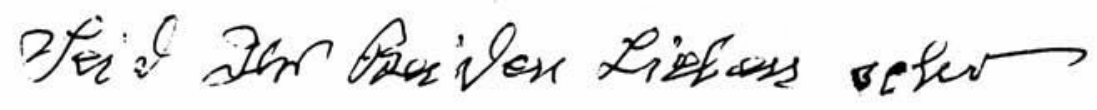
sintiticls gegarifst

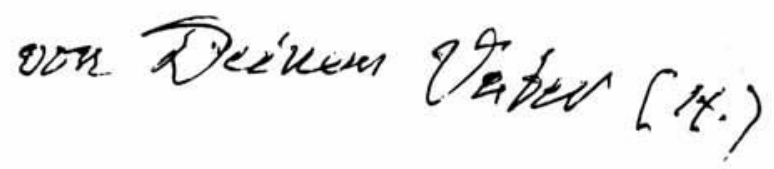




\section{Text 3}

Lieber Herr C.

Hut ab jedesmal, wenn ich

21. II. 75

die Opera Ihrer Linguistenfeder lese! Da muss

im Lexikon nachschlagen, manches kapiere ich

als lernbegieriger Pennäler von Euch gleich.

Nun also Hilferuf: im Neudruck DDG

$\mathrm{VI}$ ist meine Karte (ohne mich!)

nicht vorhanden. Schon habe ich Käuferadressen

der alten Auflage von 1920, da schon

55 Jahre (?) lang Verkauf ohne.

Hat das Exemplar der Bibliothek

das alte ohne? Von 1974 auch?

Und ja dieser Karte war ich damals

im größten DDG-Gebiet von Dorf zu

Dorf gezogen.

AltMarbacher Gruß Ihr M.

\section{Text 4}

[...]

Entschuldigen Sie die Schrift, meine Hände sind so zittrig

und steif ich hoffe, daß Sie alles lesen können! [...]

(95 Jahre)

\section{Text 5}

[...] hoffentlich schreibe ich alles richtig ich vergesse so viel und bitte um Entschuldigung, wenn was nicht stimmt. [...]

(95 Jahre)

\section{Text 6}

\section{$[\ldots]$}

Mit meinen Gedanken wird es immer mieser, ich weiss oft nicht mehr wie dies oder jenes geschrieben wird und die Hände sind so zittrig aber sonst geht es mir gut, ich freue mich über jeden Tag, ich hab es doch so gut und bin von Herzen dankbar daß ich gelernt habe alt zu sein. [...] 


\title{
AGEISMUS - Zur sprachlichen Diskriminierung des Alters
}

\author{
Undine Kramer
}

„Im Prinzip ist das Altwerden bei uns erlaubt,
aber es wird nicht gern gesehen.“
(Dieter Hildebrandt in „Scheibenwischer“)

\section{Vorbemerkungen}

Der kabarettistische Satz konfrontiert mit einem Phänomen, das gegenwärtig in Deutschland omnipräsent zu sein scheint und konfligiert es gleichzeitig: das Altwerden. Dabei ist angesichts der Tatsache, daß bereits heute 8,6 Millionen Deutsche älter als 70 sind und diese Zahl bis zum Jahr 2030 auf rund 13,3 Millionen angestiegen sein wird ${ }^{1}$, die Brisanz dieses Prozesses für unsere Gesellschaft unbestritten. Eine Nation wird älter und stellt sich auf sehr unterschiedliche Weise diesem Faktum: Thematische Serien in den Medien, Kommentare, Leserbriefe, Glossen, Fern sehdiskussionen und Rundfunkfeatures, populärwissenschaftliche und belletristische Bücher, Kabarett und Satire beschäftigen sich mit dem Alter und den Alten. Der Arzneimittelumsatz mit Geriatrieprodukten boomt, Versicherungen und Konsumgerätehersteller passen ihre Angebote einer sich verändernden Altersstruktur an, Werbeindustrie, Rundfunk- und Fernsehstationen erfassen die neue, anwachsende Zielgruppe der Älteren. Neben der wissenschaftlichen Behandlung des Themas durch Gerontologie, Geriatrie und alternsorientierte Wissenschaftsdisziplinen werden stets und ständig öffentlich Bemerkungen über das Alter und über die Alten gemacht, werden Wertungen vorgenommen und Standpunkte geäußert. In der Mehrheit dieser Aussagen spiegelt sich eine negative Einstellung zum Alter und zu älteren Menschen wider, die vom Defizitmodell des Alterns, dem Zerbrechen des Generationenvertrags und der Angst vor gesellschaftlichen Veränderungen infolge altersbedingter Umbrüche gespeist und geprägt wird. Wie bedrohlich das Alter und wie tief die Kluft zwischen den Generationen heute für viele zu sein scheint, zeigen Schlagzeilen wie „Altersheim Deutschland“, „Die demographische Zeitbombe tickt“, „Krieg den Alten!“ oder „Hilfe, wir vergreisen!“, Syntagmen wie „die graue Gefahr“, „Störfall Alter“, „gierige Grufties“ oder Wörter wie „überaltert“, „Altenlast“, „Runzelrabatt”, „Restlebenserwartung" und "Seniorenlawine“.

Diese Wörter sind Ausdruck eines tradierten und überwiegend pejorativ konnotierten Altersbildes, doch daraus auf die ausschließlich negative Spiegelung des Alters in der Gesellschaft zu schließen ist falsch: Neuere Forschungen dokumentieren eine differenziertere Sicht auf die Älteren und auf das Alter, „die die Annahmen der Existenz einer generell negativen stereotypen Wahrnehmung des Alters zweifelhaft erscheinen lassen“ (Lehr \& Niederfranke 1991, 39). Der begrüßenswerte Wandel überwiegend negativer Einstellungen zum Alter und zu den Alten, die Differenzierung und „Verjüngung“ der Altersphase, die Entwicklung eines positiven Altenbildes führen dazu, daß das einseitig negative Altersstereotyp in seiner Verbreitung abnimmt und „positiver, neutraler, situativer, differenzierter“ wird, wie Tews (1991) ein-

\footnotetext{
Vgl. Der Stern 42/1996.
} 
drucksvoll belegt. Doch in dieser begrüßenswerten Entwicklung finden sich neue Stereotype, „die die aktiven, unabhängigen, gutsituierten und gesunden Alten in den Mittelpunkt stellen und den Mythos von den ,neuen' Alten postulieren" (Lehr \& Niederfranke 1991, 39), die wiederum als „Parasiten“ der Gesellschaft abgelehnt werden und für deren „zweites Leben“ immer weniger junge Arbeitnehmer die Lasten tragen müssen ${ }^{2}$ : Auch das in den 90er Jahren kollektiv präsente doppelte Altenbild enthält bedrohliche Implikationen und offenbart Altenfeindlichkeit und Altersdiskriminierung.

\title{
2. „Ageism“
}

Altersfeindlichkeit als Form sozialer Diskriminierung, die negative Wahrnehmung des Alters und die damit zusammenhängende Stigmatisierung sowohl des Prozesses Altern als auch des Zustandes Altsein und der davon betroffenen Gruppe von Menschen wird als „Ageism“ bezeichnet. 1969 prägte Robert N. Butler in einem Beitrag des The Gerontologist diesen Begriff, umschrieb inn im Titel als Age-Ism: Another Form of Bigotry und definierte:

\begin{abstract}
„Age-ism describes the subjective experience implied in the popular notion of the generation gap. Prejudice of the middle-aged against the old in this instance, and against the young in others, is a serious national problem. Age-ism reflects a deep seated uneasiness on the part of the young and middle-aged - a personal revulsion to and distaste for growing old, disease, disability; and fear of powerless, ,uselessness' and death“" (Butler 1969, 243).
\end{abstract}

Bereits im folgenden Jahr schreibt Time ${ }^{3}$ :

„It is a though the aged were an alien race to which the young will never belong. Indeed, there is a distinct discrimination against the old that has been called age-ism. In its simplest form, says Psychiatrist Robert Butler of Washington, D.C., age-ism is, just not wanting to have all these ugly old persons around.' Butler believes that in 25 or 30 years, age-ism will be a problem equal to racism."

Sehr rasch fokussiert der Begriff auf die Diskriminierung der Älteren, die noch 1969 gegebene Nivellierung („Prejudice of the middle-aged against the old in this instan$\mathrm{ce}$, and against the young in others ...") verliert sich; „Ageism“ wird lexikalisiert und findet sich 1973 in „A Dictionary Of New English“ (Barnhart \& Langenscheidt) kodifiziert als "discriminatory practices against the aged" sowie 1979 im "The American Heritage Dictionary on the English Language" paraphrasiert als: "discrimination based on age; especially discrimination against middle-aged and elderly people“".

In den folgenden Jahren werden im anglo-amerikanischen Raum unterschiedliche Aspekte des „Ageism“ oder „Agism“ untersucht, bevorzugt aus der Sicht der Geriatrieethik und der Soziologie. ${ }^{4}$ Frühzeitig herrscht Konsens über die Qualität des „Ageism“ im Vergleich zu den anderen Arten der Diskriminierung, z.B. Rassismus und Sexismus: „Ageism is distinct from all other forms of discrimination because it cuts all of society's traditional classifications: gender, race, religion and national origin" (Nuessel 1982, 273).

\footnotetext{
2 Vgl. Der Spiegel 35/1993.

3 Zit. nach: Barnhart \& Langenscheidt $(1973,34)$.

4 Vgl. Butler (1980).
} 
In Deutschland erscheint der Terminus mit Beginn der 90er Jahre häufiger in Publikationen zur Alternsforschung. ${ }^{5}$ Illhardt $(1995,9)$ sieht „Ageism“ als Fixierung der Perspektive gegenüber den Alten und beschreibt seine „dreifache Maskierung":

1. „als Schwierigkeit, die Perspektive des Betroffenen wahrzunehmen,

2. als die geschichtlich gewachsene, nur schwach kaschierte, aber immer noch tabuisierte Aversion oder sogar Aggression gegen alte Menschen und

3. als unrealistische Wahrnehmung der Lebenswelt alter Menschen."

Neben dieser - mit der angelsächsischen Literatur korrespondierenden - allgemeinen Bedeutung etabliert sich der Terminus zudem als zentraler Begiff für die einseitig abwertende sprachliche Beurteilung des Alters und der Alten. Frank $\mathrm{H}$. Nuessel beschreibt The Language of Ageism und konstatiert:

„The language used to depict the elderly is overwhelmingly negative in its scope. [...] Such deprecatory language is a linguistic mirror of the pervasive individual and institutional ageism in our society. [...] The lexical items and phrases that allude to the potential victims of ageist bias are numerous ..." $(1982,273)$.

Auch in Deutschland deutet sich an, daß der "Generationenkonflikt maßgeblich ein Kommunikationskonflikt [ist]" (Thimm 1996, 4). Eine Austragungsform dieses Konfliktes scheint sich im sogenannten sprachlichen Terror (siehe die obigen Beispiele) gegenüber den Älteren zu zeigen. Dieser "Terror" wurde jedoch bislang trotz des evidenten Zusammenhanges von Sprache und Stereotyp häufig nur pauschal benannt oder marginal behandelt. ${ }^{6}$ Linguistische Untersuchungen des Problems - wie z.B. die o.g. für den englischen Sprachraum von Nuessel (1982) oder die knappe Darstellung von Roloff (1990) - sind rar.

Der folgende Beitrag versucht, die sprachliche Diskriminierung des Alters auf lexikalischer Basis zu erfassen, fragt nach dem - deutschen - Vokabular des „Ageism", weist auf den evaluativen und devaluativen Gebrauch spezifisch konnotierter Lexik hin, führt sowohl Tendenzen in der Wortschatzentwicklung als auch Wortbildungsprozesse und Euphemisierung als Belege für altersdiskriminierenden Sprachgebrauch an und beleuchtet die bis dato nicht erfolgte Integration des Lexems wie des Sachverhalts „Ageism“ in Wörterbüchern der deutschen Gegenwartssprache. Da es möglicherweise auch aus diesem Grunde an einem deutschen Äquivalent für das Fremdwort "Ageism“ mangelt, wird im folgenden dieser Terminus verwendet oder die partiell eingedeutschte Fassung „Ageismus“. Diese teilweise Assimilation scheint legitim, da sie wie "Rassismus" und "Sexismus" gebildet wird und dabei dem zugrunde liegenden Muster „racism“ - „sexism“ - „ageism“ folgt.

\section{Ageismus als Form sprachlicher Diskriminierung}

Mit Graumann \& Wintermantel (1989) wird unter sprachlicher Diskriminierung eine soziale Diskriminierung verstanden, die mittels Sprache realisiert wird. Soziale Diskriminierung resultiert aus der kategorialen Behandlung und einer damit verbunde-

5 Z.B. Tews (1991), Lehr \& Niederfranke (1991), Illhardt (1993).

6 Vgl. neben Tews (1979), Mohl (1993) auch Dieck (1987), Dierl (1989). 
nen Bewertung von Personen und Gruppen (vgl. Höer et al. 1996). Matthews (1979, 68) stellte in diesem Zusammenhang fest, „old age is not a social category with simple definition or an obvious membership. It is a social category with negative connotations ..." So stützt sich Diskriminierung nicht auf die effektiven Eigenschaften und Verhaltensweisen von Personen und Gruppen, sondern auf ein primäres distinktives Merkmal, durch das diese identifiziert und bewertet werden. Die Bewertung erfolgt im Prozeß der Diskriminierung über Vorurteile, Stereotype und "negative Eigenarten" (Galliker et al. 1994, 2) und prominent über pejorative und Bedrohung implizierende Konnotationen als soziale Ab- bzw. Entwertung. Der Abgrenzungsprozeß von In- und Outgroup vollzieht sich dabei einerseits für die Gruppe der Diskriminatoren als Favorisierungs- und Aufwertungsprozeß und andererseits über das $\mathrm{Zu}$ weisen von negativen Gruppenmerkmalen als Devaluationsprozeß für die markierte Outgroup. In dieser Wertzuweisung gibt es Verzerrungen, wie sie auch bei der Distinktion von "Junge" und "Alte" festzustellen sind: So verzerren und verschweigen z.B. Ausdrücke wie "Die demographische Zeitbombe tickt“, „Hilfe, wir vergreisen!“, "überaltert", „Altenlast" und „Seniorenlawine“ das Faktum, daß die Gesellschaft nicht nur "vergreist“, weil es immer mehr Alte gibt, sondern auch dadurch, daß es aus verschiedenen Ursachen, die nicht bei den Alten liegen, immer weniger Jüngere gibt, der Generationenvertrag also nicht einseitig von den Alten unterlaufen wird. Aufwertung und Vermeidung von selbstwertschädigenden Implikationen erfolgt durch die Ingroup stets über Abwertung, was die Segregation der Outgroup erleichtert.

Die Projektion der den Prozeß der sozialen Diskriminierung prägenden Aspekte 'Trennen'-'Fixieren'-'Devaluation' auf die sprachliche Diskriminierung wurde bereits in Untersuchungen zur Diskriminierung von Ausländern vorgenommen. ${ }^{7}$ Es ist anzunehmen, daß diese Mechanismen auch bei der sprachlichen Diskriminierung der Alten fassen und Ageismus konstituieren: Das Merkmal „alt“ wird zum kategorisierenden Merkmal negativer Distinktheit. Mit dessen Fixierung wird gleichzeitig dem Diskriminator (und der Gruppe, der er angehört) positive Distinktheit zugeschrieben sowie das Trennende der Gruppen durch Wertungleichheit begründet, was die soziale Herabsetzung und Wertminderung der negativ kategorisierten Gruppe zur Folge hat.

\section{Zum sprachlichen Spektrum des Ageismus}

Als Instrument sprachlicher Diskriminierung verfügt der Ageismus über ein breites Spektrum, das sich explizit an einer Vielzahl von Lexemen verdeutlichen läßt. Diese Lexeme erscheinen sowohl in der vertikalen Schichtung der Existenzformen in Dialekt (Olle, Olsche), Umgangssprache (Gruftis, Tattergreis) und Standard (Überalterung, überjährig) als auch soziolektal als Elemente von Gruppensprachen (Fossil/Fossi, Mumie als jugendsprachliche Bezeichnungen für Ältere) sowie als integraler Bestandteil sich entwickelnder Wortschatzbereiche, so z.B. als Wortbildungskonstruktionen und Abkürzungen (Ruheständler, Uhus = Unter Hundert), Neologismen (Altenlast, Gerontokratie), Archaismen (Vettel, Reff), Entlehnungen (Age-Wars, Oldtimer), aber auch als Ergebnis von Bedeutungswandel (altklug, senil) und Euphemisierung (50+, reifere Jugend). Darüber hinaus ist Ageismus in para-

Galliker et al. (1994) und Höer et al. (1996) untersuchten explizite und implizite sprachliche Diskriminierungen von Ausländern und validierten mit ihren Studien ein facettentheoretisches Modell mit den Funktionsfacetten 'Trennen'-'Fixieren'-'Devaluation'. 
digmatischen Relationen vor allem synonymisch (abgelebt, verbraucht, angegraut, verkalkt, asbach als partielle Synonyme für alt), aber auch auf syntagmatischer Ebene - insbesondere über Kollokationen - sowie durch eine relativ hohe Zahl von Phrasemen und Sprichwörtern existent.

\subsection{Die Unwörter}

Ein Unwort ist ein „böses, beleidigendes Wort“, es ist „unrichtig“ und „verwerflich“, vermerken Jacob und Wilhelm Grimm im „Deutschen Wörterbuch“ (1936, 2252).

So gesehen, kommt zweifellos unzähligen Wörtern der deutschen Gegenwartssprache ein „Unwort-Status“ zu. Aus der Masse dieser "bösen und beleidigenden“ Wörter scheinen sich einige jedoch durch besondere Verwerflichkeit herauszuheben: Sie werden in jedem Jahr von der Gesellschaft für deutsche Sprache „als typische, repräsentative, relevante und sprachlich prägnante Bildungen" ins Bewußtsein der Öffentlichkeit gerückt (vgl. Steinhauer 1997, 1).

So wurden schon 1991/92 Grufti, Komposti, Friedhofsgemüse als jugendsprachliche Benennungen älterer und alter Menschen registriert, jedoch mit dem Hinweis auf nicht-öffentliche bzw. jugendsprachliche Verwendung bagatellisiert. Die Buchungen dieser Wörter, die aus Belegen der Medien (z.B. aus der FAZ, Das Parlament, Der Spiegel, Süddeutsche Zeitung, Berliner Zeitung), aus Leserzuschriften und Hörbelegen stammen, dokumentieren schon zu Beginn der 90er Jahre einen sich vertiefenden Generationenkonflikt und gehören „gleichsam zum Bodensatz eines Sprachgebrauchs, der [...] immer aggressiver wird, wenn Jüngere über Ältere reden ..." (Schlosser 1996, 53). ${ }^{8}$

Daß sich die sprachliche Diskriminierung der Älteren nicht auf gruppensprachliche Bereiche beschränkt, zeigt die öffentlich-offizielle und frequente Verwendung von Begriffen wie Überalterung und Vergreisung als Schlagworte bei der Reflexion des demographischen Wandels in der Bundesrepublik (vgl. Roloff 1990, 5). Die in den Beispielen angedeutete Tendenz der Altendiskriminierung mit sprachlichen Mitteln verstärkt sich durch unbedachte öffentliche Äußerungen vom Rentenberg/Rentnerberg, von Alterslast und dem Seniorenboom. In den Medien erscheinen Wörter wie „Fossilienrunde“, „bebrillte Alte aus der Muppet-Show", „geriatrische Kollegen" als Bezeichnungen für Mitglieder des britischen Parlaments (taz vom 9.4.1993), und ältere deutsche Politiker, die das „biologische Verfallsdatum“ längst überschritten haben, werden in analoger Weise „verkalkte Mümmler", "gerontophile CDU/CSU“ und „Kukident-Kollegium" genannt (Der Spiegel 12/1995).

Hier handelt es sich kaum noch um zufällige sprachliche Ausrutscher oder gedankenlose jugendsprachliche Entgleisungen, sondern um intendierten Sprachgebrauch und damit bewußte Etikettierung einer gesellschaftlichen Gruppe. Drastisch zeigt sich das "Feindbild Jung gegen Alt“ (Die Zeit 31.3.1995) im Artikel einer Studentenzeitung: Seniorenstudenten werden in diesem Pamphlet als „ausgebildetes Madenfutter", „senile alte Halbtote“ und „verkalkte Wracks“ tituliert, und die Verfasserin vermerkt, daß „... die einfachste Lösung [...] ein Maschinengewehr [wäre], das die erste Reihe (in der die Seniorenstudenten in der Regel sitzen, U.K.) wegpustet." ${ }^{\text {(9 }}$

8 Das Lexem Runzelrabatt als partielles Synonym für "günstige Tarife der Deutschen Bundesbahn für ältere Leute" stammt übrigens schon aus dem Jahre 1983 (vgl. Kramer 1995).

9 Vgl. dazu auch Frankfurter Rundschau vom 13.8.1994 u. Schlosser (1996, 35). 
1995 werden „Altenplage“ und „biologischer Abbau“ Unwörter des Jahres und reflektieren damit sprachlich Erscheinungen, die für dieses Jahr „besonders typisch gewesen sind" (Steinhauer 1997, 1). ${ }^{10}$

Mit der „Rentnerschwemme“ setzt sich die Tendenz zu altersdiskriminierenden Wortneuschöpfungen 1996 fort. Ob der Entscheidung, es als das Unwort zu wählen, mußte sich die Jury z.B. vom Kuratorium Deutsche Altenhilfe Kritik gefallen lassen: Die öffentliche Aufmerksamkeit richtete sich paradoxerweise auf die Unwortwahl, aber kaum gegen die Gedankenlosigkeit, Diskriminierung, Aggressivität und Manipulationsabsicht von „Rentnerschwemme“. Dabei wird mit diesem Kompositum nur ein weiteres nach dem Muster Rentnerberg, -lawine, -boom, -last, -welle, -bombe gebildet. Schwemme hat mit der Bedeutung

"-schwemme, die [...] (emotional verstärkend): drückt in Bildungen mit Substantiven aus, daß jmd. - seltener etw. - in allzu großer Zahl vorhanden ist oder erwartet wird [...]“ (DUW 1989, 1371)

ähnlich negative Konnotationen und bedrohliche Implikationen wie -bombe, -welle, -lawine: Alle Komposita dieses Typs vermitteln „den falschen und inhumanen Eindruck, es handle sich bei Menschen, die Anspruch auf eine angemessene Altersversorgung haben, um eine nicht vorhersehbare Naturkatastrophe, gegen die man sich schützen müsse." (FD Germanistik 1997, 6). Die unangebrachten Naturmetaphern (Lawine, Welle, Schwemme) wecken einerseits ein unterschwelliges Bedrohungsgefühl und enthumanisieren gleichzeitig durch die Referenz auf Naturphänomene die Gruppe der Älteren. ${ }^{11}$

Die Unwörter der vergangenen Jahren erschweren eine sachliche Diskussion der demographischen Veränderungen in Deutschland und reflektieren sprachlich die soziale Abwertung der Älteren. Die Unwortwahl erfolgt zwar aufgrund sprachkritischer Kriterien und ist nicht sachkritisch begründet, doch zeigt sich in Prägung und Verwendung der genannten Unwörter zweifellos ein sprachgebundenes sozialethisches Bewußtsein, das von Ageismus geprägt ist und dem Muster sprachlicher Diskriminierung 'Trennen'-'Fixieren'-'Devaluierung' folgt.

\section{2 „alt" - Konnotationen, Kollokationen, Synonyme}

"Alt" gehört als Erbwort zum zentralen Bestand des deutschen Wortschatzes und ist in Wörterbüchern unterschiedlichster lexikographischer Provenienz und Entstehungszeit lemmatisiert. So lassen sich bei Durchsicht der Wörterbücher Bedeutung und Bedeutungsentwicklung, Konnotationen sowie typische Verwendungen, aber auch synonymische Relationen und diastratische Bezüge erkennen.

10 Horst Dieter Schlosser (1996, 54) kommentiert die sprachkritische Wahl folgendermaßen: „Vielleicht sind sich aber auch manche des Zynismus nicht bewußt, der in einer neueren Variante der schon älteren Umschreibung biologische Lösung für eine Problemlösung durch Tod liegt: Sie heißt biologischer Abbau und soll eine Personalreduzierung durch altersbedingtes Ausscheiden von Berufstätigen umschreiben. Hier wird nicht erst der tatsächliche Tod, sondern bereits das Erreichen einer Altersgrenze zum Ende gesellschaftlicher Existenz erklärt und zum arbeitsmarktpolitischen Instrument gemacht. Auch wenn man dieser Interpretation nicht folgen möchte, bleibt eine andere, nicht minder skandalöse Assoziation: biologischer Abbau ist gleichsam die nachträglich hergestellte Grundform für die allseits bekannte Formel biologisch abbaubar, die wir als beruhigende Etikettierung zahlreicher Chemieprodukte kennen."

11 Die Metaphern werden auch kontextualisiert, z.B. in: „Eine schrumpfende Gruppe junger Leistungsträger muß eine rapide anschwellende Altenschar durchfüttern“. (Der Spiegel 35/1993). 
Ein Vergleich ausgewählter Wörterbucheinträge zu „alt“ bestätigt den - oftmals gefühlsmäßig - begründeten Eindruck, daß sich heute mit dem Wort „alt“ überwiegend Negatives verbindet. Einträge zu "alt“ in etymologischen Wörterbüchern des Deutschen zeigen jedoch eine Bedeutungsstruktur, die eher neutral und positiv denn abwertend ist:

„alt Adj. 'hoch an Jahren, vorausliegend, längere Zeit bestehend'. Mit ahd. (8. Jh.), mhd. alt, [...] (germ. *alsa-, ...) sind eng verwandt die Verben got. altengl. alan, anord. ala 'nähren, hervorbringen'. Als außergerman. Verwandte sind vergleichbar lat. alere 'nähren, aufziehen' mit dem Adjektiv altus (eigentl. 'emporgewachsen') [...], die sich mit den germ. Bildungen an die ie. Wurzel *al'wachsen, nähren' anschließen. [...] Einem dazu mit $t$ - Formans gebildeten Verbaladjektiv ie. *altos 'auf-, herangewachsen' folgt das Adjektiv alt, dessen drei Bedeutungen 'reich an Lebensjahren, gealtert' (Gegensatz 'jung'), 'vorausliegend, früher' (Gegensatz 'später'), 'längere Zeit bestehend' (Gegensatz 'neu') bereits im Ahd. voll entwickelt sind." (Etymologisches Wörterbuch 1993, 31).

„alt Adj. (< 8. Jh.). Mhd. alt, ahd. alt, as. ald aus wg. *alda-, [...]; vermutlich to-Partizip zu g. *al-a'wachsen, nähren' in gt. alan 'aufwachsen', anord. ala, ae. alan 'nähren, aufziehen', aus ig. (eur.) *al- 'nähren' [...]. Die Ausgangsbedeutung ist also 'gewachsen, erwachsen'; ..." (Kluge 1995, 30f.)

Das „Deutsche Wörterbuch“ von Hermann Paul enthält eine zusätzliche, zunächst regional markierte Bedeutungsvariante:

„alt (eng. old) ist eine Partizipialbildung aus einem agerm. Verb got. alan >wachsen, nähren<. [...] 1 Es wurde daher wohl urspr. nur von Menschen, Tieren und Pflanzen gebraucht, und die älteste von den jetzt üblichen Bedd. ist >ein gewisses Alter habend< [...]. Danach bedeutet es denn für sich >ein hohes Alter habend< und ist Ggs. zu jung: a. und grau werden [...]. Den entsprechenden Doppelsinn haben wir bei den anderen Ausdrücken für räumliches und zeitliches Maß sowie für Intensitäten: [...] 2 Schon ahd. auch für leblose Gegenstände und Zustände gebraucht i.S.v. >seit längerer Zeit bestehend, vorhanden< [...] 3 Ebenfalls schon ahd. bezeichnet es das, was früher einmal bestanden hat, vgl. der alte Argwohn lebt wieder auf; [...] 4 In jüngerer (nordd.) Ugs. >unangenehm, leidig< [...]: ein alter Gauner, alter Angeber. [...]" (Paul 1992, 26)

Daß die sprachliche Geringschätzung des Alters und der Alten keine Erfindung der Gegenwart ist, belegt - außerhalb der lexikographischen Kodifikationen - Jacob Grimms „Rede über das Alter“: 1860 zählt er hier zeitgenössische Synonyme zu „alt“ und „die Alten“ auf: „aus einheimischen schriftstellern liesze sich eine lange reihe einstimmiger wörter entnehmen: mürrisch, grämlich, eigensinnig, altfränkisch, karger, knicker, erbsenzähler, filz, unke ..." (Grimm 1984, 226).

Allgemeine einsprachige Wörterbücher der deutschen Gegenwartssprache verzeichnen zu „alt“ ebenfalls neutrale und meliorative Sememe, weisen aber zusätzlich pejorative Bedeutungsvarianten auf, über die das Lexem ursprünglich nicht verfügte. Damit erfährt das Adjektiv „alt" durch die Erweiterung seines Semembestandes eine Bedeutungsverschlechterung.

„alt, älter am ältesten /Adj./

1. /gibt das Alter, die Lebensjahre an/ [...] 2. bejahrt, reich an Jahren, Ggs. jung [...] 3. gebraucht, Ggs. neu [...] 4. schon lange bestehend [...] 5. Ggs. modern a) antik, klassisch [...] b) weit zurückliegend [...] c) (durch sein Alter wertvoll, kostbar) [...] 6. /ohne Steigerung/ früher, Ggs. jetzig a) vorherig [...] b) ehemalig, einstig [...] 7. /ohne Steigerung/ s a I o p p a) /verstärkt die Ablehnung/ [...] b) /verstärkt die Vertraulichkeit" (WDG 1964, 111f.)

Zunächst läßt die erweiterte Polysemie des Adjektivs in den Paraphrasen nicht erkennen, daß die negativen Implikationen des Wortes wesentlich zugenommen ha- 
ben; sie scheinen sich auf Semem 7 zu beschränken. Anders stellt sich das Bild dar, wenn die lexikographischen Beispiele einbezogen werden. Hier zeigt sich, daß die negativen Implikationen von „alt“ in erster Linie auf Menschen bezogen werden, während die ursprünglichen neutralen und positiven Konnotationen vorrangig auf Dinge oder Sachen beschränkt sind.

„2. [...] s a I o p p ein a. Knabe, Semester; eine a. Jungfer; eine ältere (nicht mehr junge) Dame; ein a. (unjugendliches) Mädchen; [...] 3. [...] /bildl./ s a I o p p etw., jmdn. zum a. Eisen werfen (etw., jmd. außer Dienst setzen); (bereits) zum a. Eisen gehören (nicht mehr verwendungsfähig) sein) [...] 4. [...] /drückt einen Tadel aus/ (bis zum Überdruß) langweilig: immer das a. Lied, Thema; [...] 7. [...] a) [...] ein a. Geizkragen, Schwätzer, Egoist, Drache; ein a. (unverbesserlicher) Sünder; ein a. (gerissener) Fuchs; so eine a. (widerliche) Schachtel, Hexe, Ziege; [...]" (WDG, ebd.).

Der Wörterbucheintrag zu „alt“ im aktuellen „Duden. Das große Wörterbuch der deutschen Sprache: in acht Bänden." (DGWB) bestätigt über 30 Jahre später die Tendenz zur Bedeutungsverschlechterung bei weiterer Differenzierung der Bedeutung und der Widerspiegelung eines zunehmend abwertenden Sprachgebrauchs in den lexikographischen Beispielen:

\begin{abstract}
„alt <Adj.; älter, älteste> [mhd., ahd. alt, eigentl. = aufgewachsen, ...]: 1.a) (von Menschen, Tieren, Pflanzen) nicht [mehr] jung, in vorgerücktem Lebensalter, bejahrt: [...] a. aussehen (ugs.; das Nachsehen haben): [...] Gegen die überalterte (sic! U.K.) Gurkentruppe ... hat Breitners FC Bayern ganz schön a. ausgesehen (Spiegel 25, 1981, 165); b) Merkmale des Alters aufweisen, Alterserscheinungen erkennen lassend; gealtert: mit ihren -ten, zittrigen Händen. 2. ein bestimmtes Alter habend: [...] 3.a) eine bestimmte Zeit vorhanden, im Gebrauch befindlich: [...] b) nicht [mehr] neu, lange gebraucht, getragen; abgenutzt: [...] 4.a) seit längerer Zeit vorhanden, bestehend, vor längerer Zeit erzeugt, hergestellt u.ä. u. daher nicht [mehr] frisch: [...] b) vom letzten Jahr, vorjährig: [...] 5.a) seit langem vorhanden, bestehend; vor langer Zeit bestanden, begründet [u. deshalb bewährt]: [...] b) langjährig: [...] c) längst [überall] bekannt u. daher überholt, langweilig: [...] 6.a) einer früheren Zeit, Epoche entstammend; eine vergangene Zeit betreffend: [...] b) antik; klassisch: [...] c) durch Alter wertvoll [geworden]: [...] 7. unverändert, [von früher her] bekannt, vertraut, gewohnt [u. daher liebgeworden, geschätzt]: [...] 8. vorherig, früher, ehemalig, einstig: [...] 9.a) (fam.) in vertraulicher Anrede: na, -ter Junge, wie geht's?; b) (ugs. abwertend) verstärkend bei negativ charakterisierenden Personenbezeichnungen u. Schimpfwörtern: der -te Geizkragen!; (derb:) -es Schwein!“ (DGWB 1993, 151).
\end{abstract}

Das „Wörterbuch zur Valenz und Distribution deutscher Adjektive“ faßt das Bedeutungsspektrum von „alt“ im wesentlichen wie die gegenwartssprachlichen Bedeutungswörterbücher. Es verzeichnet 9 Sememe mit den Bedeutungen:

„V $\mathbf{V}^{\mathbf{1}} \mathbf{1}$ = , betagt', ,bejahrt', ,von bisher langer Lebensdauer'; V $\mathbf{2}=$ Altersangabe; $\mathbf{V} \mathbf{3}=$, schon lange bestehend'; V $\mathbf{4}=$, nicht neu ' (an Wert gewinnend); V $\mathbf{5}$ = , nicht neu' (an Wert verlierend); V $\mathbf{6}=$ ,ehemalig', ,vor Jahren existierend', ,vorjährig'; V 7 = ,erfahren', langjährig', ,bewährt'; V 8 = ,derselbe', ,unverändert', ,gleich': V $\mathbf{9}=$ nur verstärkend (emotional) [...] Vertraulichkeit (alter Junge, altes Haus) Ablehnung (ein alter Geizkragen), eine alte Schachtel)" (Sommerfeldt \& Schreiber $1977,51 \mathrm{ff}.)^{12}$

Stets an das Ende des Wörterbucheintrags gesetzt und mit im Verhältnis zur hohen Anzahl neutraler oder positiver Sememe geringen Bedeutungsvarianten scheint sich die These vom Ageismus im Bedeutungsspektrum von „alt“ nicht zu bestätigen; zu inre Validierung tragen jedoch die o.a. lexikographischen Beispiele und nicht zuletzt die für die pejorative Bedeutung von „alt“ angegebenen Synonyme bei: Das sind un-

12 „V“ wird im Wörterbuch als Kürzel für „Variante“ verwendet. 
verbesserlich, gerissen, widerlich, lästig, unangenehm, unangebracht im WDG (1964, 112), unangenehm, leidig bei Hermann Paul (1992, 26), das Stilwörterbuch $(1966,9)$ verzeichnet u.a. knauserig, schäbig, unausstehlich.

Während sich die meliorative Bedeutungskomponente bis heute für Sachgegenstände wie z.B. alter Wein, altes Silber, alter Cognac, altes Porzellan, alte Münzen sogar alter Käse - erhalten hat und diese Dinge als 'mit zunehmendem Alter im Wert gestiegen' markiert, ist „alt“ im Bezug auf Menschen überwiegend negativ konnotiert. Nur in wenigen Kollokationen erfolgt eine positive Bewertung, etwa in alter Freund, alter Seemann, alter Kämpfer oder altes Haus. Hier geht es jedoch in erster Linie um den Ausdruck von Vertrautheit und Anerkennung, es wird nicht automatisch auf eine höhere Anzahl von Lebensjahren referiert. Sehr viel häufiger wird "alt" als Epitheton mit negativem Assoziationspotential verwendet. Dann reflektiert „alt“ das gängige Altersstereotyp mit devaluativen Implikationen, die durch die geläufigen Synonyme noch verstärkt werden. Diese Verwendung von „alt“ belegen die folgenden Wörterbucheinträge:

„alt, älter, bejahrt, betagt, hochbetagt, bestanden (schweiz.), uralt, steinalt, senil, verkalkt (abwertend), verknöchert, (abwertend), verknorzt (abwertend, schweiz.), greis, ältlich, nicht $\uparrow$ jung; $\uparrow$ älter, $\uparrow$ altmodisch, $\uparrow$ hinfällig; a. sein, im vorgerückten Alter sein, schon viele Jahre auf dem Buckel haben (ugs.) alt wie Methusalem sein (ugs.), bei jmdm. rieselt [schon] der Kalk (salopp, abwertend); [...]" (Duden Bd. 8, 1986, 34).

„alt: abgelebt, altersgrau, abgeklärt, angejahrt, bejahrt, betagt, grauhaarig, grauköpfig, silberhaarig, steinalt, uralt, verbraucht, vergrämt, weise, weißhaarig, verlebt, verbittert, runzelig, hochbetagt, angegraut, altersschwach [...]" (Bulitta \& Bulitta 1983, 45f.).

„alt, älter, am ältesten

Sinn: (1) (hoch)betagt, bejahrt, ( )ehrwürdig, altersgrau, ein graues Haupt, im Silberhaar, hoch in den Jahren, längst über die Höhe/auf dem absteigenden Ast des Lebens; ausgedient, arbeitsmüde, nicht mehr arbeitsfähig, greisenhaft, senil, hinfällig, verknöchert, wacklig; umg klapprig [...]“" (Stilwörterbuch 1966, 9).

Auch Scheemann $(1993,15)$ verzeichnet überwiegend negative Koordinationen mit "alt" als typisch, obwohl er sie nicht so markiert:

„alt und mürrisch (werden/...); alt und siech path selten; alt und verbraucht (sein) path; alt und verknöchert (sein) path; alt und weise (sein) form selten“.

Die Konnotationsverschiebung im Bedeutungsspektrum von „alt“ zur Negativmarkierung oder -verstärkung zeigt sich ebenfalls in der - möglichen und vor allem in der Umgangssprache zu beobachtenden - synonymen Verwendung von Wörtern, die nicht unbedingt auf Personen und/oder das menschliche Alter bezogen sind, sondern ursprünglich der Kennzeichnung des Alters von Sachverhalten und Gegenständen vorbehalten waren. Durch diese Quasigleichsetzung mit unbelebten Dingen wird die menschliche Komponente in „alt“ unterdrückt. Für die Kennzeichnung menschlichen Alters werden u.a. verwendet: bemoost, schrottreif, gestrig, verkalkt, halbtot, steinzeitlich, asbach, abgetakelt, verschimmelt, angeschimmelt, ausgemustert, verblüht, abgelebt, taprig, welk, ausgeleiert ...

Die überwiegend pejorativen partiellen Synonyme verdichten die negativen Konnotationen von „alt", so daß durch Zuweisung des Adjektivs als Attribut stigmatisiert und diskriminiert werden kann: Weil Alter als lästig, unbrauchbar, störend, widerlich... empfunden wird, entwickelt „alt“ die Eigenschaft, „ein zu allen möglichen 
Schimpfwörtern und verächtlichen Bezeichnungen hinzutretendes Epitheton [zu sein] ..." (Küpper 1988, 24) und qualifiziert sich für eine „Liste abwertend verwendeter Adjektive“ (Pfeiffer 1996, 480). ${ }^{13}$ In dieser Weise wird „alt" in einer Vielzahl von Kombinationen als zusätzliches und verstärkendes Mittel der Kränkung eingesetzt, z.B. bei:
„alte Eule abfällig für eine häßliche, mißmutige (weibliche) Person.
alte Hexe [...] verächtlich für eine unangenehme, zänkische (alte) weibliche Person.
alte Jungfer abschätzig für eine ältere, altmodische, zimperliche, prüde (unverheiratet gebliebene) Frau.
alte Schachtel [...] abwertend für eine ältere, ältliche, verschrobene Frau.
alte Scharteke [...] abfällig für eine unsympathische ältere Frau.
alte Schese (alte Schäse) [...] vorwiegend bayrisch und österreichisch abfällig für eine alte Frau.
alte Schraube abschätzig für eine „verdrehte“, schrullige ältere Frau.
alte Schrippe besonders berlinerisch abfällig für eine ältere Frau.
alte Vettel grobes Schimpfwort für eine liederliche, schlampige alte Frau.

alte Wachtel salopp abwertend für eine (häßliche, unangenehme) alte Frau Vgl.: alte Spinatwachtel, $[\ldots]$.

alter Affe Schimpfwort für einen dummen, läppischen oder unsympathischen Menschen, der keineswegs alt sein muß.

alter Bock derber Spott, auch abschätzig für einen 1. alten Mann. 2. älteren Mann, der verliebt oder hinter den Frauen her ist.

Vgl. alter Gockel, alter Ziegenbock [...].

alter Esel abschätzig, auch spöttisch für einen Mann, der dadurch töricht oder lächerlich erscheint, daß er sich trotz vorgerückten Alters wie ein Junger gebärdet, z.B. jungen Mädchen nachstellt.

alter Gauner (hat nichts mit dem Alter zu tun) 1. abschätzig für einen gewohnheitsmäßigen, notorischen Gauner. 2. gemütliche Schelte für einen Mann. 3. geringschätzig, auch anerkennend für einen gerissenen, schlauen Kerl.

alter Knacker 1. salopp abwertend für einen (gebrechlichen, wunderlichen) älteren Mann. 2. spöttisch oder abschätzig für einen älteren Mann „im zweiten Frühling“, der auf erotische Abenteuer aus ist. 3. landschaftlich selten für einen notorischen Geizhals.

alter Knochen 1. salopp, auch leicht abwertend für einen alten, zähen, sturen Kerl. 2. eine vertrauliche, selten geringschätzige Anrede für einen Mann.

alter Sack (auch als burschikose Anrede unter Freunden ohne jede Abwertung) abfällig für 1. einen alten Mann. 2. einen unsympathischen oder unfähigen, dummen Kerl.

altes Eisen (eine andere Bezeichnung für „Alteisen“ = Schrott; meist in Redensarten wie „Zum alten Eisen zählen“) abfällig für alte, schwache, hinfällige, nicht mehr arbeitsfähige Menschen.

altes Reff Schimpfwort für ein (böses) altes Weib, eine Jungfer.

altes Register (nach der Redensart „ins alte Register kommen“ = zu den Alten gehören, nichts mehr wert sein) scherzhaft, auch geringschätzig für eine alte (weibliche) Person." (Pfeiffer 1996, 16ff.).

Außerdem finden sich alter Geizkragen, alte Hupfdohle, altes Suppenhuhn, alter Trottel, alter Schneckenschiß, alte Glucke, alte Kuh, alter Schwätzer, alter Drachen, alter Egoist, altes Schwein, alter Narr, alter Ochse, altes Weib, alte Ziege, alte Kuh (vgl. Tews 1991; Kramer 1995). „Der kleine Wahrig“ $(1993,57)$ verzeichnet ausdrücklich die Entsprechung „zimperlicher, feiger Mensch“ zu altes Weib. Nur am

13 Hier steht „alt“ in einer Reihe mit altersschwach, altersstarrsinnig, altjüngferlich, ältlich, altklug ... 
Rande sei vermerkt, daß die Kollokation alt + Bezeichnung $=$ Schimpfwort für eine weibliche Person sehr viel häufiger ist als die Verbindung alt + Bezeichnung $=$ Schimpfwort für eine männliche Person; außerdem referieren die mit „alt“ attribuierten weiblichen Substanitve nicht ausschließlich auf weibliche Personen. Auch die beachtliche Anzahl von Komposita wie Altweibergeschwätz, -gewäsch, -knoten, märchen, die durch das Bestimmungswort Altweiber- mit negativen Konnotationen verbunden sind, unterstützen diese Beobachtung ebenso wie die Lemmata „Altmaterial $n$ 1. Prostituierte in vorgerückten Jahren. Hat nur noch Schrottwert. 1940ff“ und „Alttier $n$ Frau nach der ersten Schwängerung; bejahrte Frau [...]“. (Küpper 1988, 25).

Die Beschimpfung durch Attribuierung mit „alt“ ist nicht immer mit der Referenz auf hohes Alter verbunden, aber fast ausschließlich mit Devaluation der so bezeichneten Personen. ${ }^{14}$ Tews $(1991,29)$ bemerkt dazu:

„Um als „altes Arschloch“ bezeichnet zu werden, muß man nicht alt sein. Anleihen im Tierreich sind auffällig und reichhaltig. Offenbar wird damit eine Steigerung erreicht: Tieren werden eindeutigere Eigenschaften zugeschrieben, in Verbindung mit alt ist eine weitere Steigerung zu erreichen. Tiere befinden sich zudem auf einer Entwicklungsstufe unter der des Menschen."

Die Dominanz negativer Konnotationen in der Bedeutungsstruktur von „alt“ wirkt sich auch auf bedeutungsähnliche Wörter wie rüstig aus und zeigt sich ebenfalls bei Adjektiven wie überjährig und überaltert. Die drei Lexeme sind lemmatisiert, weisen aber weder durch Markierung noch in der Paraphrasierung auf die pejorative Nuance hin:

„rüstig <Adj.> [mhd. rüstec = gerüstet, bereit, ahd. hrustig = geschmückt]: a) (trotz Alter) noch fähig, [anstrengende] Aufgaben zu erfüllen; noch nicht hinfällig, sondern frisch u. leistungsfähig [...]" (DUW 1989, 1278).

Eine interessante Anmerkung zu diesem Wort fand sich in einer Zeitungsglosse; Erich Böhme, der ehemalige Herausgeber der „Berliner Zeitung“, fühlt sich durch die Zuweisung der Eigenschaft „rüstig“ beleidigt. Er schreibt unter dem Titel „Rüstige aller Länder ..."

„Du fühlst dich eigentlich noch recht rüstig ... Was für ein abscheulich diskriminierendes Epithethon. Rüstig bezeichnet man den Greis oder die Greisin, die in Wirklichkeit hinfällig und gebrechlich zu sein haben und sich über das schmückende Beiwort freuen sollen. Von einem rüstigen Jüngling habe ich noch nie etwas gehört." (Berliner Zeitung 11./12.2.1995, 3)

In der Beschränkung auf die Kollokation 'rüstig' + 'Greis' sieht der Betroffene (weil alte) E. Böhme die Devaluation.

Überaltert und überjährig sind wie rüstig usuelle Elemente der deutschen Gegenwartssprache.

14 Das Negativ-Potential von „alt“ zeigt z.B. auch Auswirkungen auf Wörter wie altklug, das heute nur noch in der ironisch-abwertenden Bedeutung „aufdringlich klug“ hauptsächlich auf Kinder bezogen wird und nicht mehr in der ursprünglichen Bedeutung „durch Alter und Erfahrung klug“ verwendet wird; altklug bezeichnet also paradoxerweise Angehörige einer Gruppe, die zeitlich am weitesten von den Alten entfernt sind. 
„überaltert $<A d j .>1$. sich größtenteils aus alten Menschen zusammensetzend: eine -e Bevölkerung; [...] 2a) nicht mehr dem gegenwärtigen Stand der [technischen Entwicklung] entsprechend; überholt 2b) nicht mehr der gegenwärtigen Zeit entsprechend; überholt" (DGWB 1995, 3481).

„überjährig <Adj.> (veraltet) älter, schon länger bestehend als gewöhnlich: [...]“ (DGWB 1995, 3493).

In der Verwendung von überaltert und überjährig sind Tendenzen sprachlicher Diskriminierung erkennbar: Die Wörter werden als Gruppenindiz gebraucht, sie fixieren und devaluieren. Die Konstituente „über-“ wirkt augmentativ und suggeriert etwas, das nicht mehr der Normalität entspricht. Der Mediziner Karl-Heinz Schmidt fragt „Was ist eigentlich Überalterung?" und meint, daß dieses Wort zunehmend als wohlfeile Erklärung für eine Art höherer Gewalt herangezogen wird, für die niemand verantwortlich gemacht werden kann. Es findet eine Versachlichung, eine Enthumanisierung mittels Sprache statt:

„Es gibt Alte und Junge, aber gibt es auch Überalte? Mit welchem Alter oder Anteil soll denn das ,Überalter' beginnen, bei den Menschen oder bei den Gesellschaften? [...] Für mich ist der Schritt zur Diskriminierung nicht mehr weit, wenn man mit Überalterung argumentiert." (Schmidt 1995, 45)

Überjährig wird im DGWB als veraltet markiert, gehört aber - wie u.a. Kündigungsschreiben aus dem Öffentlichen Dienst der neuen Bundesländer belegen - durchaus noch zum aktuellen Wortbestand bzw. erfährt im Zuge eines ageistischen Sozialund Sprachverhaltens eine Wiederbelebung. Beide Adjektive fungieren zudem als Basen für Wortbildungsprodukte und Syntagmen, wie z.B. in Überalterung der Gesellschaft, der Bundesrepublik, Brandenburgs, Europas und steigende Überjährigkeit in den Verwaltungen Berlins, in typischen Frauenberufen, in den etablierten Parteien.

Neben der pejorativ geprägten Bedeutung von „alt“ und bedeutungsähnlichen Adjektiven zeigt sich Altersfeindlichkeit vor allem in den Bezeichnungen für Ältere, die als Synonyme für die eher neutralen Wörter wie Senioren, Rentner, ältere Mitbürger u.ä. nicht nur umgangssprachlich-inoffiziell und nicht nur unter Jugendlichen verbreitet sind und die quasi onomasiologisch das sprachliche Spektrum des Ageismus umreißen:

Grufties, Mumien, Kalkleisten, Dinosaurier, Spätlese, Friedhofsgemüse, Ruinen, Oldies, Zombies, Fossilien, Gespenster, Komposties, K.\&K.-Derivate, Mummelgreise, Tattergreise, Altersruinen, Krampfadergeschwader, Überlebende, Uhus (unter Hundert), Üfüs (über Fünfzig) ...

Auch Kukidents als Gruppenbezeichnung für die Älteren gehört in diese Reihe. So bezeichnete der Geschäftsführer von RTL, Helmut Thoma, Zuschauer über Fünfzig. Die Bezeichnung referiert durch den Bezug zum Produkt „Kukident“ eindeutig auf den von vielen Älteren als Makel empfundenen Umstand, ein Gebiß tragen zu müssen und wirkt dadurch verletzend. Die Wortneubildung verbreitete sich rasch, und so ist bald nach der Äußerung Thomas zu lesen, daß auch „das ZDF vom KukidentImage weg will“ und deshalb ihren Werbekunden inzwischen anbiete, „nur noch für die junge Zielgruppe zu zahlen, die Zielgruppe der Kukidents gibt es umsonst dazu“. ${ }^{15}$

15 Vgl. TV-Today 25/1994; Berliner Zeitung vom 17.10.1995. 
Nur marginal sei bemerkt, daß auch die - harmlos klingende - Gruppenbezeichnung ältere ${ }^{16}$ Arbeitnehmer nicht neutral verwendet wird, sondern vor allem in arbeitsmarktpolitischen Kontexten mit einer "beschäftigungspolitischen Problemgruppe“ gleichgesetzt wird, die - wegen der reduzierten Beschäftigungschancen älterer Erwerbstätiger - Darlehen oder Zuschüsse benötigt und sich so zunehmend als Last darstellt für die Jüngeren. ${ }^{17}$

\subsection{Wortbildung}

Während sich der vorangegangene Abschnitt vorzugsweise mit dem Adjektiv „alt“, seinen Konnotationen, Kollokationen und Synonymen als einem Fokus diskriminierender Sprachentwicklung befaßte, wird nun an einigen Beispielen gezeigt, daß auch Wortbildung Ageismus generiert und fixiert.

Wortbildungsprozesse sind bewußte und intendierte Prozesse, in denen über tradierte Muster und mit motivierten Konstituenten neue Lexeme gebildet werden. Die Bewußtheit vor allem läßt den Schluß zu, daß Bildung und Verwendung altersdiskriminierender Bezeichnungen Ausdruck einer mehrheitlichen gesellschaftlichen Einstellung ist.

Im Abschnitt 4.1 wurde bereits auf Implikationen und Konnotationen von Komposita wie Rentnerschwemme oder Seniorenlawine hingewiesen; das sich in Bildung und Gebrauch dieser Wörter spiegelnde negative Altenbild wiederholt sich in folgenden Wortbildungsresultaten:

\section{- greiseneinfach}

Das Determinativkompositum wurde zur Kennzeichnung und Anpreisung eines Computerprogrammes benutzt. Es spricht älteren Nutzern generell technische Kompetenz ab und stellt sie „auf eine Stufe mit Kleinkindern; denn früher habe man vergleichbare Anforderungen als babyleicht oder kindereinfach charakterisiert" (Schlosser 1996,54$).^{18}$

\section{- pflegenah}

Das Adjektiv wird als Eigenschaftszuweisung - z.B. in pflegenahe Jahrgänge - für alle über 60jährigen verwendet. Es signalisiert Irreparables, Unproduktives, Belastendes und weist diese Eigenschaften pauschal einer Gruppe zu, die nachgewiesenermaßen heterogen und im Strukturwandel begriffen ist. ${ }^{19}$

\section{- Alterslast/Altenlast(en)}

Dieses Kompositum soll sachlich das überproportionale Anwachsen der Alten bei Rückgang oder Stagnation der Anzahl jüngerer Menschen bezeichnen. Die Verwendung des Wortes Last impliziert jedoch Negatives, Erdrückendes und wird typisch in

16 „Ältere“ ist in diesem Fall der absolute Komparativ, der über folgende Sememe verfügt: „a) über das mittlere Lebensalter, die mittlere Zeit des Bestehens hinaus; nicht mehr jung, aber auch noch nicht ganz alt: [...] b) (verhüll.) alt." (DGWB 1993, 153).

17 Vgl. Bertelsmann (1984).

18 Greiseneinfach wurde von einem jungen EDV-Fachmann geprägt, 1995 auf einem Medienkongreß verwendet und in zahlreichen Zeitungen kommentiert. Vgl. auch Schlosser $(1996,54)$.

19 Vgl. dazu auch Mohl (1993, 21). 
Sätzen wie „In unserem Staat finanzieren die jüngeren, erwerbstätigen Menschen die Renten der Älteren. Während heute noch 100 Arbeitnehmer für 50 Rentner aufkommen müssen, werden sie im Jahr 2030 aber für doppelt soviele Rentner sorgen müssen“20 (Geo 1991, U4), mit denen Alterslast/Altenlast(en) kontextualisiert wird. Alterslastquote - als Terminus eine Folgebildung - ist lemmatisiert als "das zahlenmäßige Verhältnis zwischen den 65jährigen (u. älteren) Personen u. den 15 65jährigen" (Bertelsmann 1984, 174) und wird z.B. auch im Hinblick auf Kostenanteile der Älteren im Gesundheitswesen ermittelt. Sowohl Alterslast/Altenlast(en) als auch Alterslastquote tragen zunächst nur wenige oder gar keine negativen Konnotationen, die Übertragung des Last-Argumentes auf analoge Bildungen wie Rentenlast, Pflegelast führen jedoch zu einer Anreicherung damit: Die Verstärkung einer negativen Sicht auf die Gruppe derer, die die Last darstellt, ist die Folge. In diesem Sinne könnte die Schlußfolgerung von Mohl (1993) „Wer als Last gesehen wird, wird zur Last gemacht“ modifiziert werden zu „Wer als Last bezeichnet wird, wird zur Last“. Das Wort Alterslast gerät zudem leicht in die Nähe von zu entsorgenden Altlasten (vgl. Tews 1991, 109) und ist durch „stillgelegt" und "Müll“ doppelt semantisiert.

Neben den recht frequent verwendeten Alterslast/Altenlast(en) zeigt sich Ageismus mit zunehmender Häufigkeit auch in Wortneubildungen wie: Altersexplosion/Altenexplosion, Altenmacht, Altenschar, Altenboom, Altenplage; Altersklassenkampf, age wars, Alterskriege; Greisenfabrik (Deutschland), Greisen-Gesellschaft; Vergreisung (Europas). Die Lexeme suggerieren Bedrohung und Ausgeliefertsein und können bei anderen sozialen Gruppen Abwehrhaltungen gegenüber den Alten auslösen. ${ }^{21}$

Die als termini technici vorzugsweise von Versicherungsgesellschaften, aber auch zunehmend in der Rentendiskussion verwendeten Wörter Lebenserwartungsfaktor und Restlebenserwartung, die bei der Rentenfestlegung jährlich neu für über 65jährige ermittelt werden sollen, stigmatisieren die Älteren und erzeugen ein Bild vom Alter als (reduzierte) Lebenszeit ohne Zukunft und erleichtern die Ausgrenzung einer mit Sprache als „unnütz“ und „nicht zukunftsfähig“ deklassierten Gruppe.

\section{Ageismus - lexikalisch präsent, aber lexikographisch undokumentiert?}

„Altenfeindlich“ bedeutet „alten Menschen gegenüber feindlich eingestellt sein“ (vgl. DGWB 1993, 154). Versteckt in einem sogenannten "Nest" - zwischen Altersfleck und Alterserscheinung - findet sich das Adjektiv als Sublemma und als einziger lexikographischer Beleg der Existenz von Ageismus. Kein Wörterbuch der deutschen Gegenwartssprache verzeichnet Stichwörter wie „Alters-“ oder „Altendiskriminierung“ bzw. „Altenfeindlichkeit“, auch im aktuellen „Duden. Das Grosse Fremdwörterbuch“ (1994) sucht man „Ageism“ vergeblich. Die Tatsache überrascht, denn „Rassismus“ und "Sexismus" als Bezeichnungen und Formen sozialer Diskriminierung wurden nach ihrer Erstverwendung relativ rasch in Wörterbücher aufgenommen. ${ }^{22}$

20 Die Sätze wurden einer Anzeige von „Die deutsche Lebensversicherung“ entnommen.

21 Auch Wortgruppen wie Störfall Alter, die graue Gefahr, die graue Welle, gierige Grufties, Herrschaft der Alten, Ära der Alten dokumentieren die unterschwellige Angst vor der demographischen Zukunft.

22 Sexism ist fast zeitgleich mit ageism entstanden, seit 1968 kodifiziert und als "Sexismus" relativ rasch assimiliert und in deutschen Wörterbüchern kodifiziert, vgl. dazu Paul (1992), Kluge (1995). 
Die sich in lexikalischer Vielfalt und mit breitem sprachlichen Spektrum in der deutschen Gegenwartssprache präsentierende Altenfeindlichkeit ist lexikographisch weitestgehend - nämlich bis auf „altenfeindlich“ - undokumentiert. Damit ist nicht nur das Fehlen entsprechender Lemmata gemeint, sondern auch die u.E. notwendige, aber nicht vorhandene entsprechende Kennzeichnung oder Paraphrasierung von Lemmata wie überjährig, überaltert ... als abwertend, diskriminierend oder altenfeindlich.

Für diese (lexikographische) Nichtbeachtung des Phänomens einer alters- und altenfeindlichen Gesellschaft gibt es zweifellos eine Vielzahl von Gründen, von denen einer durchaus in der von Simone de Beauvoir zu Beginn der 70er Jahre beschriebenen „Verschwörung des Schweigens“ der Gesellschaft gegen das Alter und die Alten gesehen werden kann (de Beauvoir 1993). Ein anderer Grund kann die gängige Praxis der Lemmaauswahl und -aufnahme sein, denn: „Bevor ein Lemma im Wörterbuch aufgenommen wird, sollte es nicht nur in verschiedenen Texten, sondern auch während eines nicht zu kurzen Zeitraumes benutzt worden sein“ (Bergenholtz 1989, 774). Hier können soziolinguistische (wie die Konzentration auf die kindliche oder jugendliche Alterskultur), aber auch lexikologisch-lexikographische Forschungsdesiderate (wie z.B. die vagen Kriterien für die Stichwortauswahl bei allgemeinen einsprachigen Bedeutungswörterbüchern oder auch die noch immer uneinheitliche Markierungspraxis bei konnotierter Lexik) in der deutschen sprachwissenschaftlichen Forschung Ursache des Mangels sein.

Im englisch-amerikanischen Sprachraum erfolgte nach der erstmaligen Verwendung des Begriffs „Ageism“ schon sechs Jahre später die Wörterbuchaufnahme ${ }^{23}$ bei nahezu zeitlicher Parallelität der linguistischen Untersuchung und Beschreibung von Vokabular und Mechanismen der sozialen Diskriminierung durch "Ageism“ . ${ }^{4}$ Seit fast 25 Jahren findet sich „Ageism“ in den gängigen Wörterbüchern, z.B. in "Webster's Third New International Dictionary Of The English Language“ (1981, 55a): „age-ism
also agism [...]: prejudice or discrimination against a particular age-group and esp. against the el-
derly - age-ist also agist [...] "

„The New Shorter Oxford English Dictionary On Historical Principles“ (1993, 39): „ag(e)ism [...] prejudice or discrimination against people of a particular age, esp. against the elderly M20 (=mid twentieth century, U.K.) ag(e)ist a.\&n. (a) adj. of Ageism; (b) $n$. a person who practises Ageism L20“ (=late twentieth century, U.K.)

"Collier's Dictionary“ $(1994,24)$ : „age-ism [...] discrimination against people on the basis of age; specif., discrimination against, and prejudicial stereotyping of, older people. [...]".

Für den deutschen Sprachraum fehlen bis heute neben linguistisch ausgerichteten Untersuchungen zur Problematik von Alter und Kommunikation im allgemeinen auch solche zum sprachlichen Spektrum des Ageismus im besonderen. Aus diesem Grund versucht der vorliegende Beitrag eine erste lexikalische Erfassung der sprachlichen Diskriminierung des Alters und der Alten und verbindet mit der Kritik an Wörterbüchern, die „die deutsche Sprache in ihrer ganzen Vielschichtigkeit [...] dokumentieren und damit auch bewußt [...] machen“ und „zugleich ein Spiegelbild unserer Zeit und ihrer kulturellen und gesellschaftlichen Verhältnisse [...] sein" wollen (vgl. DGWB 1993, Vorwort) oder „Fremdwörter und Wortbildungen, politisch und

\footnotetext{
${ }^{23} \mathrm{Vgl}$. Abschnitt 2.

24 Vgl. dazu Dickman (1979) und Nuessel (1982).
} 
sozial bedeutsamen Wortschatz" zum Inhalt haben (vgl. Paul 1992, Zur Einleitung), die Hoffnung, daß ein - wenn auch ungeliebtes, und deshalb lieber "nichtbenanntes“ - gesellschaftliches Phänomen, wie der Ageismus es ist, Eingang in die wichtigsten Wörterbücher der deutschen Gegenwartssprache findet.

\title{
6. Fazit
}

„Pest, Hunger und Krieg sind glücklich überwunden - nun sind die Alten da.“ (Die Zeit 10.3.1994)

Dieser Satz steht fast programmatisch für die Bewertung des Alters und der Alten, die sich gegenwärtig auch und besonders in der Sprache zeigt, und legt wie die in den vorhergegangenen Abschnitten angeführten Beispiele ageistischen Sprachgebrauchs den Schluß nahe, daß mit Sprache über die Ablehnung des Alters und die Distanzierung von den Alten die Abwertung einer gesellschaftlichen Großgruppe stattfindet und eine soziale Polarisation vorgenommen wird. Die Wirkungsweise von Sprache als Mittel der Ab- und Ausgrenzung bzw. der sozialen Devaluation wurde schon vielfach untersucht und beschrieben ${ }^{25}$, bisher jedoch fast ausschließlich auf Bereiche rassistischen oder sexistischen Sprachgebrauchs bezogen. Ohne diese Formen sprachlicher Diskriminierung bagatellisieren zu wollen, erscheint sprachlicher Ageismus subversiver und von hoher Brisanz, da er potentiell jeden unabhängig von Rasse, Geschlecht, Herkunft oder Religion betreffen kann und zum anderen die Devaluation von Menschen und Gruppen, die bereits von diskriminierendem Sprachgebrauch betroffen sind, vertieft.

Sprachlicher Ageismus verdeutlicht und bedient das überwiegend negative Bild vom Alter als der unmittelbaren Lebensphase vor dem Tode, von „pflegenahen Jahrgängen“ und nutzlosen, nicht mehr anpassungs- und leistungsfähigen Alten. Dieses Stereotyp vom Alter ist durch Sprache stets präsent, wird von ihr permanent reproduziert und z.B. durch Neologismen oder Wortbildung „aufgefüllt“. Zur Besonderheit des Altersstereotyps stellen Rothermund et al. $(1995,52)$ fest:

\begin{abstract}
„Dabei nimmt das Altersstereotyp gegenüber anderen Stereotypen insofern eine Sonderstellung ein, als jeder dieses Stereotyp als Nichtbetroffener erwirbt und insofern von den negativen Implikationen eines solchen Stereotyps zunächst nicht berührt wird. Die Notwendigkeit der Abgrenzung oder Ablehnung des Stereotyps besteht zum Erwerbszeitpunkt nicht, was dazu führt, daß dieses Stereotyp mehr oder minder leicht übernommen wird und eine nahezu universelle Verbreitung findet."
\end{abstract}

Die "nahezu universelle Verbreitung“ erfolgt zu einem großen Teil mit der Interiorisation des Stereotyps in der Kopplung an Spracherwerb bzw. Sprachgebrauch; hier sind es vor allem die Konnotationen, die - wie oben gezeigt - überwiegend Negatives vermitteln. Mit Schippan $(1987,355)$ kann von folgendem ausgegangen werden:

„Als gesellschaftlich verfestigte Merkmale sprachlicher Einheiten sind Konnotationen Resultat der Widerspiegelung und Kommunikation, die die Geltung der denotativen Bedeutung signalisieren und in das System sozialer Normen einordnen."

25 Vgl. u.a. die Arbeiten von Galliker et al. (1994), Höer et al. (1996) u.a. zum Projekt „Sprachliche Diskriminierung" aus dem Sonderforschungsbereich 245 "Sprache und Situation“ Heidelberg/Mannheim (1989ff.) und Reiher \& Kramer (i.V.). 
In diesem Sinne generieren und fixieren die negativ konnotierten Lexeme zur Bezeichnung des Alters und der Alten Altersstereotype und Ageismus. Doch auch das sich herausbildende positive Altersimage kann kontraproduktiv wirken, weil sich die Last-Assoziationen der Jüngeren auch mit der zunehmenden Gruppe „junger und fitter Alter" verbinden.

Gegenwärtig gibt es Zeichen eines beginnenden Wertewandels, die im Ergebnis einer fortschreitenden Differenzierung des gängigen Altenbildes eine Wandelbarkeit verbreiteter Altersstereotype bezeugen.

So registriert der Wortschatz - empfindlich wie ein Seismograph - Veränderungen im sprachlichen Bild vom Alter. Sprachliche Stigmatisierung wird nicht länger unwidersprochen hingenommen, sondern kritisch reflektiert. Die Betroffenen selbst verwahren sich zunehmend gegen diskriminierende Benennungen.

Age and Attitudes z.B. - eine Studie der EU von 1993 - ermittelte aus den Antworten auf die Frage What's in a Name? ein deutliches Votum für neutrale Bezeichnungen wie 'senior citizens' and 'older people'. Die in allen EU-Ländern Befragten favorisierten diese Benennungen, lehnten jedoch Lexeme, die einen "toleranten“ oder wohl eher beschönigenden Umgang mit den Älteren signalisieren sollen, wie '50 plus', 'golden age' und 'oldies', ab. Auch golden girlies oder die deutschen Wörter Altchen, Muttchen, ältere Semester werden als ironisch oder überheblich und damit distanzierend empfunden und abgelehnt.

Rothermund et al. (1995) beschreiben in einer aktuellen Untersuchung zur selbstbildschützenden Verschiebung des „alt“-Begriffs die Anreicherung mit positiven Konnotationen und weisen darauf hin, daß eine meliorative Umdeutung des Feldes um „alt“ möglicherweise auch das Altersstereotyp mit positiven Elementen bereichern wird. In diesem Sinne zeugt auch der folgende Leserbrief von sensibilisierter und zunehmend offensiverer Öffentlichkeit:

\footnotetext{
"Steht das schlichte Wort alt wirklich für dumm, doof, blöd und häßlich? Ich kenne Junge wie Alte, auf die einiges davon zutrifft. Keiner wird darauf kommen, deshalb eine ganze Bevölkerungsgruppe mit jung als Schimpfwort zu belegen. Altern, das Phänomen unserer Zeit, kann späte Freiheit oder Loslassen bedeuten, Kompetenz oder Defizite, Besinnung oder Rückzug. Es als Gewinn für unsere Gesellschaft zu sehen ist ein Lernprozeß, bei dem wir alle erst am Anfang stehen. Eins sollte klar sein: Alt ist kein Schimpfwort und keine ansteckende Krankheit. Alt wird jeder, der nicht jung stirbt." (Tagesspiegel 25.2.1996)
}

Vor allem in den USA ist das sich verändernde Altenbild auch sprachlich nachweisbar: Die senior citizens werden als resource persons positiv bewertet: Synonym zu elderly gibt es eine Vielzahl von Benennungen und Kürzeln, die neutral oder positiv wertend sind. Diese Bezeichnungen werden von den Gruppenmitgliedern sehr bewußt als Identitätsmerkmal bzw. Identifikationsmittel eingesetzt, natürlich auch, um in Zeiten der political correctness eine sprachliche Alternative zu ageist-terms wie go-gos, slow-gos, no-gos zu geben. Hier zeigt sich zudem die Tendenz, Sprache über die Benennungen der Gruppe als Mittel einer selbstwertschützenden Identität und als Mittel der internen Gruppenfestigung zu nutzen und die Kennzeichnung der Gruppe nicht mehr ausschließlich von außen und von anderen - häufig stigmatisierend und diskriminierend - vornehmen zu lassen. Dabei referieren die neuen, positiven Bezeichnungen nicht auf das Alter als einziges gemeinsames Merkmal der Gruppe, sondern nehmen Bezug auf Lebensumstände, sozialen Status unabhängig vom Alter u.ä. So finden sich z.B. 


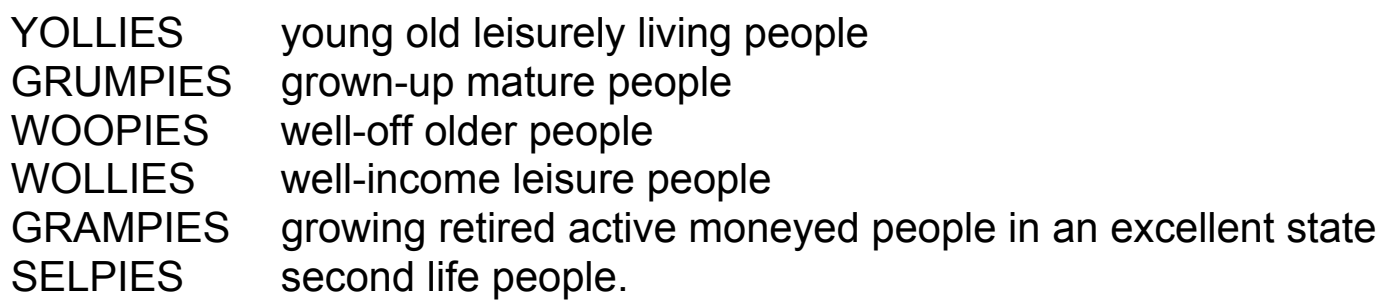

In Deutschland dokumentieren vor allem Begriffe wie Altenkompetenz oder SeniorExperten die positive Bewertung der Alten als Gebende und Beitragende, als Erfahrene und Mitgestalter und nicht nur als "Altenlast". Eine differenzierte, positive Benennung der großen Gruppe der Älteren zeigt sich zudem bei Lexemen wie die junggebliebene Generation oder die Anti-Stress-Generation.

Die in Gang gekommene sprachliche Differenzierung läßt auf eine Veränderung des gängigen Altersstereotyps hoffen, die mit einem beginnenden Wertewandel dem sprachlichen Ageismus ansatzweise entgegenwirkt. Ageismus als Form sozialer Diskriminierung verschwindet jedoch nicht im Selbstlauf, und die gegenwärtig zu beobachtende sprachliche Devaluation der Älteren verlangt kritische - auch linguistische - Beobachtung und bewußte Einflußnahme, weil die Erkenntnis, daß sprachlicher Ageismus existiert, nur der erste Schritt zu seinem Abbau sein kann.

\section{Literatur}

Age and Attitudes. Main Results from a Eurobarometer Survey. (1993). Comission of the European Communities. o.O.

Barbato, C. A. \& Freezel, J. D. (1987). The Language of Aging in Different Age Groups. In: The Gerontologist 27, 527-531.

Becker, H.-J. (1991). Das Feld um alt. Heidelberg.

Berg, L. (Hrsg.) (1994). „When I'm sixty-four“. Alter und Altern in Deutschland. München.

Bergenholtz, H. (1989). Probleme der Selektion im allgemeinen einsprachigen Wörterbuch. In: Hausmann, F. J. et al. (Hrsg.), Wörterbücher. Ein internationales Handbuch zur Lexikographie. Berlin/New York, 773-779.

Braithwaite, V. A. (1986). Old Age Stereotypes: Reconciling Contradictions. In: Journal of Gerontology 41, 353-360.

Butler, R. (1969). Age-ism: Another Form of Bigotry. In: The Gerontologist 9, 243-246.

Butler, R. (1975). Why Survive? Being Old in America. New York.

Butler, R. (1980). Ageism: a foreword. In: Journal of Social Issues, 36, 8-11.

Coupland, N., Coupland, J. \& Howard, G. (1991). Language, society and the elderly: discourse, identity and aging. Cambridge, MA.

de Beauvoir, S. (1993). Das Alter. Reinbek.

Dickman, I. (1979). Ageism - Discrimination against older people. New York.

Dieck, M. (1987). Die ältere Generation im Spiegelbild der großen Regierungserklärungen von 1949 bis 1987. In: Deutsches Zentrum für Altersfragen (Hrsg.), Die ergraute Gesellschaft. Berlin.

Dierl, R. (1989). Zwischen Altenpflege und Seniorenstudium. Alter und Alte als Zeitungsthema. Köln.

Donicht-Fluck, B. (1989). Neue Alte in den USA - Konsequenzen und Probleme einer Ausdifferenzierung des Altersbildes. In: Produktivität des Alters. Berlin, 232-255.

Drößiger, H. (1995). Wertung und Lexikon. Eine Betrachtung. In: Pohl, I. \& Ehrhardt, H. (Hrsg.), Wort und Wortschatz. Beiträge zur Lexikologie. Tübingen, 25-34.

FD Germanistik = Fachdienst Germanistik (1997). Sprache und Literatur in der Kritik deutschsprachiger Zeitungen 3, 6. 
Galliker, M., Huerkamp, M., Höer, R. \& Wagner, F. (1994). Funktionen expliziter sprachlicher Diskriminierung: Validierung der Kernfacetten des Modells sprachlicher Diskriminierung. In: Arbeiten aus dem Sonderforschungsbereich 245 „Sprache und Situation“. Bericht Nr. 73. Heidelberg/Mannheim.

Graumann, C. F. \& Wintermantel, M. (1989). Discriminatory speech acts: A functional approach. In: Bar-Tal, D. et al. (eds.), Stereotypes and prejudice: Changing conceptions. New York, 184-204.

Grimm, J. (1984). Rede über das Alter. In: Ders., Selbstbiographie. Ausgewählte Schriften, Reden und Aufsätze. München.

Hausmann, F. J. (1989). Die gesellschaftlichen Aufgaben der Lexikographie in Geschichte und Gegenwart. In: Hausmann, F. J. et al. (Hrsg.), Wörterbücher. Ein internationales Handbuch zur Lexikographie. Berlin/New York, 1-19.

Hirche, K. (1984). Die Alten kommen. Reinbek.

Hoffmann, H. (1988). Jugendwahn und Altersangst. Frankfurt a.M.

Höer, R., Galliker, M., Huerkamp, M., u.a. (1996). Implizite sprachliche Diskriminierungen: Eine facettentheoretische Modellvalidierung. In: Arbeiten aus dem Sonderforschungsbereich 245 „Sprache und Situation“. Bericht Nr. 103. Heidelberg/Mannheim.

Illhardt, F. J. (1993). Ageism: Vorurteile gegen das Alter. In: Zeitschrift für Gerontologie 26.

Illhardt, F. J. (1995). Ageism im Umgang mit alten Menschen und seine Auswirkung auf die therapeutische Beziehung. In: Zeitschrift für Gerontopsychologie und -psychatrie 8, Heft 1/2, 9-16.

Kramer, U. (1995). Runzelrabatt für gierige Grufties oder Wie geht unsere Sprache mit den Alten um? In: Langage et l'homme 2-3. Brüssel, 183-190.

Laudowitz, E. (1993). Älter werden wir doch alle. Frankfurt a.M.

Lehr, U. M. \& Niederfranke, A. (1991). Altersbilder und Altersstereotype. In: Gerontologie. Medizinische, psychologische und wissenschaftliche Grundbegriffe. Stuttgart u.a., 38-46.

Ludwig, K.-D. (1991). Markierungen im allgemeinen einsprachigen Wörterbuch des Deutschen. Ein Beitrag zur Metalexikographie. Tübingen.

Matthews, S. (1979). The social world of old women: managenemt of self-identity. Beverly Hills, CA. (zitiert nach: Nuessel, F. H. (1982). ebd.).

Mohl, H. (1993). Die Altersexplosion. Stuttgart.

Nuessel, F. H. (1982). The Language of Ageism. In: The Gerontologist 22, 273-276.

Püschel, U. (1989). Evaluative Markierungen im allgemeinen einsprachigen Wörterbuch. In: Hausmann, F. J. et al. (Hrsg.), Wörterbücher. Ein internationales Handbuch zur Lexikographie. Berlin/New York, 693-699.

Reiher, R. \& Kramer, U. (Hrsg.) (i.V.). Sprache als Mittel von Identifikation und Distanzierung. Bern u.a.

Ripfel, M. (1989). Wörterbuchkritik. Eine empirische Analyse von Wörterbuchrezensionen. Tübingen.

Roloff, E. (1990). Das diffamierte Leben. Empörende Begriffe: Überalterung und Vergreisung. In: Sprachreport 1, 5 .

Rothermund, K., Wentura, D. \& Brandtstätdter, J. (1995). Selbstwertschützende Verschiebungen in der Semantik des Begriffes „alt“ im höheren Erwachsenenalter. In: Sprache und Kognition, Bd. 14, H. 2, 52-63.

Schippan, Th. (1987). Konnotationen - ein noch immer aktuelles lexikologisches Problem. In: Zeitschrift für Germanistik 3, 355-360.

Schlosser, H. D. (1996). Von „ausländerfrei“ bis „Diätenanpassung“. Fünf Jahre Unwortsuche. In: Der Sprachdienst 2, 47-58.

Schmidt, K. (1995). Überalterung. Was ist das eigentlich? In: rtv. Die Fernsehbeilage der Berliner Zeitung 41, 24.

Steinhauer, A. (1997). Wörter des Jahres 1996. In: Der Sprachdienst 1, 1-12.

Tews, H. P. (1979). Soziologie des Alterns. Heidelberg.

Tews, H. P. (1991). Altersbilder. Über Wandel und Beeinflussung von Vorstellungen vom und Einstellungen zum Alter. Köln.

Thimm, C. (1996). Alter, Sprache, Kommunikation: Plädoyer für eine Gerontologische Linguistik. In: Der Sprachreport 1, 4-5.

Thürkow, K. (1985). Altersbilder in massenmedialen, massenkulturellen und künstlerischen Werken. Eine Literaturübersicht. Berlin. 


\section{Wörterbücher und Lexika}

Barnhart \& Langenscheidt (1973). A Dictionary Of New English. Ed. by C. L. Barnhart, S. Steinmetz \& R. Barnhart. Bronxville/New York u.a.

Bauer, B. (1990). Ullsteins Synonymenlexikon. Frankfurt a.M., Berlin.

Brockhaus Enzyklopädie in vierundzwanzig Bänden. (1986). Mannheim.

Brockhaus-Wahrig (1980). Deutsches Wörterbuch in sechs Bänden. Stuttgart.

Bulitta, E. \& Bulitta, A. (1983). Wörterbuch der Synonyme und Antonyme. Frankfurt a.M.

Collier's Dictionary (1994). New York u.a.

Der kleine Wahrig. Wörterbuch der deutschen Sprache (1993). Gütersloh.

DGWB = DUDEN. Das große Wörterbuch der deutschen Sprache: in acht Bänden (1993-1995). Mannheim u.a.

Die große Bertelsmann Lexikothek (1984). Gütersloh.

Duden Bd. 8 = Duden. Die sinn- und sachverwandten Wörter. Wörterbuch für den treffenden Ausdruck (1986). Mannheim u.a.

Duden. Das Große Fremdwörterbuch (1994). Mannheim u.a.

DUW = Duden. Deutsches Universalwörterbuch von A-Z. (1989). Mannheim u.a.

Ehmann, H. (1992). „affengeil“. Ein Lexikon der Jugendsprache. München.

Etymologisches Wörterbuch des Deutschen (1993). Berlin.

Grimm, J. \& Grimm, W. (1845-1960). Deutsches Wörterbuch. Leipzig.

Heinemann, M. (1989). Kleines Wörterbuch der Jugendsprache. Leipzig.

Kleine Enzyklopädie (1988). Das Alter. Leipzig.

Kluge, F. (1995). Etymologisches Wörterbuch der deutschen Sprache. Berlin/New York.

Küpper, H. (1987, Nachdruck 1988). Wörterbuch der deutschen Umgangssprache. Stuttgart.

Müller-Thurau, C. P. (1985). Lexikon der Jugendsprache. Düsseldorf.

Paul, H. (1992). Deutsches Wörterbuch. Tübingen.

Pfeiffer, H. (1996). Das große Schimpfwörterbuch. Über 10000 Schimpf-, Spott- und Neckwörter zur Bezeichnung von Personen. Frankfurt a.M.

Scheemann, H. (1993). Deutsche Idiomatik. Die deutschen Redewendungen im Kontext. Stuttgart/Dresden.

Sommerfeldt, K.-E. \& Schreiber, H. (1977). Wörterbuch zur Valenz und Distribution deutscher Adjektive. Leipzig.

Stilwörterbuch. (1966). Leipzig.

Strauß, G., Haß, U. \& Harras, G. (Hrsg.) (1989). „Brisante Wörter von Agitation bis Zeitgeist“. Ein Lexikon zum öffentlichen Sprachgebrauch. (Schriften des Instituts für deutsche Sprache Bd. 2) Berlin/New York.

The American Heritage Dictionary On The English Language (1979). Ed. by W. Morris. Boston, MA.

The New Shorter Oxford English Dictionary On Historical Principles. Ed. by L. Brown. (1973, 1993). Oxford/New York.

WDG = Wörterbuch der deutschen Gegenwartssprache (1964). Hrsg. von R. Klappenbach u. W. Steinitz. Berlin.

Webster's Third New International Dictionary Of The English Language (1981). Chicago u.a.

\section{Zeitungen und Zeitschriften}

Berliner Zeitung. 17.2.1994, 6.6.1994, 9.6.1994, 18./19.6.1994, 31.8.1994, 11./12.2.1995, 17.10.1995, 7.6.1996, 5./6.10.1996, 19.3.1997.

Der Spiegel. 35/1993, 12/1995.

Der Stern. 42/1996.

Die Welt. 17.10.1996.

Die Zeit. 10.3.1994, 31.3.1995.

Frankfurter Rundschau. 13.8.1994. 
GEO-Wissen. Alter und Jugendwahn. 1/1991.

rtv. Die Fernsehbeilage der Berliner Zeitung. 41/1995.

Tagesspiegel. 25.2.1996.

taz. Die Tageszeitung. 9.4.1993.

Time Aug. 3, 1970 (zit. nach Barnhart \& Langenscheidt ebd.).

TV-Today. 25/1994. 


\title{
Sprache und Demenz
}

\author{
Michael Schecker
}

\section{Anstelle einer Einleitung}

1.1 Vor nicht allzu langer Zeit wurde ich - vermittelt über eine ambulante geriatrische Einrichtung - mit einer älteren Frau konfrontiert, deren Allgemeinzustand sich innerhalb eines halben Jahres deutlich verschlechtert hatte. Für mich besonders auffällig waren ihre frisch entstehenden Gedächtnislücken.

Zunächst konnte Frau M. (wie wir sie nennen wollen) noch selbständig ihren Haushalt führen. Doch dann setzten beim Einkaufen Gedächtnisausfälle ein. Dagegen half schließlich auch kein Einkaufszettel mehr, weil sie den alsbald ebenfalls vergaß. Auch fand sie keine Schlüssel mehr; sie verlernte, wie man die Geschirrspülmaschine bedient, wie man Kaffee macht; es kamen örtliche und zeitliche Orientierungsprobleme hinzu; schließlich mußte sie - zunächst unter Einschaltung ambulanter Dienste, dann als Insassin eines Altenpflegeheims - auch noch bei der Nahrungsaufnahme und in der täglichen Körperpflege unterstützt werden.

Diagnostisch wurde der Verdacht auf eine 'Alzheimersche Demenz' (DAT) formuliert; eine sichere Überprüfung war nicht möglich.

1.2 In der Klinik werden zwei 'klinisch-diagnostische Inventare' verwendet, das ICD der Weltgesundheitsorganisation ${ }^{1}$ und das amerikanische DSM. Nach DSM IV ${ }^{2}$ liegt eine Demenz vor, wenn gilt bzw. wenn sich Folgendes beobachten läßt:

1.) Gedächtnisstörungen (zunächst das Kurz-, dann das Langzeitgedächtnis; vgl. dazu noch weiter unten)

2.) Mindestens eine der folgenden kognitiven Einbußen:
a) Aphasie (Sprachstörungen)
b) Apraxie
c) Agnosie
d) Beeinträchtigungen der Exekutivfunktionen.

3.) Die kognitiven Defizite müssen schwer genug sein, um eine Beeinträchtigung des beruflichen oder sozialen Leistungsniveaus zu verursachen, und müssen eine deutliche Verschlechterung gegenüber einem vormals höheren Leistungsniveau darstellen.

4.) Die Störungen dürfen nicht nur während eines Delirs auftreten.

Abb. 1: Demenz nach DSM IV

\footnotetext{
Weltgesundheitsorganisation (1991).

2 American Psychiatric Association (Task force) (1994).
} 
Die Kriterien des DSM sprechen weitgehend für sich; dennoch möchte ich einige zusätzliche Erläuterungen nachtragen: Wenn von der Beeinträchtigung des Gedächtnisses die Rede ist, dann ist damit zunächst so etwas wie die Fähigkeit gemeint, Gedächtnis zu bilden. Ein entsprechendes Defizit läßt sich durch einfache neuropsychologische Tests nachweisen. Beispielsweise kann man einen Patienten, der vor einem sitzt, auffordern, die Armbanduhr abzunehmen und hinter einen Bücherstapel zu legen (und das so, daß er sie - wenn er sich wieder setzt - nicht sehen kann); wenn man dann nach etwa zwei Minuten den Patienten nach der Uhrzeit fragt, stellt dieser (häufig entsetzt) fest, daß ihm seine Armbanduhr abhanden gekommen ist, und 'erinnert' sich nicht mehr daran, daß er diese ja gerade eben erst hinter einen Bücherstapel gelegt hatte.

DSM IV spricht - was die Störung kognitiver Fähigkeiten angeht - von 'Aphasie'. Das ist eine höchst unglückliche Bezeichnung für die bei Demenzen auftretenden Sprachstörungen; unglücklich für uns hier in Europa, weil wir - im Unterschied zur amerikanischen Fachliteratur - damit nicht lediglich Sprachstörungen (welcher Art auch immer) meinen, sondern - in Anlehnung vor allem an die Aachener Schule (Poeck, Huber u.a.) - spezifische Sprachstörungen, wie sie nach einer organischen Läsion im Bereich der sprachrelevanten 'Gebiete' der sogenannten 'dominanten' Seite (oder Hemisphäre) des Großhirns auftreten. - Entscheidend ist im übrigen, daß es sich bei den Sprachauffälligkeiten dementer Patienten einer frühen oder mittleren Phasen weniger um Sprachstörungen bzw. sprachsystematische Fehler handelt (die treten natürlich auch auf), als vielmehr um typische Reduktionen der sprachlichen Ausdrucksfähigkeit, auf die ich weiter unten noch näher eingehen werde.

Was ist mit 'Apraxie' gemeint? - Ganz generell vollziehen wir eine Vielzahl von alltäglichen Bewegungen und Bewegungsfolgen hoch automatisiert, 'überlernt', entsprechend abgespeicherter 'Muster' (oder 'Skripts'). Und das ist gut so, denn wenn wir alle Bewegungen und Bewegungsfolgen bewußt vollziehen müßten, würde unsere Aufmerksamkeit stark gebunden - und schnell auch überfordert sein; wir wären unfähig, kompliziertere Bewegungen hinreichend exakt und in einer überschaubaren Zeit auszuführen; und wir könnten die Durchführung verschiedener Bewegungen oder Bewegungsfolgen nicht mehr miteinander und mit anderen Aktivitäten kombinieren (ein Fahrschüler - anders als ein routinierter Autofahrer - dürfte schnell überfordert sein, wenn man inn beim Auto-fahren in eine Diskussion etwa über die Auswirkungen der Arbeitslosigkeit ziehen würde). - Von 'Apraxie' spricht man (wobei ich hier jetzt nicht auf Details und Untertypen eingehe $)^{3}$, wenn feinere und komplexere Bewegungen nicht mehr gelingen, wenn der 'Gesamtentwurf' einer komplexen Bewegung oder Bewegungsfolge verloren geht, wenn gerade komplexere Handlungen nicht mehr in Zeit und Raum geordnet vollzogen werden können.

Und was meint DSM IV mit 'Agnosie'? Hier geht es um die Unfähigkeit, z.B. einen Gegenstand (etwa einen Stuhl) als solchen zu erkennen, obwohl die Sehfähigkeit voll erhalten ist. ${ }^{4}$ Vergleichbar können auditive 'Identifikationsleistungen' betroffen

3 Es geht (a) um sequentielle Anordnungen von Einzelbewegungen zu einer Bewegungsfolge $-z$.B. 'Winken' (treten hier Defizite auf, dann sprechen wir von ideomotorischer Apraxie), und (b) um mehrgliedrige Bewegungsfolgen und deren Organisation zu einer Gesamthandlung - z.B. 'Bleistift spitzen' oder 'Kaffee kochen' (hier sprechen wir von ideatorischer Apraxie).

4 Ein sehr illustratives Beispiel ist die sog. 'apperzeptive Agnosie'; hier werden zwar Details identifiziert (grüner Stengel, grüne Blätter, rote Blüte), können aber nicht mehr zu einer Ganzheit (Rose) 
sein, so z.B. die Fähigkeit, ein bestimmtes Geräusch oder Schallereignis (das der Patient gegebenenfalls hinsichtlich seiner akustischen Qualitäten sehr genau beschreiben kann) als 'Ausruf' zu erkennen.

Daß Agnosien und Apraxien etwas miteinander zu tun haben, liegt auf der Hand: In beiden Fällen sind so etwas wie abstrakte Muster oder Vorlagen betroffen, das eine Mal Vorlagen für die Durchführung motorischer Aktivitäten, das andere Mal Vorlagen für die Analyse eines sensorischen 'input' (einen Ausruf wie „Hallo!“ 'erken-nen' heißt ja genauer, ein Schallereignis 'als Ausruf „Hallo!“ zu identifizieren'). Daß sich darüber hinaus Agnosien und Apraxien direkt auf das allägliche Sprachvermögen - auf die Sprachproduktion wie -rezeption - auswirken, dürfte ebenfalls deutlich geworden sein; bei den Apraxien sprechen wir - wenn die artikulatorischen Bewegungen und Bewegungsfolgen betroffen sind - auch von artikulatorischer oder phonematischer Apraxie.

Ein letzter Hinweis - im DSM IV ist von der Beeinträchtigung von 'Exekutivfunktionen' die Rede: Das betrifft das Zusammenspiel komplexer Verstehensleistungen und darauf abgestellter adäquater Reaktionen; - ich gehe darauf hier nicht weiter ein.

Was die Auswirkungen (und in diesem Zusammenhang insbesondere die funktionalen Auswirkungen) angeht, so bietet es sich an, Alzheimersche Demenzen und nicht-fokale vaskuläre Demenzen zu einer Gruppe zusammenzufassen und sie den fokalen vaskulären Demenzen gegenüber zu stellen. Dabei meint „nicht-fokale“ Läsionen (z.B. eine Vielzahl kleiner und kleinster Infarkte, wie das bei den nichtfokalen vaskulären Demenzen der Fall ist), die mehr oder weniger stark gestreut auftreten; „fokal“ hält dagegen fest, daß ein mehr oder weniger eng umschriebener Bereich des Gehirns betroffen ist. - Der Vielzahl kleiner und kleinster, breit gestreuter Infarkte bei den nicht-fokalen vaskulären Demenzen entsprechen bei der Alzheimerschen Demenz u.a. breit gestreute Ablagerungen im Bereich der synaptischen Verschaltungen von Nervenzellen (dazu kommen weitere Veränderungen im Zellkern); auch hier wird die Funktion von Nervenzellen in Mitleidenschaft gezogen; die neuronalen Vernetzungen werden funktionsuntüchtig; schließlich kommt es zu einem (über die Zeit breit angelegten) diffusen Hirnabbau.

Bei den nicht-fokalen vaskulären Demenzen und bei den Alzheimerschen Demenzen kommt als Faktor so etwas wie die 'negative Plastizität' des menschlichen Gehirns hinzu: was nicht mehr hinreichend regelmäßig gebraucht wird, wird abgebaut. - Die anhand einer Vielzahl von Details nachweisbare 'negative Plastizität' muß - was die Alzheimersche Demenz anbelangt - nicht einmal sekundärer Natur sein. Es ist nicht auszuschließen, daß die für die Alzheimersche Demenz so typischen Ablagerungen im synaptischen Spalt Begleiterscheinung eines zunächst rein funktional begründeten Abbaus sind. ${ }^{5}$

Nun soll die hier vorgeschlagene Zusammenfassung von Alzheimerscher Demenz und nicht-fokalen vaskulären Demenzen nicht bedeuten, daß die Auswirkungen funktionaler Art (und in diesem Zusammenhang auch die Auswirkungen auf die Sprachverarbeitung) völlig gleichartig sind; hier (allerdings nicht nur hier) ${ }^{6}$ fehlt es

zusammengesetzt werden; unterscheidende und gemeinsame Merkmale können nicht mehr erkannt werden.

5 Vgl. Bauer (1994); Bauer, Hüll \& Berger (1995); vor allem aber Bauer, Stadtmüller, Qualmann \& Bauer (1995); Cramon (Hrsg.) (1993).

6 In der klinischen Diagnostik gelten sprachliche Auffälligkeiten bei Demenz noch immer (eher) als Randphänomen (zu genaueren Details siehe weiter unten). So finden sich in den großen Lehrbü- 
bisher an empirischen Untersuchungen. Gelegentlich ist in der Fachliteratur die Vorstellung zu finden, bei nicht-fokalen vaskulären Demenzen vollziehe sich der Abbau kognitiver Leistungen im allgemeinen und sprachlicher Leistungen im besonderen 'treppenförmig'; hingegen komme es bei Demenzen vom Alzheimerschen Typ zu einem relativ gleichförmigen Leistungsrückgang. In der neuesten Literatur gibt es jedoch wichtige empirische Hinweise darauf, daß auch bei Alzheimerschen Demenzen der funktionale Abbau (in bestimmten Phasen) 'treppenförmig' erfolgt. ${ }^{7}$

1.3.1 Die Alzheimersche Erkrankung ist die häufigste Form einer organischen Demenz; heute werden unter dieser Bezeichnung sowohl präsenile wie senile Formen zusammengefaßt. - Bezogen auf andere Demenztypen ergibt sich die folgende Häufigkeitsverteilung:

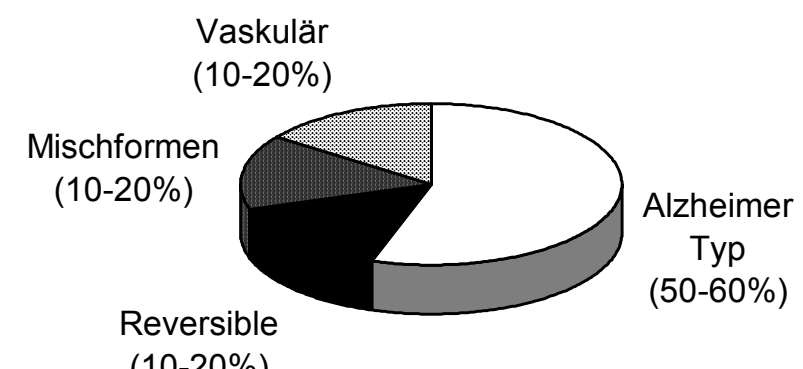

Abb. 2 (nach Fischer, Gress-Heister \& Heister (1994))

Angesichts der Häufigkeit gilt die Alzheimersche Erkrankung als eine Art Modellfall einer Demenzerkrankung.

1.3.2 Was haben Demenzen - nicht nur solche vom Alzheimerschen Typ - mit dem Alter zu tun? Dementielle Erkrankungen stellen in keinem Fall eine Art vorzeitiges Altern dar; der Zusammenhang zwischen Alter und dementiellen Erkrankungen ist gänzlich anderer Natur. Am Beispiel nochmals der Alzheimerschen Demenz: Hier müssen wir mit einer 'Vorlaufzeit' von 10 bis zu 30 Jahren rechnen, bevor es zu so großen funktionalen Ausfällen kommt, daß die diagnostischen Kriterien etwa des DSM IV greifen; erst nach so langem Krankheitsverlauf macht sich eine Alzheimersche Erkrankung als (dann relativ schnell zunehmende) Beeinträchtigung kognitiver Leistungen - und schließlich sogar vegetativer Steuerungen - bemerkbar.

Wie also sieht der Zusammenhang von Alter und dementiellen Erkrankungen aus? Dadurch, daß unsere Lebenserwartung - nicht zuletzt durch die Fortschritte

chern der Psychiatrie und Neurologie sowie in der modernen Gerontopsychiatrie und Geriatrie/Gerontologie zum Thema Sprachverarbeitung und/oder Kommunikationsverhalten bei Demenz nur wenige Hinweise (vgl. aber z.B. Füsgen (1996); Heinrich et al. (1994); Fischer et al. (1993). - Auch für die sprachwissenschaftliche (neuro- und psycholinguistische) Literatur läßt sich keine neue Tendenz erkennen: Eine Literaturrecherche in den gängigen elektronischen Datenbanken (Medline 1966-1996/2; Psyclit 1966-1995/2; Psyndex 1966-1995) ergab 519 Artikel zum Thema Demenz und Sprache; dem stehen 4714 Artikel zum Thema Aphasie gegenüber.

7 Das ist eine der zentralen Fragen, denen wir am „Neurolinguistischen Labor“ in Freiburg im Rahmen eines größeren Projektes zu 'Formen des Sprachabbaus bei dementiellen Syndromen' nachgehen. 
der modernen Medizin - kontinuierlich steigt, kommen immer mehr Menschen mit einer (zunächst noch gleichsam versteckten) dementiellen Erkrankung in ein Alter, in dem es dann - nach langem organischen $\mathrm{Abbau}^{8}$ - auch zu funktionalen Ausfällen kommt. - In epidemiologischen Studien von Cooper \& Bickel $^{9}(1989,1991)$ werden in Modellrechnungen für das Jahr 2000 Prävalenzraten für Demenzerkrankungen zwischen $5 \%$ und $15 \%$ bei den über 65Jährigen angenommen. Die $\mathrm{WHO}^{10} \mathrm{ging}$ im August 1996 von weltweit ca. 22 Millionen Menschen mit einem dementiellen Syndrom aus; Cooper \& Bickel geben 1989 bereits für Deutschland 1,4 bis 2 Millionen Menschen mit einer Demenz ${ }^{11}$ an.

\section{Dementielle Erkrankungen und Sprache}

2.1 „Den Übergang zwischen dem normalen und krankhaften Alterungsprozeß klinisch-diagnostisch faßbar zu machen, ist eine der großen medizinischen Herausforderungen unserer Zeit“, schreibt Fischer, einer der Altmeister der Geriatrie (vgl. Fischer et al. 1993, 35). Dabei wäre es von elementarer Relevanz, dementielle Entwicklungen (nicht nur vom Alzheimerschen Typus) frühzeitig zu erkennen. Das würde therapeutische Interventionen ermöglichen (neuropsychologisch fundiertes Training), die - je früher angewendet, um so größere Effekte haben. Zwar kann auf diese Weise keine dementielle Erkrankung geheilt werden; es sind jedoch Verlangsamungen der dementiellen Entwicklung erreichbar, die dazu führen, daß der Eintritt schließlich des Pflegefalls um Jahre und mehr hinausgezögert wird.

Die Diagnostik der Demenz wird insbesondere durch die folgenden Unsicherheitsfaktoren erschwert:

- Bisher gibt es keinen zuverlässigen biologischen Marker.

- Die derzeit bekannten diagnostischen Kriterien greifen erst relativ spät.

- Die Differenzierung der primären und sekundären Demenzformen (letztere als Folgedefizite anderer Erkrankungen bzw. anderer Syndrome) ist oft schwierig und unterbleibt häufig.

Was weiß man phänomenal-symptomatologisch über Demenzen? Dementielle Erkrankungen werden mit zunehmenden Gedächtnisproblemen, mit Orientierungsschwierigkeiten und dann - in fortgeschrittenerem Stadium - mit schnell zunehmenden Einbrüchen im kognitiven Bereich in Verbindung gebracht (Alltagsfähigkeiten $\left[\mathrm{ADL}^{12}\right]$; Planungsprozesse; Verlust der Fähigkeit, Aufmerksamkeit zu fokussieren; Ausfall der alltäglichen Orientierung zu Personen und in Raum und Zeit). Eine Reihe von Untersuchungen sprechen aber dafür, daß alltagsrelevante Gedächtnis- und

8 'Vorlaufzeiten' wie die der Alzheimerschen Erkrankung sind in Hinweis darauf, daß Funktionen des Gehirns 'hard-ware-mäßig' in der Regel mit einer großen Redundanz ausgestattet sind: erst nach langem organischen Hirn-Abbau kommt es zu - dann eben nicht mehr kompensierbaren - funktionalen Defiziten.

9 Cooper \& Bickel (1989, 472-482). Vgl auch Cooper (1991) und für einen generellen Überblick: Henderson (1994).

10 World Health Report (1996).

11 Alle hier genannten Studien differenzieren nicht die einzelnen Demenzformen.

12 'Activities of daily living': Ruhen und schlafen / sich bewegen / sich waschen / essen und trinken / ausscheiden / regulieren der Körpertemperatur / atmen / für sich sorgen / sich beschäftigen / kommunizieren / Sinn finden / sich als Mann oder Frau fühlen. 
Orientierungsprobleme einen bereits relativ weit vorangeschrittenen Zustand einer Demenz signalisieren. ${ }^{13}$ Und das gilt auch für sprachliche Fehlleistungen: Das DSM IV beschreibt die bei Demenzen auftretende "aphasia (language disturbance)“ als Achsensymptom; sprachliche Fehlleistungen kennzeichnen jedoch - anders als Reduktionen der Sprachverarbeitung - einen bereits relativ weit vorangeschrittenen Grad des dementiellen Abbaus.

Frühe und auch noch mittlere Formen einer Demenz sind unseren Beobachtungen nach zunächst einmal durch Reduktionen ${ }^{14}$ sprachlicher Ausdrucksmittel ${ }^{15}$ charakterisiert. Sie wurden bisher kaum bemerkt, weil bevorzugt die Fehlleistungen in einem engeren Sinne - nämlich als Fehler - registriert (diagnostiziert) werden. Auch Testbatterien wie der AAT (Aachener Aphasie Test) - in der Demenzdiagnostik ${ }^{16}$ eingesetzt - können Reduktionen nicht erfassen. - Ich komme darauf weiter unten nochmals zurück.

2.2 Was ist - über Fehler sprachsystematischer Art hinaus - über Auffälligkeiten der Sprachverarbeitung und des Kommunikationsverhaltens bei dementiellen Syndromen bekannt? In der einschlägigen Fachliteratur werden hier zuallererst Wortfindungsstörungen genannt. ${ }^{17}$

Auffällig sind auch die bereits in frühen Stadien auftretenden Schwierigkeiten, eine Kette von zusammenhängenden Ideen und Vorstellungen im Diskurs zu entwikkeln oder innen zu folgen: Die Patienten 'verlieren' gewissermaßen den 'roten Faden', verlieren die Fähigkeit, eine These argumentativ zu entfalten, sind unfähig, ein ganzheitliches Textverständnis zu entwickeln, oder 'vergessen' das Dialogthema bzw. wechseln es abrupt ${ }^{18}$.

Und ein dritter auffälliger Bereich: Patienten, auch bereits mit einer leichten Demenz, haben Schwierigkeiten, bei bildhaften Ausdrücken und indirekter Redeweise das Gemeinte aus dem Gesagten abzuleiten. Sie verharren bei der wörtlichen Bedeutung ${ }^{19}$ und sind mehr oder weniger unfähig, Humor und Ironie als solche richtig einzuschätzen.

Bei schwereren Formen der Demenz kommt es zusätzlich zunehmend zu Perseverationen - von Silben, Wörtern, Satzteilen und ganzen Sätzen; ${ }^{20}$ besonders auffällig ist in diesem Zusammenhang die Wiederholung bereits gestellter Fragen bzw. schon gegebener Antworten. - Die syntaktische Komplexität (Zahl u.a. der adverbialen Ergänzungen und der Nebensätze, Einbettungstiefe) geht - teilweise massiv zurück. ${ }^{21}$ - Im Endstadium schließlich kann es - muß es aber nicht - zum Zusam-

$13 \mathrm{Vgl}$. die in Anm. 5 genannte Literatur.

14 Dazu: Gress-Heister \& Schecker (1996): Kontext-monitoring-Defizite bei nicht-fokalen Demenzen. Vortrag auf dem Regio-Kolloquium "Forschungsperspektiven der kognitiven Neurolinguistik“ der Universitäten Basel, Freiburg und Strasbourg, 10.-11. Januar 1997 in Freiburg.

15 Eben diese sind ein weiterer zentraler Gegenstand des oben in Anm. 7 schon angesprochenen Projektes über 'Formen des Sprachabbaus bei dementiellen Syndromen'.

16 Zum Einsatz des AAT in der Demenzdiagnostik vgl. Lang et al. (1991).

17 Vgl. Bayles \& Kazniak (1987); Dick et al. (1989); Eustache et al. (1990); Fromm et al. (1991); Wallesch \& Hundsalz (1994).

18 Vgl. nochmals Bayles \& Kazniak (1987); ferner Bayles (1982).

19 Fischer et al. (1993).

20 Bayles (1982); Bayles (1982a); Hier et al. (1985).

21 Vgl. über die in der Anm. zuvor genannte Literatur hinaus Kempler et al. (1988); Bates (1995). 
menbruch der gesamten Sprachproduktion und -rezeption kommen ${ }^{22}$ (Cummings \& Benson 1983).

Ich habe mich hier auf besonders auffällige Aspekte der Sprachverarbeitung und des Kommunikationsverhaltens konzentriert; für frühe und mittlere Formen eines dementiellen Syndroms sind das Aspekte, die allem Anschein nach untereinander funktional zusammenhängen; doch genau dieser von mir vermutete Zusammenhang etwa zwischen Wortfindungsstörungen (als Phänomen) und z.B. der Unfähigkeit, bildhafte und indirekte Redeweisen als solche zu verstehen (oder dann auch etwa dem Rückgang der syntaktischen Komplexität) wird nirgends in der einschlägigen Fachliteratur thematisiert und empirisch aufgearbeitet.

2.3.1 Was steht hinter den eingangs geschilderten Wortfindungsstörungen? Wir haben am Neurolinguistischen Labor in einer Reihe von Fallstudien die Beobachtung gemacht, daß Patienten mit einer Demenz vom Alzheimerschen Typus bei Wortfindungsschwierigkeiten in Benennexperimenten - anders als Aphasiker - so gut wie nicht mit herkömmlichen Methoden 'deblockierbar' sind; deblockierbar auch nicht mithilfe semantisch relationierter Hilfestellungen. ${ }^{23}$

Interessant sind auch mit der mangelnden Deblockierbarkeit - so weit wir sehen zusammenhängende Auffälligkeiten des Assoziationsverhaltens: Läßt man Alzheimerpatienten fortlaufend z.B. Tiernamen assoziieren ${ }^{24}$ und gibt dabei spezielle 'Suchperspektiven' vor, so profitieren Alzheimerpatienten - im Unterschied zu gesunden Probanden und auch im Unterschied z.B. zu Patienten mit Parkinson oder Chorea Huntington - von dieser Art des 'cueings' nicht.

2.3.2 Daß Patienten den 'roten Faden' nicht halten können, daß sie Schwierigkeiten haben, ein ganzheitliches Textverständnis zu entwickeln, daß sie das globale Thema aus den Augen verlieren, hat nach allem, was wir aus anderen Pathologien wisse ${ }^{25}-$ mit der mangelnden bzw. gestörten Fähigkeit zu tun, hinreichend umfangreich und hinreichend differenziert den jeweiligen aktuellen Kontextzusammenhang zu repräsentieren ${ }^{26}$ und - mit Blick auf die Rezeption - in das Verstehen einer elementaren Äußerung einzubringen.

Für das oben skizzierte 'Kontext-monitoring-Defizit', sprechen auch die Schwierigkeiten, die solche Patienten mit bildhaften und/oder indirekten Redeweisen haben: Schon die Erkenntnis, daß etwas nicht wörtlich, sondern bildhaft und/oder indi-

22 Cummings (1988).

23 Wollte man auf die alte Debatte 'Abrufdefizit vs. gestörte Speicherung' zurückgreifen, so spricht das eher gegen ein Abrufdefizit. Wir werden jedoch später sehen, daß es wohl dennoch ein spezifisches Abrufdefizit ist (vgl. Abschnitt 2.3.3.), das hier zugrundeliegt.

24 Zu den Grundlagen: Strube (1984).

25 Vgl. den zusammenfassenden Überblick über entsprechende Arbeiten am Freiburger „Neurolinguistischen Labor" - Schecker \& Kindt (Hrsg.) (1997).

26 Wir verstehen 'Kontext' dynamisch als eine Art Zeitfenster: Im Rahmen jedweder Interaktion und Kommunikation baue ich eine mentale Repräsentation der relevanten Zusammenhänge auf; diese mentale Repräsentation ist zeitlich stark limitiert und wird mit der Interaktion und Kommunikation fortlaufend verändert. - Wenn wir von 'mentaler Repräsentation' (und in diesem Sinne von der 'Repräsentation der relevanten Zusammenhänge des Kontextes') sprechen, so ist damit keinerlei Erinnerung gemeint, wenngleich zum Aufbau einer solchen mentalen Kontext-Repräsentation durchaus Erinnerungen verwendet werden können; - obendrein können solche mentalen KontextRepräsentationen in Erinnerungen überführt werden bzw. im Langzeitgedächtnis eingelagert werden. 
rekt gemeint ist, verlangt den Rückgriff auf den Kontext, der nur in dem Maße gelingen kann, wie dieser aktuell repräsentiert ist oder zumindest entsprechend schnell rekonstruiert werden kann.

Eine dritte, hierher gehörende Beobachtung: Alzheimerpatienten sind häufig bereits relativ früh in ihren - wie Bühler sagen würde - 'apperzeptiven Ergänzungsleistungen' beeinträchtigt, sei es, daß eine Äußerung wegen des umgebenden Lärms teilweise unverständlich bleibt, oder sei es, daß ein Kommunikant nur andeutet, was er meint, und den Rest seinem Kommunikationspartner überläßt. Mit anderen Worten folgen Alzheimerpatienten den Ausführungen ihrer Kommunikationspartner solange (und das - so weit ersichtlich - ohne größere Probleme), wie sie nicht ihrerseits fortsetzen und/oder vervollständigen müssen, was nur im Rahmen eines ganzheitlichen Verstehens bzw. unter Rückgriff auf den Kontext möglich ist.

2.3.3 Ich möchte an dieser Stelle erneut auf die schon angesprochenen Wortfindungsschwierigkeiten zurückkommen. - Gibt man in Assoziationsexperimenten eine Suchperspektive vor, so bedeutet das so etwas wie Kontext, der die Lexikonaktivierung steuert. Dieser Effekt wird umso stärker ausfallen, je spezifischer die Suchperspektive ist. - Es entspricht nach allem den Erwartungen, wenn Alzheimerpatienten bei der Lexikonaktivierung von einer vorgegebenen Suchperspektive nicht profitieren: - Gleichartig läßt sich für (bzw. gegen) deblockierende Hilfestellungen ${ }^{27}$ argumentieren.

In Benennexperimenten kommt es - wie oben ausgeführt - bei Alzheimerpatienten bereits sehr früh zu Wortfindungsstörungen. Wenn dennoch eine mehr oder weniger passende Benennung gefunden wird, so ist dies gehäuft ein 'Prototyp', zumindest ein deutlich prototypischerer Ausdruck als die korrekte Benennung (z.B. Veilchen statt Iris oder Lilien / Bleistift statt Kugelschreiber / usw.). Könnte es sein, daß auch die in Benennexperimenten ausgelöste Aktivation lexikalischer Netze einer jeweiligen (dann allerdings nicht vorgegebenen, sondern impliziten) Suchperspektive unterliegt? Daß entlang einer - gegebenenfalls impliziten - Suchperspektive Ausschnitte eines lexikalischen Netzes gewissermaßen 'geprimt' und andere 'geblockt', unterdrückt, 'inhibiert' werden?

Wenn die Aktivierung prototypischer Einträge tatsächlich das Ergebnis einer mehr oder weniger ungerichteten diffusen Aktivierung lexikalischer Netze ist, dann könnte in der Tat so etwas wie der Grad an Prototypikalität bzw. an 'kognitiver salience' der Grund dafür sein, daß überdurchschnittlich häufig prototypische Einträge aktiviert werden. Aber - und nochmals aber: Die hier angesprochenen Vorstellungen müßten zunächst weiter präzisiert und im Rahmen geeigneter Testdesigns empirisch ausgetestet werden.

2.3.4 Vergleichsweise erst sehr spät kommt es bei Alzheimerpatienten und nichtfokalen vaskulären Demenzen zu einer auffallenden Reduktion der syntaktischen Komplexität - so die einschlägige Fachliteratur (daß im übrigen hier einige Korrekturen angebracht sind, ist einer der wesentlichen Aspekte der Arbeit von Markus Gress-Heister, in diesem Band). Zu nennen wären hier z.B. 'gapping-Phänomene' (in geeignet koordinierten Strukturen wird dennoch z.B. das Subjekt wiederholt), das

27 Ich gehe auf das Phänomen des 'Hyperpriming' hier nicht näher ein. Vgl. Nebes et al. (1986); Chertkov et al. (1989). Generell dürfte die für das 'Hyperpriming' typische drastische 'Ausdünnung' des aktuellen (Anwendungs-)Kontextes für die hier zu verzeichnenden Effekte verantwortlich sein. 
zunehmende Überwiegen des Aktiv (dort, wo wir ein Passiv oder auch bestimmte Formen von Reflexivkonstruktionen erwarten würden), der Ersatz hypotaktischer Konstruktionen durch teilweise unverbundenes Nebeneinanderstellen (was sicherlich zu dem Eindruck mit beiträgt, die Patienten würden 'vom Hölzken aufs Stöksken' kommen) und anderes mehr.

Die betroffenen morphosyntaktischen Ausdrucksmittel haben allesamt in der einen oder anderen Weise mit der Steuerung der Aufmerksamkeit des Rezipienten zu tun, was die Bewältigung des jeweils vorausgesetzten und/oder implizierten Kontextes angeht (ich kann darauf hier leider nur kursorisch eingehen); so gesehen steht es bei zunehmenden Defiziten des Kontext-monitoring geradezu zu erwarten, daß auch die betroffenen Ausdrucksmittel gewissermaßen 'rückläufig' sind.

So impliziert die Verbalisierung eines Sachverhaltes in Form einer adverbialen Erweiterung (Typ „wegen einer/deiner Gastritis“) - in Opposition zu einem Nebensatz (,weil du eine Gastritis hast“) und zu einem Hauptsatz/Aussagesatz („du hast (nämlich) eine Gastritis“) - einen spezifischen Gesprächskontext; ich kann nur erläutern, „daß du wegen deiner Gastritis mal zum Arzt gehen solltest“, wenn darüber mit dem Kommunikationspartner - dem Betroffenen - insofern ein Konsens hergestellt ist, daß dieser (mehr oder weniger wahrscheinlich) eine Gastritis hat ${ }^{28},-$ vgl.

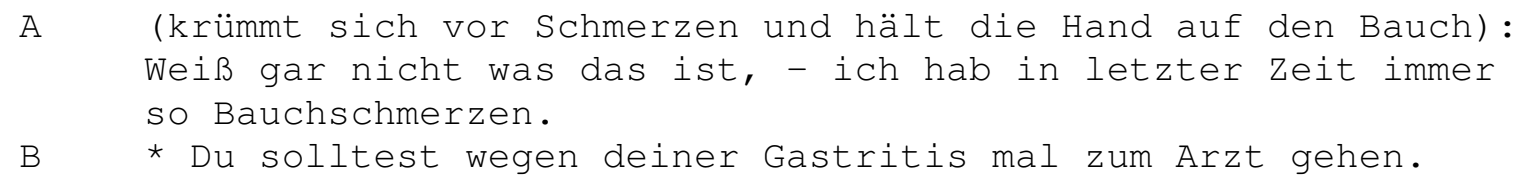

Oder man denke an passivische Formulierungen der Art „Das Zimmer ist bereits gelüftet (worden)“ (mit „Zimmer“ als Subjekt bzw. 'subjektiviertem' - und das heißt: kognitiv hervorgehobenem - Sachverhaltsausschnitt ${ }^{29}$ ) - in Opposition zu „Das Zimmermädchen hat das Zimmer bereits gelüftet“: Hier im Passiv sind hoch automatisierte (universelle - also wahrscheinlich kognitiv begründete) kommunikative Affinitäten außerkraft gesetzt ('wann immer es geht, dann Agens als Subjekt' ['wann immer es geht, dann das Subjekt in thematischer Position - im Aussagesatz auf dem ersten Platz vor dem finiten Verb']). - Affinitäten der skizzierten Art legen so etwas wie eine unmarkierte Form fest. Wird von innen abgewichen, so entsteht eine kommunikativ markierte Form der Verbalisierung eines Sachverhaltes. Markierte Formen einer Verbalisierung werden vor dem Hintergrund der unmarkierten Form rezipiert; ${ }^{30}$ zur Entschlüsselung der mit ihnen vom Sprecher/Schreiber intendierten kommunikativen Effekte ist darüber hinaus die Aufarbeitung des unmittelbaren Gesprächs- oder Textzusammenhangs erforderlich. Beispielsweise könnte es sich in unserem Fall um

28 Vgl. Posner (1972); Bartsch (1978); Schecker (1992).

29 Vgl. Ertel (1977); Engelkamp (1984); Schecker (1995).

30 Hierin gleicht die Rezeption einer markierten Form der Verbalisierung eines Sachverhaltes einer nicht-wörtlich gemeinten (bildhaften oder indirekten) Redeweise, die nachweislich ebenfalls vor dem Hintergrund der wörtlichen Bedeutung rezipiert wird. - Ein traditionelles Gegenargument war lange Zeit, daß markierte Verbalisierungen (wie auch bestimmte bildhafte oder indirekte Äußerungsformen) hoch konventionalisiert seien; hier müsse man in der Rezption doch von einem 'direkten Zugriff' ausgehen, - es sei einfach unplausibel, anzunehmen, daß der Verstehensprozeß unmarkierte Formen der Verbalisierung (bzw. - bei bildhaften oder indirekten Äußerungsweisen die wörtliche Bedeutung der geäußerten Ausdrücke) mit einbeziehe. Doch vollzieht sich der Verstehensprozeß hier im Millisekunden-Bereich, und es liegen inzwischen Ergebnisse aus primingTests vor, die den oben unterstellten 'Umweg' der Rezption belegen. Vgl. Spitzer (1993a) und Spitzer (1993b). 
ein Gespräch zwischen einem Hotelangestellten und einem Hotelgast handeln, und mit der Passiv-Formulierung und der damit möglichen Ausblendung des 'Agens'31 könnte der Hotelangestellte die Aufmerksamkeit massiv auf das Zimmer und seinen (guten oder sogar hervorragenden) Zustand richten wollen.

Über Erklärungen des obigen Typs hinaus (Erklärungen, die auf den Gesprächskontext und kommunikative Rahmenbedingungen abheben) läßt sich ergänzend auch argumentieren: daß ja auch der Aufbau morphosyntaktischer Konstruktionen den Einbezug und die Bewältigung von Kontext - hier nun von sprachlich-formalem Kontext - verlangt. Um einen eklatanten Fall herauszugreifen: Ich muß eine Klammerkonstruktion (und Nebensätze wie auch die oben angesprochenen PassivFormulierungen sind klassische Klammerkonstruktionen) als Ganzes mental repräsent halten, um bei der Ausführung einer solchen Klammerung über die eröffnende Klammer (z.B. eine unterordnende Konjunktion) hinaus auch die schließende Klammer korrekt produzieren zu können bzw. eine solche Klammer (z.B. einen Objektsatz) insgesamt in eine übergeordnete morphosyntaktische Position (z.B. die Position eines direkten Objekts) einbringen zu können. Konzentrieren wir uns auf diesen zweiten Aspekt, so lassen sich - neurowissenschaftlich orientiert - einige interessante Querverbindungen letztlich bis zu den angesprochenen Wortfindungsstörungen vermuten:

2.4 'Kontext' bedeutet neuronal so etwas wie '(zeitabhängige, dynamische) Strukturierung der Verarbeitung von Informationen', die zu spezifischen und fortlaufend wechselnden Mustern der Korrelation der Aktivation gegebenenfalls auch räumlich weit auseinander liegender Neuronengruppen führt. In Anlehnung an Vaadia et al. (1995) sprechen wir hier auch von 'funktioneller Korrelation'. 'Funktionelle Korrelationen' führen einerseits zu einer Erleichterung kontextadäquater Informationsverarbeitung, andererseits zu einer Behinderung Kontextinadquater Informationsverarbeitung. - Kann kein Kontext aufgebaut bzw. aktuell repräsent gehalten werden - so nehmen wir an - dann verfällt die für einen jeweiligen Kontext typische strukturierende Wirkung.

Nach unseren - den Freiburger - Vorstellungen lassen sich hier u.a. die zwei Fälle unterscheiden: Eine 'funktionelle Korrelation' kann erstens ausfallen, weil neuronale Verbindungen zerstört sind; das dürfte der Fall bei Alzheimerpatienten und bei nicht-fokalen vaskulären Demenzen (dazu schon weiter oben) sein; wir sprechen hier auch von einem Diskonnektionssyndrom. ${ }^{32}$ Und zweitens: Eine 'funktionelle Korrelation' kann ausfallen, weil die 'Kohärenz-Instantiierung' - vermutlich im Frontallappen - mißlingt oder aber überhaupt nicht mehr möglich ist (z.B. bei SchädelHirn-Traumatikern mit hoch selektiven Verletzungen des Frontal-Bereichs); - was ist hier mit 'Kohärenz-Instantiierung' gemeint?

Damit im Einzelfall eine 'zeitlich dynamische Strukturierung der Informationsverarbeitung' in Gang kommen kann, müssen nicht nur Muster der Aktivation von Neuronengruppen vorgegeben sein, sondern die Strukturierung muß (ebenfalls auf der Basis vorgegebener Bahnungsphänomene?) auch gleichsam angestoßen werden.

31 Die mit dem Passiv eines Handlungssatzes mögliche 'Agens-Ausblendung' und die so ausgelöste Verschiebung des 'Zentrums' einer Äußerung ist ein in der Passivforschung empirisch gut belegter kommunikativer Mechanismus, der - immer abhängig vom jeweiligen Kontextzusammenhang zu Erzeugung unterschiedlicher 'Effekte' genutzt wird. Vgl. u.a. Schoenthal (1987) und Faucher (1987).

32 Im Sinne von Geschwind (1965). 
Eben das ist ein komplexer und noch weithin unbekannter Prozeß, der zu einer singulären Instantiierung / Etablierung / Auslösung einer spezifischen (dynamischen) Strukturierung der Verarbeitung z.B. sensorischen Inputs oder auch sprachlichen Outputs führt.

2.5.1 Ich erinnere nochmals an die Vorstellung der Alzheimer-Demenz und nichtfokaler vaskulärer Demenzen als diffusen degenerativen Hirnerkrankungen. Eine 'funktionelle Korrelation' wird nun umso schneller bzw. früher davon betroffen sein, je weiter gestreut die so korrelierten Aktivationen ablaufen; wir sprechen hier von der mehr oder weniger großen oder hohen Projektivität einer 'funktionellen Korrelation'.

Wie ganz zu Anfang schon angesprochen, wird in der Fachliteratur weitgehend einhellig über früh auftretende Gedächtnisschwierigkeiten berichtet; dabei sei zunächst so etwas wie das Kurzzeitgedächtnis betroffen; erst später würde das Langzeitgedächtnis folgen. Verstehen wir das Kurzzeitgedächtnis prozedural als Prozeß der Gedächtnisbildung, so sind zweifellos sehr früh schon Prozesse der Gedächtnisbildung betroffen. Es kommt für neue Gedächtnisinhalte nicht zu einer hinreichend stabilen und zeitlich andauernden Abspeicherung. ${ }^{33}$ Davon zu unterscheiden ist aber die Unfähigkeit, gespeicherte Gedächtnisinhalte - z.B. Lexikoneinträge - zu aktivieren, und darum (um Wortfindungsstörungen) soll es hier jetzt gehen.

Es dürfte weithin unbekannt sein, daß die Abwahl und Weiterverarbeitung eines Lexikoneintrags im Rahmen alläglicher natürlicher Kommunikation (kurz: dessen Aktivierung) umfangreiche, komplexe und ziemlich heterogene mentale Repräsentationen verlang ${ }^{34}$ (Repräsentationen, denen neuronal hoch projektive 'funktionelle Korrelationen' entsprechen dürften). Anders formuliert verläuft die Aktivierung eines Lexikoneintrags - wie oben schon angedeutet - hoch selektiv ${ }^{35}$ vermutlich abhängig von einer Suchperspektive (sei diese nun explizit vorgegeben ${ }^{36}$ oder über den verbalen Kotext und/oder den situativen Zusammenhang impliziert); kontrolliert von einer Vielzahl von Selektionsrestriktionen unterschiedlichster $\mathrm{Art}^{37}$, kurz: abhängig von einer Vielzahl von Kontexteinflüßen.

Es steht nach allem durchaus zu erwarten, daß bei einer Alzheimerschen oder einer nicht-fokalen vaskulären Demenz nicht nur Schwierigkeiten der Gedächtnisbildung auftreten (das habe ich hier ausgeklammert), sondern auch bereits sehr früh Wortfindungsstörungen begegnen.

2.5.2 Unsere Überlegungen legen eine spezifische Folgerung nahe: Wenn in der Tat morphosyntaktische Komplexität erst sehr spät abgebaut wird, dann bedeutet das empirische Evidenz dafür, daß Morphosyntax wenig projektiv ist, daß der Mor-

33 In der Literatur wird gerne der Hippocampus (eine subkortikale Struktur) mit dem Einspeichern neuer Gedächtnisinhalte in Verbindung gebracht (ich kann auf Einzelheiten hier leider nicht näher eingehen). Post-mortem-Studien mit Alzheimer-Patienten scheinen zu bestätigen, daß diese Struktur in der Tat sehr früh in Mitleidenschaft gezogen ist.

34 Prinzipiell gesehen gilt das auch für Textsituationen; allerdings liegt hierin auch die Problematik von Tests und Testsituationen zur Lexikonabwahl begründet.

35 Wie sollte es auch sonst möglich sein, aus einem Wortschatz von bis zu 7.000/8.000 Einträgen mit der für einen native speaker bekannten Geschwindigkeit den richtigen Lexikoneintrag zu finden?

36 Vgl. Strube (1984).

37 Wir haben in einer Reihe von Untersuchungen unterschieden zwischen: a) morphosyntaktischen, b) lexikalisch-semantischen („lexikalische Solidaritäten“) und c) pragmatischen Selektionsrestriktionen. Zu Details: Urbach (1995) und Urbach et al. (1997). 
phosyntax relativ kleinräumige 'funktionelle Korrelationen' unterliegen, daß die Prozessierung von Morphosyntax - mit Blick auf Aphasien: in der Tat - relativ stark lokal begrenzt geschieht.

\section{Ausblick: Forschungsperspektiven}

3.1 Die folgenden Ausführungen skizzieren den Forschungsansatz, den wir am Neurolinguistischen Labor in Freiburg verfolgen. Grundlegend ist dabei, daß wir die Alzheimersche und eine nicht-fokale vaskuläre Demenz morphologisch als relativ diffusen Hirnabbau ${ }^{38}$ - und darauf aufbauend als 'Diskonnektionssyndrome' - verstehen: Der dementielle Abbau wäre danach eine Zerstörung 'funktioneller Korrelationen' (siehe dazu schon oben), wobei solche mit großer Projektivität früher betroffen sind als solche mit geringer Projektivität.- Nicht näher eingehen will ich auf die große neuronale Redundanz, die dazu führt, daß gegebenenfalls bereits sehr viel neuronales Netzwerk funktionsuntüchtig geworden bzw. zerstört sein kann, ohne daß sich das funktional schon bemerkbar macht.

Folgende zusammenfassende Thesen lassen sich formulieren:

These 1: Der Einsatz sprachlicher Ausdrucksmittel im Rahmen alltäglicher Kommunikation erfordert eine mentale Repräsentation des aktuellen Kontextes (der verbale Kontext immer eingeschlossen). Dabei dürften sich der Komplexitätsgrad solcher mentalen Repräsentationen und deren Heterogenität auf der einen Seite und der Grad der Projektivität der neuronal unterliegenden 'funktionellen Korrelationen' auf der anderen Seite in etwa entsprechen.

These 2: Sprachliche Ausdrucksmittel lassen sich mit Blick auf das Ausmaß bzw. die Komplexität und Heterogenität der bei ihrem Einsatz erforderlichen Kontextrepräsentation partiell in eine Reihenfolge bringen. Eine solche partielle Reihenfolge stellen beispielsweise (a) Aktiv und (b) Passiv (genauer: die Verarbeitung von Aktiv und Passiv) dar. Gleichartig müssen gereiht werden (a) parataktische Aneinanderreihung und (b) hypotaktische Strukturierung (und das gleich aus einer Vielzahl von Gründen). Hierher gehören aber auch (a) definite nominale Vollformen vs. (b) definite Pronomina ${ }^{39}$; oder (a) nebenordnende 'reihende' Konjunktionen wie „und“, „dann“ oder „und dann“ vs. (b) mehrteiligen Ausdrücken wie „zum einen - zum anderen“, "erstens - zweitens - ...", aber auch im Unterschied etwa zu bestimmten Tempuswechseln oder zu den sog. 'Renominalisierungen' eines 'Redegegenstan-des'.

These 3: Wenn die Thesen 1 und 2 zutreffen, dann müßte der jeweilige Grad eines dementiellen Abbaus ('funktioneller Korrelationen') an den Reduktionsstufen der sprachlichen Ausdrucksmittel und Ausdrucksverfahren ablesbar sein. Damit aber wäre uns in Ansätzen ein diagnostisches Instrumentarium an die Hand gegeben, das - anders als die bisher im Vordergrund stehende Analyse von Fehlleistungen - bereits frühe oder doch mittlere Stadien einer dementiellen Entwicklung zu erfassen (und zu therapieren) erlaubt.

${ }^{38}$ Es ist nicht möglich, an dieser Stelle auf eine Reihe von Besonderheiten einzugehen, wie sie speziell für Alzheimersche Demenzen belegt sind.

39 Zu Details: Schecker (1996); Vgl. auch Gress-Heister (i.d.Bd.). 
3.2 Ich möchte hier nochmals die Rede von der Reduktion der sprachlichen Ausdrucksmittel und Ausdrucksverfahren aufgreifen. Wir müssen unterstellen, daß Demenzpatienten (gerade auch durch die extrem langen Vorlaufzeiten) über ein erhebliches Maß an Coping-Strategien ${ }^{40}$ verfügen. Dies wird u.a. an Reduktionen der sprachlichen Ausdrucksmittel und Ausdrucksverfahren greifbar: Wenn Patienten merken (was immer das im Detail heißen mag - ganz sicher muß das nicht heißen, daß es innen bewußt wird), daß sie mit bestimmten Ausdrucksmitteln und Ausdrucksverfahren nicht mehr zurechtkommen (und das aus Gründen, die ich oben zu erläutern versucht habe), dann werden sie solche Ausdrucksmittel und Ausdrucksverfahren umgehen, lange bevor es dann zu Fehlleistungen im Sinne von sprachsystematischen Fehlern kommt.

Dies führt uns zu einer vierten These:

These 4: Die Vorstellung von der kompensatorischen Reduktion des Einsatzes sprachlicher Ausdrucksmittel birgt therapeutisch einen gewissen Sprengstoff: Wenn in der Tat Demenzpatienten bereits sehr früh gewisse Ausdrucksmittel und Ausdrucksverfahren - weil hinsichtlich ihrer Kontextrepräsentation zu komplex - vermeiden, dann tragen sie im Sinne der ganz zu Anfang angesprochenen negativen Plastizität zu ihrem kognitiven Abbau im allgemeinen und zu ihrem Sprachabbau im besonderen zunehmend selber bei. Sie treten in einen 'Teufelskreis der Adaptati$\mathrm{on}^{, 41}$ ein, der sowohl therapeutisch wie prognostisch fatal ist; vielleicht macht erst das die Forderung nach einem möglichst frühen therapeutischen Eingreifen so recht verständlich.

40 Vgl. auch Fischer, Gress-Heister \& Heister (1994).

41 Gress-Heister, Schecker, Kochendörfer \& Heister, E. (1996): Neue Aspekte der Sprach- und Kommunikationstherapie in der Geriatrie/Gerontologie. Poster-Präsentation. Symposion anläßlich der Verleihung des Preises für Hirnforschung in der Geriatrie, Zentrum für Alternsforschung Universität Witten-Herdecke 12.12.1996. Vgl. auch Fischer \& Gress-Heister (1995). 


\section{Literatur}

American Psychiatric Association (Task force) (1994). Diagnostic and statistical manual of mental disorders. Forth Edition (DSM-IV). Washington: APA, 5. Auflage, 1995.

Bartsch, R. (1978). Satzreihung, Satzgefüge oder Adverbialkonstruktion? In: Hartmann, R. u.a. (Hrsg.), Sprache in Gegenwart und Geschichte. Köln/Wien, 1-18.

Bates, E. et al. (1995). Production of complex syntax in normal aging and alzheimer's disease. In: Lang Cog Proc 10 (5), 487-539.

Bauer, J. (1994). Die Alzheimer Krankheit. Stuttgart: Schattauer.

Bauer, J., Hüll, M. \& Berger, M. (1995). Patogenetische Faktoren der Alzheimer Krankheit. In: Zeit Gerontol Geriatrie (28), 155-162.

Bauer, J., Stadtmüller, G., Qualmann, J. \& Bauer, H. (1995). Prämorbide Psychologische Prozesse bei Alzheimer Patienten und bei Patienten mit vaskulären Demenzen. In: Zeit Gerontol Geriatrie (28), 179-189.

Bayles, K. A. (1982). Language function in senile dementia. In: Brain \& Language 16 (2), 265-280.

Bayles, K. A. (1982a). The potential of language tasks for identifying senile dementia. In: J Speech Hearing Dis 47, 210-217.

Bayles, K. A. \& Kazniak, A. W. (1987). Communication and cognition in normal aging and dementia. Boston: Little, Brown \& Comp.

Chertkov et al. (1989). Priming and semantic memory loss in alzheimer dementia. In: Brain \& Language $36,420-446$.

Cooper, B. (1991). The epidemiology of primary degenerative dementia and related neurological disorders. In: European Archieves of psychiatry and neurological science 240, 223-233.

Cooper, B. \& Bickel, H. (1989). Prävalenz und Inzidenz von Demenzerkrankungen in der Altenbevölkerung. In: Nervenarzt 60, 472-482.

Cramon, D. Y. (Hrsg.) (1983). Neuropsychologische Diagnostik. Weinheim/Basel: VCH.

Cummings, J. L. et al. (1988). Alzheimer's disease and Parkinson's disease: comparison of speech and language alterations. In: Neurology 38 (5), 680-684.

Dick, K. et al. (1989). Memory for internally generated words in alzheimer-type dementia: breakdown in encoding and semantic memory. In: Brain \& Cognition 9 (1), 88-108.

Engelkamp, J. (1984). Sprachverstehen als Informationsverarbeitung. In: Engelkamp, J. (Hrsg.). Psychologische Aspekte des Verstehens. Berlin u.a., 31-53.

Ertel, S. (1977). Where do the subjects of sentences come from? In: Rosenberg, S. (Hrsg.). Sentence production. Developments in research and theory. Hillsdale/N.J.

Eustache, C. et al. (1990). Word association responses and severity of dementia in alzheimer's disease. In: Psychological reports 66, 1315-1322.

Faucher, E. (1987). Von den Toden, die da gestorben worden waren. In: Centre de Recherche en Linguistique Germanique (Nice) (Hrsg.). Das Passiv im Deutschen. Tübingen: Niemeyer, 117127.

Fischer et al. (1993). Frühdiagnose dementieller Erkrankungen im Alter. In: Meier-Ruge (Hrsg.). Die dementielle Erkrankung im Alter. Freiburg/Basel: Karger.

Fischer, B., Gress-Heister, M. \& Heister, E. (1994). Rehabilitation, Prävention und Gesundheitsfürsorge im Alter. Karlsruhe: Braun.

Fischer, B. \& Gress-Heister, M. (1995). Das ABCD-Modell bei Hirnleistungsstörungen: Ein integriertes Therapiekonzept. In: Pöldinger, W. (Hrsg.), Der Gerontopsychiatrische Patient in der Allgemeinpraxis. Karlsruhe: Braun.

Fromm, H. et al. (1991). A longitudinal study of word-reading ability in alzheimer's disease. In: Cortex 27, 367-376.

Füsgen, I. (1996). Der ältere Patient. München/Wien: U \& S.

Geschwind, N. (1965). Disconnexion syndromes in animals and men. Part I and II. In: Brain 188, 237294; 585-644.

Gress-Heister, M. (1996). Aspekte der kommunikativen Sprachverarbeitung und des Gesprächsverhaltens bei Menschen mit dementiellen Syndromen. Magisterarbeit. Universität Freiburg.

Hagenlocker, K. \& Shindler, A. G. (1985). Language disintegration in dementia: effects of etiology and severity. In: Brain \& Language 25, 117-133. 
Heinrich et al. (1994). Geriatrie. Ecomed.

Henderson, A. S. (1994). Dementia. Epidemiology of mental disorders and psychosocial problems. Geneva: World Health Association.

Hier et al. (1995). Language disintegration in dementia: effects of etiology and severity. In: Brain \& Language 25, 117-133.

Kempler, D. et al. (1988). Proverb and idiom comprehension in alzheimer's disease. In: Alz Diss Ass Diss 2 (1), 38-49.

Lang et al. (1991). Psychometric speech studies in alzheimer's dementia with the Aachen Aphasia test. In: Nervenarzt 62, 621-628

Nebes et al. (1986). Use of semantic context by patients with alzheimer dementia. In: Cortex 27, 237246.

Posner, R. (1972). Theorie des Kommentierens. Frankfurt a.M.: Athenäum.

Schecker, M. (1992). Nebensatzwortstellung im Deutschen. In: Gréciano, G. \& Kleiber, G. (Hrsg), Systemès interactifs. Paris: Klincksieck, 469-486.

Schecker, M. (1995). Grammatik und Kommunikation. Zur Leistung ausgewählter syntaktischer Ausdrucksmittel für das natürliche Sprachverstehen. In: Faucher, E. u.a. (Hrsg.), Signans und Signatum. Tübingen: Narr „Eurogermanistik“ 6, 481-496.

Schecker, M. (1996). Kontakt vs. Distanz: Systematik und Funktionsweise von Pronominalisierungen im Text. In: Pérennec, M. H. (Hrsg.), Proformen im Standarddeutschen. Tübingen: Stauffenburg, „Eurogermanistik“ 10, 161-177.

Schecker, M. \& Kindt, H. (Hrsg.) (1997). Sprache und Schizophrenie. Freiburg: HochschulVerlag "Cognitio 1“.

Schoenthal, G. (1987). Kontextsemantische Analysen zum Passivgebrauch im heutigen Deutsch. In: Centre de Recherche en Linguistique Germanique (Nice) (Hrsg.), Das Passiv im Deutschen. Tübingen: Niemeyer, 161-179.

Spitzer, M. (1993a). Assoziative Netzwerke, formale Denkstörungen und Schizophrenie. In: Der Nervenarzt 64, 147-159.

Spitzer, M. (1993b). The psychopathology, neuropsychology, and neurobiology of associative and working memory in schizophrenia. In: European Archives of Psychiatry and Clinical Neuroscience 243, 57-70.

Strube, G. (1984). Assoziation. Der Prozeß des Erinnerns und die Struktur des Gedächtnisses. Berlin u.a.: Springer.

Urbach, T. (1995). Selektionsrestriktionen und die Verarbeitung von Kontext bei Schizophrenie. Magisterarbeit. Universität Freiburg.

Urbach et al. (1997). Selektionsrestriktionen und die Verarbeitung verbaler Kontexte bei Schizophrenie. In: Schecker M. \& Kind, H. (Hrsg.) (1997), Sprache und Schizophrenie. Freiburg: Hochschulverlag.

Vaadia et al. (1995). Dynamics of neuronal interactions in monkey cortex in relation to behavioural events. In: Nature Vol. 373 (9. Febr.), 515-518.

Wallesch, C. W. \& Hundsalz, A. (1994). Language function in delirium: a comparison of single word processing in acute confusional states and probable alzheimer's disease. In: Brain \& Language $46,502-506$.

Weltgesundheitsorganisation (1991). Internationale Klassifikation psychischer Störungen. 10. Aufl. Bern u.a.: Huber.

World Health Report (1996). Internet Version. 


\title{
Abbau sprachverarbeitender Prozesse bei dementiellen Syndromen am Beispiel pronominaler Formen ${ }^{1}$
}

\author{
Markus Gress-Heister
}

\section{Einleitung}

\subsection{Pronominale Formen als Untersuchungsgegenstand bei dementiellen Syndromen}

Neuere Sprachverarbeitungsmodelle (z.B. Levelt 1989) postulieren in der Regel drei bzw. fünf Verarbeitungskomponenten. Levelt geht bei der Sprachproduktion davon aus, daß es neben der Sprachverarbeitung im direkten Sinn (gemeint ist die Formulierungskomponente: der „Formulator") hierarchisch vorgeschaltete konzeptuelle Prozesse und nachgeschaltete artikulatorische Prozesse gibt.

Betrachtet man die Produktion und das Verstehen pronominaler Formen vor diesem Hintergrund, so ist nach Levelt die Verwendung definiter Proformen und indefiniter und definiter Vollformen die Folge einer unterschiedlich differenzierten „Zugänglichkeit“ (,accessibility-status“).

\footnotetext{
„Each referent in the message will be provided with an index which states where it can be found for instance, in the current focus or elsewhere in the discourse model. This index will be taken into account in grammatical encoding, giving rise to cues in the utterance that guide the addressee's attention to where the referent is to be identified" (Levelt 1989, 144-149).
}

Levelt unterscheidet (nach dem Ausmaß der Zugangsmöglichkeit) 'tripolar' Referenzbereiche, die noch nicht in den aktuellen Diskurs eingeführt sind, gegenüber solchen Bereichen, die schon in die Diskurs- und/oder Textwelt eingeführt wurden oder in die Diskurswelt inferierbar sind; einen dritten Referenzbereich sieht er in den Äußerungen, die sich im Fokus der Aufmerksamkeit befinden (zu Details Schecker 1996). Diejenigen Bereiche, die sich im Fokus der Aufmerksamkeit befinden, bilden nach Schopp den „aktuellen Kontext“ einer Äußerung (Schopp 1994).

Wendet man dieses Modell auf die Proformen an, so sind diese ein Indikator für die Markierung der unterschiedlichen „Zugänglichkeiten“. Definite Pronomina zeigen für den Rezipienten an, daß ein entsprechender Referenzbereich sich aktuell im Fokus der Aufmerksamkeit befinden muß. Im Gegensatz dazu kennzeichnen definite Vollformen lediglich, daß der Referenzbereich bereits eingeführt wurde oder Teil des für den Rezipienten zugänglichen Weltwissens ist und entsprechend zu rekonstruieren ist. Indefinite Vollformen hingegen markieren (noch) nicht zugängliche Bereiche bzw. dienen dazu, neue Referenzbereiche in den Dialog bzw. Text einzuführen. ${ }^{2}$

\footnotetext{
1 Ich stütze mich in den folgenden Ausführungen ausführlich auf meine Magisterarbeit „Aspekte der kommunikativen Sprachverarbeitung und des Gesprächsverhaltens bei Menschen mit dementiellen Syndromen. Linguistische Untersuchung zum Zusammenhang von Demenz und Sprachverarbeitung" (Gress-Heister (1996), Erstgutachter: Michael Schecker), die vom Zentrum für Alternsforschung der Universität Witten/Herdecke den 'Preis für Hirnforschung in der Geriatrie 1996' zugesprochen bekam.

2 Auf die Problembereiche verweist Schecker (1996).
} 
Im Rahmen eines fortlaufenden Textes kennen wir auch die 'bipolare' Opposition 'definite Proform vs. definite Vollform' (in solchen Fällen spielen indefinite Vollformen keine Rolle). Bezieht man hier 'praktische Schlüsse' à la Grice mit ein, so signalisieren definite Vollformen in 'bipolarer' Opposition zu definiten Proformen, daß der Zugang zum 'gemeinten' Referenzbereich gestört bzw. problematisch ist. Und das kann dann auch Referenzbereiche des aktuellen Kontextes betreffen, - auch die Zugehörigkeit zum aktuellen Kontext bedeutet nicht notwendig direkte Zugänglichkeit; dies gilt vor allem für Mehrdeutigkeiten.

Es bleibt festzuhalten, daß die Verwendung definiter Proformen die Fokussierung der Aufmerksamkeit auf einen aktuellen Kontext voraussetzt. Der Sprecher muß dabei nicht nur seinen eigenen Kontext konstruieren oder konstruiert haben, sondern auch eine Repräsentation des Kontextes aus der Perspektive des Hörers antizipieren. Erschwerend kommt hinzu, daß solche (sehr aufwendigen) Repräsentationsleistungen offensichtlich in einem limitierten Zeitfenster stattfinden müssen; der Fokus der Aufmerksamkeit ist zeitlich stark limitiert (Gegenwartsdauer ${ }^{3}$ ); ein Referenzbereich kann entsprechend schnell wieder aus dem Aufmerksamkeitsfokus 'herausrutschen'. ${ }^{2}$

Fassen wir die wichtigsten Aspekte noch einmal zusammen, so ergibt das aus der Sicht eines Rezipienten die folgenden 'Zugänglichkeitsverhältnisse':

\section{Referenzobjekt und Zugänglichkeit}

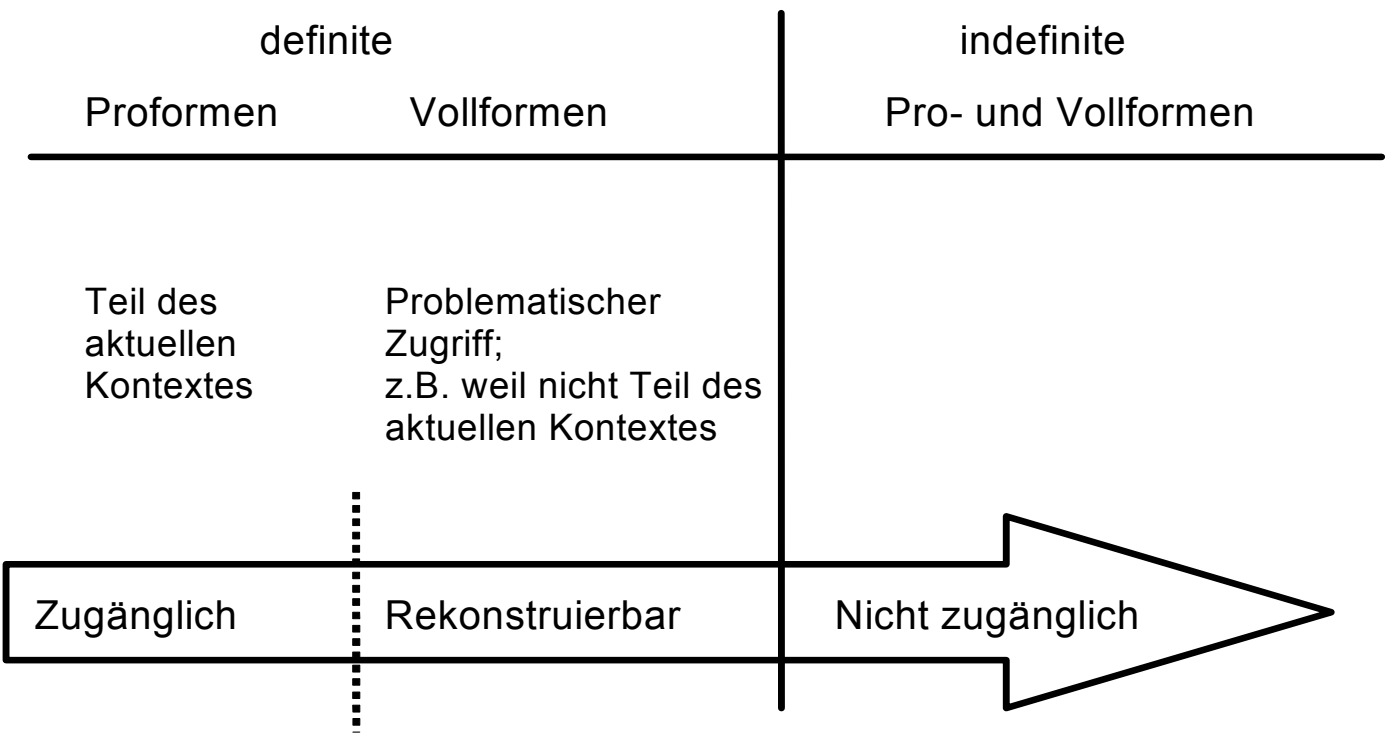

Abb. 1: Zugänglichkeitskalierung in Anlehnung an Schecker (1996)

3 Unter Gegenwartsdauer verstehen Fischer \& Lehrl diejenige Zeitspanne, die einem Menschen eine Information aktuell verfügbar ist. Die Gegenwartsdauer bei Menschen beträgt im Durchschnitt ca. 5-6 Sekunden. Überträgt man dieses Modell in den Bereich der Sprachrezeption und perzeption, so überblicken wir Sätze mit zwölf bis dreizehn Wörtern noch voll, wenn die Sprechgeschwindigkeit bei ca. 21/2 Wörtern pro Sekunde liegt. Für Details siehe: Lehrl \& Fischer (1992) und Lehrl \& Jarmark (1983).

4 Es sei denn, wir strukturieren mithilfe der Syntax geeignet: „[...] when information is structured, the span of attention can be larger [...]" (Levelt 1989, 119). 
In (rein) testpsychologisch orientierten Benennexperimenten wird der Diskurszusammenhang und (als dessen Teil) ein aktueller Kontext vom Versuchsleiter vorgegeben. Auch bei der Interpretation der Ergebnisse der pragmalinguistischen Studie Romeros ist dies noch der Fall; auch die Interpretationen Romeros (Romero 1995) erfolgen sozusagen 'freischwebend', ohne einzubeziehen, ob und auf welche Weise die Repräsentation eines aktuellen Kontextes und/oder die Konstruktion/Rekonstruktion des Diskurszusammenhangs die Sprachverarbeitung Dementer beeinflussen. Das heißt, das sehr grundlegende Vermögen, die Aufmerksamkeit auf bestimmte Referenzbereiche zu fokussieren bzw. diese als einen aktuellen Kontext zu repräsentieren, und auch die Fähigkeit, Diskurszusammenhänge zu konstruieren bzw. zu rekonstruieren und den Partner zu antizipieren, bleibt u.E. völlig unberücksichtigt ${ }^{5}$.

\subsection{Analysierte Proformen}

Bevor die Untersuchungsergebnisse präsentiert werden, seien noch einige Bemerkungen zu den untersuchten Proformen angeführt. Wir haben in Anlehnung an Schopp $(1994,37)$ im Bereich der definiten Pronomina zusätzlich unterschieden u.a. zwischen deiktischen Proformen wie „ich“/,du” und 'stellvertretenden' Proformen wie "er"/,sie“/,es". Zusammengefaßt ergibt sich das folgende Schaubild:

\section{Definite Proformen}

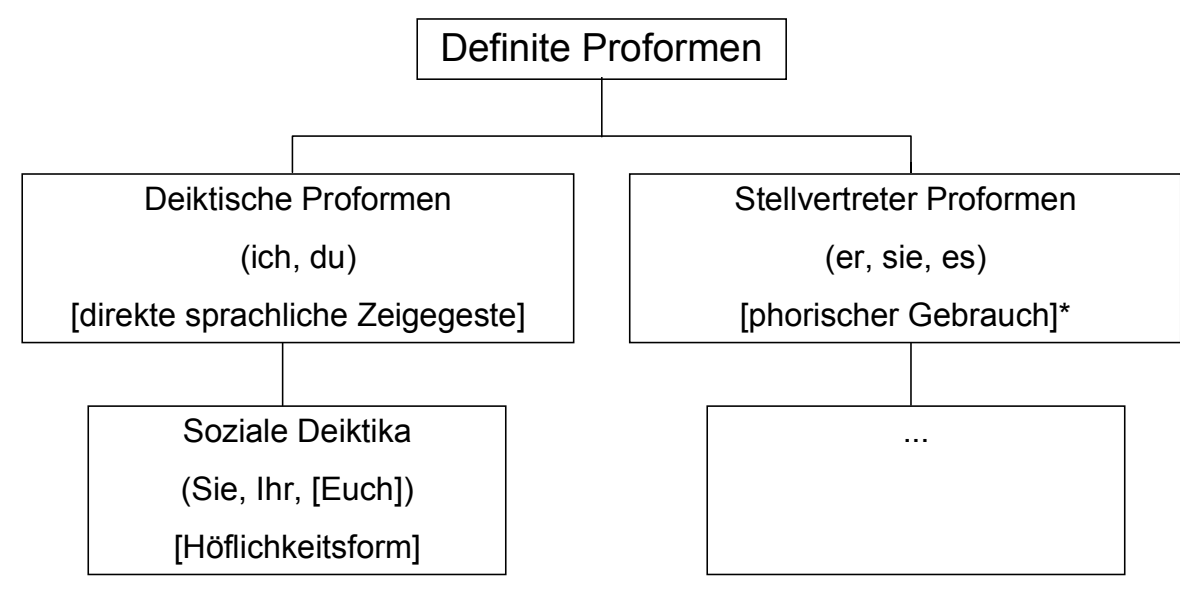

$\left.{ }^{*}\right)$ Verweise - anaphorischer oder kataphorischer Art - im Text

Abb. 2: Einteilung der Proformen (modifiziert nach Schopp 1994, 37)

5 Die Wahl der Stimuli bietet hier ein weiteres Problem. Die häufig extremen Vereinfachungen der Schwarz-Weiß-Zeichnungen verlangen nach relativ wenig Kontext, auf der anderen Seite aber auch hohe Abstraktionsleistungen. Darüber hinaus ist die Wahl möglichst einfacher und prototypikalischer Stimuli (wie sie z.B. Hundsalz (1994) in ihrer Arbeit gewählt hat) gerade im Hinblick auf die lexikalische Abwahl problematisch. Auch die Reihenfolge der Stimuli kann im Sinne einer impliziten oder expliziten Suchperspektive einen Einfluß auf eine lexikalische Abwahl haben (denkbar wäre auch ein Priming!). 


\section{Methode, Material und Auswertung}

\subsection{Kohortierung}

Es wurde die Sprache von 5 Patienten (Alter von 50 bis 79 Jahren) mit unterschiedlichen Demenzformen und eine gleiche Anzahl von Kontrollpersonen (gleiches Alter, gleiches Geschlecht) post-hoc analysiert. Die Untersuchung hatte den Charakter einer Pilotstudie; die statistische Validität ist trotz der kleinen Gruppengröße durch den Umstand gewährleistet, daß sie sich nicht auf die Anzahl der Patienten, sondern auf ein Gesamt-Korpus gesprochener Sprache bezieht.

Als Einschlußkriterien galt ein mildes bzw. moderates dementielles Syndrom (klassifiziert nach DSM-III-R bzW. ICD $10^{6}$ ). Der Informed Consent ${ }^{7}$ der Betroffenen bzw. deren Stellvertretern war gegeben. Ausschlußkriterium waren ein schweres dementielles Syndrom bzw. erhebliche Einschränkungen der kommunikativen Fähigkeiten (z.B. nicht prothetisch versorgte Hördefizite) und fehlender Informed Consent.

\subsection{Durchführung}

Analysiert werden transkribierte Anamnesegespräche im Rahmen eines geriatrischgerontologischen Rehabilitationsverfahrens. $^{8}$

Es handelt sich bei allen Gesprächen um Aufnahmegespräche zwischen Arzt und Patient, die zur diagnostischen und therapeutischen Einordnung dienen. Die Interviews sind mit einer Videokamera zu Forschungs- und Supervisionszwecken mitgeschnitten worden. Zum Zwecke der Transkription wurden sie auf Tonbandcassetten übertragen und wurden nach dem modifizierten HIAT-System transkribiert.

Interviewer und Analysierender waren nicht identisch ${ }^{9}$. Die Interviewstrategie war durch den Therapeuten in Form eines semistrukturierten Interviews vorgegeben. Dies erlaubt den interindividuellen Vergleich.

Die gesunden Kontrollpersonen (im weiteren kurz als Kontrollen bezeichnet) wurden auf identische Weise interviewt und die Interviews identisch ausgewertet.

Die vorgegebene Struktur der Interviews enthielt immer folgende Aspekte:

- Begrüßung (Name des Patienten, Name des Therapeuten)

- Orientierungsfragen (zur Person, räumlich, zeitlich)

- Vorgeschichte

- Familie

- Neuropsychologische Aufgaben (Zeichnen eines rechten Winkels, eines Kreises; Schreiben einer Ziffer [z.B. 1014]; Merken von Ziffern, Buchstaben; Addieren, Subtrahieren, Multiplizieren, Dividieren)

6 Diagnostical and statistical manual of mental disorders - revised version III - DSM-IIIR; International Classification of Diseases - ICD 10.

7 Einwilligung nach Aufklärung.

8 Ich bedanke mich bei Prof. Dr. med. B. Fischer, Rehabilitationsklinik Klausenbach, für die Bereitstellung der Interviews.

9 Dies schließt die sog. „Untersucher-Bias“ bzw. einen Halo-Effekt oder einen Projektionsfehler aus. Auch Primacy- oder Recency-Effekte lassen sich durch die Distanz von Therapeut und Analysand eliminieren. 
- Als spezielle neuropsychologische Aufgaben: Interpretieren eines Sprichwortes; Nacherzählen einer aktuellen Geschichte

- Verabschiedung

Untersuchungen von Spontansprache, und als solche kann man die Antworten in semistandardisierten Interviews verstehen, spielen eine wichtige Rolle in der neurolinguistischen Grundlagenforschung ${ }^{10}$. Gerade dem erfahrenen Arzt/Therapeuten gibt die Beurteilung der Spontansprache Dementer einen nicht unerheblichen Hinweis auf Störungsmuster und Schweregrad. ${ }^{11}$ Das Gespräch offenbart häufig die ganze Breite sprachpathologischer Probleme. Die unreduzierte Vielgestaltigkeit möglicher Untersuchungsvariablen stellt allerdings ein großes Problem für die Auswertung dar. ${ }^{12}$

Wir berücksichtigen in diesem Fall keine inhaltlichen Analysekriterien ${ }^{13}$, sondern beschränken uns auf die Proformen (zu weiteren Analysen und Detailauswertungen, vgl. Gress-Heister 1996).

\section{Ergebnisse}

\subsection{Häufigkeit von Proformen bei Demenzpatienten}

Vergleicht man den Anteil der verwendeten Proformen, so fällt auf, daß die Demenzpatienten eine signifikant geringe Anzahl an Proformen (bezogen auf die Gesamtwortzahl) verwenden $(p=0.038) .22 \%$ der Worte bei gesunden Kontrollen sind Proformen, bei den Demenzpatienten schwankt dieser Anteil zwischen einem Maximum von $18 \%$ und einem Minimum von $3 \%$.

In diesem Zusammenhang hat uns das Verhältnis von verwendeten Proformen bei den einzelnen Patienten und der Kontrollgruppe interessiert. Zu diesem Zweck wurde die Kontrollgruppe als Referenz gleich 100\% gesetzt und die Anteile der Verwendung von Proformen bei den Patienten dagegengesetzt:

10 Sie müssen allerdings immer durch standardisierbare Testverfahren ergänzt bzw. unterstützbar sein, da sonst die Interpretationen der Ergebnisse sozusagen „frei schwebend” (im Sinne der Sozialwissenschaften als sog. 'weiche' Daten) erfolgen.

11 Nach Anschütz (1978) stellen ca. 75\% aller Ärzte ihre Diagnose nach dem Erstgespräch. Nach den technischen Untersuchungsverfahren ändern lediglich ca. 10\% aller Ärzte ihre Diagnosen.

12 Vgl. dazu auch Wagenaar et al. (1975).

13 Inhaltliche Kriterienkataloge zur Analyse von Spontansprache sind z.B. zu finden in: Goodglas \& Kaplan (1972); Huber et al. (1983); Romero et al. (1995). Eine kritische Analyse in Blanken (1986). 


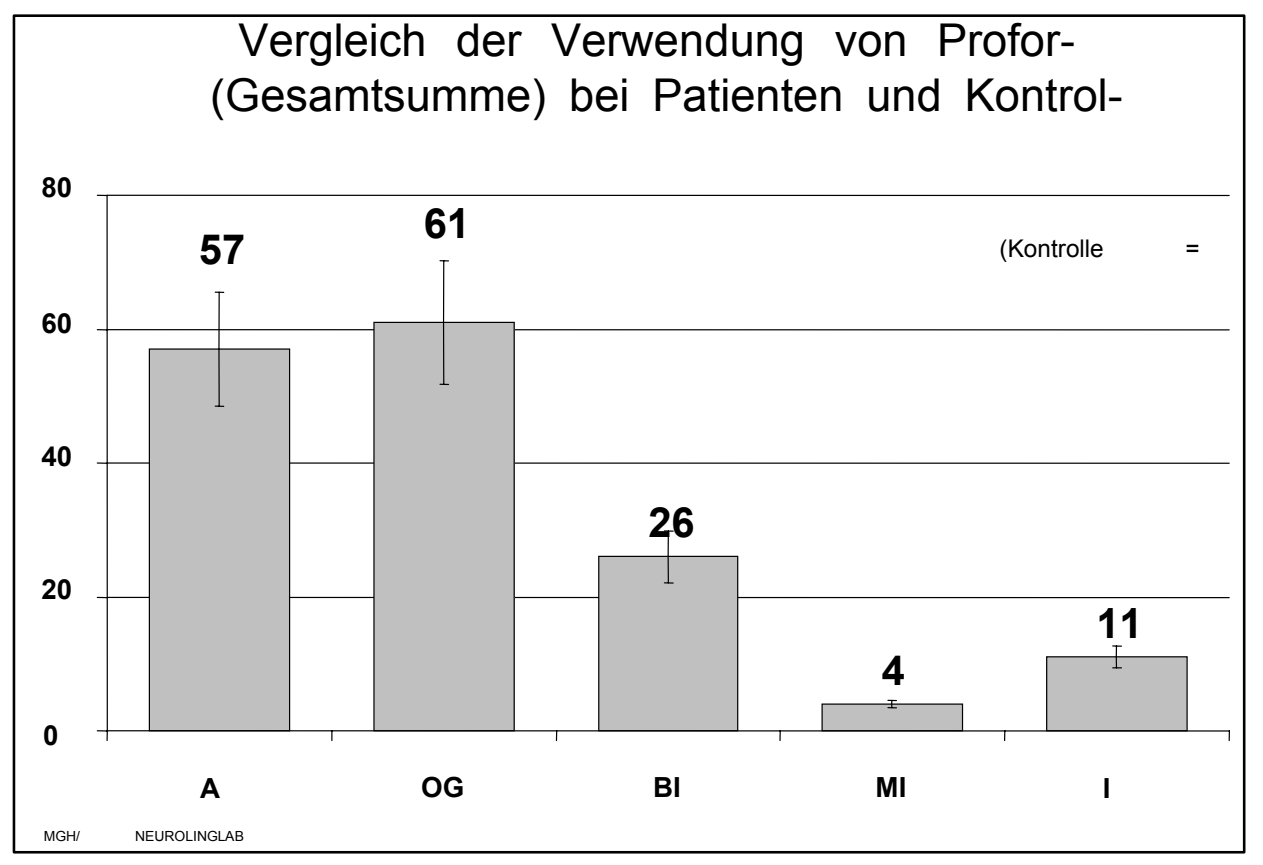

Abb. 3: Verwendung von Proformen der Patienten im Vergleich ${ }^{14}$

Es zeigte sich, daß die Demenzpatienten signifikant weniger Proformen verwenden, als die Kontrollgruppe $(p=0,008)$. Es fällt auf, daß sich die Patienten in zwei Gruppen teilen, die sich deutlich zu unterscheiden scheinen (wir kommen darauf noch später zurück). Die Patienten AZ und OG verwenden immerhin noch 57 bzw. $61 \%$ Proformen, die Patienten BI 26\%, MI nur 4\% und IA 11\% (immer bezogen auf die gesunden Kontrollen).

\subsection{Verwendung verschiedener Typen von Proformen - Auftretensdefizite bei Proformen}

Von Interesse war zunächst die Verteilung der Auftretenshäufigkeiten von definiten und indefiniten Proformen.

14 Die Patienten wurden zu Gruppen zusammengefaßt.

Legende:

$A Z=$ Demenz - wahrscheinlich vom Alzheimer'schen Typ

OG = Demenz ohne Genese (Verdacht auf Alzheimer Demenz)

$\mathrm{BI}$ = subcortikale Demenz (Binswanger) (vaskulär)

$\mathrm{MI}=$ Multi-Infarkt-Demenz (vaskulär)

$\mathrm{IA}=$ Multiple ischämische Attacken (vaskulär) 


\section{Anteil der definiten und indefiniten Proformen}

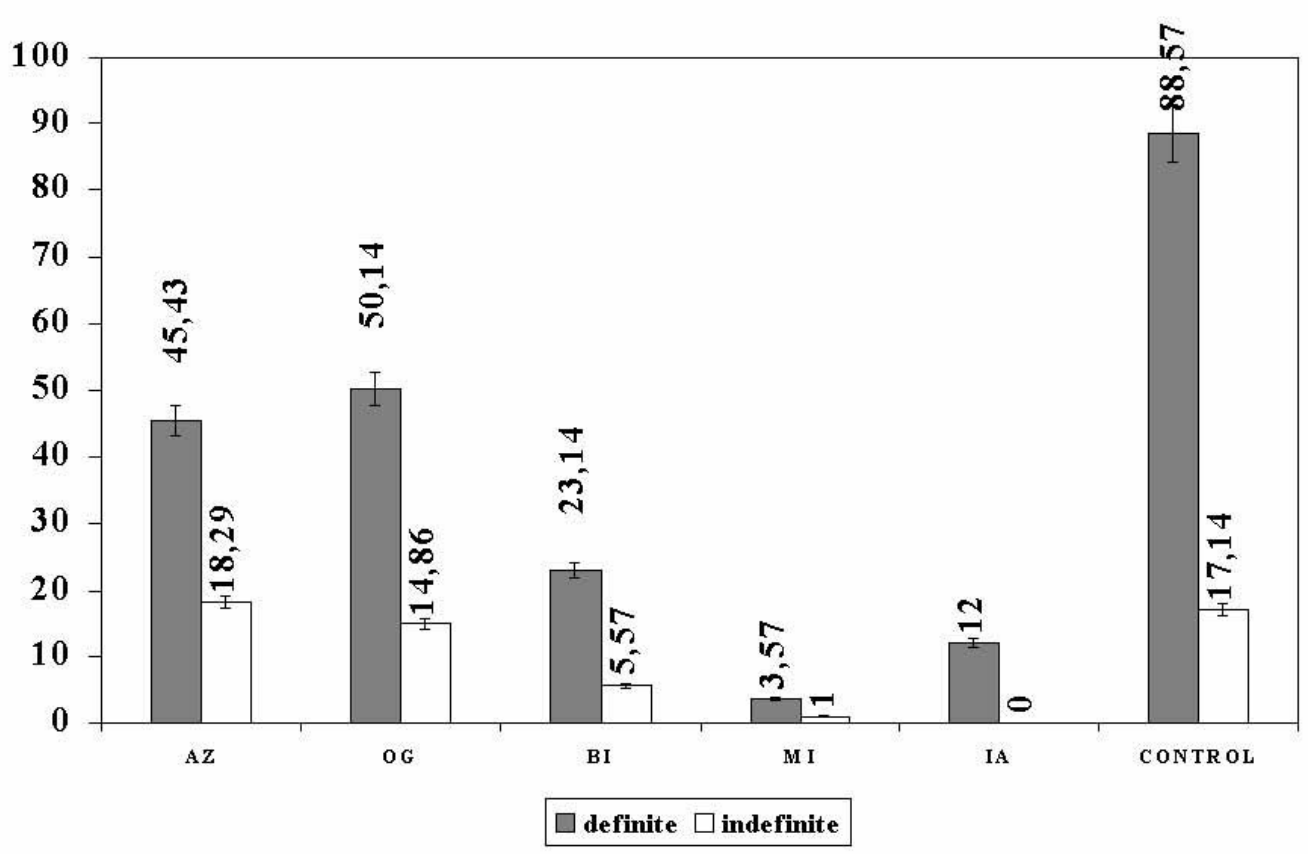

Abb. 4: Verwendung von definiten vs. indefiniten Proformen

Es wird deutlich, daß die definiten Formen den Hauptanteil der verwendeten Proformen ausmachen. So liegt der Anteil der definiten Formen bei den gesunden Kontrollen bei $88 \%$. Die Demenzpatienten verwenden signifikant weniger definite Formen als die Kontrollgruppe. Auch hier läßt sich eine Teilung in zwei Gruppen belegen, in der sich möglicherweise entweder die Demenzgenese oder der Schweregrad widerspiegeln könnte.

Die Verwendung indefiniter Formen muß vor dem Hintergrund der Gruppenanalyse differenziert betrachtet werden. $A Z$ und $O G$ haben einen deutlich geringeren Verlust indefiniter Formen, als die übrigen Patienten.

Setzt man die Werte der gesunden Kontrollpersonen auf 100, so wird deutlich, daß der Hauptabbau ganz ohne Zweifel die definiten Proformen betrifft. Abbildung 5 macht auch deutlich, daß AZ und OG eigentlich nur im Bereich der definiten Proformen einen nennenswerten Abbau zu verzeichnen haben. 


\section{Vergleich im Abbaugrad bei definiten und indefiniten Proformen}

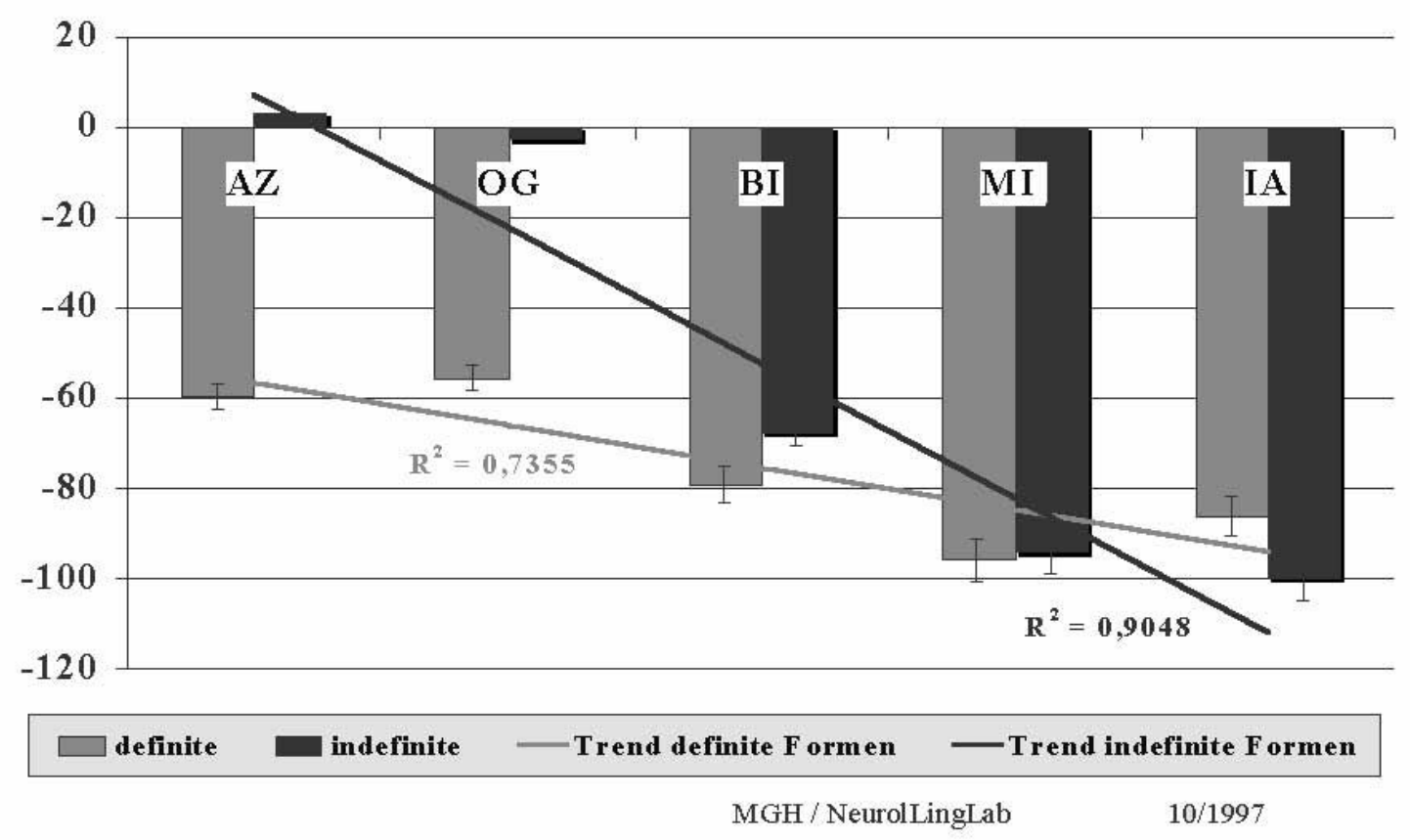

Abb. 5: Vergleich im Abbaugrad definite vs. indefinite Proformen

Fragt man nach einem Zusammenhang zwischen der Verwendung von definiten und indefiniten Proformen, analysiert man also die Korrelation zwischen definiten und indefiniten Formen, so ergibt sich für die Patienten eine hohe positive Korrelation, jedoch ohne Signifikanz (KE =0,6228; $p=0,187$ ).

Ich kann an dieser Stelle nicht auf Einzelheiten eingehen, will aber dennoch auf einige für sich selber sprechende Aspekte verweisen. Anders als vielleicht auf den ersten Blick erwartbar impliziert der Gebrauch einer definiten Proform wie 'er' die mentale Repräsentation eines ziemlich komplexen, reichhaltigen aktuellen Anwendungskontextes, - alles was gewissermaßen 'nicht gesagt wird' (wer ist dieser 'er'), muß im Kontext eindeutig enthalten sein. Genauer unterstellt der Sprecher (üblicherweise), wenn er eine solche definite Proform gebraucht, daß der Hörer weiß, von welchem 'Redegegenstand' er spricht, daß der Hörer den betreffenden Redegegenstand mental 'repräsent' hat.

Zur differenzierenden Betrachtung dieses Problems haben wir die Verluste in der Verwendung der einzelnen Proformen getrennt untersucht (die Anzahl der verwendeten jeweiligen Proformen der gesunden Kontrollenpersonen wurde hierbei zur Vereinfachung wieder auf $100 \%$ gesetzt.).

Betrachtet man die Proformen, die eine direkte sprachliche Zeigegeste symbolisieren, bzw. voraussetzen (deiktische und als Spezialfall sozial-deiktische Proformen), so findet man bei BI, MI und IA einen drastischen Verlust beider Formenklassen. 


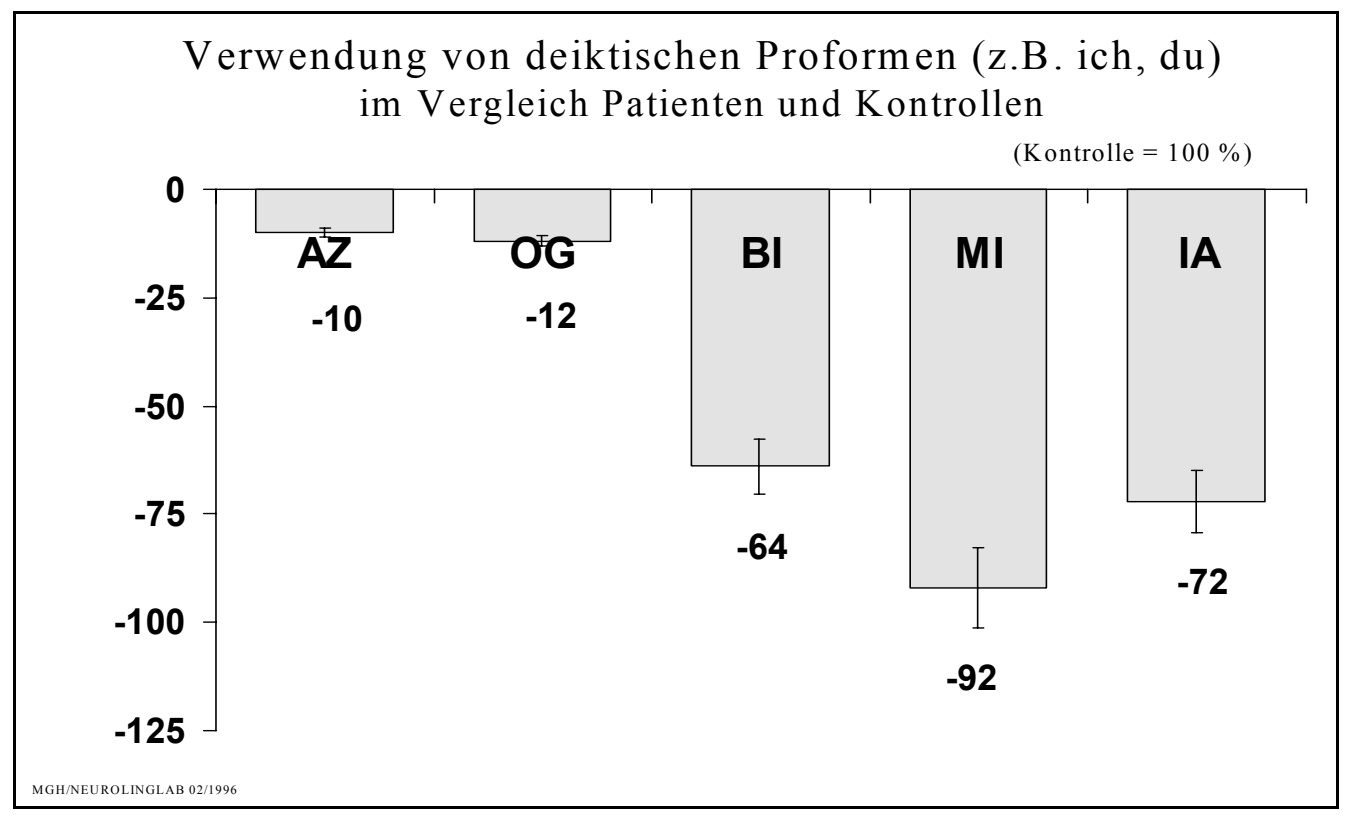

Abb. 6: Abbau deiktischer Proformen

MI verwendet lediglich noch $8 \%$ der vergleichbaren Proformen in der Kontrollgruppe. Dem gegenüber steht der geringe Verlust der Patienten $A Z$ und $O G$, die beide noch $90 \%$ der deiktischen Proformen verwenden, faktisch also einen für einen „Normalsprecher" kaum bemerkbaren Verlust aufweisen.

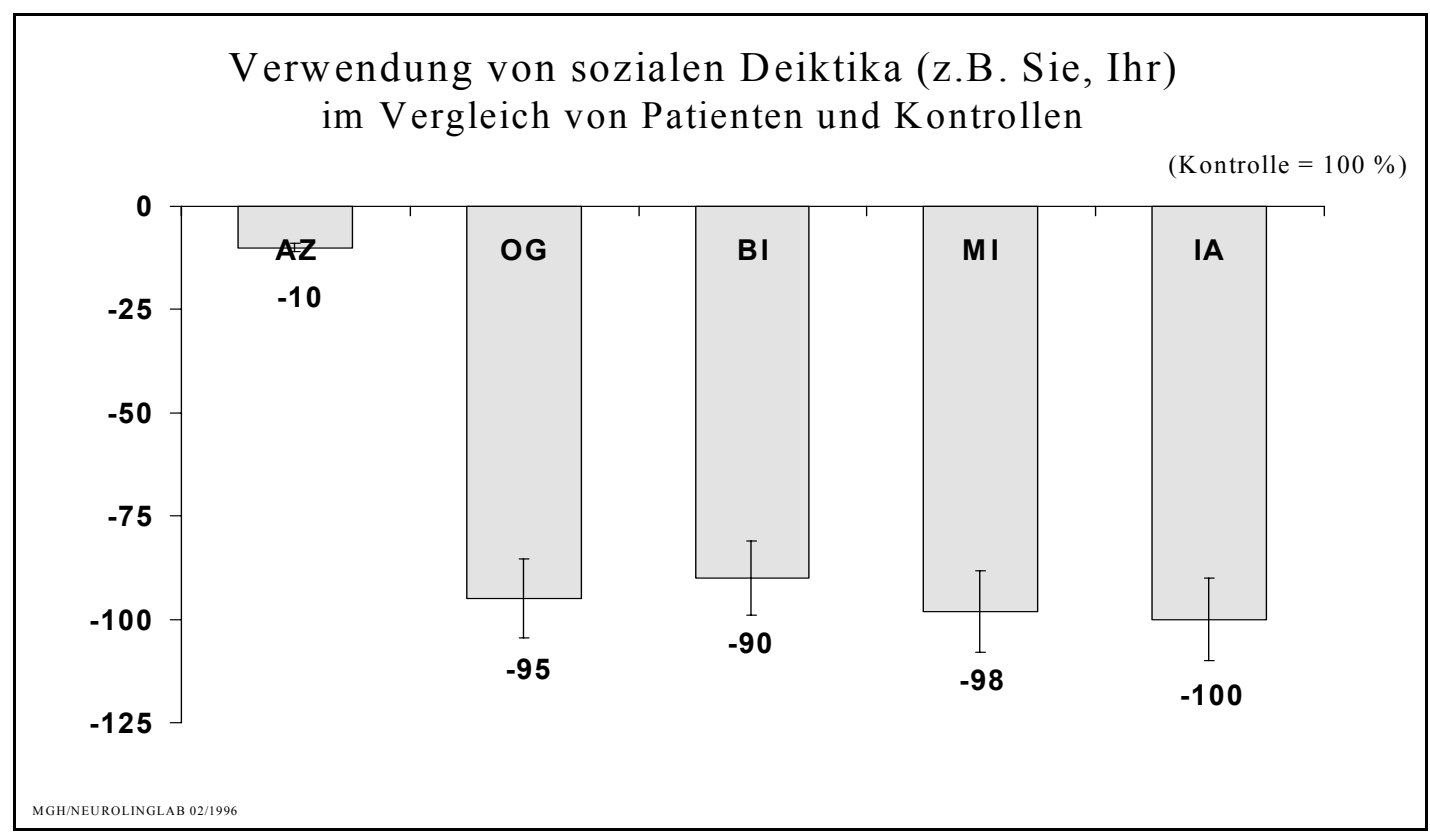

Abb. 7: Verwendung sozialer Deiktika

Auffällig ist der drastische Verlust sozialer Deiktika (der Höflichkeitsformen) bei z.B. OG $(-95 \%)$. 
In den Arztbriefen werden Patienten wie IA oder BI durch eine Art „emotionale Distanzlosigkeit" (Zitat Arztbrief) charakterisiert, durch die die Patienten besonders auffallen. Dieser Eindruck könnte auch auf den geringen Gebrauch von sozial geprägten Höflichkeitsformen zurückzuführen sein.

Ein weiterer wichtiger Aspekt ist, daß durch soziale Konventionen geprägte Formen ${ }^{15}$ - und Höflichkeitsformen sind ein Paradebeispiel - eine zusätzliche Komplexität des aktuellen Kontextes bedeuten: Hier müssen zusätzliche Informationen nämlich Wissen über konventionalisierte Rollen und ihre sprachliche Repräsentation - in den aktuellen Fokus einbezogen werden.

Ein situationsgebundener Gebrauch von Deiktika wird kognitiv fortlaufend sensorisch unterstützt: Ich nehme meine Kommunikationspartner fortlaufend wahr, kann einen aktuellen Kontext über sensorischen input also fortlaufend 'kontrollieren' und eventuell korrigieren. Ganz anders bei den 'stellvertretenden' Pronomina: Hier muß der aktuelle Kontext ausschließlich mental aktuell gehalten werden, kann also nicht fortlaufend über sensorischen Input 'aktualisiert' werden.

$A Z$ verwendet $40 \%$ weniger stellvertretende Proformen als die gesunden Kontrollen. In einer vergleichbaren Größenordnung bewegt sich auch OG mit 30\% Verlust. Signifikant höher sind die Verlustraten bei BI, MI und IA $(-80 \%,-90 \%$ und $-100 \%)$. Auch hier deutet sich eine Gruppierung an.

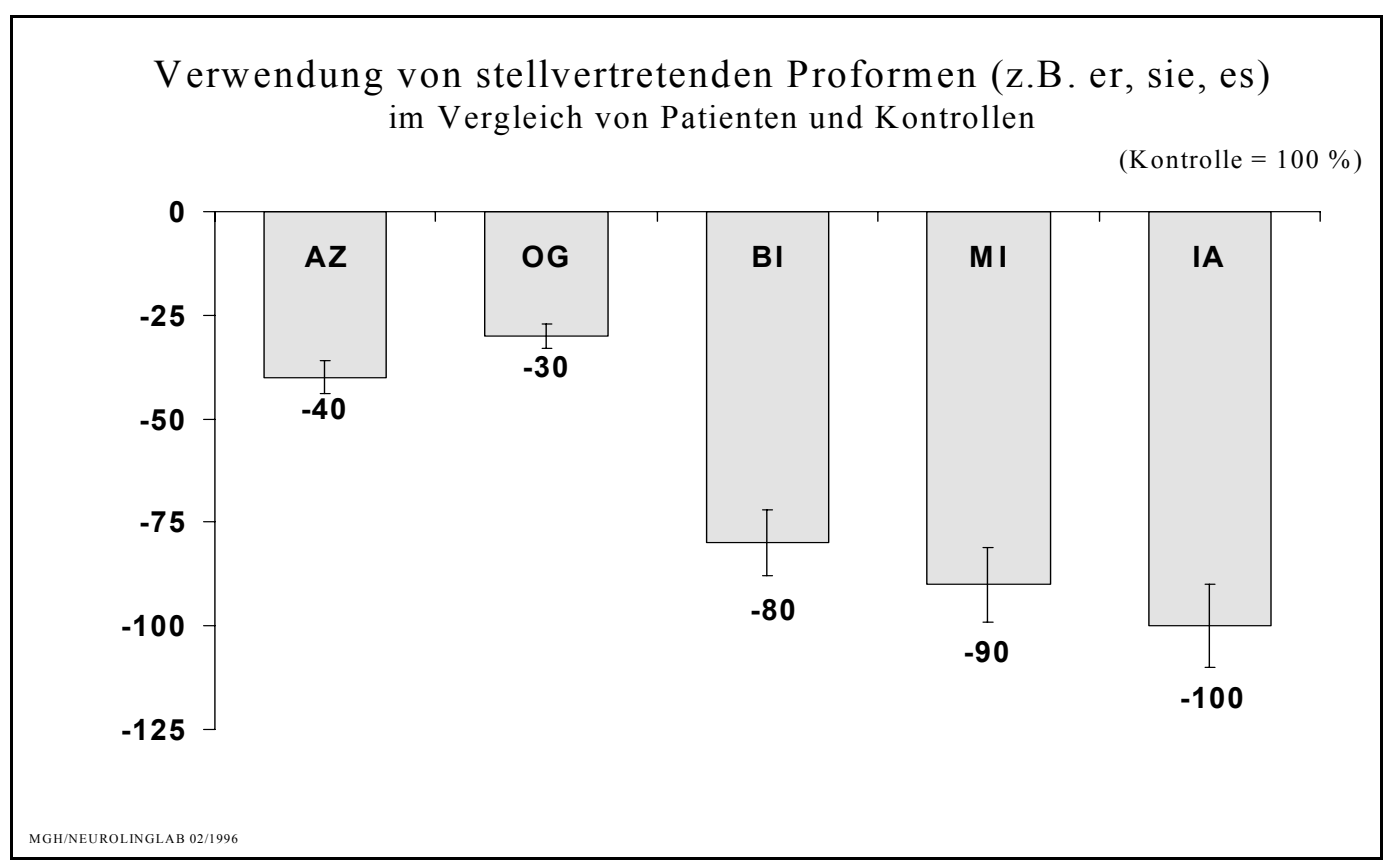

Abb. 8: Verwendung von stellvertretenden Proformen

15 Gemeint ist in diesem Falle der sozial adäquate Gebrauch der Höflichkeitsformel 'Sie'; die soziale Konvention in einem offiziellen Gespräch - und um ein solches handelte es sich ja bei der Anamnese - das höfliche 'Sie' zu verwenden ist zumindest in der untersuchten Altersgruppe evident. Lassen die Betroffenen diese Formen verbaler Höflichkeit weg und/oder ersetzen diese durch in diesem Kontext inadäquate Formen (wie z.B. das 'du') ist es nur konsequent zu vermuten, daß die Patienten die Situation nicht mehr korrekt einschätzen können (gegen diese Annahme spricht aber das sonst eher offiziellen Gesprächssituationen angepaßte sprachliche Register). 
Will man die oben genannten Ergebnisse interpretieren, so ist zu einem vollständigen Überblick noch die Detailanalyse der Verwendung von definiten Vollformen bei der Patientengruppe wichtig.

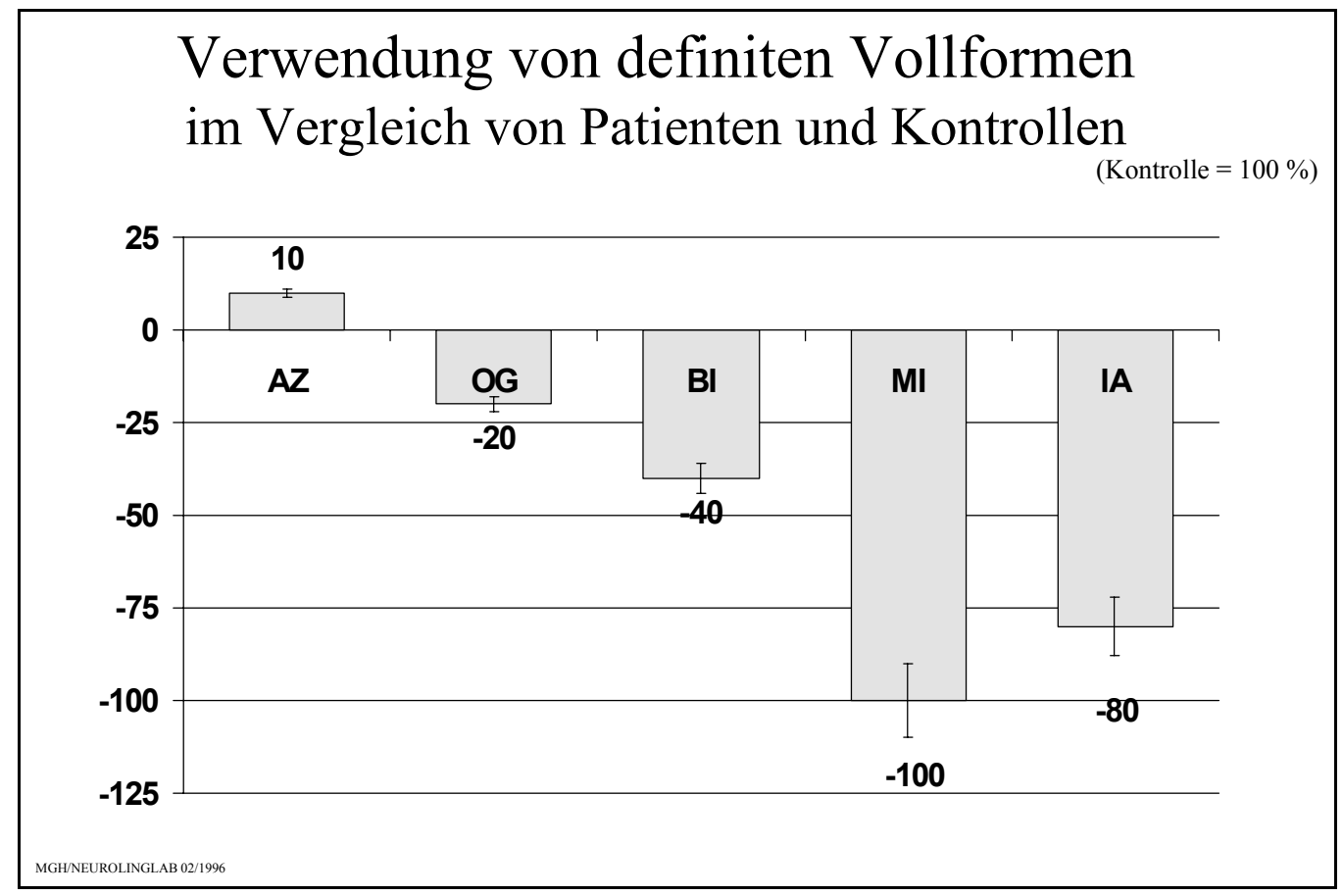

Abb. 9: Verwendung von definiten Vollformen

Hier gibt es ein auffallendes Ergebnis. AZ gebraucht mehr definite Vollformen als die Kontrollgruppe $(+10 \%[p=0,0035])$. Er unterscheidet sich damit deutlich auch von der übrigen Patientengruppe, bei der alle einen drastischen Verlust ihrer Verwendungsmöglichkeit definiter Vollformen zeigen. Interessant ist in diesem Zusammenhang ein klinisches Beispiel:

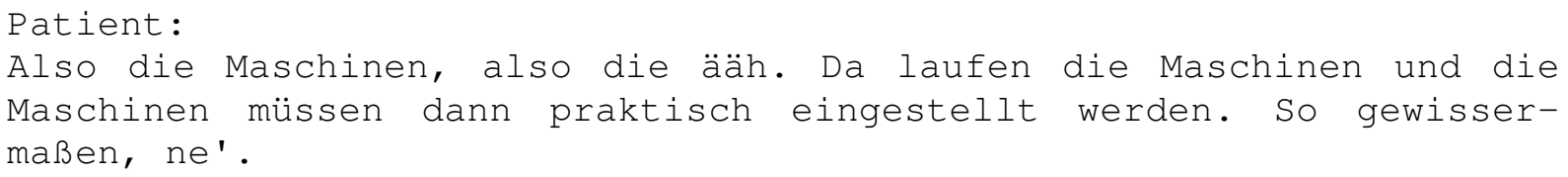

Es wird deutlich, daß hier definite Vollformen eingesetzt werden, wo in üblichen kommunikativen Kontexten von gesunden Sprechern definite Proformen verwendet würden. ${ }^{16}$

16 Ich habe bereits mehrfach darauf verwiesen, daß die Verwendung von Vollform bzw. Proform kein Ausdruck einer bestimmten 'Stilistik' ist, sondern durch kommunikative Rahmenbedingungen zwingend bestimmt wird. Zu Details siehe Schecker (1996). Ein Sprecher kann nur auf Kosten der beim Hörer erzeugten kommunikativen Wirkung von diesen 'kommunikativen Präferenzen' abweichen, z.B. zur Betonung einer wichtigen Tatsache. 


\subsection{Analyse auf Gruppenzugehörigkeit}

Wie bereits oben erwähnt, fällt die Zweiteilung der Patienten-Gruppen auf. Es hat sich uns von Anfang an die Frage gestellt, ob die Ausprägung bzw. der Grad einer Sprach- und Sprechstörung bei dementiellen Syndromen von deren Genese (Ätiologie) abhängig ist.

Zu Beginn haben wir darauf verzichtet, die Demenzgenesen gegeneinander abzugrenzen. ${ }^{17}$ Nach den vorliegenden Ergebnissen bot es sich an, Proformen als ein solches mögliches Unterscheidungsmerkmal anzusehen. Um diese Fragestellung zu klären, haben wir eine Clusteranalyse ${ }^{18}$ durchgeführt.

\begin{tabular}{|c|c|}
\hline Cluster 1 & Cluster 2 \\
\hline AZ & BI \\
OG & MI \\
& IA \\
\hline
\end{tabular}

Tabelle: Gruppenzugehörigkeit nach Proformenverwendung

In der Gruppe 2 finden sich ausschließlich Demenzen vaskulärer Genese, während die Gruppe 1 einen Patienten mit dem Verdacht auf Demenz vom Alzheimer Typ und einen mit einer Demenz unbekannter Genese (möglicherweise auch eine Demenz vom Alzheimer Typ) enthält $(p=0,035)$.

Danach liegt die Vermutung nahe, daß die Demenzgenese doch eine wichtige Rolle für die Ausprägung und den Charakter einer Sprach- und Sprechstörung bei dementiellen Syndromen spielen könnte. Insbesondere fält in der Gruppe 1 der insgesamt eher selektive Abbau auf, wie er besonders im Vergleich definiter vs. indefiniter Proformen und definiter Proformen vs. definiter Vollformen ins Auge springt.

\subsection{Abhängigkeit vom Schweregrad der Erkrankung}

Zur Klärung der Frage, ob es einen Zusammenhang der beobachteten Sprachstörungen mit dem Schweregrad der Demenz gibt, wurde eine Korrelationsanalyse der einzelnen Proformen über eine Skala der Demenzbeurteilung (MiniMentalState nach Folstein ${ }^{19}$ ) durchgeführt. Hierbei ergab sich zwar eine hohe Korrelation zwischen der

17 Interessant ist in diesem Zusammenhang, daß die neue Klassifikation DSM-IV die „aphasia (language disturbance)" als ein Achsensymptom aller Demenzformen angibt. DSM-IV (1994, 133155).

18 Die Mitglieder einer Gruppe (Cluster) weisen bei dieser Methode möglichst ähnliche Variablenausprägungen auf, die Mitglieder unterschiedlicher Gruppen möglichst unähnliche.

19 Diese Skala erlaubt eine erste Einordnung des Demenzschweregrades. Es werden getestet: 1. Orientierung, 2. Aufnahmefähigkeit, 3. Aufmerksamkeit und Rechnen, 4. Gedächtnis, 5. Sprache, 6. Ausführen eines dreiteiligen Befehls, 7. Lesen, 8. Schreiben, 9. Konstruktive Praxis. Ausgewer- 
Verwendung von definiten Vollformen und dem MiniMentalState, jedoch keinerlei Signifikanz (KE = 0,7260; $p=0,102$ ). Die Vermutung liegt nahe, daß die Menge der zur Verfügung stehenden Interviews für eine solche Korrelation zu gering war. Eine zweite Möglichkeit zur Erklärung dieser Tatsache ist, daß der MiniMentalState in unserem Bereich (Scores zwischen 20 und 24 Punkten [von 30 erreichbaren Punkten]) nicht empfindlich genug ist. ${ }^{20}$ Andere Rating-Instrumente zum Schweregrad einer Demenz, wie das SIDAM ${ }^{21}$, könnten hier deutlichere Korrelationen bringen.

\subsection{Reihenfolge im Abbau bei den Proformen}

Betrachten wir unabhängig möglicher Gruppenzugehörigkeiten den Abbau definiter Proformen ganz generell, so bietet sich für die einzelnen Proformen das folgende Bild:

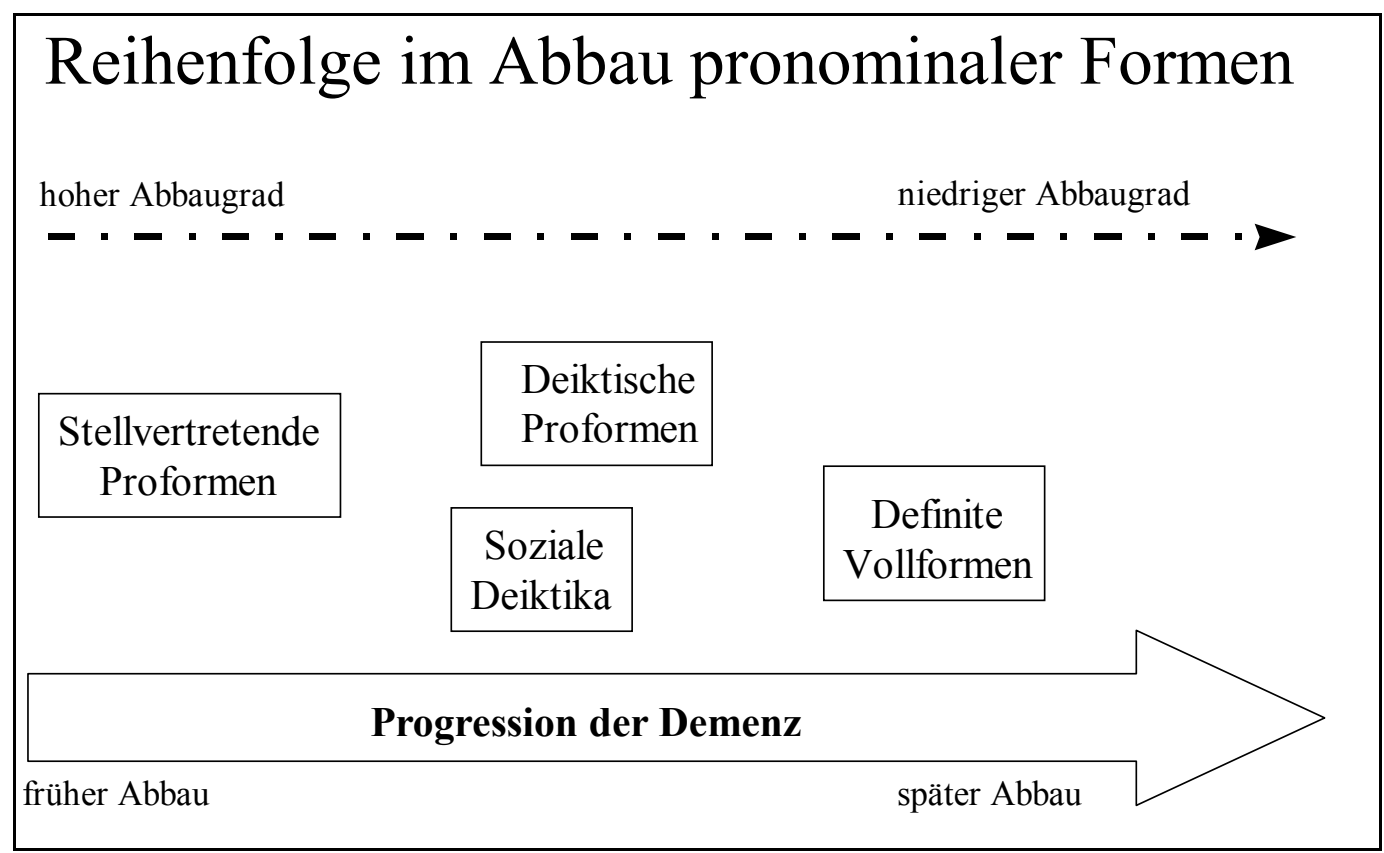

Abb. 10: Mögliche Reihenfolge im Abbau pronominaler Formen

Die definiten Vollformen sind am wenigsten abgebaut. Die deiktischen Formen sind bereits drastisch abgebaut, unter innen besonders die sozialen Deiktika. Am wenigsten verwendet werden 'stellvertretende' Proformen. - Auch die Reihenfolge, in welcher der Einsatz definiter Proformen reduziert wird, spricht dafür, daß der Abbau vom Ausmaß abhängt, in dem Kontext als aktueller Kontext repräsentiert werden muß bzw. (re-)konstruiert werden kann.

Es sind zwei weitere Interpretationen dieser typischen Reduktionsmuster denkbar: Zum einen wäre das oben skizzierte Reduktionsmuster mit dem Schweregrad eines

tet wird nach einem Summenscore: 25-30 Punkte: Keine Demenz; <22-24 Punkte: mäßige Demenz; <16 Punkte: erhebliche Demenz (Folstein 1975).

20 Deutliche Hinweise für diese Hypothese liefert auch die Untersuchung von Kannapke (1996).

21 SIDAM: Strukturiertes Interview für die Diagnose der Demenz vom Alzheimer Typ, der Multiinfarkt-Demenz und Demenzen anderer Ätiologie nach DSM-III-R und ICD-10 nach Zaudig. 
dementiellen Syndroms in Verbindung zu bringen; sind die stellvertretenden Proformen bereits abgebaut, so liegt bereits ein hoher Schweregrad vor. Zum anderen ist auch ein Zusammenhang mit der Progression der Demenz vorstellbar; wenn auch die definiten Vollformen von Abbauphänomenen betroffen sind, so muß ein weit fortgeschrittener dementieller Prozeß vorliegen. In solchen Zusammenhängen, die auch derzeit in einer großen Gruppenstudie in Freiburg näher untersucht werden, liegt der frühdiagnostische und -therapeutische Wert dieser Untersuchungen.

\section{Diskussion}

\subsection{Demenz und Sprachstörung}

Kommen wir noch einmal auf unsere Frage vom Anfang zurück. Die Behauptung, daß dementielle Syndrome einen spezifischen Sprachabbau aufweisen, ist wohl spätestens seit Einführung des DSM-IV unstrittig. Hier wird mit dem - für deutsches Schrifttum unglücklichen Begriff - „aphasia (language disturbance)” ein Achsensymptom definiert. Ein Wermutstropfen ist allerdings, daß dieses Symptom offensichtlich nicht als pathognomonisch ${ }^{22}$ für eine Demenz angesehen wird, sondern zu den allgemeinen, zwar als klassisch aber nicht als speziell zu geltenden, Symptomen für Demenzen gehört. ${ }^{23}$

Die Ergebnisse unserer Untersuchung machen zusammen mit der Fachliteratur deutlich, daß es sich bei den sprachlichen Abbauprozessen von Demenzpatienten tatsächlich um den Abbau sprachverarbeitender Prozesse handelt. Solche Störungen könnte man natürlich in althergebrachter Weise als Folgestörungen des Abbaus sog. höherer kognitiver Leistungen ansehen. Wir sind jedoch der Meinung, daß das eine heute nicht mehr tragfähige Grenzziehung impliziert; mit Levelt gehören auch die bei Demenz ganz offensichtlich gestörten konzeptuellen Prozesse zur Sprachproduktion wie -perzeption.

Unsere Untersuchung hat des weiteren deutlich gemacht (und das nicht zuletzt mit Blick auf Aphasien), daß nicht nur und nicht einmal primär Fehler ${ }^{24}$ in oder bei der Sprachproduktion relevante Phänomene sind, sondern vielmehr spezifische Veränderungen regulärer Sprachverarbeitung (Reduktionen und/oder Adaptationen) von Bedeutung sind. ${ }^{25}$.

Bringt man eine Reihe von Ergebnissen der Fachliteratur in geeigneter Weise in Verbindung mit den hier referierten Daten zum Abbau definiter Pro- und dann auch Vollformen, so läßt sich für den Sprachabbau bei Demenzen eine „Kontext-Repräsentations"-Hypothese aufstellen: Allen hier beschriebenen Symptomen gemeinsam ist ein deutlicher Bezug der aktuellen Sprachverarbeitung zu kontextuellen Aspek-

22 Als für eine Krankheit typisch.

23 Als klassische Symptome werden jene bezeichnet, die allgemein bei einer Krankheit auftreten können, z.B. Fieber; tritt zum Fieber als sog. charakteristische Symptome noch Husten und Auswurf hinzu, so engt das die Diagnose schon merklich ein; kann ich aber zusätzlich noch das Tuberkel-Bakterium messen, als sog. spezielles Symptom, so kann es sich nur noch um Tuberkulose handeln. Es hat sich in der Medizin eingebürgert, Symptome in der Krankheitslehre nach diesem Muster einzuteilen.

24 Es werden eben keine Fehler im engeren Sinn gemacht, sondern die Sprache wird „verändert”.

25 Letzteres gilt übrigens nicht nur für die Demenzen: Die moderne Agrammatismusforschung legt die Folgerung nahe, daß kompensatorische Reduktionen auch hier in Rechnung gestellt werden müssen. 
ten: Eine solche Kontextrepräsentation wird greifbar z.B. als 'Partner-antizipation' (Sprecher) bzw. '-rekonstruktion' (Hörer) in einem Gespräch. Sie liegt aber auch als 'Suchperspektive' bei der alltäglichen Abwahl und Weiterverarbeitung eines Lexikoneintrages zugrunde. Sie tritt nicht zuletzt als 'Fokusbildung' und Steuerung der Aufmerksamkeit in Erscheinung (so beim Einsatz eines definiten Pronomens in Opposition zu einer definiten nominalen Vollform).

Gelingt die mentale Repräsentation eines aktuellen (Anwendungs-)Kontextes nicht mehr - oder nicht mehr hinreichend, z.B. weil zu komplex oder zu heterogen, dann können komplexere sprachliche Ausdrucksmittel nicht mehr korrekt eingesetzt werden. Das gleiche gilt auch für das korrekte Auffinden (Benennen) eines Wortes (lexikalische Abwahl). Wir gehen davon aus, daß die betroffenen Patienten ein solches Unvermögen auch selber bemerken - und auf längere Sicht die entsprechenden Ausdrucksmittel und Ausdrucksverfahren meiden.

\subsection{Kommunikative Sprachverarbeitung als frühdiagnostischer Marker für dementielle Syndrome}

Die Prospektivstudie der Framhingham Kohorte ${ }^{26}$ hat gezeigt, daß gerade Sprachstörungen überzufällig häufig in der sog. präklinischen Phase der Alzheimer Erkrankung auffallen (Linn et al. 1995). Dies zeigt die Bedeutung sprachlicher Parameter für ein effizientes Screening auf Demenz.

Es sollte im Verlauf meiner Darlegungen deutlich geworden sein, daß komplexe sprachliche Funktionen, wie dies z.B. die hier behandelten Proformen sind, bereits recht früh betroffene Sprachbereiche sind. Eine derzeit in Freiburg durchgeführte Gruppenstudie untersucht auf breiter Front, in welchem Umfang sich sprachliche Auffälligkeiten im Sinne von Reduktionen differenzierend verwerten lassen. Die Entwicklung eines praktikablen - auch von linguistisch nicht oder nur basisgeschulten Ärzten und/oder Therapeuten verwendbaren - Screeningverfahrens wäre der nächste Schritt. Ein solches Screeningverfahren könnte dazu dienen, Ärzten und Therapeuten in der Frühdiagnostik entscheidende Hinweise zur trennscharfen Abgrenzung dementieller Prozesse von anderen Pathologien (z.B. Depression, Schizophrenie) zu geben. Eine zweite 'Stoßrichtung' eines solchen sprachlich orientierten Screeningverfahrens könnte die Einordnung in 'Schweregrade' dementieller Abbauprozesse sein. Wie ein solches Screeningverfahren konkret auszusehen hätte, müßte in weiterführenden Studien mit den klinischen Institutionen gemeinsam überlegt werden.

${ }^{26}$ Eine der größten Längschnittstudien zum Thema Demenz bisher. 


\subsection{Kommunikationstraining: Wider den therapeutischen Nihilismus bei dementiellen Syndromen}

Etliche Studien ${ }^{27}$ haben inzwischen erwiesen, daß Therapiekonzepte nicht nur Erfolg haben, sondern sich auch gesundheitsökonomisch lohnen ${ }^{28}$ Konsensfähig scheint im Moment eine Art multidimensionales integratives Therapiekonzept zu sein: ABCD-Therapie (Ärztliche Therapie, Bewegung, Cerebrales Training, Diätetik) ${ }^{29}$

Wo liegt nun der Ansatz für die Sprach- bzw. Kommunikationstherapie? Im „CBereich" des ABCD-Modells sollte sie integraler Bestandteil sein. Jedes dementielle Syndrom, dies hat auch die Framingham Studie gezeigt, ist immer auch eine Kommunikationsstörung. Die Ergebnisse der vorliegenden Studie haben gezeigt, daß es sich bei den Sprachstörungen um quantifizierbare Phänomene handelt. Es sollte deshalb auch möglich sein, Kommunikationsstörungen, die durch die o.g. Störungen entstehen, therapeutisch anzugehen.

Ein weiterer wichtiger Bereich in diesem Zusammenhang ist die Beratung von sog. "Care-givern”, also professionellen wie nicht professionellen Pflegepersonen, die mit Demenzpatienten umgehen müssen. Gerade diese klagen in hohem Maße über häufig „unverständliches” Verhalten der Betroffenen. ${ }^{30}$ Es ist von zentraler Bedeutung, die Pflegebelastung auch dadurch zu reduzieren, daß man mit den Angehörigen und auch mit professionellen Pflegepersonen Probleme bespricht, wie sie z.B. eben durch die in der Studie gezeigten Sprachstörungen auftreten. ${ }^{31}$ Darüber hinaus bietet dies natürlich auch einen Ansatz zur Schulung dieses Personenkreises. ${ }^{32}$

Dieser Ansatz kann nur interdisziplinär mit z.B. Ergotherapeuten, Physiotherapeuten, Logopäden, Ärzten, Psychologen und Pflegepersonal als eine Art „Gesamtkonzept" verwirklicht werden.

\section{Literatur $^{33}$}

American Psychiatric Association (Task force) (1994). Diagnostic and statistical manual of mental disorders - Forth Edition (DSM-IV). Washington: APA, 5. Auflage, 1995.

Anschütz, F. (1978). Die körperliche Untersuchung. Berlin/Heidelberg/New York: Springer.

Beske, F. \& Kunzick, T. (1991). Frühzeitige Therapie kann Millionen sparen. Der Kassenarzt 42, 3642.

Blanken, G. (1986). Gestörtes Sprachverhalten bei seniler Demenz und Aphasie. Diss. phil., Freiburg. Feil, N. (1992). Validation therapy with late-onset dementia populations. London/New York: Tavistock.

27 Für eine weitere Betrachtung siehe: Fischer \& Gress-Heister (1995).

28 Vgl. dazu auch Beske \& Kunzick (1991).

29 Für Details siehe Fischer \& Gress-Heister (1995).

30 Vgl. dazu auch die Studie von Powell et al. (1995).

31 Für Details siehe Richter et al. (1995).

32 Für Details siehe vor allem Jones (1992) und Ripich (1994, 1995a); auch: Jordan (1993); Feil (1992); Hallberg (1990, 1990a); Orange et al. (1994).

33 Eine vollständige Bibliographie zum Thema Sprache und Demenz enthält: Gress-Heister (1996); eine Volltextdatenbank zu diesem Thema wird entwickelt. 
Fischer, B. \& Gress-Heister, M. (1995). Das ABCD-Modell bei Hirnleistungsstörungen: Ein integriertes Therapiekonzept. In: Pöldinger, W. (Hrsg.), Der Gerontopsychiatrische Patient in der Praxis. Karlsruhe: Braun, 141-155.

Folstein M. F. (1975). Mini-Mental-Status Test. Deutsche Bearbeitung von Kessler J. \& Markowitsch H. J. (1990).

Goodglas H. \& Kaplan E. (1972). The assessment of aphasic and related disorders. Philadelphia: Lea \& Febiger.

Gress-Heister, M. (1996a). Neuere strategieorientierte Ansätze der Agrammatismus Forschung. Vortrag Workshop BKL. Maschinengeschriebenes Manuskript.

Gress-Heister, M. (1996b). Selektionsrestriktionen bei Schizophrenie. In: Riegel, M. (Hrsg.), Sémantique et cognition. SCOLIA 9, 111-132.

Gress-Heister, M. (1996c). Aspekte der kommunikativen Sprachverarbeitung und des Gesprächsverhaltens bei Menschen mit dementiellen Syndromen. Linguistische Untersuchung zum Zusammenhang von Demenz und Sprachverarbeitung. Freiburg: 'cognitio'.

Hallberg, I. R. et al. (1990). Staff interaction with vocally disruptive demented patients. In: Aging 2, 163-171.

Hallberg, I. R. et al. (1990a). Staffs interpretation of experience behind vocally disrupted demented patients. In: International Journal Aging \& Human development 31, 295-305.

Huber W. et al. (1983). Der Aachener Aphasie Test. Göttingen: Hogrefe.

Hundsalz, A. (1994). Einzelwortverarbeitung bei akutem Verwirtheitszustand und bei vermuteter seniler Demenz vom Alzheimer Typ. Diss.-Med.: Freiburg.

Jones, G. (1992). A communication model for dementia. In: Jones, G. \& Miesen, B. (Hrsg.), Caregiving in dementia. London/New York: Tavistock, 77-99.

Jordan, F. et al. (1993). The evaluation of intervention programmes for communicatively impaired elderly people. In: European Journal of disorders of communication 28, 63-85.

Kannapke, B. (1996). Differentielle Validität psychometrischer Tests zur Diagnose und Schweregradmessung dementieller Erkrankungen. Posterpräsentation 4. Preis für Hirnforschung. Witten/ Herdecke, 12.12.1996.

Lehrl, S. \& Fischer, B. (1992). Selber denken macht fit. Ebersberg: Vless, 3. Aufl.

Lehrl, S. \& Jarmark, E. (1983). Informationsverarbeitung im höheren Lebensalter. In: Fischer, B. \& Lehrl, S. (Hrsg.), Biologische und informationspsychologische Grundlagen des zerebralen Jogging. Vierte Klausenbacher Gesprächsrunde. Tübingen: Narr.

Levelt, W. J. M. (1989). Speaking. Cambridge: MIT Press.

Linn W. T. et al. (1995). The preclinical phase of probable alzheimer's disease. In: Archieves of Neurology 52, 485-490.

Orange, J. B. et al. (1994). Alzheimers disease. Physician-patients communication. Canadian Family Physician 40, 1160-1168.

Powell J. A. et al. (1995). The symptoms of communication breakdown in dementia: carer's perceptions. In: European Journal of Disorders of Communication 30, 36-42.

Richter, J. M. et al. (1995). Communicating with persons with alzheimer's disease. Archieves of psychiatric nursing 9, 279-285.

Ripich, D. (1994). Functional communication with AD Patients. Alzheimer disease Associated disorders 8, 95-109.

Romero, B., Pulvermüller, F., Haupt, M. \& Kurz, A. (1995). Pragmatische Sprachstörungen in frühen Stadien der Alzheimer Krankheit: Analyse der Art und Ausprägung. In: Neuropsychologie 6 (1), 29-42.

Schecker, M. (1996). Kontakt vs. Distanz: Systematik und Funktionsweise von Pronominalisierungen im Text. In: Pérennec, M.-H. (Hrsg.). Proformen im Standarddeutschen. Tübingen: Eurogermanistik.

Schopp, A. (1994). Pronominalisierung. Diss.-phil. Hannover.

Wagenaar, E. et al. (1975). Spontanous speech of aphasic patients. In: Brain \& Languauge 2, $281-$ 303.

Zaudig, M. et al. (1995). Demenz und leichte kognitive Beeinträchtigung im Alter. Bern/Göttingen/Toronto: Huber. 


\section{Die Autorinnen und Autoren}

Anne Betten, geb. 1943; Dr. phil; Prof., Universität Salzburg, Institut für Germanistik; Arbeitsschwerpunkte: Gesprochene Sprache, Stilistik, Textlinguistik, Literatursprache, Sprachgeschichte, Historische Syntax.

Publikationen: Bücher: Sprachrealismus im deutschen Drama der siebziger Jahre, Heidelberg 1985; Grundzüge der Prosasyntax. Stilprägende Entwicklungen vom Althochdeutschen zum Neuhochdeutschen, Tübingen 1987; Neuere Forschungen zur historischen Syntax des Deutschen. Referate der Internationalen Fachkonferenz Eichstätt 1989 (als Hrsg.), Tübingen 1990; Sprachbewahrung nach der Emigration - Das Deutsch der 20er Jahre in Israel. Teil I: Transkripte und Tondokumente, Tübingen 1995; Wir sind die Letzten. Fragt uns aus. Gespräche mit den Emigranten der dreißiger Jahre in Israel, 2.A. Gerlingen. Aufsätze u.a.: Ellipsen, Anakoluthe und Parenthesen - Fälle für Grammatik, Stilistik, Sprechakttheorie oder Konversationsanalyse? In: Deutsche Sprache 4 (1976), 207-230; Erforschung gesprochener deutscher Standardsprache (Teil I und II). In: Deutsche Sprache 5 (1977), 335-361 und 6 (1978), 21-44; Zu Satzbau und Satzkomplexität im mittelhochdeutschen Prosa-Lancelot. Überlegungen zur Beschreibung der Syntax mittelhochdeutscher Prosa. In: Sprachwissenschaft 5 (1980), 15-42; Direkte Rede und epischer Bericht in der deutschen Romanprosa. Stilgeschichtliche Betrachtungen zur Syntax. In: Sprache und Literatur in Wissenschaft und Unterricht 16 (1985), 25-41; Die Bedeutung der Ad-hoc-Komposita im Werk von Thomas Bernhard, anhand ausgewählter Beispiele aus 'Holzfällen. Eine Erregung' und 'Der Untergeher'. In: Neuere Forschungen zur Wortbildung und Historiographie der Linguistik, hrsg. v. Asbach-Schnitker, B. \& Roggenhofer, J., Tübingen 1987, 69-90; Weiblicher Gesprächsstil und feministische Gesprächsanalyse? In: Dialogananalyse II. Referate der 2. Arbeitstagung Bochum 1988, Bd. 2, hrsg. v. Hundsnurscher, F. \& Weigand, E., Tübingen 1989, 265-276; Zur Bedeutung von Textsyntax und Textlinguistik für die Sprachgeschichtschreibung. In: Deutsche Sprachgeschichte. Grundlagen, Methoden, Perspektiven, hrsg. v. Besch, W., Frankfurt u.a. 1990, 159-165; Sentence connection as an expression of medieval principles of representation. In: Internal and External Factors in Syntactic Change, hg. v. Gerritsen, M. \& Stein, D., Berlin/New York 1992, 157-174; Analyse literarischer Dialoge. In: Handbuch der Dialoganalyse, hg. v. Fritz, G. \& Hundsnurscher, F., Tübingen 1994, 519-544.

Anschrift: Universität Salzburg, Institut für Germanistik, Akademiestr. 20, A-5020 Salzburg.

Roselore Brose, geb. 1938; M.A.; (nichtwiss.) Fremdsprachen-Assistentin an der Universität Bielefeld; freiberuflich wissenschaftlich tätig; Arbeitsschwerpunkte: Altern und Alter, insbesondere Sprache und Kommunikation älterer Menschen.

Publikationen: Lebensschicksal und Weiterbildung älterer Menschen: Eine qualitative Analyse am Beispiel von Teilnehmerinnen und Teilnehmern des Programms 'Studieren ab 50'. Bielefeld 1994.

Anschrift: Universität Bielefeld, Fakultät für Linguistik und Literaturwissenschaft, Postfach 1001 31, 33501 Bielefeld.

Dieter Cherubim, geb. 1941; Dr. phil., Professor für Germanistik/Sprachwissenschaft an der Universität Göttingen; Arbeitsschwerpunkte: Historische Sprachwissenschaft, Pragmalinguistik (u.a. Sprache in Institutionen, aggressives Sprachverhalten, gesprochene Sprache), Fehlerlinguistik, Geschichte der Sprachwissenschaft.

Publikationen: u.a. Sprachwandel (als Hrsg.), Berlin/New York 1975; Grammatische Kategorien, Tübingen 1976; Fehlerlinguistik (als Hrsg.), Tübingen 1980; Gespräche zwischen Alltag und Literatur (als 
Mithrsg.), Tübingen 1985; Voraussetzungen und Grundlagen der Gegenwartssprache (als Mithrsg.), Berlin/New York 1989; Lexicon Grammaticorum (als Mithrsg.), Tübingen 1996; Sprache und bürgerliche Nation (als Mithrsg.), Berlin/New York 1998.

Anschrift: Seminar für Deutsche Philologie, Georg-August-Universität Göttingen, Humboldallee 13, 37073 Göttingen.

Reinhard Fiehler, geb. 1949; Dr. phil., Prof.; Institut für deutsche Sprache, Mannheim; Arbeitsschwerpunkte: Gesprochene Sprache, Gesprächsanalyse mit den Schwerpunkten: Arbeitskommunikation, Emotionalität, Kommunikationsberatung und -training, Sprache und Kommunikation im Alter.

Publikationen: u.a. Kommunikation und Kooperation, Berlin 1980; Kommunikation und Emotion, Berlin 1990; Technisierte Kommunikation (mit R. Weingarten, als Hrsg.), Opladen 1988; Kommunikationsberatung und Kommunikationstraining (mit W. Sucharowski, als Hrsg.), Opladen 1992; Untersuchungen zur Kommunikationsstruktur (mit D. Metzing, als Hrsg.), Bielefeld 1995; Verständigungsprobleme und gestörte Kommunikation (als Hrsg.), Opladen 1998.

Anschrift: Institut für deutsche Sprache, Postfach 1016 21, 68016 Mannheim.

E-mail: fiehler@ids-mannheim.de

Markus Gress-Heister, geb. 1963; M.A.; Wiss. Mitarbeiter am Neurolinguistischen Labor (EUCOR-AG Kognition), Universität Freiburg; Ausbildungsleiter der Prof. König und Leiser Ergotherapie und Logopädie Schulen, Kaiserslautern; Arbeitsschwerpunkte: Klinische Neurolinguistik, Neurowissenschaften, Neuropsychologie, Gerontologie, Ethik in der Medizin.

Publikationen: siehe web-site: http://www.uni-freiburg.de/neurolab/mgh.htm

Anschrift: Neurolinguistisches Labor, Universität Freiburg, Werthmannplatz 3, 79085 Freiburg.

E-mail: gress@uni-freiburg.de

Daniela Heidtmann, geb. 1973; Studium der Germanistik, Allgemeinen Linguistik, Medien- und Kommunikationswissenschaft an der Universität Mannheim.

Anschrift: Hundertmorgenstraße 25, 67134 Birkenheide.

E-mail: heidtman@rumms.uni-mannheim.de

Suzanne K. Hilgendorf, geb. 1964, PhD candidate and teaching assistant, Dept. of Germanic Languages \& Literatures, University of Illinois, Urbana/Champaign, USA; Arbeitschwerpunkte/Titel der Diss.: English in Germany: A Sociolinguistic Profile.

Publikationen: The Impact of English in Germany. In: English Today 47, 12/3, 1996, 3-14.

Anschrift: Department of Germanic Languages and Literatures, University of Illinois, $707 \mathrm{~S}$. Mathews, Urbana,III., 61801-3675.

E-mail: s-hilgen@uiuc.edu

Manfred Kohrt, geb. 1947; Dr. phil, Prof.; Rheinische Friedrich-Wilhelms-Universität Bonn; Arbeitsschwerpunkte: Graphematik/Orthographie, Wissenschaftsgeschichte der Linguistik, Linguistische Pragmatik und manch anderes.

Publikationen: u.a. Koordinationsreduktion und Verbstellung in einer generativen Grammatik des Deutschen, Tübingen 1976 (Linguistische Arbeiten, 41); Sprache als Struktur. Eine kritische Einführung in Aspekte und Probleme der generativen Transformationsgrammatik (mit Manfred Geier, Christoph Küper und Franz Marschallek), Tübingen 1976 (Reihe Germanistische Linguistik, 4); Phonetik, Phonologie und die „Relativität der Verhältnisse“. Zur Stellung Jost Wintelers in der Geschichte der Wissenschaft, Stuttgart 1984 (Beihefte zur Zeitschrift für Dialektologie und Linguistik, 47); Problemgeschichte des Graphembegriffs und des frühen Phonembegriffs, Tübingen 1985 (Reihe Germanistische Linguistik, 61); Theoretische Aspekte der deutschen Orthographie, Tübin- 
gen 1987 (Reihe Germanistische Linguistik, 70); Schreibprozesse - Schreibprodukte. Festschrift für Gisbert Keseling (mit Arne Wrobel, als Hrsg.), Hildesheim/New York 1992; Zahlreiche Aufsätze zu verschiedenen Themen im Bereich der germanistischen Linguistik.

Anschrift: Rheinische Friedrich-Wilhelms-Universität Bonn, Germanistisches Seminar, Am Hof 1d, 53113 Bonn.

Undine Kramer, geb. 1957; Diplomlehrerin für Deutsch/Englisch, Dr. phil.; Humboldt-Universität zu Berlin, Institut für deutsche Sprache und Linguistik; Arbeitsschwerpunkte: Lexikologie/Lexikographie, Sondersprachen, Phraseologie, Orthographie.

Publikationen: u.a. Von Ossi-Nachweisen und Buschzulagen. Nachwendewörter-sprachliche Ausrutscher oder bewußte Etikettierung? In: Reiher, R. \& Läzer, R. (Hrsg.): Von Buschzulage und Ossi-Nachweis. Ost-West-Deutsch in der Diskussion, Berlin 1996, 55-70; „David schlägt Goliath“ oder Greenpeace gegen Shell. Zur Lexik in der aktuellen Publizistik. In: Kramer, U. \& Vajickova, M. (Hrsg.): Einblicke in die Deutschlehrer-Ausbildung, Bratislava 1997, 48-65. Deutsche Phraseologie. Ein Lehr- und Übungsbuch (mit M. Vajickova, als Hrsg.), Bratislava 1997. Sprache als Mittel von Identifikation und Distanzierung (mit R. Reiher, als Hrsg.) i.V.

Anschrift: Humboldt-Universität zu Berlin, Institut für deutsche Sprache und Linguistik, Schützenstr. 18-25, 10099 Berlin.

E-mail: undine=kramer@rz.hu-berlin.de

Kerstin Kucharczik, geb. 1961; Dr. phil; Wiss. Mitarbeiterin an der Ruhr-Universität Bochum; Arbeitsschwerpunkte: Historiographie der Linguistik; Linguistische Prag-matik.

Publikationen: u.a. Sprecher- und hörerseitige Verwendungsweisen der Interjektion „HM“. In: Kowal, Sabine \& Posner, Roland (Hrsg.): Zeitliche und inhaltliche Aspekte der Textproduktion, Berlin 1989 (= Arbeitspapiere zur Linguistik. 20), 168-191; Der Organismusbegriff in der Sprachwissenschaft des 19. Jahrhunderts. Diss.phil., TU Berlin 1995; Organisch - „um den beliebten aber vildeutigen ausdruck zu gebrauchen“. Zur Organismusmetaphorik in der Sprachwissenschaft des 19. Jahrhunderts. In: Sprachwissenschaft 22 (1997).

Anschrift: Ruhr-Universität Bochum, Germanistisches Institut, 44780 Bochum.

Margitta Lambert, geb. 1945; Dr. phil.; Arbeitsschwerpunkte: (etholinguistisch orientierte) Gesprächsanalyse, Altenkommunikation, Frauenkommunikation.

Anschrift: Mexikoring 13, 22297 Hamburg.

Stefanie Maier, geb. 1966; Diplom-Psychologin, Diplom-Gerontologin; Doktorandin (Heildelberg). Arbeitsschwerpunkte: Sprachpsychologie, Sozialpsychologie; Erwachsenenbildung.

Anschrift: Otto-Beck-Str. 28, 68165 Mannheim.

Achim Pothmann, geb. 1967; Dr. phil., Diplomkaufmann; Motivations-, Verkaufs- und Kommunikationstrainer; Arbeitsschwerpunkte: Diskursanalyse und Kommunikationsberatung, Verkaufsgespräche.

Publikationen: Diskursanalyse von Verkaufsgesprächen, Wiesbaden 1997.

Anschrift: Hardenbergstr. 7, 59425 Unna.

Ellen B. Ryan, geb. 1947; PhD. in Psycholinguistik, Professorin für Psychologie und Gerontologie, Direktorin der Gerontological Studies an der McMaster University in Hamilton/Ontario, Canada; Arbeitsschwerpunkte: Psychologische Aspekte von Sprache, Kommunikation, Alter und Gesundheit, Alter und kognitive Kompetenz, Computerkommunikation im Alter, institutionelle Kommunikation in pflegerischen Kontexten. 
Publikationen: u.a. Attitudes toward language variation: social and applied contexts. (mit H. Giles, als Hrsg.), London/Baltimore 1982; Language, communication and the elderly (special issue, mit H. Giles, als Hrsg.). In: Language and Communication 6 (1/2) 1986; Intergenerational communication (special issue). In: International Journal on Aging and Human Development 39 (1); Communication, Aging and Health (special issue of health communication, als Hrsg), 8 (3) 1996; Zahlreiche Aufsätze zu altersbezogenen Fragestellungen im Bereich Psycholinguistik.

Anschrift: Office of Gerontological Studies, McMaster University, Hamilton, Ontario, Canada, L8S 4KL.

E-mail: ryaneb@mcmail.CIS.McMaster.CA

Svenja Sachweh, geb. 1965; Doktorandin (Freiburg); Arbeitsschwerpunkte: Gesprächsanalyse, Kommunikation in der Altenpflege, Sprache und Alter.

Publikationen: „schätzle hinsetzen“: Der Einsatz der Babysprache in der Altenpflege. In: Zegelin, A. (Hrsg.): Sprache der Pflege, Wiesbaden 1997; „Maria können=ehr de popo mal hebe“. Das Gesprächsverhalten von AltenheimpflegerInnen. In: Germanistische Linguistik, Marburg (im Druck); Granny darling's nappies - Secondary Babytalk in German nursing homes for the aged. In: Journal of Applied Communication Research (im Druck).

Anschrift: Haslacher Str. 60a, 79115 Freiburg.

E-mail: sachweh@sun1.ukl.uni-freiburg.de

Michael Schecker, geb. 1944; Dr. phil., PD; Leiter des Neurolinguistischen Labors (Deutsches Seminar I) der Albert-Ludwigs-Universität Freiburg; Arbeitsschwerpunkte: Grammatik, Neurolinguistik/Klinische Linguistik.

Publikationen: u.a. Neurologische Vorstellungen zur Sprachverarbeitung. In: Lüdi, G. \& Zuber, C.A. (Hrsg.): ARBA 1, 1993, 251ff.; Zwischen Sprecherrekonstruktion und Hörerantizipation - Gestörtes Gesprächsverhalten bei Schizophrenie. In: Löffler, H. (Hrsg.): Dialoganalyse IV, Tübingen 1993, Teil II, 247ff.; Assoziative Entgleisungen bei Schizophrenie - und was sie uns über das Lexikon verraten. In: Schecker, M. \& Kindt, H. (Hrsg.): Sprache und Schizophrenie, Freiburg 1997; Konkretismus, Kontext und Informationsverarbeitung bei Schizophrenie. In: Schecker, M. \& Kindt, H. (Hrsg.), Sprache und Schizophrenie, Freiburg 1997; Assoziationen und Kontextverarbeitung Ansätze zu einer Simulation schizophrenen Sprachverhaltens (mit G. Kochendörfer). In: Rickheit, G. (Hrsg.): Studien zur Klinischen Linguistik - Modelle, Methoden, Interventionen, Opladen 1997; Schizophrenie, Halloperidol, Stottern: Zur Erklärung und Simulation von Psychopharmaka (mit G. Kochendörfer), Freiburg 1997.

Anschrift: Albert-Ludwigs-Universität, Neurolinguistisches Labor, Werthmannplatz 3, Postfach 39, 79085 Freiburg.

Guido Schnieders, geb. 1963; M.A.; Studium der Linguistik, Philosophie und der Neueren deutschen Literaturwissenschaft in Berlin (FU), Wien (U) und London (UCL). DAAD-Lektor an der JósefAttila-Universität Szeged; Arbeitsschwerpunkte: Linguistische Pragmatik, Diskursanalyse, Textlinguistik, Intonationsforschung.

Publikationen: u.a. Authentische und zitierte Reklamationsgespräche - ein exemplarischer Vergleich. In: Rehbein, J. (Hrsg.): Spektrum der Funktionalen Pragmatik, i.V.; Kommunikationsprobleme in Reklamationsgesprächen (mit R. Fiehler und W. Kindt). In: Brünner, G., Fiehler, R. \& Kindt, W. (Hrsg.): Angewandte Diskursforschung. Kommunikation untersuchen und lehren, i.V.

Anschrift: Jósef-Attila-Tudományegyetem Szeged, German Filológiai Intézet, Egyetem u. 2, 6722 Szeged, Ungarn. 
Sheree T. Kwong See, geb. 1965; PhD. in Psychologie, Assistenzprofessorin im Department of Psychology an der University of Alberta in Edmonton/Canada; Arbeitsschwerpunkte: kognitive und soziale Einflüsse auf Sprache und Verhalten im höheren Lebensalter.

Publikationen: u.a. Language and Aging (mit E. Ryan). In: Dulbecco, R. (ed.): Encyclopedia of human biology. Vol. 1, Toronto 1991, 119-127; Age-based perceptions of the conversational skills of younger and older adults (mit E. Ryan, W. Meneer \& D. Travato). In: Hummert, M. L., Nussbaum, J. \& Wieman (eds.): Interpersonal communication and older adulthood, Newbury Park, 1539.

Anschrift: Department of Psychology, University of Alberta, Edmonton, Alberta, Canada T6G 2E9.

Caja Thimm, geb. 1958; Dr. phil., wissenschaftliche Mitarbeiterin an der Universität Heidelberg, z.Zt. Habilitationsstipendiatin des Landes Baden-Württemberg; Arbeitsschwerpunkte: Politische Kommunikation, Psycholinguistik, linguistische Geschlechterforschung, Kommunikation am Arbeitsplatz, Sprache im Alter.

Publikationen: u.a. Dominanz und Sprache, Wiesbaden 1990; Strategisches Handeln im politischen Konflikt: Frauen und Männer im kommunalen Parlament. In: Reiher, R. (Hrsg.): Sprache im Konflikt. Berlin/New York 1995, 72-92; Intergruppenkommunikation, soziales Vorurteil und konversationale Implikaturen: Alt und Jung im Dialog. In: Liedtke, F. (Hrsg.): Implikaturen. Tübingen 1995, 187-208; Power-related talk: control in verbal interaction (mit U. Rademacher \& L. Kruse). In: Journal of Language and Social Psychology, 1995, 14(4), 382-407; Die sprachliche Symbolisierung des Alters in der Werbung. In: Jäckel, M. (Hrsg.): Die umworbene Gesellschaft. Wiesbaden 1998, 11-140.

Anschrift: Universität Heidelberg, Germanistisches Seminar, Hauptstr. 207-209, 69117 Heidelberg. 